\title{
Archaeological Data Recovery (41TR198) and Survey Within the Riverside Oxbow Project Tarrant County, Texas
}

Duane E. Peter

James Harrison

Geo-Marine, Inc.

Follow this and additional works at: https://scholarworks.sfasu.edu/ita

Part of the American Material Culture Commons, Archaeological Anthropology Commons, Environmental Studies Commons, Other American Studies Commons, Other Arts and Humanities Commons, Other History of Art, Architecture, and Archaeology Commons, and the United States History Commons

Tell us how this article helped you.

This Article is brought to you for free and open access by the Center for Regional Heritage Research at SFA ScholarWorks. It has been accepted for inclusion in Index of Texas Archaeology: Open Access Gray Literature from the Lone Star State by an authorized editor of SFA ScholarWorks. For more information, please contact cdsscholarworks@sfasu.edu. 


\section{Archaeological Data Recovery (41TR198) and Survey Within the Riverside Oxbow Project Tarrant County, Texas}

\section{Creative Commons License}

\section{(c) (i) $\Theta($}

This work is licensed under a Creative Commons Attribution-NonCommercial-No Derivative Works 4.0 International License. 


\title{
ARCHAEOLOGICAL DATA RECOVERY (41TR198) AND SURVEY WITHIN THE RIVERSIDE OXBOW PROJECT TARRANT COUNTY, TEXAS
}

\author{
DRAFT \\ by \\ Duane E. Peter \\ James Harrison \\ with contributions by \\ Chester Walker, PhD \\ Charles Frederick, PhD \\ Charles Randklev \\ Steve Wolverton, $\mathrm{PhD}$ \\ Julie Densmore \\ Ben Fullerton \\ David Shanabrook \\ Maynard Cliff, $\mathrm{PhD}$ \\ Michelle D. Wurtz-Penton \\ Tim Perttula, $\mathrm{PhD}$ \\ Principal Investigator \\ Duane E. Peter
for
U.S. Army Corps of Engineers
Fort Worth District \\ TeXAs ANTIQuities PeRmit NuMBer 5040 \\ MisCELLANEOUS REPORTS OF INVESTIGATIONS \\ NUMBER 467 \\ Geo-Marine, Inc. \\ $2201 \mathrm{~K}$ Avenue, Suite A2 \\ Plano, Texas 75074
}

January 2011 


\section{CONTRACT DATA}

The preparation of this document was accomplished under Contract No. W9126G-05-D-0009,

Delivery Order No. 0040 (Geo-Marine, Inc., Project No. 10509.00.40) with the U.S. Army Corps of Engineers, Fort Worth District, P.O. Box 17300, Fort Worth, Texas, 76102-0300. 


\section{MANAGEMENT SUMMARY}

This report presents the findings of the survey of 75 acres and the excavation of 28 cubic meters of site 41TR198 (Crooked Oxbow Site) within the Riverside Oxbow Project sponsored by the U.S. Army Corps of Engineers, Fort Worth District, in partnership with the City of Fort Worth and the Tarrant County Water District. Planned impacts from this proposed project include habitat restoration, channel reestablishment, vegetation plantings, new roads, and sports field construction. The deepest impacts planned for the Area of Potential Effects are one meter and involve the excavation of a shallow lake utilizing the relict oxbow bordering site 41TR198. Impacts planned for the remainder of the project area will be less than one-half meter deep. Overall, the project will attempt to use the existing landscape as much as possible in order to reduce impacts. As a federal agency the USACE is required to undertake cultural resource investigations for their projects in accordance with the National Historic Preservation Act of 1966, as amended through 2001. Since the Tarrant Regional Water District is the landowner and co-sponsor of the project, and a political subentity of the state of Texas, this project was also conducted under Texas Antiquities Permit No. 5040.

Backhoe trenching and geophysical survey conducted at site 41TR198 revealed potential features over an area of 19.5 acres. Like many sites within the Trinity River basin, the site context is the West Fork paleosol within the Pilot Point Alloformation. Geomorphological data provided by Dr. Charles Frederick indicate that the site was situated at the former confluence of Sycamore Creek and the West Fork of the Trinity River. A paleochannel of the West Fork forms the north and west boundaries of the site. 
Site 41TR198 offers a unique data set related to use of the West Fork flood plain between 410 B.C. and A.D. 1040. Multiple data sets recovered from discrete living surfaces suggest that groups frequenting the site may have been distinct from those exploiting the woodlands/prairie ecotone elsewhere. Intensity of the occupation of the site and subsistence patterns also differ between the Late Archaic and Late Prehistoric occupations of the site. The presence of distinctive thermal features and a diverse faunal assemblage contribute to an emerging synthesis of northcentral Texas archaeology. Comparison of the assemblage recovered from site 41TR198 with other site assemblages within the region (41TR170, 41DL203, 41COL172, 41CO144, and 41CO150) permits a better understanding of the cultural dynamics along the woodland/prairie ecotone.

Previous work along the West Fork of the Trinity River has frequently encountered extremely low density sites with very few lithic tools and small scatters of fire-cracked rock and fragile faunal elements. Understanding these sites can be frustrating because any given excavation block reveals a very limited data set. Site 41TR198 is no different for the lithic assemblage recovered from $28 \mathrm{~m}^{3}$ of excavation totals only 219 specimens. Fortunately, the distribution of features, the limited tool assemblage, and well preserved faunal assemblage provides a data set that is significant when compared to other sites in the region. In addition, the excavations yielded four poorly made grit-tempered ceramic sherds dating to A.D. 900. These sherds likely represent a first attempt at ceramic technology by the occupants of this site.

Features include shell and faunal lenses, basin-shaped hearths and burned rock concentrations. No evidence of substantial structures was found. These features are more substantial than those found on nearby sites along the West Fork; however, investigations within the larger Trinity River basin indicate that burned rock features, including middens, become more common as one moves west and south. As Lintz (2005) indicated in the analysis of site 41 TR170 located farther upstream along the West Fork, the prominence of burned rock features to the west in the Brazos drainage clearly indicates that subsistence technologies, and possibly the food elements being cooked, are different. At site 41TR198, analysis of the macrobotanical remains recovered through flotation by Dr. Phil Dering revealed the presence of multiple onion or camas bulb fragments in feature contexts between A.D. 140 and A.D. 340. It is postulated that the geographic range of camas may have extended farther into the Blackland Prairie/Cross Timbers ecotone during the Late Archaic period. None of the other Late Archaic assemblages in the region demonstrate this type of preservation. Wood charcoal from oak, walnut, hackberry, and sycamore 
was found also. All of these are expected species in the gallery forest along the West Fork of the Trinity.

The presence of formal burned rock features and the processing of bulbs suggest activities more commonly represented to the west. The lithic assemblage which is primarily chert, likely derived from the local Uvalde gravels or from Central Texas sources, stands in contrast to other northcentral Texas assemblages where quartzite is the predominant raw material. The stylistic shapes of the dart points also indicate differential preferences or different interaction spheres. The Axtell dart points likely represent influence from the south in the Blackland Prairie or to the west. The Yarbrough, on the other hand is more common to the east. Perhaps, our normative perspective limits our consideration of the multiple scenarios that might have contributed to the assemblages found at site 41TR198. Social groups and social interactions are complex; consequently, we should instead be looking at the Woodlands/Prairie ecotone as a rich environment where multiple peoples would gather to collect its abundance. Site 41TR198 may reflect usage by groups from multiple directions at different times, or it may reflect a gathering of bands at various times to trade raw materials and finished products, see the relatives who married into a different band, or to find marriage partners. The challenge for us as archaeologists today is determining the theoretical constructs and associated methodologies that will inform us of the social dynamics along the woodland/prairie ecotone. 


\section{TABLE OF CONTENTS}

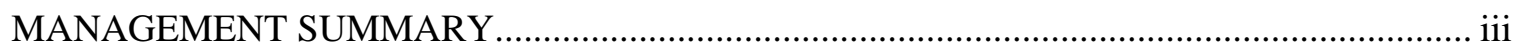

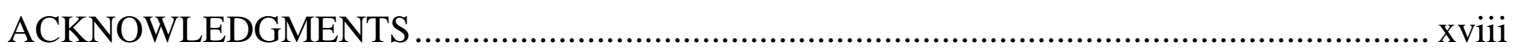

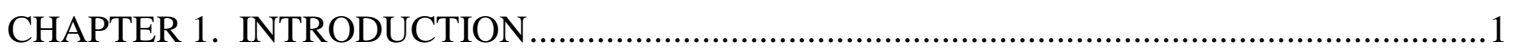

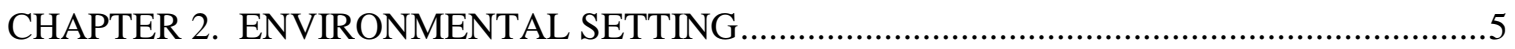

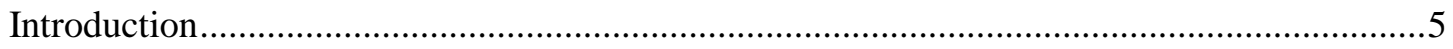

Geology

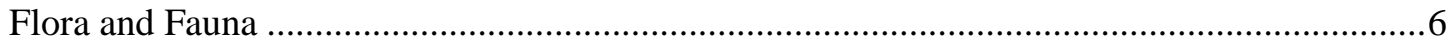

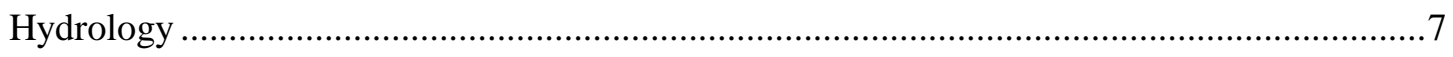

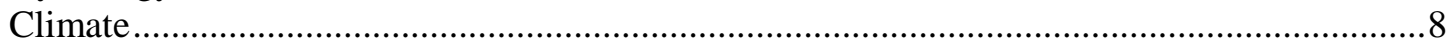

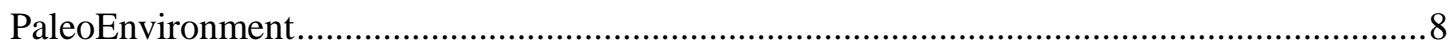

Late Pleistocene

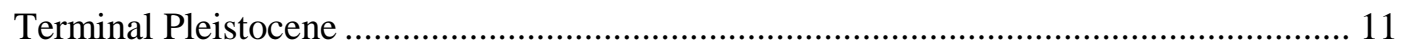

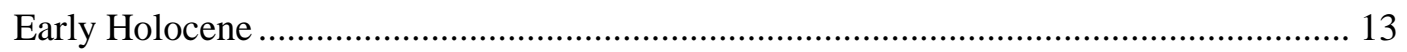

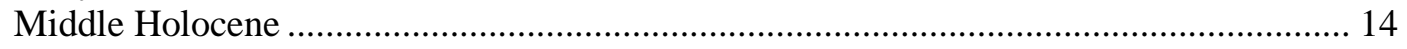

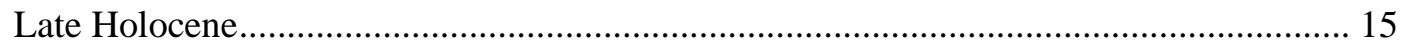

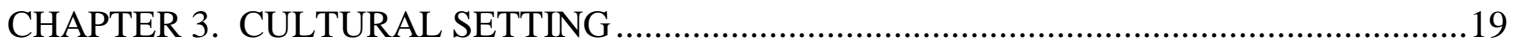

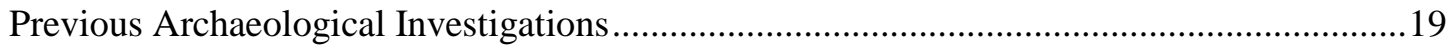

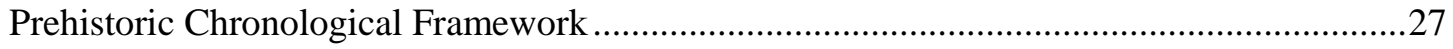

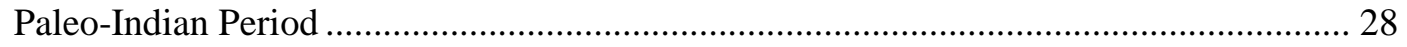

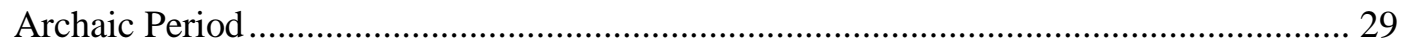

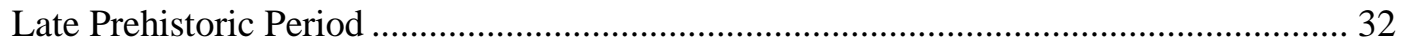

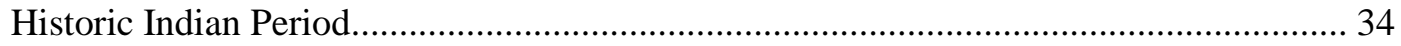

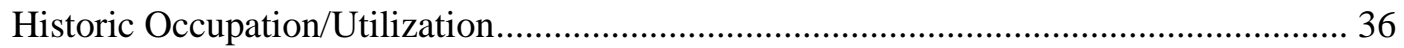

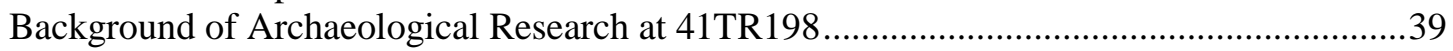

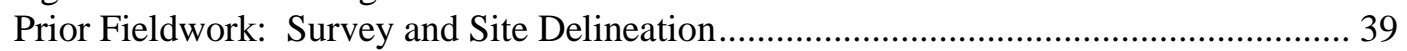

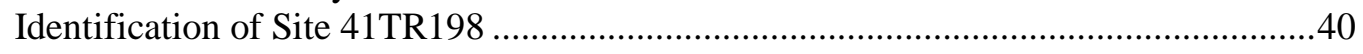

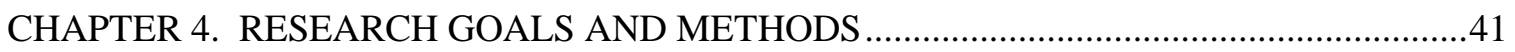

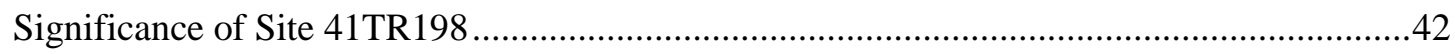

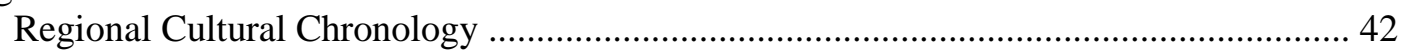

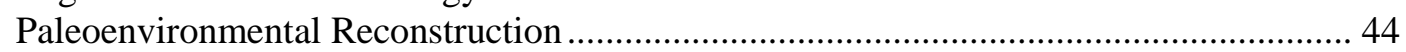




\section{Table of Contents}

(cont'd)

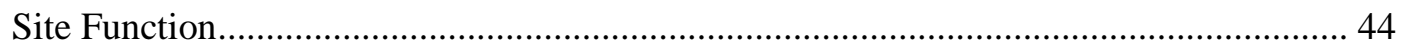

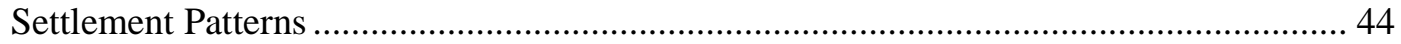

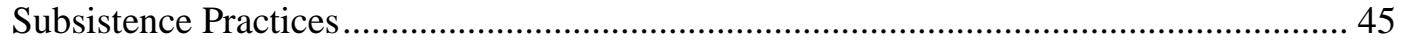

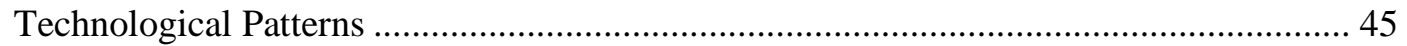

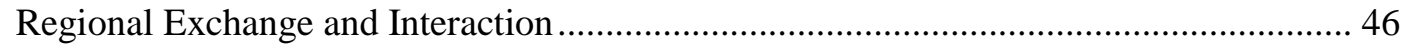

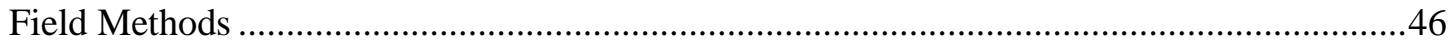

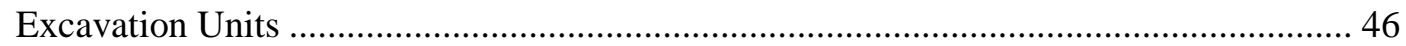

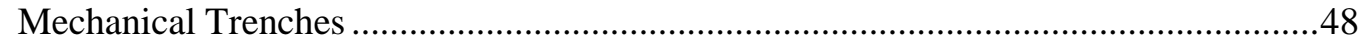

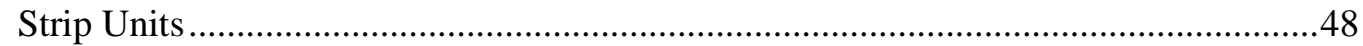

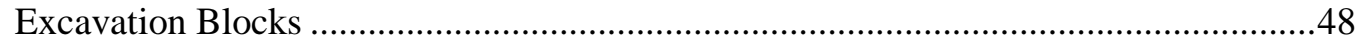

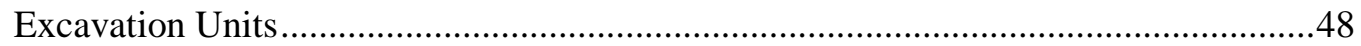

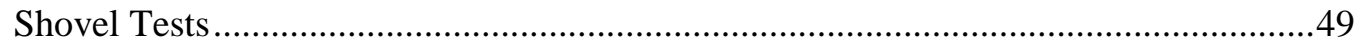

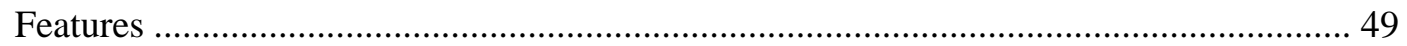

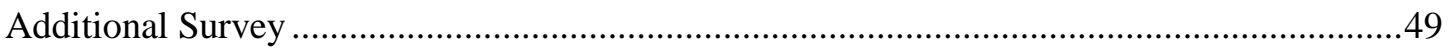

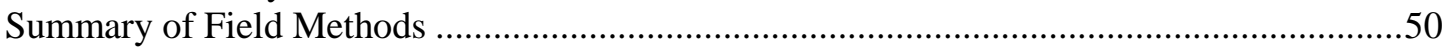

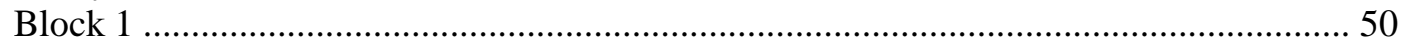

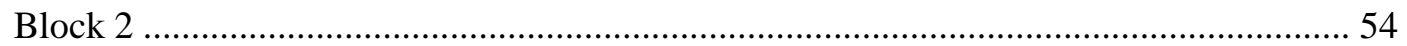

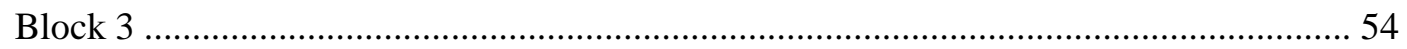

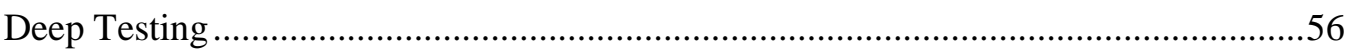

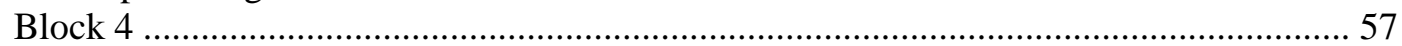

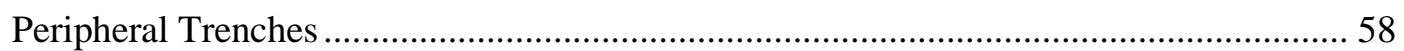

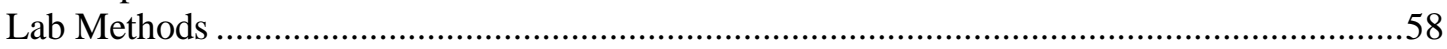

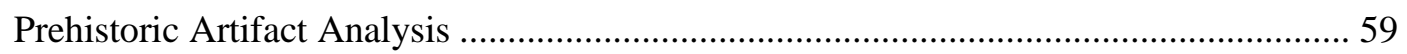

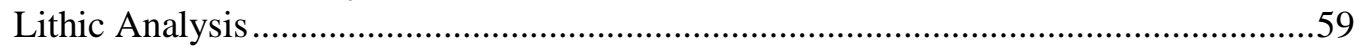

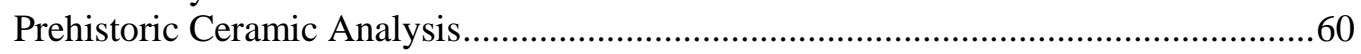

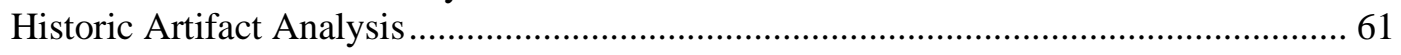

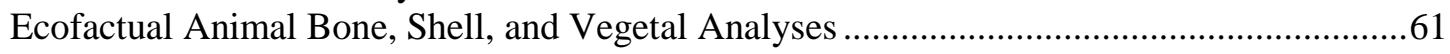

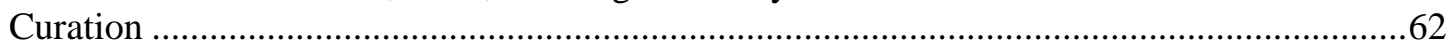

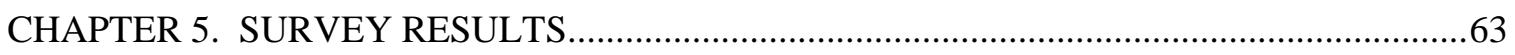

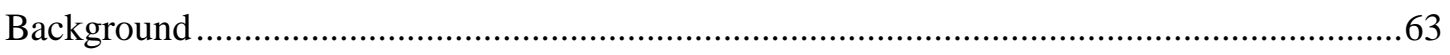

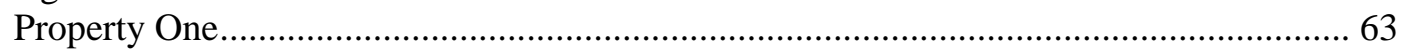

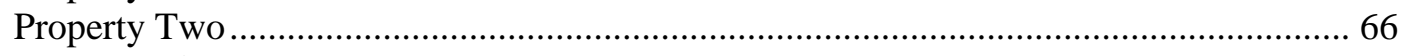

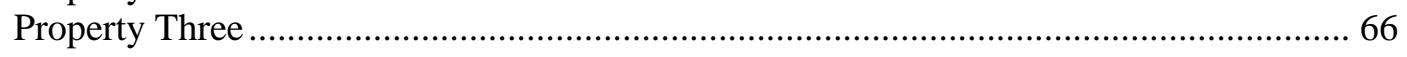

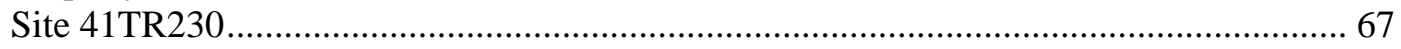

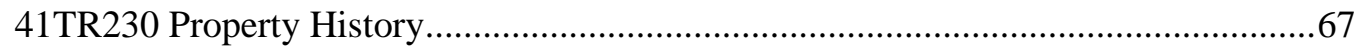

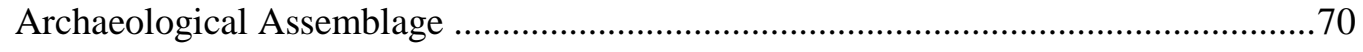

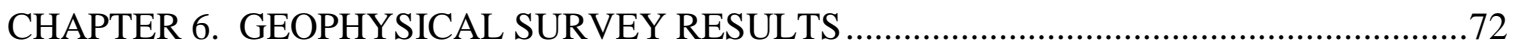

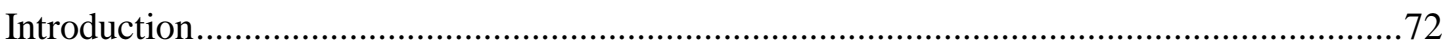

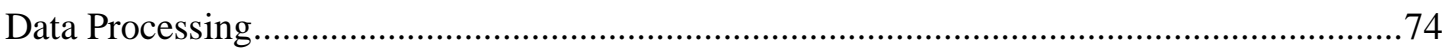

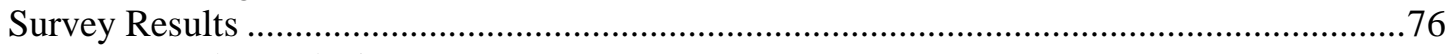

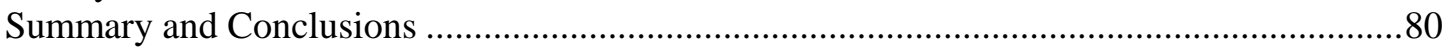


Table of Contents

(cont'd)

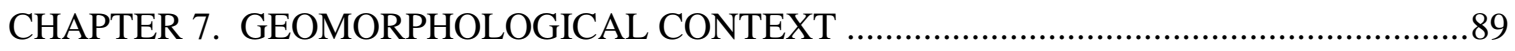

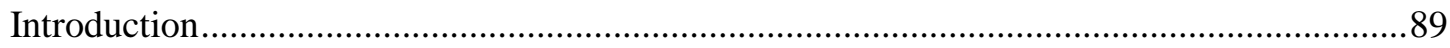

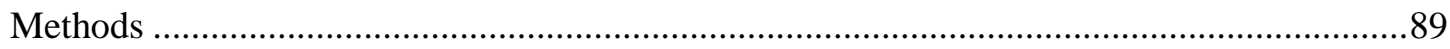

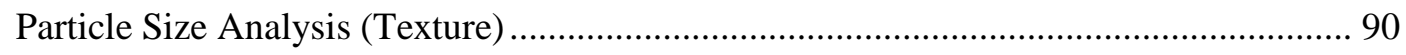

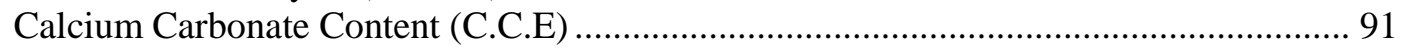

Organic Carbon and Stable Carbon Isotopic Analysis ..................................................... 92

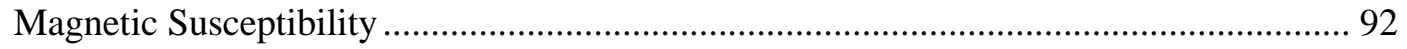

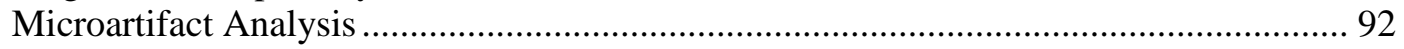

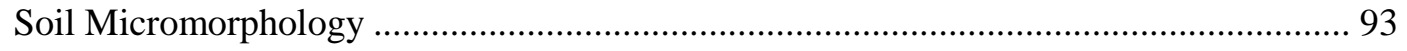

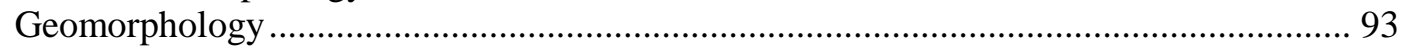

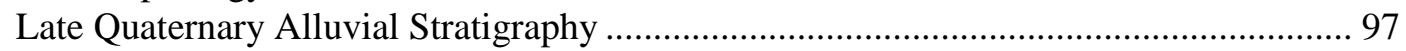

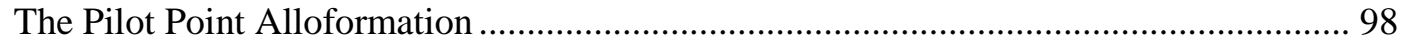

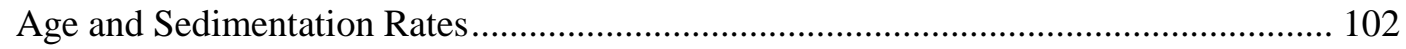

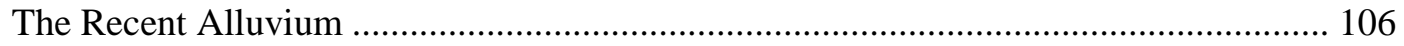

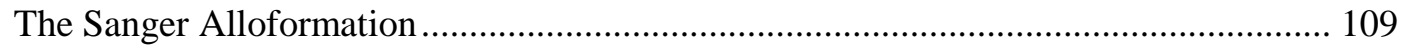

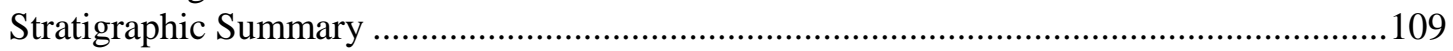

Context and Integrity of the Prehistoric Occupations and Observations

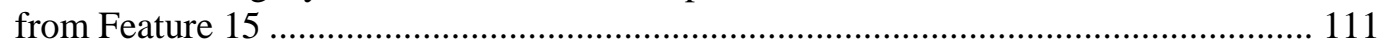

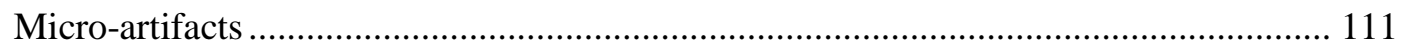

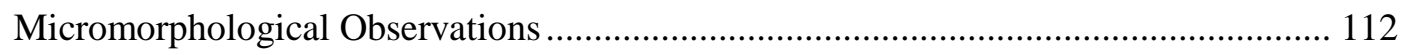

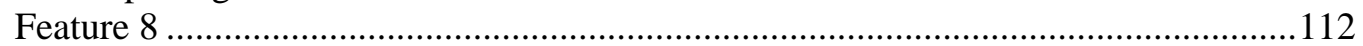

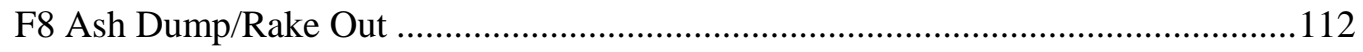

Occupation Surface Adjacent to Feature 8 …….....................................................113

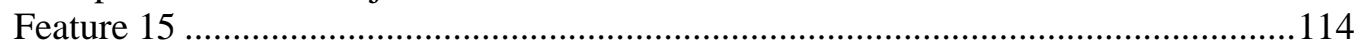

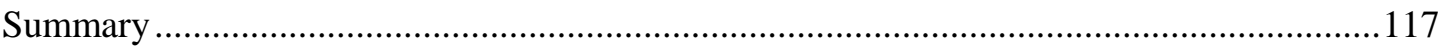

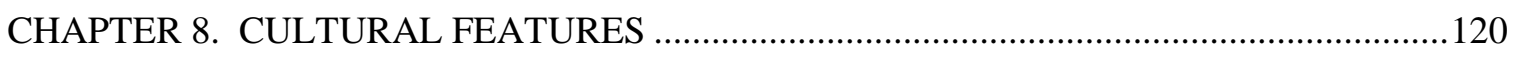

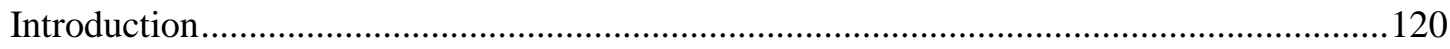

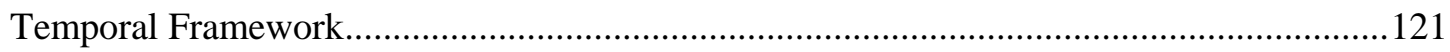

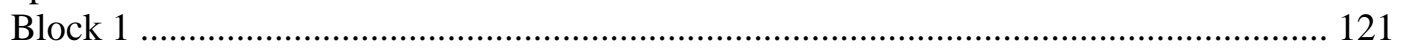

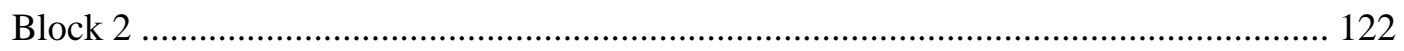

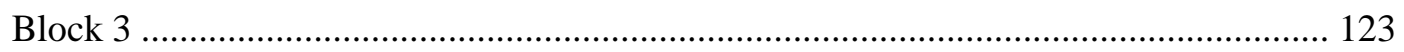

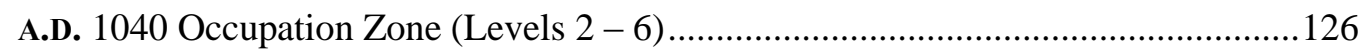

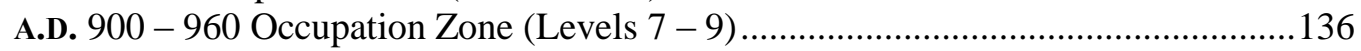

A.D. 700 - 900 Occupation Zone (Levels 10 - 11) ......................................................139

A.D. 350 - 700 Occupation Zone (Levels 12 - 15) ...................................................141

A.D. 250 - 350 Occupation Zone (Levels 16 - 19) .................................................146

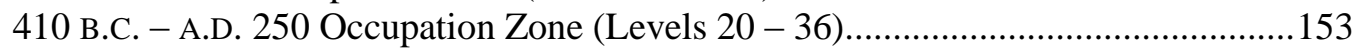

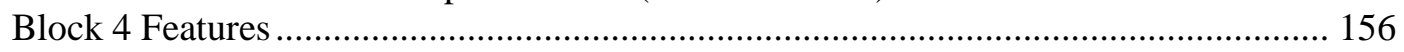

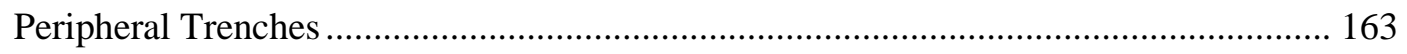

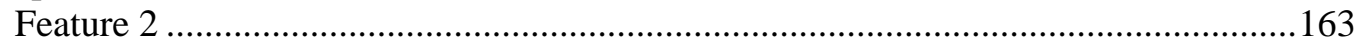

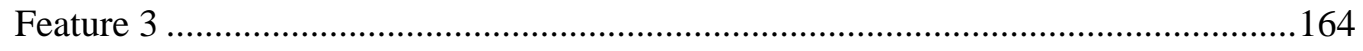

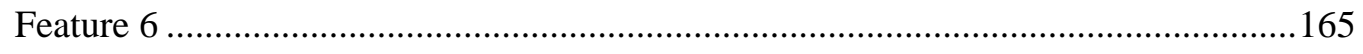




\section{Table of Contents}

(cont'd)

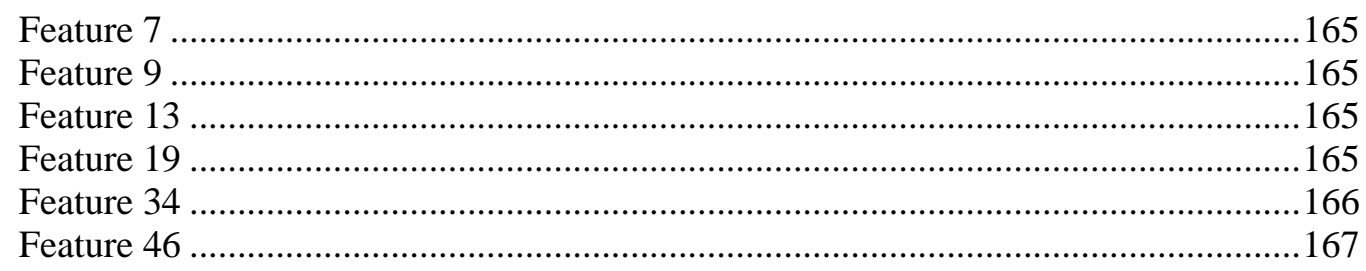

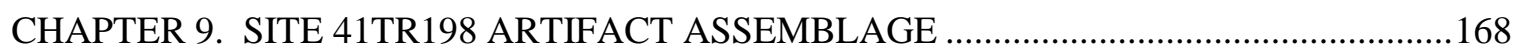

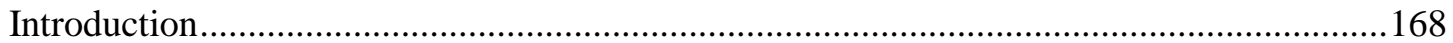

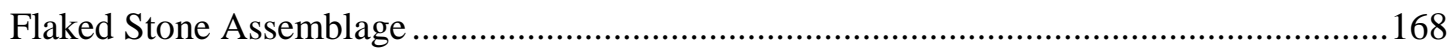

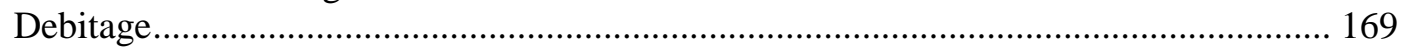

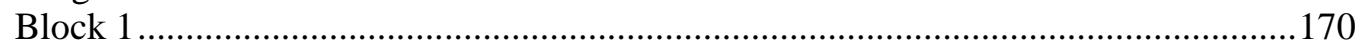

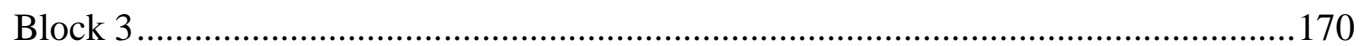

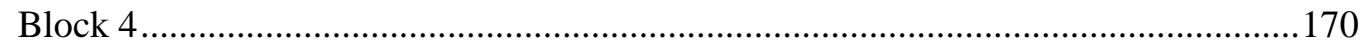

Block 4 Midden Cobble Reduction Sub-assemblage...................................................... 171

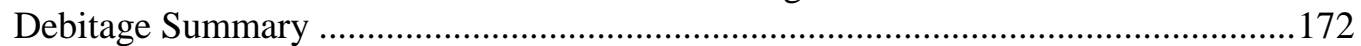

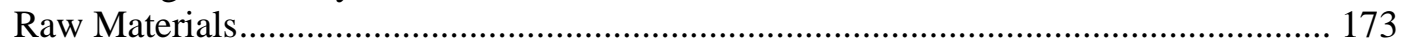

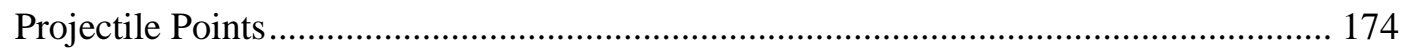

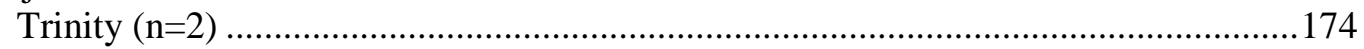

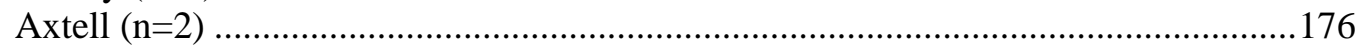

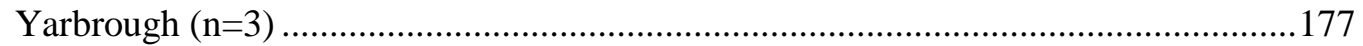

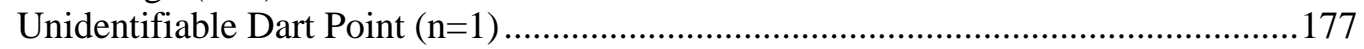

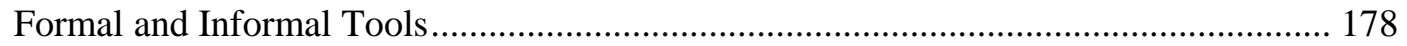

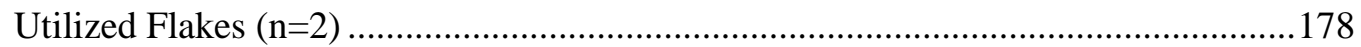

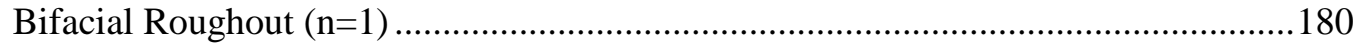

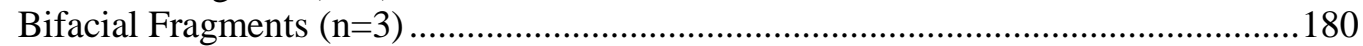

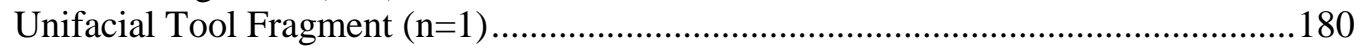

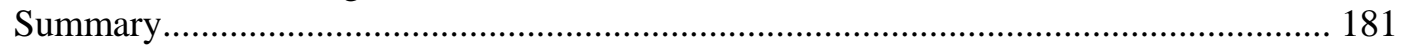

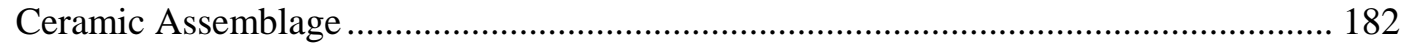

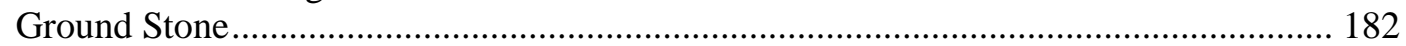

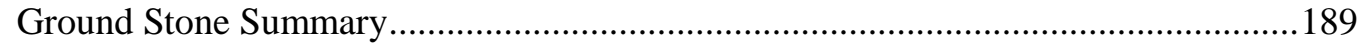

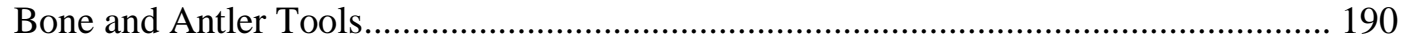

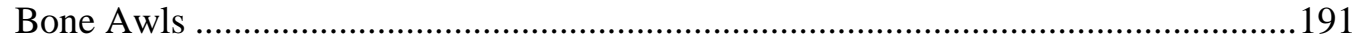

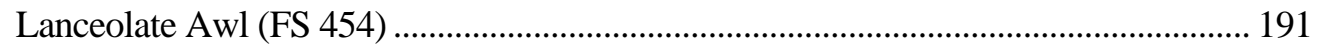

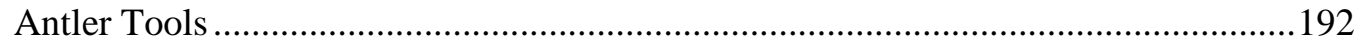

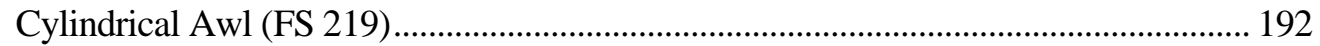

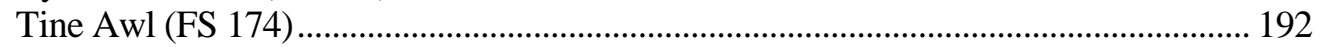

Bone and Antler Tools Summary …......................................................................192

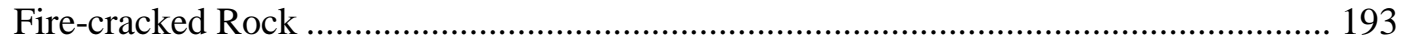

CHAPTER 10. SUBSISTENCE RESOURCES RECOVERED AT SITE 41TR198 …..............203

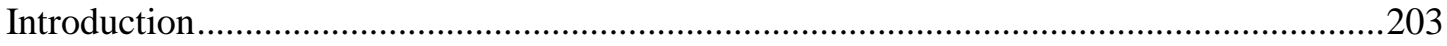

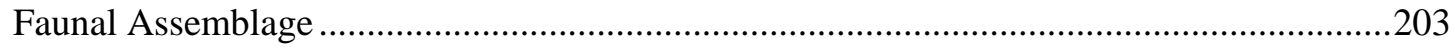

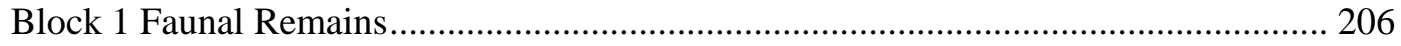

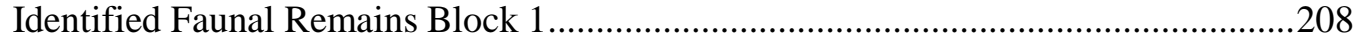




\section{Table of Contents}

(cont'd)

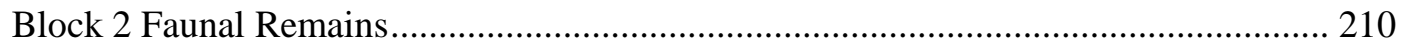

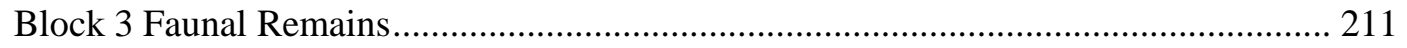

Identified Faunal Remains from A.D. 1040 Occupation Zone (Levels 2 - 6).................. 215

Identified Faunal Remains from A.D. 900 - 960 Occupation Zone (Levels 7 - 9)......... 217

Identified Faunal Remains from A.D. 700 - 900 Occupation Zone (Levels 10 - 11)..... 220

Identified Faunal Remains from A.D. 350 - 700 Occupation Zone (Levels 12 - 15)..... 222

Identified Faunal Remains from A.D. 250 - 350 Occupation Zone (Levels 16 - 19)...... 224

Identified Faunal Remains from 410 B.C. - A.D. 250 Occupation Zone

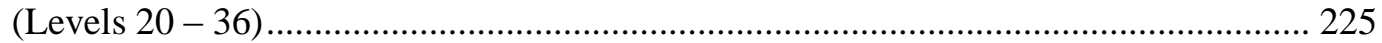

Comparison of Faunal Remains within Block 3 Occupation Zones.............................. 227

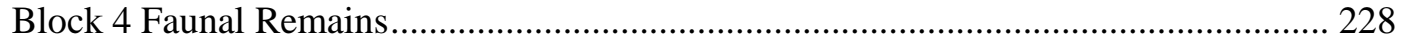

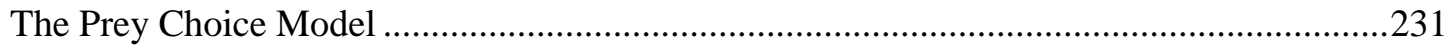

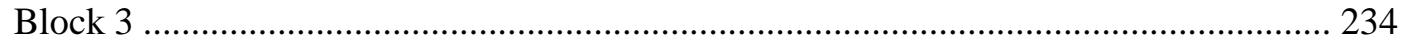

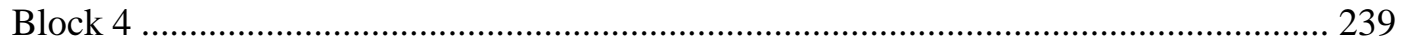

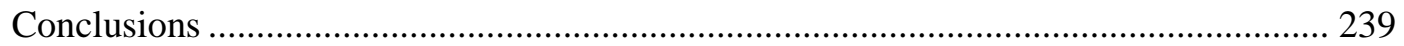

Analysis of Archaeological Freshwater Shellfish Remains from Site 41TR198 ..................240

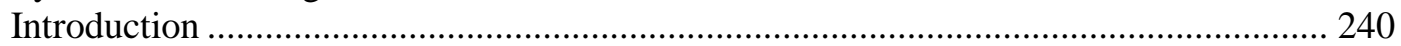

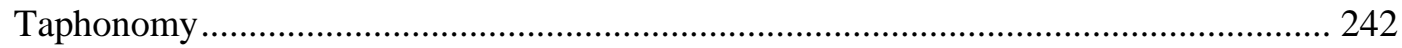

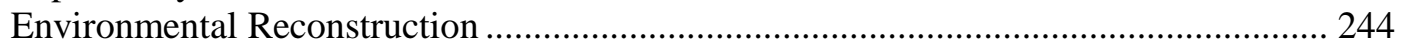

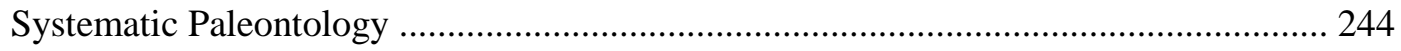

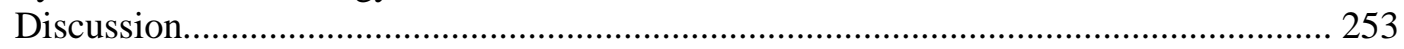

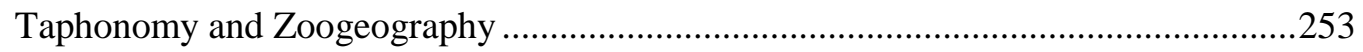

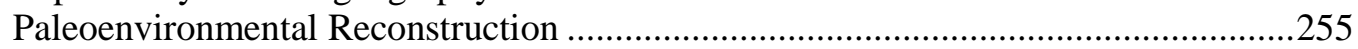

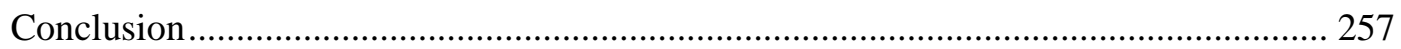

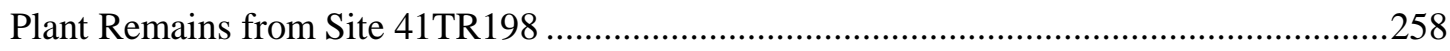

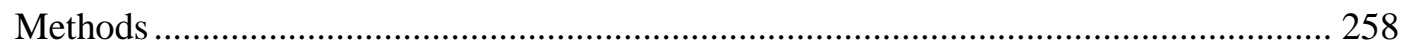

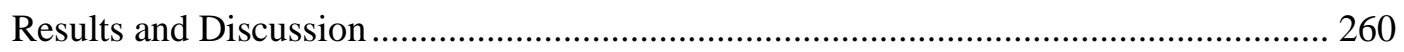

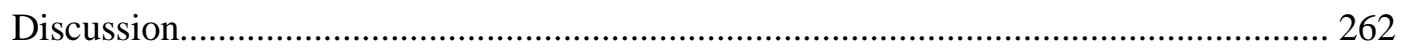

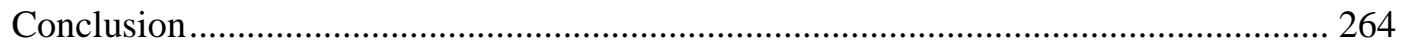

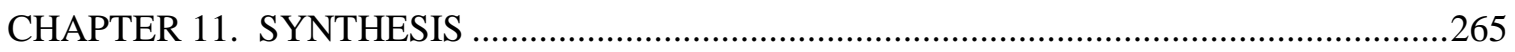

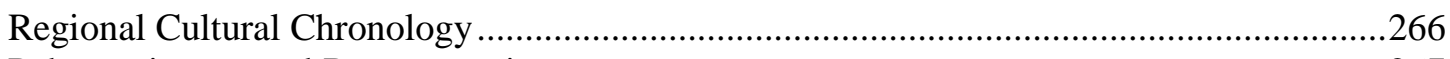

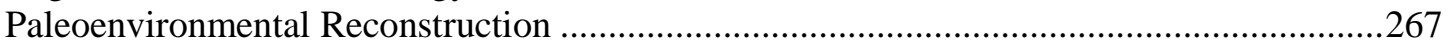

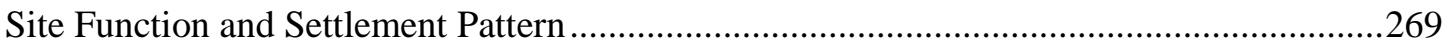

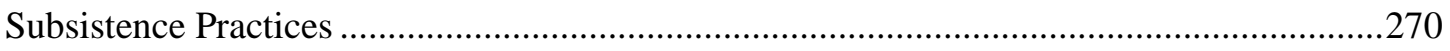

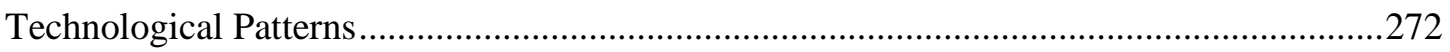

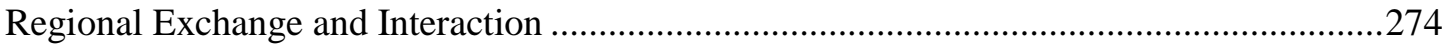

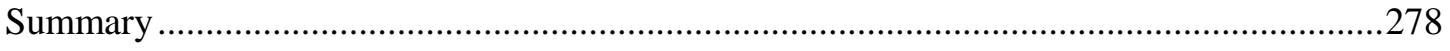

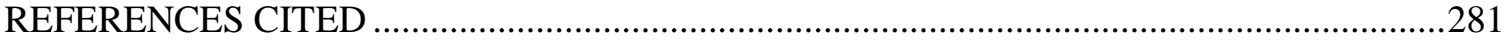


Table of Contents

(cont'd)

\section{APPENDICES:}

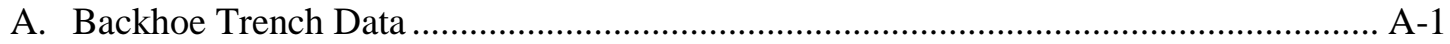

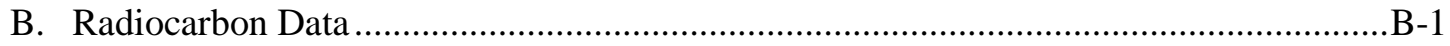

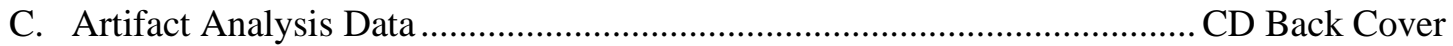




\section{LIST OF FIGURES}

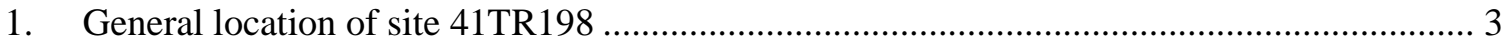

2. Map of site showing locations of trenches, strip units, and excavation blocks ..................... 47

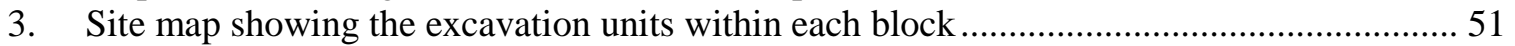

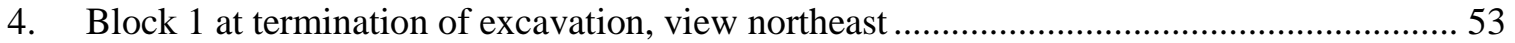

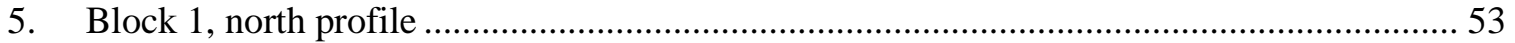

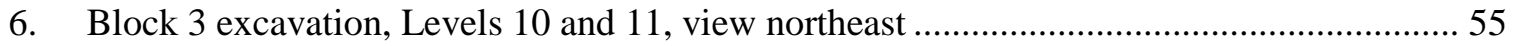

7. Block 3 at completion of data recovery, view west …...................................................... 55

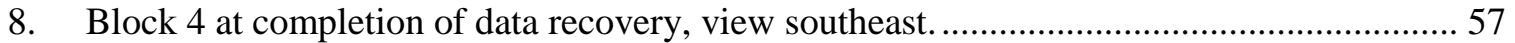

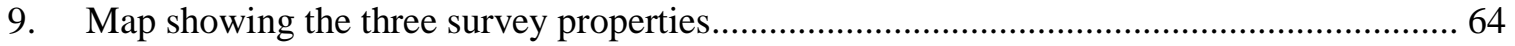

10. 1892 Sam Street's map showing six structures near site 41TR230..................................... 69

11. 41TR198 magnetometer survey areas on the Haltom City Southeast Digital

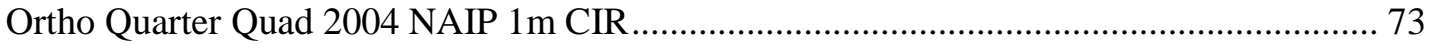

12. 41TR198 magnetometer data processing of the initial 2 ha collection ............................... 75

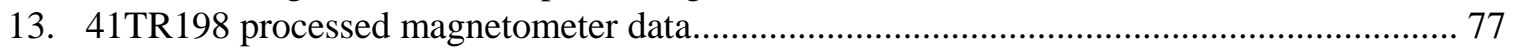

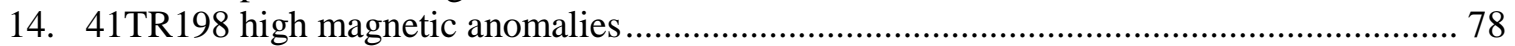

15. 41TR198 high magnetic anomalies on the Haltom City southeast digital ortho

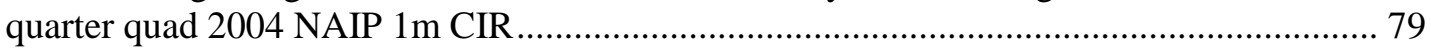

16. Locations of tested anomalies, backhoe trenches and strip units at 41TR198 ..................... 81

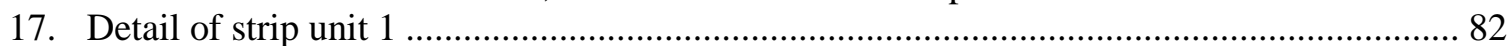

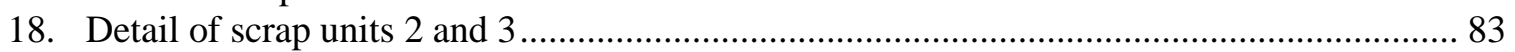

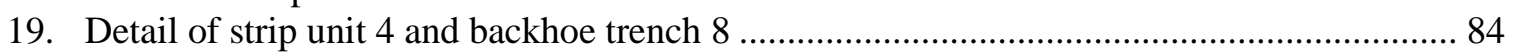

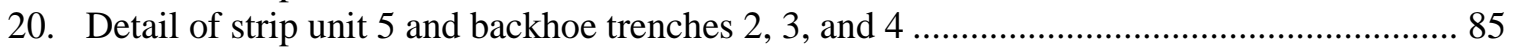

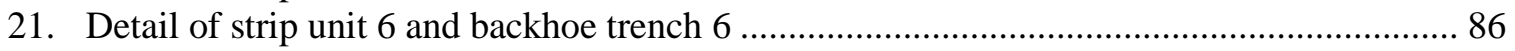

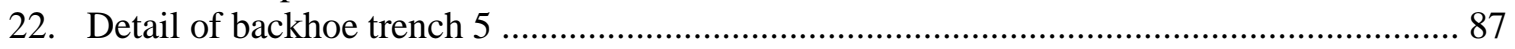

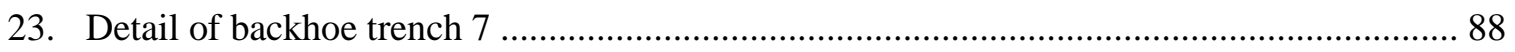

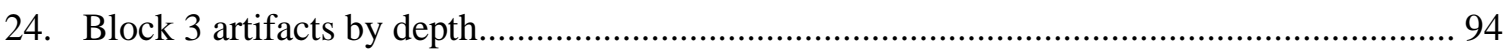

25. 1955 aerial view of 4 site 1TR198 and illustration of the interpretation of the local

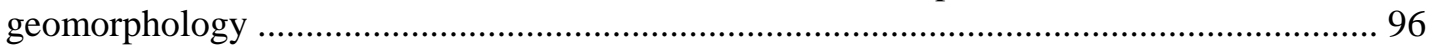

26. Plot of the radius of curvature vs. the meander wavelength for the West Fork of the Trinity River, Sycamore Creek, and the paleochannel in the immediate vicinity of 41TR198 measured from the 1955 aerial photograph 


\section{List of Figures}

(cont'd)

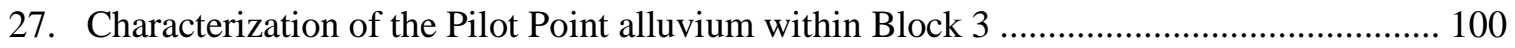

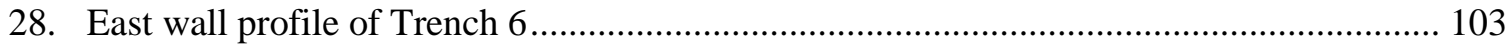

29. 41TR198 sedimentation rates calculated from the radiocarbon dates ................................. 105

30. Comparison of the sedimentation rate at 41TR198 with sedimentation rates at

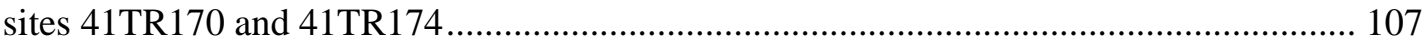

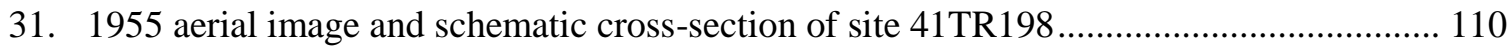

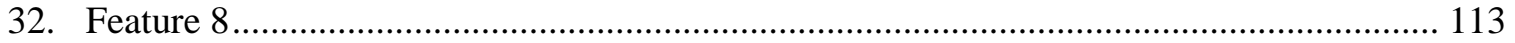

33. Feature 15

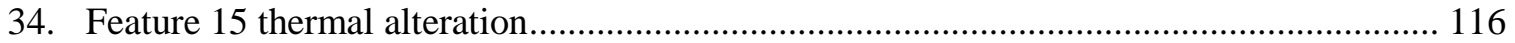

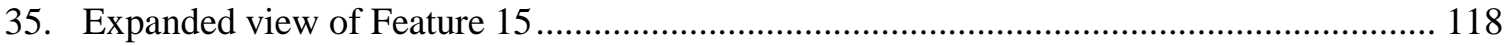

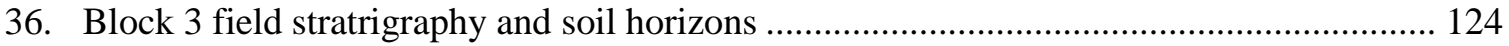

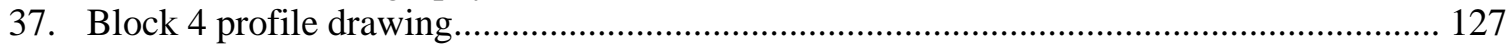

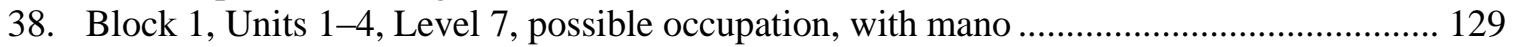

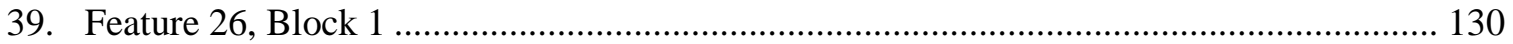

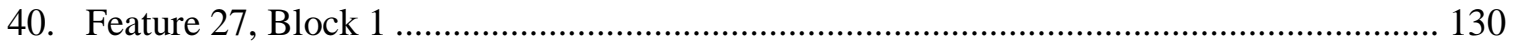

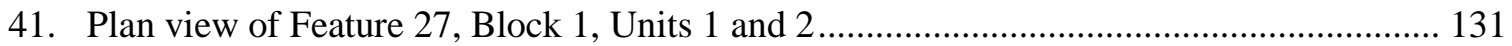

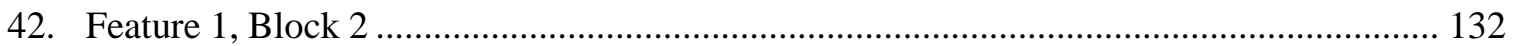

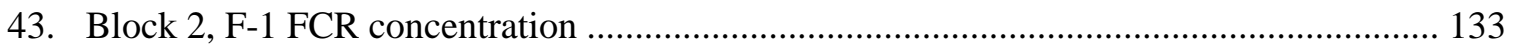

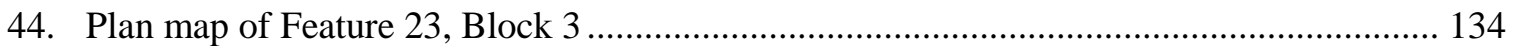

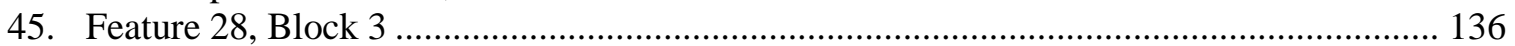

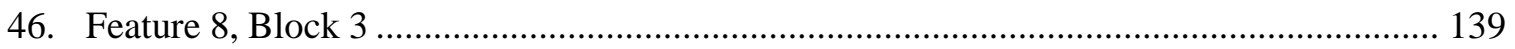

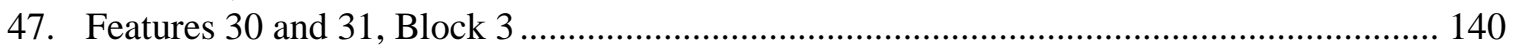

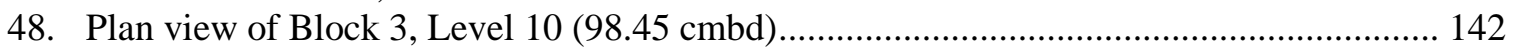

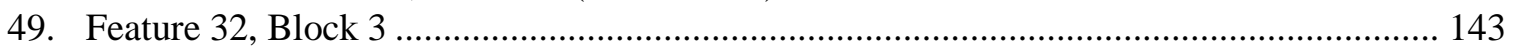

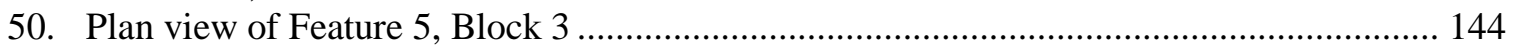

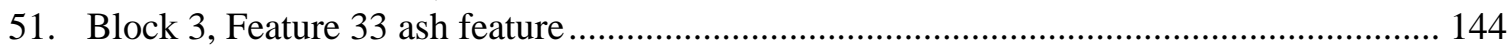

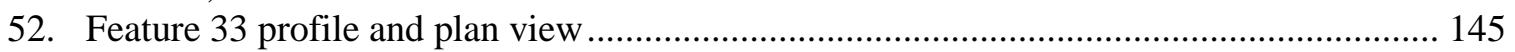

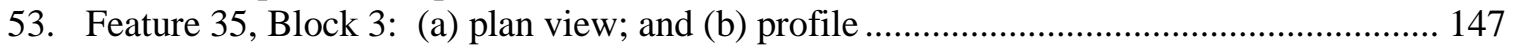

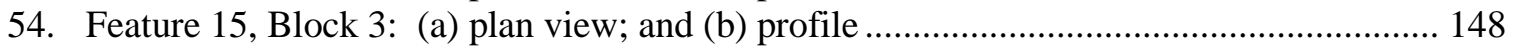

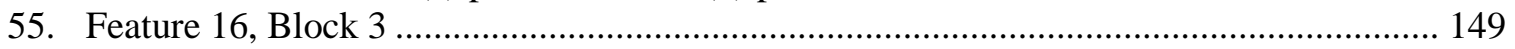

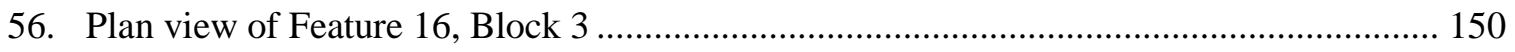

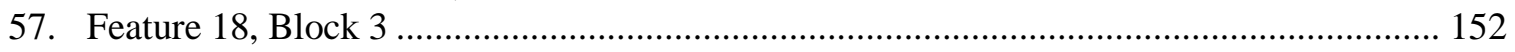

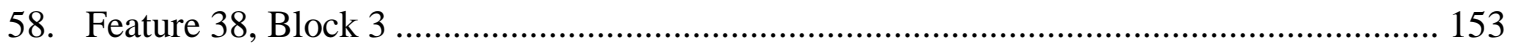

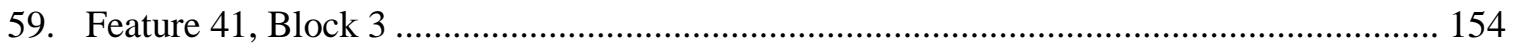

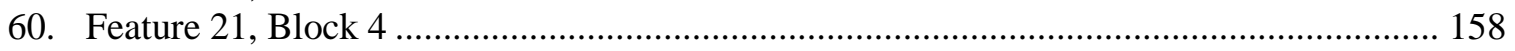

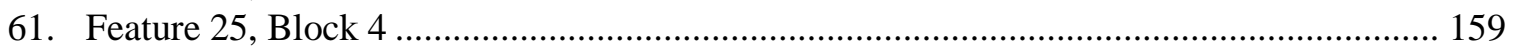

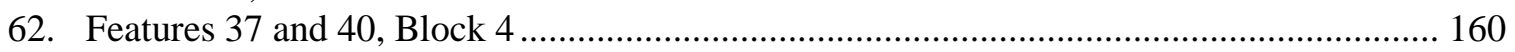

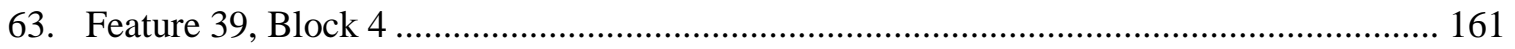

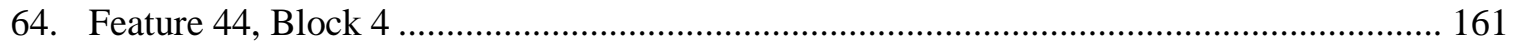

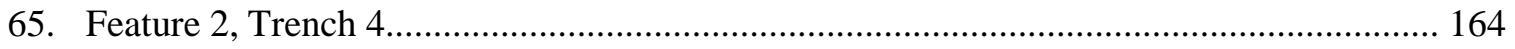

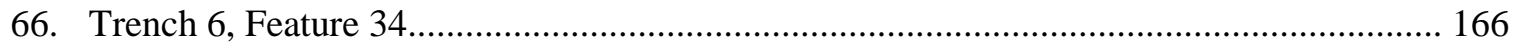

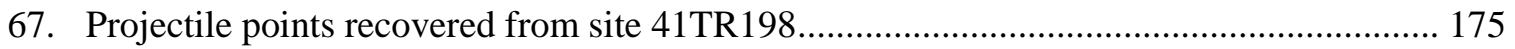

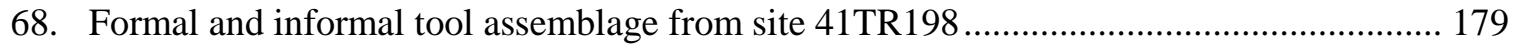




\section{List of Figures}

(cont'd)

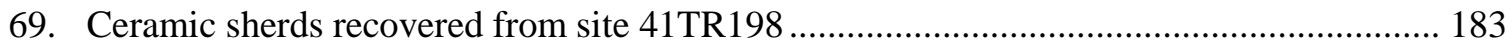

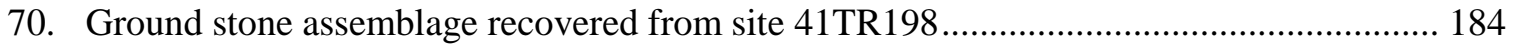

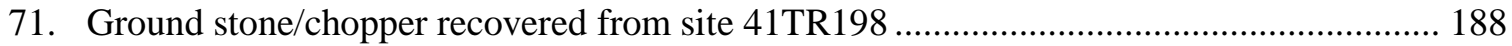

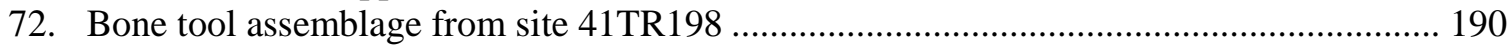

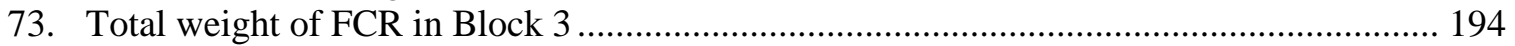

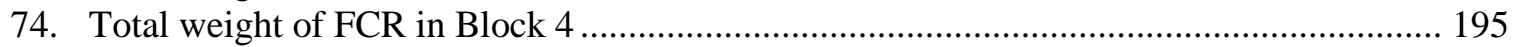

75. Simulated size curves indicating (a) low reuse activity, and (b) high reuse activity .......... 196

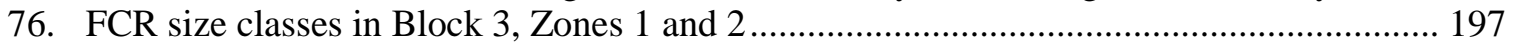

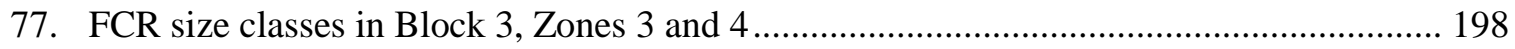

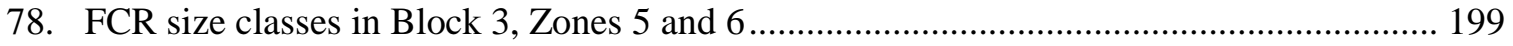

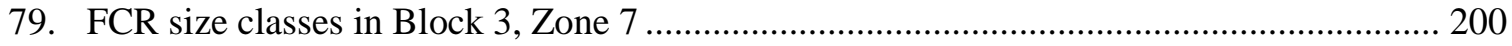

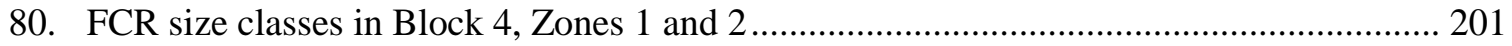

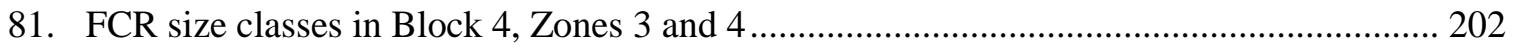

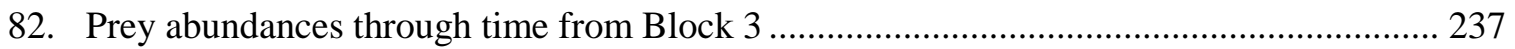

83. Abundances of deer, turtles, small mammals and carnivores through time

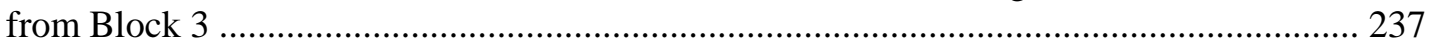

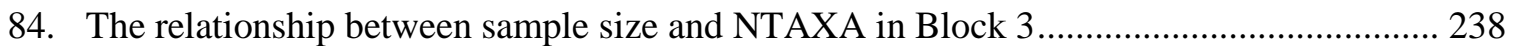

85. Abundances of deer, turtles, and fish through time from Block 3 .................................... 239

86. Prey abundances in the Late Archaic Period for Blocks 3 and 4 ..................................... 240

87. Three-dimensional lollipop graph portraying the average proportional taxonomic abundance of each species from six late Holocene zooarchaeological assemblages

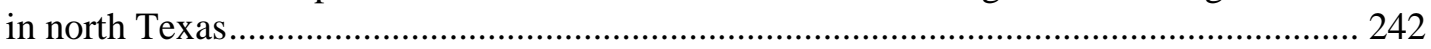

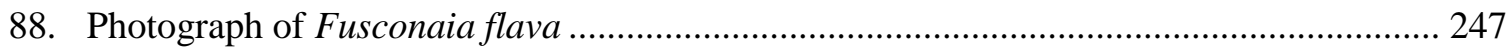

89. Photograph comparing Fusconaia flava and Fusconaia sp. from site 41TR198 ............... 248

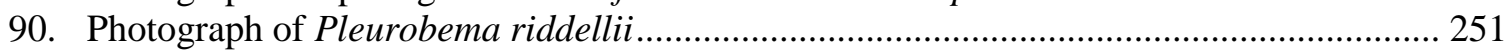

91. Habitat preference scores generated by the spreadsheet program UNIO, based on qualitative (presence/absence) data per time period for 41TR198 .................................... 257

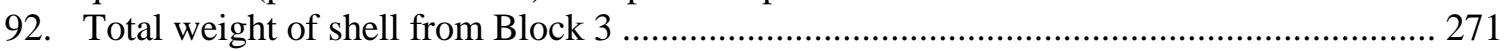

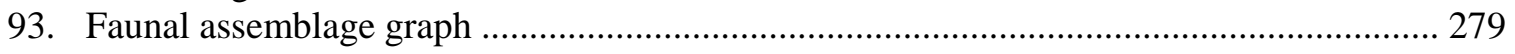




\section{LIST OF TABLES}

1. Native American Chronology for the Upper Trinity River Basin ...................................... 27

2. Data Sets Available at Site 41TR198 to Address Research Domains ................................... 43

3. Data Processing Steps for Magnetometer Data at Site 41TR198 …..................................... 76

4. River Morphology Attributes of Streams Near the Site ...................................................... 90

5. Radiocarbon Ages Obtained from Block 3, and Apparent Sedimentation Rates .................. 90

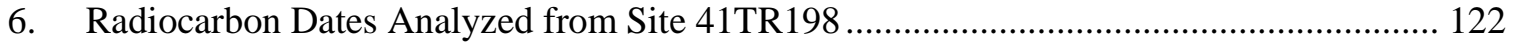

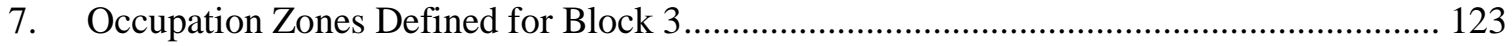

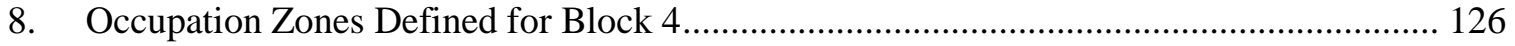

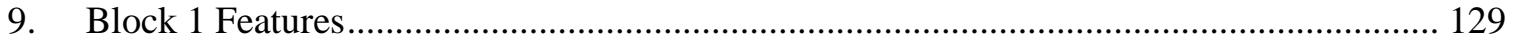

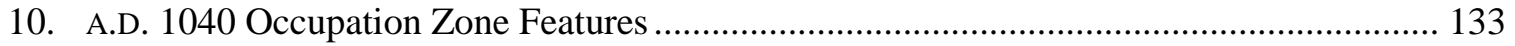

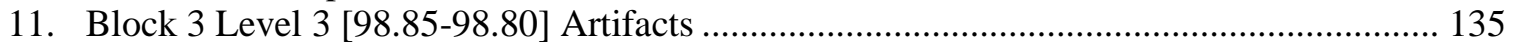

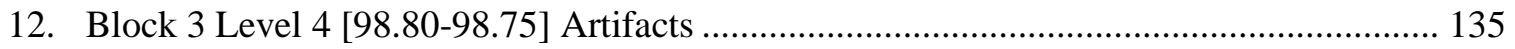

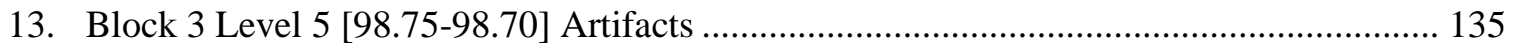

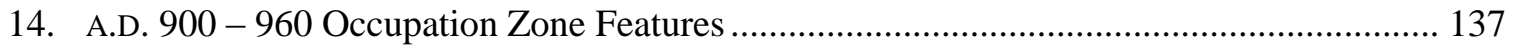

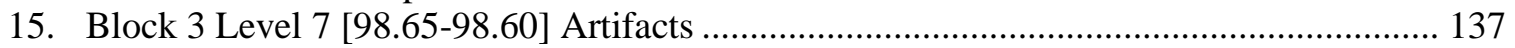

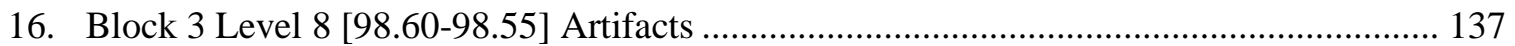

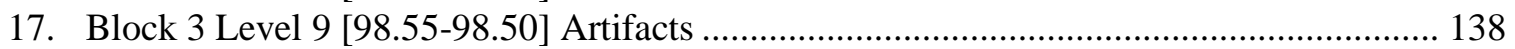

18. A.D. 700 - 900 Occupation Zone Features from Block 3 ................................................ 140

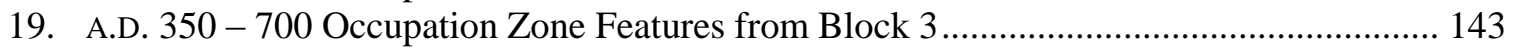

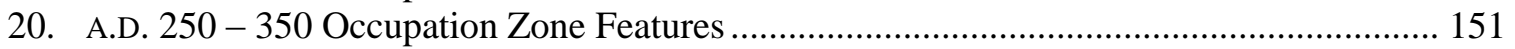

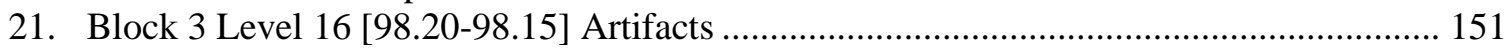

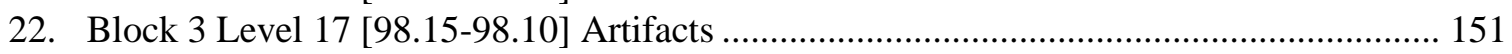

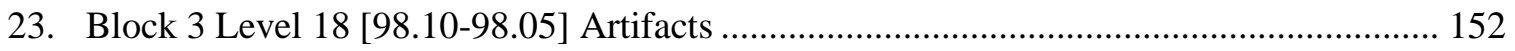

24. 410 B.C. Occupation Zone Artifact Counts from 1-x- m Unit 21, Depth Range

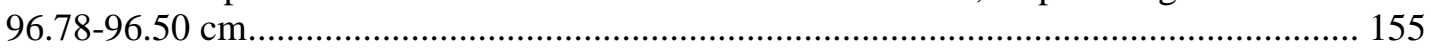

25. 410 B.C. Occupation Zone Artifact Weights (grams) from 1-x-m Unit 21, Depth

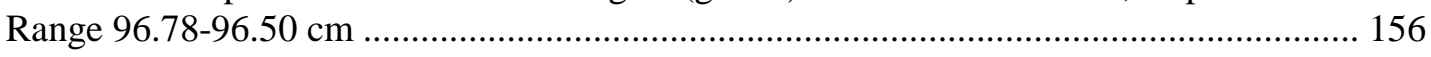

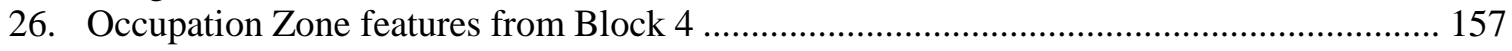

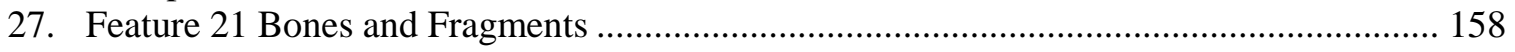

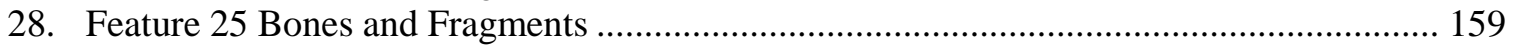

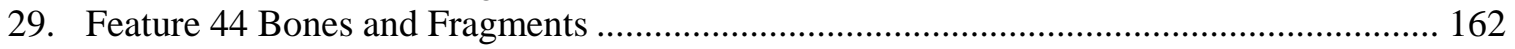

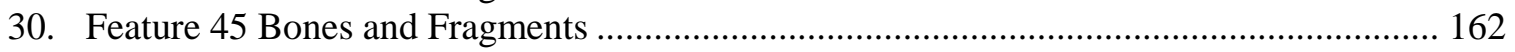


List of Tables

(cont'd)

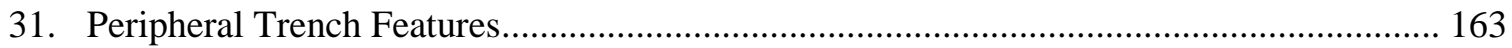

32. Descriptive Statistics for the 86 Pieces of Debitage Comprising the Block 4 Cobble

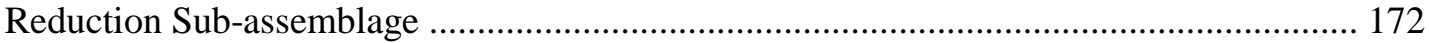

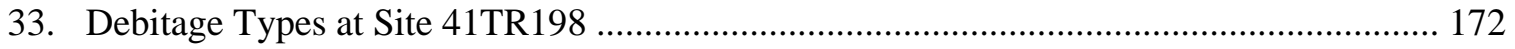

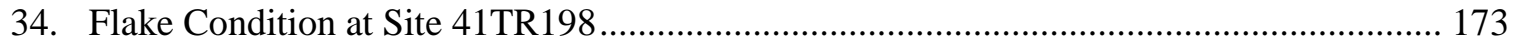

35. Metric Attributes of the Crooked Oxbow Site Dart Points .................................................. 174

36. Raw Material and Condition of the Crooked Oxbow Site Dart Points ................................ 175

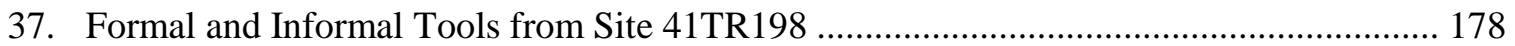

38. Summary of the Crooked Oxbow Site Ground Stone Assemblage ..................................... 184

39. Summary of the Crooked Oxbow Site Bone and Antler Tool Assemblage ......................... 190

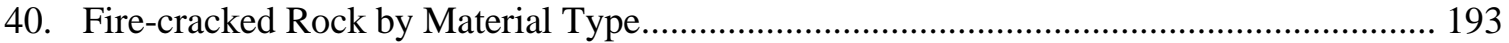

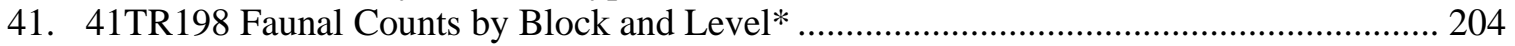

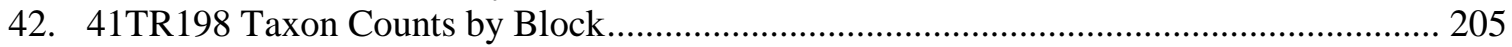

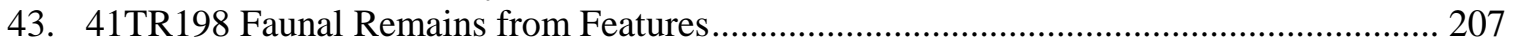

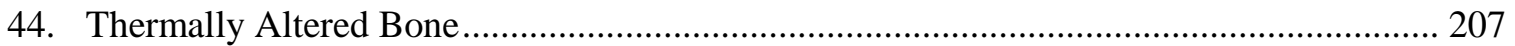

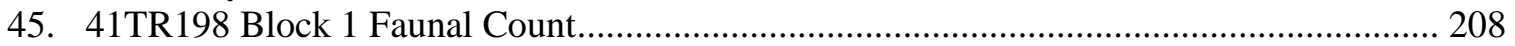

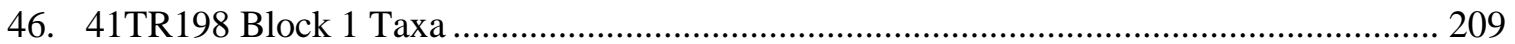

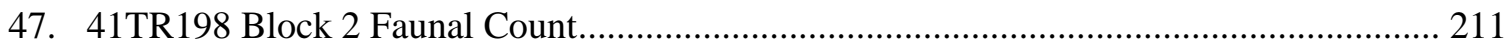

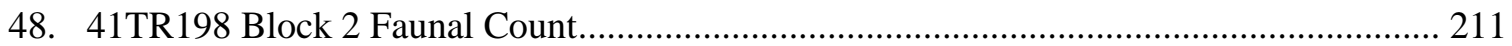

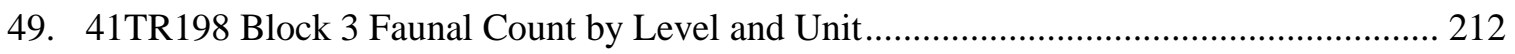

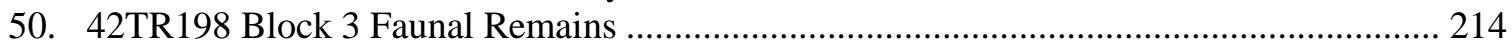

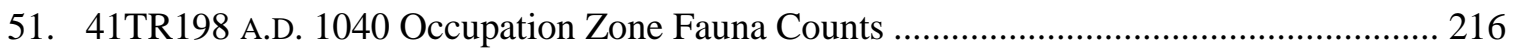

52. 41 TR198 A.D. 900 - 960 Occupation Zone Faunal Count ................................................... 217

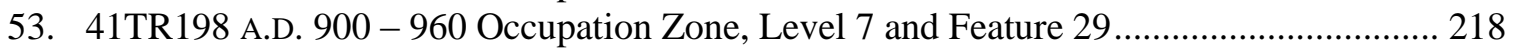

54. 41 TR198 A.D. 900 - 960 Occupation Zone, Level 8 and Features 8/29 ........................... 219

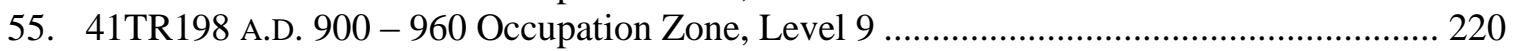

56. 41TR198 A.D. 700 - 900 Occupation Zone Fauna Count .................................................. 220

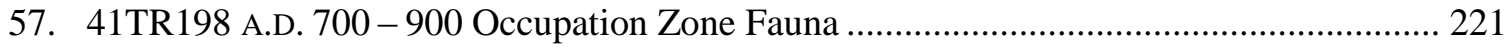

58. 41TR198 A.D. 350 - 700 Occupation Zone Fauna Count................................................... 222

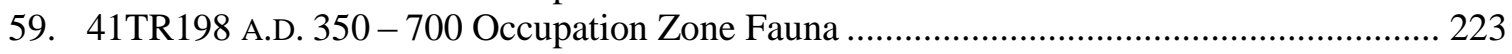

60. 41TR198 A.D. 250 - 350 Occupation Zone Fauna Count................................................... 224

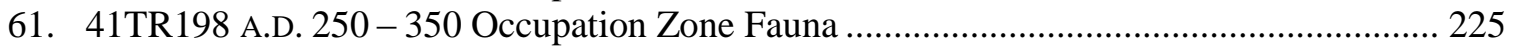

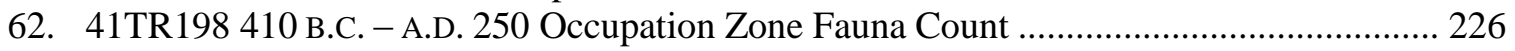

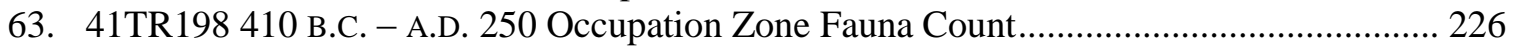

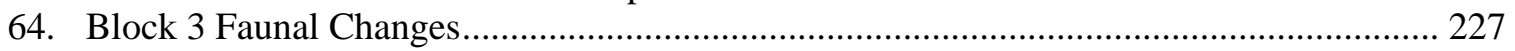

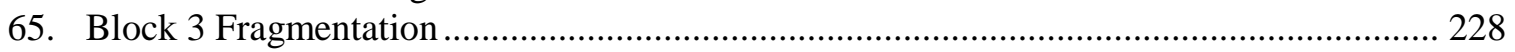

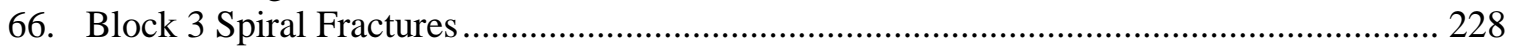

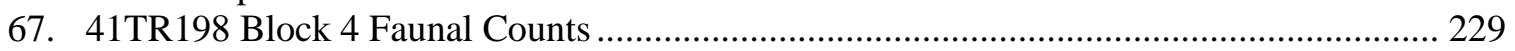

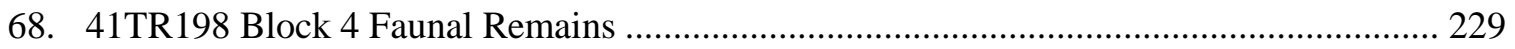

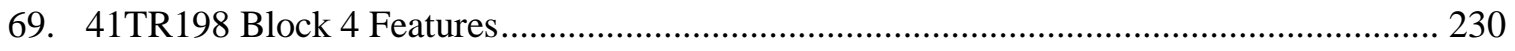

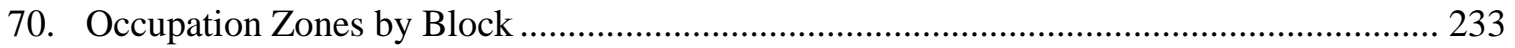

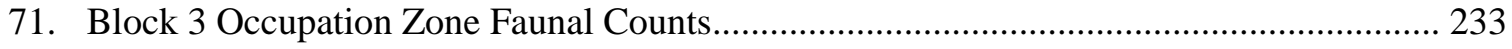

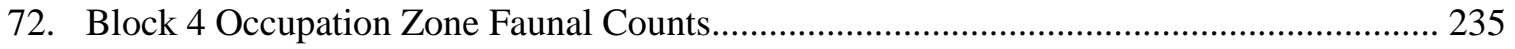




\section{List of Tables}

(cont'd)

73. NTAXA Relative to Deer Abundances Through Time

74. List of Species and NRE for Unionid Remains from 41TR198

75. Taxonomic Abundance, Richness, and Fragmentation Data for Levels from Block 3 ....... 243

76. Flotation Sample Summary

260

77. Results from Flotation and Macrobotanical Samples from Site 41TR198........................ 261

78. The Provenience of Diagnostic Artifacts from Site 41TR198 


\section{ACKNOWLEDGMENTS}

The authors would like to express their appreciation to the many individuals and organizations who contributed to the successful completion of this project. Ms. Nancy Parrish of the U.S. Army Corps of Engineers (USACE), Fort Worth District, was particularly supportive of our efforts and provided both administrative support and guidance. The Tarrant County Water District was helpful in providing access to the property. In the field, the diligence and dedication of the crewmembers were essential to the successful completion of the fieldwork. Thank you to Chris Kugler (Crew Chief) and crewmembers Nick Coleman, Megan Statham, Clay Newton, Steve Dunn, and Craig Cosby. Mr. Steve Hunt, Ms. Bethany Oliver, and Ms. Lindsey Skelton conducted the laboratory analysis and curation, flotation, and assistance with the artifact analysis.

Geologists Dr. Charles Fredrick and Mr. Dave Shanabrook provided geoarchaeological expertise while Dr. Chet Walker (Archaeo-Geophysical Associates, LLC) was responsible for the geophysical survey. Ms. Julie Densmore and Mr. Ben Fullerton analyzed the vertebrate faunal remains. Mr. Charles Randklev and Dr. Steve Wolverton of the University of North Texas analyzed the molluscan fauna. The macrobotanical remains were analyzed by Dr. Phil Dering. Dr. Maynard Cliff and Dr. Tim Perrtula graciously provided their expertise for the recognition of the ceramic assemblage. 
The primary authors would also like to thank those archaeologists who provided their seasoned knowledge and experience, fundamentally and collectively improving this document, specifically Phil Dering, Elton Prewitt, Dr. Maynard Cliff, Dr. Tim Perttula, Dr. Solveig Turpin and Dr. Charles Frederick.

Ms. Michelle Wurtz-Penton and GIS specialists, Mr. Christian Mears, Ms. Erin King, and Mr. Casey Gomez produced all plan views, profiles, and maps. Ms. Wurtz-Penton was also responsible for assembling the prehistoric background section. Ms. Denise Pemberton conducted the manuscript formatting and final production. Without their efforts, this report could not have been completed. 


\section{CHAPTER 1 INTRODUCTION}

This project was undertaken as part of the Riverside Oxbow Project, proposed to restore wetland environments, a riparian corridor, and grassland areas along the West Fork of the Trinity River east of downtown Fort Worth in Tarrant County. This urban renewal project is being sponsored by the U.S. Army Corps of Engineers (USACE), Fort Worth District, in partnership with the City of Fort Worth, and the Tarrant County Water District. Planned impacts from this proposed project include habitat restoration, channel reestablishment, vegetation plantings, new roads, and sports field construction. As a federal agency the USACE is required to undertake cultural resource investigations for their projects in accordance with various state and federal laws including: The National Historic Preservation Act of 1966, as amended through 2001 (16 U.S.C. $\S 470$ et seq.; P.L. 89-665; 80 Stat. 915); the Archeological and Historical Preservation Act of 1974, as amended (16 U.S.C. § 469 et seq.; P.L. 93-291; 88 Stat. 174); the National Environmental Policy Act of 1969 (42 U.S.C. §§ 4321-4347; P.L. 91-190; 83 Stat. 852); Executive Order \#11593; and Native American Graves Protection and Repatriation Act of 1990 (25 U.S.C. § 3001 et seq.; P.L. 101-601; 104 Stat. 3048). Since the Tarrant Regional Water District is the landowner and co-sponsor of the project, and a political subentity of the state of Texas, this project was also conducted under Texas Antiquities Permit No. 5040.

The Area of Potential Effects (APE) includes a 635 acre portion of the flood plain and 330 acres of sloping terraces which bound the river valley to the north and south. The largest area, the flood plain, and the location of 41TR198, is an area of largely undeveloped land traditionally

utilized for agriculture. It is located between a cut off meander of the West Fork of the Trinity River and the straightened modern channel that parallels the north side of Interstate Highway 30. 
Located east of downtown Fort Worth within the city limits, the project area is bound by East First Street on the north, I-30 on the south, Riverside Drive on the west, and the West Fork of the Trinity River on the east side. The Sycamore Heights Addition and the Tandy Hills Park located south of I-30 and east of Beach Street are also part of the project area. The project area is situated between industrialized Fort Worth to the north and the residential area to the south, and consists of unutilized terraces, improved park land, industrial areas, and agricultural fields.

Much of the APE was previously surveyed and evaluated by investigations reported on by GeoMarine, Inc. (Geo-Marine), in 2004 (Huhnke and Wurtz). These investigations resulted in the delineation of one site (41TR198). It was recommended that site 41TR198, because of its depth and integrity, offers a unique opportunity to potentially identify discrete habitation surfaces, thus allowing some understanding of potential changes in adaptation through time. Given the research potential of 41TR198 and limited possibilities for undisturbed flood plain deposits along the West Fork of the Trinity, site 41TR198 was recommended eligible for inclusion in the National Register of Historic Places (NRHP). Avoidance of the site was recommended, but if avoidance was not possible, it was recommended that data recovery be conducted to mitigate the potential damage to the site context. Although avoidance of the site was considered by the project sponsors, USACE, Fort Worth District and the Tarrant Regional Water District, it was decided that data recovery was the preferred mitigation strategy. This report presents the analysis of the materials recovered from site 41TR198 and the results of the survey of an additional 75 acres within the APE (Figure 1).

The deepest impacts planned for the APE are one meter and involve the excavation of a shallow lake utilizing the relict oxbow bordering site 41TR198. Impacts planned for the remainder of the project area will be less than one-half meter deep. Overall, the project will attempt to use the existing landscape as much as possible in order to reduce impacts.

Geo-Marine was contracted by the USACE, under Contract No. W9126G-05-D-0009, Delivery Order 0040 (Geo-Marine project number 10509.00.40). James Harrison served as Project Archaeologist and Duane Peter served as the Principal Investigator. The field crew consisted of Chris Kugler (Crew Chief), Nick Coleman, Megan Statham, Clay Newton, Steve Dunn, and Craig Crosby. The investigations included the systematic survey of 75 acres through shovel testing and backhoe trenching, geophysical survey of site 41TR198 and the excavation of 28 cubic meters of 
Figure Redacted 
matrix within the core area of site 41TR198, the Crooked Oxbow Site. The survey resulted in the recording of one new site, 41TR230, a late nineteenth to early twentieth century house site.

The previous investigations of site 41TR198 (Huhnke and Wurtz 2004:29-33) recognized seven key research domains that might be addressed by the data set potentially present within site 41TR198. These domains were: regional culture history, paleoenvironmental reconstruction, site function, settlement pattern structure, subsistence pattern, technological pattern, and identity and regional exchange and interaction. The methodologies used for the excavation and analysis were designed to collect data essential for addressing these research domains. Geophysical survey was conducted by Dr. Chet Walker to aid identification of features and activity areas. Geoarchaeological studies were conducted by Dr. Charles Frederick and David Shanabrook to provide a better understanding of the site building and transformation processes. Analysis of the faunal (Julie Densmore and Ben Fullerton - vertebrate fauna; Charles Randklev and Dr. Steve Wolverton - molluscan fauna) and macrobotanical remains (Dr. Phil Dering) was designed to aid the interpretation of site function and subsistence practices. Dr. Maynard Cliff and Dr. Tim Perttula graciously provided their expertise concerning the ceramic assemblage. The analysis and synthesis of the data from site 41TR198 provide new insights into the prehistoric usage of the West Fork of the Trinity River valley; however, these insights provide new questions and challenges that demand new and creative methodologies. 


\section{CHAPTER 2 ENVIRONMENTAL SETTING}

\section{INTRODUCTION}

Environmentally, the upper Trinity River basin includes three physiographic zones. Moving from east to west, these are the Blackland Prairie, the Eastern Cross Timbers, and the Grand Prairie (see Yates and Ferring 1986:12-31 for a treatment of the environment of the upper Trinity basin). The project area is located within the Eastern Cross Timbers region, a north-south-trending zone of scrub oak woodland that coincides with a band of sandy soil. The Cross Timbers region is bound to the east by the Blackland Prairie and to the west by the Grand Prairie - both of which are characterized by black, calcareous clay soils and a dominance of grasses. Shrubs and trees are present along stream bottoms and flood plains. The understory of the Cross Timbers is essentially the same as the prairie vegetation, but the sandier soils permit a dense upper story of scrub oak to thrive in the uplands (McMahan et al. 1984).

The entire upper Trinity River basin, including the project area, falls within Blair's (1950:100102) Texan biotic province. Yates and Ferring (1986:22) point out that the Texan province is not so much a distinct geographic unit as it is a giant ecotone in which species from both the east and the west overlap at the limits of their ranges. Species composition and forest density varies greatly among the Grand Prairie, Eastern Cross Timbers, and Trinity River Floodplain Forest. For prehistoric hunter/gatherers, the potential for each zone to provide exploitable floral and faunal resources would have been different from zone to zone. 


\section{GEOLOGY}

Geologically, the project is located primarily in Holocene alluvium and Pleistocene fluviatile terrace deposits. The project border areas are underlain by the Upper Cretaceous Woodbine Formation and the Lower Cretaceous Grayson Marl and Main Street Limestone, undivided. The alluviums are flood plain deposits including indistinct low terrace deposits composed of gravel, sand, silt, silty clay, and organic matter. Fluviatile terraces are composed of gravel, sand, silt, and clay. The Woodbine consists primarily of sandstone and some clay and shale, whereas the Grayson Marl formation consists mostly of calcareous clay and marl (Bureau of Economic Geology 1972).

\section{FLORA AND FAUNA}

The spread of the Dallas/Fort Worth metroplex over the last 100 years has greatly altered the floral and faunal species that historically inhabited the Eastern Cross Timbers, in which the majority of the Riverside Oxbow project area occurs. Historically, the area would have been a distinctive forest type, composed of mast-producing trees. The trees in the cross timbers region, although fewer in number than those in the forest proper, would have produced more mast per tree because of the lack of competition between trees and the ample room for canopy development. Oak would have dominated this zone, producing the acorns that were a major source of carbohydrates for human populations in the early autumn. Oak is also a primary feed for wild turkey and deer, and therefore the Eastern Cross Timbers would have been a desirable environment for those game sources. The undergrowth of berries and grasses would have provided a variety of microhabitats of exploitable floral and faunal resources for early hunter/gatherers (Yates and Ferring 1986).

The Upper Trinity River Floodplain Forest consists of the flood plain forest and the bottomland prairie and occurs where the Eastern Cross Timbers bisects the flood plain. Historically, the bottomland prairie often contained lakes and was subject to seasonal overflow where surface water was retained. The vegetation in these pockets of prairie was similar to the Grand Prairie, primarily grasses and few trees. The flood plain forests contained a large and diverse range of tree species. The forest produced nuts and fruits in abundance as well as providing an attractive habitat for a variety of game animals. 
The number of faunal species currently inhabiting the Trinity River Basin is greatly decreased because of factors such as urbanization and habitat reduction (Yates and Ferring 1986:22). Nevertheless, some of the mammal species that would have previously inhabited the area include coyote (Canis latrans), raccoon (Procyon lotor), squirrel (Sciurus sp.), rabbit (Sylvilagus sp.), skunk (Spilogale sp.), opossum, and armadillo (Dasypus novemcinctus), as well as avian species such as sparrow (Ammondramus sp.), wild turkey, grackle, blackbird (Agelaius sp.), starling, robin, cardinal, and bluejay (see Yates and Ferring, 1986 for complete list). In addition to the large numbers of mammals and birds attracted to it, the riverine flood plain area was also a source of fish, various turtle species, water fowl, and shellfish for prehistoric peoples. Reptile and amphibian species found in the project area include box turtle (Terrapene spp.), snapping turtle (Chelydra spp.), Texas spiny lizard (Sceloporus olivaceus), water snakes (Nerodia spp.), copperhead (Agkistrodon contortrix), bullfrog (Rana catesbiana,) and Texas toad (Bufo compactilis; see Yates and Ferring 1986 for complete list).

The resources in the Eastern Cross Timbers and the Trinity Floodplain Forest would have been the most reliable and abundant source of sustenance for hunter/gatherers because of the variety of foodstuffs available in these zones during spring, summer, and fall. The Grand Prairie would have supported occasional herds of large mammals opportunistically hunted for protein and fat. The region as a whole was characterized by high species diversity (Yates and Ferring 1986:22) corresponding to the variety of ecotones. Despite the presence of large mammal prairie species, such as buffalo and pronghorn, faunal remains recovered from archaeological contexts indicate that deer, found predominantly in the Eastern Cross Timbers and Trinity River Floodplain Forest zones, was the primary source of meat protein throughout the prehistoric period (Yates and Ferring 1986:27).

\section{HYDROLOGY}

The Trinity River is located in an upland divide between the older Red and Brazos rivers. The east-flowing West Fork, the south-flowing Elm Fork, and the south-flowing East Fork are the three major tributaries of the Trinity River. Large creeks such as Sycamore Creek, Big and Little Fossil creeks, Village Creek, and the Clear Fork feed the West Fork itself. The major tributaries are perennial streams, whereas the smaller feeder creeks are classed as intermittent or ephemeral. 
Flash flooding occurs periodically in the Trinity River basin because of high runoff and land alterations resulting from urbanization (Yates and Ferring 1986:12). In order to stem the effects of flooding in the urbanized Riverside area of Fort Worth, the West Fork was channelized in the 1950s. Normal river meander has created abandoned oxbows along the length of the river; one such abandoned oxbow, referred to as the "old oxbow" is located within the flood plain of the study area. The oxbow that currently bounds the flood plain is referred to as "the historic WF Trinity River channel" and the channelized portion of the river is referred to as "the modern WF Trinity River channel."

\section{CLIMATE}

The climate along the West Fork of the Trinity River is described both as subtropical with humid hot summers, and as continental, meaning that the area experiences a wide range of temperature extremes during the year. Winters, which are mild, are punctuated by sudden drops in temperature lasting for about three days each, and brought on by northerly winds. Summers are known to be hot with fair skies and low humidity. Westerly winds prevail. Moisture-laden southerlies from the Gulf of Mexico cause periodic thunderstorms lasting for three to five days each.

The average annual temperature is 65.7 degrees Fahrenheit $\left({ }^{\circ} \mathrm{F} ; 18.9\right.$ degrees Celsius $\left.\left[{ }^{\circ} \mathrm{C}\right]\right)$, with an average annual high temperature of $76.1^{\circ} \mathrm{F}\left(24.7^{\circ} \mathrm{C}\right)$ and an average annual low temperature of $55.2^{\circ} \mathrm{F}\left(13^{\circ} \mathrm{C}\right)$. The average annual precipitation is 32.10 inches (in; $81.5 \mathrm{~cm}$ ); April, May, and June receive the most rain with an average of 3.1 in $(7.9 \mathrm{~cm})$ per month during that span. The average annual snowfall is $2.9 \mathrm{in}$.

\section{PALEOENVIRONMENT}

Paleoenvironmental reconstruction in the West Gulf Coastal Plain has been based largely on faunal assemblages; palynological research in bogs throughout eastern Texas, southern Oklahoma, and Arkansas; and flood plain geology (for recent overviews of paleoenvironmental studies in this area, see Davis 1989 and Story 1990). Generally, hypotheses of prehistoric 
climatic history in northcentral Texas posit a gradual warming trend following the end of the Pleistocene, probably interrupted by several periods of warmer temperature than that of today (Brown 1994a; Bryant and Holloway 1985:56-66; Delcourt and Delcourt 1985:12-22; Ferring 1990:44).

\section{Late Pleistocene}

Paleoenvironmental data from Texas relevant to conditions prior to the last full glacial interval are limited, but suggest increasingly humid conditions after 30,000 years ago in southern Texas (Story 1990:1:22), while pollen data from playa lake deposits on the Llano Estacado may indicate, among other things, a cool and moist climate in West Texas from about 33,500 to 22,500 B.P., during the Rich Lake Interpluvial (Bryant and Holloway 1985:41, 44). Based on this, and on fossil pollen records from southcentral Missouri (Mehringer et al. 1970), Bryant and Holloway (1985:44) suggest moist conditions for North and Central Texas, with the region dominated by "an open vegetation consisting of grasses and herbaceous plants with only a few scattered conifers around 30,000 years ago." Additional support for this reconstruction comes from East Texas, where three stratified paleosols dating to the Middle Wisconsin period Farmdalian interstade (22,000-28,000 B.P.), identified on Caney Creek in Cass County (Cliff and Peter 1992), yielded stable carbon isotope ratios (-27.1\%o, $-24.5 \%$, and $-25.0 \%$ ) that suggest a higher component of $\mathrm{C}_{3}$ plants (i.e., cool-season grasses, most trees, and most aquatic plants; see Herz 1990 and Caran 1998:120-123) and presumably moister conditions.

Within the upper Trinity River valley, Ferring (1990) proposes that the period from 76,000 to 30,000 years ago was very similar to that of today, with fluctuating minor wet and dry intervals (Ferring 1990:Figure 16). He assigns an early to middle Wisconsin date to the Coppell-Tioga alluvium, which he believes was deposited by "a relatively low energy suspended load stream environment" (Ferring 1990:27). Data suggest that during the deposition of this alluvial unit, the Elm Fork valley underwent lateral and headward flood plain extension and slow valley alluviation (Ferring 1990:43-44, Figure 16). Ferring (1990:43) also notes that "the earlier Coppell alluvium contains Rancholabrean vertebrate faunas indicative of moist climates," while "the younger Coppell alluvium has yielded faunas indicative of climatic conditions drier that those of 
early Coppell time." Ferring dates the early Coppell alluvium to the early to middle Wisconsin, and the late Coppell alluvium to the middle Wisconsin.

During the late Wisconsin, climatic conditions in northcentral Texas were probably much cooler and more mesic than those of today (Bryant and Holloway 1985:44), although the increased moisture content may have been a product of greatly reduced summer temperatures. Bryant and Holloway (1985) suggest that North Texas may have been characterized by a mixed deciduous forest. Other evidence (primarily the distribution of mastodon and mammoth remains) suggests that the boundary between the prairie and woodland environments in northcentral Texas may have existed in roughly the same area as it does today (Slaughter and Hoover 1963; Story 1990:1:23). Fossil vertebrates on the Edwards Plateau to the south indicate that from 20,000 to 14,000 B.P. there was "reduced seasonality, with cool and moist summers but with average winter temperatures that were not substantially different from today" (Toomey et al. 1993:304). Based on pollen data, Delcourt and Delcourt (1985:Figure 7a, 15-16) have placed the general Dallas area just north of the ecotonal boundary between boreal forest (similar to that which today characterizes eastern Canada) to the north and a narrow belt of mixed conifer-northern hardwood forest to the south. The pollen records at a number of sites believed to be in similar locations in the southeastern United States at this time are dominated by Jack pine (Pinus banksiana) — today a dominant tree within the southern boreal forest of Manitoba and east-central Ontario. These records and low coefficients of dissimilarity between full-glacial pollen assemblages and modern pollen samples from eastern Canada, suggest that "community composition of full-glacial boreal forests at $36 \mathrm{E} \mathrm{N}$ latitude was within the range of variation in species occurrence and abundance within modern boreal forests of southern Manitoba and east-central Ontario" (Delcourt and Delcourt 1985:16). Pollen records from several bogs in eastcentral Texas indicate a mixed grassland and parkland with northern species such as spruce (Picea) and birch (Betula) between 20,000 and 14,000 B.P. that suggest average summer temperatures in this area as much as $5^{\circ} \mathrm{C}$ lower that today (Toomey et al. 1993:304-305). On the Edwards Plateau, pollen data from Friesenhahn Cave indicate open savanna with mixed grass understory, with cold climate woodlands, including spruce, along the valley bottoms (Toomey et al. 1993:305).

Ferring (1990) characterizes the period from 30,000 to 14,000 B.P. as one of rapid valley incision, which left behind the Hickory Creek terrace in the upper Trinity River valley. He dates the Carrollton alluvium to the early part of this period, suggesting that it was deposited by "bedload 
streams during a period of apparently rapid valley incision and headward channel cutting, following abandonment of the Hickory Creek flood plain" (Ferring 1990:30). He also suggests that "high energy meandering stream environments prevailed during deposition of the Carrollton alluvium" (Ferring 1990:30). Late Rancholabrean fauna, including Bison antiquus, recovered from a series of gravel and sand pit exposures south of Dallas appears to date to the period from around 23,000 to 20,000 B.P. (Willimon 1972). Ferring states that the "vertebrate and invertebrate faunas from Willimon's Carrollton alluvium are more indicative of cooler and moister climates than those of the earlier Coppell alluvium" and notes that Willimon "proposed that there were diminished seasonal temperature extremes compared to today's climate, and also greater stream discharge" (Ferring 1990:45).

\section{Terminal Pleistocene}

Plant response to the onset of the terminal Wisconsin in this portion of northcentral Texas must have been almost immediate, given its hypothesized location close to the southern full-glacial limit of the boreal forest. The decline of northern Diploxylon Pinus species, accompanied by increasing populations of mesic boreal and cool-temperate deciduous taxa, between 16,500 and 12,500 B.P., may indicate the persistence of a cool climate with an increased availability of precipitation during the summer growing season (Delcourt and Delcourt 1985:18-19). Vertebrate cave faunas on the Edwards Plateau indicate that between 15,000 and 13,000 B.P., average summer temperatures increased rapidly while effective moisture decreased between 14,000 and 10,500 B.P. and apparently increased again following 10,500 B.P. (Toomey et al. 1993:305-306). Pollen records from the Edwards Plateau suggest open grassland with some pine and minor amounts of spruce around 13,000 B.P. Cave faunas indicate a dominance of short grasses on the western plateau, mixed grasses in the central plateau, and grassland with riparian woodlands on the eastern margin of the plateau (Toomey et al. 1993:307).

In his most recent overviews (Ferring 1995:Figure 7; Humphrey and Ferring 1994:201), Ferring seems to ascribe the deposition of most, if not all, of the Aubrey alluvium to the "last phase of valley incision into bedrock" in the upper Trinity River valley (Ferring 1990:45). He feels that this "last phase of valley trenching was likely completed between about 20,000 and 15,000 yr B.P.” (Humphrey and Ferring 1994:201). He gives a conjectural date of 25,000? B.P. for its onset 
(Humphrey and Ferring 1994:Table 1) at the Aubrey Clovis site (41DN479), in the Elm Fork valley north of Dallas, while previously noting dates of 20,660 B.P. to 22,130 B.P. for the top of the preceding Carrollton alluvium at localities south of Dallas (Ferring 1990:Table 11).

Ferring identifies a lacustrine facies of the Aubrey alluvium at the Aubrey site, associated with "a spring pool created by apparent channel neck cut-off' (Ferring 1990:30). Dates on these pond deposits range from about 14,200 to 12,330 years ago. These deposits are overlain by Clovis material with dates of 11,540 B.P. and 11,590 B.P. (Humphrey and Ferring 1994:Figure 3). Ferring notes that:

The spring pool at the site filled with marl and peat between ca. 14-11 ka [thousand years ago]. The pond was at the level of the flood plain during this interval, yet only trivial alluvium was deposited, and no erosional disconformity is present. A steep slope remained stable above the pond during this interval, and only just before $11 \mathrm{ka}$ is there evidence for colluvial deposition in the pond depression. Immediately after $11 \mathrm{ka}$, rapid alluviation began the Holocene phase of valley filling.

Ferring concludes that "the last major phase of valley incision was followed by a period of reduced fluvial activity and probable slow erosion of the Aubrey alluvium" (Ferring 1990:33) and that there was "no significant change in the Trinity River valley" between about 14,000 and 11,000 years B.P. (Ferring 1990:45).

Ferring (1990:Figure 16) characterizes the interval from 14,000 to 11,000 B.P. as one of dry climate, stability, and minor erosion. Elsewhere, Humphrey and Ferring (1994:211) note:

Prior to the early Holocene, isotopic, faunal, and botanical evidence at the Aubrey site suggest a latest Pleistocene climate that was cool and dry. Pond dessication and deflation occurred sometime after 12,000 yr B.P. Clovis artifacts occur on this deflationary surface and on the surface of Unit D (deposited up to ca. 11,000 yr B.P.). Shortly after Clovis occupations, alluviation resumed at the Aubrey site. . .

The boundary between the Aubrey alluvium and the overlying Sanger alluvium is reportedly marked by "an erosional disconformity . . . and a weakly developed soil" (Ferring 1990:26), supporting Ferring's contention of a period of stability and minor erosion following the deposition of the Aubrey alluvium.

Regarding the sedimentary environment of the Aubrey alluvium, Ferring (1990:30) states that "along the Elm Fork Trinity Valley, from Ray Roberts Lake to below Dallas, scarps of large entrenched meanders are preserved against bedrock and Carrollton-Coppell alluvium." Ferring interprets these data to indicate "a stream that had meanders 4-5 times as large as those of the 
modern Elm Fork Trinity" that suggest a "high energy stream that incised bedrock following abandonment of the Carrollton flood plain" (Ferring 1990:30). The data suggest to him that "the last major phase of valley incision was accomplished by a bedload stream with large amplitude meanders" (Ferring 1990:30).

\section{Early Holocene}

During the succeeding early Holocene, cool-temperature, mesic tree species became dominant throughout the mid-latitudes of the southeastern United States (Delcourt and Delcourt 1985:19). Reconstructed vegetation maps suggest that the Dallas area was located on or near the ecotone between the Southeastern Evergreen forest to the south and east, and a Mixed Deciduous forest to the north and west, with prairie farther to the west (Delcourt and Delcourt 1985:Figure 7b). In the Ouachita Mountains of eastern Oklahoma, pollen data from Ferndale Bog indicate that grasslands were replacing the previous deciduous conifer woodlands in that area, and that spruce trees were probably no closer than $160 \mathrm{~km}$ (Bryant and Holloway 1985:53-54). Whether pollen data from the Ouachita Mountains are directly applicable to northcentral Texas remains to be demonstrated, however. As Bryant and Holloway (1985:55) suggest, the changes during this period were probably compositional in that the proportions of certain species increased while others decreased. On the Edwards Plateau, changes in cave microvertebrate fauna indicate "gradual and protracted decreases in effective moisture" from 10,500 to 5,000 B.P. (Toomey et al. 1993:307-308). Likewise, "pollen records from the southern Edwards Plateau and eastcentral Texas ... reflect a protracted trend towards drier climatic conditions" (Toomey et al. 1993:309).

As noted above, Ferring suggests that a period of rapid alluviation in the upper Trinity River valley began around 11,000 B.P., and continued throughout the early Holocene, until around 7,500 B.P. (Ferring 1990:45). He interprets this as an indication of a climate wetter than the preceding terminal Wisconsin but not as wet as the late Wisconsin (Ferring 1990:Figure 16). He dates the deposition of the Sanger alluvium to this time period, with its lower boundary identified as the contact with the Aubrey alluvium and its upper boundary being a buried soil and the contact with the Pilot Point alluvium (Ferring 1990:26). A suite of dates on the Sanger alluvium at the Aubrey Clovis site range between about 10,950 and 6,750 B.P., with additional dated locales on the West Fork at Village Creek (ca. 6,450 and 5,700 B.P.) and at Gateway Park (ca. 
8,950 B.P.) near Fort Worth (Ferring 1990:46; Humphrey and Ferring 1994:Table 2). Ferring suggests that "the abrupt shift to valley alluviation [was] caused by an increase in annual precipitation and/or an increase in convectional storm activity" (Ferring 1990:48). Humphrey and Ferring (1994:210-211) note a period of depleted stable carbon isotopes in pedogenic carbonates between 11,000 and 7,500 B.P. that they interpret as the consequence of a period "of higher precipitation when a predominance of the more humid $\mathrm{C}_{3}$ and $\delta^{13} \mathrm{C}$-depleted flora would be expected." In addition to the dominance of cool-temperature, mesic tree species throughout the mid-latitudes of the southeastern United States at this time (Delcourt and Delcourt 1985:19), Ferring (1990:48) notes evidence of moist climates on the Southern Plains during the early Holocene.

\section{Middle Holocene}

The middle Holocene, variously known as the Altithermal, the Climatic Optimum, the Thermal Maximum, the Xerothermic, or the Hypsithermal, is generally believed to have been a period of warming and drying that resulted in the expansion of prairie at the expense of forest (Antevs 1955; Delcourt and Delcourt 1985:19; Wright 1976). Ferring ascribes the development of the Arlington soil in the upper Trinity River valley to the middle Holocene period, feeling that it denotes a "period of flood plain stability or very slow flood plain aggradation that lasted ca. 2-3 millennia" (Ferring 1990:48). He goes on to characterize this period as having "drier climates, with reduced runoff and reduced sediment yields" (Ferring 1990:48).

By 5,000 B.P., the postulated areas of Mixed Deciduous forest north and west of the Dallas area had migrated to the northeast. Meanwhile, the Southeastern Evergreen forest had shifted from one dominated by xeric species of oak and hickory to one dominated by species of southern pine (Delcourt and Delcourt 1985:7c, 20). Although Delcourt and Delcourt place the Dallas area within the Southeastern Evergreen forest at 5,000 B.P., it is more probable that the area was largely bluestem prairie with narrow gallery forests on the valley floors, similar to the western portion of the Osage Plains area in Oklahoma (see Madole et al. 1991).

Recent data from several areas in northcentral Texas suggest that the Altithermal may have had a severe effect in this area. Carbon isotope data from the Aubrey Clovis site and from the Finley Fan site (41HP159) at Cooper Lake on the South Sulphur River indicate a middle Holocene dry 
period with relatively harsh conditions (Ferring 1995; Gadus et al. 1992). Geomorphologic data also indicate reduced sedimentation rates and soil formation in the Trinity and North Sulphur river basins, as well as the formation of middle Holocene dune fields in the upper Trinity River basin (Ferring 1995:30-33). However, at the same time that carbon isotope data from the Aubrey site show a middle Holocene dry period,

the Aubrey oxygen isotopic data show no evidence for higher middle Holocene temperatures. The Aubrey data suggest that mean annual temperatures were not significantly different from those of the present regime; however, we cannot exclude the possibility that differences in middle Holocene seasonality may have existed [Humphrey and Ferring 1994:211].

Farther east, a matrix sample of organic carbon from a loamy fluvial deposit in the flood plain of the East Fork of Elliott Creek in Bowie County yielded a middle Holocene age of 6,370 \pm 100 B.P. which falls in the middle of the Altithermal, and a stable carbon isotope ratio of $-18.8 \%$ (Peter et al. 1991:Appendix H). This is heavier than the ratio of $-23.5 \%$ associated with a soil with a modern date from the same area and suggests that moist-climate $\mathrm{C}_{3}$ plants were less of a component of the biosphere than today, as climatic conditions were significantly warmer and drier, even in deep Northeast Texas. Two buried soils in the Sulphur River flood plain in Cass County have yielded dates which also fall within the middle Holocene (6,540 \pm 90 B.P. and 4,310 \pm 90 B.P.; Cliff and Peter 1992). The first of these dates to the middle of the Altithermal, while the second dates just subsequent to its end. The stable carbon isotope ratios for these two soils (-19.9\% and $-23.1 \%$, respectively) are also heavier than that of the modern soil, also suggesting climatic conditions that were warmer and drier than today, with the harshest conditions present between approximately 6,500 and 6,000 years ago.

\section{Late Holocene}

Following the end of the middle Holocene, climatic conditions apparently became cooler and more mesic, changes that would have been very noticeable near the eastern margin of the Southern Plains. Delcourt and Delcourt (1985:20-21) suggest that modern climatic conditions, with minor fluctuations, became prevalent following the start of the Christian era. The renewal of valley alluviation during the late Holocene was accompanied by the deposition of the Pilot Point alluvium in the upper Trinity River valley (Ferring 1990:48). Subsequent to 4,500 B.P., the thick, cumulic West Fork soil may have begun to form on top of the Pilot Point alluvium (Ferring 
1990:48). Ferring feels that "the Pilot Point alluviation is probably the result of increased precipitation, following the drier middle Holocene" (Ferring 1990:48). Humphrey and Ferring (1994:210-211) note another period of depleted stable carbon isotopes between 3,500 and 2,000 B.P. at the Aubrey site, which they interpret as indicating "overall moist" conditions in the late Holocene, "with a dry excursion from ca. 2000 to 1000 yr B.P."

Most researchers agree that the late Holocene in northcentral Texas was a period of fluctuating wet-dry climatic trends, with disagreement only about the timing of such fluctuations. In a review of paleoenvironmental data from northcentral Texas and the adjacent Southern Plains, Peter and Jurney (1988) suggested that a dry-moist-dry trend in effective moisture occurred between 3,200 and 150 B.P. They projected an initial dry period prior to 2,000 B.P., with a moist period following until approximately 1,000 B.P. Finally, they suggested that drought conditions were prevalent between about 1,000 and 750 B.P., and that a drying trend that continues today was initiated. Ferring (1990) more or less follows this model, suggesting a wet period characterized by moderate to rapid alluviation from 5,000 to 2,000 B.P., followed by a dry period with slow alluviation and pedogenesis from 2,000 to 1,000 B.P., and another wet period with moderate alluviation after 1,000 B.P. (Ferring 1990:Figure 16).

Additional support for a late Holocene "fluctuation" model comes from Cass County in Northeast Texas. Three buried soils dating to the late Holocene, one of which is very recent, were identified within the Sulphur River flood plain (3,480 \pm 80 B.P.; 3,030 \pm 100 B.P.; and $106.2 \pm .8$ percent of modern; Cliff and Peter 1992). These soils would probably have formed under what were essentially modern climatic conditions, although the earliest late Holocene soil appears to have formed under conditions wetter than today, the second under conditions drier than today, and the third under present conditions. The stable carbon isotope ratio for the earliest soil $(-24.4 \%$ ) suggests a higher component of $\mathrm{C}_{3}$ plants and moister conditions than today. The ratio for the second soil (-21.9\%o) suggests that $\mathrm{C}_{3}$ plants were less of a component of the biosphere with climatic conditions possibly harsher than today. The ratio for the recent soil provides a baseline ${ }^{13} \mathrm{C} /{ }^{12} \mathrm{C}$ ratio (-23.5\%) for interpreting the data from the earlier periods. These data suggest that the reconstruction of the period from 5,000 B.P. to 2,000 B.P. as having a uniformly cool and moist climate may gloss over additional climatic fluctuations. 
A cycle of late Holocene climatic fluctuations has also been identified in Central Texas by Toomey et al. (1993), although they reconstruct a dry-wet-dry cycle in that region. Using faunal remains, they characterize the period from 5,000 to 2,500 B.P. as the culmination of "the general decrease in effective moisture that began at the end of the Pleistocene . . when climatic conditions were drier than at any time during the last 20,000 years" (Toomey et al. 1993:309). They further suggest that this period was associated with generally xeric vegetation on the Edwards Plateau, with a very strong west to east gradient. Semi-desert scrub may have prevailed on the southwestern margin of the plateau; the central plateau may have been dominated by short grasses or "probably semi-desert scrub"; and a mixed grassland may have dominated the eastern portion of the plateau, near the Balcones Escarpment (Toomey et al. 1993:310). This dry period was apparently followed by the return of mesic conditions "by ca. 2500 yr B.P. or shortly thereafter" (Toomey et al. 1993:310). Toomey et al. (1993:310-311) note that pollen records from Central Texas and elsewhere in the Southern Plains show a return to mesic conditions by 2,500 B.P. on the southwestern edge of the Edwards Plateau, between 2,500 and 1,500 B.P. east of the Balcones Escarpment, and between 2,500 and 2,000 B.P. in southcentral Oklahoma. Finally, they reconstruct the period from ca. 1,000 B.P. to the present with more xeric conditions (Toomey et al. 1993:311).

More recently, a study of changes in oxygen and carbon isotopic values for freshwater mussel shells from a series of archaeological features at the Denton Creek site (41DL270) provided more support for late Holocene climatic fluctuations in northcentral Texas (Brown 1994b, 1998). Following Toomey et al. (1993), Brown believes that a "warmer drier climate is apparently reflected in the high $\delta^{18} \mathrm{O}$ values between 2600 and 3200 B.P. for Features 9 and 16 at 41DL270" (Brown 1998:168). He goes on to note that "the earliest sample, from Feature 44 in Unit 8 [with an estimated age of 3570 B.P.], seems to reflect cooler and wetter conditions" but admits that "whether this sample reflects a short-term fluctuation or an actual mesic interval is impossible to see from the limited data" (Brown 1998:168). He goes on to note that "a wetter/cooler period in central and north-central Texas after 2500 BP . . is, in fact, supported by the lower $\delta^{18} \mathrm{O}$ values (although some variation is apparent)" and "the rise in Denton Creek $\delta^{18} \mathrm{O}$ values after 1500 BP suggests a return to warmer and drier conditions" (Brown 1998:168). Brown concludes by stating that the oxygen isotope data from the Denton Creek site (41DL270): 
suggest a cooler or wetter period, or at least one with more fall and winter or less summer rain (or possibly even a cooler, drier interval), between 1500 and 2500 years ago, framed by a period which might be generally described as warmer, drier, or with an increased tendency toward summer rainfall and fall/winter droughts. Perhaps even more interesting is the suggestion of a cooler/wetter period before 3500 years ago, a possible hint of a mesic interval in an otherwise warm, dry interval [Brown 1998:169]. 


\section{CHAPTER 3 CULTURAL SETTING}

\section{PREVIOUS ARCHAEOLOGICAL INVESTIGATIONS}

Several major reports concerning the archaeology of the upper Trinity River basin (Peter and McGregor 1988; Prikryl 1987, 1990; Yates and Ferring 1986) summarize the history of archaeological investigations within the upper Trinity River drainage and the cultural-historical framework for the area. Although the combined efforts of professional and avocational archaeologists have recorded numerous sites, much research remains to be done. As noted by McGregor (1988:27-29), many of the excavation efforts within the upper Trinity River basin have focused on reservoir development, especially along the Elm Fork (Crook and Harris 1957, 1958, 1961; Skinner and Baird 1985; Skinner et al. 1982) and the East Fork (Dawson and Sullivan 1973; Lorrain and Hoffrichter 1968; Lynott 1975; Ross 1966). Field school excavations by the University of Texas at Arlington at the Northlake site on Grapevine Creek were also reported in the mid-1970s (Morgan 1975). More recent investigations at Joe Pool Lake (Jurney et al. 1988; Peter and McGregor 1988) and the test excavations of the River Bend site, 41TR68 (Peter et al. 1987), have provided the initial assemblage data necessary for an understanding of the adaptations along the West Fork of the Trinity River.

Several archaeological studies in the upper Trinity River basin have occurred east of the current project area in Arlington, Grand Prairie, and southwest Dallas. These studies suggest that prehistoric archaeological sites are relatively common along the West Fork of the Trinity (Burson and Cliff 1999; Burson et al. 2000; Ferring 1994; Ferring and Byers 1996; Peter and Gaither 
1990; Shaunessy et al. 1994; Trask et al. 1995). In general, these sites are both well preserved and deeply buried within flood plain deposits. Despite their density, however, they tend to be rarely documented and poorly understood, in part because deposits often consist primarily of bone, shell, and hearth features as opposed to obvious lithics or other artifacts.

In recent years the city of Arlington has sponsored several cultural resources investigations. In 1990, a survey of the proposed 47.6-acre Northeast Neighborhood/Community Park in Arlington was undertaken by Geo-Marine (Peter and Gaither 1990). Intensive survey located no cultural resources. In 1991, 110 acres of the proposed Village/Rush Creek Greenspace were surveyed by Geo-Marine (Hunt 1991). No cultural resources were identified during the survey, and the proposed examination of the Village Creek cutbanks proved futile due to high water conditions. Late in 1992, a survey was conducted of the proposed 85-acre Rush Creek Linear and Neighborhood parks (Hunt and Peter 1993a). One previously recorded prehistoric site, 41TR14 (Whitsett 1976), was known to be present within the survey area; a Carrollton or a Bulverde dart point, indicating a possible Middle Archaic cultural affiliation, and lithic debris were recovered from the site. No evidence of this site could be found, presumably because the site was destroyed by construction of the Rush Creek interceptor. Two localities, one historic and one prehistoric, were identified during the investigation. In 1993, a survey of portions of the existing Cravens Park (Hunt and Peter 1993b) identified three historic localities. In the spring of 1994, a survey of the proposed Lynn Creek Linear and Neighborhood parks discovered two historic localities (Hunt et al. 1994), but the 1994 intensive survey of the proposed Bowman Springs Road Park failed to identify cultural resources (Hunt and Peter 1995). In the fall of 1995, a similar survey was conducted for the 15-acre proposed Kelly Elliott Road Park; one historic site (41TR154) was located, which, based on historic maps, might have been first occupied in the late nineteenth century and whose occupation continued until the property was purchased by the city of Arlington. Although extant structures were present at site 41TR154, very limited cultural deposits were encountered, and the site was recommended as ineligible for inclusion in the NRHP (Hunt and Peter 1996a).

During early 1996, Geo-Marine undertook survey of the proposed 9-acre East Arlington Neighborhood Park in January (Hunt and Peter 1996b) and the proposed 10-acre Tri-City Park in April (Hunt and Krapf 1996), but no cultural resources were identified during either project. In October 1996, Geo-Marine survey of the 110-acre Southwest Arlington Sports Center (Hunt and 
Krapf 1997) yielded one historic site (41TR159) and one historic structure; both properties were considered ineligible for inclusion in the NRHP or for nomination as a State Archeological Landmark (SAL). In January 2000, Geo-Marine conducted a survey of the proposed 9.95-acre California Lane Neighborhood Park, but again, no cultural resources were identified (Hunt 2000). Finally, in March, 2000, Geo-Marine surveyed the 104.3-acre Community Park site in southeastern Arlington, documenting one historic site (41TR175), four historic localities, and five structures. None of these cultural resources was considered eligible for inclusion in the NRHP or for nomination as an SAL (Clow 2000).

Recent cultural resources investigations for the Trinity River Regional Park were undertaken by Geo-Marine for the city of Arlington (Tiné 2002), during which a single historic locality was discovered during investigations for the proposed park. A search of TARL site files, however, revealed eight previously recorded prehistoric sites (41TR141, 41TR142, 41TR143, 41TR144, 41TR145, 41TR146, 41TR161, and 41TR167) located along the Trinity River or one of its abandoned meander channels near the project location. These sites generally occurred as deeply buried deposits, visible primarily through inspection of cutbanks or through backhoe trenching. The exception was site 41TR141, which was identified through exposed materials on the ground surface. Typically, these sites were temporary occupation sites identifiable by the presence of hearth-type features, fire-cracked rock, lenses of mussel shell, animal bone, and very few lithic artifacts. Temporally diagnostic artifacts were limited, although geological contexts suggest occupation primarily during the Early to Late Archaic periods, but possibly extending into the Late Historic period. Such sites are consistent with others identified along the West Fork of the Trinity River in Dallas and Tarrant counties (e.g., Burson et al. 2000; Buysse 2000; Ellis 1998; Peter and McGregor 1988; Yates and Ferring 1986). All eight of these previously recorded sites are unique in comparison to the majority of previously identified sites along the upper Trinity River basin in terms of their artifact assemblages, and they may represent a less well-documented cultural or occupational horizon (Burson et al. 2000).

Many of the archaeological investigations undertaken in Tarrant County have been associated with reservoir projects. Lake Benbrook was surveyed by the River Basin Survey in 1948, but no sites were discovered (Stephenson 1949). Survey, testing, and mitigation efforts were undertaken in the 1970s and 1980s at the above-mentioned Joe Pool Lake (formerly Lakeview Reservoir; Ferring and Reese 1980; Jurney et al. 1988; Peter and McGregor 1988; Raab and Woosley 1982; 
Raab et al. 1982; Skinner and Connors 1979). The Texas Water Board also sponsored several investigations in the county (Jurgens 1982; Whitsett 1976; Whitsett and Fox 1979, 1980). Considerable work by the archaeological societies of both Dallas and Tarrant counties has been done in the region. Johnson (1956) reported the excavations at site 41 TR56 by the Tarrant County Archeological Society.

Closer to the current project area, several cultural resources surveys have been conducted in the Big Fossil Creek watershed subsequent to 1976 (Texas Historical Commission [THC]). A search of THC records produced two reports that covered small surveys for alternative locations of a wastewater interceptor (Fox 1979; McCormick 1976). Both surveys were conducted near the confluence of Little Fossil and Big Fossil creeks. Neither survey recovered cultural material. Both authors conceded that prehistoric remains may be deeply buried in the flood plain deposits, but both also asserted that those remains would be widely scattered and sparse, and discovery of such remains via survey would be unlikely. Another survey in 1996 undertaken for the proposed Villages of Fossil Creek also revealed no cultural resources (Krapf and Hunt 1996).

In 2002, Geo-Marine conducted an archaeological survey of an approximate 900-acre tract, 600 acres of which were within the flood plain of the West Fork of the Trinity River. The survey was in response of the U.S. Army Corps of Engineers (USACE), Fort Worth District, proposed undertaking a Corp of Engineer environmental restoration plan for the Riverside Oxbow Project, focusing on the restoration of wetlands environments, a riparian corridor, and grassland areas in Tarrant County, Texas. Pedestrian survey was conducted over 121.4 ha (300 ac) of the project area consisting of the riverbanks of the West Fork of the Trinity River and upland terraces were surveyed. A total of 91 judgmentally placed shovel tests failed to reveal the presence of any archaeological deposits in those areas. Forty-one backhoe trenches excavated in deep, intact, alluvial flood plain sediments (242.8 ha [600 ac]), however, revealed the presence of one site, 41 TR198.

A search of TARL site files revealed nine previously recorded prehistoric sites (41TR68, 41TR141, 41TR142, 41TR143, 41TR144, 41TR145, 41TR146, 41TR161, and 41TR167) located along the West Fork of the Trinity River or one of its abandoned meander channels near 41TR198. These sites generally occur as deeply buried deposits, visible primarily through inspection of cutbanks or through backhoe trenching. The exception was site 41TR141, which 
was identified through exposed materials on the ground surface. Typically, these sites are temporary occupation sites identifiable by the presence of thermal features, fire-cracked rock, lenses of mussel shell, animal bone, and a very limited amount of flaked stone artifacts.

Temporally diagnostic artifacts were limited, although geological contexts suggest occupation sometime during the Early to Late Archaic periods, with some possibly extending later. Such sites are consistent with others identified along the West Fork of the Trinity River in Dallas and Tarrant counties (e.g., Burson et al. 2000; Buysse 2000; Ellis 1998; Peter and McGregor 1988; Yates and Ferring 1986). All nine of these previously recorded sites are unique in comparison to the majority of previously identified sites along the upper Trinity River basin in terms of their artifact assemblages, and they may represent a little documented cultural focus or adaptation (Burson et al. 2000).

Site 41TR68, the River Bend Site, along the West Fork of the Trinity River, was visible in the cutbank of the river 0.75-1.5 m below the ground surface (Peter and Yates 1987). The site was described as a riverside campsite/mussel-collecting area measuring approximately $150-\mathrm{x}-30 \mathrm{~m}$, but was thought to have been larger during its occupation. Similar to the cultural materials found during the investigations in Trinity River Regional Park, artifacts of shell, burned rock, and lithic material were recorded. Excavations at this site have helped to lay the foundation for understanding adaptations along this portion of the West Fork of the Trinity River.

Site 41TR132 is similar in nature to prehistoric site 41TR68. Site 41TR132 was recorded as a prehistoric shell lens exposed in the creek bank near the junction of the two arms of Whites Creek. The site, approximately one $\mathrm{m}$ below the ground surface and extending three to four $\mathrm{m}$ along the bank, consisted of a 10-cm-thick layer of fire-reddened limestone slabs associated with fresh-water mussel shells. The site was interpreted as a mussel-collecting locality although no bone, flaked stone, etc. were found in association with the shell lens (Skinner and Whorton 1993).

Within the city of Fort Worth, Geo-Marine conducted a project at the East First Street Bridge, which revealed National Register-eligible prehistoric site 41TR138 (Peter et al. 1998). Site 41TR138, another mussel-collecting site located west of 41TR68 on the east bank of the West Fork, measured approximately 300-x-50 m (TARL site data form; Peter et al. 1998). The site was exposed through backhoe trenching and hand-excavated units. Artifacts identified included two 
flakes, bone, and turtle shell. Observed features consisted of three fire-cracked rock features exposed in the backhoe trenches and a thick shell lens located $1.7 \mathrm{~m}$ below ground surface. The fire-cracked rock features were basin-shaped in profile. Concentrations of charcoal were also found in association with these deposits, and site 41TR138 was recommended eligible for inclusion in the NRHP (Peter et al. 1998).

Although not on the West Fork, another noteworthy project was the testing and excavation of 41TR170 on the Clear Fork of the Trinity River in Fort Worth (Lintz et al. 2005). This project documented multiple well preserved, low density occupations and a regionally atypical burned rock midden.

Site 41TR72 is located just west of the Saginaw airport along Willow Creek (TARL site data form). The site was described as a 15-x-15-m scatter of historic period material dating from approximately 1890 through 1950 and was located on the edge of the first low terrace formed by the creek. The site was too small to represent the location of a house or other structure, but rather, was likely trash associated with an occupation.

Sites 41TR131 and 41TR132 were recorded during a 100-acre survey of a portion of Whites Creek conducted by AR Consultants in 1993 (Skinner and Whorton 1993). The survey was carried out in this area via limited subsurface shovel testing and visual inspection of the eroded creek bank and surrounding surface. Site 41TR131 is a historic trash scatter likely associated with a residence shown on the 1924 soils map of the area. Artifacts included bottle glass, brick, earthenware, plastic, and cans dating from the 1930s to approximately the 1960s. The trash was accumulated on a small "bench" and spilled down the eroded slope of the bench almost to the creek, covering an area of approximately 15-x-20 m (Skinner and Whorton 1993). Site 41TR132 is similar in nature to prehistoric site 41TR68. Site 41TR132 was recorded as a prehistoric shell lens exposed in the creek bank near the junction of the two arms of Whites Creek. The site, approximately $1 \mathrm{~m}$ below the ground surface and extending 3-4 $\mathrm{m}$ along the bank, consisted of a 10-cm-thick layer of fire-reddened limestone slabs associated with fresh-water mussel shells. The site was interpreted as a mussel-collecting locality although no bone, lithic debitage, or chipped stone tools were found in association with the shell lens (Skinner and Whorton 1993). 
Within the city of Fort Worth, Geo-Marine conducted projects at the Fort Worth Zoo (Edwards and Peter 1991) and the Tarrant County Railtran corridor (Hunt et al. 1993), as well as at the East First Street Bridge, which revealed National Register-eligible prehistoric site 41TR138 (Peter et al. 1998). Site 41TR138, another mussel-collecting site located west of 41 TR68 on the east bank of the West Fork, measured approximately 300-x-50 m (TARL site data form; Peter et al. 1998). The site was exposed through backhoe trenching and hand-excavated units. Artifacts identified included two flakes, bone, and turtle shell. Observed features consisted of three hearths exposed in the backhoe trenches and a thick shell lens located $1.7 \mathrm{~m}$ below ground surface. The hearths were described as basin-shaped lenses of fire-cracked rock. Concentrations of charcoal were also found in association with these deposits, and site 41TR138 was recommended eligible for inclusion in the NRHP (Peter et al. 1998).

Investigations by AR Consultants (Skinner 1997; Skinner and Whorton 1993; Trask and Whorton 1995; Whorton and Skinner 1995) along Whites Creek and at the confluence of Whites and Big Fossil creeks indicate that, while the potential for prehistoric remains exists, the likelihood of discovery is diminished by the depth of the flood plain deposits, the ephemeral nature of prehistoric use of the area, and modern development. Skinner and Whorton (1993:21) did, however, conclude from their historic research of the Whites Creek area that the Chisolm Trail may have run close to their project area. In particular, they cite the 1870s General Land Office map that shows a north-south trail passing east of Whites Creek. The trail is unnamed on the map, and Skinner and Whorton (1993:16) note that "Creeks to the east and west are mapped wrong." If the Chisolm Trail did indeed pass through the area, the wagons and cattle following the trail would have left a mark in the landscape in the form of wagon swales. These swales could still be visible today in relatively undeveloped areas in the region.

In 2001, Geo-Marine conducted a background research and pedestrian reconnaissance survey of the Big Fossil Creek drainage. A geographical information system (GIS) model was designed to evaluate the probability for both surface and subsurface cultural resources deposits and to make recommendations for further treatment of any properties (Parrish and Burson 2002). The results of the GIS model combined with the research and field observations were analyzed to create a predictive model for site potential within the Big Fossil Creek drainage. Recommendations suggested that future archaeological survey be limited to undisturbed cutbanks in the eastern half of the drainage. In the southeastern portion of the drainage, near the confluence of Big Fossil 
Creek and the West Fork of the Trinity River, backhoe trenching in flood plain areas, along with intensive cutbank survey, was recommended to locate deeply buried deposits. No future archaeological survey was recommended for the upland prairie region of the drainage west of Interstate 35, and archival data indicated that the potential for historic buildings adjacent to the channel was extremely limited.

Geo-Marine conducted a cultural resources investigation for the Trinity River Authority (TRA) sanitary sewer relief interceptor project along 16,000 feet of the Trinity River's West Fork in Grand Prairie and Arlington (Burson et al. 2000). Although no cultural resources were identified at the proposed construction area in Grand Prairie, the western end of the project area in Arlington yielded a previously undocumented prehistoric site (41TR174) at the Trinity River crossing. Site 41TR174 lies within a previously documented but unreported expansion of site 41TR167, radiocarbon-dated to roughly 1,000 years before present, extending along the banks of the Trinity River. The former Bird's Fort site also fell within several hundred meters of the project area, but was not to be impacted. Because the proposed West Fork relief interceptor would affect subsurface prehistoric deposits, further archaeological investigations of the project area in Arlington were recommended.

In summary, ongoing systematic survey of the Trinity River basin continues to reveal a growing number of buried flood plain sites. These sites are sometimes identified through cutbank survey, but most often during mechanical trenching. Their deposition in deep alluvial sediments (1-2 m bs) has aided in the preservation of these cultural remains. Sites consist mainly of hearth-like features containing fire-cracked rock in association with mussel shell beds. Other artifacts recovered from these sites include animal bone but very few lithic artifacts. Buried flood plain sites are geologically consistent with an Early to Late Archaic timeframe. Ferring and Yates (1997) speculate that a relative high population density of hunter-gatherers was present here during the Late Archaic Period. Conversely, few Early or Middle Archaic sites have been found, although this is possibly the result of the depth of burial. 


\section{PREHISTORIC CHRONOLOGICAL FRAMEWORK}

Despite a long history of archaeological research in northcentral Texas and the southern plains (Jelks 1967; Krieger 1946, 1947; Prewitt 1981, 1985), as well as several more recent summary overviews (Hofman et al. 1989; Prikryl 1990; Story et al. 1990; Vehik 1994), the chronological framework for the upper Trinity River basin is not well developed. The available data allow the delineation of only a generalized chronology. Investigations at Joe Pool Lake (Peter and McGregor 1988) provided evidence for a refinement of the chronology for the Late Prehistoric period, although the overall regional applicability of the phases recognized there are still in some dispute. Prikryl (1990) presented a chronological sequence of six periods, but he relied almost entirely on diagnostic artifacts from surface contexts and comparisons to dated contexts distant from the upper Trinity River basin. Despite this, chronological data from recent excavations at Ray Roberts Lake and Lewisville Lake reportedly conform well to his suggested sequence (Ferring and Yates 1997, 1998).

The chronology presented here (Table 1) is taken from the introduction to the regional preservation plan for the Prairie-Savanna Archeological Region, of which the upper Trinity River basin is a part (Prikryl 1993). A brief summary of the adaptations and archaeological remains associated with these periods is presented below.

Table 1

Native American Chronology for the Upper Trinity River Basin (after Prikryl 1993)

Temporal Periods and Subdivisions

Years B.C./A.D.

$\begin{array}{lr}\text { Paleo-Indian } & 9950-6500 \\ \text { Archaic } & \\ \text { Early } & 6500-4000 \\ \text { Middle } & 4000-1500 \\ \text { Late } & 1500 \text { B.C. }- \text { A.D. } 7 \\ \text { Late Prehistoric } & \\ \text { I } & \text { A.D. } 700-1200 \\ \text { II } & \text { A.D. } 1200-1700 \\ \text { Historic Indian } & \text { A.D. } 1700-1850\end{array}$




\section{Paleo-Indian Period}

The Paleo-Indian period in northcentral Texas (ca. 9950-6500 B.C.) generally includes those remains of human presence that can be dated to the very late Pleistocene and the immediate postPleistocene periods (for reviews relevant to this period in northcentral Texas, see Hofman 1989a; Johnson 1989; Prikryl 1990; and Story 1990). Unfortunately, the Paleo-Indian occupation of the upper Trinity River basin is known primarily through diagnostic projectile points from surface collections or from stratigraphically mixed contexts (Meltzer 1987; Meltzer and Bever 1995). The Field Ranch site (41CO10) along the upper Elm Fork is a prime example of typical site contexts (Jensen 1968). Based on a sample of projectile points from surface sites, Prikryl (1990) has suggested that the most common Paleo-Indian point types in this area are Plainview and Dalton. Ferring and Yates (1997) suggest that these types date to about 9,500-10,000 years ago, based on cross dating with other regions. The suggested age for these types may correspond with the onset of early Holocene alluviation in the Trinity River valley.

Clovis and Plainview points are commonly found along both Denton and Clear creeks in the Eastern Cross Timbers, northwest of Dallas. Until recently, the Lewisville Lake site (41DN71) was the best known Paleo-Indian site within the region, containing large burned features interpreted as hearths, and a low density of artifacts, including a Clovis point (Crook and Harris 1957, 1958, 1961). Although the original radiocarbon dates on the hearths suggested an anomalously early age for Clovis points (ca. 37,000 B.P.), more recent work by the Smithsonian Institution (Stanford 1981) appears to have resolved the controversy concerning the date of the occupation there. It appears that the presence of naturally-occurring lignite in these hearths, either as a fuel or as an inadvertent inclusion, contaminated the radiocarbon samples. Consequently, the usually accepted date of 12,000-10,000 B.P. for Clovis period occupations is probably a reasonable estimate for the first human occupation of northcentral Texas.

An exception to the generally limited data on Paleo-Indian sites in northcentral Texas is the deeply buried Clovis-age Aubrey site (41DN479), located on the Elm Fork of the Trinity River north of Dallas (Ferring 1989, 2001). The discovery of this site, buried approximately 7-8 m below the top of the Elm Fork flood plain just below the Lake Ray Roberts dam, suggests that well-preserved Paleo-Indian sites in northcentral Texas will only be found by examining deeply stratified Holocene alluvium in modern flood plain situations. 
Despite the lack of extensive data relating to the early Paleo-Indian period in northcentral Texas, some attempts have been made to generalize regarding settlement mobility and intensity of site occupation, drawing on what is known and on assumptions based on comparisons with other areas. For instance, a number of researchers have seen evidence for a high degree of group mobility in the broad distribution of Paleo-Indian artifacts over the landscape and in the variety of presumably nonlocal lithic raw materials from which the artifacts were made (Meltzer and Smith 1986; Shafer 1977; Story 1990:177). Likewise, the well-documented exploitation of megafauna by Paleo-Indians in the western United States, coupled with the known presence of similar animals in northcentral Texas between 11,000 and 9,000 years ago (see Slaughter and Hoover 1963), has resulted in the popular (and logical) conclusion that big game hunting was part of the Paleo-Indian subsistence strategy in northcentral Texas. Nonetheless, the recent important excavations at the Aubrey site have indicated that subsistence efforts did not focus on big game animals alone. Rather, the entire range of prairie and forest species was used by the occupants of the site, including bison, deer, rabbits, squirrels, fish, and abundant turtle (Ferring 1989; Ferring and Yates 1997). Interestingly, although mammoth remains are present, their exploitation has not been substantiated (Ferring and Yates 1997). Whether this pattern of a more generalized foraging subsistence system is characteristic of Clovis adaptations on the fringes of the Eastern Woodlands and the focus on now extinct, big game species is more characteristic of a Plains adaptation remains to be documented; but Ferring and Yates (1997:5) suggest that, in general, the Clovis people probably employed "very flexible adaptive strategies."

\section{Archaic Period}

The Archaic period in northcentral Texas is tentatively dated between 6500 B.C. and A.D. 700. As is true for many areas, a threefold division of the Archaic period, consisting of early, middle, and late subdivisions, has been applied in northcentral Texas (Prikryl 1990, 1993). Thus, the Early Archaic has been dated from 6500 to 4000 B.C., the Middle Archaic from 4000 to 1500 B.C., and

the Late Archaic from 1500 B.C. to A.D. 700. Relatively recent overviews that cover the Archaic in this portion of Texas include Hofman (1989a), Prikryl (1990), and Story (1985, 1990). Archaic remains are usually found in upland settings and are frequently mixed with later material. In fact, the initial treatment of the Archaic period in northcentral Texas (Crook and Harris 1952, 1954), which defined the Carrollton and Elam foci, was based upon materials from such mixed 
terrace contexts. Consequently, these time-space constructs are no longer recognized as being acceptable for this area of Texas (Peter and McGregor 1988; Prikryl 1990; Yates and Ferring 1986). General trends that have been proposed as characterizing the Archaic period in northcentral Texas include an increasing complexity of settlement systems, increasing population size and density, decreasing mobility, and the development of distinct group territories (Prikryl 1990; Story 1985:52).

During the Early Archaic (ca. 6500-4000 B.C.), in general, the occurrence of small and widely distributed sites has been suggested to reflect high group mobility within large and poorly defined territories, with a generalized hunting and gathering economy (Meltzer and Smith 1986; Story 1985:35, 39). Unfortunately, Early Archaic occupations in northcentral Texas are poorly documented, and no sites with isolable Early Archaic components in this area are known (Prikryl 1990). Based on surface collections, Prikryl (1990) hypothesizes a generalized hunting-andgathering economy during this period, with high group mobility, a lack of regionalization, and "little in the way of recognized territorial boundaries" (Prikryl 1990:71). Projectile point forms that may be associated with the Early Archaic in northcentral Texas include Early Split Stemmed and possibly Angostura (Prikryl 1990; Story 1990:Figure 31).

In comparison to the Early Archaic, the Middle Archaic period in northcentral Texas (40001500 B.C.) is even less well known. Fewer sites are known with Middle Archaic components than for any other period, but the few surface collections available suggest the beginnings of regional cultural differences by the end of the period (Prikryl 1990). Diagnostic dart points that may be associated with the Middle Archaic consist of the Basal Notched group (which includes Calf Creek, Bell, and Andice), Wells, Dawson, Carrollton, and Bulverde (Prikryl 1990; Story 1990:Figure 31). An intact Middle Archaic component was identified at the Calvert site (41DN102) at Lake Ray Roberts (Ferring and Yates 1997), and it is summarized as follows.

\footnotetext{
Hearths, a burial, an unmixed assemblage of artifacts and fauna provide new evidence of adaptations to a drier Middle Holocene landscape. Artifact types are similar to those from adjacent regions (Story 1990) suggesting broad cultural interactions. The foraging economy emphasized procurement of small game and deer. It is assumed that these people were quite mobile, as repeated occupations of the site during the [Middle Archaic] period are evident [Ferring and Yates 1997:305].
} 
Population density may have reached a peak during the Late Archaic period in northcentral Texas (ca. 1500 B.C.-A.D. 700). Evidence for this can be found in an apparent increase in the number of Late Archaic sites, a greater distribution of sites over the landscape, and evidence of decreasing group mobility (Prikryl 1990). At the same time, interregional contact may have diminished. If greater spatial dispersal of sites is not a result of sampling error due to unequal destruction or burial of earlier sites, it may reflect an economic system making increasing use of all available floral and faunal resources. Throughout northcentral Texas, Late Archaic period occupation sites are relatively common in the uplands, and a relatively large number of buried sites are also known from the Trinity River flood plain (Ferring 1990:51). Dart points that may be diagnostic of the Late Archaic include Castroville, Marshall, Edgewood, Ellis, Trinity, Palmillas, Yarbrough, Dallas, Godley, Elam, and Gary (Prikryl 1990; Story 1990:Figure 31).

Investigations at Joe Pool Lake (Peter and McGregor 1988) and Lake Ray Roberts (Ferring and Yates 1997) indicate that remains of the Late Archaic period are characterized by assemblages apparently left by small bands of foraging hunters and gatherers who occupied a locality for a limited time period and then moved to another locality. These sites were apparently reoccupied numerous times on a seasonal basis. Faunal remains indicate that Late Archaic populations exploited a mix of prairie, forest, and riparian species, with white-tailed deer, rabbits, turtles, and mussels being primary food resources (Ferring and Yates 1997:6). In summarizing the results of investigations at a number of Late Archaic sites at Lake Ray Roberts, Ferring and Yates (1997:305) state:

\begin{abstract}
The most substantial occupations of the project area took place in the later part (post-3,000 yr bp) of the [Late Archaic] period. This is clearly a broad regional trend ... although poor site exposure limits our understanding of earlier periods. Late Archaic sites here uniformly register mobile foragers that exploited all habitats available to them. Residential mobility ... is implied. Repeated occupations at multiple sites were characterized by use of rock-lined and unlined hearths. On stable surfaces these are recorded as rock middens. In aggrading environments, discrete hearth construction events are clear. Import and curation of chert tools is evident, and contrasts with core-biface curation in the [Middle Archaic] period. Chert was preferentially used for straight, expanding and corner-notched points, while local raw materials were reduced on-site and dominate the contracting-stemmed forms. Despite quite good resource availability, dietary stress is recorded from skeletal and dental analyses.
\end{abstract}

The documentation of large pits associated with Late Archaic period sites in the Richland Creek and Chambers Creek drainages just south the Dallas (Bruseth and Martin 1987) also suggests that important sociopolitical changes may have been occurring during this time period. Unfortunately, the significance of these pits remains an enigma despite their excellent documentation. 


\section{Late Prehistoric Period}

The beginning of what is called the Late Prehistoric period in the upper Trinity River basin (ca. A.D. 700-1700) is marked by the initial appearance of arrow points. The A.D. 700 date for the start of this period is based upon dated contexts for similar material in the Brazos River drainage to the west. Both Lynott (1977) and Prikryl (1990) have proposed that the Late Prehistoric period be divided into an early and a late phase, with the early phase reflecting a continuation of the foraging subsistence system of the preceding Late Archaic period and the late phase reflecting Southern Plains influences. In this view, the early phase dates between A.D. 700 and 1200 and is characterized by sand- and grog-tempered ceramics and Scallorn, Steiner, Catahoula, and Alba arrow points (Lynott 1977; Prikryl 1990). The late phase dates from A.D. 1200 to 1700. It is associated with the appearance of shell-tempered Nocona Plain ceramics, various unstemmed triangular points (e.g., Maud, Fresno, Harrell, and Washita), and Perdiz points (Lynott 1977; Prikryl 1990). Evidence of horticulture and bison procurement also appears in sites of this period (Harris and Harris 1970; Morris and Morris 1970).

As a result of intensive excavations at the Cobb-Pool site (41DL148) at Joe Pool Lake, Peter and McGregor (1988) proposed a reformulation of the Late Prehistoric period. The Cobb-Pool site yielded house structures, roasting pits, Alba points, grog-tempered ceramics, and charred corn cupules. Radiocarbon dates from several features indicate the site was occupied during the late twelfth or early thirteenth century. Present evidence suggests that the site does not represent an intrusive Caddoan occupation; consequently, a significant adaptive change appears to have occurred, in at least some areas, during a middle phase of the Late Prehistoric period. It is also likely that ceramics were not introduced to the region before this time.

In regard to the Late Prehistoric components investigated at Lake Ray Roberts, Ferring and Yates (1997:305) summarized the results of that research as follows:

\footnotetext{
There are no woodland-like sites in north central Texas, suggesting that Plains Woodland influence or contact did not characterize the transition to the Late Prehistoric period. No ceramics were found with LPI [Late Prehistoric I] assemblages, which have Scallorn, Alba and small Gary points. These appear to be short-term occupations that took place under conditions of reduced precipitation compared to the Late Archaic. Except for the replacement of darts with bow-arrow weaponry, these occupations are essentially similar to the Late Archaic. Regional exchange of technological information, rather than environmental change, probably is the factor behind the Late Archaic to Late Prehistoric shift.
} 
Late Prehistoric II occupations are characterized by multiple, short-term use of probably logistic sites which lack ceramics and architecture. The architectural remains at 41DN102 are the only ones in the project area. At best, this was a small hamlet, occupied ca. 500-650 yr. bp. No evidence of horticulture was recovered, and the [Late Prehistoric II] fauna indicate a foraging strategy that emphasized deer procurement and occasionally bison as well. Transport and curation of chert raw materials was about as frequent as in the [Late Archaic], and long-distance raw material acquisition (e.g., Edwards, Alibates) is not evidenced. Ceramic traditions are dominated by locally produced shell-tempered wares, which by this time were being produced in the Southern Plains region generally. As recorded by previous synthesis (Story 1990) little if any interaction with the Caddoan area is indicated. Thus, the Ray Roberts prehistoric data suggest that regional traditions emerged at the end of the [Late Prehistoric] period largely independent of the Plains or East Texas Woodlands.

More recently, McGregor (personal communication 1999) has argued strongly for a "middle subperiod" of the Late Prehistoric, that he dates between A.D. 1000 and 1350. He believes that arrow points with straight or rectangular stems are most diagnostic of this period and identifies three sites or site areas with relatively clean (or minimally mixed) components of this middle subperiod - the Cobb-Pool site, Area B at the McDonald site (41HI105) on Hackberry Creek in the middle Brazos River drainage, and Area F at the Haley's Point site (34MA15) on the Red River (Brown et al. 1987; Peter and McGregor 1988; Rohn 1998). McGregor also notes that maize is common at Haley's Point, as it is at Cobb-Pool, and suggests that these sites are representative of a relatively short-lived, region-wide subsistence pattern involving a partial dependence on agriculture during this middle subperiod (McGregor, personal communication 1999).

Although no one can dispute the presence of domesticates at Cobb-Pool and Haley's Point, the lack of any evidence for Late Prehistoric agriculture at Ray Roberts Lake and Lewisville Lake leaves open the question of how extensive and how early this agricultural pattern was. Maize agriculture is known to have been present at Late Prehistoric sites along the East Fork, based on the recovery of maize from the Hogge Bridge, Butler Hole, and Campbell's Hole sites earlier during this century (Stephenson 1952:305), but the dating of these remains has always been uncertain (Prikryl 1990:77). As late as 1993, the available data allowed Fritz (1993:241) to state that, apart from Cobb-Pool, Late Prehistoric sites in northcentral Texas seemed to show a generalized adaptation in which the most important plant foods were nuts, wild seeds, fruits, and the problematic, possible tuber that might be a species of Psoralea. Since then, several small projects have shed additional light on the introduction of maize horticulture into northcentral Texas. The Harbor Pointe site (41DL369), located on Rowlett Creek (a tributary of the East Fork of the Trinity River), yielded remains of at least four individuals dated by AMS analysis of bone 
collagen to cal A.D. 1010 (1035) 1165. No pottery was recovered with these remains, although shell beads and a shell gorget were present, and a stable carbon isotope ratio of $-21.6 \%$ indicates that the group's diet contained little or no maize (Cliff et al. 1996; cf. Lynott et al. 1986:Figure 2). More recently, a disturbed burial (41DL373), located on Spring Creek (a tributary of Rowlett Creek), was dated by AMS analysis of bone collagen to cal. A.D. 1155 (1220) 1275, with a stable carbon isotope ratio of $-17.8 \%$ (Peter and Clow 1999). This value is similar to stable carbon isotope values believed to represent the initial introduction of maize agriculture in New York around A.D. 1000 (van der Merwe and Vogel 1977) and is comparable to values of $-18.0 \%$ o to $-20.0 \%$ for initial maize-consuming Caddo populations in Arkansas (Rose and Hoffman 1989). Assuming that (1) these carbon isotope ratios directly reflect changes in the $\mathrm{C}_{4}$ plant contribution to the human diet (see Herz 1990 for a discussion of other possibilities), and (2) these burials are representative of more regional changes in prehistoric dietary patterns, then maize horticulture may have been introduced into northcentral Texas around A.D. 1200.

\section{Historic Indian Period}

Within northcentral Texas, the time from A.D. 1700 to 1850 has been designated the Historic Indian period (Prikryl 1993). Prior to Spanish settlement of New Mexico in 1598, the European presence in the Southwest and on the Southern Plains was sporadic at best (Coronado in 15401541, the Rodriguez-Chamuscado party in 1581, Espejo in 1582-1583, etc.). After 1598, Spanish influence was never absent from the Southern Plains, although actual contact with Europeans continued to be limited and there are only brief records of journeys into or through the area (Hofman 1989b; John 1975). Despite this, it was not until the beginning of the nineteenth century that the physical presence of Europeans on the Southern Plains became commonplace. This was the result of increasingly peaceful relations between the Spanish in Texas and the Plains Indians to the north, and the acquisition of Louisiana by the United States in 1803. Prior to about 17251750, Apachean groups appear to have dominated the western portion of the Southern Plains, known as the High Plains. After this time, the area was increasingly controlled by the Comanche and Kiowa. On the eastern portion of the Southern Plains, within the area now known as the Lower Plains and northcentral Texas, the Wichita tribes became dominant (Bell et al. 1967; Hofman 1989b:91). 
Unfortunately, since good historical documentation is very sparse for the upper Trinity River basin during the early historic era, it is not clear which specific aboriginal groups were residing in the present-day Dallas/Fort Worth area at the beginning of this period. What is clear is that the early Historic period in northcentral Texas was a time of population fluctuation, movement, and amalgamation (see Newcomb 1993a). Available data suggest that many, if not all, of the aboriginal occupants of the eastern margin of the Great Plains, including northcentral Texas, were Caddoan language speakers, from the Arikara in the north to the Wichita and Kichai in the south. In this light, it is worth noting that it has also been suggested that the Socoatino, encountered by the survivors of the de Soto expedition in the sixteenth century, were Caddoan speakers and were the same as the Canohatino, identified by the French in the latter part of the seventeenth century, apparently located at that time "on the Blackland Prairies between the Guadalupe and Trinity rivers to the east of present-day San Antonio, Austin, and Waco" (Newcomb 1993a:24). If the prehistoric occupants of the eastern margin of the plains in Texas were indeed Caddoan speakers, it would explain how they were absorbed very early by other Caddoan-speaking groups (such as the Yojuane, Kichai, Tawakoni, Taovayas, Iscani, and Wichita proper) who arrived in northcentral Texas in the late seventeenth and early eighteenth centuries. Most of these groups, in turn, amalgamated to form the historic Wichita Tribe. Some, however, were probably absorbed by the united Caddo Tribes, and some may even have joined amalgamations of a variety of groups, such as the Tonkawa, during the late eighteenth and early nineteenth centuries.

The term Wichita is commonly used to refer to a group of linguistically related tribes, including the Wichita, Taovayas, Tawakoni, Iscani, Waco, and Kichai. Many of these groups apparently entered the Southern Plains in the seventeenth century, probably from Kansas and southern Nebraska, to escape the hostilities of the Osage (Webb and Carroll 1952:2:904). The Wichita were true Plains Villagers, with an economy that was jointly dependent upon agriculture and bison hunting. They occupied permanent villages of beehive-shaped, grass houses, from which they conducted seminomadic bison hunts. In 1719 their villages were located along the Arkansas River in northern Oklahoma (Hofman 1989b:95). By 1750, they had moved some of their villages to southern Oklahoma, along the Red River. Others were located on the upper end of the Sabine and Neches rivers in Texas and subsequently on the middle Trinity and upper Brazos rivers. In 1772, the year they concluded a nominal peace with the Spanish, one of their villages was on the Salt Fork of the Brazos, on the Lower Plains west of present-day Dallas/Fort Worth (John 1975:Map 3; Webb and Carroll 1952:2:705). Wichita groups were included in treaties 
made with the Republic of Texas in 1843 and with the United States in 1837 and 1856 (Webb and Carroll 1952:2:709). In Texas, they continued to live between the upper Brazos and Trinity rivers until 1855. In that year, the Tawakoni and Waco were placed on the Brazos Indian Reservation, south of Fort Belknap, in company with a number of other Native American remnant groups (Smith 1996; Webb and Carroll 1952:1:212; 2:905). Subsequently, as a result of increasing animosity from white settlers, they were removed to Indian Territory in 1859 (Smith 1996; Webb and Carroll 1952:1:210). The remnants of the Wichita moved to Kansas during the Civil War, but returned to Oklahoma after the war to settle permanently near present-day Anadarko (Hofman 1989b:95).

Archaeological remains that can be associated with these early historic groups are rare compared to the remains of earlier periods. Within the upper Trinity River basin, and in Dallas County itself, little evidence of these historic Indian groups has been found, with the exception of a few Native American sites with European items (Sollberger 1953).

\section{Historic Occupation/Utilization}

The early history of Tarrant County is poorly documented. One of the earliest accounts of AngloAmerican intrusion into the vicinity of the project area concerns the Battle of Village Creek. During May 1841, Gen. Edward H. Tarrant and a group of volunteer rangers pursued Indians who had conducted a raid on settlers in Titus County. Since the historical accounts of the eventual Battle of Village Creek rely on little more than personal recollections recorded decades after the actual event, the actual place of the battle and the account itself are more a part of folklore than historical fact. This account is even more interesting when one realizes that a year later in 1842 the original participants of the battle could not relocate the villages.

It is noteworthy that, following the battle, General Tarrant and company did not seek out the nearby blockhouse of Bird's Fort, which had been established by Capt. Jonathan Bird and a small group of settlers in 1840. Apparently, Bird's Fort offered little in the form of safety for the retreating volunteers, for it was inadequately manned and served more as a trading station than as a fort. Although additional families joined the initial occupants of the fort in the fall of 1841, the fort was abandoned by the spring of 1842. Bird's Fort was not used again until the summer of 
1843 when Sam Houston, President of the Republic of Texas, attempted to meet with the Indian tribes and establish a peace treaty. The treaty was not signed until September 29, 1843, by representatives of the Delaware, Chickasaw, Waco, Keechi, Caddo, Ionic, Biloxi, and Cherokee (Garrett 1972; Sergeant 1953).

In 1845, a trading post was established at Marrow Bone Springs (later named Mary Le Bone Springs) along Johnson Creek (formerly called Mill Creek). Although Carol Werdman's (1969:10) account of its location suggests either a Rush Creek or Johnson Creek location, an 1872 map of Texas (Petermann 1872) places Marrow Bone Springs on Johnson Creek. Col. Middleton Tate Johnson and a company of Texas Rangers also established their headquarters at Marrow Bone Springs in 1847. Two years later Colonel Johnson received a land grant for his services, and he established a plantation near Marrow Bone Springs. The community which grew around the Colonel's plantation came to be known as Johnson Station.

The settlement of Birdville, located between Little Fossil Creek and Big Fossil Creek, was founded in 1848 after Bird's Fort, 12 miles to the southeast, was abandoned. Birdville consisted of a community of approximately 50 farmers and ranchers. Shortly thereafter, Camp Worth was established on June 6, 1849, at the junction of the Clear and West forks of the Trinity River in order to provide protection for settlers along the western frontier. Camp Worth, named for Brig. Gen. William Jenkins Worth, was renamed Fort Worth on November 14, 1849. That same year, Colonel Johnson was instrumental in establishing Tarrant County, and the role of county seat was sought by both Birdville and Fort Worth. In the 1850 election, Birdville won the seat, and promptly built a courthouse. In 1856, a special election was held to re-determine the county seat; this time, Fort Worth won by a few votes. Fort Worth citizens retrieved the county courthouse furniture and records. At the cost of at least $\$ 30,000$ and several lives, the election results were contested for years. In the election of 1860, Fort Worth had grown sufficiently to soundly defeat Birdville, and the county seat was permanently set in Fort Worth (City of Haltom City 1997).

Although Colonel Johnson supported Sam Houston's stance against secession, the county voted for secession in 1861. Johnson organized and trained calvary units for the war effort, and his blacksmith shop provided molds for cannon balls and bullets. As Houston had predicted, however, the cause was costly and in the end futile. Tarrant County was seriously affected by the Civil War, which reduced the population of Fort Worth from 6,000 to just 1,000, only 16 percent 
of its prewar inhabitants (Werdman 1969:19). Although the arrival of the Texas \& Pacific railway brought increased economic growth and modernization to Tarrant County, it was the blossoming cattle industry, however, that motivated population and economic growth in the area through the end of the nineteenth century, as hundreds of thousands of cattle were driven to the region. The combination of the newly constructed stockyards and the railroad led to Fort Worth becoming a leading packing-house center. The economic stimulus in the 1880s and 1890s resulted in the installation of water and sewer systems and paved roads.

As World War I began, the military established several bases in the area. The U.S. Army's Camp Bowie was set up as a training installation, and the U.S. Army Air Force converted nearly airfields into flight training facilities. The discovery of oil near Ranger, Texas, in 1917 contributed to a great economic boom during World War I and World War II (Skinner et al. 1997). Oil companies such as Sinclair Refining Company, Texaco, and Humble Oil and Refining Company all set up offices in Fort Worth. As the city grew, the city limits were expanded in 1924 to incorporate surrounding towns such as Arlington Heights, Riverside, and Niles City. Federal funds obtained during the Great Depression of the 1930s led to the construction of the Will Rogers Memorial Coliseum and Auditorium, and to the renovation and construction of public schools. Higher education was available through Texas Christina University, Texas Wesleyan College, and Southwestern Baptist Theological Seminary.

During the interwar years, Braniff Airways and American Airlines began offering commercial and passenger air service from Meacham Field, which opened in 1927. At the outbreak of World War II, the aviation industry moved into Fort Worth and began production of the bombers that played such an important role in defeating the Axis powers. The Army Air Force established the Tarrant Field Air Drome, which, after the war, became Carswell Air Force Base, part of the Strategic Air Command and a base for the B-36.

In the mid-1950s, the Trinity River Floodway was completed as a response to previous flooding associated with the river. By the 1960s and 1970s, the deterioration of the downtown area had been reversed, and a revived economy again led to construction of the Tarrant County Convention Center, the Amon Carter Museum, and the Kimbell Art Museum, as well as the Dallas/Fort Worth International Airport. The population of Fort Worth over the last 100 years 
has grown from 6,663 in 1880 to 447,619 in 1990, but the city is still known for its reputation as the place "Where the West Begins" (FORT WORTH, TX).

\section{BACKGROUND OF ARCHAEOLOGICAL RESEARCH AT 41TR198}

\section{Prior Fieldwork: Survey and Site Delineation}

Data recovery was preceded by two earlier phases of fieldwork, survey and site delineation/testing (Huhnke and Wurtz 2004). The original surveyed project area was 900 acres in size, 600 acres of which is located on the flood plain of the West Fork of the Trinity River. Initially a pedestrian survey was conducted which included an examination of accessible cutbanks. Survey was accomplished using 30-m interval pedestrian transects. Shovel tests were placed in areas of high probability for containing intact archaeological deposits. A total of 75 shovel tests was excavated within the project area to a maximum depth of $80 \mathrm{~cm}$ below surface.

Backhoe trenching within the flood plain was undertaken on June 5-6, 2002, by geoarcheologist David Shanabrook and archaeologists Marie Huhnke and Angela Tiné of Geo-Marine. A series of 13 backhoe trenches was excavated within the flood plain of the West Fork flood plain in order to examine buried strata to search for archaeological deposits and to assess the geomorphology of the landscape. Trench placement and depth was generally based on the extent and depth of proposed impacts.

Stratigraphic profiles and major flood sequences were recorded, while trench side walls and back dirt were visually examined for cultural material. A total of 34 trenches was placed within the flood plain with the expenditure of 11 person days. The mechanical trenches were short, averaging $3 \mathrm{~m}$ in length and were $75 \mathrm{~cm}$ in width. 


\section{Identification of Site 41TR198}

During the initial mechanical trenching, prehistoric archaeological deposits were identified in backhoe trenches 9 and 10, located roughly in the center of the area now defined as the site. Archaeological signatures included lenses of burned clay, charcoal, ash, and fire-cracked rock, bone fragments and mussel shell. These materials were concentrated between $70 \mathrm{~cm}$ bs and 160 $\mathrm{cm}$ bs although some were deeper. A fragment of historic porcelain and two saw cut animal bones were also noted within the upper $29 \mathrm{~cm}$ in backhoe trench 11 . These three trenches were the basis for identification of 41TR198, later dubbed the Crooked Oxbow Site.

Later, during a second phase of field work, an array of additional trenches was placed in order to delineate the newly discovered site. A total of 24 trenches was used in this manner. Cultural material was found in backhoe trenches $9,10,14,15,16,20,21,23,24,26,31,32$, \& 33 (Huhnke and Wurtz 2004:Figure 28). Starting at the initial positive finds, trenches were excavated in a systematic cruciform grid until the trenches encountered natural barriers or until the trenches failed to yield cultural material. Trenches were excavated in a west and southwesterly direction to the forested area at the banks of the historic West Fork channel, in a south and southeasterly direction to the levee road, in a northeasterly direction into the old oxbow, and to the north until sterile.

These trenches yielded bone and shell artifacts, deposits of fire-cracked rock, and at least four features buried between 40 and 200 cmbs. Profiles of selected trenches were drawn, photos taken, and the relative positions of features and artifacts were recorded. The two radiocarbon dates obtained from this newly recorded site were reported at 1,910 and 520 radiocarbon years before present, plus or minus 80 years. 


\section{CHAPTER 4 RESEARCH GOALS AND METHODS}

Site 41TR198, because of its depth and contextual integrity, offers the unique opportunity to address compelling research questions, particularly those relating to ecological adaptation, human ecology, and economic behavior. Two facets of research can be pursued simultaneously in order to better understand the Archaic and Late Prehistoric periods. The first addresses the natural siteformation processes. Current environmental reconstructions only indicate trends and major ecological changes of the past. Short-term fluctuations, however, present a much more compelling force behind the daily changes in residential and logistical patterns of hunter-gatherer groups. As Peter and McGregor (1988:19) state, "whether or not archaeologists can relate changes in socioeconomic organization or adaptive technology to environmental shifts is dependent upon the sensitivity and specificity of the paleoenvironmental record." In order to address these questions, much more must be learned about the hydrology and climate of the Trinity River basin.

The Trinity River valley Archaic period sites are typically sparse in terms of artifact densities and distributions that traditionally have been the basis for evaluating intersite variability. These alluvial sites, although they do not lend themselves to identifying activity areas within a particular episode, do possess an "enhanced resolution" caused by rapid sedimentation (Yates and Ferring 1986:189). Thus, the opportunity exists to identify separate habitation episodes. On a broader scale, site 41TR198 provides an opportunity to examine site densities and sizes in the Trinity River valley in comparison with the region. For example, pollen samples indicate that the laterdated sites at Joe Pool Lake was dominated by prairie grasses, but the earlier, Trinity River valley Archaic sites were covered with riparian forest (Peter and McGregor 1988:352-353). Further 
studies of the region should include discussions as to whether shifts in territorial utilization were related to time and the introduction of horticulture.

Today, few natural, undisturbed, and nonurbanized flood plain areas exist that can provide the opportunity to collect these types of data from a site with the size, density, and depth of site 41TR198. The research potential of 41TR198 includes the possibility of identifying discrete habitation surfaces, and thus illuminating the processes of human ecology in the West Fork of the Trinity drainage. Given the research potential for 41TR198 and the limited possibilities for undisturbed flood plain deposits along the West Fork of the Trinity, this site was recommended as eligible for inclusion in the NRHP.

\section{SIGNIFICANCE OF SITE $41 T R 198$}

Establishing the significance of site 41TR198 required an assessment of whether or not the data potentially present within the site would allow researchers to address pertinent regional research domains. Table 2 provides a list of seven research issues and data sets relevant to understanding site 41TR198 and its role in the prehistory of northcentral Texas. In addition, specific classes of materials necessary to contribute information to the research domain are identified. The right column provides an assessment of the level of expectation that additional excavations will have in terms of providing data relevant to the research issues. Each of the seven research domains is briefly discussed in this section.

\section{Regional Cultural Chronology}

One significant research potential of site 41TR198 relates to the refinement of the regional cultural chronology. The existence of potential discrete occupational components within the West Fork basin of the Trinity River with datable material is a rarity. The majority of the regional understanding of prehistory is based on multicomponent sites with mixed assemblages. Site 41TR198 immediately establishes testable hypotheses, because artifact types and styles are often time transgressive. Thus, the site has the unique ability to test the pre-established regional date ranges for these diagnostic artifacts. Although site 41TR198 has multiple components, they 
Table 2

Data Sets Available at Site 41TR198 to Address Research Domains

Research Domain Required Data Set

Research Potential

\begin{tabular}{ll} 
1. Regional Culture History & \\
$\quad$ Diagnostic artifacts & Medium \\
Radiocarbon dates (cultural deposits) & High \\
2. Paleoenvironmental Reconstruction & High \\
$\quad$ Sediment texture & Low \\
Pollen potential (from sediment samples) & Unknown \\
$\quad$ Macrobotanical remains (from sediment or flotation) & High \\
Faunal remains potential & \\
3. Site Function & High \\
$\quad$ Spatial pattern of artifacts and features & High \\
Identification of site function & \\
4. Settlement Pattern Structure & High \\
Landscape setting & High \\
Literature review & \\
5. Subsistence Pattern & Unknown \\
$\quad$ Macrobotanical (feature flotation) & High \\
Faunal studies & High \\
Butchering/animal processing & \\
6. Technological Pattern & High \\
Hearth or earth oven features and faunal assemblage & Low \\
Stone tool manufacture & \\
7. Identity and Regional Exchange and Interaction & Unknown \\
Ceramics & Unknown \\
Distant lithic resources utilization & \\
\hline
\end{tabular}

are stratigraphically separated, which preserves some of the integrity originally put forth for single-component sites.

In order to further enhance the collective understanding of the regional cultural history, absolute dates will need to be associated with the diagnostic artifacts. Ideally, carbon from an annual plant from within feature contexts should be processed to obtain reliable chronometric dates. Several samples of datable carbon have been collected at site 41TR198, and carbon has been observed 
and collected in limited quantities from other areas of the site. The further collection of carbon for the purpose of radiocarbon dating must be a priority during the mitigation of site 41TR198.

\section{Paleoenvironmental Reconstruction}

Collection and identification of macrobotanical and faunal remains were given a high priority. Site 41TR198 clearly exhibits excellent preservation of the faunal assemblage. The presence of defined features at site 41TR198 indicates the potential for charred plant remain. Thus, relevant samples are available for potential paleoenvironmental reconstruction. Flotation remains were examined by Dr. Phil Dering for the presence of plant remains. The potential research value of the faunal assemblage includes the analysis of data relating to seasonality such as tooth eruption and wear from deer and bison remains. These data are important for developing insights into the function of site 41TR198, and ultimately its role in the regional settlement system employed by Late Archaic and Late Prehistoric period peoples in northcentral Texas.

\section{Site Function}

The determination of site function is critical to the placement of site 41TR198 within the overall settlement pattern of the Late Prehistoric period. Significant quantities of both artifacts and features in primary, isolable contexts are essential for determining site function. The excavations at site 41TR198 revealed a sizable quantity of faunal materials and the presence of several features within isolable contexts or within contexts that are interpretable. Given the lack of tools encountered during the initial recording of site 41TR198, the interpretation of features, their distribution, and the associated faunal debris will focus on the recognition of activity areas and associated functions.

\section{Settlement Patterns}

It was hypothesized that site 41TR198 represents a type of hunting and animal processing station that may have been used on a cyclical basis. The ability of site 41TR198 to provide information relating to the settlement patterns of the Late Archaic and Late Prehistoric periods is directly 
connected to the understanding of the range of activities present on the site. Presently, the previous investigations provide only a very generalized view of multiple hearth-related activities and the processing of game. The use of block excavation across the site will provide the necessary information to be able to identify site function, and ultimately the site's role in the seasonal round of Late Prehistoric peoples.

\section{Subsistence Practices}

The high level of preservation present at site 41TR198 provides a unique opportunity for the collection of a sizeable faunal assemblage. A sizeable faunal assemblage can be used to address research questions relating to subsistence practices through consideration of foraging efficiency by prey choice as compared to diet breadth models. The presence of such well-preserved fauna material indicates a high probability that floral evidence is likewise preserved on these sites. Consequently, the collection of sample columns for flotation from within these block excavations on site 41TR198 would provide the opportunity to capture and ultimately observe this material if present.

One of the most significant questions in need of clarification relates to the presence or absence of bison. There are only a few regional archaeological sites dating to the Late Archaic or Late Prehistoric periods with associated bison remains. Site 41TR198 has the opportunity to shed light on the temporal and spatial distribution of bison within northcentral Texas.

\section{Technological Patterns}

Technology and the processes prehistoric people used to convert raw materials into consumable goods is the basis for understanding behaviors of Late Archaic and Late Prehistoric period populations in the West Fork of the Trinity River drainage. In light of the kinds of materials associated with these sites, analysis should focus on issues relating to hearth and/or oven construction, associated fire-cracked rock, and the processing of game. 


\section{Regional Exchange and Interaction}

Since there are no specific items presently known from site 41TR198 that would be immediately labeled as exotics in the assemblage, it was difficult to predict the potential for addressing this research domain. Nevertheless, the potential presence of discrete components related to the Late Archaic and Late Prehistoric periods suggests the potential for selected categories of artifacts (e.g., lithics or ceramics) to provide some indication of changing spheres of interaction.

\section{FIELD METHODS}

\section{Excavation Units}

Throughout the duration of the project, 15 trenches and six strip units (see below) were mechanically excavated within site 41TR198 (Figure 2). Although most trenching was carried out during the first two days of fieldwork, some was conducted later in order to supplement the ongoing investigative needs of the project. At the beginning of the project, the primary focus was on identifying the most promising areas of the site in which to place the larger-scale excavations. Initial trench and unit positions were based mostly on the locations of geophysical anomalies or clusters of anomalies identified by fluxgate magnetometer during the earlier archeogeophysical phase of the project but also took into account the distribution and contents of the 2002 testing phase trenches (Huhnke and Wurtz 2004).

Four 2-x-2-m (6.6-x-6.6 ft) blocks (or their equivalency) were placed in specific areas to conduct a controlled test of subsurface archaeological resources within three localities of the site. These preliminary activities were subsequently followed by the labor-intensive expansion of Blocks 3 and 4 into larger, more significant units of study; the bulk of the effort was centered on Block 3. Small peripheral excavations, notably in Trenches 4 and 6, were carried out during the course of the project.

Several types of analytical units were used during the 41 TR198 data recovery project. The following types of units were employed, depending on the methodological objectives. 


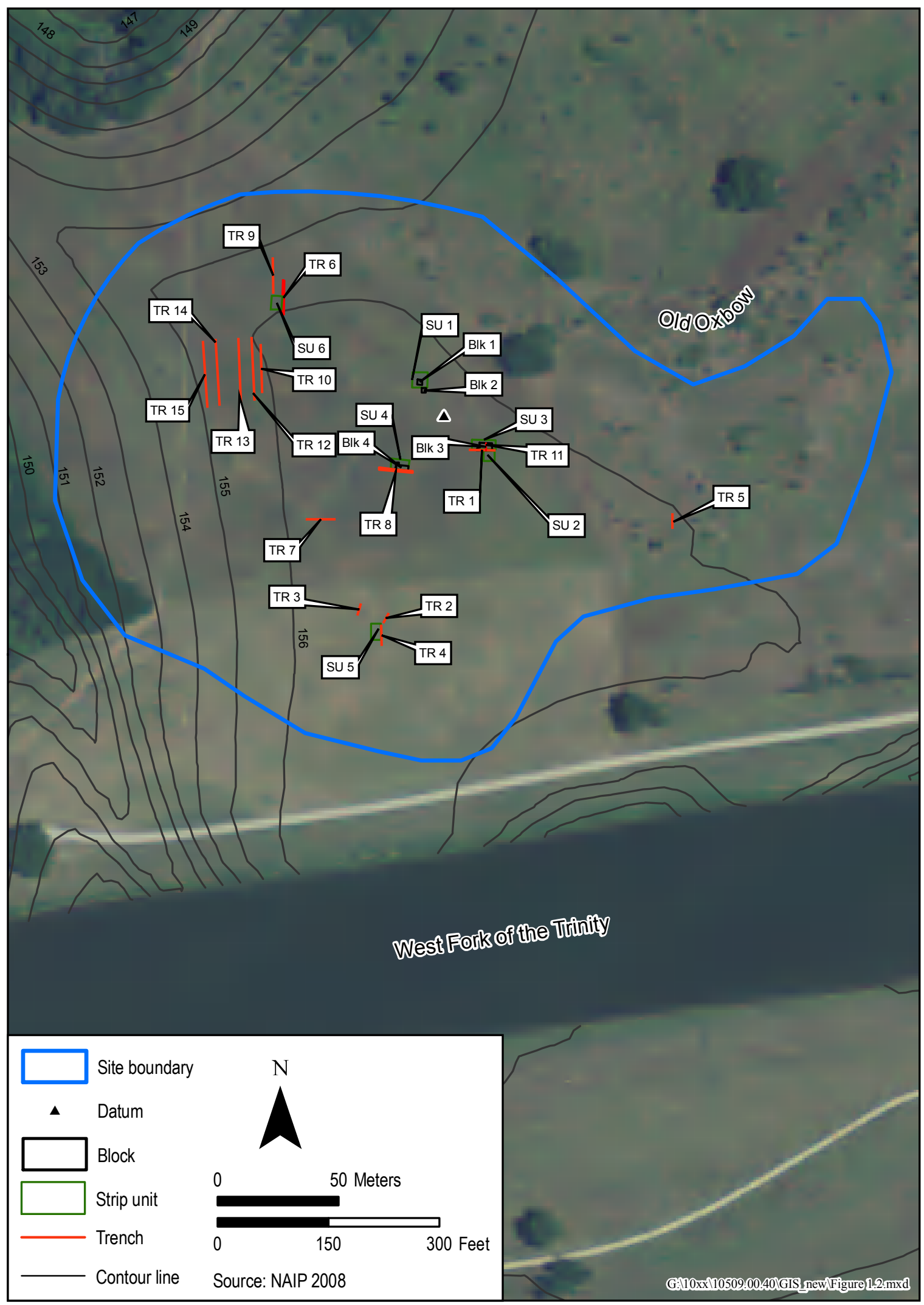

Figure 2. Map of site showing locations of trenches, strip units, and excavation blocks. 


\section{Mechanical Trenches}

Fifteen linear mechanical trenches (TR) were used to expediently examine the subsurface of the site for buried archaeological strata and/or features in profile. Mechanical trenches were further differentiated as those associated with data recovery trenches (TR) and those associated with the survey (TR-S) portion of the project.

\section{Strip Units}

Strip units (SU) were broad, mechanically excavated units used to remove a controlled portion of alluvial "overburden" from an area and/or to strip down vertically to expose buried archaeological strata or features in plan view. Six of these unit types were used during data recovery.

\section{Excavation Blocks}

Excavation blocks were contiguous collections of horizontal 1-x-1-m $(3.3-\mathrm{x}-3.3 \mathrm{ft})$ hand excavation units collectively sized as 2-x-2 m (6.6-x-6.6 ft) or larger. Four blocks were laid out in the form of a Cartesian plane. Individual excavation units within a block were excavated either in tandem or sequentially.

\section{Excavation Units}

Excavation units were 1-x-1-m (3.3-x-3.3 ft) horizontal units oriented north-south by east-west. Thirty-nine units were excavated in levels that were either arbitrary (i.e., $5 \mathrm{~cm}$ [2 in] or $10 \mathrm{~cm}$ [4 in] in depth) or natural (i.e., following natural/cultural soil contours). Levels within excavation units were the primary units of artifact provenience, secondary only to feature context or pointprovenienced artifacts. Although any given excavation unit was the primary unit of provenience, more specific information regarding quadrants or halves of the units in which artifacts or features were found was noted when possible. 


\section{Shovel Tests}

The 33 shovel tests (ST) were small, roughly circular, hand excavation units approximately $35 \mathrm{~cm}$ (14 inches) in diameter by $50-100 \mathrm{~cm}(20-40 \mathrm{in})$ in depth. Soil excavated in the shovel tests was screened through $0.64-\mathrm{cm}(0.25$-in) mesh, and the side walls were examined for stratigraphic changes. Shovel tests were excavated primarily during the survey portion of the project, although one was used during data recovery efforts.

\section{Features}

As the result of the above excavation methods, numerous cultural features were identified throughout the site. Forty-one of the identified 46 features were defined as discrete units of culturally meaningful space distinguished from the surrounding matrix through differences in color, soil texture, shape, or artifact content. The majority of the features either represent hotrock cooking activities or the detritus resulting from such activities. Five features initially thought to be of cultural origin were subsequently defined as non-cultural root burns.

\section{ADDITIONAL SURVEY}

The 41TR198 data recovery project also involved a survey component that included several parcels of land east of the site boundary in or near Gateway Park. This survey was undertaken on February 4 and March 11-12, 2009. Depending on the particular landform examined during survey, trenches, shovel tests, and pedestrian examination of the ground surface were all employed. One new site, 41TR230, was discovered as the result of the survey (see Figure 1). This site consists of a shallow, buried historic artifact scatter near the intersection of First and Elliott streets and is interpreted as either the location of a former domestic structure or a historic dump from other nearby domestic contexts. 


\section{SUMMARY OF FIELD METHODS}

Due to the sprawling nature of the site, the primary goal of the data recovery was the identification of high potential archaeological deposits able to address the research questions and to gain an understanding of the general structure of the site. As such, the initial fieldwork was undertaken through close coordination with the geophysical specialist who had previously mapped the site and identified numerous anomalies.

During the first days of the project potential high value anomaly targets were selected for "ground truthing" while also keeping in mind the general distribution of archaeological resources noted in the earlier series of trenches. A variety of anomaly types were tested including dipoles, high monopoles, and low monopoles. Cultural features were noted in 4 of the initial 5 trenches.

The next objective was the placement of four 2-x-2 m excavation blocks in order to test the site and to identify the relative data value of various portions of it (Figure 3). The plan of work called for the mechanical removal of $50 \mathrm{~cm}$ of alluvial sediments prior to controlled excavation, unless of course archaeological resources were noted at a shallower depth. The extent of this mechanical overburden removal also roughly corresponds to recent sediments overlaying the top of the West Fork Paleosol.

In order to maintain vertical control elevations were noted in relation to an arbitrary datum established at $100.00 \mathrm{~cm}$ through the use of an optical level and stadia rod. Generally, features and potential features encountered were exposed in plan view, bisected, profiled, a flotation sample taken from the richest portion, and then completely excavated to reveal their full shape.

\section{Block 1}

Block 1 [Us 1-4] was the first 2-x-2 m unit excavated; it was placed on a pair of promising dipole anomalies. Block 1 was never expanded horizontally, but it was still a fairly substantial undertaking, with the excavation of 5.05 cubic meters of soil (Figure 4). Block 1 contained three cultural features (Features 11, 26, and 27). Initially, a westward sloping mussel shell midden (Feature 26) was encountered. Below this shell lens, two fire-cracked rock features (11 and 27) were encountered at two separate depths. Block 1 stratigraphy exhibited a distinct and precipitous downward slope toward the west (Figure 5). 


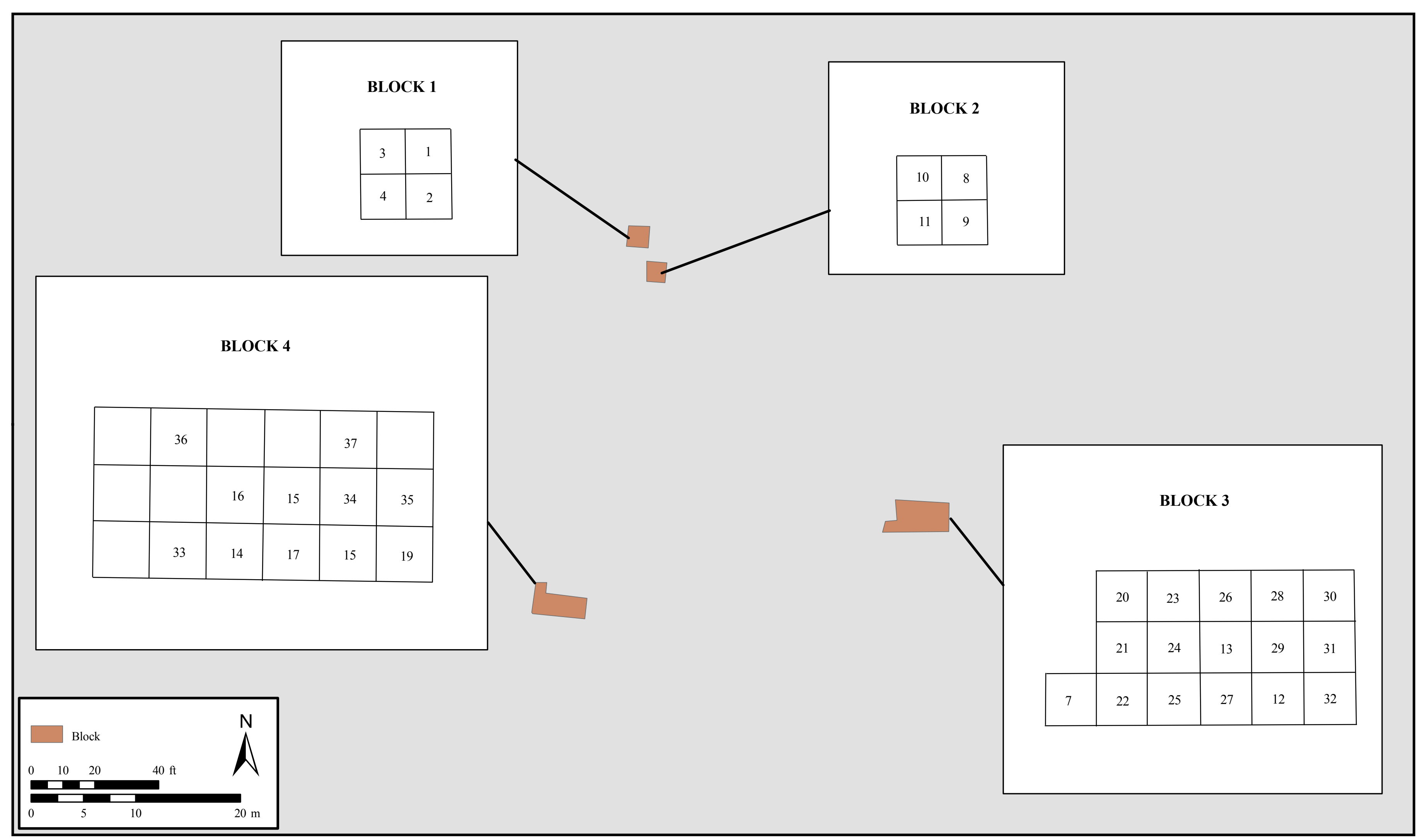

Figure 3. Site map showing the excavation units within each block. 


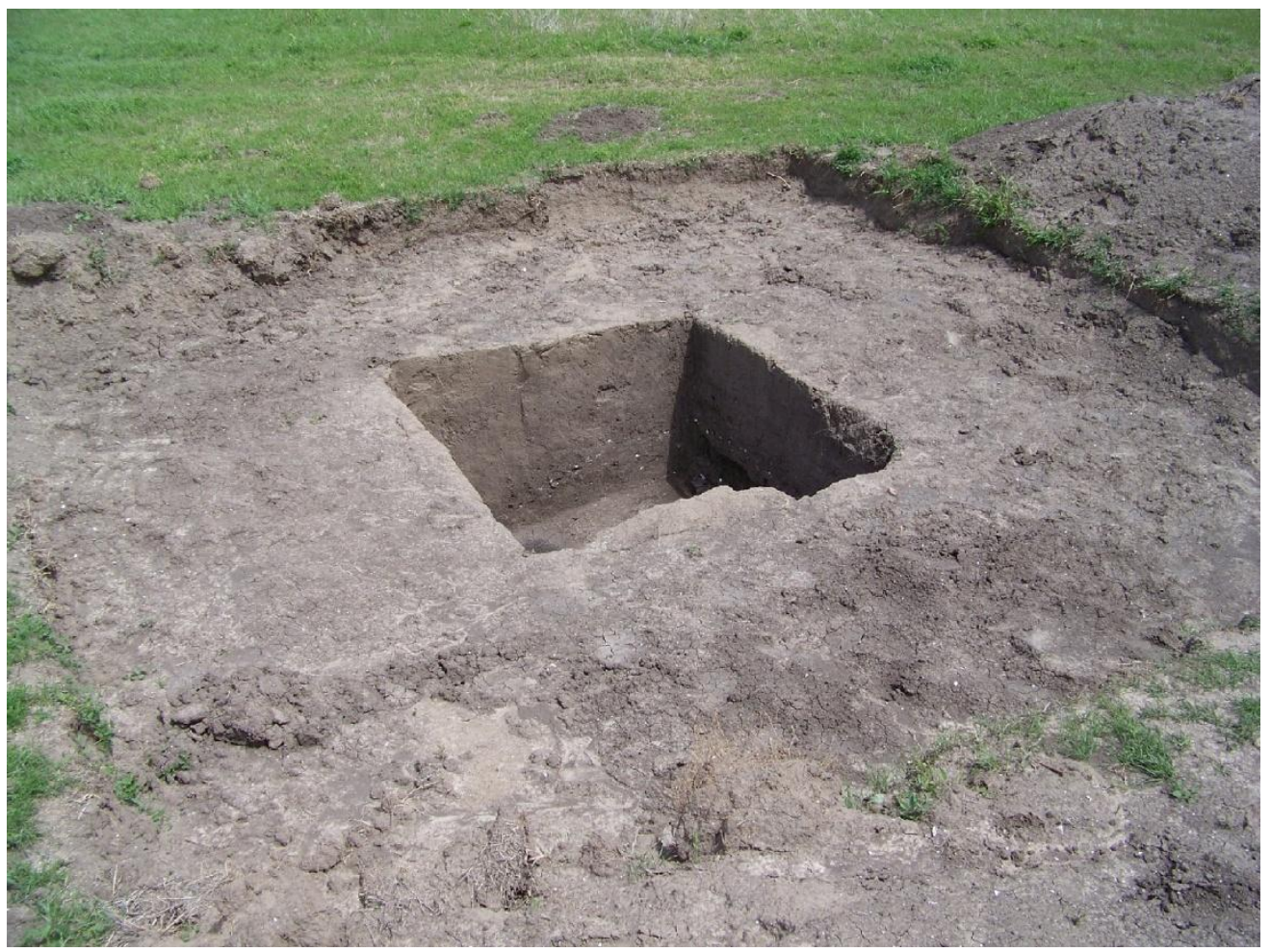

Figure 4. Block 1 at termination of excavation, view northeast.

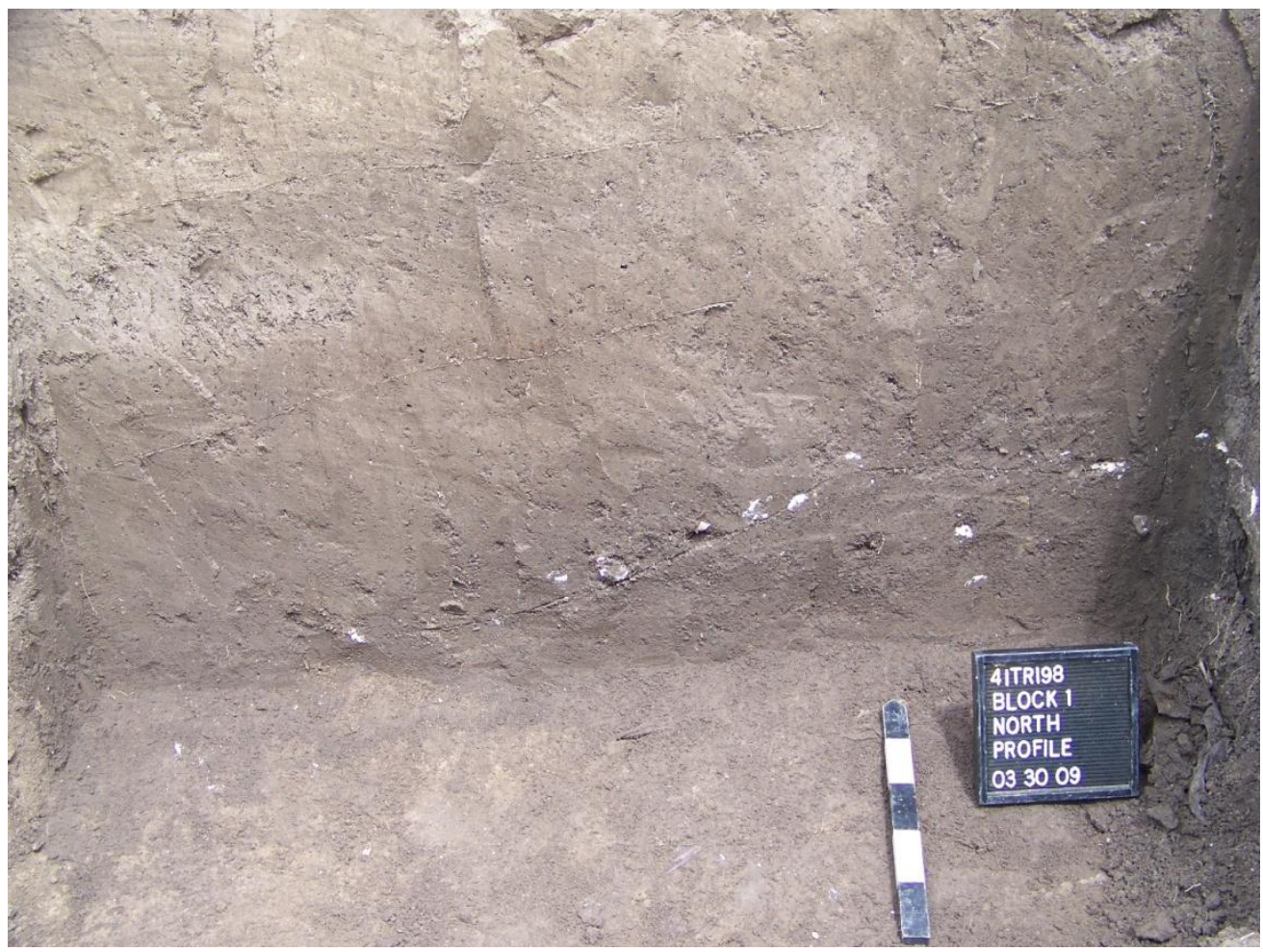

Figure 5. Block 1, north profile. 


\section{Block 2}

Block 2 was the second 2-x-2 m unit excavated, and is located just southwest of Block 1. Block 2 is centered on a fire-cracked rock feature (Feature 1) that was clipped during the excavation of Strip Unit 1, used to remove the recent alluvial deposits from the top of Block 1. Feature 1 consisted of a concentration of large fire-cracked rock buried less than $30 \mathrm{~cm}$ bs. Block 2 was placed on top of Feature 1, with two units within Strip Unit 1 and two within an adjacent 4-x-4 m Strip Unit 1a. Due to the proximity with Block 1 and the desire to attain better coverage of other portions of the site, Block 2 was only excavated to an extent adequate to fully expose and recover Feature 1.

\section{Block 3}

Block 3 was the centerpiece of the excavation (Figures 6 and 7). The first trench excavated during the project (Trench 1) ultimately proved to be the most fruitful, intersecting four cultural features including a large shell lens, a fire cracked rock feature, and two pits. This $11 \mathrm{~m}$-long trench was placed to bisect a large low amplitude, monopole anomaly, which proved to be a firecracked rock feature (Feature 5).

Due to its numerous and vertically stratified features, the area adjacent to Trench 1 was selected for further controlled excavations. The initial aim was to sample both the shell and fire-cracked rock bearing strata. Initially two $1-\mathrm{x}-1 \mathrm{~m}$ units were placed adjacent to the trench in order to best intersect two features. The first unit (Unit 7) was located on top the fire-cracked rock feature (Feature 5) while the second (Unit 12) was placed on the densest portion of the shell lens (Feature $8)$.

Units 7 and 12 both proved to be quite promising, uncovering a series of archaeological features and strata. Unit 7 alone contained a total of five features. Because the promising recovery from these two initial units, a decision was made to expand the area into a 3-x-5 m block (Block 3), the primary data recovery unit of the project. 


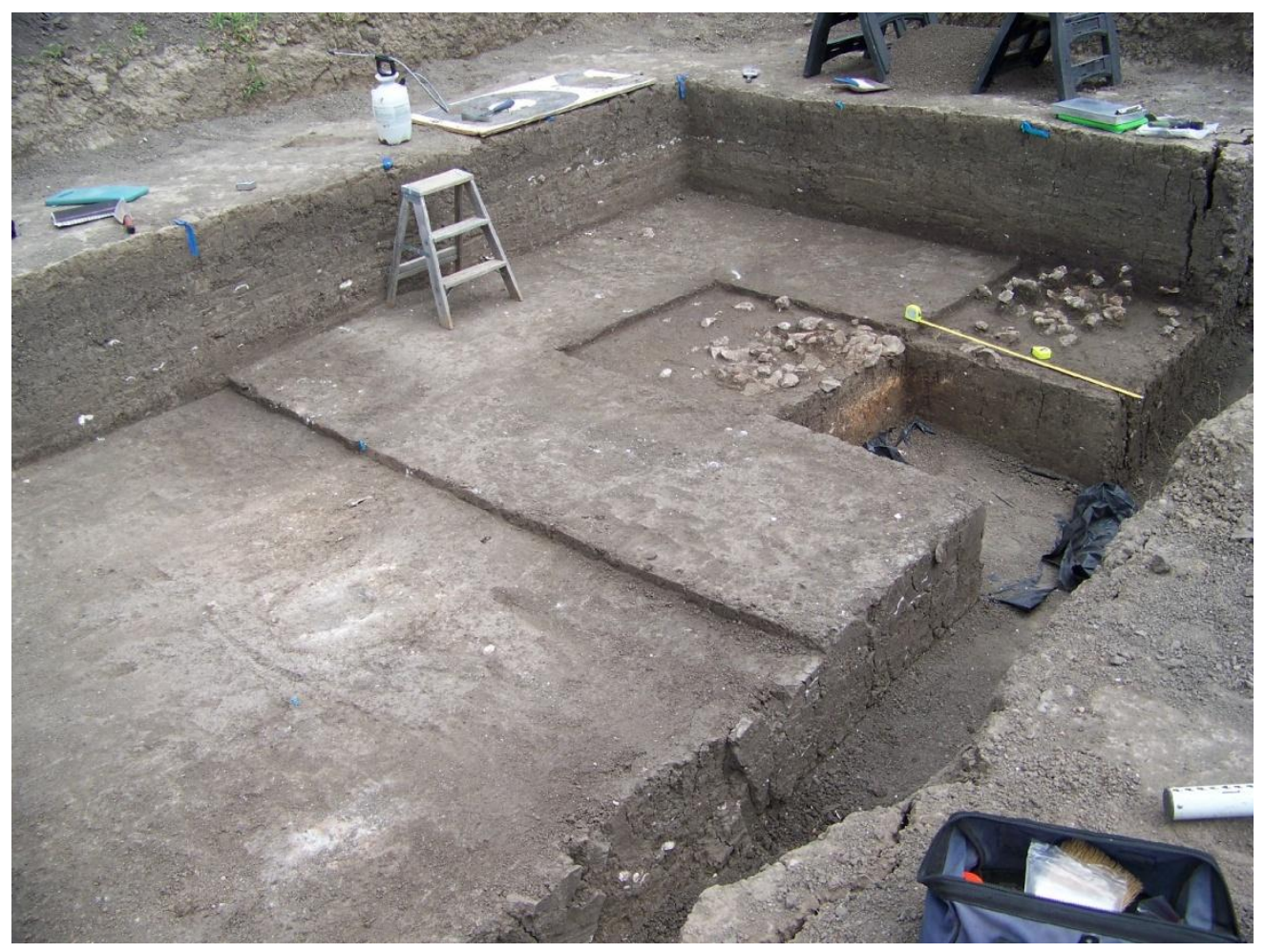

Figure 6. Block 3 excavation, Levels 10 and 11, view northeast.

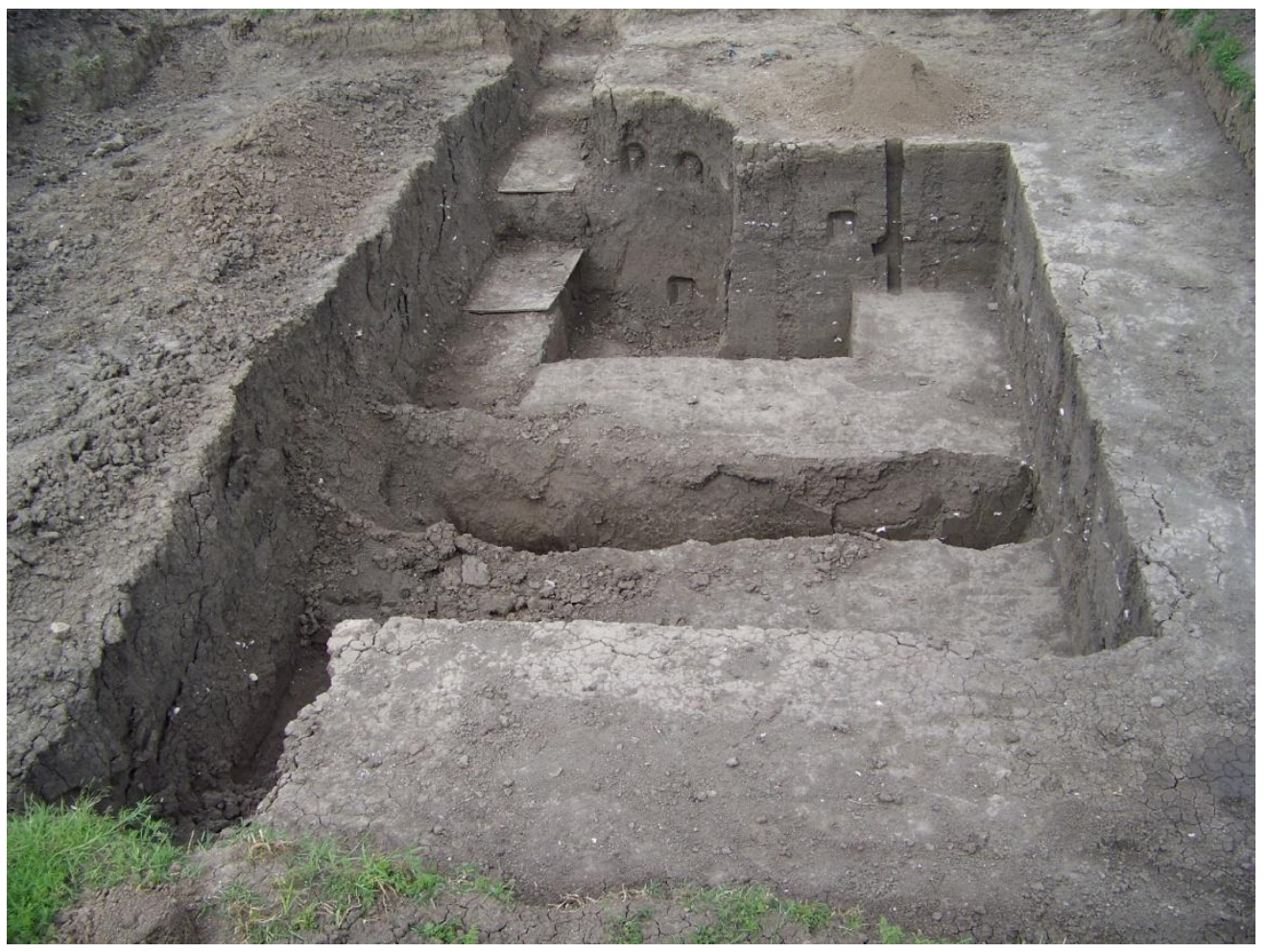

Figure 7. Block 3 at completion of data recovery, view west. 
Starting at bottom of Strip Unit 3, the first $15-20 \mathrm{~cm}$ of Block 3 were excavated as a single unscreened level, due to low cultural return from this stratum from Units 7 and 12. From this point, Block 3 was excavated in a series of 17, five $\mathrm{cm}$ levels $(98.90-98.05 \mathrm{~cm})$. Each day's objective included the excavation of one level across the block. In order to better observe features and stratigraphic changes, a clean and level plan view was exposed at the conclusion of each level via shovel skimming and troweling.

\section{Deep Testing}

Due to the constraints of time the excavation of Block 3 was halted at an elevation of $98.05 \mathrm{~cm}$, the same level as the initial Units 7 and 12, and approximately the same level as the bottom of Trench 1. Fully aware that there was potential for deeper deposits, an effort was made to test for deeper components using the base of Block 3 as a starting point.

The deeper testing was accomplished in $10 \mathrm{~cm}$ levels. Unit 12 was the first to be excavated in this manner. This unit was nearly sterile for over $45 \mathrm{~cm}$ before a discrete cultural lens consisting of charcoal, bone and snail shells was discovered at an elevation of $97.52 \mathrm{~cm}$. Because cultural occupations at this depth were previously unknown at this site and appeared to represent a completely separate and possibly much older component, a contract modification was negotiated with the USACE in order to obtain the funds for an additional week of field work to test these deeper strata.

Units 21 and 22 were excavated down from the base of Block $3(98.5 \mathrm{~cm})$ and the initially deep occupation from Unit 12 was further documented. After this recovery, a shovel probe was placed in the base of Unit 21 in order to examine greater depths. deeper. Burned clay and fire-cracked rock appeared in the screen at an elevation of $96.58 \mathrm{~cm}$, nearly one meter below the last cultural deposits.

In order to expose and document this find, Unit 21 was again pushed deeper. In addition, a backhoe trench was placed north/south into the floor of Block 3 in order to obtain a second point of observation of the deeper strata. The lower strata may in fact represent two lenses, and expands at least between Units 21 and Trench 11 (a distance of 2.5 meters). This deeper stratum is highly eroded relative to the high-integrity of findings in the upper portion of the block. 


\section{Block 4}

Block 4 was located adjacent to Trench 8 , and was the last block initiated. Block 4 was initially a 2-x-2 m unit, but due to the significant nature and character of the artifact and feature assemblage it was quickly expanded into a 2-x-4 m block with three adjoining 1-x-1 m units (Units 14-19, 33-37) (Figure 8). Block 4 was excavated in a combination of 5 and $10 \mathrm{~cm}$ levels, and was relatively shallow in comparison to Block 3. This area appears to represent a principle site midden; it contains ashy soil with rich deposits of fire-cracked rock, mussel shell, and animal bone along with lithics, bone tools, and ground stone. Block 4 also contained an array of features comparable to those in Block 3, including two hearths (Features 25 and 37), two pits (Features 39 and 44), and a burned clay hearth with an ash cap (Feature 45) comparable to Feature 15.

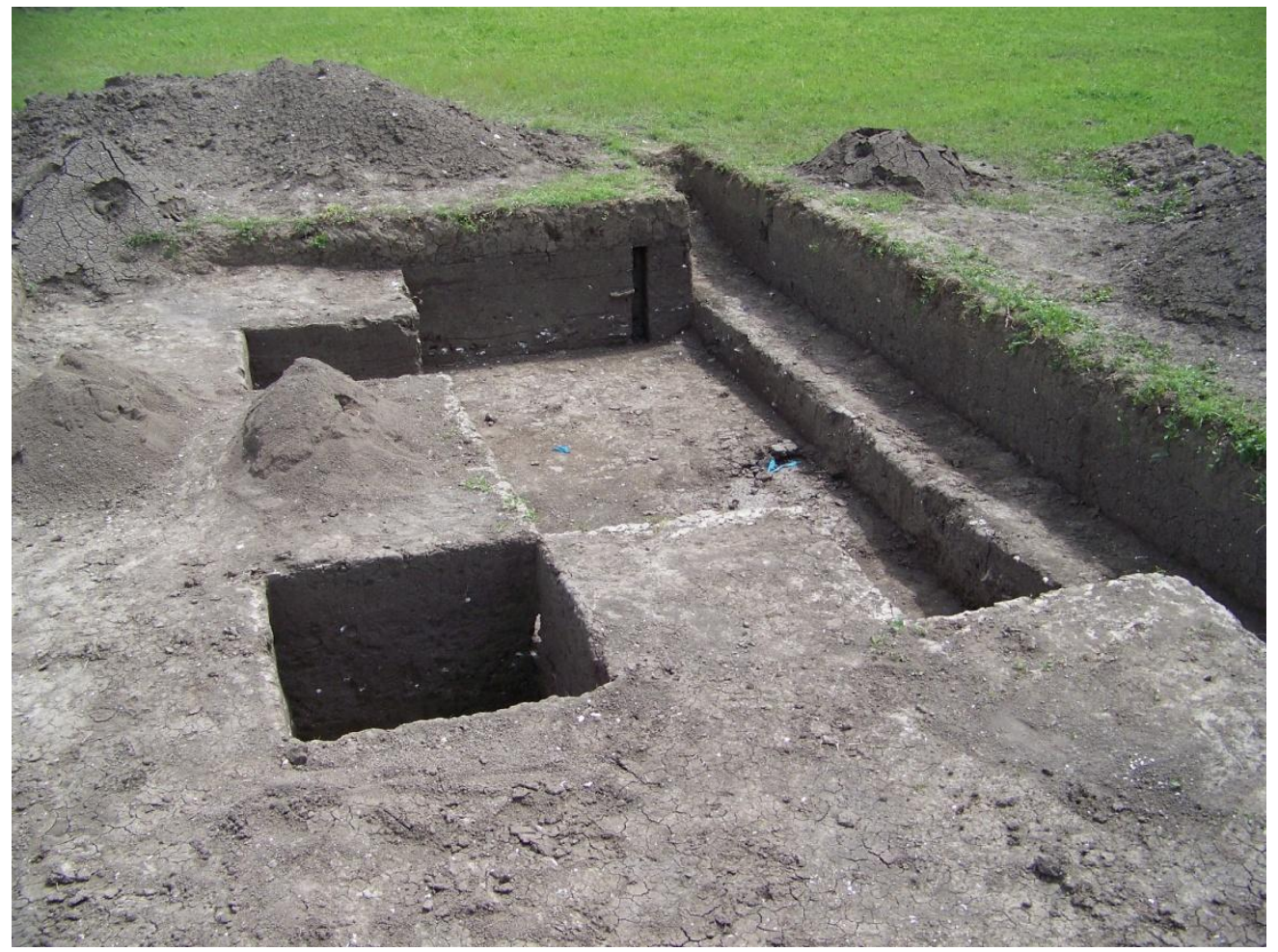

Figure 8 . Block 4 at completion of data recovery, view southeast. 


\section{Peripheral Trenches}

The mainstay of the excavation occurred in Blocks 1-4. These blocks were in the core area of the site, corresponding to a slightly higher landform west/southwest of the southern bend in the old oxbow. Although this area proved to yield the most rich archaeological deposits, a series of additional trenches were excavated throughout other portions of the site. Features were encountered in the majority of these trenches, but not at the same frequency as within this "core area".

The most substantial excavation activities in these peripheral trenches were associated with Trenches 4 and 6, respectively, in the south and northwest portions of the site. During the excavation of Trench 4 a large fire-cracked rock feature (Feature 2) was clipped. The portion of this large in situ hot rock cooking feature within the trench was excavated (Units 5 and 6).

Trenches 6, 7, and 8 were excavated on February 13, 2009 during the middle portion of the project. Trench 6 revealed several circular soil stains, and while three of these proved to be root burns, one proved to be a large pit feature (Feature 34). Trenches 6 and 7 also both contained lenses of mussel shell.

During the final phase of the fieldwork Archaeo-Geophysical Associates, LLC was contracted to expand upon the initial geophysical survey increasing the magnetometer coverage to include the entirety of the site. Two, large, unusual circular anomalies were identified in the northwest portion of the site west of Trench 6. Although these circular anomalies were only of medium confidence, a decision was made to trench at least one in order to insure that they were not something significant. This mechanical excavation was accomplished using an array of five, 30 m long parallel trenches (Trenches 10, 12-15). One oxidized pit feature (Feature 46), several ephemeral cultural lenses and a major relict channel feature were identified in these trenches.

\section{LAB METHODS}

All cultural materials collected during the assessment of site 41TR198 were brought to the GeoMarine laboratory facilities in Plano, Texas. Once the artifacts arrived at Geo-Marine headquarters, all artifacts were cleaned, catalogued, and labeled in compliance with TARL 
standards. Artifacts were washed using soft brushes under nonpressurized running cold water, with the exception of the charcoal and burned clay/earth. This material was not washed because the combination of running water and use of a soft brush tends to accelerate the decomposition of these artifact classes. After washing, artifacts were laid out on drying racks in the Geo-Marine laboratory to dry at room temperature. Once the artifacts were dry, they were rebagged by provenience into their freshly cleaned and dried original bags. The artifacts were then sorted and separated into major artifact classes for further analyses.

Fifty flotation samples from feature contexts were processed, totaling 4801 of feature fill. An oildrum flotation apparatus with upward water flow-sometimes called a Siraf system-was employed to separate cultural material from extraneous matrix. The light fraction, i.e. charcoal fragments and other buoyant objects floating on the water's surface were scooped out then dried and passed through 0.25 in $(6.35 \mathrm{~mm})$ and 0.02 in $(0.5 \mathrm{~mm})$ mesh. The heavy fraction, i.e. material that sank to the bottom of the apparatus was dried and passed through 0.25 in $(6.35 \mathrm{~mm})$ and 0.0625 in $(1.6 \mathrm{~mm})$ screens. Heavy fraction objects larger than 0.25 in were sorted into material classes (FCR, lithics, bone, etc.) and integrated into the corresponding collections from the excavations. Heavy materials smaller than 0.25 in were set aside for later discard, with the exception of bone fragments and lithics, which were integrated into the appropriate assemblages with the larger pieces.

\section{Prehistoric Artifact Analysis}

\section{Lithic Analysis}

The major classes of lithic artifacts consist of chipped stone-tools (dart and arrow projectile points, knives, bifaces, unifaces/modified flakes); lithic debitage (flakes and shatter), and coresand ground/battered/pecked stone (metate, mano, abrader, etc.), as well as unworked stone brought onsite.

All tools were identified to subclass or type and examined for use/modified areas, and variables of length, width, thickness, weight, heat treatment, and raw material type/color recorded. Projectile points were identified to named types and varieties when possible, as well as 
measurements taken for stem length, thickness, and widths. Bifaces were identified as biface stages 2-5 (ranging from roughout to final/thinned perform, as defined by Callahan 1979), biface/knife, or drill. Unifaces were assigned to subcategories of edge-modified flake, scraper, borer, burin, graver, spokeshave, and further described by the location/type of modification.

Recorded variables for unmodified debitage included flake reduction type (core [single-facet platform], biface thinning [multifacet platform], blade, notching, rejuvenation), amount of cortex remaining (primary [50 - 100 percent dorsal cortex]; secondary [1-49 percent dorsal cortex]; tertiary $[0$ percent dorsal cortex]), and attributes of raw material, heat alteration, and size categories (measuring less than $6.4 \mathrm{~mm}, 12.7 \mathrm{~mm}, 19.0 \mathrm{~mm}, 25.4 \mathrm{~mm}, 38.1 \mathrm{~mm}, 51.8 \mathrm{~mm}$, or greater than $51.8 \mathrm{~mm}$ ). The extant portion of all flakes was identified as whole or fragment (proximal, medial, distal). Shatter represented blocky pieces that were detached from the core during reduction that exhibited no bulb or platform; attributes for flakes applied to shatter. Cores were identified as tested cobbles, amorphous, prepared, utilized, or exhausted, based on flake removal patterns.

Ground stone was classified by type (abrader, hammerstone, mano, metate, polished stone, etc.) and the same attributes for chipped stone artifacts (extant portion, size, and heat alteration) recorded. The unworked stone classification denoted fire-cracked rock and unworked stone brought onsite, identifying raw material when possible.

\section{Prehistoric Ceramic Analysis}

The ceramic artifacts were sorted into two primary artifact subtypes - ceramic vessel/fragment and baked clay. Ceramic analysis consisted of recording variables related to location on vessel (body or rim sherd), paste and temper, surface finish, and typology. Nonplastic inclusion data were recorded for the two most prevalent types of inclusions. Sherds that were too small (less $1.25 \mathrm{~cm}[0.5 \mathrm{in}]$ ) or too fragmentary (missing one or both vessel faces) were classified as sherdlets and counted but not analyzed. 
Baked clay specimens were examined for impressions of vegetable fibers or other vegetable remains indicating architectural daub from wattle-and-daub structures. If none were present, the fragments were considered to be unimpressed baked clay-nondiagnostic clay fragments of unknown origin that could represent the residue of hearths or other open-firing activities, the remains of baked clay cooking balls, or even possibly indistinguishable fragments of architectural daub - and simply counted.

\section{Historic Artifact Analysis}

Historic artifacts were examined for particular attributes and diagnostic traits, using morphological and/or functional classification systems based on the methodology developed by South (1977) and with chronological information on historic ceramics developed by Lofstrom (1976) as used by Hahn and Castille (1988). Recovered artifacts were assigned to four primary categories - domestic, architectural, personal, and activities - or as indeterminate. The domestic category designation was used for items related to food service (tableware) and food storage (including food preparation and tin cans). Furnishings, a subcategory of domestics, consisted of household items such as furniture, stove parts, and lamp glass. The architectural category included all items related to buildings, such as brick, mortar, plaster, nails, window glass, and electrical items. The personal category contained such items of individual use as clothing, buttons, shoes, dolls, and smoking pipes. Nonhousehold items, transportation items, farm-related equipment, tools, and firearms were assigned to the activities category. Fragments of unidentifiable metal, ceramics, and glass (i.e., those artifacts unidentifiable as to domestic tableware or storage, architectural, personal, or activities) were simply recorded as indeterminate.

\section{ECOFACTUAL ANIMAL BONE, SHELL, AND VEGETAL ANALYSES}

Nonartifactual cultural materials, or ecofacts, were categorized by class (animal bone, shell, or vegetal) and analyzed for taphonomic characteristics and type (burned/unburned, worked/unworked, and vegetal type [e.g., charcoal]). When possible, each specimen was identified to species level or to at least bone type and animal/size (e.g., long bone fragment, medium-large mammal, etc.). All indications of calcination and/or human modification were noted and described. 


\section{CURATION}

All artifacts were catalogued, labeled, and bagged in compliance with standards, procedures, and guidelines set forth in 36 CFR 79, "Curation of Federally Owned and Administered Archeological Collections," and with the requirements of the Texas Archeological Research Laboratory for the preparation and curation of archaeological material collections. All documentation and photographic records compiled during the investigations were catalogued in compliance with these standards. 


\section{CHAPTER 5 SURVEY RESULTS}

\section{BACKGROUND}

As part of this project Geo-Marine was contracted to survey additional parcels of land that may be affected during the Riverside Oxbow Restoration Project. There were three survey properties totaling 75 acres in size (Figure 9). Each area is located in an upland environment relative to the 41TR198 landform, and is slated for grassland restoration and selective native tree plantings.

This survey was undertaken on February 4 and March 11-12, 2009. The methods of the survey varied depending on the type of landform examined. Backhoe trenching was the preferred method to look for prehistoric sites within the flood plain, because it is the only method able to reach the depths at which such sites are typically found. However, shovel probes were utilized on the flood plain in areas of suspected historic occupation. Survey areas outside of the flood plain were examined by a combination of pedestrian survey and shovel tests. Disturbed areas were avoided.

\section{Property One}

Property One is a 30 -acre parcel located south of $1^{\text {st }}$ Ave., east of Elliot St., and west of Disposal road. It is situated on the uppermost slope of the flood plain. Older maps and the mature trees themselves indicate that this area was once a pecan orchard. 


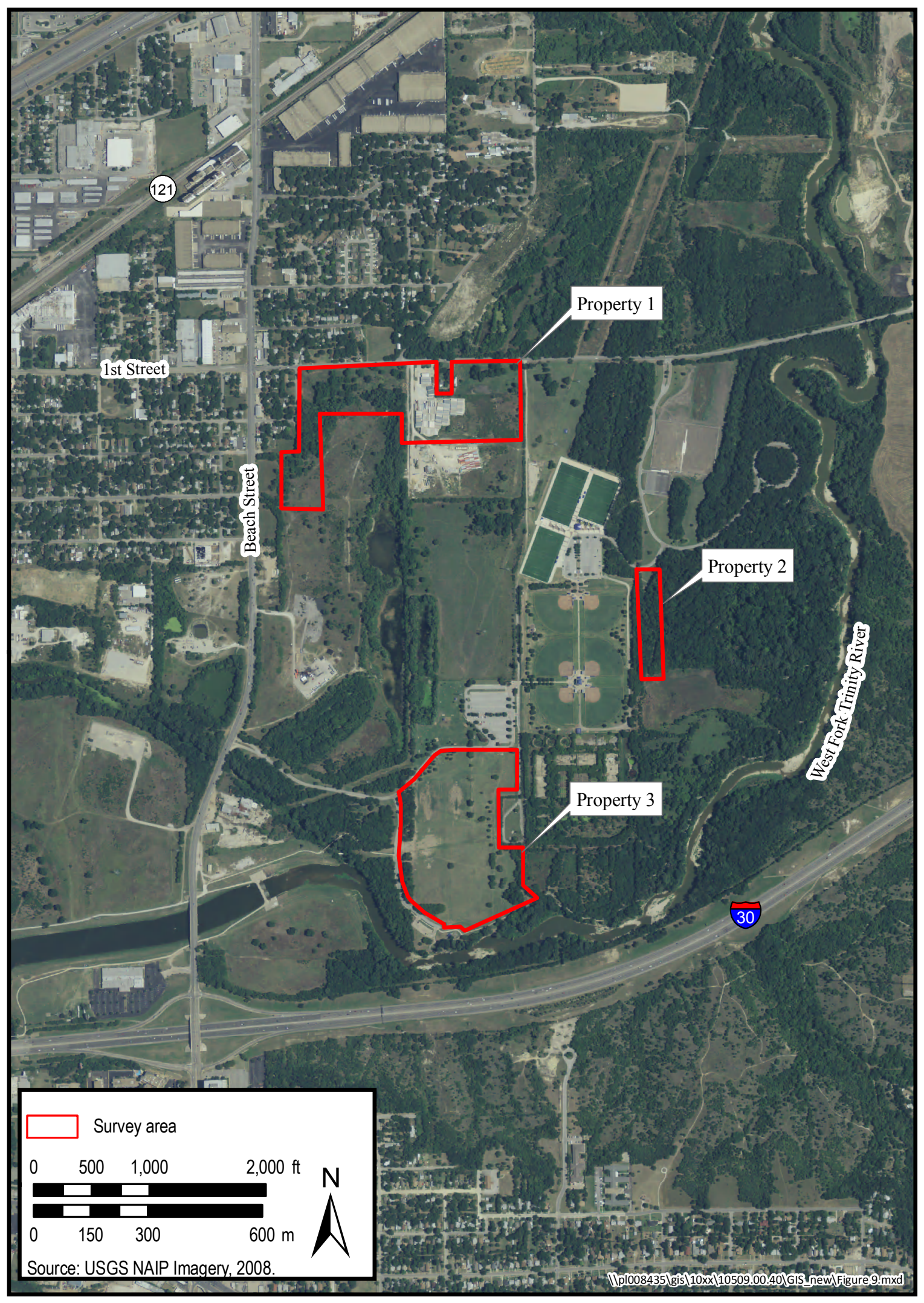

Figure 9. Map showing the three survey properties. 
Property One is divided roughly in half by a 12-acre area that has been affected by industrial activity. Part of this disturbed area consists of a large rock-covered industrial parking facility visible on aerial photos. The southeast portion of Property One is also disturbed, and consists of a large excavated basin associated with the former sewage plant. Neither of these disturbed areas was surveyed; any archaeological or historic features within them are either thoroughly disturbed, capped by modern impermeable overburden, or are very deeply buried.

The western and eastern portions of Property One were surveyed. The western part of Property One consists of a parcel of currently undeveloped land that generally slopes from south and east. The northeast part of Property One consists of pre-Holocene age sediments. The characteristics of the soil in this area are radically different than that of any of the flood plain contexts. The dominant soil type in this area is sand. This portion of Property One consists of a thin, moderately developed sandy loam topsoil (7.5YR 3/4 dark brown sandy loam) and red, iron-rich sandy clay subsoil (5YR 4/6 yellowish red sandy clay).

The extreme northwest corner of Property One is the highest elevation within the project area. From this area a series of drainage gullies slope down toward the southeast. South of these gullies, the property is wooded (partially with pecan trees) and the soil consists of a sandy loam. The southernmost portion of Property One, south of the wooded area has been mechanically graded. Initially an array of seven shovel tests was excavated in the western portion of Property One. Of these, Shovel Test 1 contained historic artifacts. A previously unrecorded historic period site (The East $1^{\text {st }}$ Street Pecan Orchard Site) was delineated and recorded based on this positive probe (see below).

A second area of Property One that was surveyed is located at the southwest corner of $1^{\text {st }}$ Ave. South and Disposal roads. This is the northeast portion of Property One, which consists of an intact area of the upper flood plain. This area is an open grassy field with a few large pecan trees. There is a large metal shed located along its western edge. There are also several major buried utilities in and around this portion of Property One, including gas, sewer and electrical lines.

This portion of Property One was first probed with two backhoe trenches (see Appendix A for profile descriptions of Trenches $5 \mathrm{~S}$ and $6 \mathrm{~S}$ ). No cultural material was encountered in either trench. During the pedestrian survey, a large pile of structural debris was located in the southeast 
corner of this fenced property. A series of seven shovel probes was excavated in the vicinity to determine whether or not it is associated with a potential historic property. However, all of the findings within this survey area were negative.

\section{Property Two}

Property Two is located within Gateway Park and is four acres in size. Property Two is located on the upper flood plain. It is linear in nature and heavily wooded. Property Two is oriented on an existing dirt two-track road leading north/south from Streams and Valleys Circle to a large fenced depression. Soils within this area are Holocene in age, but older than soils of comparable depth (below surface) at 41TR198. For example, trenches within Property Two contained common calcium carbonate concretions within the Pilot Point alluvium.

Four backhoe trenches (Trenches $1 \mathrm{~S}, 2 \mathrm{~S}, 3 \mathrm{~S}$, and $4 \mathrm{~S}$; see Appendix A) were placed within Property Two and a pedestrian examination was conducted. The results of both were negative for cultural resources. It was also determined that the large depression south of Property Two was a former borrow pit, that the road was a former haul road, and that the area below and adjacent to the road has been heavily compacted by industrial traffic. The southern portion of this property also appears to have been graded.

\section{Property Three}

The third property is 31 acres in size and is located within Gateway Park due east of site 41TR198. This area is currently a series of manicured soccer fields. It is located on the flood plain, but on a higher landform than site 41TR198. Property Three was not surveyed during this project. The surface of Property Three appears to have been graded and disturbed. Backhoe trenching was an option, but it was ultimately decided against, due to the limited depth of the projected disturbances here; along with the undue impact that would have been caused by mechanical trenching of the actively utilized soccer fields. 


\section{Site 41TR230}

Site 41TR230 represents the remains of a historic occupation found in the southeast corner of the intersection of East $1^{\text {st }}$ Street and Elliott Avenue (see Figure 1). A total of 20 shovel tests was excavated at site 41TR230, revealing a soil profile consisting of a dark yellowish brown (7.5YR 3/4) sandy loam (0 - $20 \mathrm{~cm}$ bs) overlying a yellowish red (5YR 4/6) sandy clay. Seventeen shovel tests contained cultural materials within an area that measures approximately $60-\mathrm{x}-30 \mathrm{~m}$ $\left(1,800 \mathrm{~m}^{2}\right)$ in size. The site is grass-covered with a few isolated trees found along the edges of the road. A pecan orchard is present south and east of the site. The site has fair to good contextual integrity. Erosion has formed gullies along the eastern edge of the site and concrete, brick, and stone rubble has been dumped along this edge, probably in an effort to prevent continuing erosion.

\section{TR230 Property History}

Site 41TR230 is located on the northwest corner of the Robert Cross survey in the City of Fort Worth, Tarrant County, Texas. According to General Land Office (GLO) records a patent deed was issued to Robert Cross in 1857. The record shows that the property was originally a 210.2 acre parcel out of the Robertson third class land grant (GLO 2010a). Archival research conducted at the Tarrant County Clerk's office was able to track the ownership of the property on which site 41TR230 is located back to 1880 . Between 1857 and 1880 the property was deeded to T.F. Cheeks and J.A. Cornelius, who in 1880, granted the property to A.A. Stephens and C.D.Y. Gulley. The property granted in the 1880 deed includes all of the 210.2-acre Robert Cross survey except for a "100 square foot lot where the Pendleton Cheeks family graveyard is located". The deed does not specify the location of the graveyard; nor does it appear on historic maps. Furthermore, the 1880 deed indicates that the land was in cultivation, but does not specify what type of agricultural product was grown (Tarrant County Clerk, Fort Worth, Texas [TCC] 1880:Deed Book [DB] 33:603).

In 1887, A.A. Stephens and wife Alabain Stephens granted the property to Frank L. Twombly. This deed grants Frank L. Twombly the 210.2-acre Robert Cross survey excluding one acre of land containing the Pendleton Cheeks family graveyard. In addition to the graves themselves, the land excluded from sale include an oak grove and a 20 -ft-wide right-of-way leading from the 
nearest public road or highway; however, the deed does not specify the location of the oak grove or the name of a public road or highway (TCC 1887:DB 49:20). Ownership of the property was maintained by Frank L. Twombly until 1890, at which time he sold it to E.E. Chase. Again, the property description includes the Robert Cross survey, Pendleton Cheeks family graveyard, oak grove, and the 20-ft-wide right-of-way (TCC 1890:DB 71:74). In 1893, E.E. Chase was forced to sell the property in a Sheriff's sale to N.H. Stewart. The property description of the 1893 deed includes the 210.2-acre Robert Cross survey, but does not mention the Pendleton Cheeks family graveyard (TCC 1893:DB 90:553). Review of the 1893 Tarrant County Sam Street's map shows that there is one dwelling and two rental properties located on the north edge of the Robert Cross survey, but it does not show the location of a graveyard (Sam Street's Map of Tarrant County 1893). It is unknown why the graveyard is not mentioned in the 1893 deed, or why it is excluded from all future deeds.

In 1907, N.H. Stewart sold the property to J.W. Irion, who maintained ownership for several years, likely until his death (TCC 1907:DB 247:229. The deed showing when the property was transferred from J.W. Irion was not found; however, a 1945 deed shows Malinda Weber Stephenson (formerly Malinda Weber Irion) and C.J. Stephenson as the property owners. In 1945, Malinda Weber Stephenson and C.J. Stephenson sold the land to R.C. Bowen (TCC 1945:DB 1740:448), who between 1945 and 1972, granted the property to Doris Bowen Frost and husband Hidreth Frost, Jr. In 1972, Doris and Hidreth Frost granted the property in a trust to their heirs Robert Hidreth Frost and Edmund Bowen Frost (TCC 1972:DB 5244:477). According to Tarrant County Appraisal District records the current owner of the property is Robert Hidreth Frost (Tarrant County Appraisal District 2010).

Georeferencing Sam Street's Map of Tarrant County, Texas (1892) with the GIS data shows six structures near the site (Figure 10), but none correspond exactly to the site location. The georeferencing highlights the inaccuracies of a Sam Street's map. Though the wagon trail probably corresponds to East $1^{\text {st }}$ Street, site 41 TR230 is plotted on the north side of the road and not the south. It seems likely that the site is associated with one of the two structures south of the wagon trail. After reviewing historic topographic maps, GLO maps, soil maps, and historic aerials, it appears that between 1893 and 1924, the three structures located on the north end of the Robert Cross survey were removed. Review of the 1924 Tarrant County Soils map shows that there are no structures on the property. Furthermore, the 1925 Greater Fort Worth New City map 


\section{Figure Redacted}

Figure 10. 1892 Sam Street's map showing six structures near 41TR230. 
shows the Robert Cross survey as subdivided for development (The Portal to Texas History 2010; GLO 2010b). At this time the city of Fort Worth expanded its city boundary lines to include the Riverside Addition where the Robert Cross survey is located (Schmelzer 2010). The anticipation of development of this property could have been the cause for the removal of the structures; however, for reasons unknown the plans to develop the property were never completed.

Aerial photographs from 1938, 1952, 1956, 1963, 1970, 1979, 1990, 2001, and 2004 were also consulted. The resolution of the 1938 aerial is too poor to determine if a structure is present in the site area. The later aerials are higher resolution, but no structure is visible in the site area. Although the land was not developed, it was used for agricultural purposes as is indicated by the 1952 historic aerial and 1955 topographic map. The map and aerial show the land from East $1^{\text {st }}$ Street south to the West Fork of the Trinity River being used as an orchard (Perry-Castaneda Library Map Collection 1955). By 1968, only the northwest part of the orchard was still extant while the remaining land was vacant and overgrown (Earth Explorer 2010). Part of the orchard remains today to the west of the site at the corner of East $1^{\text {st }}$ Street and Elliott Avenue.

\section{Archaeological Assemblage}

A total of 251 historic artifacts was collected from site 41TR230, consisting of Activities-related $(n=5)$, Architectural $(n=20)$, Domestic $(n=180)$, Furnishings $(n=4)$, Indeterminate $(n=41)$, and Personal $(n=1)$ artifacts. In addition, beer cans, bottles, and plastic fragments were noted on the surface, but these are thought to be recent refuse from the nearby roads.

Thirteen pieces of Domestic ceramics were collected. The stonewares collected consist of Bristol and cobalt exterior/Bristol interior stoneware ( $\mathrm{n}=2$; post-1915), Bristol interior/exterior stoneware $(\mathrm{n}=2$; post-1900), Bristol interior/no exterior stoneware $(\mathrm{n}=1 ;$ post-1890) and Bristol interior/unglazed exterior ( $\mathrm{n}=1$; post-1890). Whitewares included light blue-tinted $(\mathrm{n}=2 ; 1880$ 1930), pure white ( $n=2$; post-1890), and a burned/discolored sherd. In addition, a piece of porcelain and a piece of yellowware was collected. 
In all, 169 pieces of Domestic glass was collected. Body sherds included amber/brown ( $n=69)$, amber/brown with stippling ( $n=9$; post-1940), aqua $(n=5)$, clear with ash tint body sherds $(n=28$; post-1915), clear $(n=18$; post-1880), dark green $(n=1)$, emerald green $(n=2)$, light green $(n=5)$, opaque milk glass $(n=1)$, and manganese/solarized ( $n=19 ; 1870 s-1920)$. Two possible light green fruit jar fragments were also collected. A clear with ash tint basal sherd with stippling ( $n=1$; post1940) was also found. Bottle finishes included an aqua, non-applied, turn molded bottle neck (pre-1910) and a manganese/solarized bottle neck with a crown cap finish (1892-1920). Table glass includes a clear with ash tint basal fragment (post-1915) and a clear glass rim sherd (post1880).

Architectural items recovered include handmade brick ( $\mathrm{n}=2$; pre-1903), a porcelain electrical part $(n=1)$, window glass (aqua [n=2], clear [ $n=1$; post-1880], light green [n=7], and light tint [n=2]), wire nails $(n=4)$, and roofing nails $(n=1)$. Activities-related items include a piece of barbed wire (post-1878), an iron buckle, a possible valve stem, and a piece of asphalt. Furnishing-related artifacts consists of clear ( $n=1$; post-1880) and clear with ash tint ( $n=3$; post-1915) lamp glass fragments. Indeterminate items included clear with ash tint $(n=4$, post-1915), aqua $(n=1)$, light green $(n=1)$, and clear ( $n=1$; post-1880) angular glass fragments, as well as clear ( $n=2$; post-1880) and light green $(n=1)$ burned glass fragments. Metal artifacts included a unidentified small brass cylinder, an iron rod, an iron strap, a screw, thin iron fragments $(n=20)$, and wire $(n=2)$. Two pieces of bakelite (1906-1940s) and two pieces of modern plastic (post-1942) were also collected. Personal items were limited to a snuff bottle fragment with well-rounded lip (post-1920).

The artifacts collected at site 41TR230 appear to indicate an occupation beginning in the very late nineteenth or early twentieth centuries. The limited archival research suggests that the site is related to one of two structures shown south of a wagon trail on Sam Street's Map of Tarrant County, Texas (1893) and was abandoned by the mid-1920s. The site is considered to have fair to good contextual integrity, although erosion has affected the area immediately east of the site.

Given the prior investigations of late nineteenth and early twentieth century sites at Joe Pool Lake (Jurney et al. 1988), it is unlikely that site 41TR230 would contribute data important to our understanding of local history. The existing archival research has not revealed any connection to important persons or events. Therefore, it is recommended that site 41TR230 is not eligible for inclusion in the NRHP under Criteria A, B, C, or D. 


\section{CHAPTER 6 GEOPHYSICAL SURVEY RESULTS}

\section{INTRODUCTION}

Based on consultation with Geo-Marine, surveys using a fluxgate gradiometer were conducted in order to identify potential archaeological features at site 41TR198. Geophysical data were initially collected over an area totaling 20,000 $\mathrm{m}^{2}$ (4.94 acres) (Walker 2008). Given the exceptional quality of the geophysical data Geo-Marine requested an expanded survey of the site totaling 78,785 $\mathrm{m}^{2}$ (19.46 acres). A Bartington Grad 601-2 dual sensor fluxgate gradiometer (Figure 11) was used for the survey. A Sokkia Radian IS and Sokkia 2650 LB RTK GPS system was used for laying out the grid and mapping in surface features. These geophysical surveys were successful in locating several archaeological features, which have been subsequently excavated by Geo-Marine field crews. The geophysical surveys also demonstrate the horizontal extent of the site and provide useful information regarding the distribution and density of the archaeological features.

Magnetic data were collected using a $1.0 \mathrm{~m}$ traverse interval and a $0.125 \mathrm{~m}$ sample interval (8 readings per $\mathrm{m}$ ). The extended magnetometer survey was collected using an RTK GPS system to position the readings. The gradiometer and the GPS antenna were attached to a two wheeled nonmagnetic hand cart. Real time data output was stored in an Allegro CX field computer and integrated with the GPS coordinates. A grid projected on the display of the filed computer was used to guide the surveyor across the collection area allowing the surveyor to walk along "virtual" grid lines to ensure complete coverage. The gradiometer data output was $10 \mathrm{~Hz}$ and the GPS was $2 \mathrm{~Hz}$. The data collection software interpolates the GPS positions for the gradiometer data points that fall between the $2 \mathrm{~Hz}$ GPS cycle. 


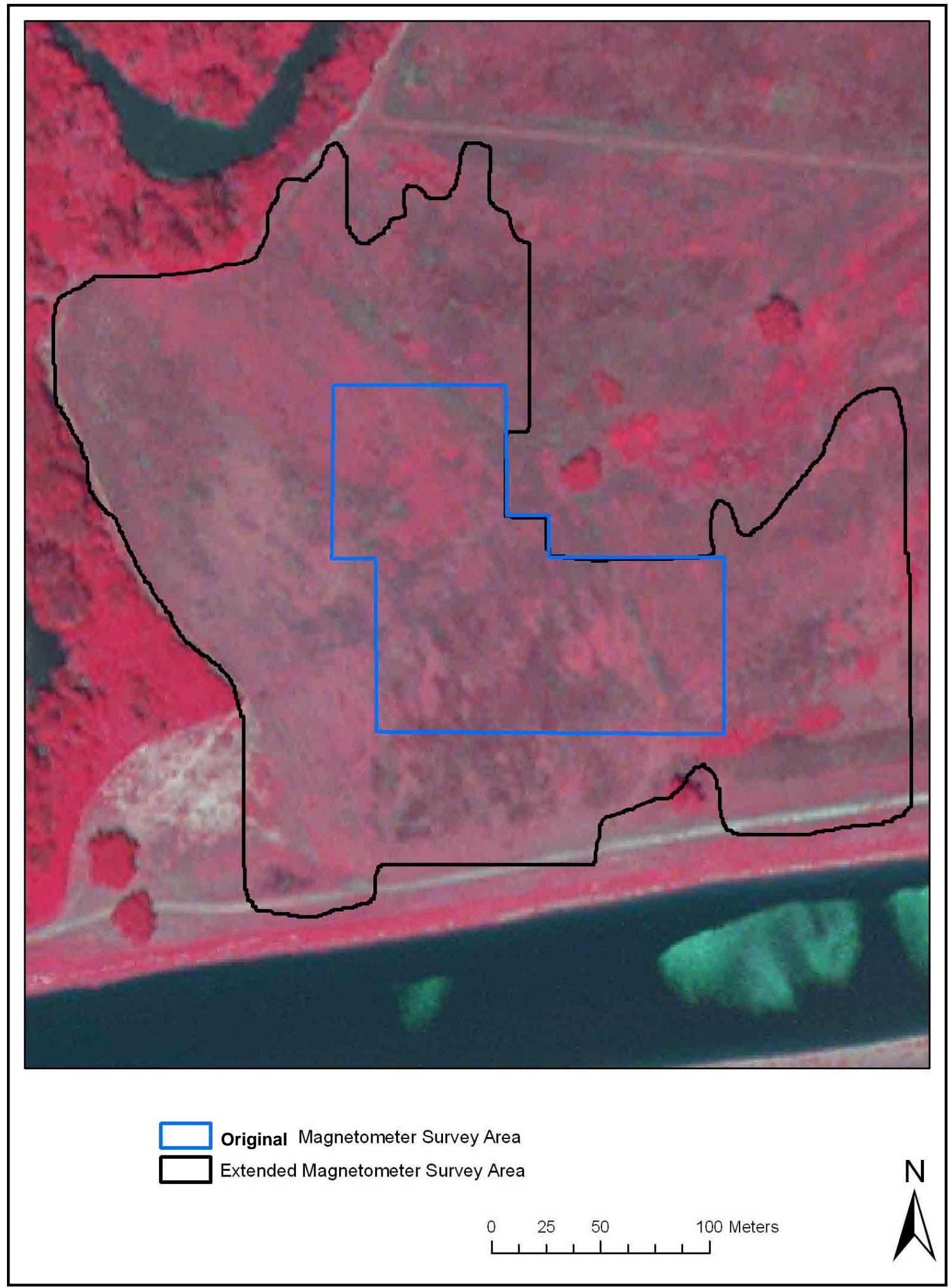

Figure 11. 41TR198 magnetometer survey areas on the Haltom City Southeast Digital Ortho Quarter Quad 2004 NAIP $1 \mathrm{~m}$ CIR. The blue outline shows the extent of the original 2 ha magnetometer survey and the black outline shows the total extent of the magnetometer survey at 41TR198. 


\section{DATA PROCESSING}

All data were processed and filtered to remove extraneous false readings (spikes and drop-outs). Data processing levels the datasets so adjacent grids are combined into a single image with no "grid lines." Datasets were processed to enhance the visibility of the target features and geophysical anomalies through statistical manipulation of the recorded data as well as through image processing of the image file output. The general goal of data processing is to lessen the effects of background "noise" and to enhance the quality of the "signal" or "target." In field geophysics in general, and archaeo-geophysics in particular, the term noise is used to discuss any return that is not a result of the object under investigation - the latter being referred to as the "target" or "signal." Hence, in some cases what is discussed as noise can in another case become the signal or target (Milsom 2005:13-14). Accuracy of the geophysical readings are not as important for resolving targets as is the contrast between the target and its surrounding matrix.

Figure 12 displays the various data processing steps. Figure 12A shows a plot of the raw data. Figure 12B shows the data clipped to $\pm 5 \mathrm{nt}$ to redistribute the grey scale on the parts of the data set with archaeological significance. Clipping replaces all values outside a specified minimum and maximum range. These minimum and maximum values are specified in either absolute values or \pm Standard Deviations (SD). Clipping also minimized effects from spikes in the data caused by ferrous material. A zero median de-stripping filter was applied (Figure 12C).

De-stripping is a process used to equalize the underlying differences between grids caused by instrument drift, inconsistencies during setup, delays between surveying adjacent grids, or heading error from magnetic instruments. The median of each grid or traverse was subtracted from the grid or traverse, effectively zeroing the median.

The data were then passed through a low pass filter to help dampen the overall noise. Low pass filters are used to remove low frequency components in a geophysical survey by calculating the mean of a window of a specified size, and replaces the center value with the mean. Low pass filters are commonly applied to lessen the effects of background noise (Kvamme 2006b). Finally a Fourier Transform was used to help minimize the diagonal stripes caused from plowing. 


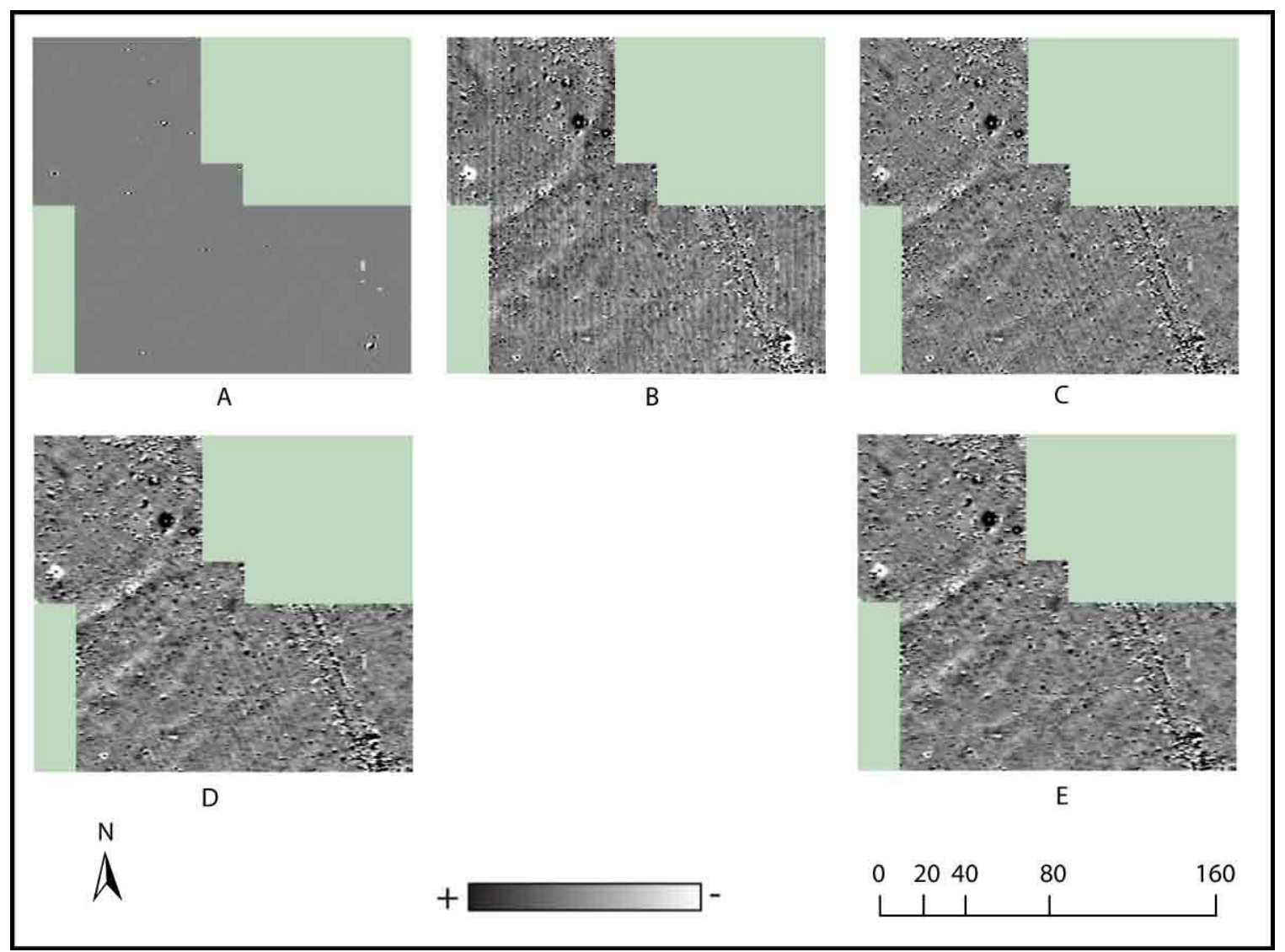

Figure 12. 41TR198 magnetometer data processing of the initial 2 ha collection.

A 2D Fast Fourier Transform (FFT) is a frequency domain filtering process where the data set is analyzed as a sum of phase shifted sine waves (Perkins 1996:139). FFT filters allow the isolation of both frequency and direction and are useful for removing repeating noise such as that caused by modern agriculture. The main constraint of FFT filtering is the source of the noise has to be systematic and repeating. With regards to filtering out plow furrows, an FFT filter can help minimize the effects of areas that were ploughed in straight parallel passes. Table 3 outlines the data processing steps employed in the processing of the geophysical data from 41TR198.

GPS guided gradiometer data required a much different data processing workflow than the data collected in individual collection units. Magnetometer data were interfaced with UTM coordinates in the data collection application. Raw data are exported as an xyz file and passed through a time domain zero median de-stripping filter (see discussion above for details of the application of De-stripping filters). De-stripped data was then imported into Surfer 9.0 and 
Table 3

Data Processing Steps for Magnetometer Data at Site 41TR198

\begin{tabular}{ll}
\hline 1 & Base Layer \\
2 & Clip to \pm nt \\
3 & De-Strip Median Traverse: Grids: All \\
4 & Low pass Faussian filter: Window $3 \times 3$ \\
5 & FFT Filter : 2 Areas Selected \\
\hline
\end{tabular}

gridded to $10 \times 10 \mathrm{~cm}$ cells using Kriging set with a $2 \mathrm{~m}$ search radius. Surfer was then used to create a greyscale image that was clipped to $+/-5 \mathrm{nT}$ exported as a Geo Tiff world file. Finally the raster was imported into ArcGIS 9.2 where the vector polygon interpretive maps were created and overlaid on various base maps.

\section{SURVEY RESULTS}

Findings from exploratory backhoe trenching and shovel testing conducted by Geo-Marine (Huhnke and Wurtz 2004) has characterized 41TR198 a as "typical flood plain site with multiple occupational surfaces containing hearth like features consisting of burned clay, charcoal, and firecracked rock (Huhnke and Wurtz 2004:iii)." The site is situated within the West Fork Paleosol and is covered by $50-200 \mathrm{~cm}$ of alluvium.

The magnetometer data from 41TR198 are characterized by a low background signal with many small high magnetic anomalies (Figure 13). Figures 14 and 15 show the truncated high magnetic anomalies that have a geophysical profile consistent with thermal archaeological features recovered at the site by Geo-Marine.

Given the large number of magnetic anomalies recovered during the initial geophysical data collection (Walker 2008:7), AGA accompanied Geo-Marine field crews during the excavations to aid in the ground truthing process. RTK GPS was used to survey in the locations of anomalies for ground truthing using backhoes to excavate trenches. It became quickly evident that many of the truncated high magnetic anomalies (see Figures 14 and 15) corresponded to various types of deeply buried thermally altered archaeological features or clusters of features. The quality of the 


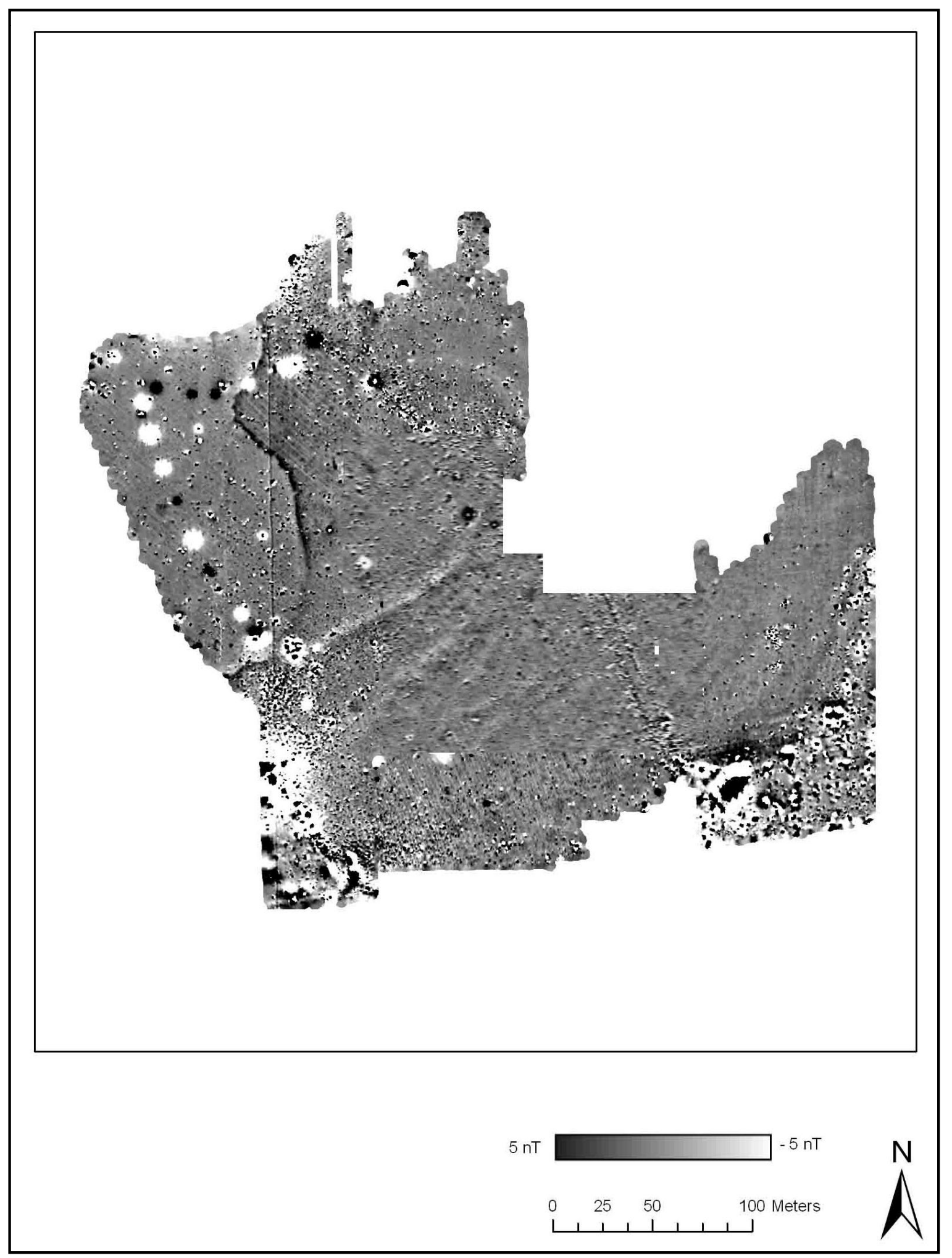

Figure 13. 41TR198 processed magnetometer data. 


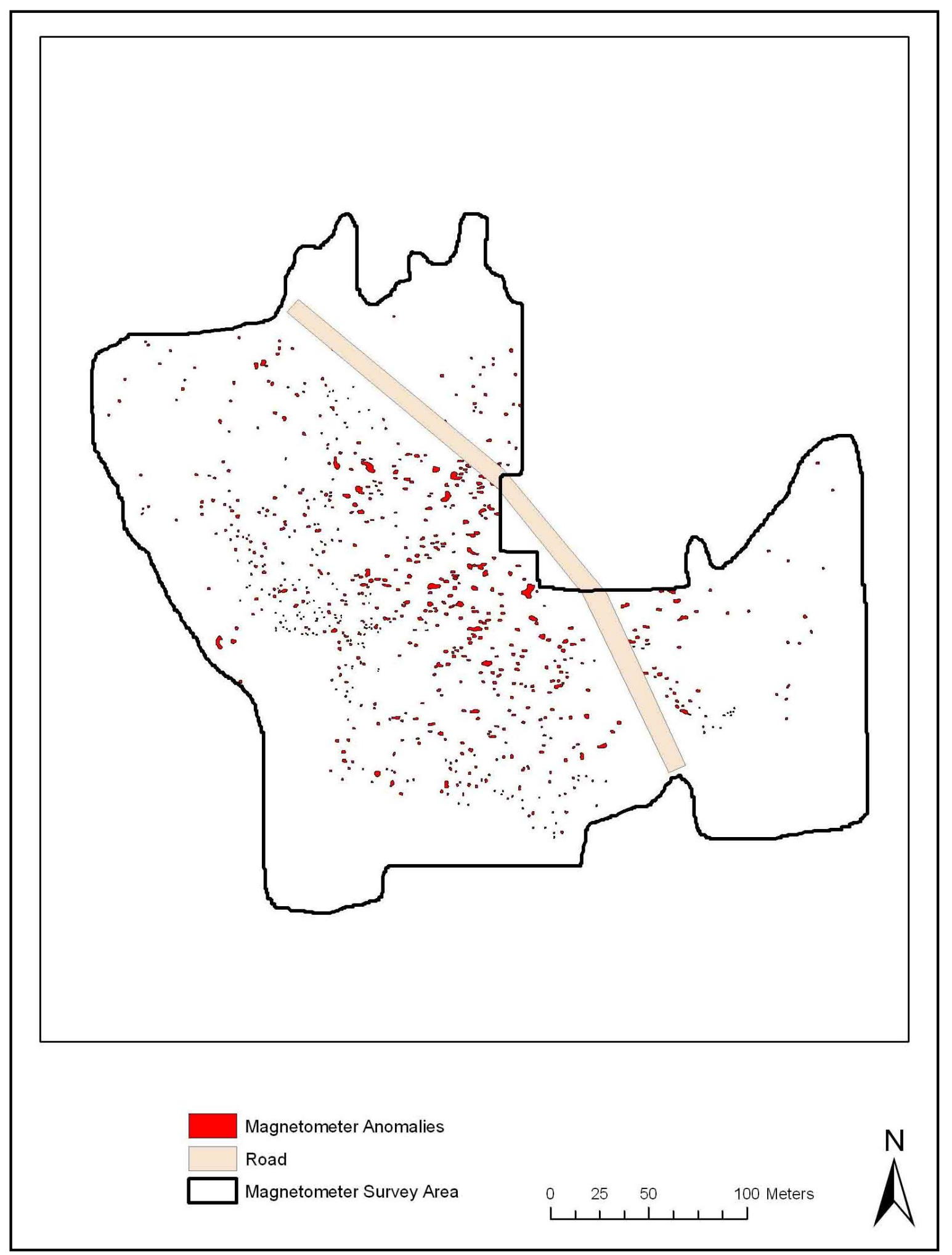

Figure 14. 41TR198 high magnetic anomalies. 


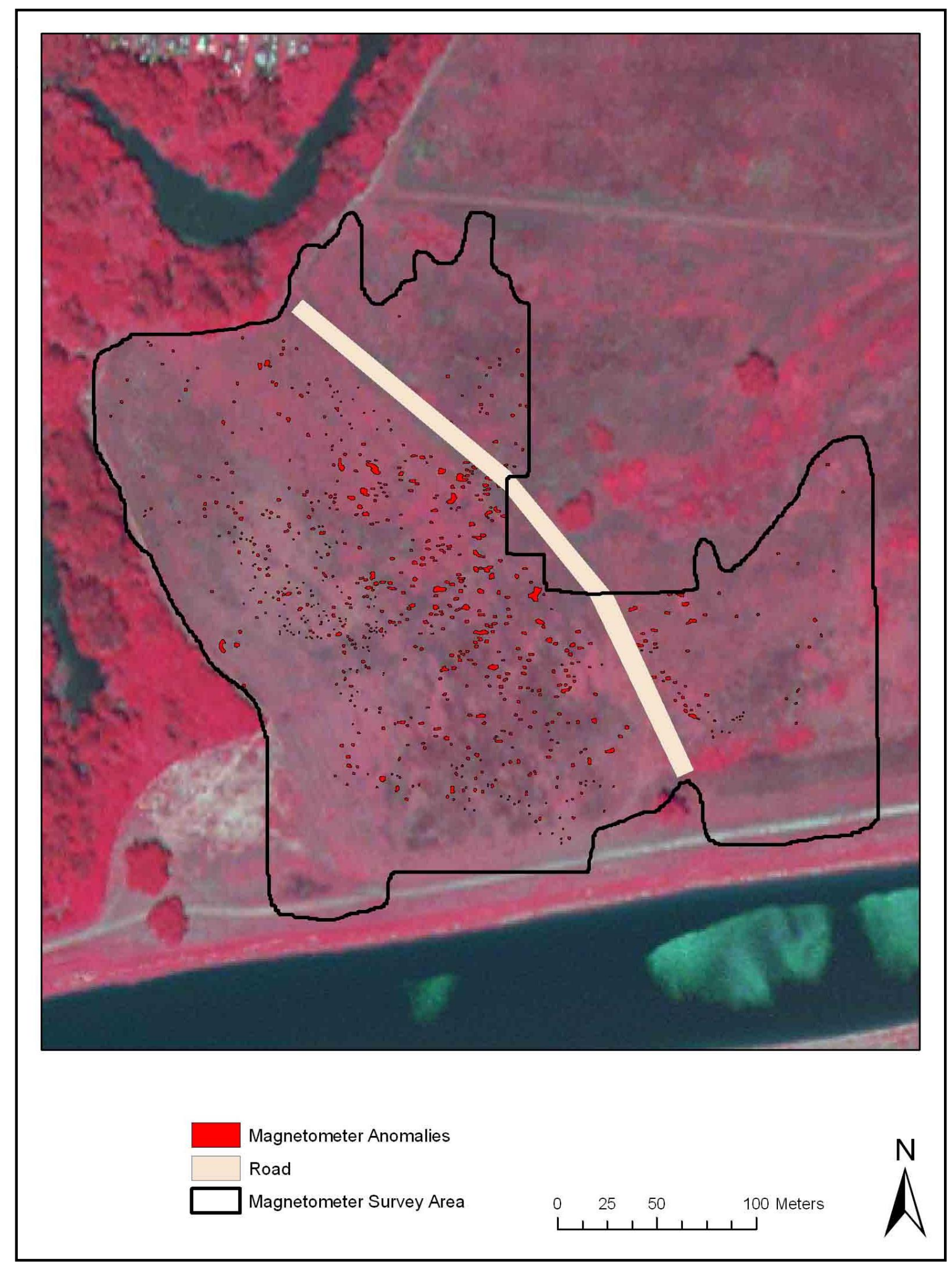

Figure 15. 41TR198 high magnetic anomalies on the Haltom City southeast digital ortho quarter quad 2004 NAIP $1 \mathrm{~m}$ CIR. 
geophysical data warranted Geo-Marine to request an extension of the original geophysical survey.

Figure 16 shows the locations of the anomalies that were ground truthed. Anomalies were chosen for ground truthing by researchers from both AGA as well as Geo-Marine based on their size, position, and geophysical signature. Several of the exploratory trenches were expanded into strip units in which hand excavation units were then placed.

Figures $17-23$ show the locations of the individual strip units and backhoe trenches on the magnetometer data. The targeted anomalies in each case were high magnetic anomalies, which show up as dark shades of grey or black. These data precisely pinpoint the locations of features and feature clusters. However, due to the two-dimensional nature of the data representation and the stratigraphic overlay of the site, the geophysical signatures shown in these images generally reduce the amount of complexity demonstrated by the manual excavations.

\section{SUMMARY AND CONCLUSIONS}

A magnetometer survey was conducted at 41TR198 over 78,785 $\mathrm{m}^{2}$ (19.46 acres). Several truncated high magnetic anomalies were tested and proved to be thermally altered archaeological features consistent with the types of features recovered during previous archaeological investigations at the site (Huhnke and Wurtz 2004). The magnetometer data suggest that there are hundreds of similar features still intact at 41TR198. The site appears to have modern boundaries on the east and south sides and is clipped by geological features on the north and west. The distribution of thermal features as shown in the magnetometer data shows a dense cluster of features in the core area of the site which was subsequently excavated most intensively. Given the high contrast of these data, future projects in similar geological settings with similar cultural deposits should benefit from the use of geophysical surveys. Tests with ground penetrating radar could also aid in gaining vertical control of the archaeological deposits prior to exploratory trenching. 


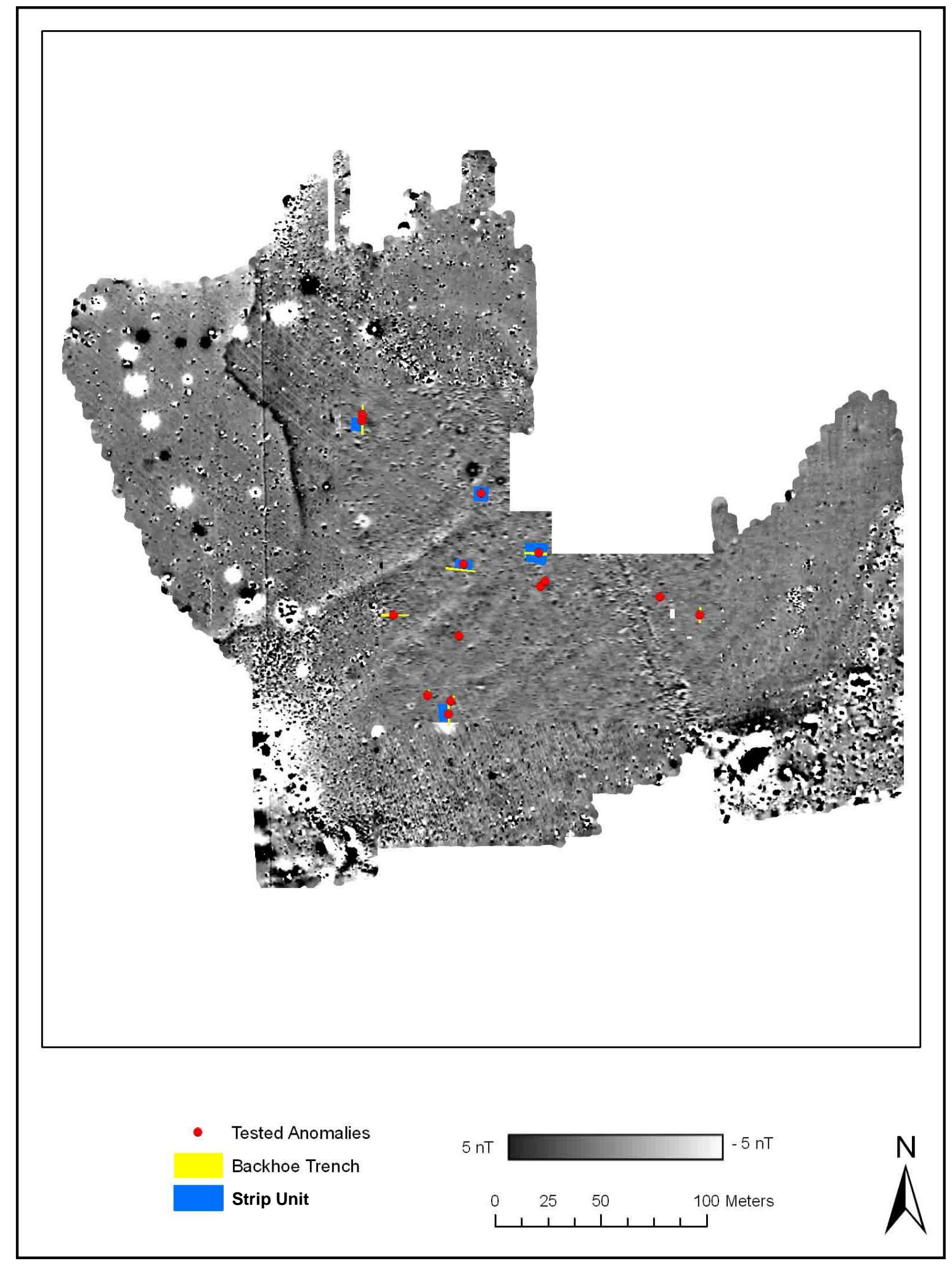

Figure 16. Locations of tested anomalies, backhoe trenches and strip units at 41TR198. 


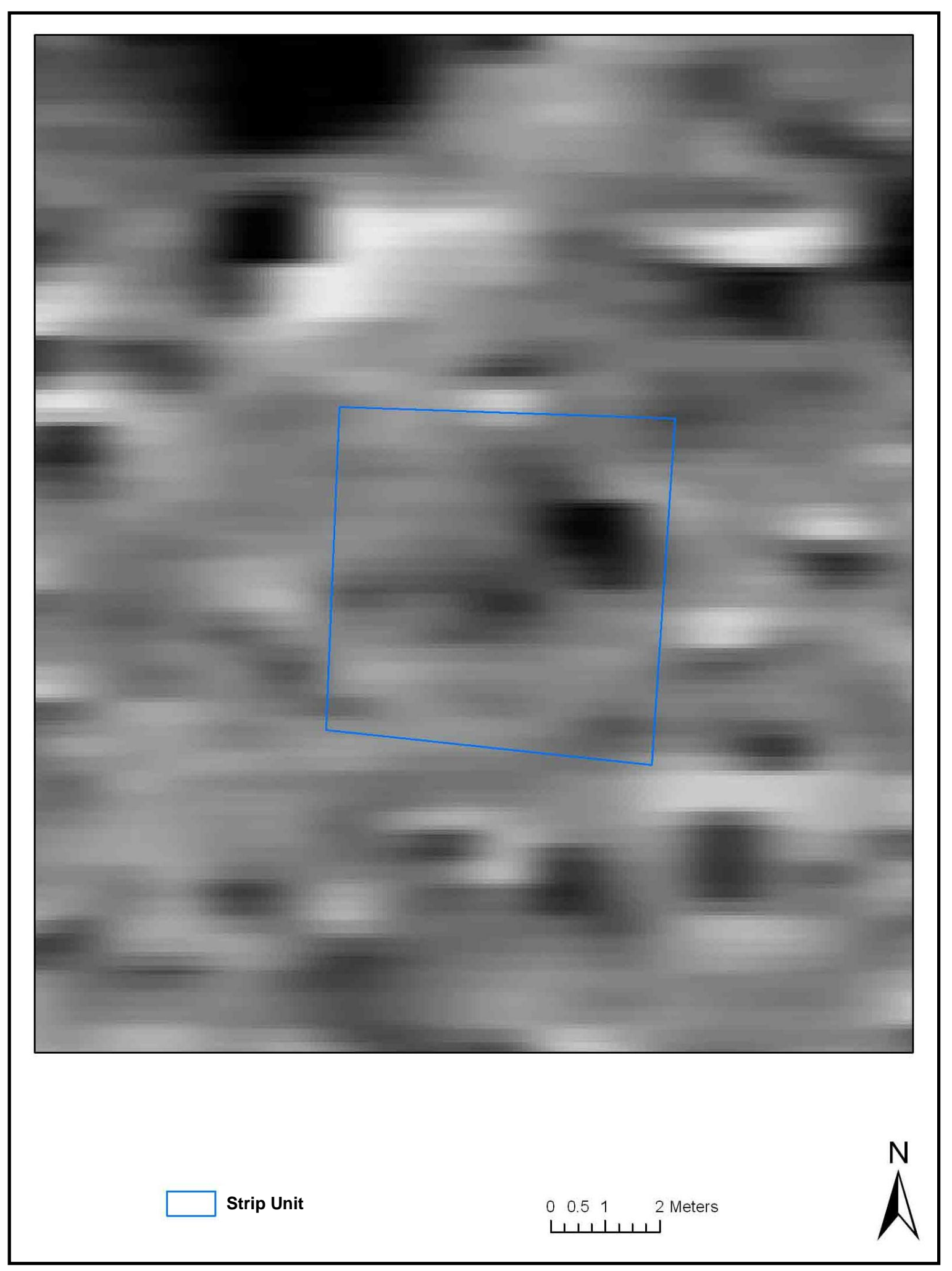

Figure 17. Detail of strip unit 1. 


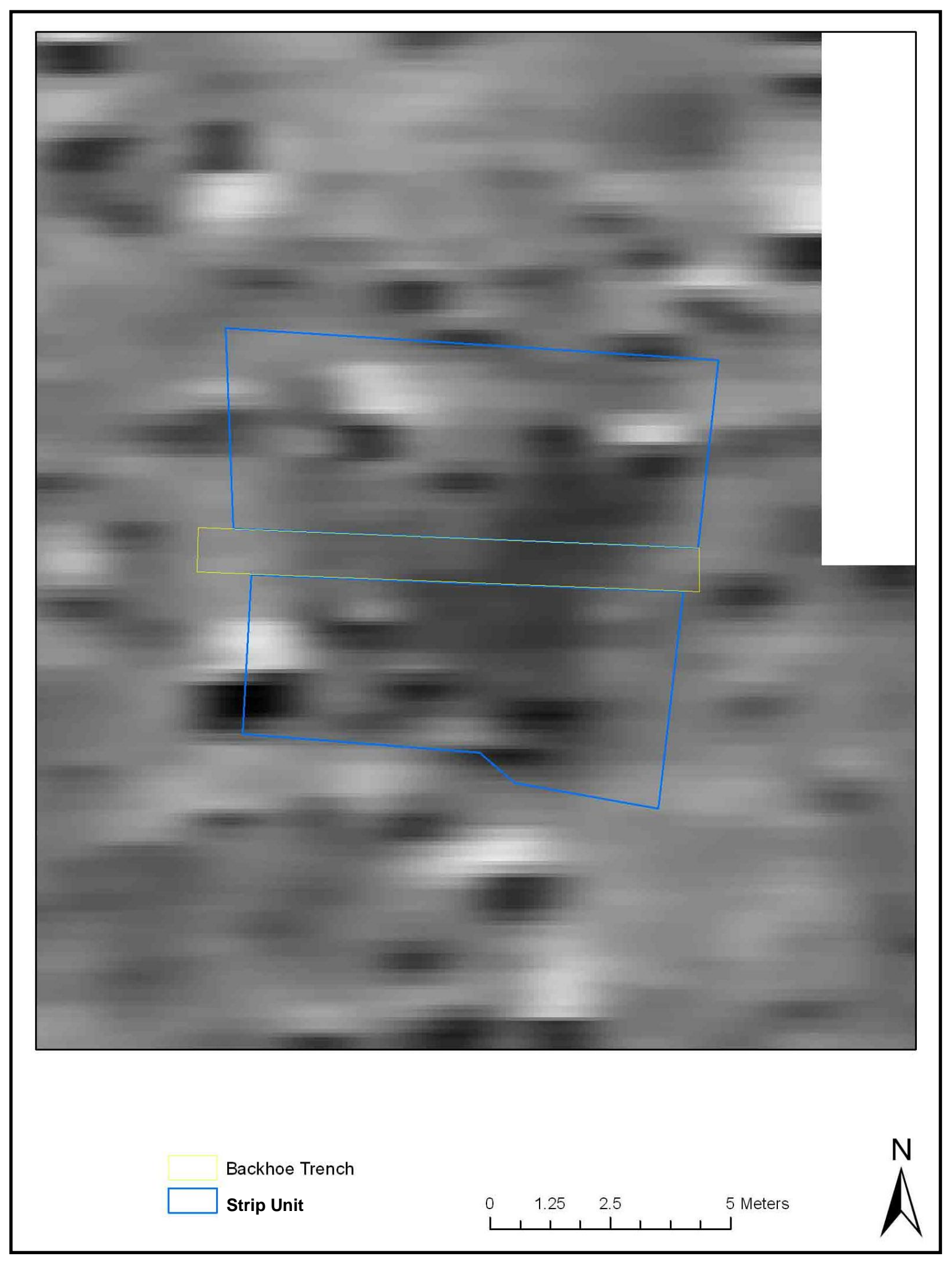

Figure 18. Detail of strip units 2 and 3. 


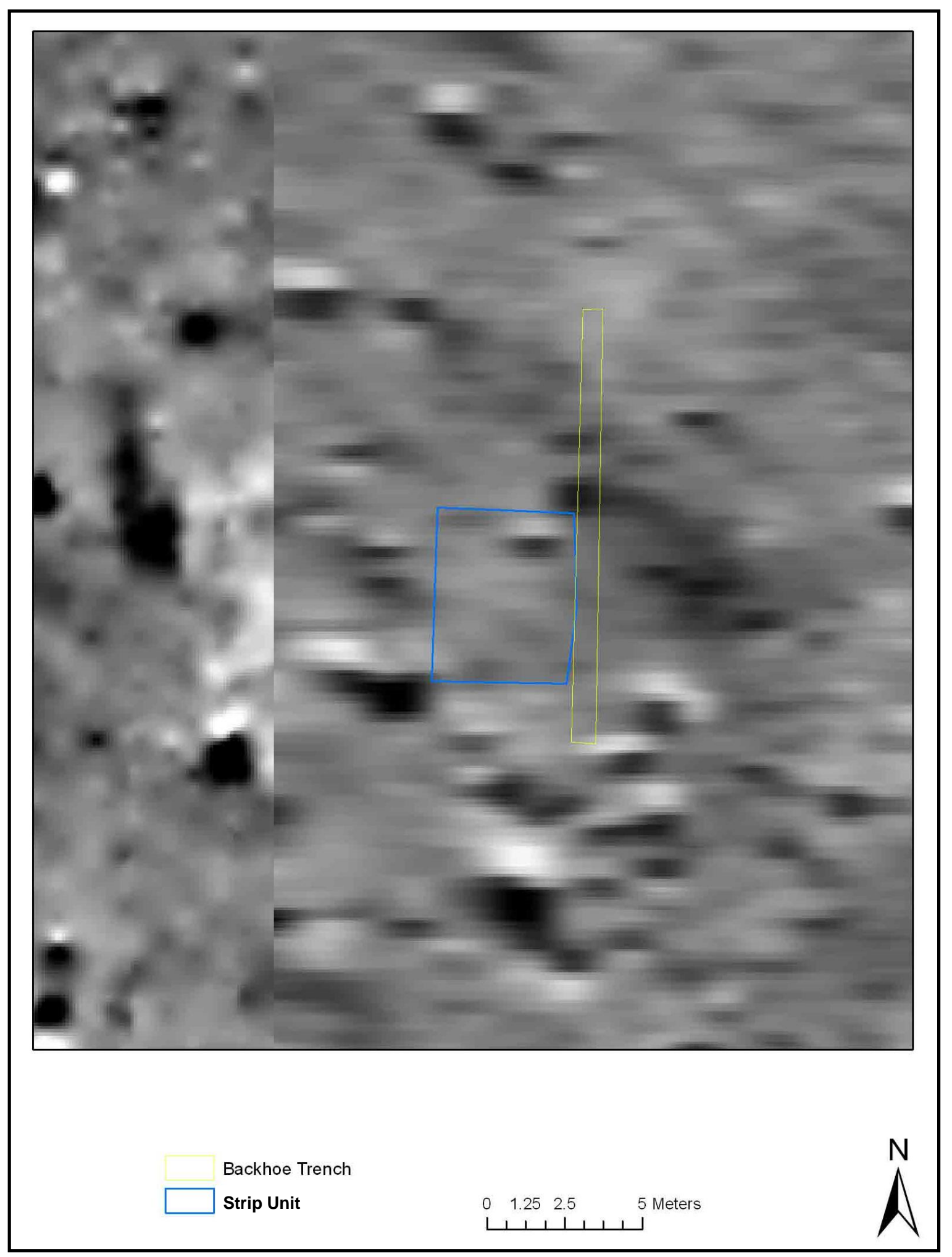

Figure 19. Detail of strip unit 4 and backhoe trench 8 . 


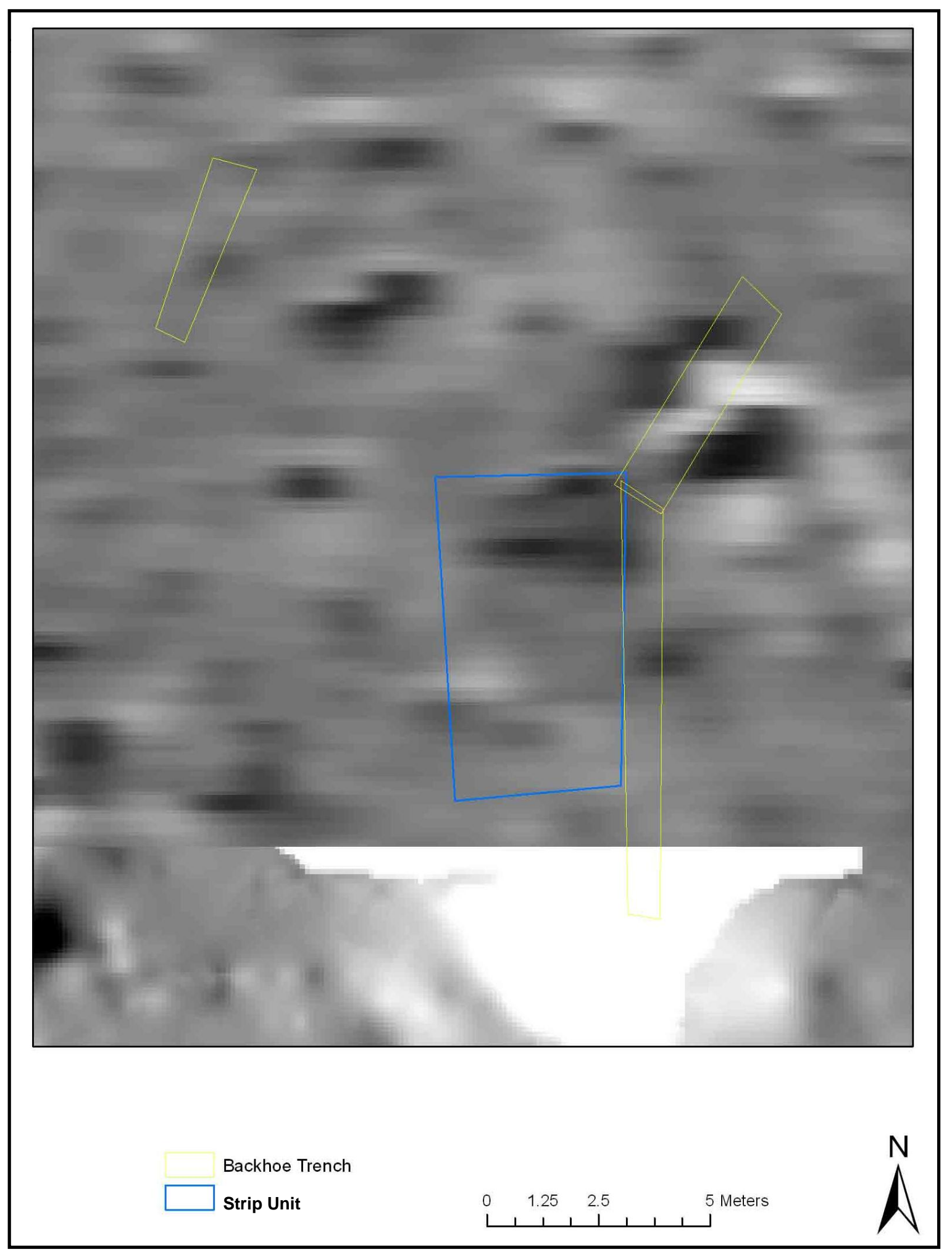

Figure 20. Detail of strip unit 5 and backhoe trenches 2, 3, and 4. 


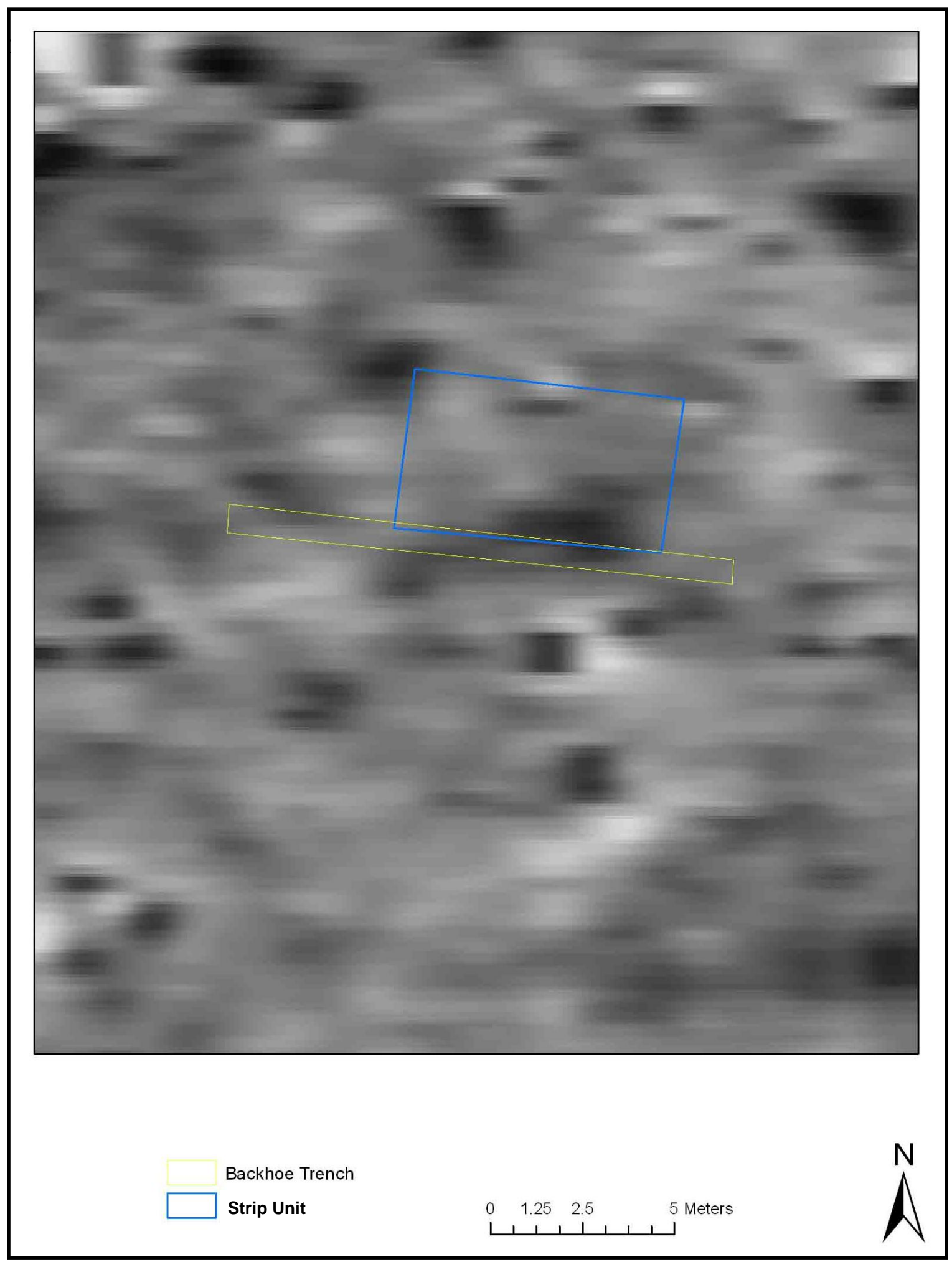

Figure 21. Detail of strip unit 6 and backhoe trench 6 . 


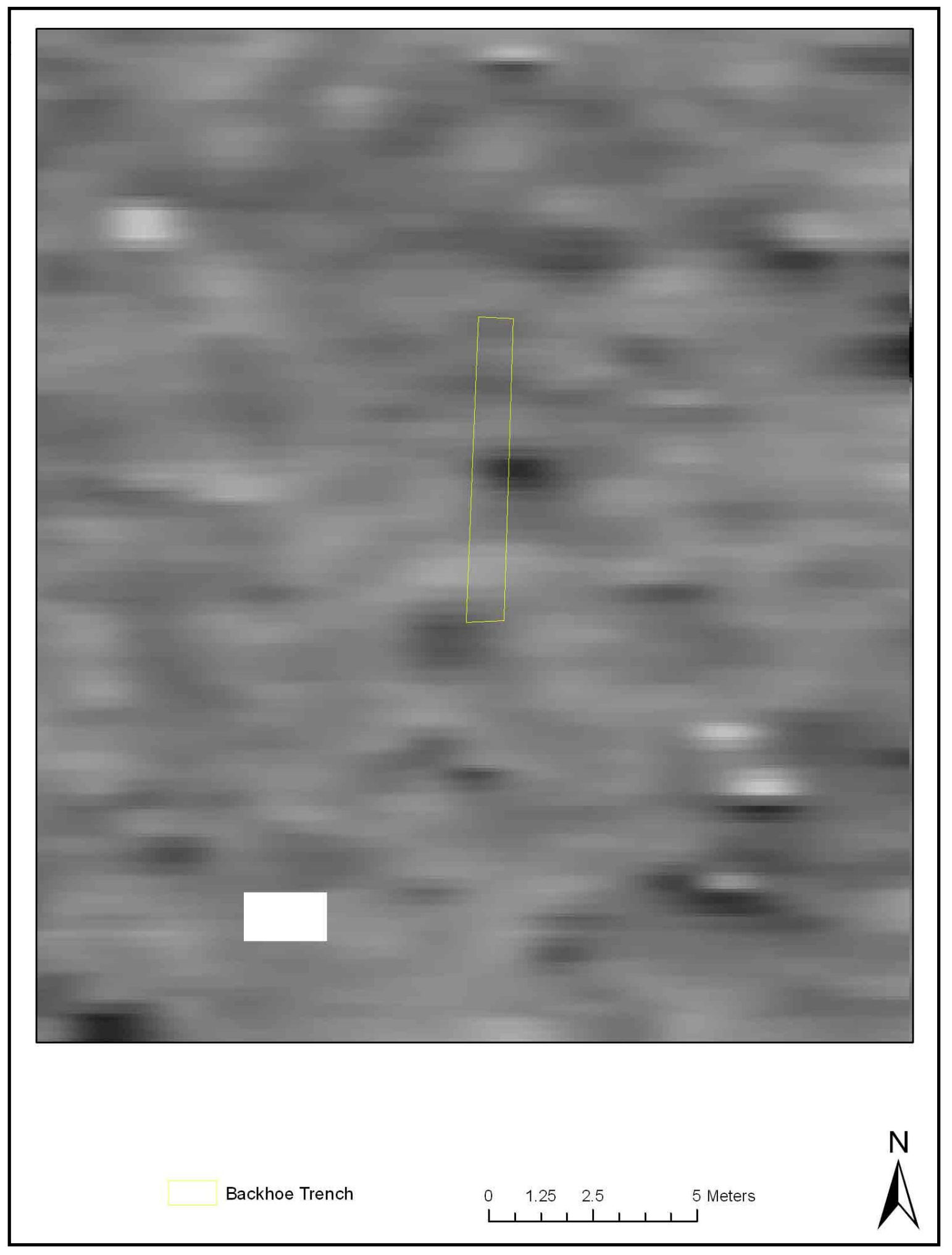

Figure 22. Detail of backhoe trench 5. 


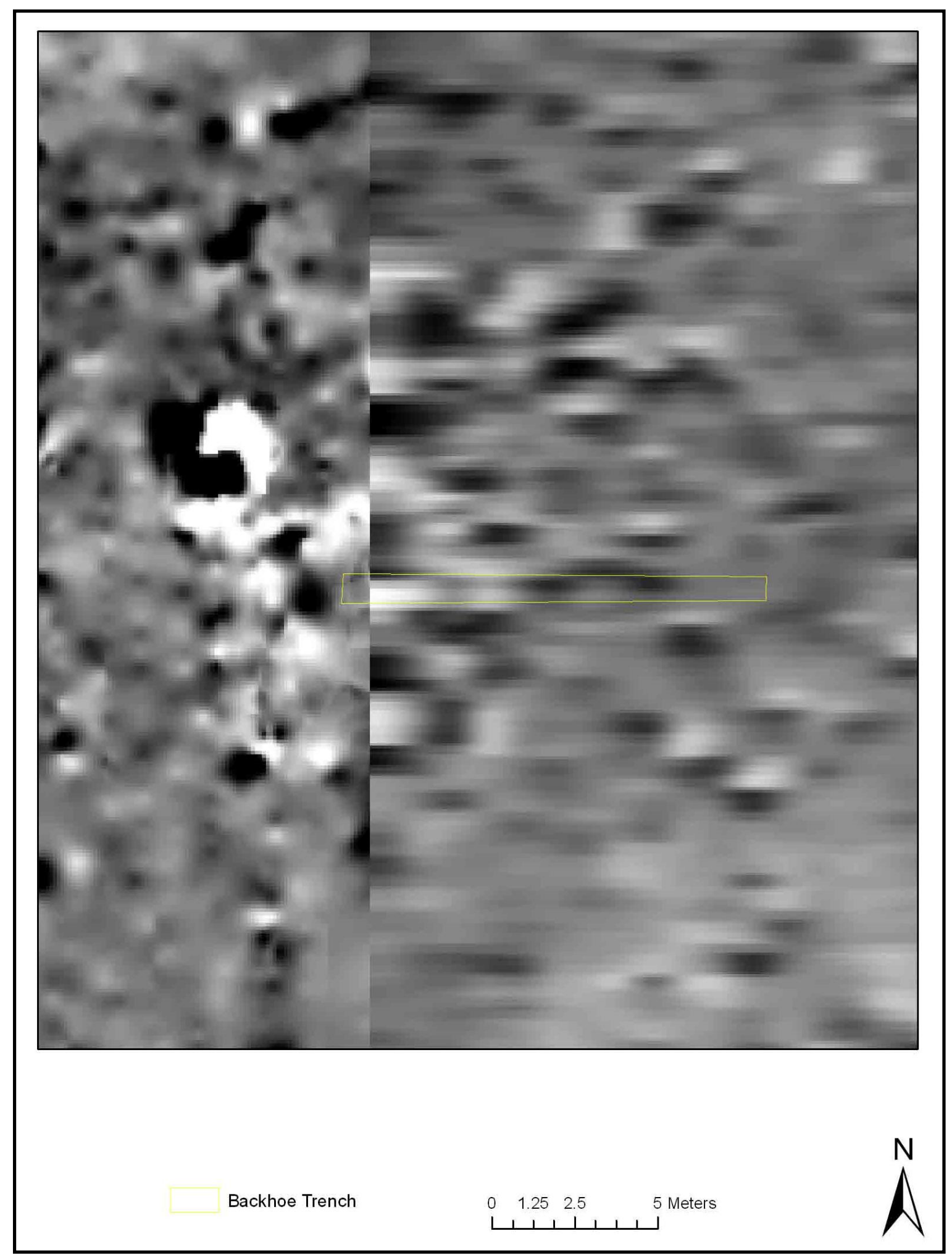

Figure 23. Detail of backhoe trench 7. 


\section{CHAPTER 7 \\ GEOMORPHOLOGICAL CONTEXT}

\section{INTRODUCTION}

This chapter reports the results of geoarchaeological investigations at the site, which were performed towards the end of the data recovery excavations. These studies were designed to elucidate information on the environmental history of the site, as well as document the nature of the prehistoric occupations present. The primary forms of information used in this work include documentation of the stratigraphy at the site with special attention devoted to Block 3. A suite of samples collected at $5 \mathrm{~cm}$ increments through Block 3 were used to obtain specific information on the site deposits and how they changed through time. In addition to these samples a limited suite of oriented block samples were cut from the excavation walls from selected contexts for micromorphological examination of specific occupation surfaces and features.

\section{METHODS}

The physical properties of the sedimentary matrix of the site were documented from a series of 26 samples collected from a $10-\mathrm{x}-10 \mathrm{~cm}$ sample column samples collected at $5 \mathrm{~cm}$ increments during the excavation from Block 3. For each sample the texture (or particle size distribution), calcium carbonate content, magnetic susceptibility, organic carbon content and stable carbon isotopic composition were determined. A select suite of samples was also collected for thin section preparation and soil micromorphological analysis. The details of the analytical methods employed are described below, and the results of the lab work are presented in Tables 4 and 5. 
Table 4

River Morphology Attributes of Streams Near the Site

\begin{tabular}{|c|c|c|c|}
\hline Stream & Sinuosity & Meander Wavelength (m) & Radius of Curvature (m) \\
\hline \multirow[t]{3}{*}{ Modern Trinity River } & 1.24 & $\operatorname{Max}=385$ & $\operatorname{Max}=288$ \\
\hline & & $\operatorname{Min}=170$ & $\operatorname{Min}=114$ \\
\hline & & Average $=306.5$ & Average $=203$ \\
\hline Paleochannel & 1.56 & 463 & 109 \\
\hline \multirow[t]{3}{*}{ Sycamore Creek } & 1.33 & $\operatorname{Max}=193$ & $\operatorname{Max}=82$ \\
\hline & & $\operatorname{Min}=93$ & $\operatorname{Min}=41$ \\
\hline & & Average $=134$ & Average $=48$ \\
\hline
\end{tabular}

Table 5

Radiocarbon Ages Obtained from Block 3, and Apparent Sedimentation Rates

\begin{tabular}{ccccccc}
$\begin{array}{c}\text { Beta Lab } \\
\text { Number* }\end{array}$ & $\begin{array}{c}\text { Radiocarbon } \\
\text { Age (years B.P.) }\end{array}$ & $\begin{array}{c}\text { Plot Elevation } \\
(\mathrm{m})\end{array}$ & $\begin{array}{c}\text { Elevation } \\
\text { Difference } \\
(\mathrm{cm})\end{array}$ & $\begin{array}{c}\text { Age } \\
\text { Difference } \\
\text { (years) }\end{array}$ & $\begin{array}{c}\text { Sedimentation } \\
\text { Rate (cm/year) }\end{array}$ & $\begin{array}{c}\text { Sedimentation } \\
\text { Rate } \\
(\mathrm{cm} / \text { century) }\end{array}$ \\
\hline assumed & 0 & 99.60 & 45 & 500 & 0.0900 & 9.00 \\
assumed & 500 & 99.15 & 42.5 & 460 & 0.0924 & 9.24 \\
259837 & 960 & 98.725 & 17.5 & 150 & 0.1167 & 11.66 \\
259838 & 1110 & 98.55 & 20 & 250 & 0.0800 & 8.00 \\
259839 & 1360 & 98.35 & 17.5 & 340 & 0.0515 & 5.14 \\
259843 & 1700 & 98.175 & 17.5 & 50 & 0.3500 & 35.00 \\
259841 & 1750 & 98 & 145 & 650 & 0.2231 & 22.30 \\
259836 & 2400 & 96.55 & -- & -- & - & - \\
\hline
\end{tabular}

*see Appendix B

\section{Particle Size Analysis (Texture)}

Texture analysis was performed using the hydrometer-sieve method (cf. ASTM 1985; Gee and Bauder 1986; Bouyoucos 1962). Samples were first weighed moist and then gently passed through a $2 \mathrm{~mm}$ sieve taking care not to crush fragile bits of burnt earth that might be present. When more than $200 \mathrm{~g}$ of $<2 \mathrm{~mm}$ sediment was obtained, the remainder of the sample was transferred to a $100 \mathrm{ml}$ beaker and a 5 percent sodium hexa meta phosphate solution was added to break down the clays and to permit separation of the $>2 \mathrm{~mm}$ artifacts and gravels. After soaking for 2 days during which time the samples were repeatedly stirred, the samples were wet sieved through a $2 \mathrm{~mm}$ sieve and the coarse fraction separated and dried. Coarse material caught on the $2 \mathrm{~mm}$ sieve, if detrital sediment (and not artifactual), was then sieved at a 1 phi interval and the 
mass on each sieve recorded. In this particular case, cultural material (see micro-artifacts, below) were counted and weighed separately for each size class, so their depth distribution could be examined, as well as to exclude them from the detrital totals used to determine the properties of the alluvial sediments. A split of the $<2 \mathrm{~mm}$ size material (roughly 40 grams) was then soaked in $50 \mathrm{ml}$ of a 5 percent sodium hexametaphosphate solution overnight, and then mixed in a mechanical mixer for 5 minutes before being diluted to 1 liter with distilled water. This mixture was placed in a 1 liter settling jar, mechanically agitated for 1 minute, and then set on a table, after which point hydrometer readings were made a different time intervals (specifically 1, 3.5, 15, 45, 300, and 1440 minutes). A control hydrometer and temperature reading on an empty jar with nothing but distilled water and the sodium hexametaphosphate solution was made at intervals throughout the analysis to permit calibration of the hydrometer. A small split of the $<2$ $\mathrm{mm}$ soil was also oven dried to determine the moisture content and correct the sample mass used in the hydrometer analysis (hygroscopic moisture correction). After 24 hours, the contents of the hydrometer jar were wet sieved through 37 micron sieve, and the sand retained on the sieve was transferred to a beaker and oven dried at $105^{\circ} \mathrm{C}$. This sand was subsequently sieved at 0.5 phi intervals once dry and the mass retained on each sieve recorded. From these data the percentage of gravel, sand, silt and clay, as well as various descriptive statistics were calculated for the grain size distribution using a spreadsheet written by Paul Lehman.

\section{Calcium Carbonate Content (C.C.E)}

A small split (either $1.7 \mathrm{~g}$ or $0.85 \mathrm{~g}$ ) of the ground $<2 \mathrm{~mm}$ fraction of each soil sample was used to determine the calcium carbonate equivalent (C.C.E.) by means of a Chittick apparatus (Dreimanis 1962; Machette 1986). This sample was finely ground (to pass a $0.075 \mathrm{~mm}$ sieve), and then weighed, and placed into a small $(250 \mathrm{ml})$ Erlenmeyer flask. Once attached to the Chittick apparatus, the liquid level in the measuring burette was set to $-10 \mathrm{ml}$, then the stopcock was closed so no gas could leave the system, and the leveling bulb was dropped in order to establish a vacuum inside the sample chamber. At this point the barometric pressure and temperature in the room were recorded. Then $10 \mathrm{ml}$ of 50 percent hydrochloric acid (ca. $6 \mathrm{~N}$ $\mathrm{HCl}$ ) was delivered to the sample flask, which was agitated intermittently until the reaction had ceased (usually 1-2 minutes). At this point, the leveling bulb was raised to the point that the liquid level inside of it was equal in elevation to the liquid in the burette, and the volume of gas evolved was then measured and the calcium carbonate equivalent calculated. 


\section{Organic Carbon and Stable Carbon Isotopic Analysis}

In order to determine the carbon content of each sample, splits of the $<2 \mathrm{~mm}$ size fraction were submitted to the Analytical Chemistry Lab at the Institute of Ecology, University of Georgia. The carbon content was determined on a Micro-Dumas NA1500 Combustion Elemental $(\mathrm{C} / \mathrm{H} / \mathrm{N})$ Analyzer (Carlo Erba Strumentazione, Milan). Details of the procedures used at in the procedure may be found on the institute's web page (http://www.uga.edu/ sisbl/soilerb.html) and general aspects of the method are discussed by Schulte and Hopkins (1996). Prior to submission calcium carbonate was removed from the samples by treating a 2 gram split of the $<2 \mathrm{~mm}$ size soil with 6 $\mathrm{N} \mathrm{HCl}$. The samples were allowed to sit 5 hours or until the supernant liquid was clear, and then decanted and subsequently refilled three times in order to remove all traces of acid. After the third rinse, the decanted sample was dried at $105^{\circ} \mathrm{C}$, and subsequently finely ground once dry.

\section{Magnetic Susceptibility}

Dry sediment samples that had been sieved to remove the $>2 \mathrm{~mm}$ size material were packed into $2.5 \mathrm{~cm}$ plastic cubes, weighed, and then the low frequency $(470 \mathrm{~Hz})$ and high frequency (4700 $\mathrm{Hz}$ ) magnetic susceptibility (kappa) was measured on the o.1 setting on a Bartington MS2 meter and an MS2b sensor. The mass corrected magnetic susceptibility (chi, or $\chi_{\mathrm{lf}}$ ) and coefficient of frequency dependency $\left(\chi_{\mathrm{fd}}\right)$ were then calculated. The coefficient of frequency dependency $\left(\chi_{\mathrm{fd}}\right)$, is the percent difference in magnetic susceptibility measured at low and high frequencies (calculated as: $\left.\left.\chi_{\mathrm{fd}}=\left(\chi_{\mathrm{lf}}-\chi_{\mathrm{hf}}\right) / \chi_{\mathrm{lf}}\right) * 100\right)$. Elevated values of $\chi_{\mathrm{fd}}(\mathrm{ca} .>10 \%$; Gale and Hoare 1991:213) are indicative of increased concentrations of fine-grained ferrimagnetic minerals, most often maghemite, in top soils (Dearing et al 1996). The magnetic susceptibility values are presented on Table 4 and are reported in SI units $\left(10^{-8} \mathrm{~m}^{3} \mathrm{~kg}^{-1}\right)$.

\section{Microartifact Analysis}

The dry coarse fraction splits obtained during the particle size analysis were passed through a suite of three sieves ( $8 \mathrm{~mm}$ (-3 phi), $4 \mathrm{~mm}$ (-2 phi), and $2 \mathrm{~mm}(-1 \mathrm{phi}))$ and sorted under a low power binocular microscope (Leica S8 APO) into gravel and various artifact categories (specifically burnt earth, debitage, fire cracked rock, mussel shell, and bone). These were then 
counted and weighed and the results are presented on Table 5. Selected results are plotted on Figure 24.

\section{Soil Micromorphology}

Small oriented blocks of sediment were cut from the excavation wall near Feature 8 and from Feature 15 in Block 3. The samples from Feature 8 were intended to examine a range of presentations of what appeared to be a fairly discrete occupation surface. Samples were collected from the feature (a hearth), a rake out or ash dump, and from a general occupation surface nearby. A single large monolith was collected from Feature 15, which had a deeply oxidized and reddened rim beneath it and a prominent ash accumulation on top.

Upon returning to the lab the micromorphology field samples were oven dried and then vacuum embedded with polyester resin and subsequently cut into slabs on an oil lubricated rock saw when hardened. The slabs were first scanned on a flatbed scanner, and then blanks for thin section were selected, trimmed to size and then submitted to National Petrographic Inc. (Houston, Texas) for thin section preparation. The thin sections were subsequently examined at a range of magnifications. Low magnification examination was performed with the aid of a flat bed scanner and the slides were scanned at 1200 dpi using transmitted light (slide mode). Full page color laser prints of the slides were used to perform the first pass assessment of each slide. Areas of interest were then identified and examined with a Leica S8 APO binocular microscope fitted with transmitted light base and polarizing filters. Higher magnification examination employed a Leica DMEP polarizing light microscope.

\section{Geomorphology}

The site is situated on a piece of slightly elevated ground that, prior to extensive earthmoving activities in the 1950's, was bounded on the west by the modern channel of the west Fork of the Trinity River, on the north and east by a paleochannel of the West Fork, and on the south by the channel of Sycamore Creek (Figure 25). The construction of an east-west oriented rectified channel in the 1950s cut off the modern channel of the West Fork from immediately southwest of the site to a point about one mile to the east, and this excavation obliterated most evidence of the 


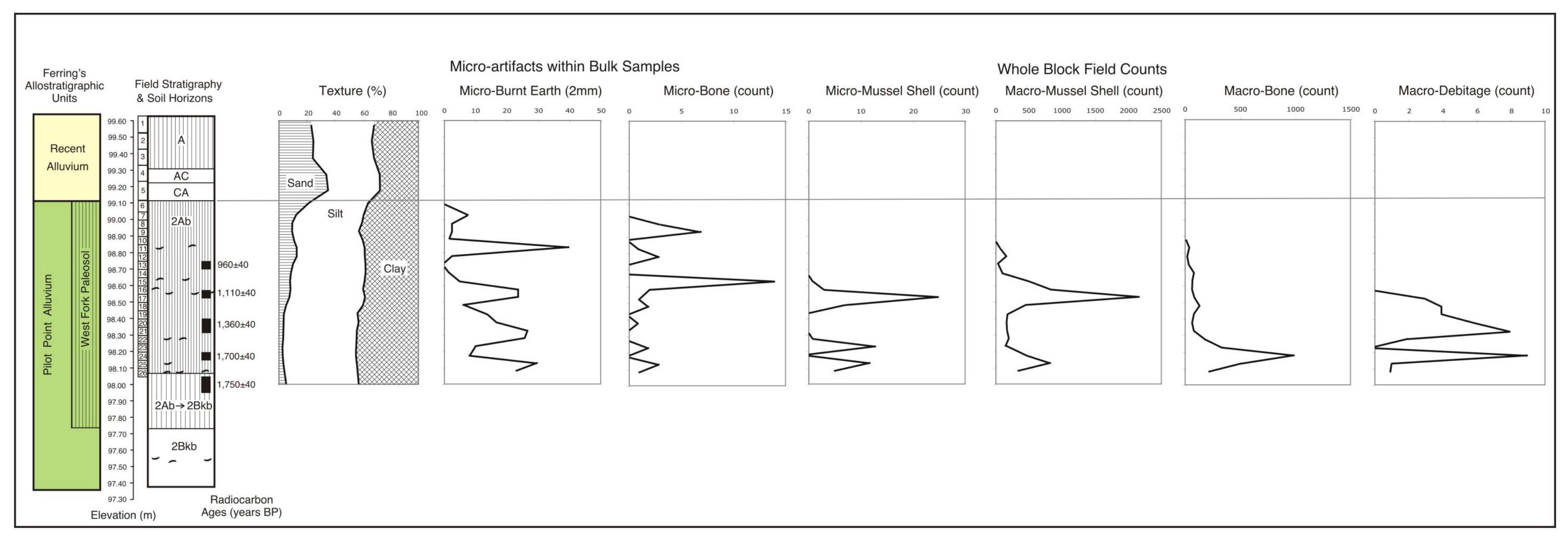

Figure 24. Block 3 artifacts by depth. 
Figure Redacted

Figure 25. 1955 aerial view of site 41TR198 and illustration of the interpretation of the local geomorphology. 
most recent channel of Sycamore Creek near the site. The top part of Figure 25 shows an aerial view of the site and its immediate vicinity in 1955, when the Trinity River diversion and Interstate Highway 30 were both under construction. The lower panel of this illustration is an interpretation of the local geomorphology based upon features visible in the 1955 aerial photo and observed in the field at the time of fieldwork.

At the time of the fieldwork it was not clear if the paleochannel that comprises the northern site boundary was an abandoned channel of the West Fork of the Trinity River, or an abandoned course of Sycamore Creek. But following completion of the geomorphic map it was apparent that the morphology of the paleochannel (specifically the radius of meander curvature, meander wavelength, and the meander belt width) is most consistent with the Trinity River and not Sycamore Creek (Figure 26; see Table 4). The most obvious difference at first glance at Figure 16 is that the modern Trinity River meander belt is significantly wider than the Sycamore Creek meander belt (200-300 m vs. $<140 \mathrm{~m}$ ). But when other descriptive attributes of local streams are examined, it is apparent that the radius of curvature and the meander wavelengths are also significantly different. Given that Dury (1965) found that the meander wavelength is directly related to the bank full discharge, the fact that the paleochannel properties are slightly larger than the modern Trinity River suggests that the stream that created the paleochannel had a similar or slightly larger bank full discharge than the modern West Fork of the Trinity River. Hence, it seems clear on morphological grounds that the paleochannel is an old Trinity River channel.

\section{Late Quaternary Alluvial Stratigraphy}

The Late Quaternary alluvial stratigraphy of the Upper Trinity River has been previously described by Ferring (1986; 1994; 1990; Ferring and Yates 1997). Drawing on stratigraphic work along the Elm Fork and the West Fork of the Trinity River, Ferring recognized seven distinct alloformations, four of which are of Late Glacial and Holocene age. These deposits, from oldest to youngest, are the Aubrey alloformation (14,200 to 11,500 years B.P.), the Sanger alloformation (9,500 to 6,000 years B.P.), the Pilot Point alloformation (4,500 to 500 years B.P.) and the Recent

alluvium (< 500 years B.P.). Since Ferring's initial work, numerous archaeological studies have generated data that support the geochronology of the latter part of this stratigraphic study (e.g. 


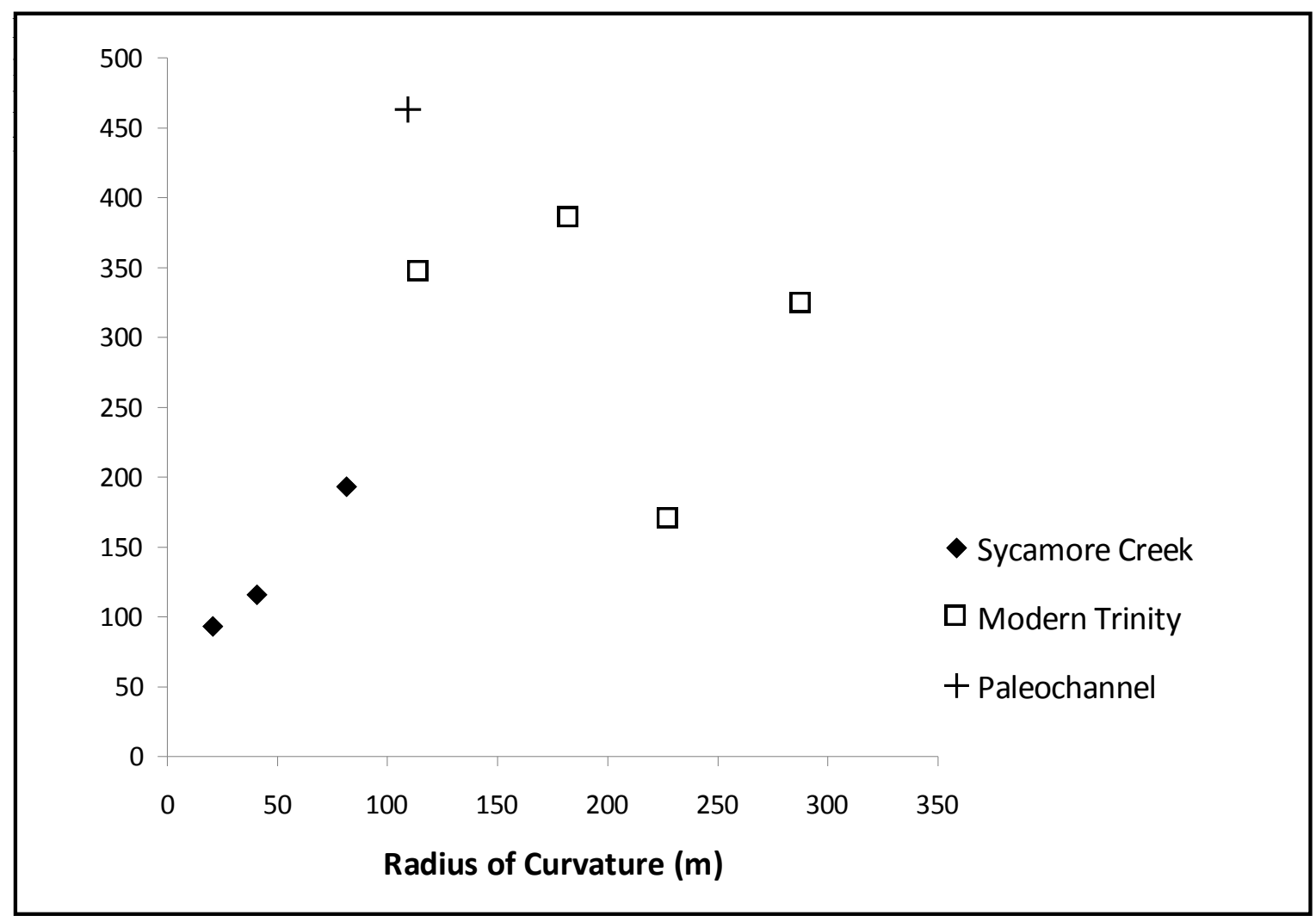

Figure 26. Plot of the radius of curvature vs. the meander wavelength for the West Fork of the Trinity River, Sycamore Creek, and the paleochannel in the immediate vicinity of 41 TR198 measured from the 1955 aerial photograph. Note that the morphology of the paleochannel is most consistent with the Trinity River and not Sycamore Creek.

Lintz et al. 2004; Lintz et al. 2005; Osburn et al. 2005). Initial work at 41TR198 by Shanabrook (2003) identified two of these deposits in the immediate vicinity of the site: the Pilot Point alloformation and the Recent alluvium.

\section{The Pilot Point Alloformation}

All of the prehistoric archaeology at 41TR198 is contained within the buried soil formed at the top of the Pilot Point alloformation, which was named the "West Fork Soil" (when not buried) or the "West Fork Paleosol" (when buried by recent alluvium) by Ferring (1986b). Unfortunately, there was no easy way to correlate prehistoric occupations within the West Fork Paleosol because of the relatively homogeneous nature of the deposit and the absence of any clear sedimentary 
marker beds. All of the trenches excavated during the Phase III investigations exposed the Pilot Point alluvium, but a detailed characterization of this deposit was made using a column of bulk samples collected in $5 \mathrm{~cm}$ increments within Block 3, and this was supplemented with 5 additional samples collected in $10 \mathrm{~cm}$ intervals through the overlying Recent alluvium. The results of this work are plotted on Figure 27.

Within Block 3, the Pilot Point alluvium ranged in texture from silty clay loam in the upper part of the West Fork Paleosol, to a silty clay at depth. Within these deposits a $2 \mathrm{Ab}-2 \mathrm{Ab} \rightarrow 2 \mathrm{Bk}-$ $2 \mathrm{Bk}$ soil profile has formed. The $2 \mathrm{Ab}$ horizon was black (10YR 2/1, moist) to very dark gray (10YR 3/1, moist), very friable, and exhibited a weak medium prismatic structure that parted to either strong medium to fine subangular blocky structure or a strong fine granular structure. It was separated from the $2 \mathrm{Ab} \rightarrow 2 \mathrm{Bk}$ horizon by a diffuse, smooth boundary. The underlying horizon appears to have originally been merely an A horizon, but has since been accumulating secondary (pedogenic) calcium carbonate, and this zone consisted of a dark gray (10YR 4/1, moist) to dark grayish brown (10YR 4/2, moist) silty clay. It exhibited a weak medium prismatic structure that parted to strong medium angular blocky structure, and occasionally a strong fine to very fine granular structure. It contained between 5 to 7 percent calcium carbonate filaments and pressure faces were common within it. A diffuse smooth boundary separated this horizon from the $2 \mathrm{Bk}$ horizon below it, which was a grayish brown (10YR 5/2, moist) to dark grayish brown (10YR 4/2, moist) very friable clay. This horizon exhibited calcium carbonate filaments and pressure faces similar to the overlying horizon.

Although Ferring (1994) notes that in most cases the texture fines upwards through the flood basin facies of the Pilot Point alloformation, here the texture gradually coarsens, which is mostly reflected by an incremental increase in sand in the top $40 \mathrm{~cm}$ of the West Fork Paleosol. Such a trend could have been caused by a variety of processes, such as migration of the channel towards this location toward the end of the Pilot Point deposition, an increase in flood magnitude over the same period, or significant pedoturbation and downward migration of sand from the Recent alluvium in the last 500 years. The absence of any clear bedding and presence of the classic cumulic or overthickened soil indicate that the flood plain surface was only episodically flooded during this period, and that pedoturbation and the deposition of organic material were occurring faster than sedimentation. Further support of this impression is the increase in organic carbon in the top $40 \mathrm{~cm}$ of the West Fork Paleosol. As is typical of the West Fork Paleosol, no evidence of 


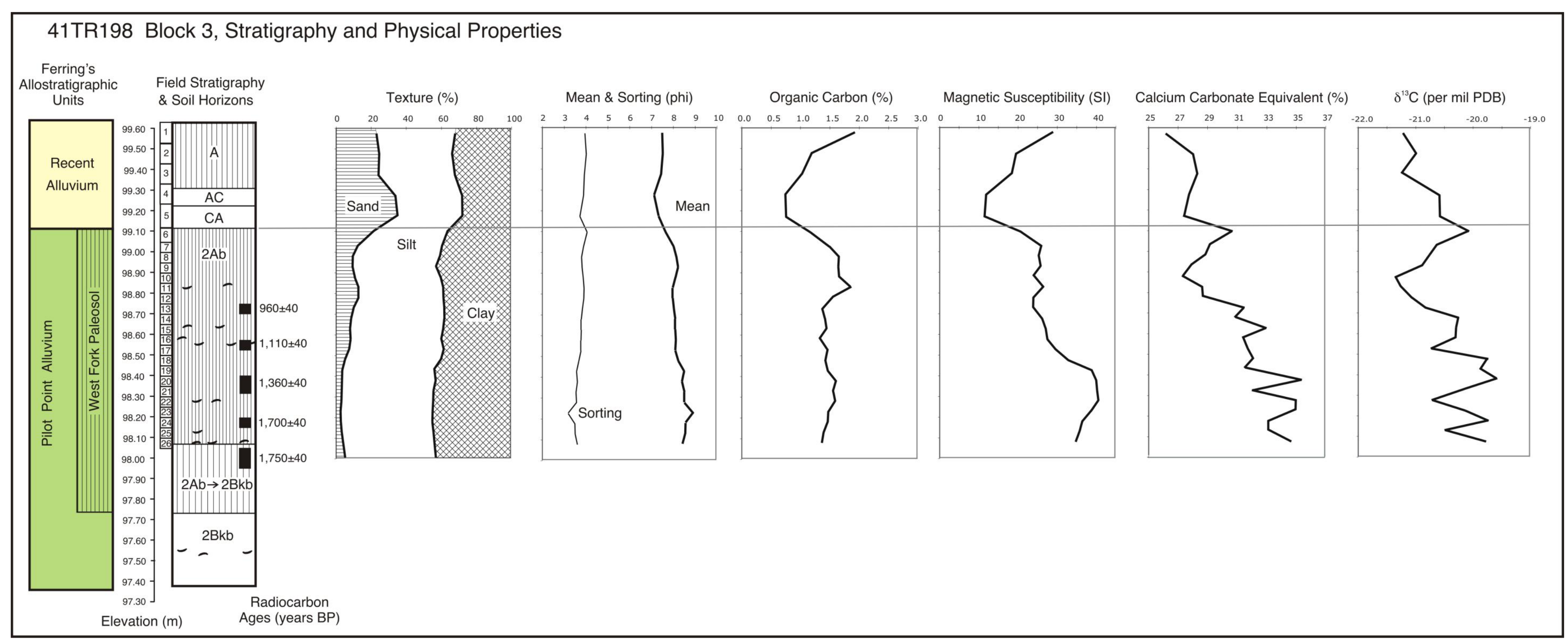

Figure 27. Characterization of the Pilot Point alluvium within Block 3. 
bedding or sedimentary stratification was observed in any of the Pilot Point exposures (see also Lintz et al. 2005; 2005) which suggests that the site was somewhat removed from the channel during the period the site was occupied. Although no clear paleotopography was visible within the Pilot Point deposits, mussel shell observed with Trench 6 (Figure 28) appear to define a paleosurface that slopes down towards the paleochannel, which suggests that this ancient channel was here when the site was occupied. The lack of event specific bedding within the Pilot Point alloformation along the shoulder of the paleochannel (as in Trench 6) suggests that this paleochannel was not the active Trinity River channel at the time of the site was occupied.

As noted previously, organic carbon gradually increases upward through the West Fork Paleosol, although a slight bulge is present between 98.2 and $98.4 \mathrm{~m}$, which is also a point in the profile where the magnetic susceptibility exhibits a broad peak. It is not clear if this represents more intense occupation or a period of slightly enhanced soil development, but this occurs during a period when the apparent sedimentation rate decreases dramatically (see discussion, below). The calcium carbonate content increases gradually with increasing depth through the West Fork Paleosol, and appears to be clearly leached from the upper part of this soil. The stable carbon isotopic composition of the bulk organic matter in this profile exhibits significant variation in the lower half of the West Fork Paleosol (values oscillating between ca. 19.5\%o and 20.7\%o) and become slightly lighter towards the top of the soil where they peak at $-21.3 \%$, which suggests a slight increase in $\mathrm{C}_{3}$ vegetation occurred throughout the period of West Fork Soil Formation. The $\delta{ }^{13} \mathrm{C}$ values increase about $1 \%$ in the upper $20 \mathrm{~cm}$ of the West Fork Paleosol which suggests conditions became slightly drier during this period.

\section{Age and Sedimentation Rates}

The radiocarbon ages obtained from the excavation are generally consistent with previous work in the West Fork of the Trinity River Basin, which places formation of the West Fork cumulic paleosol over a 2000 year period starting around 2500 years B.P. and continuing to around 500 years B.P. The sedimentation rates calculated from the radiocarbon dates (Figure 29; see Table 5) suggest that at the base of the block excavation and below it the deposit was aggrading fairly rapidly, around 20 to $35 \mathrm{~cm}$ per century, but soon after 1360 years B.P. the rate slowed dramatically to around $5 \mathrm{~cm}$ per century for a short while and then continued until the end of Pilot 


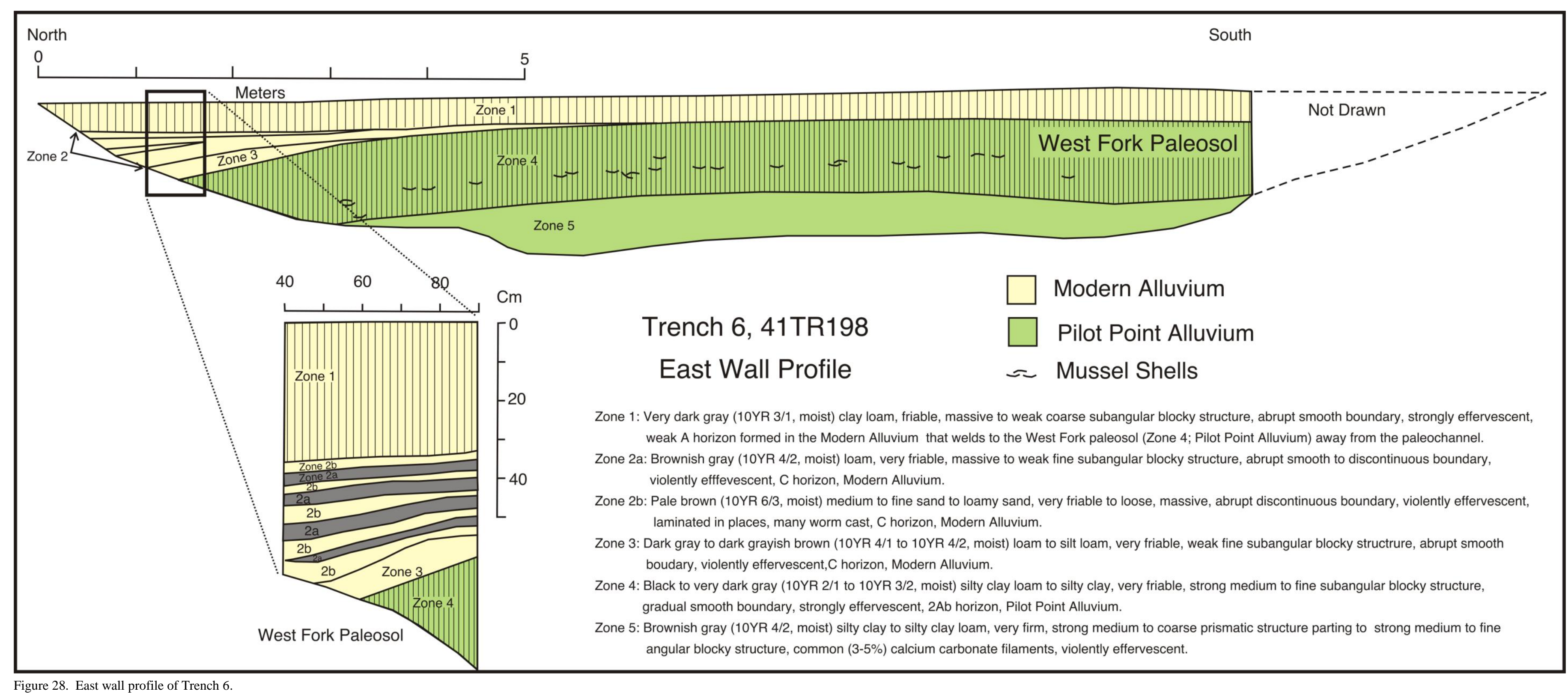




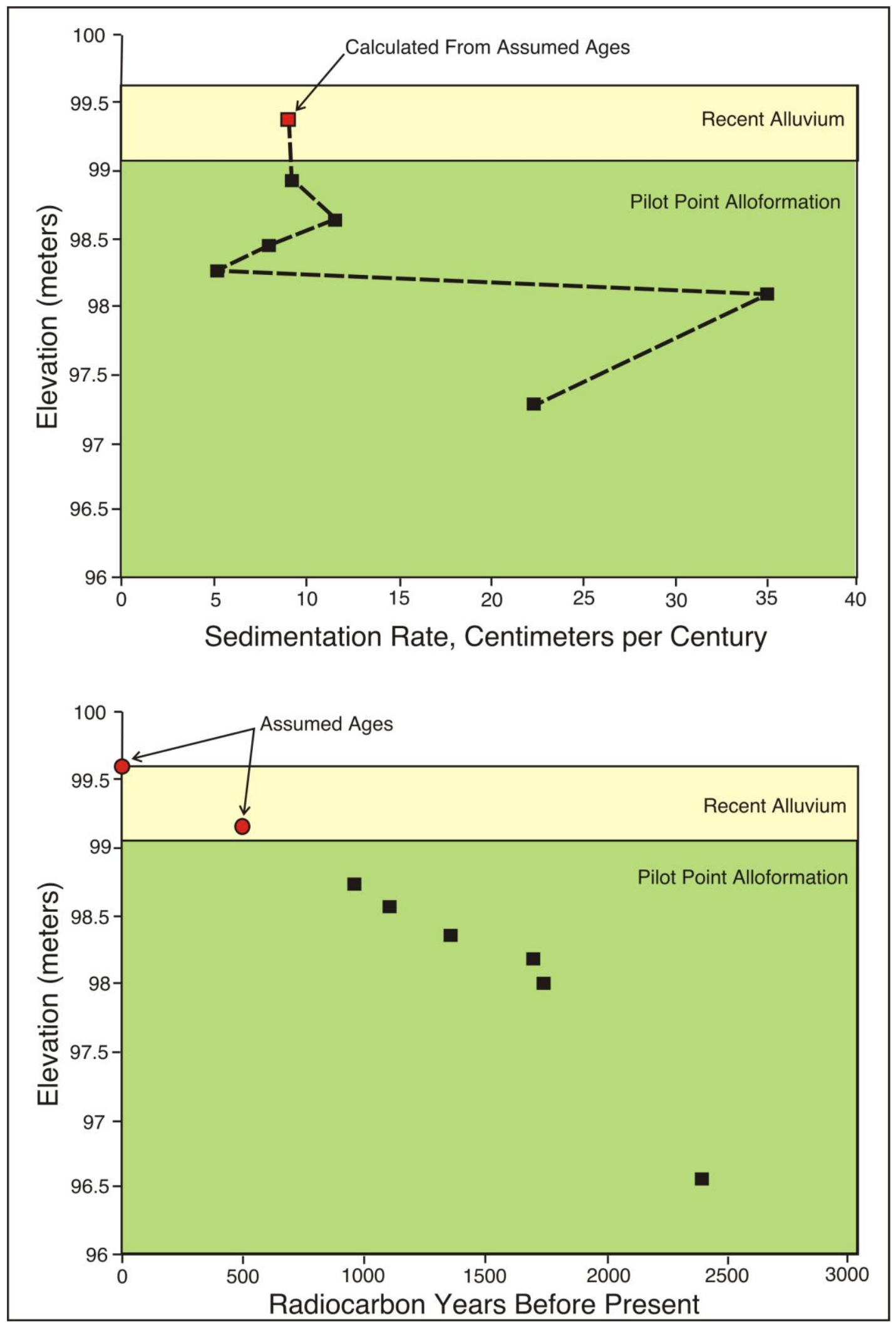

Figure 29. 41TR198 sedimentation rates calculated from the radiocarbon dates. 
Point deposition at a rate that varied between 8 and $12 \mathrm{~cm}$ per century. Figure 30 shows how the apparent sedimentation rate at 41TR198 compares with two other sites in similar stratigraphic position in this catchment (41TR170, Lintz et al. 2005; and 41TR174, Lintz et al. 2004). At 41TR170 the sedimentation rates compare favorably with the rates observed at 41TR198, with the exception of the lowest and oldest part of the profile, and Lintz et al. (2004:108) openly cast doubt on the validity of their lowest radiocarbon age. If the lowest date and the implied sedimentation rate for the period around 2,500 B.P. is ignored, both sites indicate aggradation prior to 1,500 years B.P. was faster than the period after 1,500 years B.P., and after which it varied little. Comparison with the data from 41TR174 is more problematic given that there were several age reversals in the lowest part of the profile and the sedimentation rate calculations vary significantly depending upon which dates are used. Nevertheless, the data from this site show a peak in sedimentation rate around 1,400 years B.P. and a prominent decline thereafter. It should be noted that the most recent sedimentation rate calculated for 41 TR174 is based upon a bulk radiocarbon age obtained from the Recent alluvium. If the sedimentation rate here had been calculated in a manner similar to the other two sites (namely by dividing the thickness of the recent alluvium by 500 years (the period Ferring (1994) identifies as the period of deposition for this unit) the rate would be similar.

In summary, radiocarbon dates from all three sites suggest that sedimentation rates were somewhat higher prior to approximately 1,400-1,500 years B.P., and slowed thereafter in the waning phases of Pilot Point deposition and the final period of West Fork Soil formation. Prior to 2,000 years B.P. two of the site suggest that deposition was much slower, but dating irregularities associated with these deposits suggest that accurate sedimentation rates may not be available at this time. But the sedimentation rates from the lowest part of 41TR198 suggest that significantly higher sedimentation rates occurred prior to the formation of the West Fork Paleosol.

\section{The Recent Alluvium}

Unlike the Pilot Point Alloformation, the Recent alluvium at the site exhibits significant textural variation as well as some bedding. Two facies are present at the site, and these represent the major flood plain textural lithofacies identified by Ferring (1994:81-82): flood basin and narrow channel elements. 


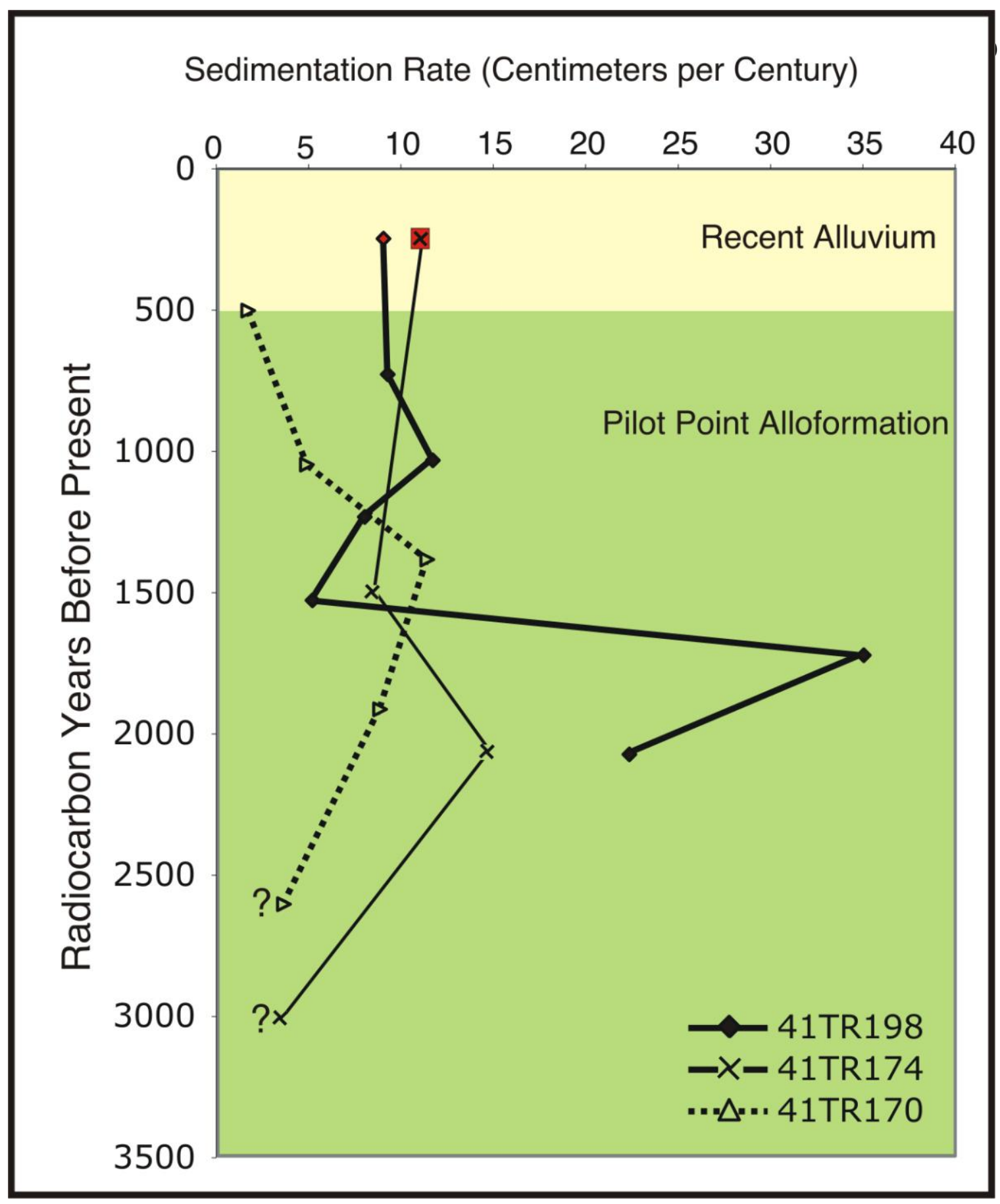

Figure 30. Comparison of the sedimentation rate at 41TR198 with sedimentation rates at sites 41 TR170 and 41 TR174. 
The flood basin deposits drape the core of the site and consist of clay loam, which contains a significantly greater amount of sand that the underlying Pilot Point alloformation. Three distinct soil horizons were observed within the flood basin facies in Block 3, and the profile exhibited an A-AC-CA horizon sequence. The A horizon was a very dark gray-very dark grayish brown (10YR 3/1.5, moist) friable clay loam that exhibited a moderate coarse to medium subangular blocky structure. A gradual smooth boundary separated it from the AC horizon beneath, which was a very dark grayish brown (10YR 3/2, moist) friable clay loam with moderate medium to fine subangular blocky structure. A clear smooth boundary separated the AC horizon from the CA horizon. The latter appears to have originally been a brown (10YR 5/3, moist) sand or loamy sand but has been transformed into a dark grayish brown (10YR 4/2, moist) clay loam through incremental pedoturbation by worms, which have moved more clayey material into this horizon from above and below. This deposit exhibited a weak coarse subangular blocky structure and was separated from the West Fork Paleosol by a clear smooth boundary. In a few exposures the sandier lower portion of the recent alluvium was absent and the A horizon formed within the more clayey facies was clearly welding into the West Fork Paleosol, and in these trench exposures the Recent alluvium was often difficult to distinguish from the Pilot Point in strong direct sunlight.

Along the margin of the paleochannel as well as the eastern margin of the modern Trinity River meanderbelt, the Recent alluvium thickened and expanded into a highly bedded deposit of event specific flood sediments that generally consisted of alternating fine (muds) and coarse (sandy to loamy) sediments (see the inset for the north end of Trench 6 (see Figure 28; as well as strata present in Block 2). This deposit is typical of the lithofacies Ferring (1994) describes as the narrow channel elements and these fining upward couplets of sediment appear to represent individual flood events, the number of which increased into the paleochannel. No trenches were excavated into the paleochannel during the Phase III investigations, but it is likely that a thick wedge of such deposits are present in this structure. The transition from the flood basin facies, where individual flood events were not distinguishable, into the narrow channel facies was relatively abrupt, generally occurring in a 2-3 m wide section where the sandier beds gradually pinched out and became difficult to observe (see Figure 28 for an example). 
No radiocarbon ages were obtained from the Recent alluvium, but it is assumed that this unit was deposited in the last 500 years, as has been demonstrated previously by Ferring (1994; 1990). The stable carbon isotopes obtained for bulk soil organic matter within the Recent alluvium show that toward the end of the period of Pilot Point sedimentation the organic matter shifted about $1 \%$ o in favor of more arid adapted $\mathrm{C}_{4}$ plants, and then gradually drifted back toward more $\mathrm{C}_{3}$ plants during the period of recent sedimentation, with the composition of the modern surface material being almost the same now as it was toward the end of Pilot Point deposition.

\section{The Sanger Alloformation}

A deep excavation (ca. $4 \mathrm{~m}$ ) unrelated to the phase III archaeological investigation located north of the paleochannel revealed the presence of the Sanger alloformation beneath a drape of the Pilot Point alloformation. This profile was noted but not described.

\section{STRATIGRAPHIC SUMMARY}

The upper panel of Figure 31 shows a close up view of the site taken from the 1955 aerial image, upon which specific geomorphic features visible on the magnetometer map have been superimposed. These features include the boundary between the Recent alluvium and the Pilot Point alloformation on the west side of the site (at the eastern boundary of the modern Trinity River meander belt; denoted by the pink dotted line) and a series of arcuate lines (green lines) within the Pilot Point alloformation which are inferred to be scroll-bars that denote the general direction of meander migration (shown by the lighter green arrow). Although it is not clear that these features are within the Pilot Point alloformation, the general direction of migration appears to be consistent with the paleochannel.

The lower portion of Figure 31 is a schematic cross-section of the site along cross-section A-A' (shown in the top half) that depicts the general stratigraphic relationships observed during the fieldwork. Given that with the exception of the deep excavation north of the paleochannel, all of the site trenches were only $2 \mathrm{~m}$ or less deep, features below this depth are inferred. 
Figure Redacted

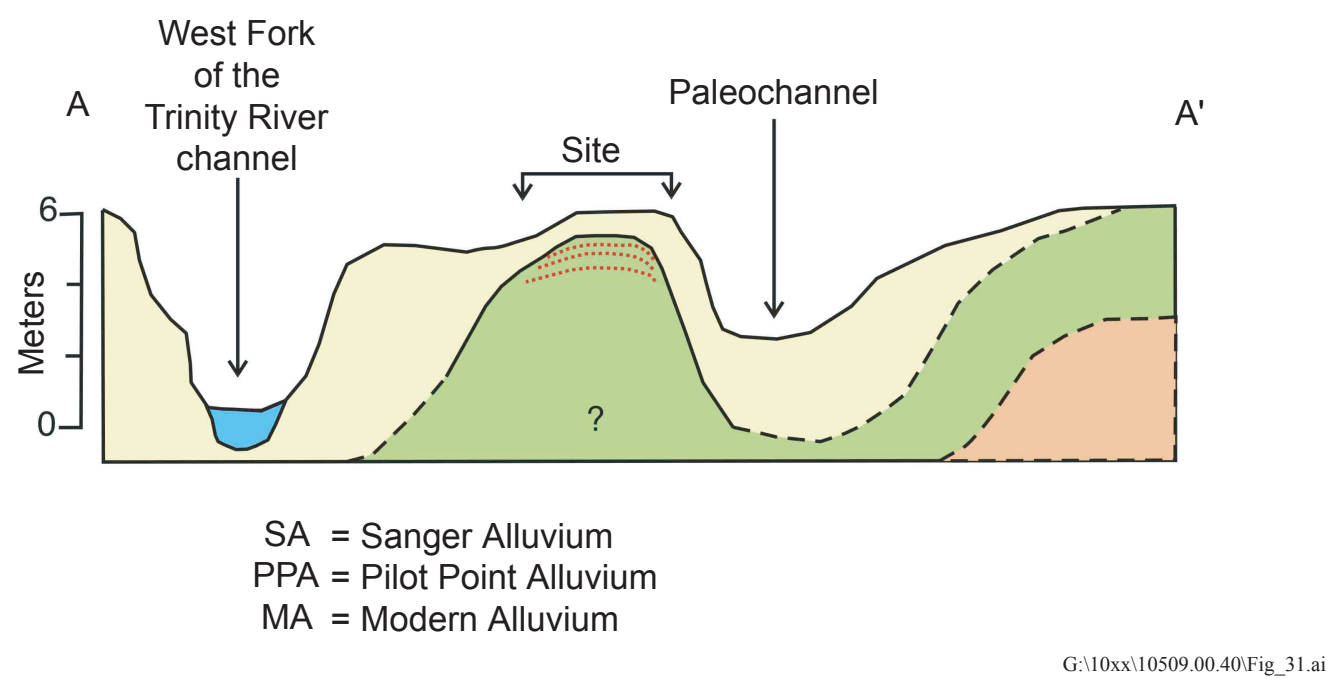

Figure 31. 1955 aerial image and schematic cross-section of 41TR198. 


\section{Context and Integrity of the Prehistoric Occupations and Observations from Feature 15}

The general impression obtained from field inspection of the prehistoric occupations at 41TR198 is one of multiple, thin, discrete occupation surfaces. This was apparent in the immediate vicinity of features owing to a variety of objects discarded onto the surface near them, but identification of the occupation surfaces away from prominent loci of activity was often challenging. In order to more closely examine the integrity of the prehistoric occupations two studies were performed: 1) the depth distribution of micro artifacts in the bulk samples processed for granulometry was tallied, and 2) a suite of soil micromorphology samples were collected from the deposits for thin section preparation and microscopic examination.

\section{Micro-artifacts}

When processing the bulk samples it became apparent that most of the gravel sized material in the samples were actually artifacts (either materials brought to the site by people (like bone and shell) or materials transformed by people on the occupation surface (like small fragments of burnt earth which were created in hearths and scattered across the occupation surface when ash was cleaned out of the hearths). The depth distribution of the microartifacts present within these samples is tallied on Table 5 and shown on Figure 24. The pattern exhibited by the microartifacts fits with the general impression of the site, specifically of multiple, discrete occupation surfaces. The amount of different microartifact classes varies significantly from one surface to another with the burnt earth fragments being perhaps the most cosmopolitan. Nearly all of the burnt earth fragments observed were $<4 \mathrm{~mm}$ in diameter and appeared to be hardened soil peds. The right side of Figure 24 shows the aggregate distribution of macro-artifacts by level for Block 3, and it is apparent that this view averages the variability present within the block. Plotting of the artifact distribution for individual test units within the block reveals a pattern more similar to the microartifacts. 


\section{Micromorphological Observations}

In order to obtain a somewhat different view of one occupation surface, a suite of three micromorphological blocks were collected from the occupation surface associated with Feature 8 near Test Unit U12 and the west walls of Units 20 and 21 in Block 3. One micromorphological block was collected through Feature 8, a second was collected from the occupation surface to the west of the feature where it appeared to be represented only by mussel shell, and a third was collected from a clean out/ash dump that was visible in the west wall of Unit 21.

\section{Feature 8}

Feature 8 is a simple hearth which consisted of a flat lying to very shallow basin-shaped ash-filled burnt surface which was underlain by an oxidized rim that was about $5 \mathrm{~cm}$ thick (Figure 32). The oxidized rim was carbon cored in places indicating that carbon had not been completely oxidized during use. The ashy matrix overlying the oxidized rim was upwards of $7 \mathrm{~cm}$ thick in the sampled block.

Examination of the three thin sections made from this feature revealed an intimate mixture of burnt, oxidized or reddened earth and ash together with small fragments of bone, charcoal and mussel shell. Fragments of burnt earth upwards of $2 \mathrm{~cm}$ long were present within the ash, but smaller subrounded fragments, around 2-4 mm in diameter are much more common. Small charcoal fragments which retain evidence of the plant structure were also widely scattered throughout, with the largest being about $1.3 \mathrm{~mm}$ long. All of the slides exhibited numerous worm passages and reworking of the feature by worms appears to have extensively altered the fabric at a small scale. That said, the feature was clearly recognizable in the field, which indicates the very local nature of much of this reworking.

\section{F8 Ash Dump/Rake Out}

Two thin sections were made from a deposit that was immediately adjacent to Feature 8 in the west wall of Unit 20, but clearly separate from the hearth. On the basis of the stratigraphic appearance and composition this deposit was provisionally interpreted as either an ash dump or a 


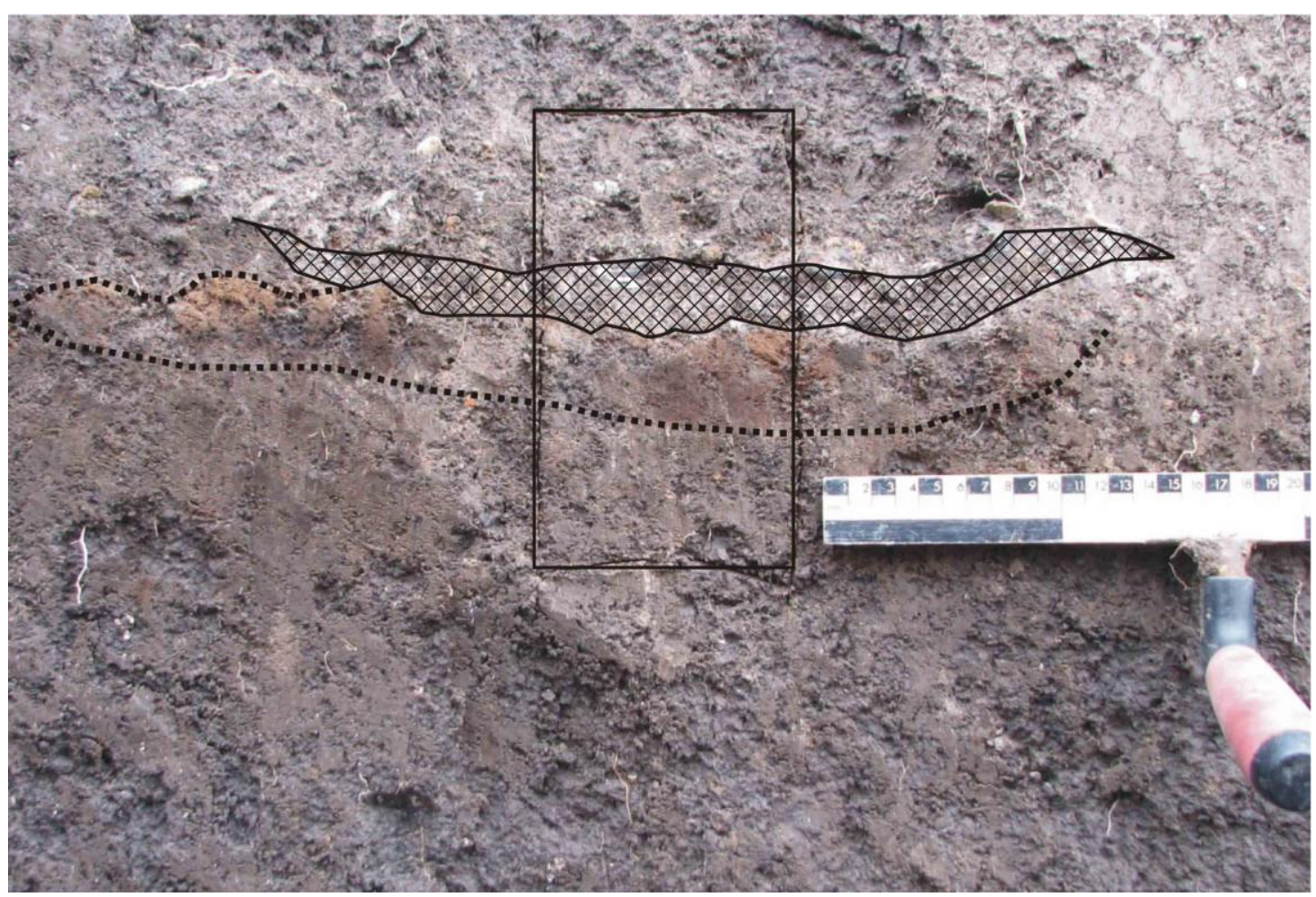

Figure 32 . Feature 8.

rake out, and examination of the thin sections revealed that this structure shared much in common with Feature 8. The overall deposit was approximately $5.5 \mathrm{~cm}$ thick, and consisted of a mixture of rubified subrounded bits of earth, the largest of which was about $5 \mathrm{~mm}$ in diameter. Charcoal fragments here were less abundant and considerably smaller than within the feature, with most being between 0.1 and $0.25 \mathrm{~mm}$ in diameter. Ash was common in the thin section, but mostly in proximity to the rubified soil fragments, and within worm passage features. None of the matrix exhibited fabrics indicative of compaction, but a few of the burnt earth pieces exhibited prominent platy structure, and these may have derived from the compacted surface immediately adjacent to the hearth.

\section{Occupation Surface Adjacent to Feature 8}

A single thin section was made from a micromorphological block collected immediately southwest of Feature 8 through the occupation surface where it was largely visible owing to mussel shell fragments. The cultural debris in this section was between 2 and $3 \mathrm{~cm}$ thick, and 
consisted of small fragments of mussel shell and bone (generally $<2.5 \mathrm{~mm}$ long) and a few subrounded fragments of burnt earth which were generally $<1 \mathrm{~mm}$ in diameter. The subangular blocky microstructure associated with the surrounding matrix dominated the fabric, and no compaction related fabrics were apparent. The small platy artifacts (specifically bone and mussel shell fragments) exhibited a wide range of orientations from subhorizontal and horizontal to almost vertical and aligned with ped boundaries, which suggests that some may be in their original orientation and others have clearly been reoriented by post-depositional pedoturbative (either shrink-swell or worm passage) processes.

Considered together, the micromorphological examination of the Feature 8 occupation surface suggests that the cultural material is thickest in primary deposits (like the hearth or ash dump) where they range between 6 to $10 \mathrm{~cm}$ thick, and thin dramatically away from such features, to a thin $(2-3 \mathrm{~cm})$ zone of accumulation. The omnipresent worm pedoturbation features suggest that this occupation zone may well have been dispersed slightly by worm activity following deposition and burial.

\section{Feature 15}

Feature 15 consisted of a flat lying to shallow basin hearth that exhibited a thin $(2-3 \mathrm{~cm})$ layer of ash, and an anomalously thick oxidized rim underneath it that was more than $18 \mathrm{~cm}$ thick in places (Figure 33). The oxidized rim was uniformly rubified (as opposed to carbon cored; some variations in red color were apparent) indicating that it had been exposed to prolonged heating. The only dark areas observed within this feature were post-depositional worm passages that had brought organic-rich sediment into the feature from above or below. Parts of the oxidized rim were lithified from exposure to intense heat (discussed in more detail, below).

The degree of oxidation associated with Feature 15 is anomalous, given that most simple hearths exhibit thin oxidation rims $(<5 \mathrm{~cm})$ owing to the fact that earth is a good insulator and that the temperature profiles decrease rapidly with depth (Courty et al. 1989:107; Raison 1979). Experimental hearths created using a variety of methods (simple hearth, and using bellows) show that single event fires create reddened rims which are generally less than $3 \mathrm{~cm}$ thick (Berna et al. 2007:365-366) which is consistent with thermal structures like Feature 8. Extensive repeated use, 


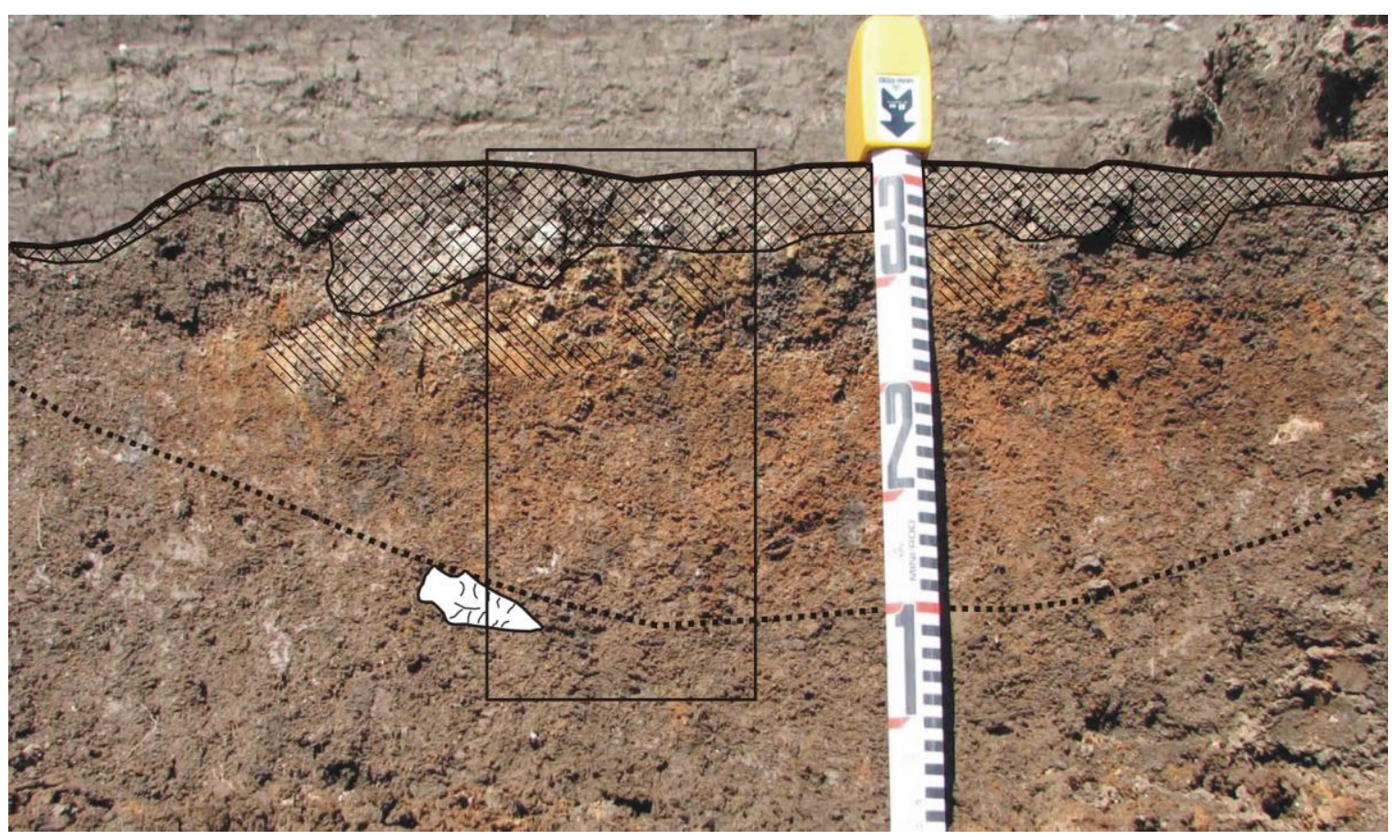

Figure 33. Feature 15.

and/or prolonged exposure to high temperatures (i.e. increased "soaking time" can be expected to produce thicker rubified rims below the heat source, but it is not clear if simple repeated kindling of a fire in the same location would result in such a deeply oxidized rim. The depth of this rubified rim implies that the ground was heated hot enough to oxidize the carbon to almost $20 \mathrm{~cm}$.

As noted previously, some of the earth within the reddened rim was found to be "crunchy" or lithified when the micromorphological block was excavated, and thin sections of this material demonstrate that some of these areas, which were not right at the ash interface but up to $5 \mathrm{~cm}$ below it, had begun to develop a uniform undifferentiated micromass that lacked the porosity and optical activity of nearby, less-rubified material, but these areas were not yet vitrified (which would be isotropic in cross-polarized light). These areas are sintered, which is the initial stage of vitrification of the clays that occurs when the clay minerals begin to lose their crystallinity. Sintering renders the micromass optically inactive (whereby the appearance of the material does not change when it is rotated under the stage of a polarizing light microscope with the polarizers crossed), which typically occurs between 800-900 C (Whitbread 1995; Henderson 2000:132). Figure 34 (part A) shows the interface between a sintered ped adjacent to an unsintered adjoining 


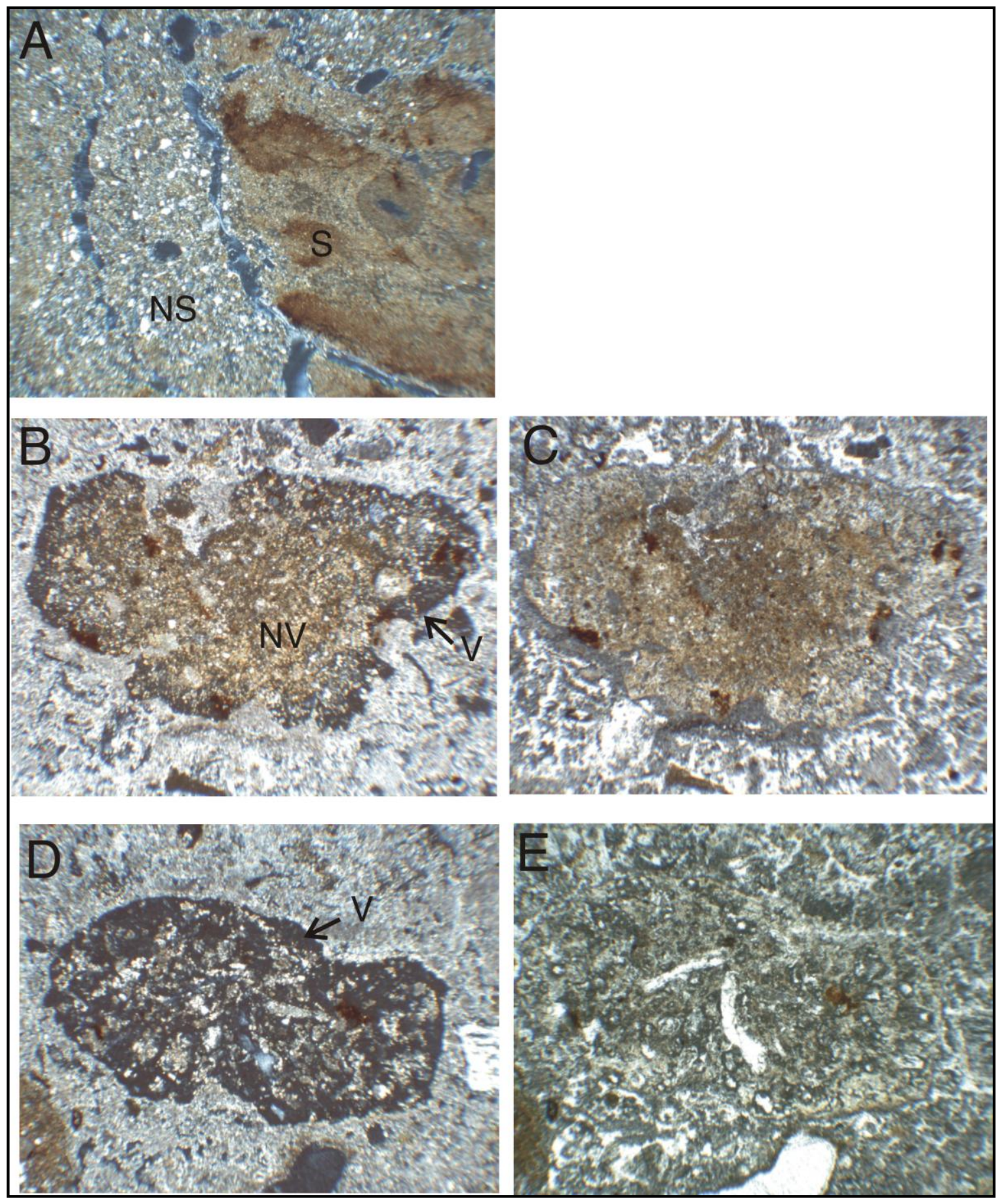

Figure 34. Feature 15 thermal alteration. 
ped. The non-sintered material (NS in the photo) is optically anisotropic and has a speckled appearance, where as the sintered material is much more uniform in appearance. It is clear from the expanded view of thin section F15-a on Figure 35, that the sintered material retains the subangular blocky structure of the natural matrix, and has been altered in place.

Examination of the ash associated with Feature 15 revealed numerous small fragments of earthen material in various stages of vitrification. Figure 24 (parts B and C) show a fragment of the matrix that has been partially vitrified around the edges (the black or isotropic material is now glass) whereas the center of the fragment is non-vitrified. Figure 34 (parts D and E) show a fragment of the matrix that has been completely vitrified and is entirely isotropic under crosspolarizers. In general terms, complete vitrification of the clay matrix requires temperatures in excess of $950^{\circ} \mathrm{C}$, but more study would be required to pin this temperature down precisely.

The deep oxidation of earth beneath a common hearth is uncommon because earth is a good insulator (Berna et al. 2007:360) and the temperatures implied by the sintering and vitrification of the earthen matrix within Feature 15 are generally associated with pyrotechnological practices that are unknown from hunter-gatherer populations in Late Archaic north Texas (e.g. pottery production, smelting metal, and glass production). Without further, very specific experimental work, it is impossible to define the thermal conditions that created Feature 15, but the depth and degree of apparent heating is clearly anomalous and begs the question what activities were associated with this feature.

\section{SUMMARY}

The geoarchaeological investigations at 41TR198 indicate that the prehistoric occupations were situated in a flood basin facies of the Pilot Point alloformation, which accumulated during the period between 2,300 and ca. 500 years B.P. Most of the occupations examined by the block excavations were situated with the West Fork Paleosol, but older occupations are probably present at depth beneath the soil. Vestiges of paleotopography exhibited by some of the occupation surfaces situated along the margin of a prominent paleochannel located immediately north of the site suggests that this channel was present at the time of the occupation, but may have already been abandoned at that time. Although the plan form and orientation of the paleochannel 


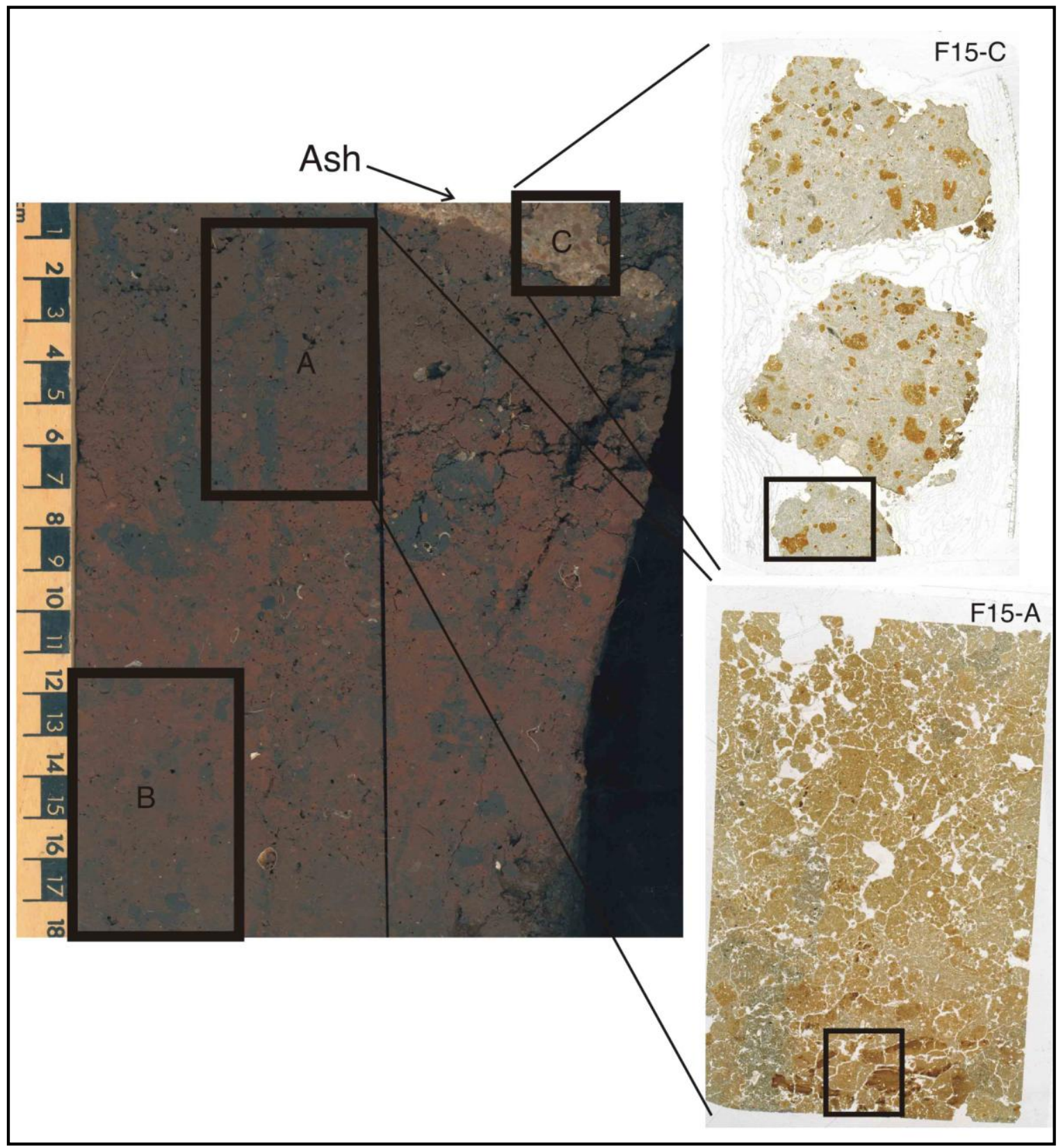

Figure 35. Expanded view of Feature 15.

suggested that it could have been associated with Sycamore Creek, which borders the site to the south, an examination of the fluvial morphology of the paleochannel, the West Fork of the Trinity River and Sycamore Creek suggests that the paleochannel is most likely a former course of the Trinity River. 
The fine-grained overbank sediments that comprise the site matrix ranged from silty clay at depth to silty clay loam near the top of the West Fork Paleosol, and these deposits appear to preserve numerous, thin prehistoric occupation surfaces. Micromorphological examination of one such surface indicates that primary features contained cultural deposits approaching $10 \mathrm{~cm}$ in thickness, but that the occupation surfaces away from such features were much more discrete, often ranging between 2 and $3 \mathrm{~cm}$ thick. In the absence of macro-artifacts like mussel shell, these occupations surfaces have very low archaeological visibility. A few of the features exhibited evidence of extreme thermal histories which are anomalous in Texas prehistory, but the behavioral origins of these structures is presently unknown. 


\section{CHAPTER 8 CULTURAL FEATURES}

\section{INTRODUCTION}

In general, the features and stratigraphy of the Crooked Oxbow Site consist of numerous occupational lenses and living surfaces buried and stratified within a flood plain setting along an abandoned channel of the West Fork of the Trinity River. The remote sensing conducted at the site combined with the trenching and controlled excavations clearly demonstrate that this landform was repeatedly occupied over a 1,500 year period. Thermal features, fire-cracked rock scatters, and shell lenses represent occupations of varying intensity during this period.

As was suggested by the testing and magnetometer survey, a high frequency and diversity of subsurface cultural features were identified at this site. Even with the contextual integrity demonstrated at site 41TR198, not all soil anomalies were clearly definable as cultural features. It appears that prior clearing for agriculture may have resulted in burning that produced carbonized stains which were initially interpreted as cultural in nature; however, some may be the direct result of roots burning and may not be related to the prehistoric occupation of the site. Such potential will be discussed in the following discussion of the features and their contexts within each excavation block or unit. 


\section{TEMPORAL FRAMEWORK}

The nature of the flood plain landscape and the use of that landscape obviously changed over time, for the Block 3 excavations revealed more intensive use between A.D. 50 and 1040 while the Block 4 excavations revealed intensive use between A.D. 140 and 540. Examination of the stratigraphic positioning of cultural features and associated living surfaces in relation to eight radiocarbon dates (Table 6) from Blocks 3 and 4 resulted in the definition of six occupational zones in Block 3 (Table 7, Figure 36) and four occupational zones in Block 4 (Table 8; Figure 37). No radiocarbon samples from Block 1 were analyzed; Block 2 did not yield any dateable material. The division of the stratigraphic sequence is admittedly arbitrary to a certain extent; however, the stratigraphic positioning of features was a primary criterion. The sequence could have been more finely divided, but sample sizes within each zone would have limited meaningful comparisons. The temporal boundaries for the zones in Block 4 are dependent on the assumption that aggradation was consistent between A.D. 140 and circa A.D. 600.

\section{Block 1}

Block 1 was excavated to explore the nature of a pair of geophysical anomalies. A large mano (FS 334), likely the source of one of the anomalies, was observed lying flat at an elevation of $98.80 \mathrm{~cm}$ in this block (Figure 38). Feature 4 (Table 9) was initially noted at an elevation of $98.65 \mathrm{~cm}$ in Level 8 of Unit 1. Recognized as a circular, ashy stain at the base of Level 8, the feature was bisected with one half of the perceived stain collected for flotation. However, this excavation demonstrated that the ashy deposit was not a distinctive feature but merely part of a larger lens of ashy sediment and mussel shell.

Below this stratum an interesting lens of ash and shell was noted, beginning in the east half of Block 1 and diving to the west. Designated Feature 26, this stratum of shell extended across the entire block at a thickness of one to two shells. This lens is associated with a low density concentration of ash; however, it is definable by the distribution of the shells themselves, some of which are burned. Feature 26 is likely a refuse disposal area located on the bank of the paleochannel (Figure 39). 
Table 6

Radiocarbon Dates Analyzed from Site 41TR198

\begin{tabular}{|c|c|c|c|c|c|}
\hline Sample Data & $\begin{array}{l}\text { Measured } \\
\text { Radiocarbon Age }\end{array}$ & $\begin{array}{l}{ }^{13} \mathrm{C} /{ }^{12} \mathrm{C} \\
\text { Ratio }\end{array}$ & $\begin{array}{l}\text { Conventional } \\
\text { Radiocarbon Age }\end{array}$ & $\begin{array}{l}\text { Intercept with } \\
\text { Calibration Curve }\end{array}$ & Provenience \\
\hline $\begin{array}{l}\text { Beta } 259836 \\
\text { Bone Collagen }\end{array}$ & $2,320 \pm 40$ B.P. & -20.3 o/oo & $2,400 \pm 40$ B.P. & Cal B.C. 410 & $\begin{array}{l}\text { Block 3, Unit 21, } \\
96.55 \mathrm{~cm}\end{array}$ \\
\hline $\begin{array}{l}\text { Beta } 259841 \\
\text { Charred material }\end{array}$ & 1,780 \pm 40 в.Р. & -26.8 o/oo & $1,750 \pm 40$ В.Р. & $\begin{array}{l}\text { Cal A.D. 260, 300, } \\
\text { and } 310\end{array}$ & $\begin{array}{l}\text { Block 3, Unit 13, } \\
98.00 \mathrm{~cm}\end{array}$ \\
\hline $\begin{array}{l}\text { Beta-259843 } \\
\text { Bone Collagen }\end{array}$ & $1,630 \pm 40$ в.P. & -20.6 o/oo & $1,700 \pm 40$ в.Р. & Cal A.D. 350 & $\begin{array}{l}\text { Block 3, Unit 26, } \\
98.175 \mathrm{~cm}\end{array}$ \\
\hline $\begin{array}{l}\text { Beta-259839 } \\
\text { Charred material }\end{array}$ & $1,360 \pm 40$ в.Р. & $-24.8 \mathrm{o} / \mathrm{oo}$ & $1,850 \pm 40$ в.P. & Cal A.D. 660 & $\begin{array}{l}\text { Block 3, Unit 24, } \\
98.35 \mathrm{~cm}\end{array}$ \\
\hline $\begin{array}{l}\text { Beta-259838 } \\
\text { Bone Collagen }\end{array}$ & $1,020 \pm 40$ B.P. & -19.3 o/oo & $1,110 \pm 40$ B.P. & $\begin{array}{l}\text { Cal A.D. 900, 920, } \\
\text { and } 960\end{array}$ & $\begin{array}{l}\text { Block 3, Unit 21, } \\
98.55 \mathrm{~cm}\end{array}$ \\
\hline $\begin{array}{l}\text { Beta-259837 } \\
\text { Bone Collagen }\end{array}$ & $920 \pm 40$ B.P. & $-22.3 \mathrm{o} / \mathrm{oo}$ & $960 \pm 40$ в.P. & Cal A.D. 1040 & $\begin{array}{l}\text { Block } 3 \text {, Unit } 20, \\
98.725 \mathrm{~cm}\end{array}$ \\
\hline $\begin{array}{l}\text { Beta- } 259840 \\
\text { Charred material }\end{array}$ & $1,830 \pm 40$ в.P. & $-23.5 \mathrm{o} / \mathrm{oo}$ & $1,850 \pm 40$ в.P. & Cal A.D. 140 & $\begin{array}{l}\text { Block 4, Unit 33, } \\
98.80 \mathrm{~cm}\end{array}$ \\
\hline Beta-259842 & $1,490 \pm 40$ в.Р. & -20.6 o/oo & $1,700 \pm 40$ в.Р. & Cal A.D. 540 & $\begin{array}{l}\text { Block 4, Unit 19, } \\
99.20 \mathrm{~cm}\end{array}$ \\
\hline $\begin{array}{l}\text { Beta-172562* } \\
\text { Charred material }\end{array}$ & 1,920 \pm 80 в.P. & $-25.7 \mathrm{o} / \mathrm{oo}$ & $1,910 \pm 80$ B.P. & Cal A.D. 90 & $100 \mathrm{~cm}$ b.s. \\
\hline $\begin{array}{l}\text { Beta-172563* } \\
\text { Charred material }\end{array}$ & $510 \pm 80$ В.Р. & $-24.5 \mathrm{o} / \mathrm{oo}$ & $520 \pm 80$ в.P. & Cal A.D. 1420 & $100 \mathrm{~cm}$ b.s. \\
\hline
\end{tabular}

* Samples analyzed during previous phase of investigations at 41TR198 (Huhnke and Wurtz 2004: Appendix C)

Feature 27 is a basin-shaped pit that was excavated into the slope described above (Figure 40). The pit fill was dark grayish brown (10YR 4/2); fire-cracked rock are present along the perimeter of the pit and within the fill (Figure 41). However, there is no evidence that Feature 27 served as a thermal feature or that the rocks were burned in situ. Instead, it appears that this pattern is the result of secondary deposition at the terminal use of this feature. In addition to fire-cracked rock the feature fill contained a low density of bone and charcoal.

\section{Block 2}

Block 2 was a shallow excavation designed to expose and excavate Feature 1 a shallow rock feature exposed during backhoe stripping. Feature 1 (Figures 42 and 43) consists of a concentration of fire-cracked rocks, many of which are atypically large in size. The core of this 


\begin{tabular}{|c|c|c|c|c|}
\hline \multirow[b]{2}{*}{$\begin{array}{l}\text { Projected Temporal } \\
\text { Period for Zone }\end{array}$} & \multicolumn{3}{|c|}{$\begin{array}{c}\text { Table } 7 \\
\text { Occupation Zones Defined for Block } 3\end{array}$} & \multirow[b]{2}{*}{ Associated Features } \\
\hline & $\begin{array}{l}\text { Radiocarbon } \\
\text { Dates/Period }\end{array}$ & Sample Type & $\begin{array}{l}\text { Zone Depth } \\
\text { (elevation in } \mathrm{cm})\end{array}$ & \\
\hline A.D. 1040 & $\begin{array}{l}\text { A.D. } 1040 / \\
\text { Late Prehistoric }\end{array}$ & Wood charcoal from a pit $(\mathrm{F}-28)$ & $98.80-98.65$ & F-23, F-28 \\
\hline A.D. $900-960$ & $\begin{array}{l}\text { A.D. } 900,920 \text {, } \\
\text { 960/Late } \\
\text { Prehistoric }\end{array}$ & Deer bone from midden (F-29) & $98.65-98.50$ & F-8, F-29 \\
\hline A.D. $700-900$ & $\begin{array}{l}\text { None/Late } \\
\text { Prehistoric }\end{array}$ & & $98.50-98.40$ & $\begin{array}{l}\text { Features 5, 30, 31, 32, } \\
33,35\end{array}$ \\
\hline A.D. 350 - 700 & $\begin{array}{l}\text { A.D. } 660 / \\
\text { Late Archaic }\end{array}$ & Wood charcoal from a pit (F-33) & $98.40-98.20$ & F-15, F-16, F-35 \\
\hline A.D. 250 - 350 & $\begin{array}{l}\text { A.D. } 350 \\
\text { A.D. } 260 \text {, } \\
\text { 300, } 310 / \\
\text { Late Archaic }\end{array}$ & $\begin{array}{l}\text { Bone Sample } \\
\text { Wood charcoal from a pit (F-41) }\end{array}$ & $98.20-98.00$ & F-41, F-38, F-18 \\
\hline 410 B.C. - A.D. 250 & $\begin{array}{l}\text { B.C. } 410 / \\
\text { Late Archaic }\end{array}$ & Deer astragalus & $98.0-96.60$ & $\mathrm{n} / \mathrm{a}$ \\
\hline
\end{tabular}

feature is located in the southeast corner of Unit 8 and is approximately $90 \times 50 \mathrm{~cm}$ in size. A scatter of fire cracked rocks extended out both horizontally and vertically $(17 \mathrm{~cm})$ from the feature core. The soil within the core of the feature was slightly darker (7.5YR 4/2) than that surrounding it and contained a low density scatter of mussel shell, animal bone, and charcoal). Feature 1 may have served as an earth oven; however, its shallow context within the potential plow zone at the site indicates that the contextual integrity of the feature was compromised long ago.

\section{Block 3}

The excavation of Trench 1 was designed to investigate a large geophysical anomaly. A series of cultural features was exposed in the trench wall: basin-shaped hearths, a shell lens, and ash features. Fifteen features were documented within the 1.55 meters of sediment exposed during excavation (see Figure 36). These features represent multiple occupations from about the time of Christ until A.D. 1100. These features are presented in sequence from youngest to oldest. 


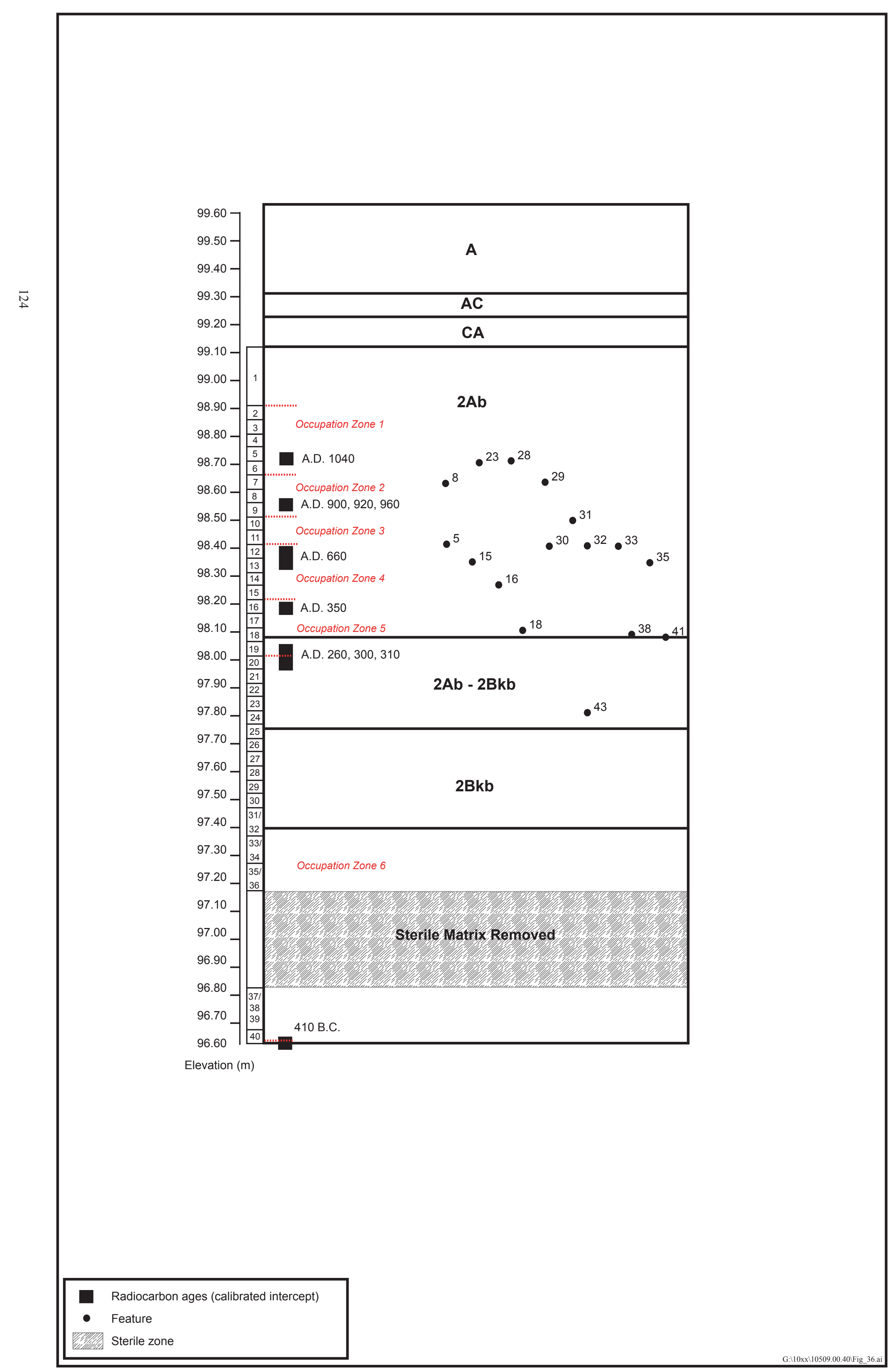

Figure 36. Block 3 field stratigraphy and soil horizons. 
Table 8

Occupation Zones Defined for Block 4

\begin{tabular}{|c|c|c|c|c|}
\hline $\begin{array}{l}\text { Projected Temporal } \\
\text { Period for Zone }\end{array}$ & $\begin{array}{l}\text { Radiocarbon } \\
\text { Dates/Period }\end{array}$ & Sample type & $\begin{array}{l}\text { Zone Depth } \\
\text { (elevation in } \mathrm{cm})\end{array}$ & Associated Features \\
\hline A.D. 390 - A. D 590 & A.D. 540/Late Archaic & Bone Collagen & $99.50-99.10$ & $\mathrm{n} / \mathrm{a}$ \\
\hline A.D. 340 - A.D. 390 & None/Late Archaic & & $99.10-99.00$ & \\
\hline A.D. 140 - A.D. 340 & None/Late Archaic & & $99.00-98.80$ & $\begin{array}{l}\text { Features } 21,25,37, \\
39,40,44,45\end{array}$ \\
\hline A.D. 140 & A.D. $140 /$ Late Archaic & $\begin{array}{l}\text { Charred material } \\
\text { (F-39) }\end{array}$ & $98.80-98.70$ & $\mathrm{n} / \mathrm{a}$ \\
\hline
\end{tabular}

\section{A.D. 1040 Occupation Zone (Levels 2 - 6)}

The A.D. 1040 occupation zone consists of the area in Block 3 between 98.80 and $98.65 \mathrm{~cm}$ where the first significant quantities of artifacts and cultural features were encountered. Overall this zone consisted of a single pronounced lens of shell, several discontinuous lenses of shell, and two pit features (Table 10).

Feature 23 is a circular, basin-shaped pit that is relatively large in volume compared with many of the other pit features excavated. This feature was first identified in the profile of Trench 1 . The remainder of the pit was exposed in plan view in Unit 22 (Figure 44) and then excavated. The perimeter of the pit is more oxidized (7.5YR 5/8) through thermal alteration; the pit fill is a dark brown (10YR 3/2). Associated cultural material includes FCR, mussel shell, and animal bone (Table 11).

The close association of Feature 23 with an adjacent root burn (originally designated as Feature 10) raises questions concerning the cultural origin of Feature 23 . It is entirely possible that the differential burning in this area produced the appearance of a cultural feature when it is actually natural in origin. However, after the excavation of both it was determined that Feature 23 was cultural while Feature 10 was natural based on form. Wöcherl 2005:31 suggests that pits such as this with prepared (thermally oxidized) interiors may have served as short term storage pits. 


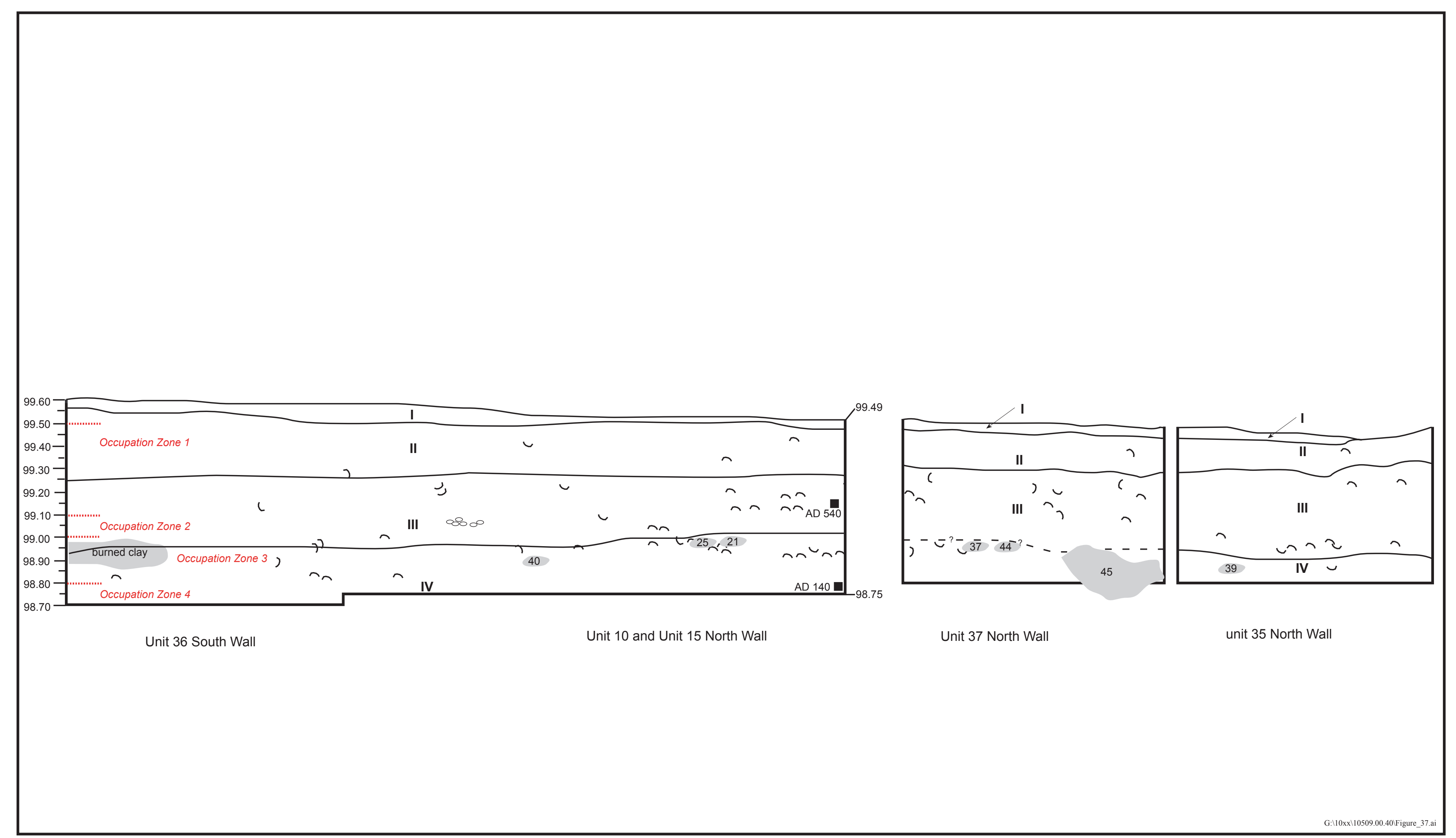

Figure 37. Block 4 profile drawing. 


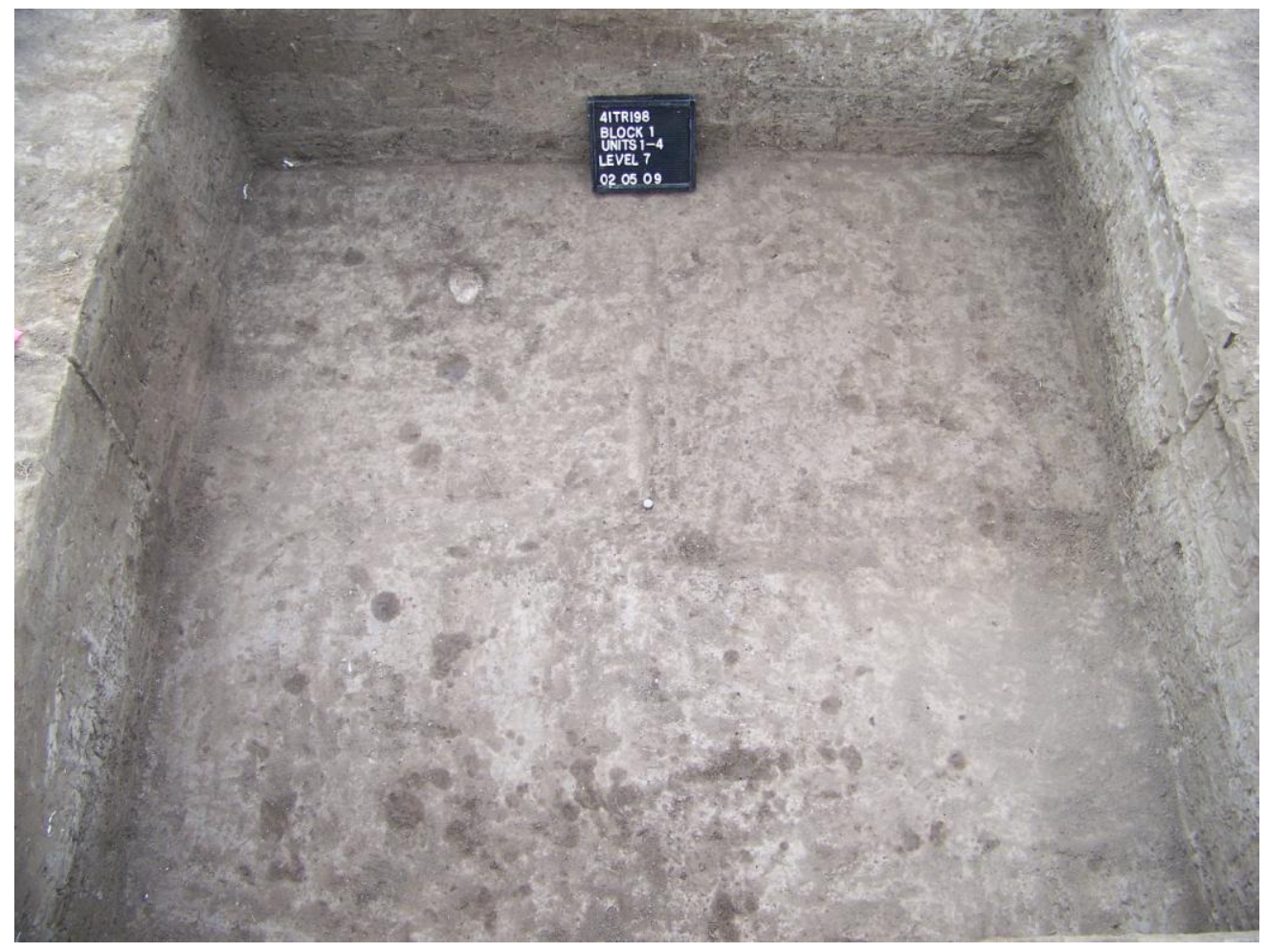

Figure 38. Block 1, Units 1-4, Level 7, possible occupation, with mano.

Table 9

Block 1 Features

\begin{tabular}{|c|c|c|c|c|c|c|}
\hline$\#$ & $\begin{array}{l}\text { Feature } \\
\text { interpretation }\end{array}$ & Unit & Depth & $\mathrm{L} \times \mathrm{W} \times \mathrm{T}$ & Feature Fill & Shape \\
\hline 4 & $\begin{array}{l}\text { Ash and shell } \\
\text { scatter }\end{array}$ & $\begin{array}{l}1,2,3, \\
4\end{array}$ & $98.65-98.55$ & $\begin{array}{l}\text { Extends throughout units; } \\
\text { approximately } 10 \mathrm{~cm} \text { thick }\end{array}$ & & Lens \\
\hline 11 & FCR scatter & 3 & $97.93-97.84 \mathrm{~cm}$ & $35 \times 25 \times 10 \mathrm{~cm}$ & $\begin{array}{l}\text { FCR/7.5YR } 4 / 2 \\
\text { clay loam }\end{array}$ & Scatter \\
\hline 26 & Shell lens & $\begin{array}{l}1,2,3, \\
4\end{array}$ & $98.19-97.97 \mathrm{~cm}$ & $>200 \times>200 \times 3 \mathrm{~cm}$ & mussel shell & Slope \\
\hline 27 & Basin-shaped pit & 1,2 & $98.27-98.10 \mathrm{~cm}$ & $78 \times>48 \times 17 \mathrm{~cm}$ & $\begin{array}{l}10 \text { YR } 3 / 2 \text { very } \\
\text { silty loam }\end{array}$ & Basin \\
\hline
\end{tabular}

A significant mussel shell scatter was observed at $98.80 \mathrm{~cm}$, marking the second $5 \mathrm{~cm}$ level of the occupation zone (Level 4). This shell lens extended across the whole block but was most pronounced in the east half, where it remained one of the most notable characteristics of the Block 3 profile. Associated cultural material includes FCR and animal bone (Table 12). 


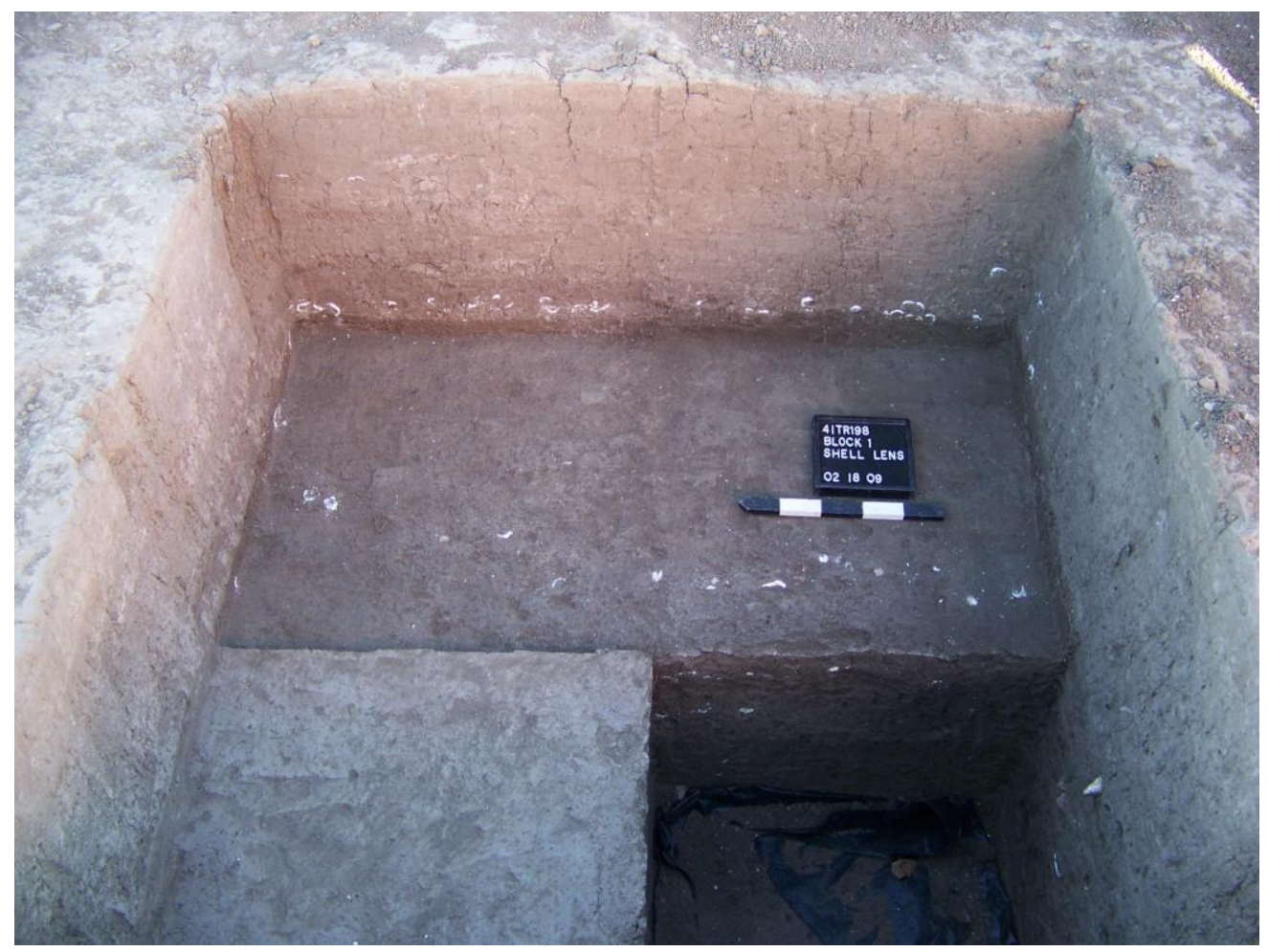

Figure 39. Feature 26, Block 1.

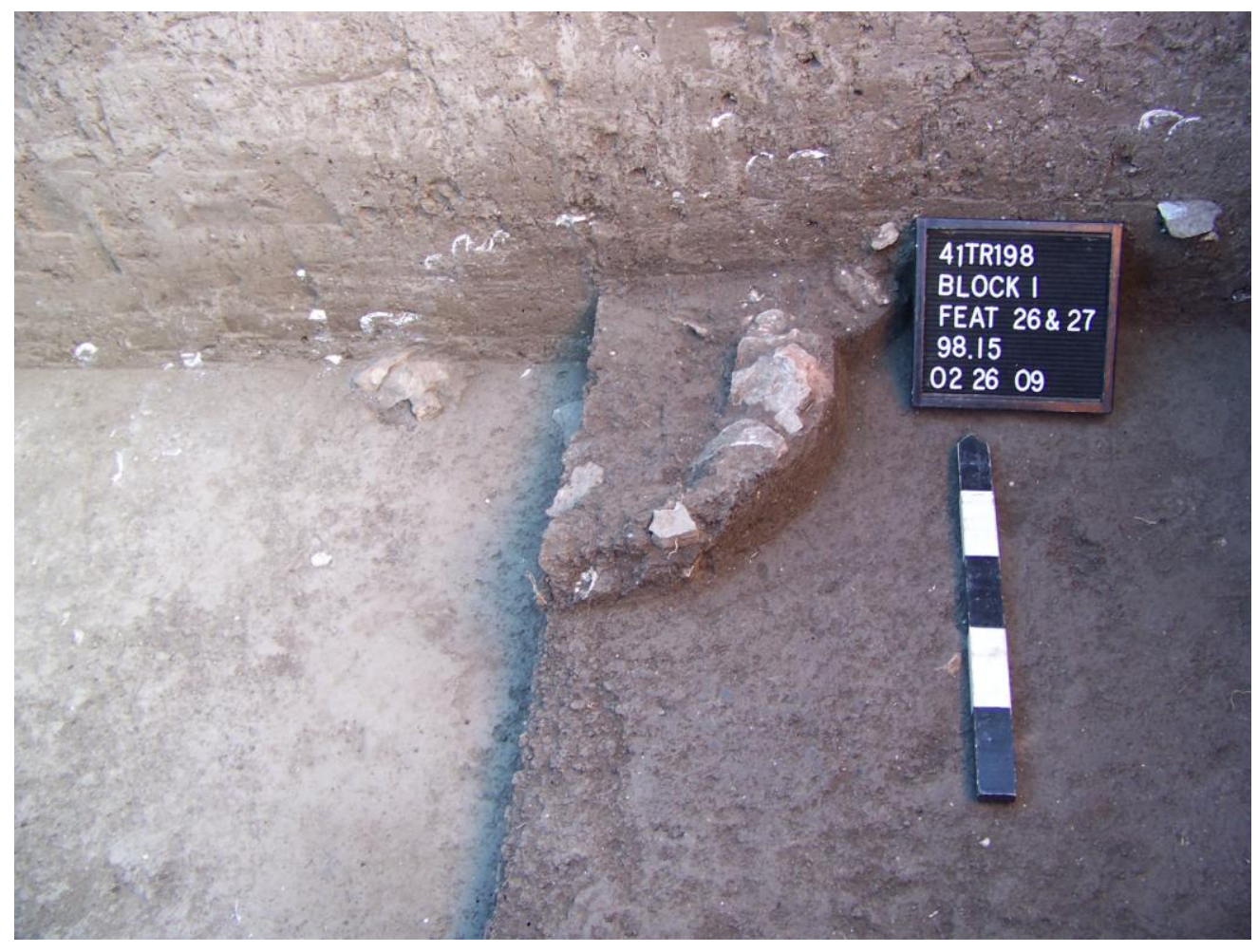

Figure 40. Feature 27, Block 1. 


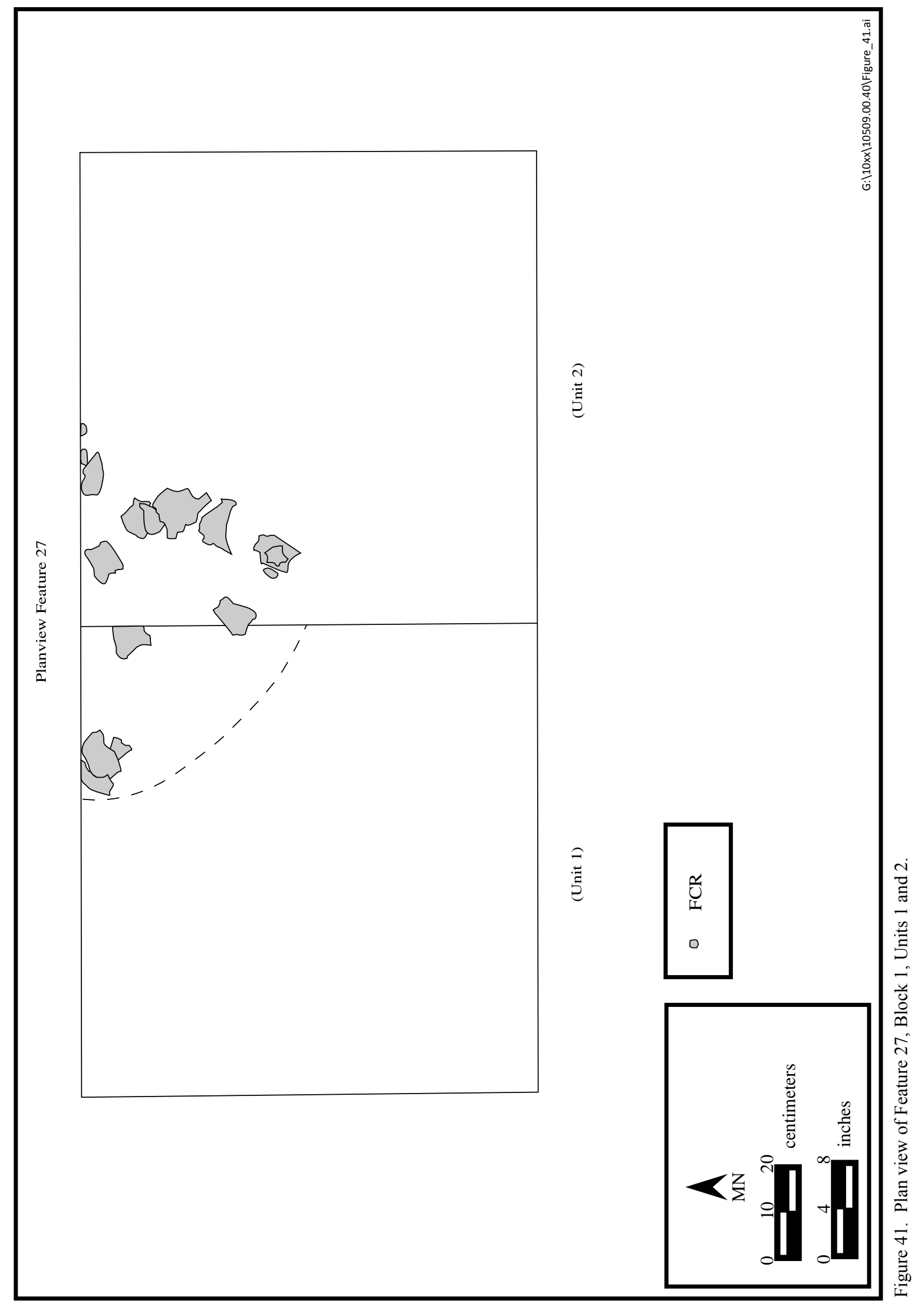




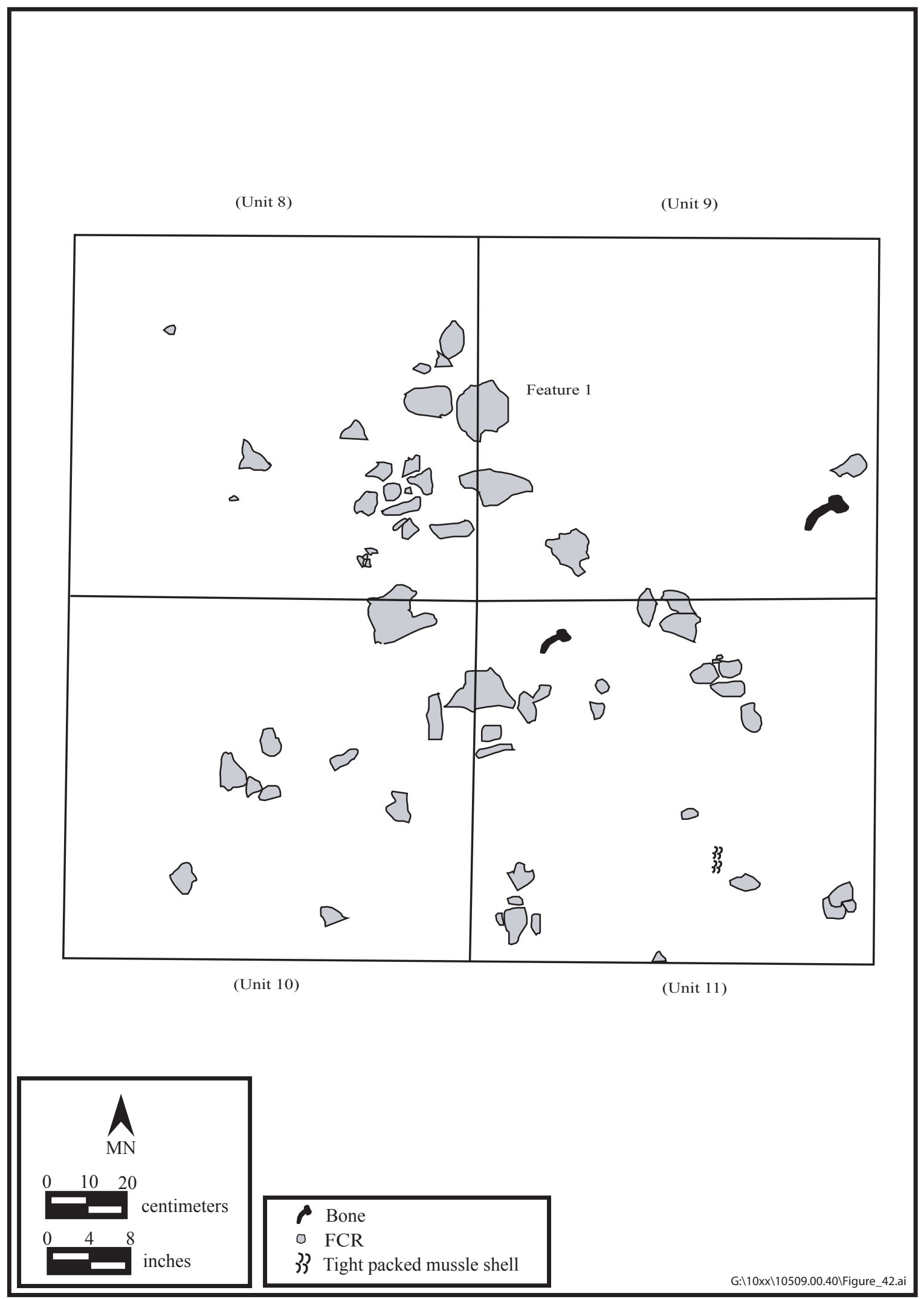

Figure 42. Feature 1 Block 2. 


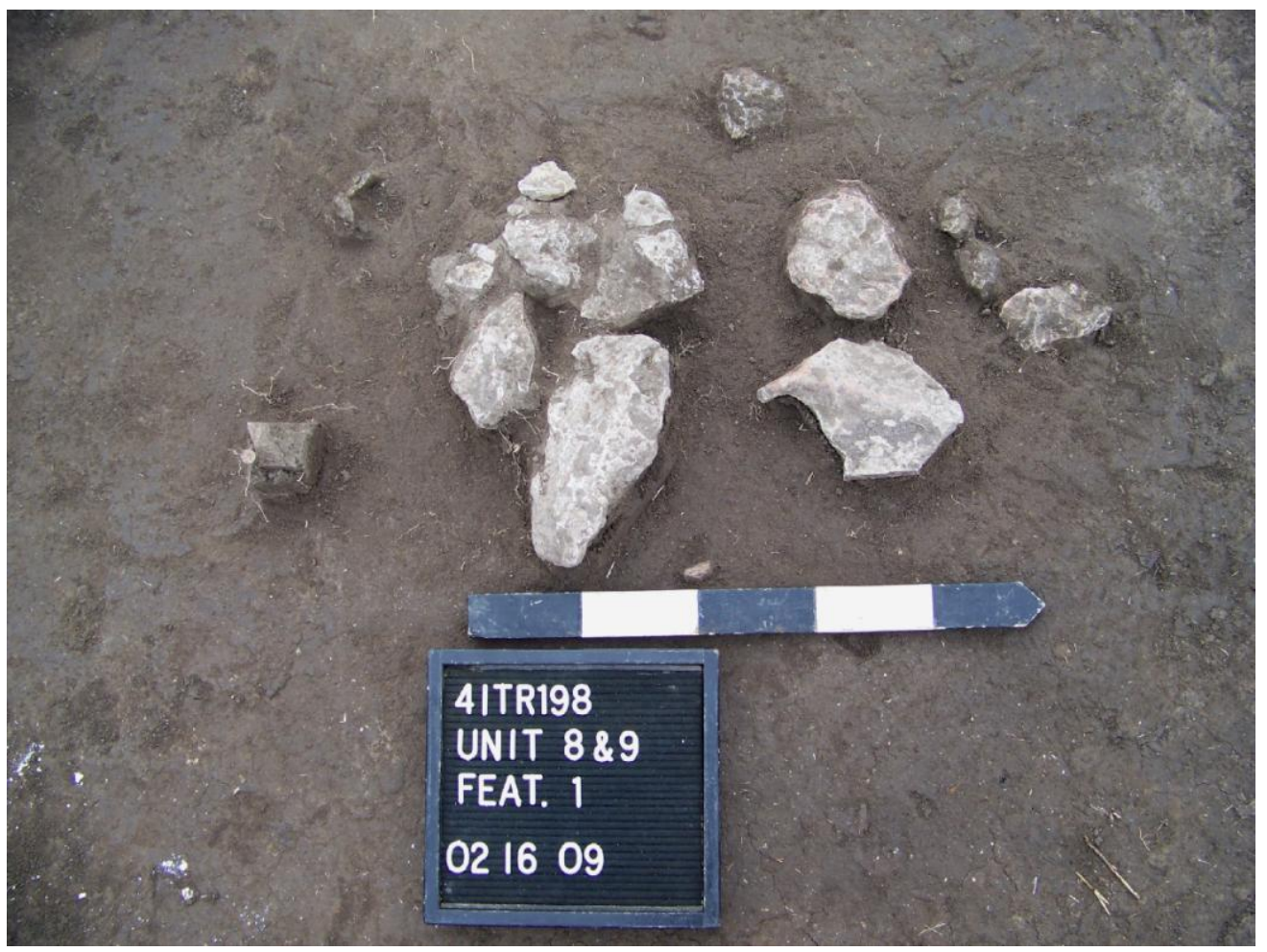

Figure 43. Block 2, F-1 FCR concentration.

Table 10

A.D. 1040 Occupation Zone Features

\begin{tabular}{llllllll} 
& $\begin{array}{l}\text { Feature } \\
\text { interpretation }\end{array}$ & Unit & Depth & L x W x T & $\%$ exc. & Feature Fill & Shape \\
\hline 23 & Storage Pit & 22 & $98.80-98.63$ & $55 \times>40 \times 17 \mathrm{~cm}$ & $75 \%$ & $\begin{array}{l}10 \text { YR 3/4 } \\
7.5 \text { YR 5/8 (rim) } \\
\text { clay loam }\end{array}$ & Cylindrical \\
& & & & & & \\
28 & Pit (n.f.s.) & 20 & $98.70-98.59$ & $32 \times>20 \times 11 \mathrm{~cm}$ & $60 \%$ & 10 YR 4/2 loam & Basin \\
\hline
\end{tabular}

The subsequent level below the shell lens (Level 5) contained moderate amounts of mussel shell, animal bone, and an antler awl in Unit 13 (Table 13). 


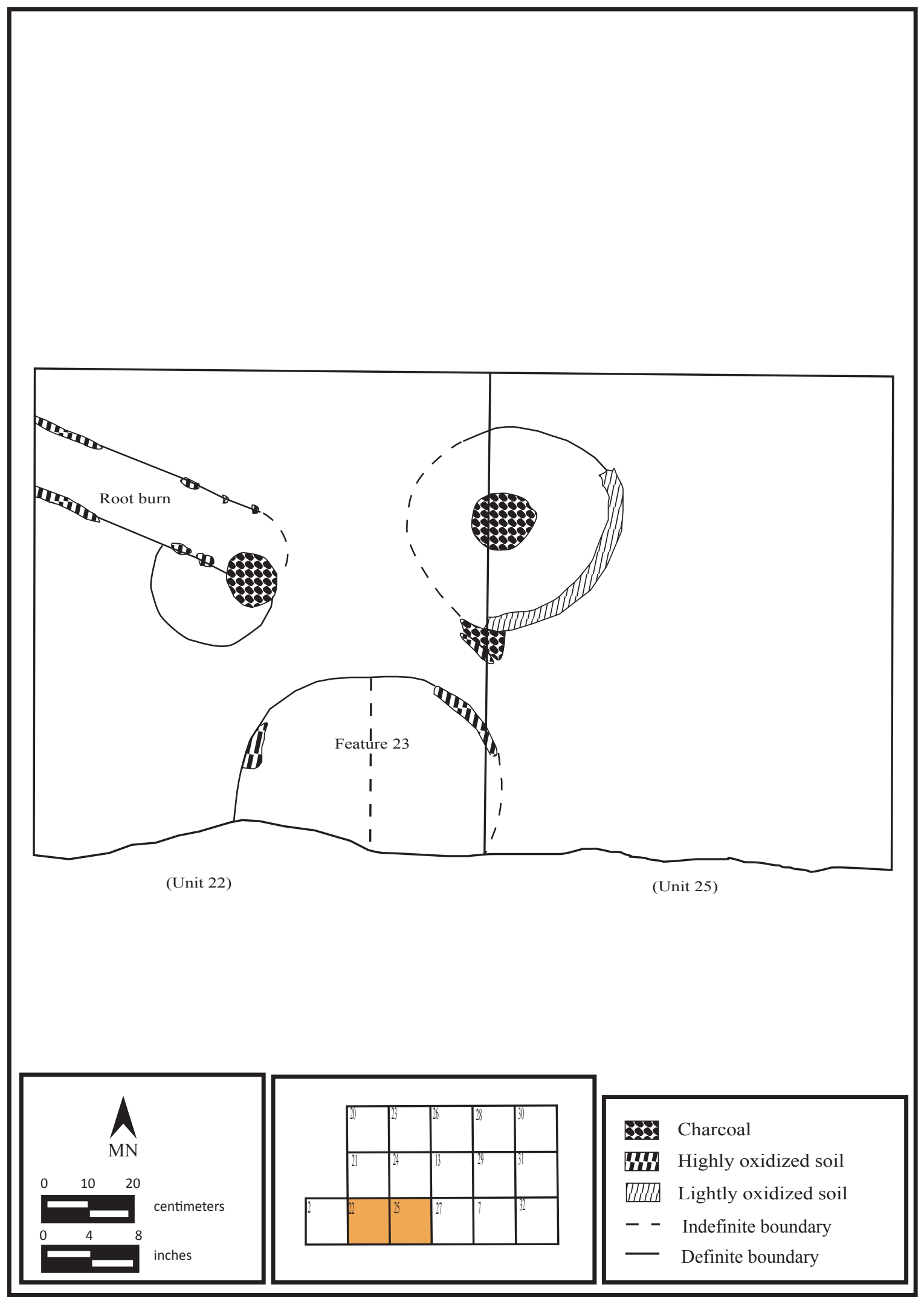

Figure 44. Plan map of Feature 23, Block 3. 
Table 11

Block 3 Level 3 [98.85-98.80] Artifacts

\begin{tabular}{llllllllllllllll} 
Unit/Artifact & 20 & 21 & 22 & 23 & 24 & 25 & 26 & 13 & 27 & 28 & 29 & 30 & 31 & 32 & $\mathrm{~F} 23$ \\
\hline FCR & 0 & 0 & 0 & 1 & 0 & 0 & 0 & 0 & 0 & 0 & 4 & 1 & 4 & 1 & $\mathrm{~F}$ \\
Mussel shell & 0 & 0 & 4 & 1 & 0 & 12 & 0 & 1 & 7 & 14 & 8 & 26 & 3 & 7 & $\mathrm{~F}$ \\
Animal bone & 1 & 1 & 1 & 1 & 4 & 0 & 1 & 1 & 2 & 6 & 14 & 2 & 11 & 5 & $\mathrm{~F}$ \\
Ground stone & 0 & 0 & 0 & 0 & 0 & 0 & 0 & 0 & 0 & 0 & 0 & 0 & 0 & 0 & $\mathrm{~F}$ \\
Debitage & 0 & 0 & 0 & 0 & 0 & 0 & 0 & 0 & 0 & 0 & 0 & 0 & 0 & 0 & $\mathrm{~F}$ \\
F.S. tool & 0 & 0 & 0 & 0 & 0 & 0 & 0 & 0 & 0 & 0 & 0 & 0 & 0 & 0 & $\mathrm{~F}$ \\
Projectile point & 0 & 0 & 0 & 0 & 0 & 0 & 0 & 0 & 0 & 0 & 0 & 0 & 0 & 0 & $\mathrm{~F}$ \\
Bone tool & 0 & 0 & 0 & 0 & 0 & 0 & 0 & 0 & 0 & 0 & 0 & 0 & 0 & 0 & $\mathrm{~F}$ \\
\hline
\end{tabular}

Table 12

Block 3 Level 4 [98.80-98.75] Artifacts

\begin{tabular}{lllllllllllllll} 
Unit/Artifact & 20 & 21 & 22 & 23 & 24 & 25 & 26 & 13 & 27 & 28 & 29 & 30 & 31 & 32 \\
\hline FCR & 0 & 0 & 0 & 6 & 1 & 9 & - & 0 & 2 & 3 & 6 & 2 & 0 & 0 \\
Mussel shell & 3 & 11 & 5 & 8 & 16 & 31 & - & 12 & 8 & 11 & 4 & 71 & 3 & 0 \\
Animal bone & 2 & 3 & 0 & 0 & 4 & 3 & - & 4 & 6 & 1 & 4 & 4 & 0 & 0 \\
Ground stone & 0 & 0 & 0 & 0 & 0 & 0 & - & 0 & 0 & 0 & 0 & 0 & 0 & 0 \\
Debitage & 0 & 0 & 0 & 0 & 0 & 0 & - & 0 & 0 & 0 & 0 & 0 & 0 & 0 \\
F.S. tool & 0 & 0 & 0 & 0 & 0 & 0 & - & 0 & 0 & 0 & 0 & 0 & 0 & 0 \\
Projectile point & 0 & 0 & 0 & 0 & 0 & 0 & - & 0 & 0 & 0 & 0 & 0 & 0 & 0 \\
Bone tool & 0 & 0 & 0 & 0 & 0 & 0 & - & 0 & 0 & 0 & 0 & 0 & 0 & 0 \\
\hline
\end{tabular}

Table 13

Block 3 Level 5 [98.75-98.70] Artifacts

\begin{tabular}{llllllllllllllll} 
Unit/Artifact & 20 & 21 & 22 & 23 & 24 & 25 & 26 & 13 & 27 & 28 & 29 & 30 & 31 & 32 & F 28 \\
\hline FCR & 0 & 0 & 0 & 0 & 0 & 3 & 0 & 0 & 4 & 0 & 0 & 2 & 0 & 0 & 0 \\
Mussel shell & 8 & 3 & 2 & 2 & 1 & 0 & 3 & 6 & 3 & 2 & 6 & 2 & 1 & 0 & 1 \\
Animal bone & 5 & 2 & 0 & 1 & 3 & 3 & 5 & 11 & 1 & 1 & 2 & 3 & 8 & 0 & 0 \\
Ground stone & 0 & 0 & 0 & 0 & 0 & 0 & 0 & 1 & 0 & 0 & 0 & 0 & 0 & 0 & 0 \\
Debitage & 0 & 0 & 0 & 0 & 0 & 0 & 0 & 0 & 0 & 0 & 0 & 0 & 0 & 0 & 0 \\
F.S. tool & 0 & 0 & 0 & 0 & 0 & 0 & 0 & 0 & 0 & 0 & 0 & 0 & 0 & 0 & 0 \\
Projectile point & 0 & 0 & 0 & 0 & 0 & 0 & 0 & 0 & 0 & 0 & 0 & 0 & 0 & 0 & 0 \\
Bone tool & 0 & 0 & 0 & 0 & 0 & 0 & 0 & 1 & 0 & 0 & 0 & 0 & 0 & 0 & 0 \\
\hline
\end{tabular}


A small pit feature was found in the north half of Unit 20, later radiocarbon dated at A.D. 1040. Feature 28 is a small, basin shaped pit, differentiated from its surrounding matrix by a subtle color change and the presence of charcoal. One of its main defining characteristics was texture; its fill was a loam while the soil which surrounded it was a clay loam. Feature 28 was approximately $32 \mathrm{~cm}$ in diameter and $11 \mathrm{~cm}$ deep. The base of Feature 28 was flat and its sides were sloping. The northern half of Feature 28 is located in the north balk of Block 3 where it was barely visible in profile (Figure 45).

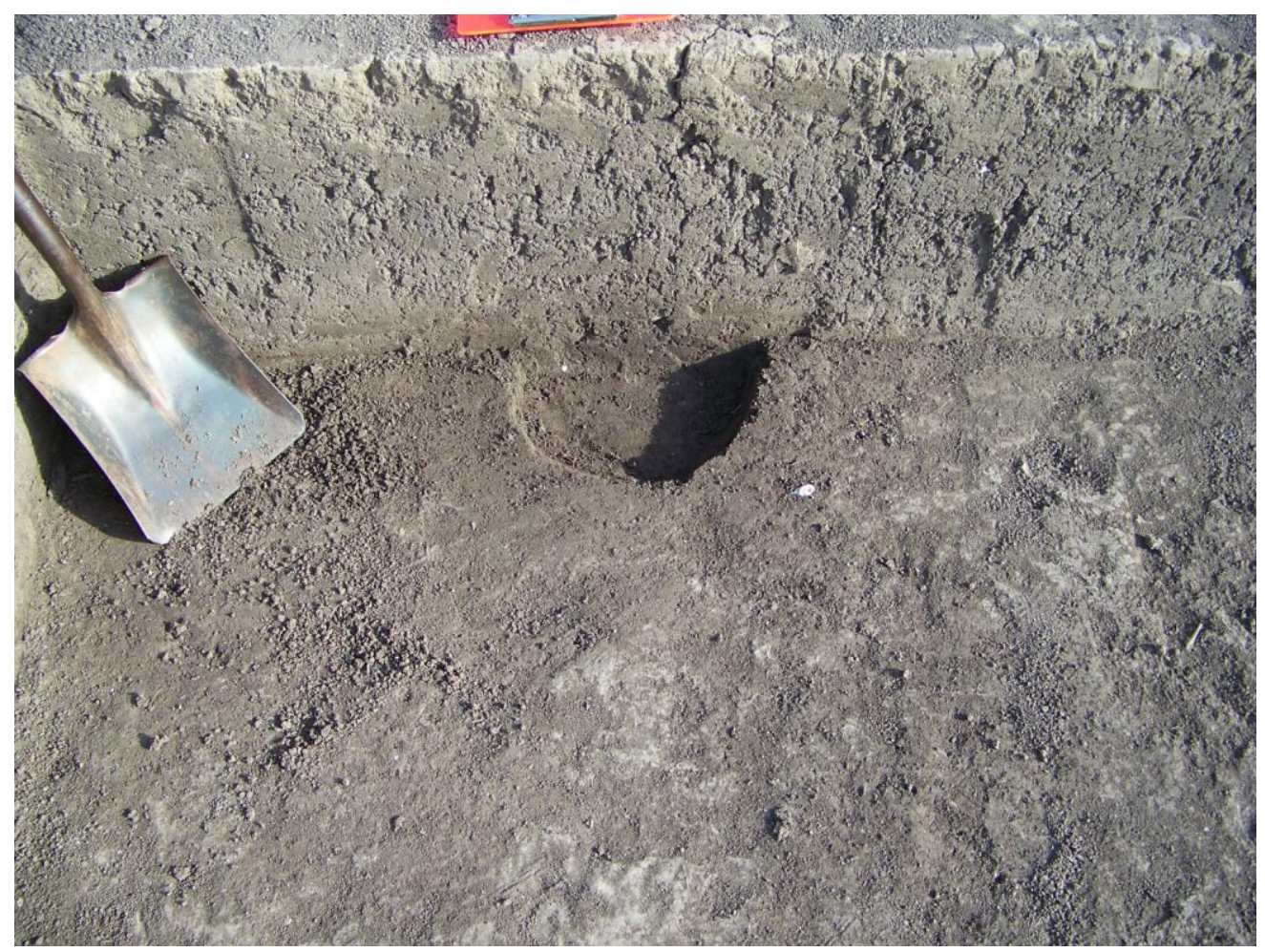

Figure 45. Feature 28, Block 3.

\section{A.D.900 - 960 Occupation Zone (Levels 7 -9)}

This occupation zone consists of two overlapping proto-middens, one consisting of mussel shell (Feature 8), the other of animal bone and related organic subsistence refuse (Feature 29) (Tables 14-17). These two proto-middens are overlapping and partially interlocked with one another and therefore associated. They are interpreted as an intact subsistence refuse disposal areas associated 
Table 14

A.D. 900 - 960 Occupation Zone Features

\begin{tabular}{|c|c|c|c|c|c|c|}
\hline \# & $\begin{array}{l}\text { Feature } \\
\text { interpretation }\end{array}$ & Unit & Depth & $\mathrm{L} \times \mathrm{W} \times \mathrm{T}$ & Feature Fill & Shape \\
\hline 8 & Shell midden & $\begin{array}{l}12,21,22 \\
24, \& 25\end{array}$ & $98.65-98.50$ & $4 \times 3 \times 0.15 \mathrm{~m}$ & $\begin{array}{l}\text { Mussel shell, } \\
\text { ash }\end{array}$ & Flat/undulating \\
\hline 29 & Proto- midden & $\begin{array}{l}7,13,20-21 \\
23-25,26-29\end{array}$ & $98.67-98.55$ & $3.2 \times 2.6 \times 0.12 \mathrm{~m}$ & $\begin{array}{l}\text { 10YR 4/2 } \\
\text { loam }\end{array}$ & Mounded \\
\hline
\end{tabular}

Table 15

Block 3 Level 7 [98.65-98.60] Artifacts

\begin{tabular}{|c|c|c|c|c|c|c|c|c|c|c|c|c|c|c|}
\hline Unit/Artifact & 20 & 21 & $\begin{array}{l}22 / \\
\text { F8 } \\
\end{array}$ & 23 & $\begin{array}{l}24 / \\
\text { F29 }\end{array}$ & $\begin{array}{l}25 / \\
\text { F29 }\end{array}$ & 26 & $\begin{array}{l}13 / \\
\text { F29 }\end{array}$ & $\begin{array}{l}27 / \\
\text { F29 }\end{array}$ & 28 & 29 & 30 & 31 & 32 \\
\hline FCR & 0 & 0 & $4^{1}$ & 1 & 0 & - & 0 & 0 & 2 & 2 & 0 & 0 & 0 & 0 \\
\hline Mussel shell & 42 & 130 & $2229 / 98^{2}$ & 0 & 0 & - & 34 & 28 & 15 & 21 & 14 & 15 & 11 & 32 \\
\hline Animal bone & 33 & 23 & $10 / 0^{2}$ & 47 & 54 & - & 1 & 3 & 1 & 0 & 0 & 0 & 0 & 0 \\
\hline Ground stone & 0 & 0 & $1^{1}$ & 16 & 1 & - & 0 & 0 & 0 & 0 & 0 & 0 & 0 & 0 \\
\hline Debitage & 0 & 0 & 0 & 0 & 0 & - & 0 & 0 & 0 & 0 & 0 & 0 & 0 & 0 \\
\hline F.S. tool & 0 & 0 & 0 & 0 & 0 & - & 0 & 0 & 0 & 0 & 0 & 0 & 0 & 0 \\
\hline Projectile point & 0 & 0 & 0 & 0 & 0 & - & 0 & 0 & 0 & 0 & 0 & 0 & 0 & 0 \\
\hline Bone tool & 0 & 0 & 0 & 0 & 0 & - & 0 & 0 & 0 & 0 & 0 & 0 & 0 & 0 \\
\hline
\end{tabular}

${ }^{1}=98.65-98.56 \mathrm{~m}^{2}=\mathrm{U} 22 \mathrm{~F} 8 / \mathrm{U} 22^{3}=$ FS list says F8/29

Table 16

Block 3 Level 8 [98.60-98.55] Artifacts

\begin{tabular}{|c|c|c|c|c|c|c|c|c|c|c|c|c|c|c|}
\hline Unit/Artifact & $\begin{array}{l}20 / \\
\text { F29 }\end{array}$ & $\begin{array}{l}21 / \\
\text { F29 } \\
\text { F8 }\end{array}$ & $\begin{array}{l}22 / \\
\text { F8 }\end{array}$ & $\begin{array}{l}23 / \\
\text { F29 }\end{array}$ & $\begin{array}{l}24 / \\
\text { F29 } \\
\text { F8 }\end{array}$ & $\begin{array}{l}25 / \\
\text { F8 }\end{array}$ & $\begin{array}{l}26 / \\
\text { F29 }\end{array}$ & $\begin{array}{l}13 / \\
\text { F29 }\end{array}$ & $\begin{array}{l}27 / \\
\text { F29 }\end{array}$ & $\begin{array}{l}28 / \\
\text { F29 }\end{array}$ & $\begin{array}{l}29 / \\
\text { F29 }\end{array}$ & 30 & 31 & 32 \\
\hline FCR & 2 & $10 / 0^{1}$ & 0 & 1 & 2 & 3 & 0 & 1 & 0 & 0 & 5 & 7 & 2 & 3 \\
\hline Mussel shell & 29 & $0 / 14$ & 13 & 32 & 674 & 441 & 15 & 49 & 41 & 15 & 46 & 20 & 7 & 6 \\
\hline Animal bone & 12 & $140 / 0$ & 2 & 0 & 3 & 9 & 3 & 8 & 5 & 2 & 1 & 0 & 3 & 3 \\
\hline Ground stone & 0 & $0 / 0$ & 0 & 0 & 0 & 0 & 0 & 0 & 0 & 0 & 0 & 0 & 0 & 0 \\
\hline Debitage & 0 & $0 / 0$ & 0 & 0 & 0 & 0 & 0 & 0 & 0 & 0 & 0 & 0 & 0 & 0 \\
\hline F.S. tool & 0 & $0 / 0$ & 0 & 0 & 0 & 0 & 0 & 0 & 0 & 0 & 0 & 0 & 0 & 0 \\
\hline Projectile point & 0 & $0 / 0$ & 0 & 0 & 0 & 0 & 0 & 0 & 0 & 0 & 0 & 0 & 0 & 0 \\
\hline Bone tool & 0 & $0 / 0$ & 0 & 0 & 0 & 0 & 0 & 0 & 0 & 0 & 0 & 0 & 0 & 0 \\
\hline
\end{tabular}

\footnotetext{
${ }^{1}=\mathrm{U} 21 / \mathrm{U} 21 \mathrm{~F} 8$
} 
Table 17

Block 3 Level 9 [98.55-98.50] Artifacts

\begin{tabular}{lllllllllllllll} 
Unit/Artifact & & $21 /$ & 22 & \multicolumn{1}{c}{$24 /$} & $25 /$ & & & & & \\
FCR & 6 & 6 & 3 & 2 & 1 & 0 & 5 & 2 & 2 & 3 & 2 & 7 & 0 & 4 \\
Mussel shell & 100 & 74 & 23 & 36 & 8 & 3 & 37 & 71 & 24 & 94 & 40 & 24 & 15 & 5 \\
Animal bone & 3 & 3 & 11 & 8 & 16 & 2 & 2 & 5 & 19 & 4 & 5 & 0 & 8 & 7 \\
Ground stone & 1 & 1 & 0 & 0 & 0 & 0 & 0 & 0 & 0 & 0 & 0 & 0 & 0 & 0 \\
Debitage & 0 & 0 & 0 & 0 & 0 & 0 & 0 & 0 & 0 & 0 & 0 & 0 & 3 & 3 \\
F.S. tool & 0 & 0 & 0 & 0 & 0 & 0 & 0 & 0 & 0 & 0 & 0 & 0 & 0 & 0 \\
Projectile point & 0 & 0 & 0 & 0 & 0 & 0 & 0 & 0 & 0 & 0 & 0 & 0 & 0 & 0 \\
Bone tool & 0 & 0 & 0 & 0 & 0 & 0 & 0 & 0 & 0 & 0 & 0 & 0 & 0 & 0 \\
\hline
\end{tabular}

what may be a single occupation. The 1,110 B.P. radiocarbon date (calibrated intercept of A.D. 900, 920, and 960) was obtained from a deer long bone recovered from the interface between Features 8 and 29, providing temporal context.

Feature 8 is a large mussel shell proto-midden located in the southwest quadrant of Block 3 (Figure 46). Feature 8 was first noted in Trench 1 as a 5-10 cm-thick lens of mussel shell. It appears that the majority of this feature was intersected by either Trench 1 or Block 3, specifically units $12,21,22,24$, and 25 . Remnant portions of Feature 8 remain intact in the west balk of Block 3 and in the south profile of Trench 1.

Feature 8 consists of a 5-15 cm thick layer of tightly packed, articulated mussel shells with an undulating top and bottom surface. A small proportion of the shells are clearly burned (i.e. decomposed, gray, and coated in ash). This feature is interpreted as a disposal area for mussel refuse from a short term occupation based on its integrity and lack of internal stratigraphy. Feature 8 is believed to be contemporaneous with Feature 29, representing the same occupation or possibly series of sequential occupations.

Feature 29 is a roughly $3 \mathrm{~m}$ in diameter proto-midden distinguishable by its dark, waxy 10YR 4/2 fill. During excavation Feature 29 was observed to have a low, broad mounded shape. At an elevation of $98.65 \mathrm{~cm}$ its diameter is one $\mathrm{m}$ across while at $98.60 \mathrm{~cm}$ its diameter is approximately $3 \mathrm{~m}$. 


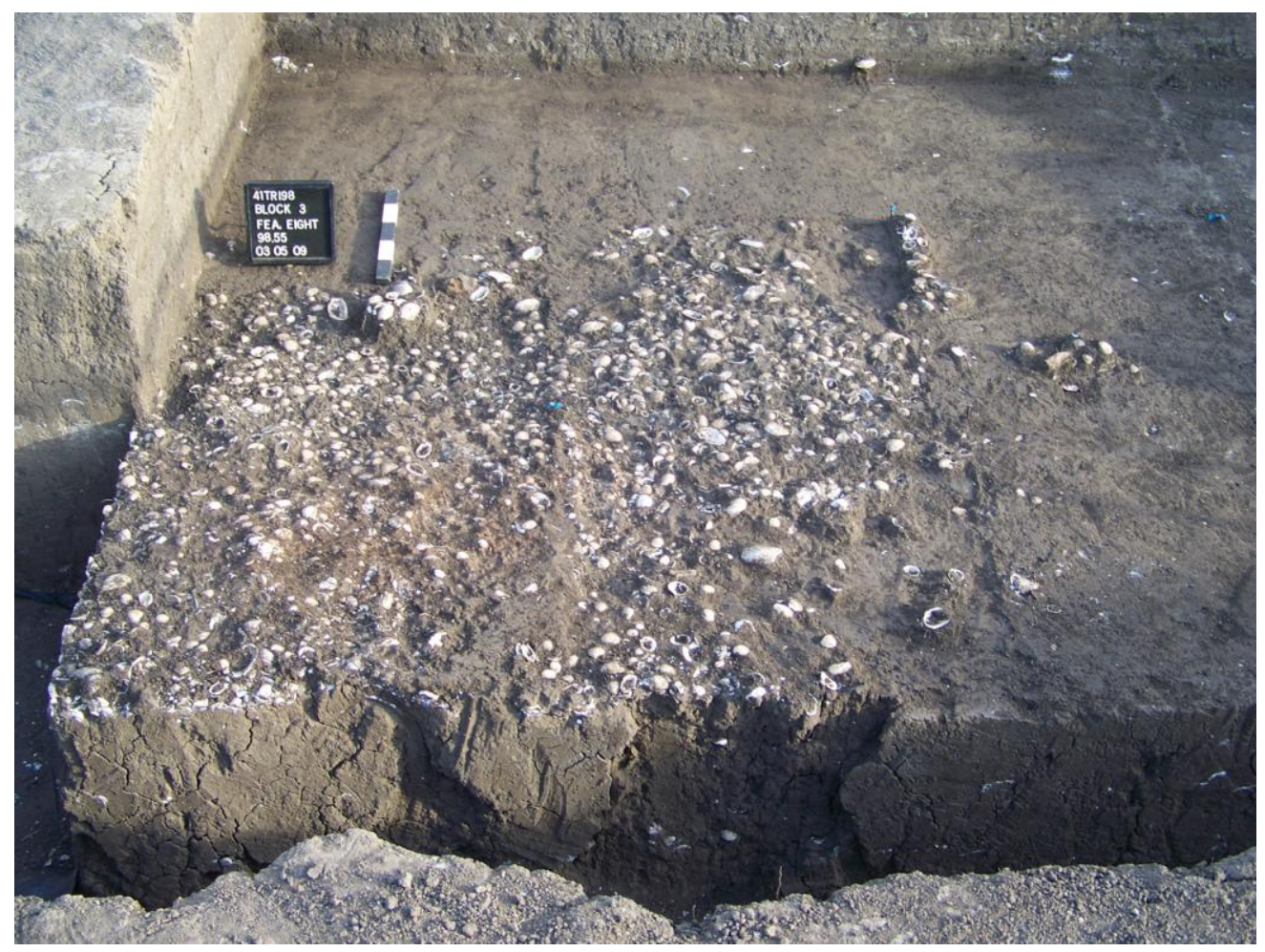

Figure 46. Feature 8, Block 3.

Feature 29 is significant because it appears to represent a single short term occupation, based on the uniform nature of the distribution of artifacts within it. Feature 29 contained an interesting faunal assemblage consisting mostly of turtle, fish, and bird bones. No flaked or ground stone artifacts are present within this proto-midden. Fish vertebrae are the most distinctive characteristic of this feature. None were found throughout the remainder of the excavation units.

Below these two proto-middens, Level 9 contained an increasing frequency of burned clay originating from a significant oxidized surface in the east-central portion of the block (Units 13, 26,28 , and 29).

\section{A.D. 700 - 900 Occupation Zone (Levels 10 - 11)}

Three features (F-30, 31, and 32) are present within this zone (Table 18). Feature 31 consists of numerous articulated fire-cracked rock in a sub-circular pattern measuring 90-x-75 cm (Figure 47). The fire-cracked rocks along the edge of the feature are slightly higher in elevation than 
Table 18

A.D. 700 - 900 Occupation Zone Features from Block 3

\begin{tabular}{|c|c|c|c|c|c|c|c|}
\hline \# & $\begin{array}{l}\text { Feature } \\
\text { interpretation }\end{array}$ & Unit & Depth & $\mathrm{L} \times \mathrm{W} \times \mathrm{T}$ & $\%$ exc. & Feature Fill & Shape \\
\hline 31 & Hearth & 7,29 & $98.51-98.37 \mathrm{~cm}$ & $90 \times 75 \times 14 \mathrm{~cm}$ & $100 \%$ & $\begin{array}{l}\text { FCR/10YR } 3 / 2 \\
\text { silty clay }\end{array}$ & Basin \\
\hline 30 & $\begin{array}{l}\text { FCR discard } \\
\text { pile }\end{array}$ & 31,32 & $98.45-98.35 \mathrm{~cm}$ & $\begin{array}{l}105 \mathrm{x}>100 \times 10 \\
\mathrm{~cm}\end{array}$ & $85 \%$ & $\begin{array}{l}\text { FCR/10YR 3/2 } \\
\text { silty clay }\end{array}$ & $\begin{array}{l}\text { Sub- } \\
\text { circular }\end{array}$ \\
\hline 32 & Ash pit & 23,26 & $98.44-98.40 \mathrm{~cm}$ & $45 \times 40 \times 6 \mathrm{~cm}$ & $100 \%$ & $\begin{array}{l}\text { 5YR 4/1 (ashy) } \\
\text { loam }\end{array}$ & Basin \\
\hline
\end{tabular}

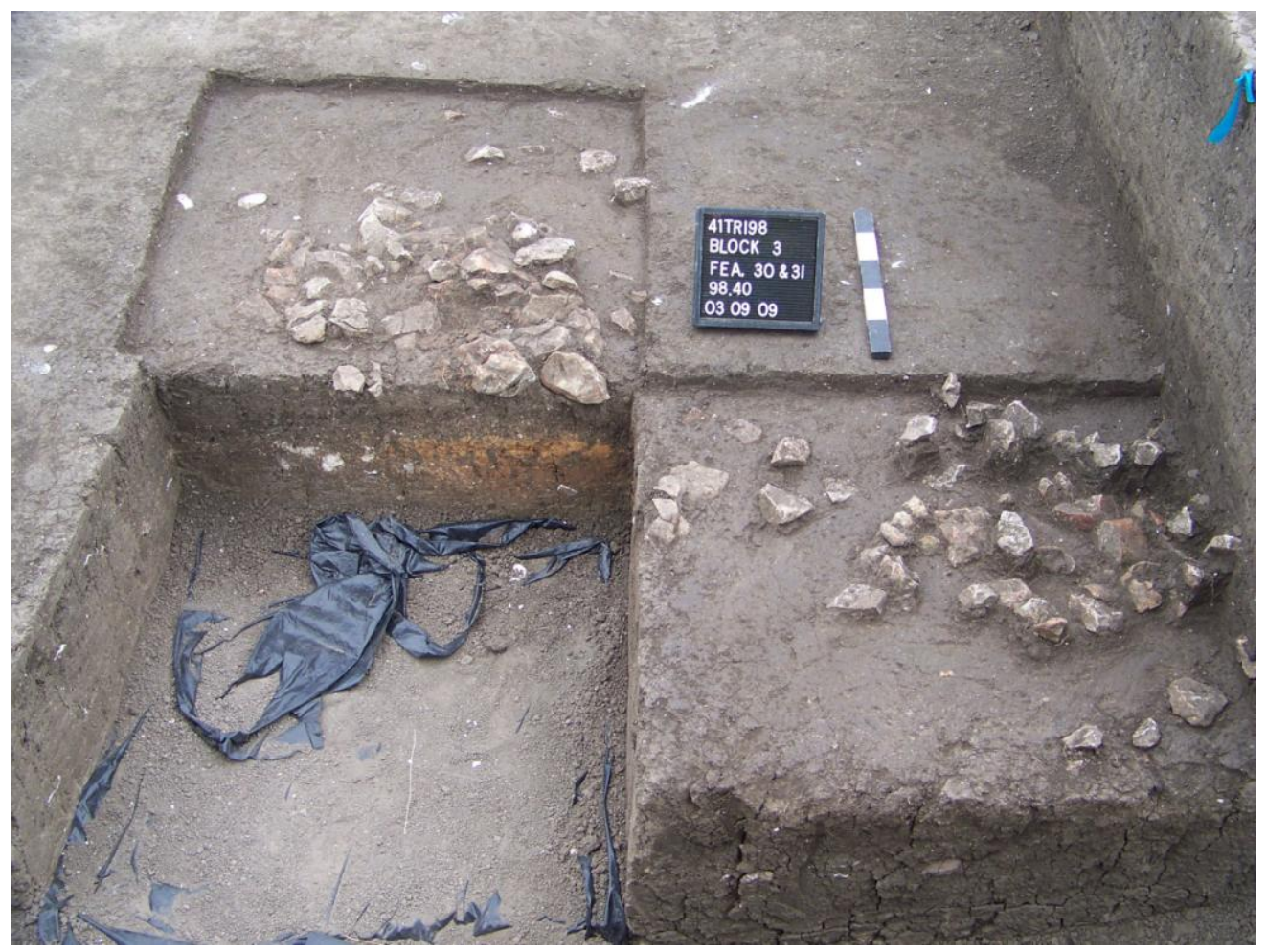

Figure 47. Features 30 and 31, Block 3.

those in the middle, an indication of its basin shape. The faunal remains from this feature include two spirally fractured long bone fragments of an undetermined bird. 
Feature 30, located in Units 31 and 32 (Figure 48), is a fire-cracked rock discard pile associated with Feature 31 (see Figure 47). This scatter of fire-cracked rock varied in elevation by about $10 \mathrm{~cm}$. There was also a cluster of stacked fire-cracked rock extending into the east balk of Unit 32 which was only partially exposed. Overall Feature 30 is comparable to Feature 21 in Block 4. The faunal remains from this feature include three long bone fragments that are spirally fractured, the incisor of a rodent, two mammal fragments, and the spirally fractured long bone of an undetermined bird.

Feature 32 is an extremely shallow, roughly circular-shaped pit (Figure 49) located in Units 23 and 26. Its fill was predominantly ash but it also contained mussel shell and charcoal. The east margin of the feature was ringed by a series of small mussel shells. Feature 32 also had a pronounced flat bottom.

\section{A.D. 350 - 700 Occupation Zone (Levels $12-15$ )}

This occupation zone exhibits a combination of basin-shaped hearths and ash pits (Table 19).

Feature 5, first noted in the north wall of Trench 1, is a shallow basin-shaped pit lined with firecracked rock (Figure 50). The first test unit in this area (Unit 7) was placed in order to expose this feature. The elevation of the individual fire-cracked rocks that delineate this feature slope downward from the outside margin toward the interior of the feature. Feature 5 fill is roughly comparable to the surrounding soil with the addition of charcoal and burned clay chunks around and below the fire-cracked rocks near the core of the feature. Bone and mussel shell were noted within it. Three flakes were noted in close proximity to the feature but not directly within it.

Feature 33 is a second, slightly less thermally reddened formal hearth, comparable in most respects to Feature 15. Feature 33 was observed in plan view at an elevation of $98.40 \mathrm{~cm}$ as a circular concentration of ash and charcoal associated with a rim of oxidized soil (Figures 51 and 52). Like Feature 15, Feature 33 contains two strata. The upper stratum consisted of a compacted layer of ash and charcoal. The second stratum consisted of a loamy soil with a distinctive, lightly oxidized brownish color. The shape of Feature 33 after excavation was that of a medium-sized, basin-shaped pit with a flat bottom. A well preserved bone awl was recovered at or near the bottom of the feature. 


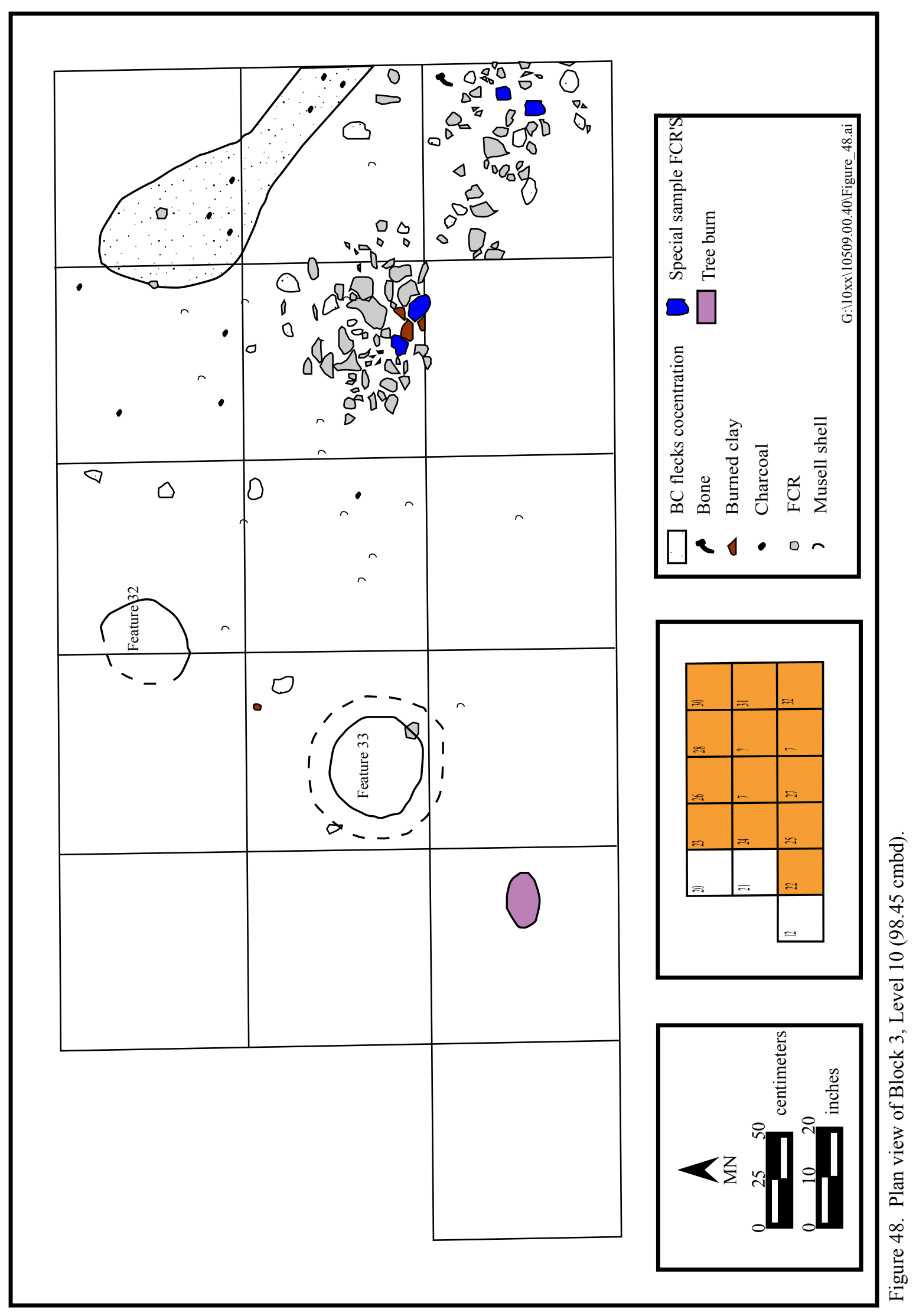




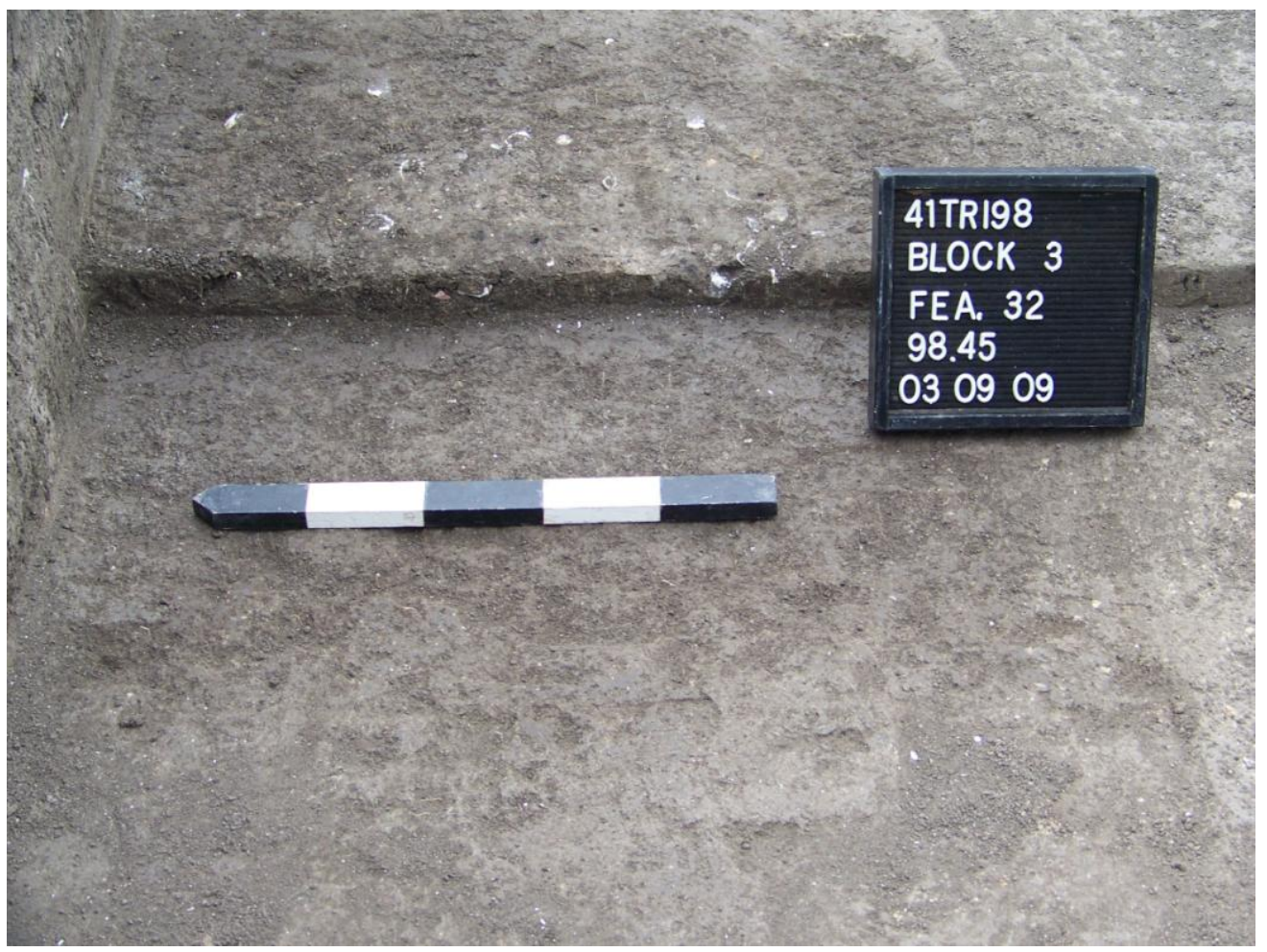

Figure 49. Feature 32, Block 3.

Table 19

A.D. 350 - 700 Occupation Zone Features from Block 3

Feature

\begin{tabular}{|c|c|c|c|c|c|c|c|}
\hline$\#$ & interpretation & Unit & Depth & $\mathrm{L} \times \mathrm{W} \times \mathrm{T}$ & $\%$ exc. & Feature Fill & Shape \\
\hline 5 & Hearth & 7 & $98.40-98.29 \mathrm{~cm}$ & $\begin{array}{l}78 \times>50 \times 11 \\
\mathrm{~cm}\end{array}$ & $50 \%$ & $\begin{array}{l}\text { FCR/10YR 3/2 } \\
\text { silty clay }\end{array}$ & Basin \\
\hline 33 & Formal hearth & 24,25 & $98.40-98.20 \mathrm{~cm}$ & $\begin{array}{l}56 \times 51 \times 20 \\
\mathrm{~cm}\end{array}$ & $100 \%$ & $\begin{array}{l}\text { 10YR 3/6 \& } \\
10 Y R \text { 4/3 loam }\end{array}$ & Basin \\
\hline 35 & Ash pit & 13 & $98.35-98.24 \mathrm{~cm}$ & $\begin{array}{l}33 \times 30 \times 10 \\
\mathrm{~cm}\end{array}$ & $100 \%$ & $\begin{array}{l}\text { 10YR 5/2 clay } \\
\text { loam }\end{array}$ & Hemispherical \\
\hline 15 & Formal hearth & 7,29 & $98.33-98.11 \mathrm{~cm}$ & $\begin{array}{l}75 \times 60 \times 22 \\
\mathrm{~cm}\end{array}$ & $100 \%$ & $\begin{array}{l}10 Y R \text { R/4 - 5/6 } \\
\text { silty clay }\end{array}$ & Basin \\
\hline 16 & Ash pit & 7 & $98.25-98.17 \mathrm{~cm}$ & $40 \times 32 \times 8 \mathrm{~cm}$ & $100 \%$ & $\begin{array}{l}\text { 10YR 3/2, } \\
\text { 10YR 6/2, } \\
\text { 10YR 6/3 silty } \\
\text { clay }\end{array}$ & Basin \\
\hline
\end{tabular}




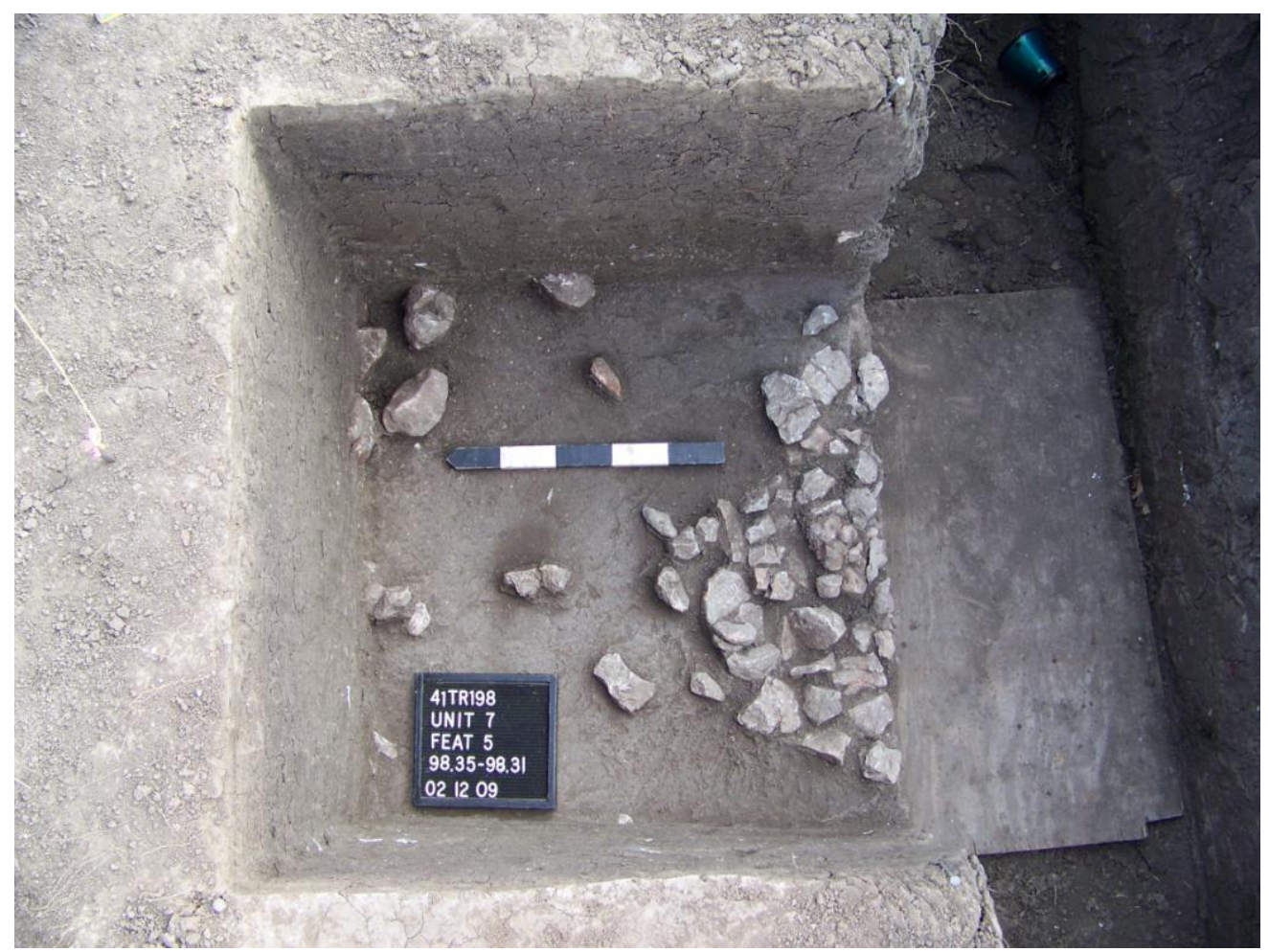

Figure 50. Plan view of Feature 5, Block 3.

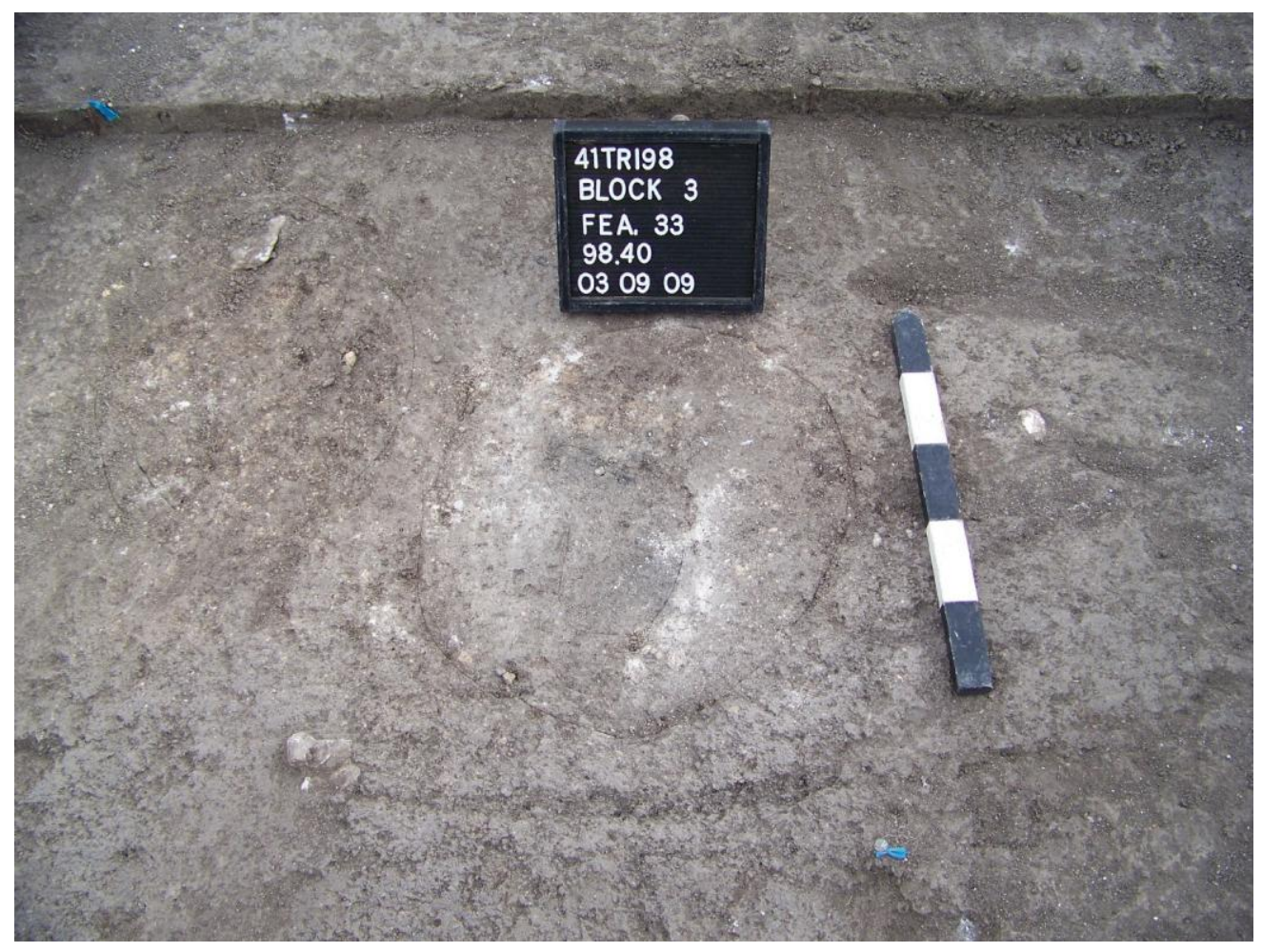

Figure 51. Block 3, Feature 33 ash feature. 


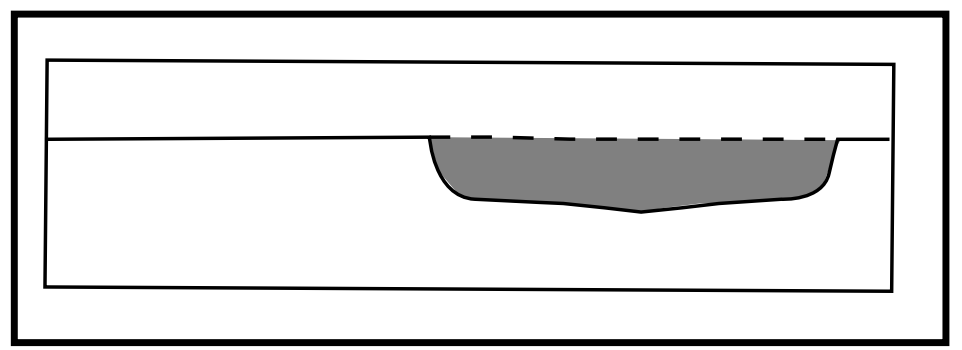

Feature 33 profile

(Unit 24)
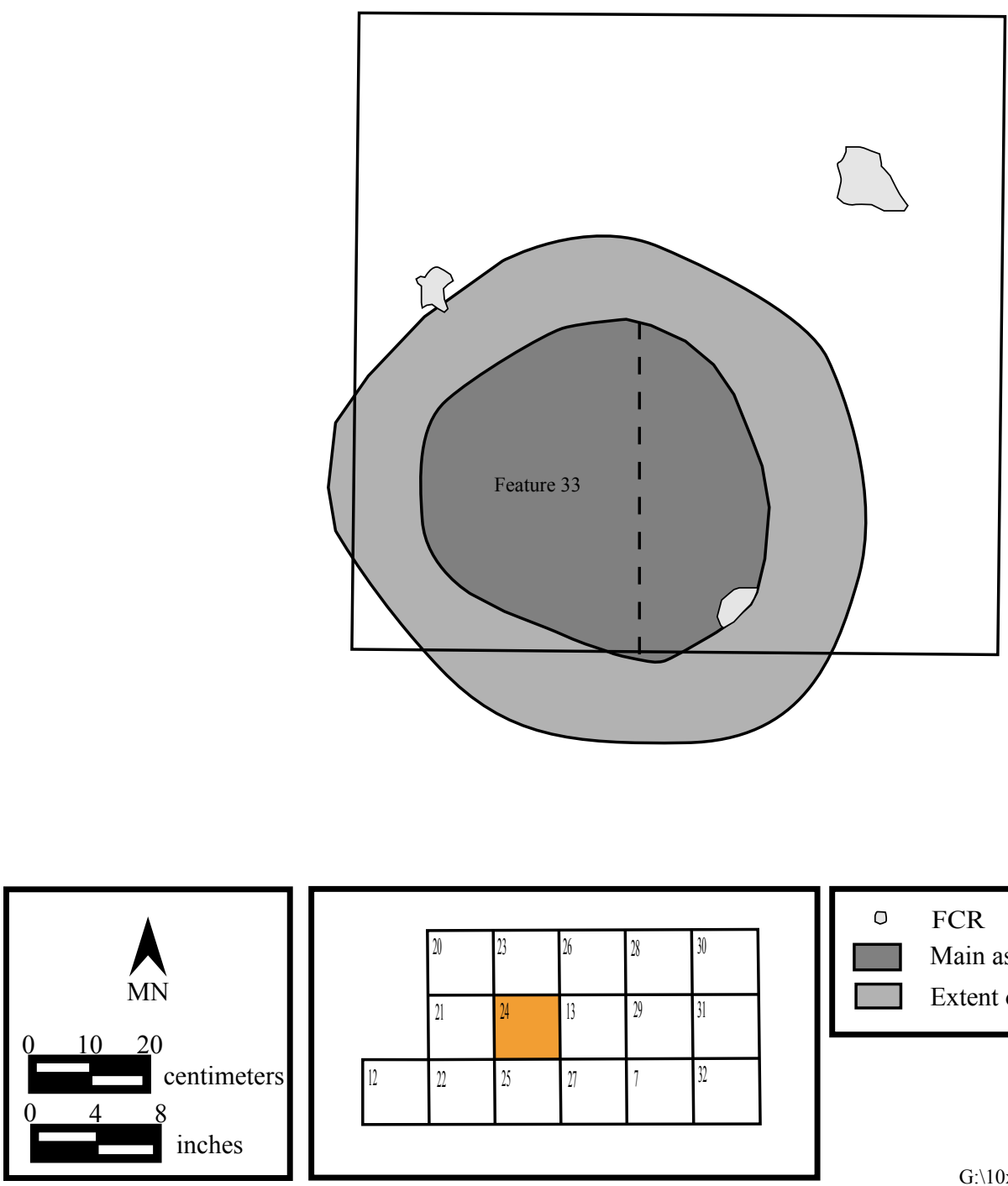

o FCR

$\square$ Main ash concentration

$\square$ Extent of ash concentration

Figure 52. Feature 33 profile and plan view. 
Feature 35 is a small hemispherical-shaped pit with ashy fill, containing chunks of wood charcoal and burned clay. It has a round shape in plan view and a distinctive rounded bottom (Figure 53).

Feature 15 was first noticed in the north portion of Unit 7 and was later fully exposed in Unit 29. Feature 15 consists of a semi-circular basin-shaped pit with a stratified pattern of oxidization transitioning from lighter to darker from top to bottom (Figure 54). Feature 15 was capped by an undulating, concreted two cm-thick lens of ash and charcoal. A complete Yarbrough dart point was recovered from the feature fill near the bottom of the pit.

Feature 15 yielded a total of 35 bones with only one identifiable to a species, white-tailed deer (carpal). Of the five long bone fragments, four are spirally fractured. Also recovered were two vertebrae fragments of a large mammal, one cancellous bone fragment, and 20 unidentifiable mammal fragments.

Feature 16 is a shallow, ash-bearing pit located just below and southwest of Feature 15 (Figures 55 and 56). Feature 16 is roughly circular in plan view and around $37 \mathrm{~cm}$ in diameter. It had a shallow, basin-shaped appearance in profile. Feature 16 was not visibly oxidized. The faunal remains from this feature include two mandible fragments of a small mammal and two rib fragments that are calcined, cut in half, and refit together as one.

\section{A.D. 250 - 350 Occupation Zone (Levels 16-19)}

The artifact and feature content of this zone varies radically from the zone located just above it. Three features are present within these levels (Table 20). The first indication of this occupational zone was in Level 16, which was marked by a generally rich, waxy matrix marked by high frequencies of Odocoileus virginianus bone. Many of the long bones are fractured, possibly the result of marrow rendering activity. The base of Level 16 was marked by discontinuous scatters of mussel shell, burned clay, charcoal, fire-cracked rock, and animal bone. A small amount of lithic debitage was also present within this stratum; three flakes were of the same material type (Tables 21-23). 


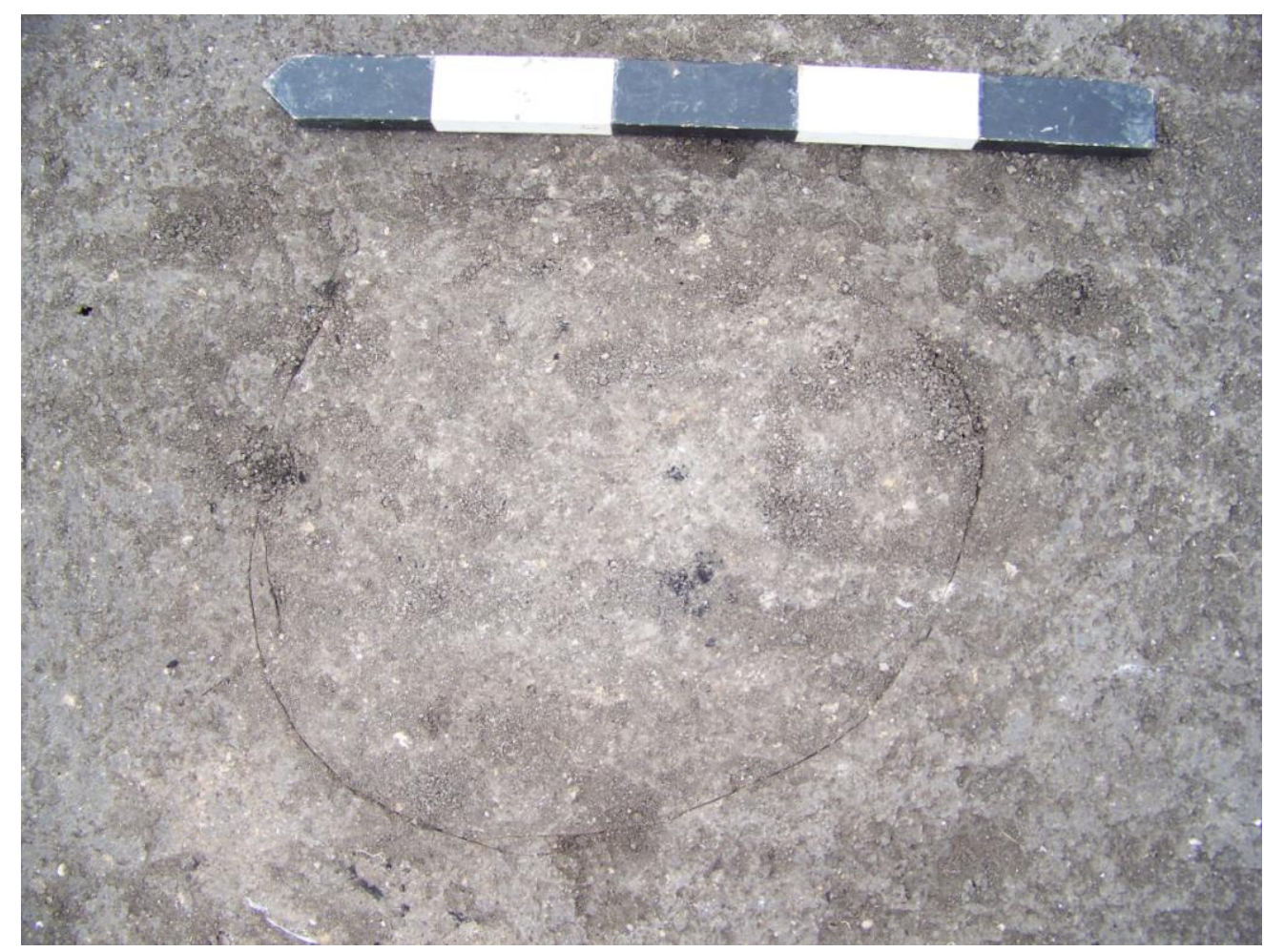

a

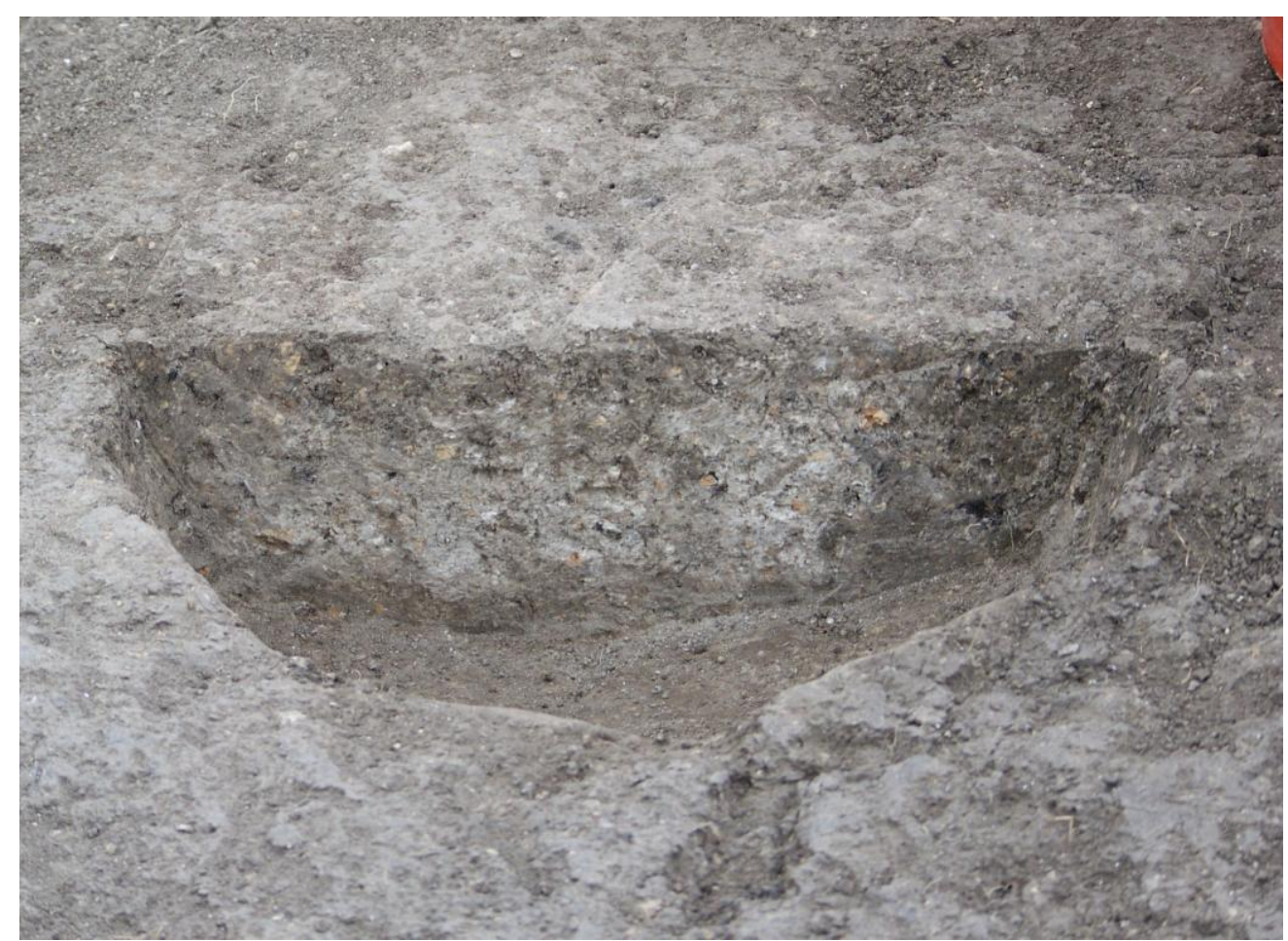

b

Figure 53. Feature 35, Block 3: (a) plan view; and (b) profile. 


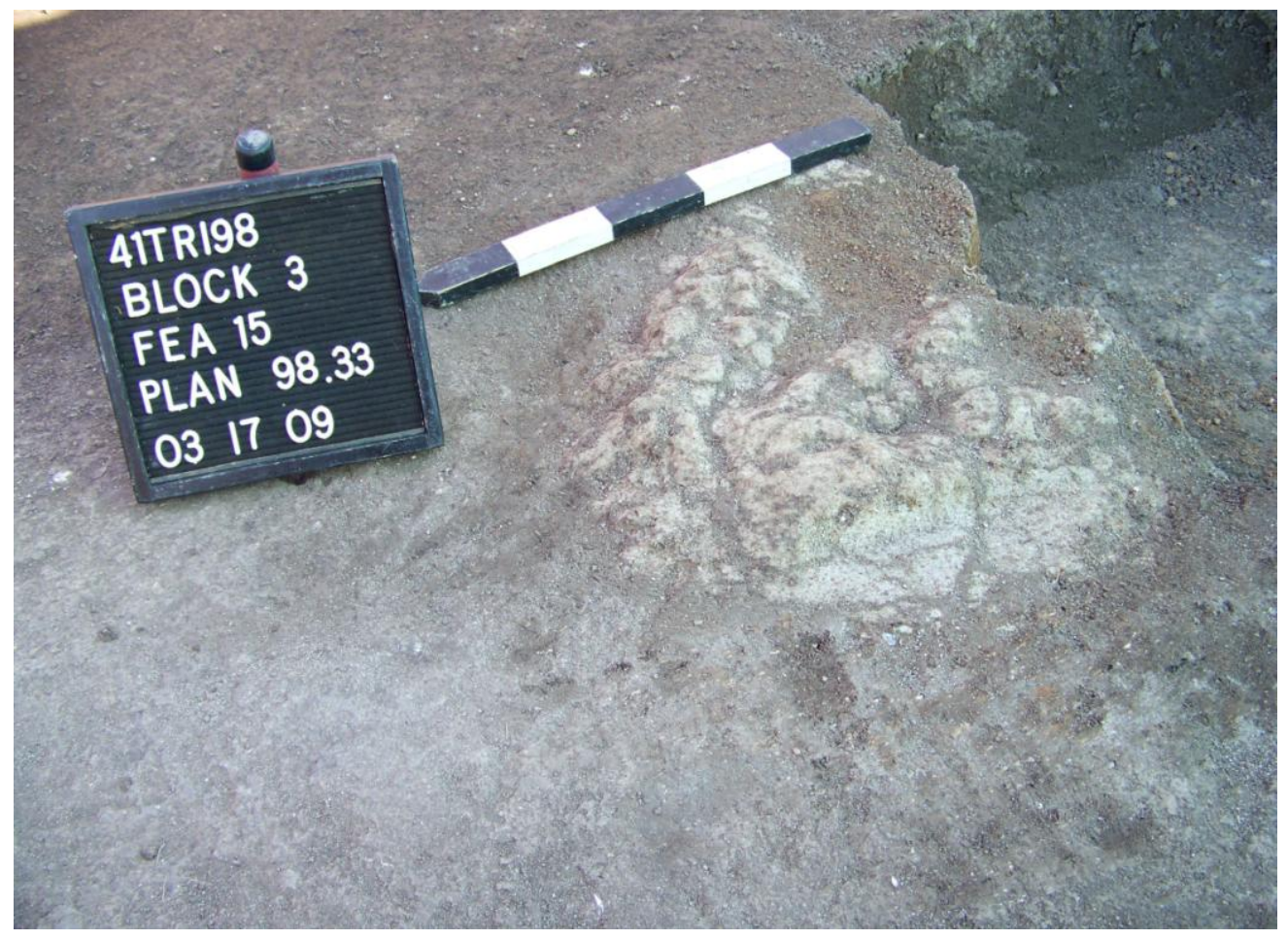

a

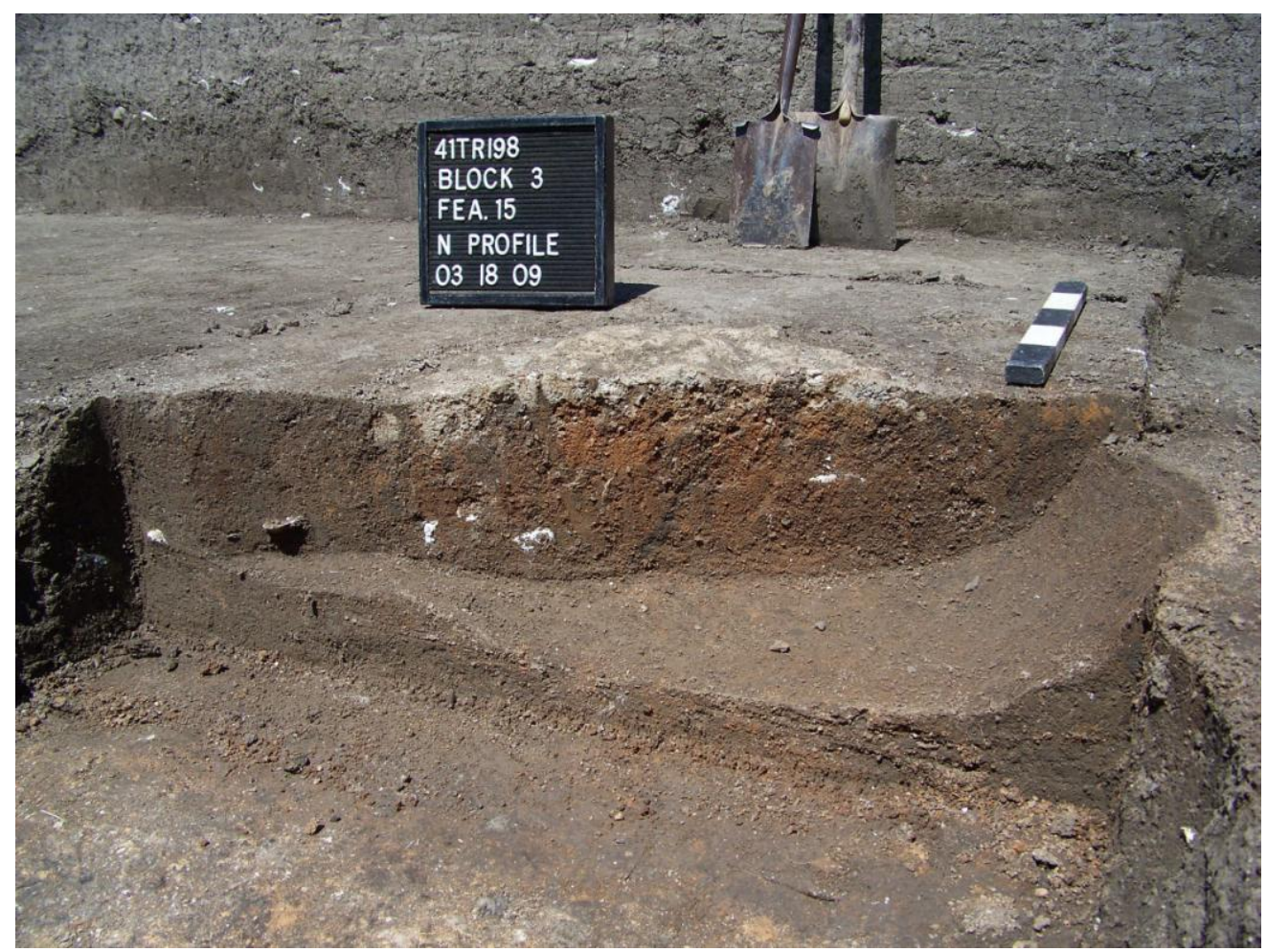

b

Figure 54. Feature 15, Block 3: (a) plan view; and (b) profile. 


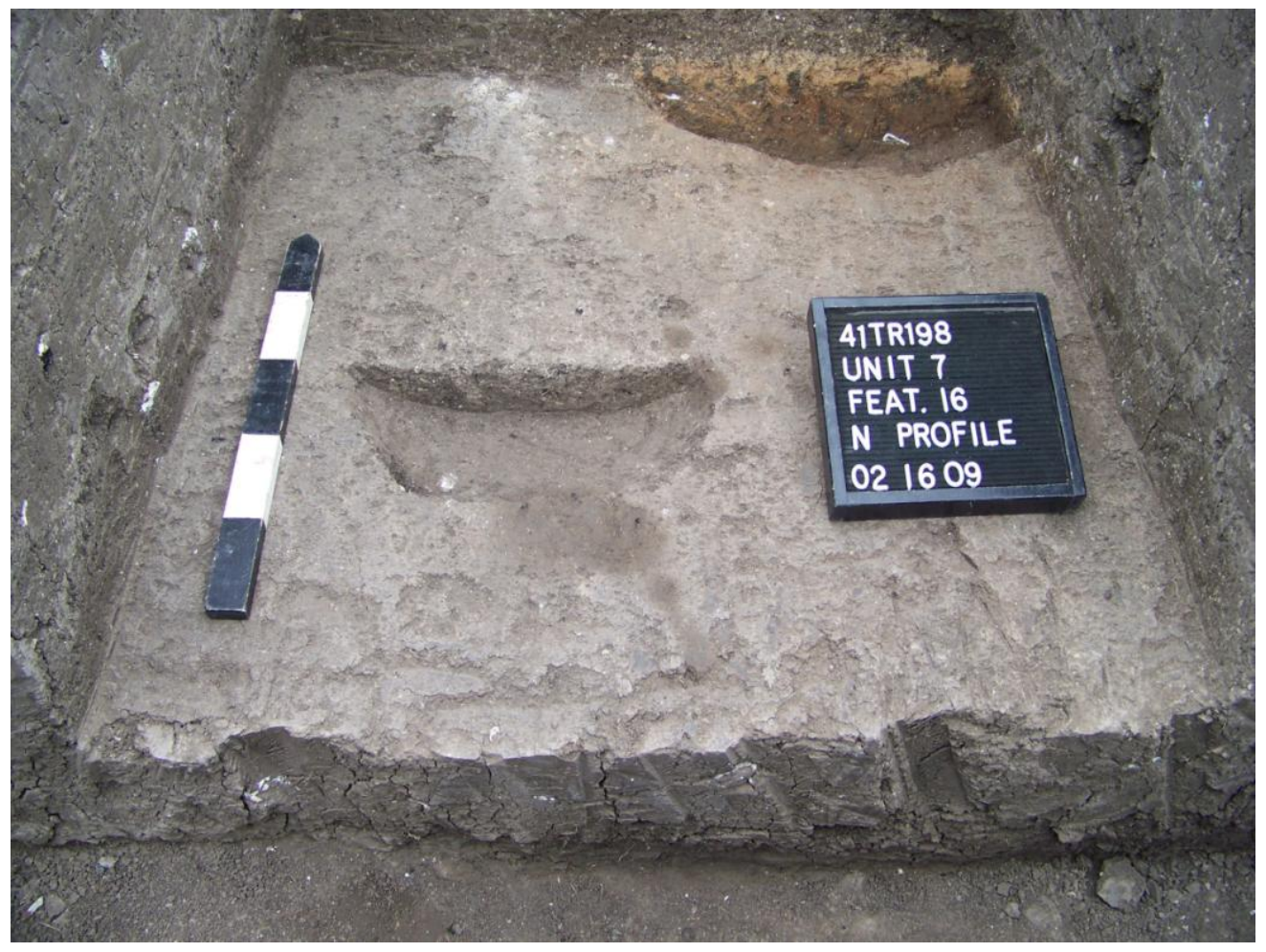

Figure 55. Feature 16, Block 3.

Three pit features of various forms were exposed in plan view between elevation 98.09 and $98.05 \mathrm{~cm}$ in Units 7,13 , and 23. There were also two oxidized surfaces at this level, one in Units 20 and 23 and the second in Unit 30.

Feature 18 was identified in Unit 7. It is circular in plan view with a hemispherical shape in profile. Its dark feature fill stood out extremely well from its surrounding matrix. Its depth was $5 \mathrm{~cm}$ (Figure 57). Given the notably shallow form and the dark charcoal-rich fill of this feature, it is interpreted as a possible smudge pit used to produce smoke. Smudge pits have been found in numerous prehistoric contexts although none have been specifically documented within the Late Archaic period of northcentral Texas. The only faunal remains from this feature was a pelvis fragment of an unidentified rodent. 


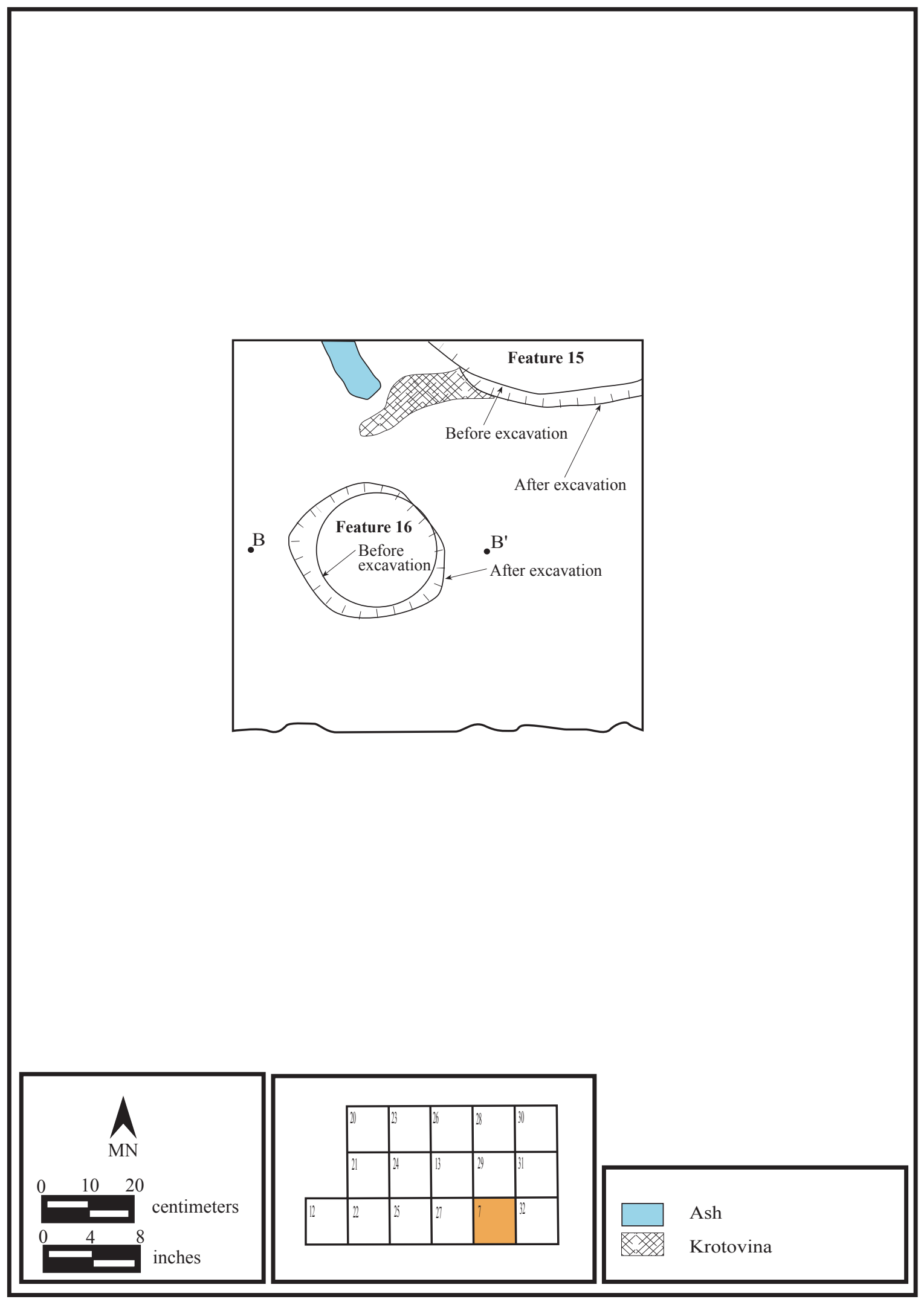

Figure 56. Plan view of Feature 16, Block 3. 
Table 20

A.D. 250 - 350 Occupation Zone Features

\begin{tabular}{|c|c|c|c|c|c|c|c|}
\hline$\#$ & $\begin{array}{l}\text { Feature } \\
\text { Interpretation }\end{array}$ & Unit & Depth & $\mathrm{L} \times \mathrm{W} \times \mathrm{T}$ & $\%$ exc. & Feature Fill & Shape \\
\hline 38 & Pit & 23 & $98.09-97.96 \mathrm{~cm}$ & $\begin{array}{l}73 \times>43 \times 13 \\
\mathrm{~cm}\end{array}$ & $60 \%$ & $\begin{array}{l}\text { 10YR } 3 / 2 \text { clay } \\
\text { loam }\end{array}$ & hemispherical \\
\hline 41 & Pit & 13 & $98.05-97.95 \mathrm{~cm}$ & $\begin{array}{l}29 \times 29 \times 15 \\
\mathrm{~cm}\end{array}$ & $100 \%$ & $\begin{array}{l}\text { 10YR } 3 / 1--3 / 2 \\
\text { clay loam }\end{array}$ & Cylindrical \\
\hline 18 & Smudge Pit & 7 & $98.10-98.05 \mathrm{~cm}$ & $39 \times 38 \times 5 \mathrm{~cm}$ & $100 \%$ & 10YR 3/1 clay & Hemispherical \\
\hline
\end{tabular}

Table 21

Block 3 Level 16 [98.20-98.15] Artifacts

\begin{tabular}{lllllllllllllll} 
Unit/Artifact & 20 & 21 & 22 & 23 & 24 & 25 & 26 & 13 & 27 & 28 & 29 & 30 & 31 & 32 \\
\hline FCR & 0 & 2 & 2 & 14 & 22 & 5 & 3 & 0 & 0 & 12 & 2 & 4 & 0 & 1 \\
Mussel shell & 5 & 25 & 84 & 9 & 29 & 65 & 17 & 16 & 27 & 27 & 109 & 8 & 32 & 19 \\
Animal bone & 67 & 54 & 72 & 48 & 133 & 72 & 46 & 45 & 109 & 146 & 53 & 24 & 14 & 2 \\
Ground stone & 0 & 0 & 0 & 0 & 0 & 0 & 0 & 0 & 0 & 0 & 0 & 0 & 0 & 0 \\
Debitage & 0 & 6 & 1 & 6 & 0 & 1 & 0 & 0 & 0 & 0 & 0 & 1 & 0 & 0 \\
F.S. tool & 0 & 0 & 0 & 0 & 0 & 0 & 0 & 0 & 0 & 0 & 0 & 0 & 0 & 0 \\
Projectile point & 0 & 0 & 0 & 0 & 0 & 0 & 0 & 0 & 0 & 0 & 0 & 0 & 0 & 0 \\
Bone tool & 0 & 0 & 0 & 0 & 0 & 0 & 0 & 0 & 0 & 0 & 0 & 0 & 0 & 0 \\
\hline
\end{tabular}

Table 22

Block 3 Level 17 [98.15-98.10] Artifacts

\begin{tabular}{llllllllllllllllll} 
Unit/Artifact & 20 & 21 & 22 & 23 & 24 & 25 & 26 & 13 & 27 & 28 & 29 & 30 & 31 & 32 & F18 & F38 & F41 \\
\hline FCR & 8 & 6 & 2 & 35 & 1 & 1 & 19 & 3 & 14 & 3 & 1 & 6 & 1 & 1 & F & 14 & 0 \\
Mussel shell & 15 & 50 & 49 & 52 & 57 & 31 & 127 & 73 & 43 & 125 & 61 & 28 & 18 & 0 & $\mathrm{~F}$ & 8 & 2 \\
Animal bone & 128 & 87 & 28 & 20 & 1 & 10 & 129 & 9 & 3 & 9 & 0 & 7 & 2 & 7 & $\mathrm{~F}$ & 1 & 9 \\
Ground stone & 0 & 0 & 0 & 0 & 1 & 0 & 0 & 0 & 0 & 0 & 0 & 0 & 0 & 0 & $\mathrm{~F}$ & 0 & 0 \\
Debitage & 0 & 0 & 0 & 0 & 0 & 0 & 0 & 0 & 0 & 0 & 0 & 0 & 0 & 0 & $\mathrm{~F}$ & 1 & 0 \\
F.S. tool & 0 & 0 & 0 & 0 & 0 & 0 & 0 & 0 & 0 & 0 & 0 & 0 & 0 & 0 & $\mathrm{~F}$ & 0 & 0 \\
Projectile point & 0 & 0 & 0 & 0 & 0 & 0 & 0 & 0 & 0 & 0 & 0 & 0 & 0 & 0 & $\mathrm{~F}$ & 0 & 0 \\
Bone tool & 0 & 0 & 0 & 0 & 0 & 0 & 0 & 0 & 0 & 0 & 0 & 0 & 0 & 0 & $\mathrm{~F}$ & 0 & 0 \\
\hline
\end{tabular}

${ }^{1}=$ Does not include material from flotation 
Table 23

Block 3 Level 18 [98.10-98.05] Artifacts

\begin{tabular}{lllllllllllllll} 
Unit/Artifact & 20 & 21 & 22 & 23 & 24 & 25 & 26 & 13 & 27 & 28 & 29 & 30 & 31 & 32 \\
\hline FCR & 27 & 24 & 0 & 7 & 2 & 1 & - & 0 & 0 & 0 & 1 & 3 & 0 & 5 \\
Mussel shell & 50 & 59 & 18 & 22 & 69 & 0 & - & 0 & 0 & 1 & 3 & 5 & 5 & 6 \\
Animal bone & 32 & 50 & 13 & 3 & 6 & 5 & - & 13 & 10 & 11 & 8 & 12 & 2 & 3 \\
Ground stone & 0 & 0 & 0 & 0 & 0 & 1 & - & 0 & 0 & 0 & 0 & 0 & 0 & 0 \\
Debitage & 0 & 0 & 0 & 0 & 0 & 0 & - & 0 & 0 & 0 & 0 & 1 & 0 & 0 \\
F.S. tool & 0 & 0 & 0 & 0 & 0 & 0 & - & 0 & 0 & 0 & 0 & 0 & 0 & 0 \\
Projectile point & 0 & 0 & 0 & 0 & 0 & 0 & - & 0 & 0 & 0 & 0 & 0 & 0 & 0 \\
Bone tool & 0 & 0 & 0 & 0 & 0 & 0 & - & 0 & 0 & 0 & 0 & 0 & 0 & 0 \\
\hline
\end{tabular}

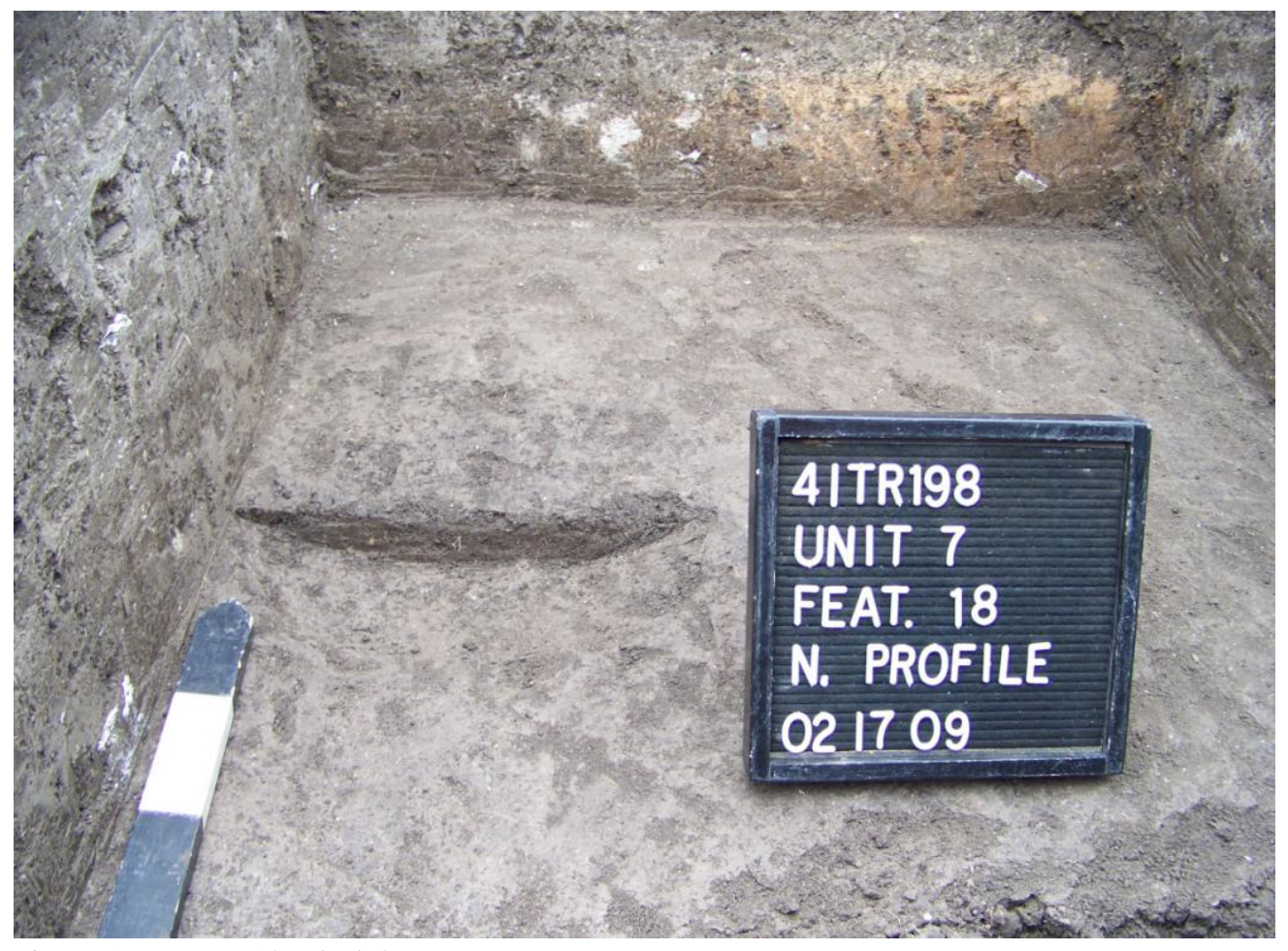

Figure 57. Feature 18, Block 3.

Feature 38 is a circular pit with a hemispherical profile (Figure 58). It is a relatively small feature with a diameter of $38 \mathrm{~cm}$ and a depth of less than five $\mathrm{cm}$. It contained a general mixture of hearth-related refuse including charcoal, mussel shell, fire-cracked rock, and burned clay. Feature 38 was associated with an oxidized surface, soil stain and cluster of both mussel shell and animal bone. The faunal remains from the feature itself included two incisors of an undetermined rodent. 


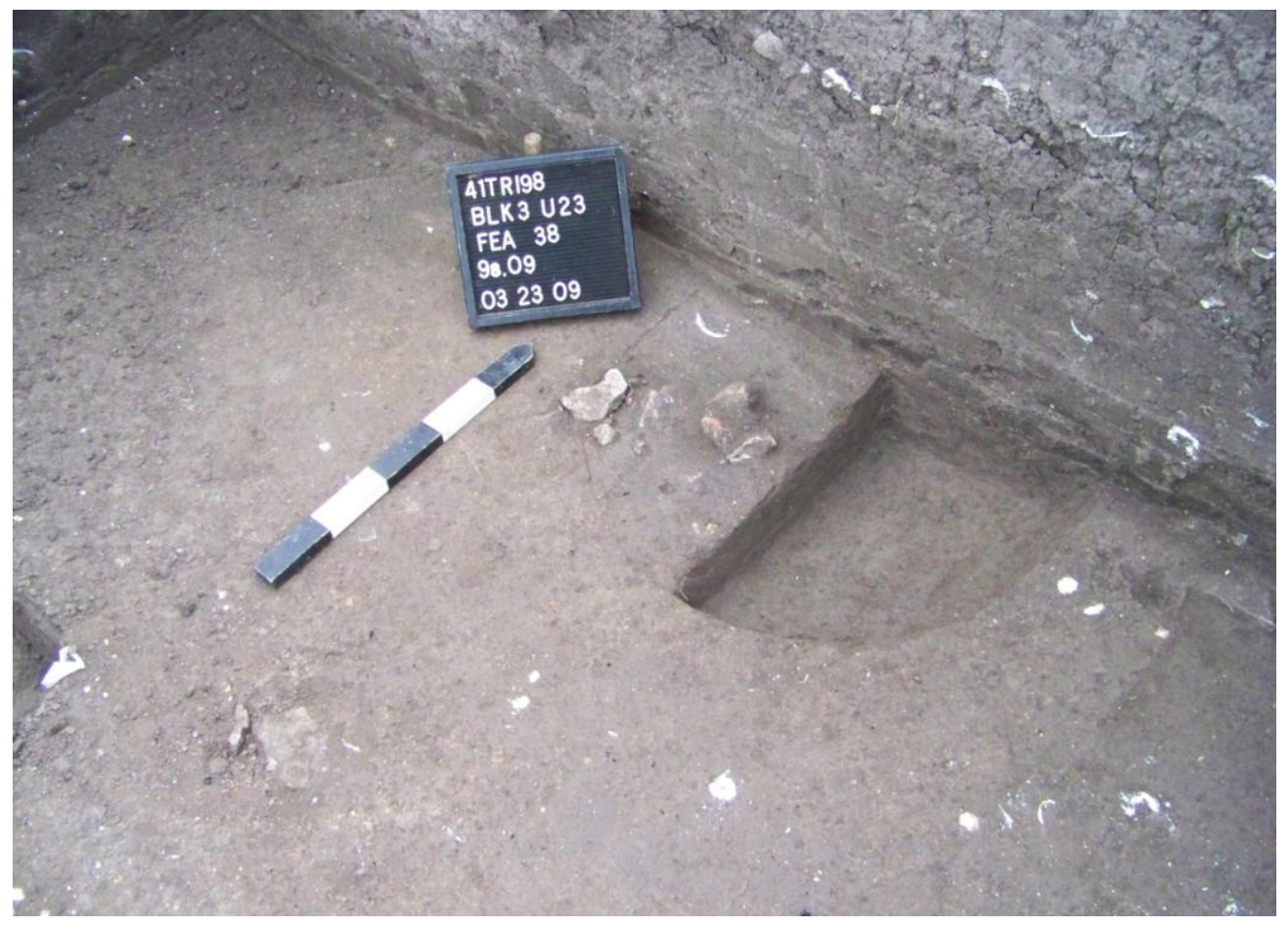

Figure 58. Feature 38, Block 3.

Feature 41 is a small cylindrical pit located near the center of Block 3 in Unit 13 (Figure 59). Its fill varied from that of Feature 38 in that it contained a higher proportion of ash and charcoal although it also contained a small amount of bone and mussel shell. Wood charcoal from this feature yielded a radiocarbon date of $1750 \mathrm{bp} \pm 40$ years (calibrated intercept of A.D. 260, 300, and 310). The faunal remains from this feature include two fragments of a large mammal (a spirally fractured ulna and one epicondyle fragment), an innominate fragment of a small mammal, and six unidentified mammal fragments.

410 B.C. - A.D. 250 Occupation Zone (Levels $20-36$ )

Deep exploratory testing at the base of Block 3 revealed that the cultural presence at the site extended much deeper than had been previously identified, separated by long expanses of sterile West Fork paleosol. Deep testing in Unit 21 intersected two separate cultural strata over one and a half meters below the base of Block 3, Level 18. One radiocarbon date was obtained, in order to assign a temporal context to this zone. A well preserved deer astragalus from elevation $96.60 \mathrm{~cm}$ in Unit 21 yielded a date of 2,400 \pm 40 years B.P. (Cal B.C. 410 [Cal B.P. 2,360]). 


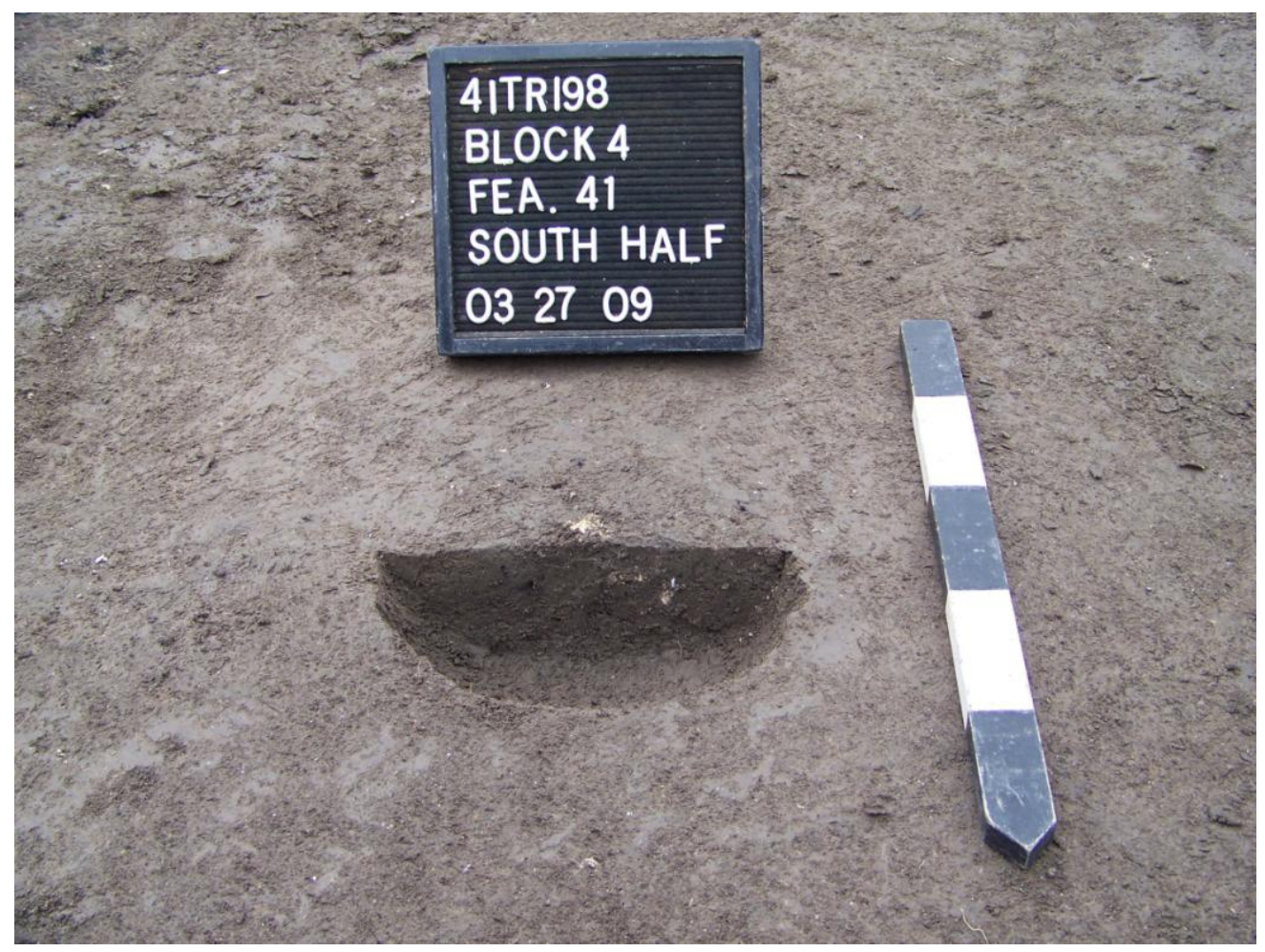

Figure 59. Feature 41, Block 3.

The first cultural signature corresponds to a noticeable paleosol where the soil again transitions to dark yellowish brown in color and where a notable increase in calcium carbonate nodules occurs. This feature occurs in the northwest corner of Unit 21 at an elevation of $97.52 \mathrm{~cm}$. This first cultural signature consists of an isolated lens of rabdotus shell, animal bone, and a few mussel shells and small fragments of burned clay. No manufactured artifacts, such as flaked or ground stone, were recovered although only a small sample of this area was investigated.

A second more consistent area of cultural material was noted in Units 20 and 21 approximately one $\mathrm{m}$ deeper than the first. In order to formulate a second point of observation of these deeper strata, a linear backhoe excavation designated as Trench 11 was placed north/south through the center of Block 3, Units 13, 26, and 27. The cutting of Trench 11 revealed Feature 43 which consists of a shallow basin-shaped pit feature $62 \mathrm{~cm}$ in length. Little can be said about this feature as it was only noted in profile, but it does correspond with a 10 to $15 \mathrm{~cm}$ thick cultural stratum containing burned clay, charcoal and scattered mussel shell occurring between 97.83 and $97.68 \mathrm{~cm}$. Feature 43 consists of a $4 \mathrm{~cm}$ thick, basin-shaped lens of ash that is flat on the bottom, 
curving up slightly on either side. This ash lens appears to reflect the bottom of a broad shallow pit.

Both Units 20 and 21 and Trench 11 indicate a fairly robust series of highly eroded occupational lenses occurring between 96.81 and $96.56 \mathrm{~cm}$, over $3 \mathrm{~m}$ below the ground surface. It is interesting to note that the rate of aggradation between this lower occupation surface $(96.60 \mathrm{~cm})$ and the next dated level within the stratigraphic sequence $(98.05 \mathrm{~cm})$ is quite rapid at $22 \mathrm{~cm}$ per century while the rate of aggradation above $98.05 \mathrm{~cm}$ is only $8 \mathrm{~cm}$ per century.

The deepest identified cultural lenses at the site are characterized by diffuse distributions of burned clay, bone, charcoal, animal bone and mussel shell (Tables 24 and 25). In comparison to the excellent preservation present in the first 18 levels of Block 3, the lower strata are greatly deteriorated, the artifacts small and horizontally diffused. The level of feature and living surface preservation here is uncharacteristic of that seen in the later occupation zones. Artifacts include animal bone, burned clay, charcoal, mussel shell, fire-cracked rock, and one piece of flaked stone debitage.

Table 24

410 B.C. Occupation Zone Artifact Counts from 1-x- m Unit 21, Depth Range 96.78-96.50 cm

Artifact Type

FCR

Mussel shell

Burned Clay

Animal bone

Charcoal

Debitage
Count 52

28

220

92

36 
Table 25

410 B.c. Occupation Zone Artifact Weights (grams) from 1-x- m Unit 21, Depth Range 96.78-96.50 cm

\begin{tabular}{lc} 
Artifact Type & Weight $(\mathrm{g})$ \\
\hline FCR & 688 \\
Mussel shell & 258 \\
Burned Clay & 74 \\
Animal bone & 79 \\
Charcoal & 1 \\
Debitage & 2 \\
\hline
\end{tabular}

\section{Block 4 Features}

Of note in Block 4 is that the temporal period for the dense accumulation in that area of the site predates much of the more dense occupation in Block 3. The seven features in Block 4 fall within an approximate time frame of 500 years (A.D. 100 to 600).

Feature 21 is the uppermost feature encountered in Block 4 (Table 26). Feature 21 is located in units 14 and 17, but primarily in Unit 17. Feature 21 is an irregular scatter of fire-cracked rock that likely represents clean-out debris from a thermal feature (Figure 60). Excavators indicate that the scatter articulates with Feature 25 in the northeast corner of Unit 14; however, the vertical provenience of the two features does not support such an interpretation.

Feature 21 has a total of 34 bones; none are identifiable to species (Table 27). There is an auditory bullae of a large mammal that compares favorably to deer, 15 bird bones (three are long bones, one of them has cut marks, another is spirally fractured), 10 carapace fragments of an undetermined pond turtle, 7 mammal bones (two skull fragments of a large mammal, and five fragments not identifiable to an element). In addition there is one gar scale.

Features 25, 37, 39, and 40 all appear at the same stratigraphic level within the Block 4 excavations. Feature 25 is an oval shaped, basin-shaped hearth feature (Figure 61) located near the center of Block 4. Wood charcoal was common within and below the feature; it also contained chunks of burned clay and charred bulbs. Feature 25 is unique among the features, for it was the only feature to yield onion or camas bulbs. A bulb was also found in a non-feature 
Table 26

Occupation Zone features from Block 4

\begin{tabular}{|c|c|c|c|c|c|c|}
\hline \# & $\begin{array}{l}\text { Feature } \\
\text { interpretation }\end{array}$ & Unit & Depth & $\mathrm{L} \times \mathrm{W} \times \mathrm{T}$ & Feature Fill & Shape \\
\hline 21 & FCR discard pile & 14,17 & $99.16-99.04 \mathrm{~cm}$ & $116 \times 88 \times 8 \mathrm{~cm}$ & $\begin{array}{l}\text { FCR/10YR } 3 / 2 \\
\text { silty clay }\end{array}$ & $\begin{array}{l}\text { Irregular } \\
\text { scatter }\end{array}$ \\
\hline 25 & Hearth feature & $\begin{array}{l}14,15 \\
16,17\end{array}$ & $98.98-98.86 \mathrm{~cm}$ & $110 \times 65 \times 12 \mathrm{~cm}$ & $\begin{array}{l}\mathrm{FCR} / 10 \mathrm{YR} 3 / 2 \\
\text { silty clay loam }\end{array}$ & Basin \\
\hline 37 & $\begin{array}{l}\text { FCR } \\
\text { concentration }\end{array}$ & 18,19 & $98.98-98.83 \mathrm{~cm}$ & $43 \times 41 \times 14 \mathrm{~cm}$ & $\begin{array}{l}\mathrm{FCR} / 10 \mathrm{YR} 3 / 2- \\
3 / 3 \text { clay loam }\end{array}$ & Semi-circular \\
\hline 39 & $\begin{array}{l}\text { Possible smudge } \\
\text { pit }\end{array}$ & & $98.80-98.75$ & $\begin{array}{l}45 \mathrm{~cm} \text { in diameter } \\
\text { x } 5 \mathrm{~cm}\end{array}$ & $\begin{array}{l}\text { 10YR } 4 / 2 \text { to } \\
10 \mathrm{YR} 2 / 1\end{array}$ & Basin \\
\hline 40 & Discarded FCR & 19 & 98.93-98.8 & $40 \times 30 \times 13$ & 10YR 3/2 loam & Irregular \\
\hline 44 & Pit & 37 & $98.94-98.79 \mathrm{~cm}$ & $49 x>42 \times 15$ & 10YR 3/2 loam & Basin \\
\hline 45 & Formal hearth & 37 & $98.94-98.79 \mathrm{~cm}$ & ind. & $\begin{array}{l}10 \text { YR } 3 / 3 \text { clay } \\
\text { loam, } 10 \text { YR } 5 / 8 \\
\text { clay loam }\end{array}$ & indeterminate \\
\hline
\end{tabular}

context of Unit 30, Level 18 in Block 3 that dates between A.D. 300 and A.D. 350. The firecracked rocks at the core of this feature appear to have lined a shallow, basin-shaped pit. In the center of the feature the fire-cracked rock was stacked two to three courses high in places.

There are 34 bones and fragments from this feature (Table 28). The distal end of a second phalanx and two carpal bones were identified as white-tailed deer. Turtles are represented by the ornate box turtle and the red-eared slider. There is one long bone fragment of an undetermined bird. Of the 21 mammal fragments, 16 are not identifiable to an element, including one unfused epiphyseal end of a long bone that is so severely gnawed that it cannot be determined end is represented. There are also five long bone fragments; three are from a large mammal (one is burned (carbonized), another is calcined, and another has cut marks).

Features 37 and 40 appear in close spatial association in Units 18 and 19 (Figure 62). Feature 37 exhibits only a single course of fire-cracked rock while Feature 40 has three to four courses. These two features are likely associated with a particular cooking activity conducted in this area. 


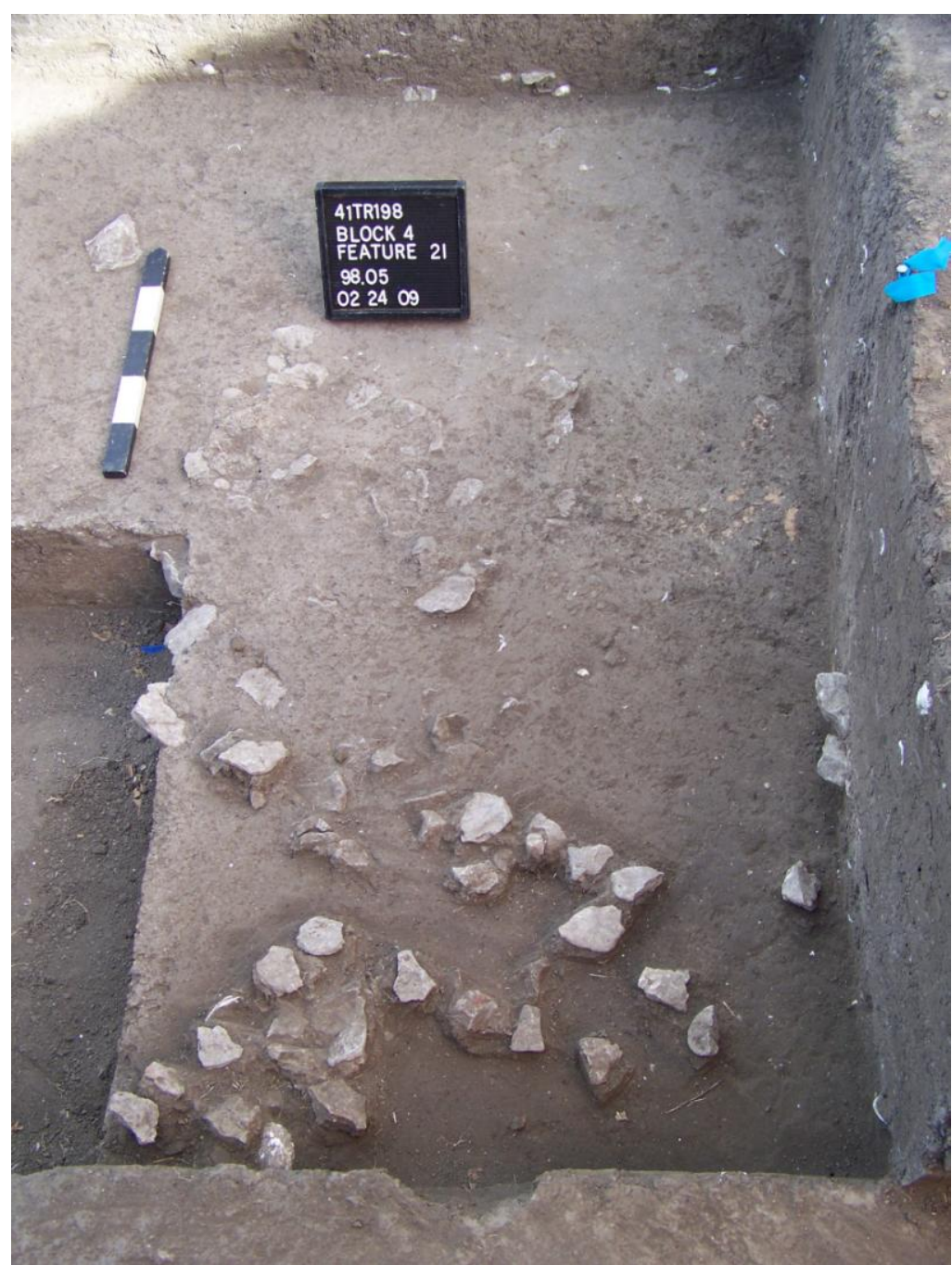

Figure 60. Feature 21, Block 4.

Table 27

Feature 21 Bones and Fragments

\begin{tabular}{lc}
\hline Deer & 1 \\
Unid bird & 15 \\
Unid Gar & 1 \\
Unid Mammal & 7 \\
Unid Pond turtle & 10 \\
\multicolumn{1}{r}{ Total } & 34 \\
\cline { 2 - 2 }
\end{tabular}




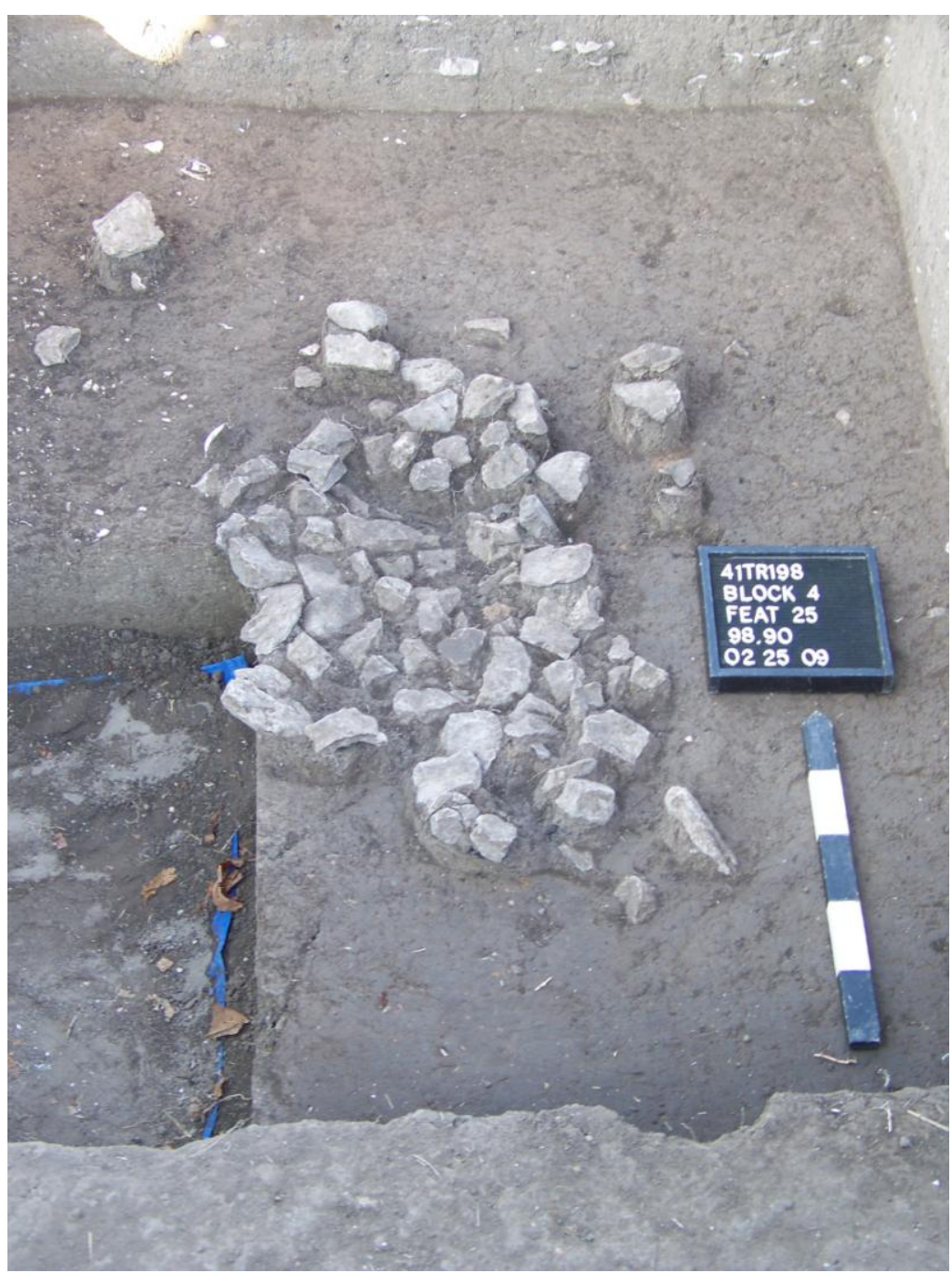

Figure 61. Feature 25, Block 4.

Table 28

Feature 25 Bones and Fragments

\begin{tabular}{lr}
\hline Ornate box turtle & 3 \\
Red-eared slider & 5 \\
UNID bird & 1 \\
UNID Mammal & 21 \\
UNID Turtle & 1 \\
White-tailed deer & \multicolumn{2}{c}{3} \\
\hline Total & \multicolumn{2}{c}{34} \\
\hline
\end{tabular}




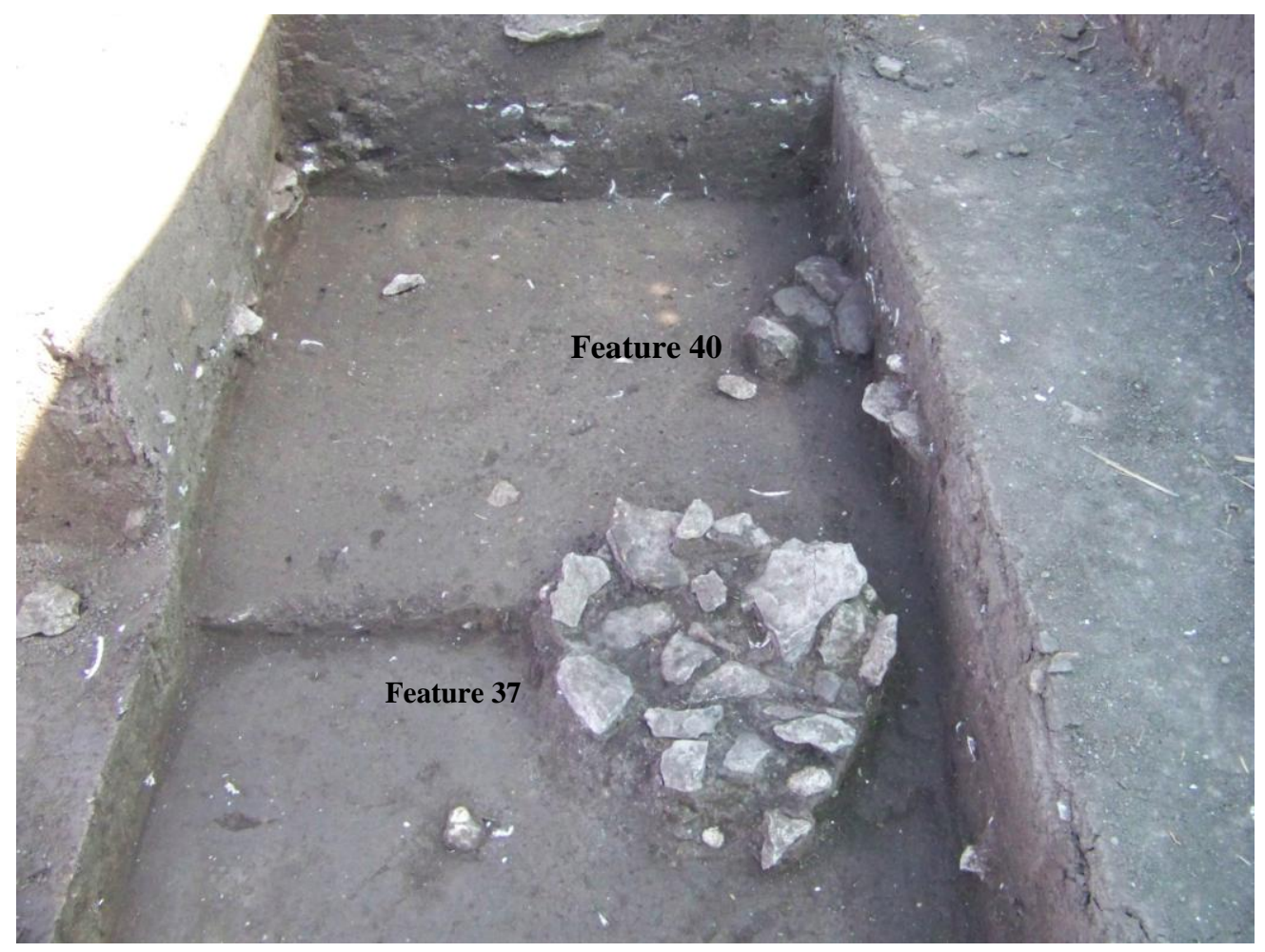

Figure 62. Features 37 and 40, Block 4.

Feature 39 is distinctive for it is $45 \mathrm{~cm}$ in diameter and only $5 \mathrm{~cm}$ deep (Figure 63). Its charcoalrich fill ranges in color from dark grayish brown (10YR 4/2) to black (10YR 2/1). A few small pieces of fire-cracked rock are present. Like Feature 18 in Block 3, Feature 39 may represent a smudge pit. Only two bones were recovered from Feature 39; the long bone fragment of a small mammal and the long bone fragment of a bird. Neither is burned or has cut marks.

Features 44 and 45 were encountered in Unit 37 (Figure 64). Feature 45 was only partially exposed in the northeast corner of the excavation unit. It is a basin-shaped hearth with a significant amount of oxidized clay. Feature 44 may be related for it appears at relatively the same elevation and consists of a shallow, flat-bottomed basin with a primarily ashy fill. It appears that the two features were used for distinct purposes; however, there must have been a functional relationship between the two features. 


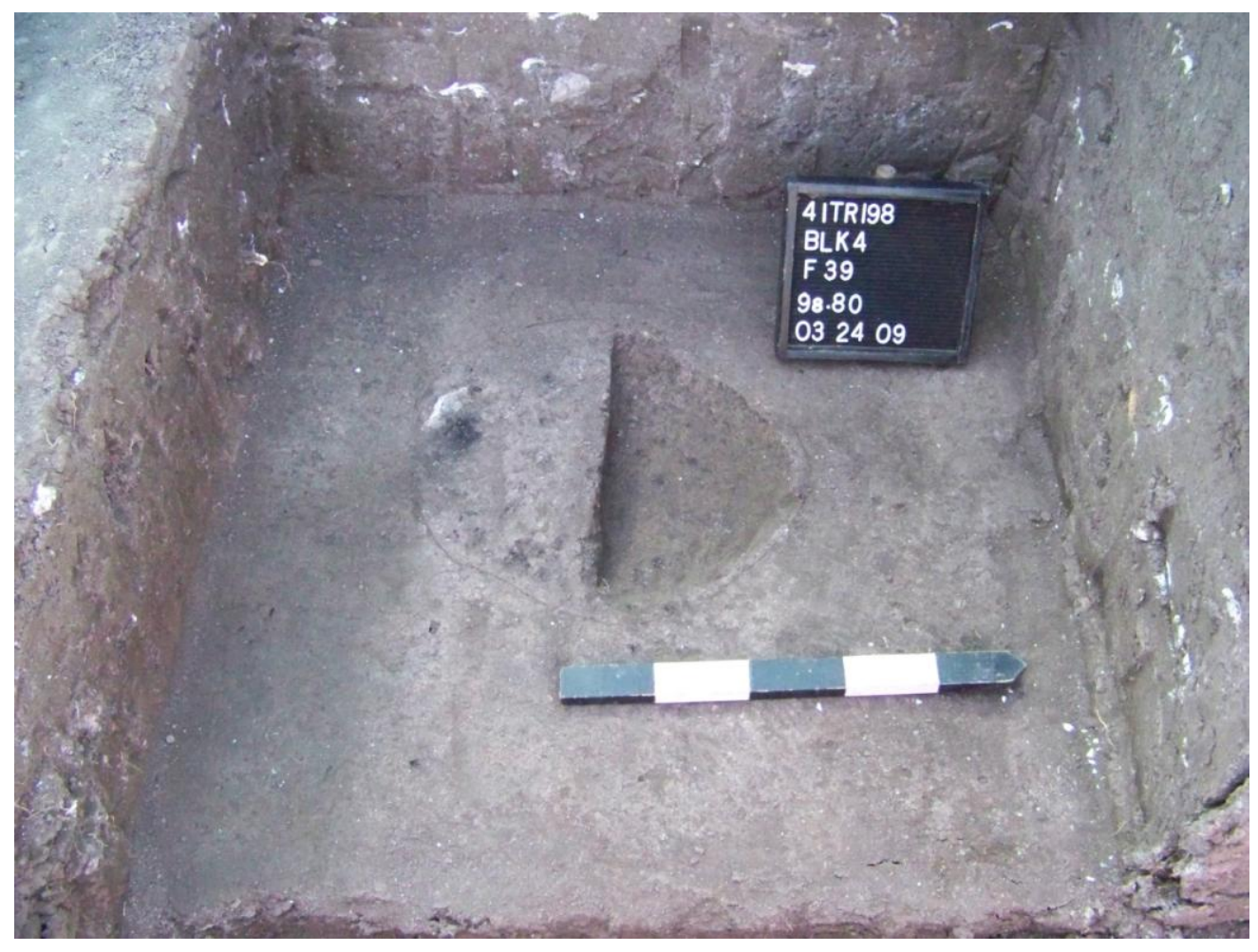

Figure 63. Feature 39, Block 4.

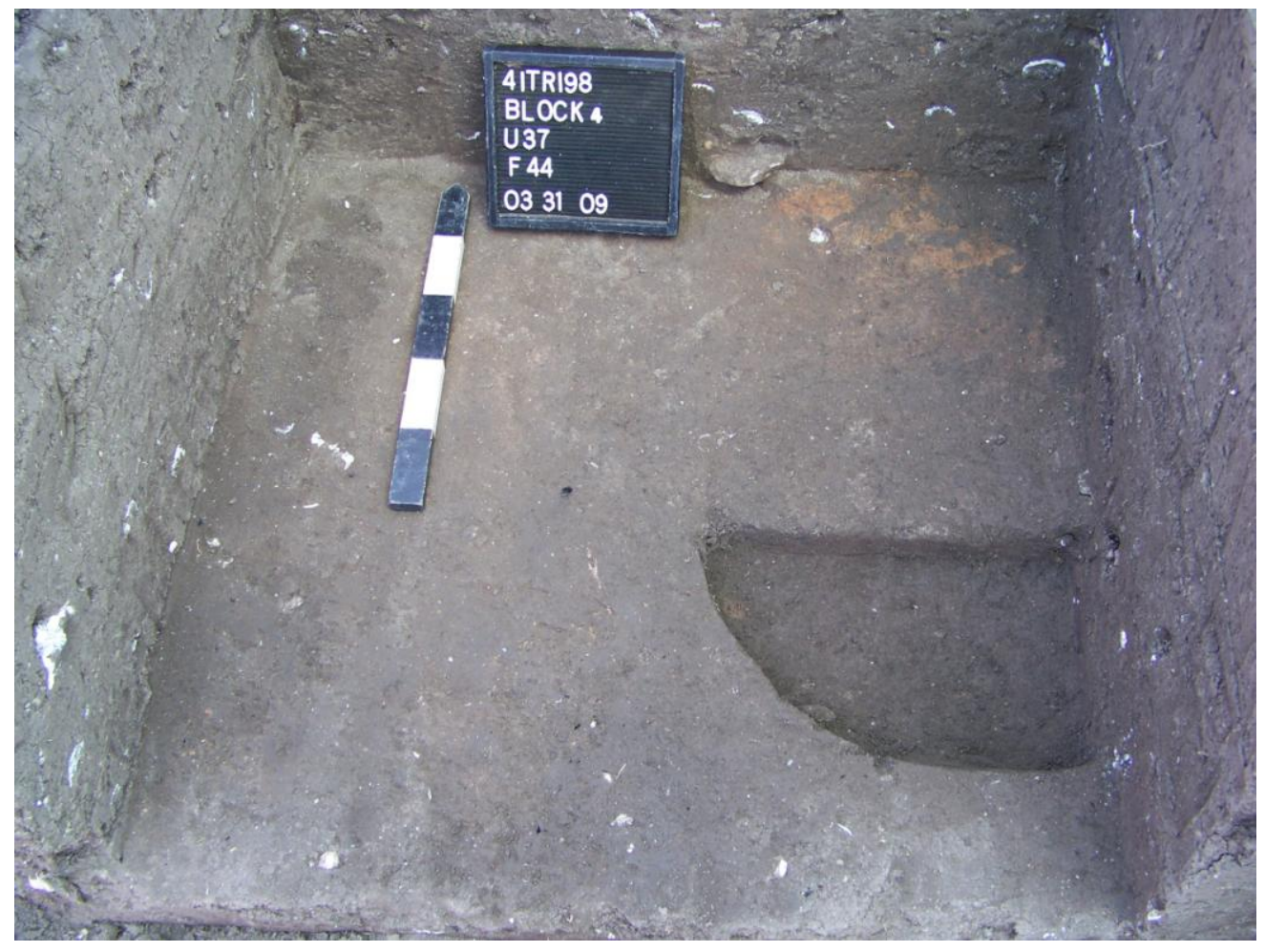

Figure 64. Feature 44, Block 4. 
Feature 44 yielded 44 faunal elements; the majority are mammal bone fragments $(70 \%$, Table 29). Most of these are from large mammals, including the proximal end of a scapula, seven spirally fractured long bones, three rib fragments, and two large spirally fractured bone fragments that cannot be identified to an element. One of these fragments is calcined and the other is carbonized. There are two illium fragments of an eastern fox squirrel, three spirally fractured long bones of an undetermined bird, one gar scale, four rodent bones, and three turtle carapace fragments.

Table 29

Feature 44 Bones and Fragments

\begin{tabular}{lr}
\hline Eastern fox squirrel & 2 \\
UNID bird & 3 \\
UNID Gar & 1 \\
UNID Mammal & 31 \\
UNID Rodent & 4 \\
UNID Turtle & 3 \\
$\quad$ Total & 44 \\
\hline
\end{tabular}

Feature 45 yielded a total of 59 bones and fragments; 64 percent represent mammals (Table 30). These include 26 calcined antler/ horn fragments, and eight long bone fragments of a large mammal. There are two bird long bones, 16 carapace and plastron fragments of a red-eared slider, the calcaneus of a cottontail rabbit, and one rodent bone fragment.

Table 30

Feature 45 Bones and Fragments

\begin{tabular}{lr}
\hline Eastern cottontail rabbit & 1 \\
Red-eared slider & 16 \\
UNID & 1 \\
UNID bird & 2 \\
UNID Mammal & 38 \\
UNID Rodent & 1 \\
$\quad$ Total & 59 \\
\cline { 2 - 2 }
\end{tabular}




\section{Peripheral Trenches}

Six cultural features were identified in the outlying peripheral trenches beyond the core area of the site. A number of others were noted in profile, recorded but not excavated. They are, however, briefly discussed in Table 12.27 and below.

\begin{tabular}{|c|c|c|c|c|c|c|}
\hline \multirow[b]{2}{*}{$\#$} & \multicolumn{6}{|c|}{$\begin{array}{c}\text { Table } 31 \\
\text { Peripheral Trench Features }\end{array}$} \\
\hline & interpretation & Unit & Depth & $\mathrm{L} \times \mathrm{W} \times \mathrm{T}$ & Feature Fill & Shape \\
\hline 2 & Earth oven & $\begin{array}{l}\text { TR 4, } \\
\text { Units 5-6 }\end{array}$ & $98.32-98.16 \mathrm{~cm}$ & ind $\mathrm{x}$ ind $\mathrm{x} 16 \mathrm{~cm}$ & $\begin{array}{l}\text { FCR/10YR 3/2 } \\
\text { silty clay }\end{array}$ & Basin \\
\hline 3 & $\begin{array}{l}\text { Fire-cracked } \\
\text { rock cluster }\end{array}$ & TR 5 & $98.65-98.55$ & $25 \times 25 \mathrm{~cm}$ & & Cluster \\
\hline 6 & $\begin{array}{l}\text { Burned clay } \\
\text { concentration }\end{array}$ & TR 5 & $99.24-99.01 \mathrm{~cm}$ & $26 \mathrm{x}$ ind $\mathrm{x} 21 \mathrm{~cm}$ & $\begin{array}{l}\text { 10YR } 6 / 6 \text { (burned) } \\
\text { clay loam }\end{array}$ & $\begin{array}{l}\text { Sub- } \\
\text { circular }\end{array}$ \\
\hline 7 & $\begin{array}{l}\text { Burned clay } \\
\text { concentration }\end{array}$ & TR 4 & $98.40-98.29 \mathrm{~cm}$ & $47 \mathrm{x}$ ind $\mathrm{x} 31 \mathrm{~cm}$ & $\begin{array}{l}7.5 Y R 6 / 6 \\
\text { (burned) clay loam }\end{array}$ & $\begin{array}{l}\text { Sub- } \\
\text { circular }\end{array}$ \\
\hline 9 & $\begin{array}{l}\text { Ash } \\
\text { concentration }\end{array}$ & TR 1 & $98.39 \mathrm{~cm}$ & $32 \times 17-x 0$ ind $\mathrm{cm}$ & $10 \mathrm{YR} 5 / 1$ & V-shaped \\
\hline 13 & Shell lens & TR 7 & $98.98-98.89 \mathrm{~cm}$ & $165 \mathrm{x}$ ind $\mathrm{x} 4 \mathrm{~cm}$ & Mussel shell & Flat \\
\hline 19 & $\begin{array}{l}\text { Charcoal and } \\
\text { fire-cracked } \\
\text { rock lens }\end{array}$ & TR 8 & $98.59 \mathrm{~cm}$ & $79 x$ ind $x-5 \mathrm{~cm}$ & $\begin{array}{l}10 Y R \quad 4 / 3 \text { ashy } \\
\text { loam }\end{array}$ & Lens \\
\hline 34 & Storage pit & TR 6 & $98.15-97.93 \mathrm{~cm}$ & $64 \mathrm{x}$ ind $\mathrm{x} 82 \mathrm{~cm}$ & $\begin{array}{l}10 \mathrm{YR} 4 / 310 \mathrm{YR} \\
4 / 4 \text { (burned) clay, } \\
10 \mathrm{YR} 8 / 1 \text { burned } \\
\text { clay/ash \& } 10 \mathrm{YR} \\
5 / 1 \text { (ashy) loam }\end{array}$ & Basin \\
\hline 46 & Pit (n.f.s) & TR 12 & $98.43-98.13 \mathrm{~cm}$ & $80 \mathrm{x}$ ind $\mathrm{x} 31 \mathrm{~cm}$ & $\begin{array}{l}\text { 10YR 4/2 loam, } \\
10 \mathrm{YR} 5 / 1 \text { (ashy) } \\
\text { loam, and 10YR } \\
6 / 6 \text { (burned) clay }\end{array}$ & Basin \\
\hline
\end{tabular}

\section{Feature 2}

Feature 2 is a fire-cracked rock feature located at the north end of Trench 4 (Figure 65). Feature 2 is comparable to several of the other excavated hot rock cooking features; however, it does appear to have been one of the largest. The fire-cracked rock appear to have been located in a shallow basin-shaped pit as evidenced by the lower "sunken" center portion of the feature relative to the higher or elevated outer stones. 


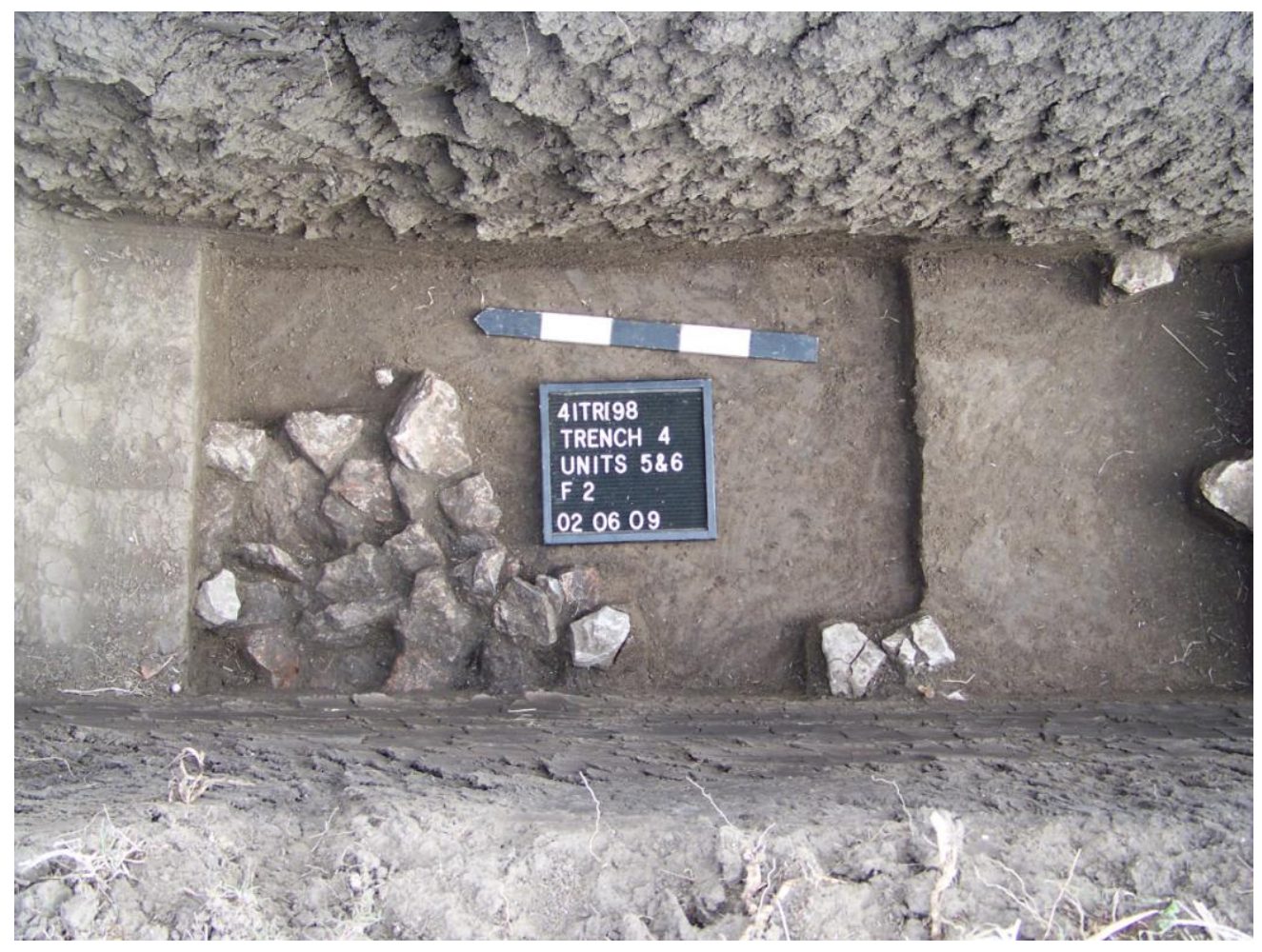

Figure 65. Feature 2, Trench 4.

Feature 2 fill is comparable to the surrounding soil matrix with the addition of a scatter of charcoal. As evidenced by the west profile, fire-cracked rock in the center of the feature was stacked two to three courses high. Only the portion of Feature 2 that was located in the floor of Trench 4 was accessible to excavation, the rest remains intact in the west balk of the trench.

This feature yielded a total of 10 bones. These include the canine and molars of a raccoon, the skull fragment of a small mammal, four long bone fragments of a large mammal, and a mandible fragment of an undetermined rodent.

\section{Feature 3}

Feature 3 was originally recognized as a feature separate from Feature 2 which is 1.5 meters away in Trench 4. However, review of the data suggests that these isolated fire-cracked rocks are likely discards from the activity related to Feature 2. 


\section{Feature 6}

Feature 6 is a burned clay feature in the east wall of Trench 5. Like Feature 22, Feature 6 appears roughly circular when traced in profile. There is one piece of mussel shell visible in profile within the feature near its northwestern margin. There appear to be no other artifacts, fire-cracked rock, or oxidized surfaces associated with this feature.

\section{Feature 7}

Feature 7 consists of an area of lightly colored oxidized clay and was noted in the west profile of Trench 4. It was $47 \mathrm{~cm}$ in width, $31 \mathrm{~cm}$ in thickness, and roughly circular.

\section{Feature 9}

Feature 9, an ash feature with some charcoal and burned clay, is located in the south wall of Trench 1 at an elevation of $98.39 \mathrm{~cm}$. It is approximately $32 \mathrm{~cm}$ long and $19 \mathrm{~cm}$ deep as exposed by the backhoe trench.

\section{Feature 13}

Feature 13 is a layer of mussel shell located in both walls at the east end of Trench 7. The main lens of shell is $120 \mathrm{~cm}$ long by four cm thick. There is also a small patch of outlying shell $40 \mathrm{~cm}$ east along the same horizontal plain, also on either side of the trench. The undulating surface of Feature 13 is hypothesized to reflect the paleotopography of the landform.

\section{Feature 19}

Feature 19 was exposed in the north wall of Trench 8 at an elevation of $98.59 \mathrm{~cm}$. Small firecracked rock $(<5 \mathrm{~cm}$ in diameter) are clustered at each end of a concentration of charcoal. The charcoal concentration is approximately $5 \mathrm{~cm}$ thick and extends for $79 \mathrm{~cm}$. 


\section{Feature 34}

Feature 34 was observed during the excavation of Trench 6 at an elevation of $98.15 \mathrm{~cm}$. Feature 34 was obviously a thermal feature. Where it was exposed in plan view, two-thirds of the rim was outlined by a lightly to moderately thermally oxidized rind of soil. This rind is between two and three $\mathrm{cm}$ thick. Oxidation does not appear deeper within the pit. There were also two very large pockets of charcoal exposed in plan view; one was $28-\mathrm{x}-9 \mathrm{~cm}$ and the other was $23-\mathrm{x}-10$ $\mathrm{cm}$. Relative to where it is cut in profile, the interior width of the pit is $58 \mathrm{~cm}$. Just above the base of the pit ( $20 \mathrm{~cm}$ deeper) the interior width is $54 \mathrm{~cm}$, rounding to a flat bottom. Based on its projected circumference, the pit would have had a diameter of $68 \mathrm{~cm}$ (Figure 66). Feature 34 contained a small fragment of a bone tool.

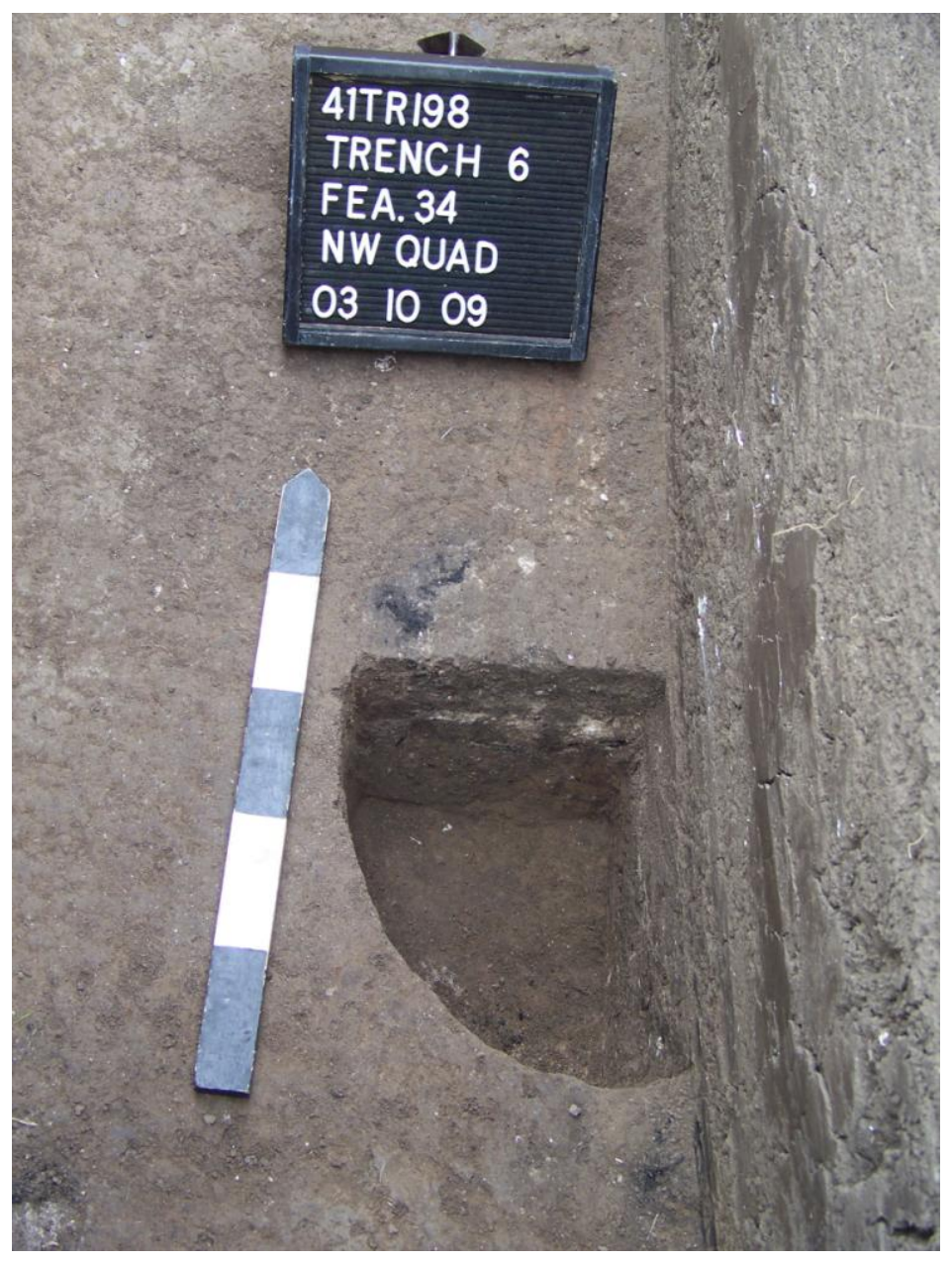

Figure 66. Trench 6, Feature 34. 


\section{Feature 46}

Feature 46 is a large, thermally oxidized pit intersected in Trench 12. This feature was only observed in profile. The two margins of the pit are asymmetrically oxidized. This feature contains ash, fire-cracked rock, and charcoal, but only ash was observed in significant quantities. When viewed in profile, Feature 46 has a smooth hemispherical shape. With a minimum width of $80 \mathrm{~cm}$, this feature was among the largest pits recorded during the project. 


\section{CHAPTER 9 SITE 41 TR198 ARTIFACT ASSEMBLAGE}

\section{INTRODUCTION}

Data recovery efforts at site 41TR198 resulted in the collection of a total of 6,954 artifacts consisting of 213 pieces of flaked stone, eight ground stone artifacts, four bone or antler tools, and 6,729 fire-cracked rocks. Although such an assemblage seems quite unique, the lack of flaked stone debitage and tools is not that uncommon in alluvial sites near the confluence of the West and Elm forks of the Trinity River. The amount of fire-cracked rock is unusual in comparison to other sites along the Elm and East forks of the Trinity River. Recent work at site 41TR170 three miles upstream along the Clear Fork of the Trinity River (Lintz 2005) indicates that fire-cracked rock is more common at sites to the west and southwest.

\section{FLAKED STONE ASSEMBLAGE}

A total of 213 flaked stone artifacts was recovered from this site including eight projectile points, five formal tools, two informal tools, and 198 pieces of debitage. Therefore the ratio of tools to debitage is approximately $1: 13$. Some questions to be addressed in this section include the nature of the flaked stone assemblage, the ratio of artifact types, local vs. non-local material types, lithic reduction strategies, and the contexts within which flaked stone artifacts were found. 
This flaked stone analysis was conducted as part of the greater 41TR198 data recovery project. The objectives are the classification and analysis of 100 percent of the flaked stone artifacts recovered during the project. Raw material, artifact type, and metric attributes are recorded with the end goal of summarizing the lithic assemblage in order to contribute to the overall understanding of the nature of site and to provide specific evidence of intrasite behavioral, activity and discard patterns.

Artifacts are classified using standard archaeological taxonomic classes including projectile points, formal tools (bifaces and unifaces), informal tools (utilized flakes), and debitage. Debitage is further classified as primary flakes (50-100\% dorsal cortex), secondary flakes (1-49\% dorsal cortex), tertiary flakes ( $0 \%$ dorsal cortex), and shatter (non flake debitage). All artifacts are assigned to as specific a raw material type as possible.

Visual inspection of the artifacts was accomplished with the aid of a combination of five and 10 power hand loupes. Artifacts are weighed to $0.1 \mathrm{~g}$ using an EHM-200H scale. Size attributes are determined using General Ultra-tech digital stainless steel calipers with accuracy to $.01 \mathrm{~mm}$. Maximum lengths, widths, and thicknesses are tabulated for each artifact. Flake lengths are relative to the central axis of the flake between the proximal and distal ends as indicated by the platform and eraillure scars.

\section{Debitage}

There are 198 pieces of flaked stone debitage found during the 41TR198 data recovery project. Eighty-two of these artifacts came from the general site assemblage recovered in the field, specifically from Blocks 1-4, and excluding the synchronic reduction episode discussed below. Although some amount of lithic debitage was found in each of the excavation blocks, debitage was by no means uniformly found in all stratigraphic contexts. Twenty-five pieces of debitage were recovered from the heavy fraction of feature flotation samples. In addition, eighty-six artifacts represent a single reduction episode of chert from the context in Block 4, Unit 19, Level 5. No lithic debitage was recovered from Block 2. 


\section{Block 1}

Seven pieces of debitage were recovered from Block 1. Five tertiary flakes (four of chert and one of limestone were recovered between elevations 98.15 and $98.00 \mathrm{~cm}$. Two of the flakes were associated with Feature 27. All exhibited single faceted $(n=3)$ or crushed platforms $(n=2)$. The remaining specimens consist of a tertiary chert bifacial thinning flake from Feature 11 and a distal, primary chert flake fragment from an elevation of $97.80 \mathrm{~cm}$.

\section{Block 3}

The amount of debitage within the Block 3 excavation units is extremely limited; only 52 pieces of debitage were deposited as the result of ephemeral occupations spanning a period of over 2,000 years. The majority of lithic debitage was deposited during occupations dating between A.D. 250 and 900. These flakes reflect limited mid- to late cobble reduction. Within the deeper zones where extremely limited occupational evidence is present within a 600 year period, only three chert flakes are present. It is apparent that none of the occupants of this location focused on the reduction of cores or cobbles for tool production. Most tools were likely produced elsewhere during the band's seasonal round.

\section{Block 4}

One hundred and twenty-five pieces of debitage were recovered from Block 4. This block has been divided into three zones based on the stratigraphy and vertical distribution of features within the $60 \mathrm{~cm}$ of sediments. The upper zone $(99.3-99.2 \mathrm{~cm})$ contains no debitage. Zone $2(99.2-$ $99.0 \mathrm{~cm})$ contains 17 pieces of debitage. Zone $3(99.0-98.75 \mathrm{~cm})$ contains most of the debitage assemblage with 104 pieces represented. Eighty-six of these pieces are within Feature 37. Only four pieces are present in Zone $4(98.75-96.60 \mathrm{~cm})$.

Within the small samples from Zones 2 and 4, the ratio of primary and secondary flakes to tertiary flakes is almost equal. However, within Zone 3, there are over three times as many tertiary flakes as primary and secondary flakes combined. Examination of the largest dimension of all complete flakes (tertiary: $n=46$; secondary: $n=7$; primary: $n=5$ ) within Zone 3 revealed that 
mean flake size for the three categories (tertiary: $\bar{x}=15$; secondary: $\bar{x}=15$; primary: $\bar{x}=20$ ) is not significantly different. It is most likely that bifacial reduction of large flake blanks or a small cobble is represented. The high percentages of crushed $(23.1 \%)$ or multifaceted platforms $(11.5 \%)$ in relation to single faceted $(22.1 \%)$ or cortical platforms $(10.7 \%)$ suggests that bifacial reduction was the primary activity. Nevertheless, lithic reduction was not a primary activity at this location.

\section{Block 4 Midden Cobble Reduction Sub-assemblage}

Eighty-six flakes, or 43.4 percent of the total debitage assemblage, were recovered from a single level $(99.0-98.8 \mathrm{~cm})$ in Feature 37 within Block 4. This sub-assemblage represents the mid to late stage reduction of a single nodule of Edwards chert probably into some type of tool, preform, or biface. All of the debitage from this sub-assemblage are of the same material type, a silky brownish-grey chert with occasional grey and tan mottling. The cobble cortex is yellowish brown.

The spatially discrete nature $(1-\mathrm{x}-1-\mathrm{x}-0.1 \mathrm{~m})$ of this lithic reduction episode reflects the excellent internal context of the Block 4 midden. Of the 86 pieces of debitage, eight are primary flakes, 14 are secondary flakes, 63 are tertiary flakes, and one is a piece of shatter (Table 32). Flake platforms vary and appear to indicate a range of both hard and soft hammer percussion. One platform on a tertiary flake indicates that it was removed from the margin of a nearly complete tool based on numerous flake and pressure flake scars along that edge. No actual pressure flakes were recovered from this sub-assemblage; however, their absence is not unexpected due to the use of $6.35 \mathrm{~mm}(1 / 4 ")$ mesh.

The general artifact assemblage and flotation recovery indicate a low amount of tool production, mostly using non-local raw materials, specifically chert. A lesser amount of quartzite debitage (a locally available raw material) was observed. Within this group of artifacts the ratio of flake types is generally characteristic of a moderate to low degree of mid to late stage tool manufacturing. Five bifacial thinning flakes were noted or 2.6 percent of all of the debitage. Likewise, there were seven pressure flakes from the heavy fraction assemblage, or 26 percent of the heavy fraction flaked stone. The presence of pressure flakes and bifacial thinning flakes indicates that at least some late stage tool manufacturing and/or tool rejuvenation was taking place on site. 
Table 32

Descriptive Statistics for the 86 Pieces of Debitage Comprising the Block 4 Cobble Reduction

Sub-assemblage

\begin{tabular}{llllllll} 
Artifact Type & Condition & $\mathrm{n}=$ & $\%$ & $\mu$ length & $\mu$ width & $\mu$ thickness & $\mu$ weight \\
\hline Primary flake & whole & 4 & 4.7 & $19.8 \mathrm{~mm}$ & $16.8 \mathrm{~mm}$ & $3.7 \mathrm{~mm}$ & $1.2 \mathrm{~g}$ \\
Primary flake & distal fragment & 4 & 4.7 & $9.9 \mathrm{~mm}$ & $11.6 \mathrm{~mm}$ & $1.9 \mathrm{~mm}$ & $0.2 \mathrm{~g}$ \\
Secondary flake & whole & 6 & 7.0 & $15.5 \mathrm{~mm}$ & $12.9 \mathrm{~mm}$ & $3.2 \mathrm{~mm}$ & $0.6 \mathrm{~g}$ \\
Secondary flake & proximal fragment & 3 & 3.5 & $13.6 \mathrm{~mm}$ & $14.3 \mathrm{~mm}$ & $2.3 \mathrm{~mm}$ & $0.4 \mathrm{~g}$ \\
Secondary flake & distal fragment & 5 & 5.8 & $14.7 \mathrm{~mm}$ & $14.9 \mathrm{~mm}$ & $2.8 \mathrm{~mm}$ & $0.7 \mathrm{~g}$ \\
Tertiary flake & whole & 37 & 43.0 & $14.6 \mathrm{~mm}$ & $11.8 \mathrm{~mm}$ & $1.9 \mathrm{~mm}$ & $0.3 \mathrm{~g}$ \\
Tertiary flake & proximal fragment & 5 & 5.8 & $14.6 \mathrm{~mm}$ & $13.7 \mathrm{~mm}$ & $1.9 \mathrm{~mm}$ & $0.4 \mathrm{~g}$ \\
Tertiary flake & distal fragment & 20 & 23.3 & $10.2 \mathrm{~mm}$ & $13.1 \mathrm{~mm}$ & $1.6 \mathrm{~mm}$ & $0.2 \mathrm{~g}$ \\
Shatter & n/a & 1 & 1.2 & $19.0 \mathrm{~mm}$ & $6.1 \mathrm{~mm}$ & $3.5 \mathrm{~mm}$ & $0.3 \mathrm{~g}$ \\
Unid. flake frag. & indeterminate & 1 & 1.2 & $9.1 \mathrm{~mm}$ & $8.8 \mathrm{~mm}$ & $1.3 \mathrm{~mm}$ & $0.1 \mathrm{~g}$ \\
\hline
\end{tabular}

\section{Debitage Summary}

The proportion of primary to secondary to tertiary flakes within the overall debitage assemblage is roughly $1 / 2 / 5$ (Table 33). About one half of the debitage was composed of complete flakes; the remaining half consisted of fragmentary flakes or shatter (Table 34). One interesting observation is that there were about twice as many distal flake fragments as proximal fragments; this is true of both the Block 4 sub-assemblage and the overall debitage assemblage.

Table 33

Debitage Types at Site 41TR198

\begin{tabular}{lcc} 
Artifact Type & Count & Proportion \\
\hline Primary Flake & 26 & $13.3 \%$ \\
Secondary Flake & 42 & $21.4 \%$ \\
Tertiary Flake & 119 & $60.7 \%$ \\
Shatter & 8 & $4.1 \%$ \\
Pot Lid & 1 & $0.5 \%$ \\
Total & 196 & \\
\hline
\end{tabular}


Table 34

Flake Condition at Site 41TR198

\begin{tabular}{lcc} 
Flake Condition & Count & Proportion \\
\hline Whole Flake & 101 & $51.5 \%$ \\
Proximal Fragment & 23 & $11.7 \%$ \\
Medial Fragment & 6 & $3.1 \%$ \\
Distal Fragment & 48 & $24.5 \%$ \\
Split Flakes & 6 & $3.1 \%$ \\
Unidentified Flake Fragments & 3 & $1.5 \%$ \\
Shatter & 8 & $4.1 \%$ \\
Pot Lid & 1 & $0.5 \%$ \\
$\quad$ Total & 196 & \\
\hline
\end{tabular}

\section{Raw Materials}

Flaked stone debitage included four material types: chert (90.9\%), quartzite (7.1\%), limestone $(0.5 \%)$, and an unidentified material type (1.5\%). Furthermore, two types of chert could also be identified within the assemblage including chert that is likely derived from Uvalde lag gravels in the region and Alibates. A large percentage of the chert was originally thought to be Edwards chert; however, the fossiliferous inclusions and the cortex that suggests a cobble source rather than chert beds indicate that the source for this chert was more likely the lag gravels from the upland divides in the area. These flakes also did not fluoresce under a black light. Consequently, the conclusion that Uvalde gravels were more likely the source of the tool stone than the chert beds present in Central Texas. The quartzite that was identified is a local raw material that is coarser grained than chert and probably would have been less desirable for flaked tool production by the prehistoric inhabitants of this region for most purposes.

One flake of Alibates chert was also noted during analysis. Alibates chert is a second form of high quality Texas tool-stone native to the Canadian River valley of the northern Panhandle. It is possible, however, to find an occasional cobble of Alibates within stream gravels in northcentral Texas. Alibates chert is not actually a chert, but a form of silicified dolomite and is typically banded or marbled with various bright colors. A beige, pink, and grey banded piece of debitage of high quality, opaque cryptocrystalline material from this assemblage was typed as Alibates chert. 
Fourteen pieces or seven percent of, the debitage is quartzite. These included four primary flakes, one secondary flake, three tertiary flakes, and six pieces of shatter. Unlike chert, quartzite is a locally available raw material, but is generally coarse grained and less suitable for flaking. This characteristic is reflected in the ratio of shatter to flakes. Within this assemblage the ratio of shatter to flakes for quartzite is $3 / 4$ while that for chert is $1 / 177$.

\section{Projectile Points}

Eight dart points were recovered during the Crooked Oxbow Site data recovery project. All except one are complete and can be typed (Tables 35 and 36, Figure 67). No arrow points were found.

Table 35

Metric Attributes of the Crooked Oxbow Site Dart Points

\begin{tabular}{|c|c|c|c|c|c|c|c|c|}
\hline FS & Type & $\begin{array}{l}\text { Total } \\
\text { Length }\end{array}$ & $\begin{array}{l}\text { Shoulder } \\
\text { Width }\end{array}$ & $\begin{array}{l}\text { Axial } \\
\text { Thickness }\end{array}$ & $\begin{array}{l}\text { Base } \\
\text { Length }\end{array}$ & $\begin{array}{l}\text { Neck } \\
\text { Width }\end{array}$ & $\begin{array}{l}\text { Base (max) } \\
\text { Width }\end{array}$ & Weight \\
\hline 60 & Trinity & $28.19 \mathrm{~mm}$ & $16.83 \mathrm{~mm}$ & --------- & $7.81 \mathrm{~mm}$ & $12.04 \mathrm{~mm}$ & $14.13 \mathrm{~mm}$ & $2.0 \mathrm{~g}$ \\
\hline 128 & unidentified & $29.35 \mathrm{~mm}$ & $17.27 \mathrm{~mm}$ & $5.71 \mathrm{~mm}$ & ------- & ------- & ------- & $3.0 \mathrm{~g}$ \\
\hline 141 & Axtell & $36.44 \mathrm{~mm}$ & $15.11 \mathrm{~mm}$ & $7.16 \mathrm{~mm}$ & $9.99 \mathrm{~mm}$ & $11.51 \mathrm{~mm}$ & $12.87 \mathrm{~mm}$ & $2.9 \mathrm{~g}$ \\
\hline 304 & Axtell & $37.84 \mathrm{~mm}$ & $14.74 \mathrm{~mm}$ & $5.87 \mathrm{~mm}$ & $10.31 \mathrm{~mm}$ & $10.91 \mathrm{~mm}$ & $12.57 \mathrm{~mm}$ & $2.5 \mathrm{~g}$ \\
\hline 485 & Yarbrough & $49.37 \mathrm{~mm}$ & $21.39 \mathrm{~mm}$ & $7.07 \mathrm{~mm}$ & $11.53 \mathrm{~mm}$ & $11.63 \mathrm{~mm}$ & $15.40 \mathrm{~mm}$ & $5.6 \mathrm{~g}$ \\
\hline 523 & Yarbrough & $37.55 \mathrm{~mm}$ & $14.48 \mathrm{~mm}$ & $4.75 \mathrm{~mm}$ & $8.48 \mathrm{~mm}$ & $9.45 \mathrm{~mm}$ & $11.21 \mathrm{~mm}$ & $2.1 \mathrm{~g}$ \\
\hline 591 & Yarbrough & $42.74 \mathrm{~mm}$ & $17.43 \mathrm{~mm}$ & $6.62 \mathrm{~mm}$ & 10.80 & $10.77 \mathrm{~mm}$ & $12.39 \mathrm{~mm}$ & $4.2 \mathrm{~g}$ \\
\hline 591 & Trinity & $28.08 \mathrm{~mm}$ & $12.37 \mathrm{~mm}$ & $5.39 \mathrm{~mm}$ & $9.28 \mathrm{~mm}$ & $10.32 \mathrm{~mm}$ & $14.17 \mathrm{~mm}$ & $2.0 \mathrm{~g}$ \\
\hline
\end{tabular}

\section{Trinity $(n=2)$}

Two Trinity points were recovered, one from Block 3 (exact provenience unknown) and one from Block 4 (Unit 36, $98.9-98.8 \mathrm{~cm}$ ). These two dart points have a mean length of $28.1 \mathrm{~mm}$. Their average maximum width is $15.5 \mathrm{~mm}$, although for one artifact the widest point is the blade while for the other it is the shoulder. 
Table 36

Raw Material and Condition of the Crooked Oxbow Site Dart Points

\begin{tabular}{lllll} 
FS & Type & Condition & Raw Material & Color \\
\hline 60 & Trinity & Whole & Chert & Beige + reddish purple \\
128 & unidentifiable & stem broken & Novaculite & Grey with light grey flecks \\
141 & Axtell & Whole & Chert & Light grey and dark grey mottled \\
304 & Axtell & Whole & Chert & Grey \\
485 & Yarbrough & Whole & Chert & Beige with black specks \\
523 & Yarbrough & Whole & Chert & Light grey \\
591 & Yarbrough & Whole & Chert & Light grey \\
591 & Trinity & Whole & Chert & Light grey with white and black speckles \\
\hline
\end{tabular}

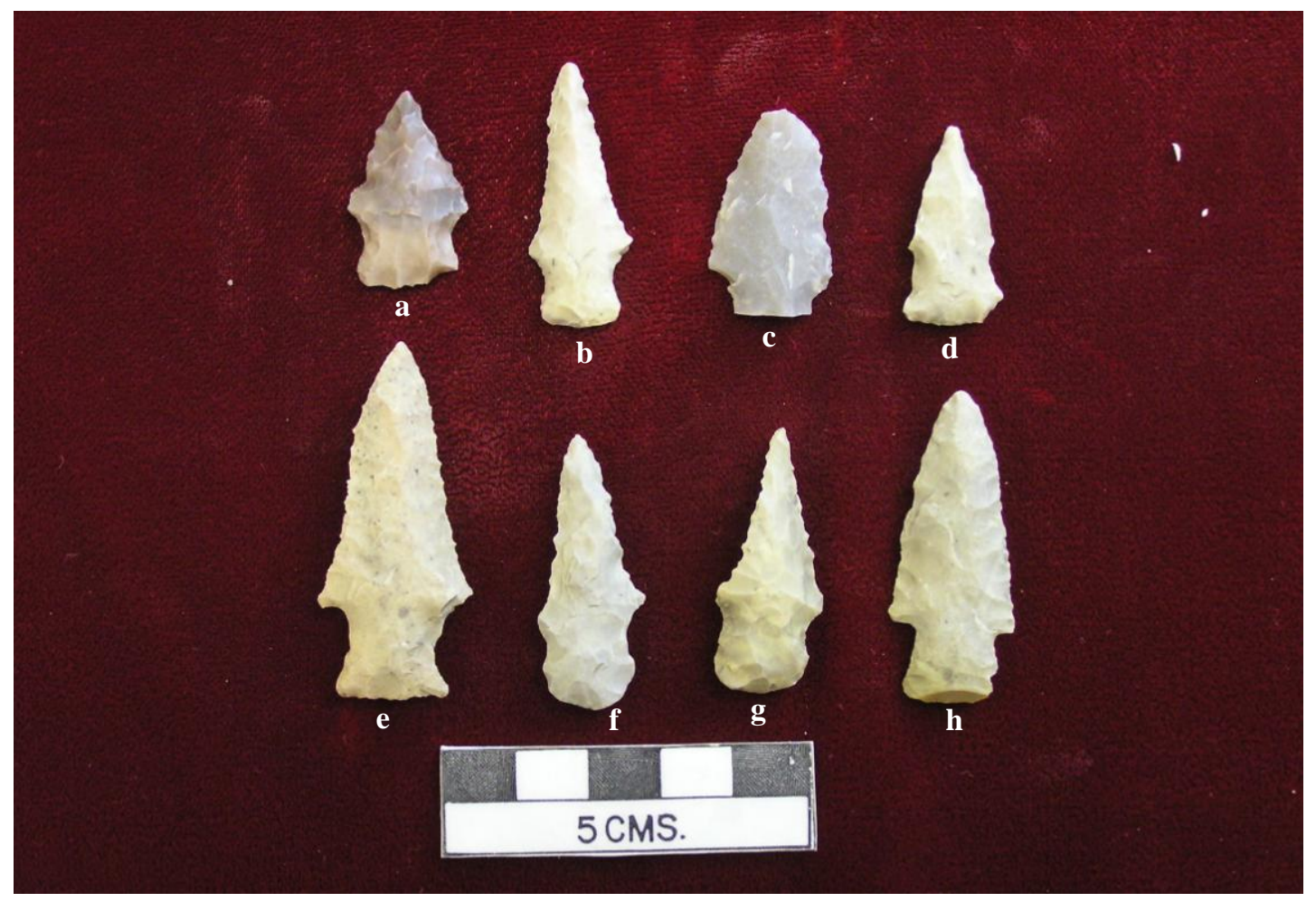

Figure 67. Projectile points recovered from site 41TR198: (a) Trinity (FS 60); (b) Yarbrough (FS 523); (c) unidentified (FS 128); (d) Trinity (FS 591); (e) Yarbrough (FS 485); (f) Axtell (FS 304); (g) Axtell (FS 141); and (h) Yarbrough (FS 591).

The first (FS 60) was recovered from an anomalous context on the surface of Block 3 approximately $50 \mathrm{~cm}$ below ground surface. This Trinity point is composed of beige and reddish purple chert. Its most distinguishing characteristics are that its heavily resharpened blade and the 
presence of a pot lid fracture on one side. The opposite side of the blade contains step fractures. These step fractures prohibited further resharpening, which would have been difficult in any case due to the diminished length and angle of the blade. This suggests that this artifact was discarded on site because it had reached the end of its useful lifespan. It may have been discarded into a thermal context resulting in the pot lid fracture.

The second Trinity point (FS 591) was recovered from the Block 4 midden in Unit 36 between 98.90 and $98.80 \mathrm{~cm}$. This artifact is composed of chert, which is light grey in color with tiny white and black specks throughout the matrix of the stone. Like FS 60, this Trinity point is heavily resharpened, almost to the extent of being non functional. In the case of this dart point the blade has been resharpened to the point that the base is wider than the shoulders of the blade. This artifact was recovered in the same level as one of the Yarbrough points.

\section{Axtell $(n=2)$}

Two Axtell points were found, both in Block 4. The primary diagnostic characteristic of each is a distinctively rounded stem. The first specimen was from Unit 17 at a depth of between 99.21 and $99.11 \mathrm{~cm}$. The second was from Unit 17 where it was recovered between 99.85 and $98.75 \mathrm{~cm}$. The Axtell points have a mean length of $37.1 \mathrm{~mm}$ and a mean maximum width of $14.9 \mathrm{~mm}$.

The first Axtell point (FS 141) is composed of mottled chert. The bulbous base is either ground or heavily smoothed from hafting and use. Although probably still functional as a dart point, the blade on this artifact is heavily resharpened. Its blade is alternately and deeply beveled, giving it a corkscrew-like appearance when viewed on point. The margins of its blade are concave and slightly serrated.

The second Axtell point (FS 304) is composed of grey chert. In terms of both shape and style it is reminiscent of the first, especially in terms of the concave blade margins, slightly protruding shoulders (due to resharpening), and near circular base. This dart point is also heavily resharpened and there are numerous step fractures on one side. This projectile point is lightly serrated. This artifact appears to have evidence of basal smoothing at the area where the point would have been hafted. 


\section{Yarbrough $(n=3)$}

There are three dart points from site 41TR198 that can be best classified as Yarbrough. All are corner notched with expanding stems and straight bases. Two are from the Block 4 midden. The first Yarbrough point (FS 523; Unit 33, 99.00 - $98.9 \mathrm{~cm}$ ) is composed of chert. This artifact is intact, but has been heavily resharpened. Thus, the margins of the blade are slightly concave. The tip of the point is intact, but fairly blunt and rounded.

The second Yarbrough (FS 591; Unit 36, $98.9-98.8 \mathrm{~cm}$ ) is larger than the first, partially due to the fact that its blade is less heavily refurbished. The base and one lateral side of the blade retain some cortex. There are step fractures around the area where there is cortex on the blade making the resharpening of this particular artifact difficult or perhaps precluding it. The remnant cortex also reduced the thinning capacity of this side of the blade, giving this point a somewhat curved shape in profile.

The third Yarbrough point was found at the bottom of thermal Feature 15 in Block 3. This artifact is in perfect condition. It has a expanding stem and straight base. One edge of the stem is ground. The blade edges are deeply alternately beveled and serrated. This artifact is composed of a beige/tan colored chert with black specks. It appears to be in very fine condition compared to the other points within the assemblage.

\section{Unidentifiable Dart Point $(n=1)$}

The only novaculite artifact from the entire assemblage was a broken projectile point found in Unit $14(98.97-98.88 \mathrm{~cm})$ in the Block 4 midden. The artisanship of this tool is fairly crude. It has subtle, slightly sloping shoulders and a slightly excurvate blade. The base of this dart point is broken near the juncture with the blade prohibiting type classification.

This projectile point appears to have broken upon impact. The tip of the point is broken and crushed. From this point there is a single long channel-like flake scar starting at the point of impact and traveling down the center of one axis of the artifact and stopping just short of the point where the base is broken. Due to the force involved in this event it is likely that the base 
may have snapped at the same time. This dart point was likely discarded on site because it was broken beyond the point of repair and no longer functional.

\section{Formal and Informal Tools}

There were seven non projectile point flaked stone tools in the Crooked Oxbow Site artifact assemblage, including two utilized flakes, one bifacial roughout, three non diagnostic bifacial fragments, and one unifacial tool (Table 37 and Figure 68).

\begin{tabular}{lllllll}
\hline & \multicolumn{5}{c}{ Table 37 } \\
& & \multicolumn{2}{c}{ Formal and Informal Tools from Site 41TR198 } & \\
FS & Artifact Type & length $(\mathrm{mm})$ & width $(\mathrm{mm})$ & thickness $(\mathrm{mm})$ & weight $(\mathrm{g})$ & Raw Material \\
\hline 530 & Utilized flake & 44.6 & 24.9 & 10.8 & 8.8 & Chert \\
595 & Utilized flake & 22.4 & 16.6 & 4.9 & 1.4 & Chert \\
127 & Bifacial roughout & 50.5 & 38.5 & 16.9 & 32.9 & Chert \\
331 & Bifacial fragment & 18.6 & 8.9 & 4.5 & 0.5 & Chert \\
591 & Bifacial fragment & 29.6 & 23.1 & 7.4 & 4.2 & Chert \\
352 & Bifacial fragment & 37.1 & 21.0 & 10.6 & 7.0 & Chert \\
160 & Unifacial fragment & 17.0 & 14.8 & 11.3 & 2.6 & Chert \\
\hline
\end{tabular}

Utilized Flakes $(n=2)$

There are two utilized flakes in this assemblage. In this report the term utilized flake refers to a flake with evidence of lateral use wear in the form of repetitive micro flake scars that appear to have been caused by use, not intentional retouch or sharpening with a hammer or billet. Utilized flakes are therefore distinguished on one hand from scrapers or other flake tools with retouched margins and on the other from debitage and other flakes that may have been used as incidental tools but whose use-wear is light and cannot be reliably recognized without, perhaps aid of a microscope or more advanced analytic techniques than were utilized herein. 


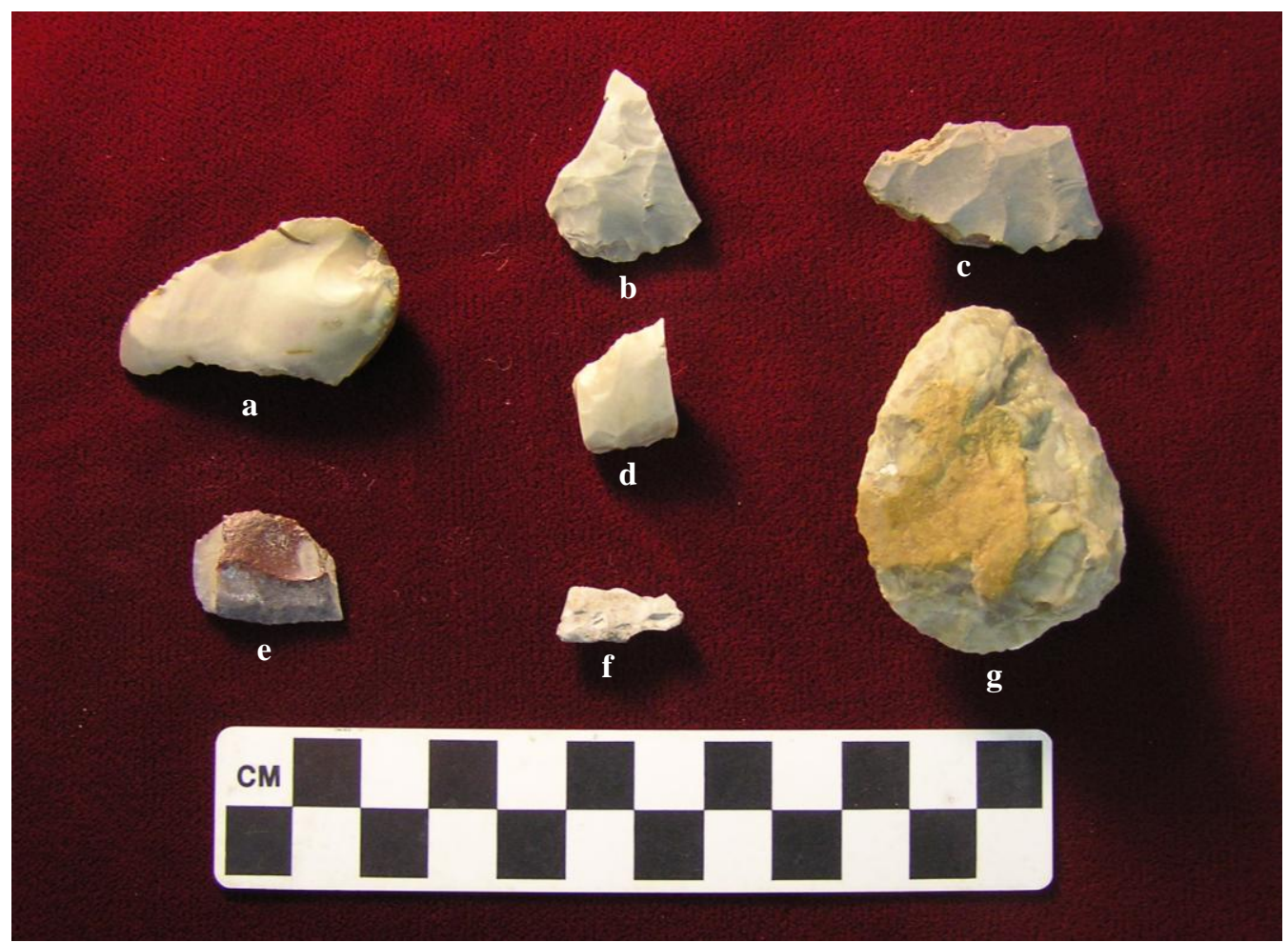

Figure 68. Formal and informal tool assemblage from site 41TR198: (a) utilized flake (FS 530); (b) biface fragment (FS 591); (c) biface fragment (FS 352); (d) uniface fragment (FS 160); (e) utilized flake (FS 595); (f) biface fragment (FS 331); and (g) bifacial roughout (FS 127).

The first utilized flake (FS 530) is a robust, whole chert flake that measures $44 \mathrm{~mm}$ long. The dorsal side of this primary flake is composed of 100 percent thick brown cortex; the ventral side is banded cream-colored chert. One lateral side of the artifact is concave and measures $32.7 \mathrm{~mm}$ in length. There are small use-wear flake scars along this side of the artifact. It may have functioned as a spoke shave.

The second utilized flake (FS 595) is much smaller than the first and is composed of purplish grey chert. It is a distal, primary flake fragment with 60 percent purplish/red cortex on its dorsal surface. The sharp, non cortical margin of this flake measures $21.2 \mathrm{~mm}$. Use-wear flake scars appear along $11 \mathrm{~mm}$ of the edge. This artifact probably functioned as a graver. 


\section{Bifacial Roughout $(n=1)$}

One bifacial roughout was recovered from the Block 4 midden (FS 127; $98.88-98.79 \mathrm{~cm}$ ). It is composed of yellow and grey mottled chert, with yellow-brown cortex on either side. The knapper was apparently trying to bifacially reduce a small cobble. It was probably discarded due to the inability to bifacially reduce the specimen further; specifically, an irremovable knot on one lateral surface and a series of step fractures on the other precluded further reduction. A number of the flakes within the Block 4 sub-assemblage were likely removed from this cobble or others like it.

\section{Bifacial Fragments $(n=3)$}

Two biface fragments were recovered from Block 3 while the remaining specimen was recovered from Block 4. The bifacial fragment from Block 3, Unit 30, Level 10 (98.5-98.45 cm; FS 331) is very small (see Table 37). It is composed of a fine-grained blue gray chert. This specimen likely represents an unsuccessful attempt at bifacial thinning. A shattered fragment of a biface (FS 352) was found in Block 3, Unit 26, Level 11 (98.45 - $98.4 \mathrm{~cm}$ ). This artifact is composed of dark grey chert with a slight swirl pattern. One side of the artifact is shattered; the opposite side is bulbous with step fracturing evident. It is likely that this bifacial blank was abandoned during the bifacial thinning process which failed.

A bifacial fragment (FS 591) from Block $4(98.9-98.8 \mathrm{~cm})$ is more typical in form but very small (see Table 37). This chert biface has no cortex on either side. The two fractures indicate that the biface may have broken as a result of end shock during manufacture.

\section{Unifacial Tool Fragment (n=1)}

FS 160 consists of a small broken piece of a unifacial tool. The original tool blank may have been a flake; however, only a $17 \mathrm{~mm}$ segment of the tool remains. The lateral ventral edges are both unifacially steeply retouched. The color of the chert is light grey; very pale yellow cortex is present on a portion of the dorsal surface. 


\section{Summary}

Eight projectile points, one unifacial tool fragment, two utilized flakes, one preform, three broken bifaces, and 198 pieces of flaked stone debitage were recovered from this site. Therefore, in comparison to other subsistence-related activities lithic reduction and tool manufacture were not primary or persistent activities at the Crooked Oxbow Site. Relatively few lithic tools appear to have been produced, broken, or discarded on site in comparison to a typical Texas Archaic base camp where debitage and bifacial thinning flakes are abundant. Interestingly, this pattern is very characteristic of many of the sites examined along the West Fork of the Trinity River.

In general, when present, the assemblage of lithic debitage at 41TR198 is characteristic of limited mid- and late-stage stone tool manufacturing. This is true of both the general site assemblage and the Block 4 sub-assemblage of debitage, which is interpreted as a single reduction event. Based on platform characteristics and the low number of bifacial thinning flakes, it is postulated that finished tool rejuvenation and resharpening were carried out on site, but even those activities were minimally represented.

The assemblage at this site is characteristic of hunter-gatherer groups with a high degree of mobility. The blades of the majority of the dart points had been heavily resharpened, a characteristic suggestive of high group mobility and tool curation. The low proportion of quartzite within the assemblage suggests that there was little need to utilize poorer quality locally available tool-stone sources.

Dart points dominate the flaked stone tool assemblage. Other than projectile points the diversity of tools is unremarkable; a few broken bifaces, a couple of utilized flakes, and a discarded preform. Only one unifacial tool fragment was recovered. The absence of generalized or specialized flaked stone tool forms suggest that activities requiring scraper-type flaked stone tools were not persistent behaviors at this site. Of course, the general curated nature of a flaked stone tool kit used by mobile hunter-gatherers suggests that unifacial and bifacial tool forms would not have been left on site. They would have been part of a mobile tool kit to be carried away to be used elsewhere at the end of the occupation. Three exceptions are loss, storage, or breakage and disposal at the site in which case such tools would have become part of the archaeological record. 


\section{Ceramic Assemblage}

Four ceramic sherds were recovered from site 41TR198 (Figure 69). One sherd was recovered from Block 4, Unit 35. Level $4(99.10-99.00 \mathrm{~cm})$ while the remaining three were recovered from Block 3, Unit 29, Feature $31(98.49-98.37 \mathrm{~cm})$. The three sherds from Feature 31 are possibly from the same vessel. All of the sherds are poorly made and poorly fired, are not smoothed on the interior or exterior, and were possibly hand-made rather than coiled. The sherds exhibit uneven thicknesses and are made of a fine gritty paste and fine grit temper.

The limited number of sherds together with the contexts of the finds suggest that experimentation with ceramic technology was occurring much earlier in northcentral Texas than previously thought. The context within Block 3 is pre-A.D. 900 while that in Block 4 is pre-A.D. 540. The potential for bioturbation within these deposits could place a single sherd within a secondary or tertiary context. The presence of molluscan shells vertically oriented in the north wall of Block 4 suggests that bioturbation was a factor in this area. However, the presence of the three sherds within Feature 31, a fire-cracked rock feature, suggests disposal within a defined context. Of course, it is also possible that Feature 31 was excavated from a higher surface and that the sherds were inadvertently included in the Feature 31 matrix. Even under this scenario, however, the sherds easily predate A.D. 1000.

\section{Ground Stone}

Overall the assemblage of ground stone artifacts from 41TR198 is relatively small; seven ground stone artifacts were recovered from the excavations (Table 38). The assemblage consisted of four manos, a metate fragment, a boat stone fragment, and a tabular piece of limestone exhibiting ground surfaces and characteristics of a chopper (Figure 70).

\section{Manos}

Four manos were recovered from this site. Three are unshaped hand stones; the fourth mano was intentionally ground into a more circular shape. 

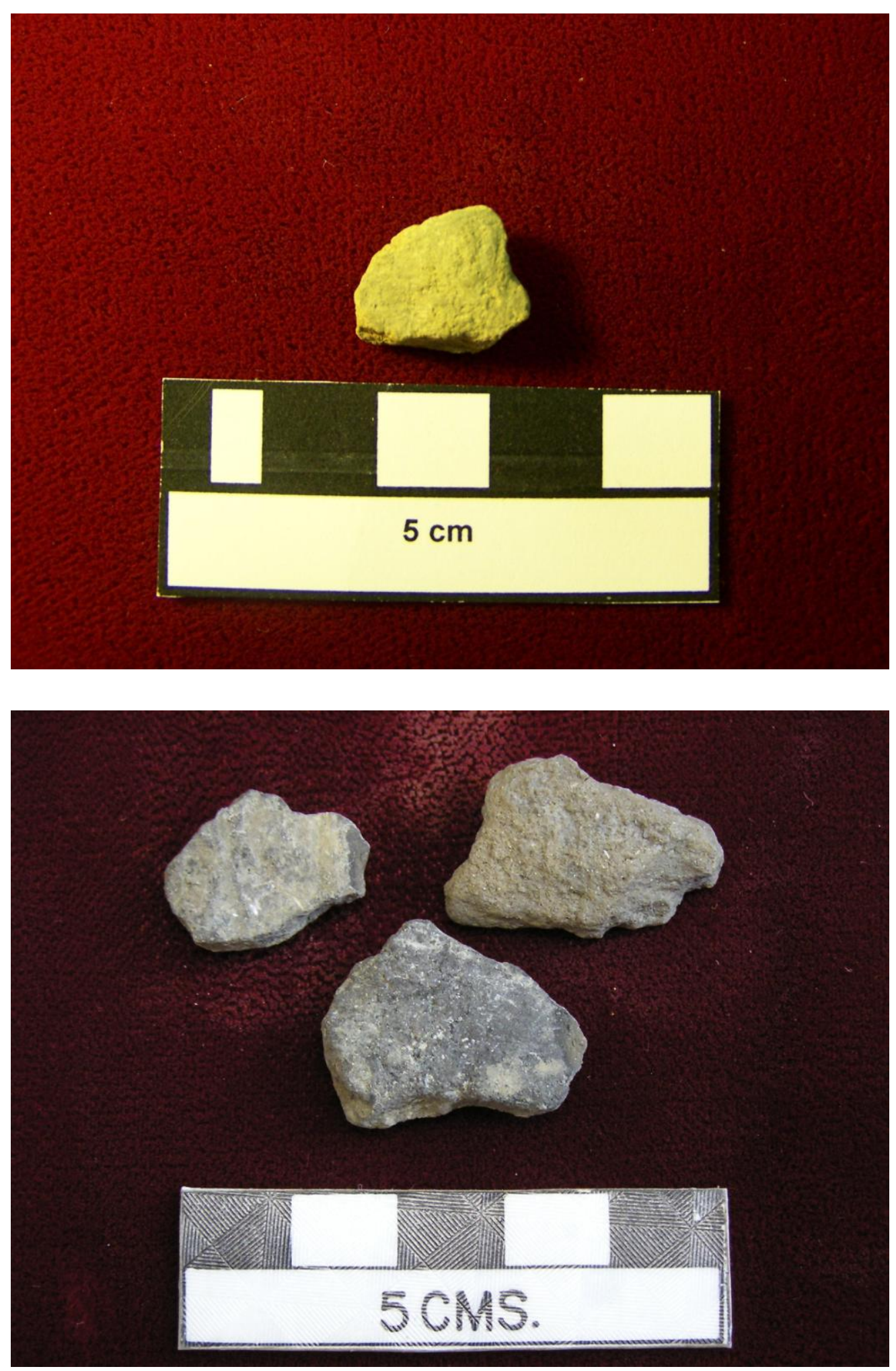

Figure 69. Ceramic sherds recovered from site 41TR198. Lower three sherds were found in Block 3, Unit 29, Feature 31 (98.49 - $98.37 \mathrm{~cm})$; upper sherd was recovered from Block 4, Unit 35, Level $4(99.10-99.00 \mathrm{~cm})$. 
Table 38

Summary of the Crooked Oxbow Site Ground Stone Assemblage

\begin{tabular}{lllllll} 
FS & Artifact Type & Length & Width & Thickness & Weight & Raw Material \\
\hline 596 & Two-sided mano & $96.93 \mathrm{~mm}$ & $91.24 \mathrm{~mm}$ & $39.16 \mathrm{~mm}$ & $465 \mathrm{~g}$ & sandstone \\
532 & Two-sided mano & $98.51 \mathrm{~mm}$ & $64.02 \mathrm{~mm}$ & $28.76 \mathrm{~mm}$ & $340 \mathrm{~g}$ & limestone \\
334 & One-sided mano & $103.01 \mathrm{~mm}$ & $74.14 \mathrm{~mm}$ & $51.04 \mathrm{~mm}$ & $547 \mathrm{~g}$ & quartzite \\
15 & Two-sided mano & $119.68 \mathrm{~mm}$ & $91.84 \mathrm{~mm}$ & $46.75 \mathrm{~mm}$ & $783 \mathrm{~g}$ & quartzite \\
589 & Basin metate fragment & $103.00 \mathrm{~mm}$ & $78.94 \mathrm{~mm}$ & $32.03 \mathrm{~mm}$ & $267 \mathrm{~g}$ & sandstone \\
525 & Boatstone fragment & $59.85 \mathrm{~mm}$ & $33.75 \mathrm{~mm}$ & $21.33 \mathrm{~mm}$ & $29 \mathrm{~g}$ & volcanic tuff \\
$254 / 256$ & Ground stone/chopper & $130.0 \mathrm{~mm}$ & $100.0 \mathrm{~mm}$ & $15.0 \mathrm{~mm}$ & $19.4 \mathrm{~g}$ & Limestone \\
573 & Two-sided mano & $65.54 \mathrm{~mm}$ & $51.97 \mathrm{~mm}$ & $38.32 \mathrm{~mm}$ & $114.0 \mathrm{~g}$ & Quartzite \\
\hline
\end{tabular}

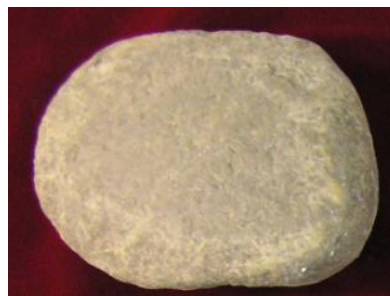

$\mathbf{a}$

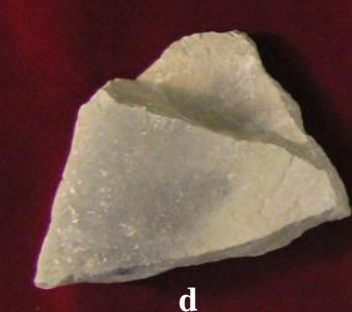

d

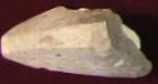

g

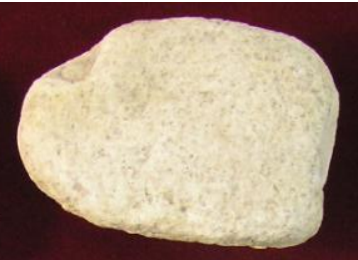

b

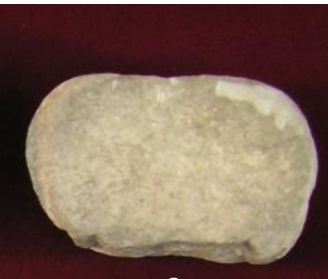

c

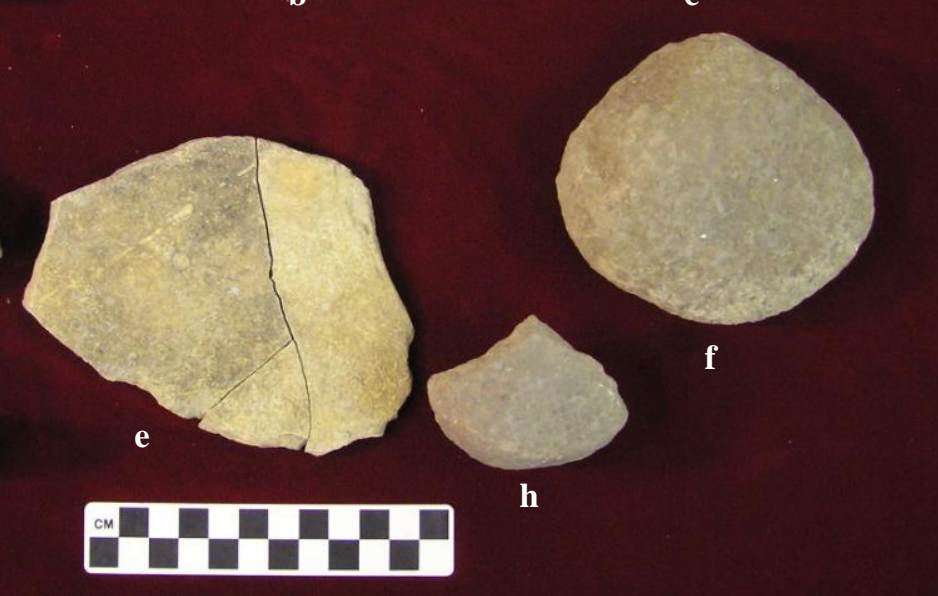




\section{FS 334}

A single one-sided mano was recovered from Unit $16(98.81-98.77 \mathrm{~cm})$ in Block 4 . This weighty artifact is composed of white quartzite. It has a loaf-like to roughly triangular shape in profile. This tool fits snugly in a large individual's hand with the ridge on the dorsal side of the tool resting in the palm. The working surface measures $92-\mathrm{x}-69 \mathrm{~mm}$.

\section{FS 596}

This two-sided, unshaped mano is composed of sandstone. It was recovered from the backdirt of Trench 11. It has a sub-circular shape with a working surface that measures $84-\mathrm{x}-84 \mathrm{~mm}$ on one side and $87-\mathrm{x}-77 \mathrm{~mm}$ on the opposite side. The first working surface of this artifact is both pecked and lightly ground while the second is only ground. The first working surface is covered by numerous small pits, which are not part of the natural surface of the stone. These small pits were pecked into the surface of the mano presumably in order to increase the grinding texture of the tool. The opposite side of the stone exhibits grinding but lacks the coarse pecking of the first side. Because of these dual textures, this mano is considered to be a multiple-use tool useful for at least two intensities or forms of grinding. The smooth side of the mano also has a large shovel scar from the process of excavation.

\section{FS573}

This fragmentary, two-sided mano is made of a sugar quartzite and may have been used secondarily as a hearth stone. Both sides exhibit evidence of grinding and the edges are battered, most likely from the intentional shaping of the mano. The one side of the mano exhibits evidence of grinding and pitting. This side may have been used as an anvil also.

\section{FS 15}

The second two sided, unshaped mano is the largest and heaviest of the recovered ground stone implements. It was recovered in Block 1 (Unit 4, 98.7 - 98.65). This may have been a twohanded tool. This mano has a roughly ovular shape and is composed of quartzite. It has a dual- 
convex surface and appears to have been used in some form of reciprocal grinding, perhaps with a corresponding basin or slab concave metate. One side of the mano demonstrates a much more advanced grinding polish than does the second and appears to be the primary working surface. This side of the mano measures 110-x-90 mm. The margins of this aspect of the mano exhibit a distinctive smooth lip. The opposite side of the artifact is lightly ground in comparison to the first. It was used for grinding in at least a few instances, but served primarily as the grasping surface of the implement. This second working surface measures 77-x-55 mm.

\section{FS 532}

A single mano that was intentionally shaped in order to produce a more effective or efficient grinding tool was recovered in Block 4 (Unit 35, 99.3 - $99.2 \mathrm{~cm}$ ). However, the shaping of this implement was not extensive and consisted merely of the grinding of either end into a more circular shape. The side of either long axis of the mano demonstrates a naturally rough rock cortex that would have provided an excellent gripping surface, while the end of either short axis has been ground smooth and rounded in order to produce an overall more desirable shape.

This mano is composed of limestone. One side of this artifact appears to have been exposed to fire. It is reddened, slightly cracked, and has a thin concretion of ash. Both aspects of the tool are ground although asymmetrically; one of the sides is convex, the other is concave.

The first grinding surface on this mano is convex and measures $79-x-57 \mathrm{~mm}$. This form of wear is the result of reciprocal grinding. The second grinding surface is slightly concave with evidence of light battering near the center where the tool was apparently used in at least one instance as a hammer stone. The flat/concave nature of the second side of the mano indicates that it was used in conjunction with a flat/undulating or possibly slightly convex grinding slab. FS 532, therefore, is a multi-use tool that appears to have been used in conjunction with both a basin, flat/concave metate or a grinding slab depending on which aspect of the mano was used. 


\section{Metate}

A single metate fragment (FS 589) was recovered during this data recovery. This artifact was found adjacent to a pit feature lying flat on a probable occupation surface on one of the lower levels of Block 3 at $98.07 \mathrm{~cm}$. This metate fragment is composed of sandstone and has a thin coating of ash and charcoal. This artifact is most likely a basin metate, but due to its fragmentary nature its absolute form is not certain. The extant portion of the working surface is roughly triangularly shaped. Based on this fragment, the depth of the basin of the metate is $13.25 \mathrm{~mm}$. This metate fragment appears to be fire cracked. Several other fire-cracked rocks were recovered from its vicinity; all are believed to be in a secondary refuse context.

\section{Boatstone}

Likely the most extraordinary artifact from the 41TR198 data recovery project is a fragmentary boatstone from the Block 4 midden (Feature 37; $98-98.9 \mathrm{~cm}$ ). This fragmentary object measures $60 \times 34 \times 21 \mathrm{~mm}$ and has six ground surfaces. Although only one fragment of the artifact is represented, it appears to be similar in form to the boatstones depicted in Seeman 2004 (see Figure 22). The boatstone is composed of welded tuff, an igneous rock composed of consolidated volcanic ash, glass shards, and other rock fragments, a material non-local to northcentral Texas. The nearest source of tuff is the Ouachita Mountains of western Arkansas; the second closest source is likely West Texas, possibly the Davis or Glass mountains.

Various proposed interpretations of boatstones include their functioning as atl atl weights, small vessels, censers, and/or as ceremonial items. Although they are perhaps most often associated with the Hopewell Culture, in Texas, boatstones are found in eastern and Gulf Coast regions of the state in Archaic and Woodland cultural contexts. Whole boatstones are often found in mortuary contexts. However this artifact is broken and found in a midden context where it was likely discarded. Due to its exotic raw material and rarity this artifact is considered to be a nonutilitarian object. 


\section{Ground Stone/Chopper}

A natural tabular piece of fossiliferous limestone (FS 254/256/311) exhibits characteristics of having been used for both grinding and chopping (Figure 71). This piece exhibits irregular patches of smoothing on one rather rough surface. The remaining surface exhibits no ground surfaces. More interesting, however, is the general shape of the piece and the presence of unifacial retouch along $48 \mathrm{~mm}$ of one edge. What appears to be the distal end has suffered damage. The general shape and nature of the tool appears to resemble artifacts that have been designated "choppers" in the literature previously (Gwin 1941:41-43; Peter et al. 1988:72-73, 212). The exact function of these tools is unknown; however, they may have been used to chop wood, crush bones, or as a digging tool.

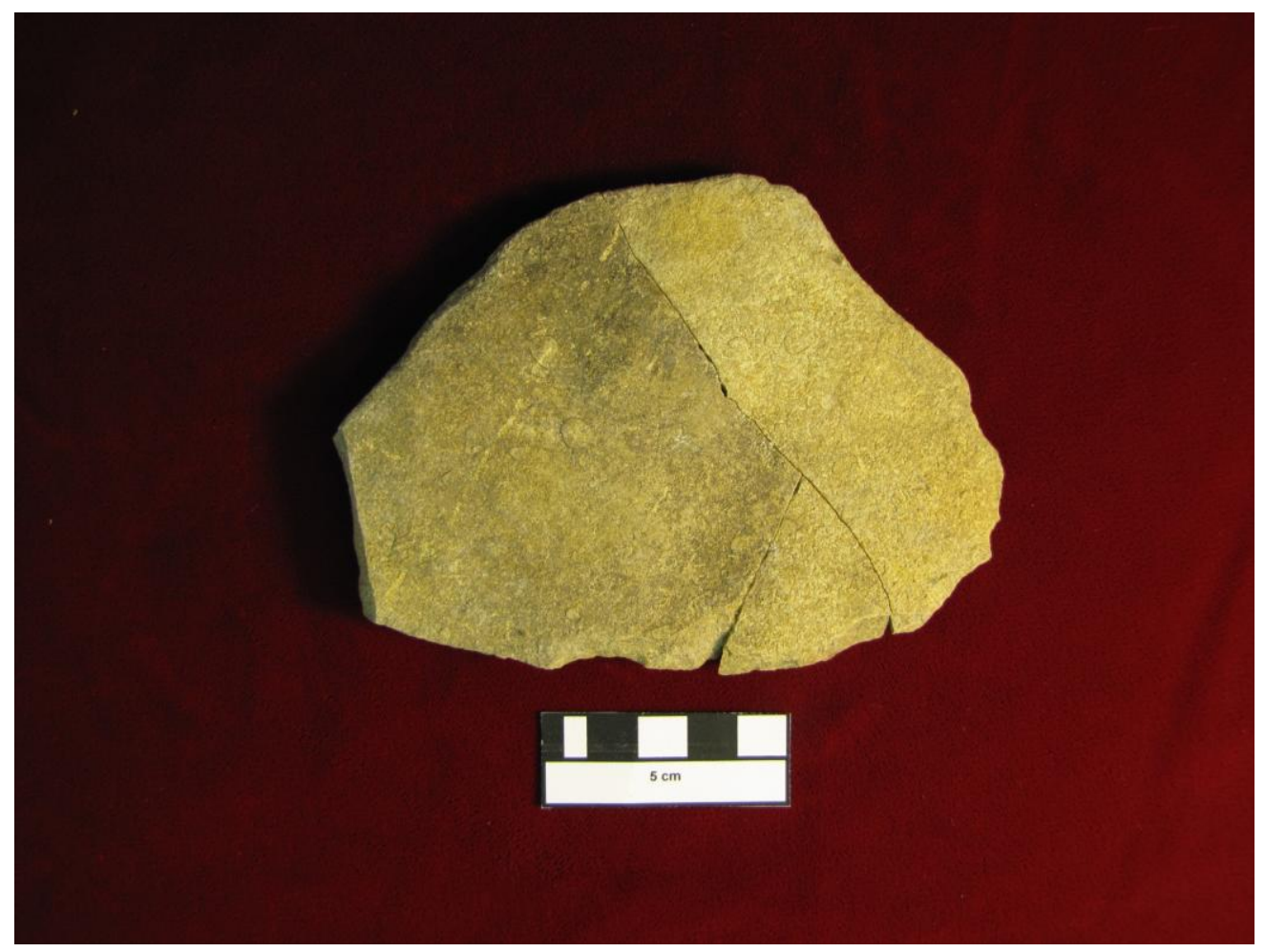

Figure 71. Ground stone/chopper recovered from site 41TR198. 
Previously discovered specimens have been recovered from southwestern Dallas County and Ellis County. These specimens are typically more robust than this specimen from site 41TR198. They are typically $4 \mathrm{~cm}$ thick, 8-9 cm wide, and 10-13 cm long. Both site 41DL199 and site 41DL149 at Joe Pool Lake yielded these chopper tools from Late Archaic and Late Prehistoric period contexts (Peter et al. 1988:72-73, 212). The specimen from site 41TR198 is much smaller; consequently, it suffered damage and was discarded. Three pieces, which mended, were found in Units 20 (Level 9, 98.55 - $98.50 \mathrm{~cm}$ ), 21 (Level 9, 98.55 - $98.50 \mathrm{~cm}$ ) and 22 (Feature 8, 98.65 $98.56 \mathrm{~cm})$, a context that dates to A.D. $900-960$.

\section{Ground Stone Summary}

In general the ground stone artifact assemblage at 41TR198 is indicative of a medium intensity Archaic period resource processing site. Ground stone artifacts were found in two subsurface contexts, occupational surfaces and in secondary refuse contexts. Overall the character and scale of the ground stone assemblage are indicative of a moderate intensity occupation. The huntergatherer groups who occupied the Crooked Oxbow Site were not practicing a well developed ground stone industry; tool types were not formalized. Instead they are expedient, simple and presumably effective. Two of the four manos are multi-use implements with two different grinding surfaces. These are not refurbished tools, instead they are a form of "Swiss Army knife" capable of at least two grinding tasks. Such multi-use tools would have been particularly valuable for mobile hunter-gatherers, who would have wanted to limit the amount of heavy and bulky ground stone that they needed to carry from place to place.

The ground stone assemblage is not large enough and discard rates not high enough to represent systematic reuse of ground stone for thermal cooking stone. However, it is clear that when ground stone was discarded it was often done so in a thermal context, i.e. along with ash and other thermal waste. On the other hand the propensity to reuse ground stone as thermal cooking rock appears to have been minor at this site as only one ground stone artifact is actually fire cracked. 


\section{Bone and Antler Tools}

Four bone or antler tool fragments were recovered from the Crooked Oxbow Site (Table 39 and Figure 72). Two consist of bone while two are composed of antler. All were recovered by means of $6.35 \mathrm{~mm}\left(1 / 4^{\prime \prime}\right)$ dry screening. Criteria useful for identifying the function of bone and antler tools based on use-wear (Griffitths and Waters 2005:128-139) were followed.

Table 39

Summary of the Crooked Oxbow Site Bone and Antler Tool Assemblage

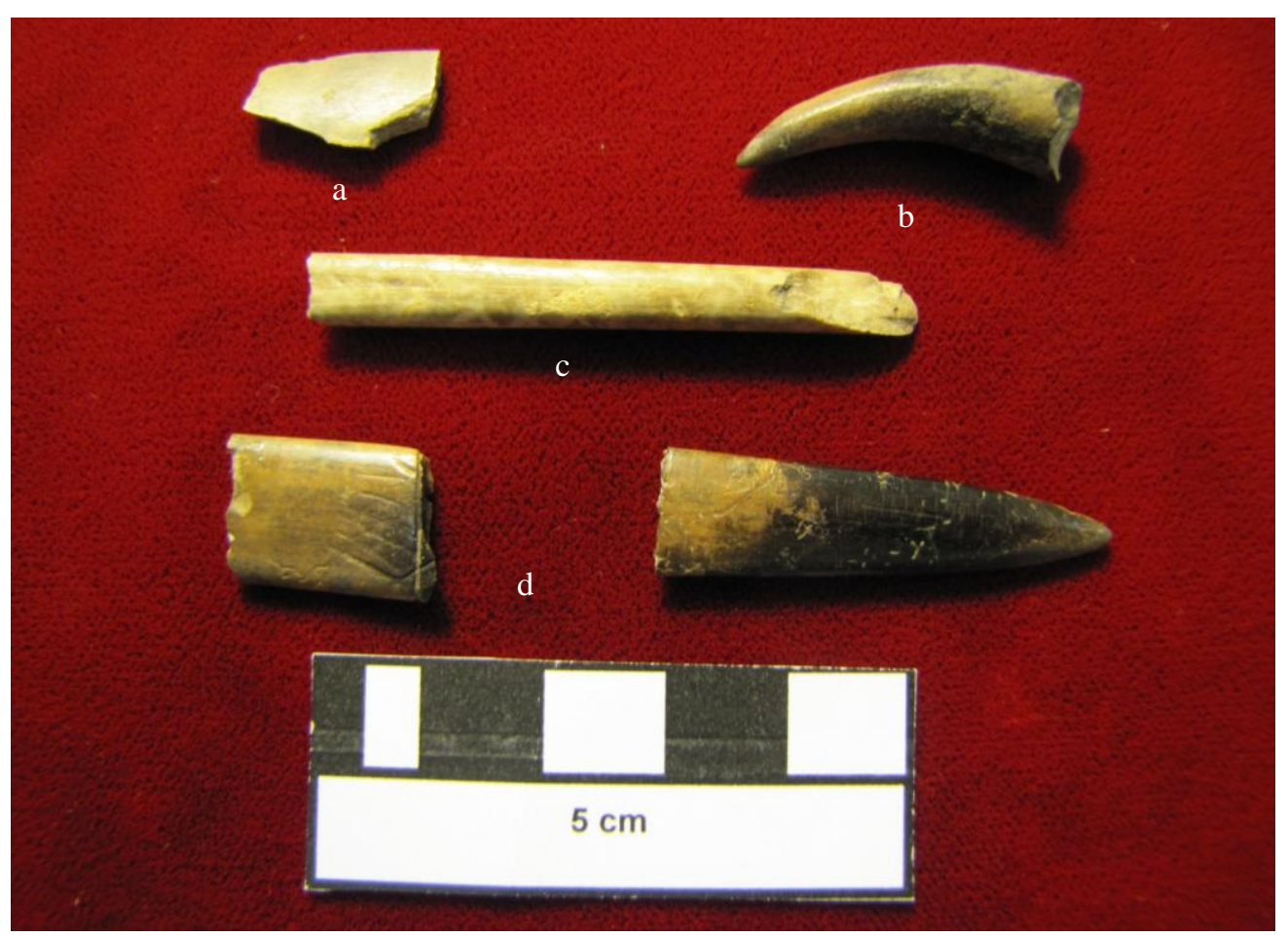

Figure 72. Bone tool assemblage from site 41TR198: (a) bone awl fragment (FS 594); (b) antler tine awl (FS 174); (c) antler awl (FS 219); and (d) bone awl fragments (FS 454). 


\section{Bone Awls}

\section{Lanceolate Awl (FS 454)}

This artifact is a burnished, worn bone awl that is broken into two non articulating pieces. This artifact was recovered from Feature 33 (Block 3; $98.4-98.35 \mathrm{~cm}$ ). The medial portion of the artifact is missing, but the distal and proximal sections are intact. This awl is best described as lanceolate in shape. It has a pointed tip and flat sides. The distal end of the artifact appears to have been formed by the scoring of the bone around the circumference of the tool which was then snapped leaving a lipped break. There is also a series of six parallel, horizontal lines emanating out from the base of the tool, each about $6 \mathrm{~mm}$ in length. These marks do not appear to be incidental; they are probably decorative and/or intended to provide a small gripping platform.

The initial $33 \mathrm{~mm}$ of the proximal end of the awl is black and heavily burnished. It also has macroscopic evidence of multidirectional (particularly longitudinal) striations and pitting. The distal segment of the artifact has a color pattern perhaps analogous to the fire-clouds sometimes seen on aboriginal pottery; however this taphonomy is inferred based on the recovery of the artifact in a thermal context. According to Griffitths and Waters' (2005:128-131) the pattern of use wear demonstrated by this awl is most characteristic of hide or leather working activities as opposed to plant processing, woodworking, or pressure flaking.

\section{FS 594}

FS 594 consists of a small piece of what may be a lanceolate or other flat bone awl measuring 18 x 11 x $3 \mathrm{~mm}$. Little can be said about this small splintered artifact other than it is hypothetically similar to FS 454. The use wear demonstrated by this artifact is similar, but not as extreme as the former. 


\section{Antler Tools}

\section{Cylindrical Awl (FS 219)}

FS 219 is an antler awl shaft fragment that could also possibly be described as a pin. Both the proximal and distal ends of the artifact are broken and absent. It was recovered from a non feature context in Block 3. This awl is crafted out of antler rather than bone. Either end of this artifact is broken; leaving an extant near cylindrical tool that is on average about $5.5 \mathrm{~mm}$ in diameter. Although at first glance this tool appears parallel sided, it does in fact taper from one end to the other, from 6.3 to $5.5 \mathrm{~mm}$. The surface of this artifact exhibits strong lateral striations, pitting, and polishing. With regard to Griffitths and Water's use-wear classification (2005:128131) this pattern of wear appears to be most characteristic of hide or leather working activities. This artifact does not appear to have been thermally modified.

\section{Tine Awl (FS 174)}

This antler tool consists of a curved antler tine that is $31 \mathrm{~mm}$ in length. It exhibits a high degree of use wear including burnishing, striations, lateral scars, pitting, and polishing. Such wear indicates that this artifact functioned as a perforator (an awl) used repeatedly on a relatively soft, pliable material. The proximal $12 \mathrm{~mm}$ of the tine are polished quite smooth and worn down. The remainder exhibits a black burnish similar to that seen on FS 454. The black burnish is likely missing from the tine tip due to the extent of wear and polish. According to Griffitths and Water's (2005) criteria the patterns of wear appear consistent with leather or hide working, in which case this tool, in its non broken form, likely served as a hide/leather punch.

\section{Bone and Antler Tools Summary}

The bone and antler tool assemblage recovered at the Crooked Oxbow Site consisted of five artifacts, one nearly complete bone lanceolate awl, two small fragmentary pieces of what also appears to be an awl, one cylindrical antler awl, and one antler tine awl. Generally, the bone and antler tool assemblage is indicative of a hunter-gatherer population practicing curatorial 
technology. All three of the near complete bone or antler implements exhibit use-wear typical of hide or leather working activities, including extensive polishing, parallel and multidirectional striations, and limited pitting.

\section{Fire-cracked Rock}

In the Geo-Marine laboratory, fire-cracked rock collected at the site was washed, sorted, and analyzed according to the protocols described in Chapter 5. Fragments were divided into the following size classes:

Class A: smaller than 0.5 in $(<12.7 \mathrm{~mm})$

Class B: $0.5-1$ in $(12.7-25.4 \mathrm{~mm})$

Class C: $1-1.5$ in $(25.4-38.1 \mathrm{~mm})$

Class D: $1.5-2$ in $(38.1-50.8 \mathrm{~mm})$

Class E: $2-4$ in $(50.8-101.6 \mathrm{~mm})$

Class F: 4-6 in (101.6-152.4 mm)

At site 41TR198, several features were examined that contained burned rock, or in some cases, were defined by the cluster of burned rock. Data recovery resulted in the collection of 263.3 kilograms of fire-cracked rock $(n=6,729)$, most of which was recovered from Blocks 3 (99.4 kilograms; $n=2,103)$ and 4 (131.7 kilograms; $n=4,009)$. As expected along the West Fork of the Trinity River, limestone is the primary raw material source for the fire-cracked rock (Table 40).

Table 40

Fire-cracked Rock by Material Type

\begin{tabular}{|c|c|c|}
\hline Material Type & Quantity (n) & Weight (kg) \\
\hline Limestone & 6,588 & 257.8 \\
\hline Quartzite & 60 & 3.8 \\
\hline Sandstone & 67 & 1.6 \\
\hline Hematite & 5 & 0.01 \\
\hline Chert & 7 & 0.08 \\
\hline Conglomerate & 2 & 0.01 \\
\hline Total & 6,729 & 263.3 \\
\hline
\end{tabular}


Comparison of the vertical distribution of the fire-cracked rock in these two blocks (Figures 73 and 74) is difficult due to the effects of the different stratigraphic contexts, for Block 3 represents over 1,000 years of occupation while Block 4 represents a significantly lesser period, perhaps no more than 600 years. However, if one compares roughly comparable time periods for the two blocks (Block 3, Zones 4 and 5 [A.D. 250 - 700] and all of Block 4), it is very obvious that thermal activities requiring fire-cracked rock are significantly more prevalent in the Block 4 sample. In Block 3, fire-cracked rock is truly a significant part of the assemblage between A.D. 700 and 900 only. The differences between the two areas sampled are particularly significant when one compares the overall weight of the fire-cracked rock in relation to the volume of soil matrix excavated $\left(14.7 \mathrm{~kg} / \mathrm{m}^{3}\right.$ in Block 3 [A.D. $250-700$ ] versus $17.1 \mathrm{~kg} / \mathrm{m}^{3}$ in Block 4).

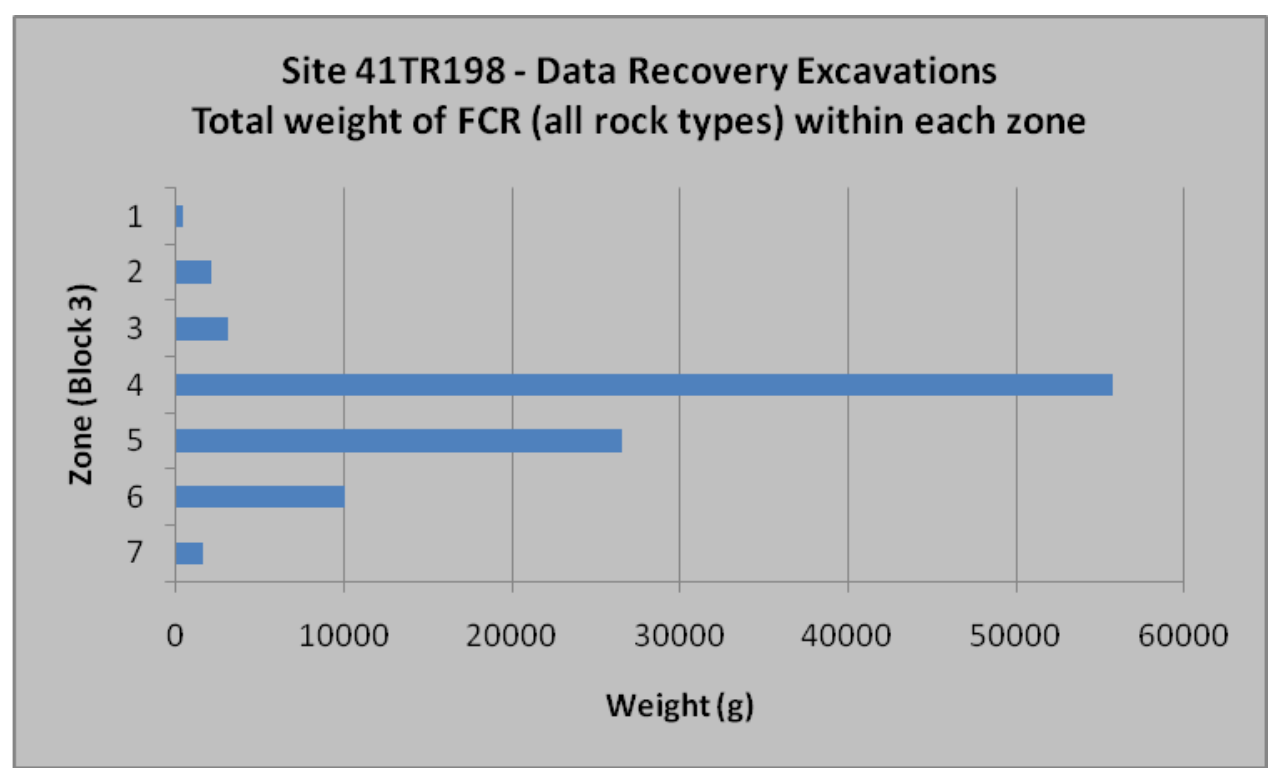

Figure 73. Total weight of FCR in Block 3.

Fire-cracked rock is a common class of archaeological materials throughout North America (Thoms 2009) and is of particular interest in central Texas, where fire-cracked rock concentrations - variously dubbed burned rock middens, thermal features, and rock ovens, among other terms- "have long received a large share of archaeologists' attention" due to their ubiquity(Collins 2004:109). Despite this attention, little progress linking fire-cracked rock patterns to particular activities or behavior patterns was made until the 1990s, when a flurry of studies, ably reviewed in Collins's recent synthesis of Central Texas archaeology, resulted in "the 


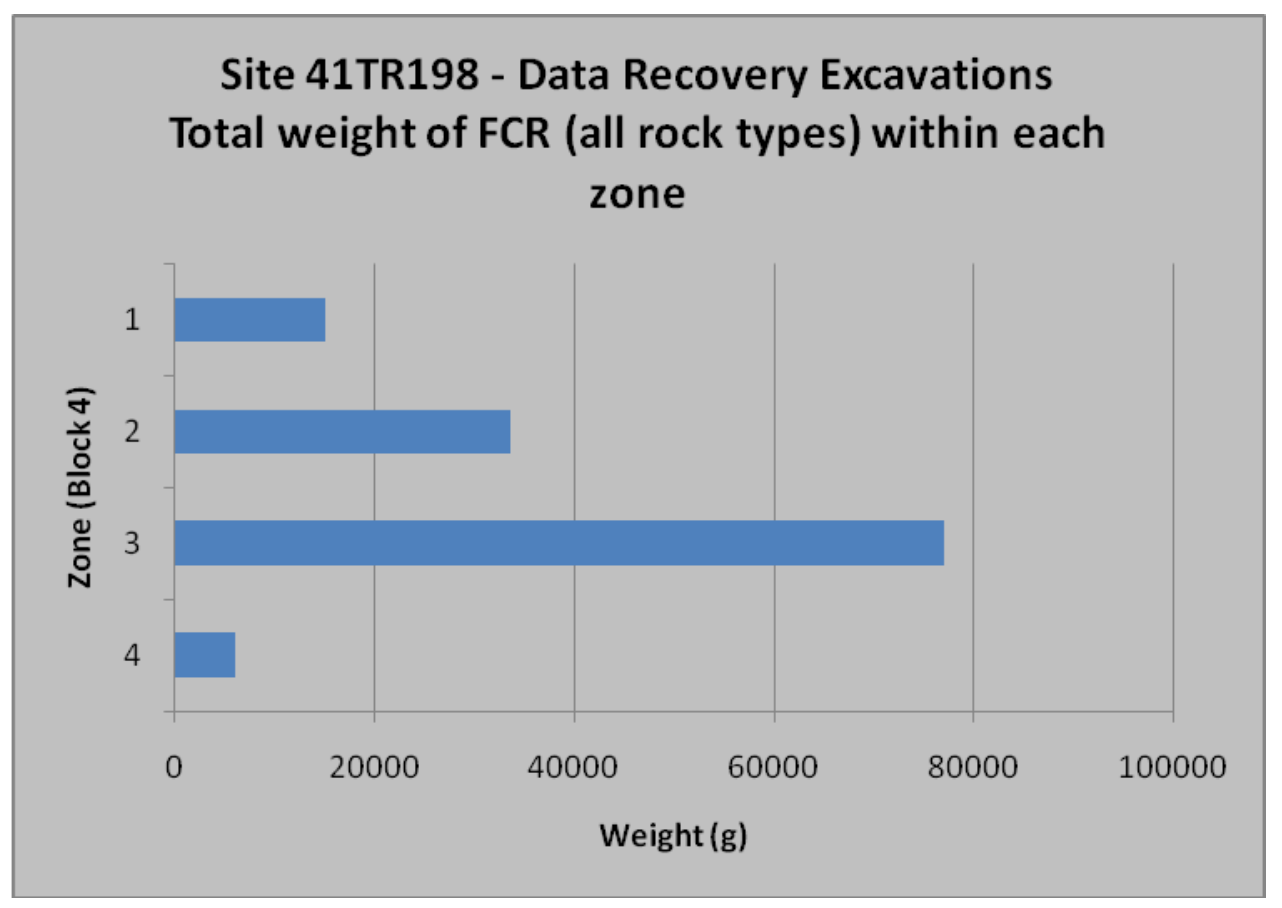

Figure 74. Total weight of FCR in Block 4.

single most fundamental conceptual advance in burned rock midden research . . . [the] recognition that burned rock middens likely formed in several different ways" (Collins 2004:109). Although fire-cracked rock is present on a far smaller scale in northcentral Texas (for a rare exception, see Lintz et al. 2008), it is nonetheless an important material class with the potential to illuminate changes in behavior patterns, particularly at a stratified site where a particular locality may be used for different purposes or in a different way during different periods. Since Collins's synthesis, recent studies have produced data and models with implications beyond Central Texas, some focusing on fire-cracked rock fragment morphology (e.g., Backhouse and Johnson 2007) and others on fire-cracked rock size distributions as an indicator of repeated reheating (e.g., Pagoulatos 2005; Thompson and Mauldin 2008).

Thompson and Mauldin's (2008) work is particularly useful, with experimentally derived models of size distributions tested against archaeological assemblages from 41KM69, a Central Texas site with several dozen fire-cracked rock features dating from the middle of the Late Archaic period (ca. 2,500 yr B.P.) to the end of the Late Prehistoric period (after $500 \mathrm{yr}$ B.P.). In sum, Thompson and Mauldin find generally consistent patterns of moderate to low fire-cracked rock 
reuse, indicated by fire-cracked rock collections with fewer small fragments and more mid-sized larger fragments, throughout the Late Archaic and the initial portion of the Late Prehistoric period (Figure 75a). Then, they document fire-cracked rock collections at the end of the Late Prehistoric period dominated by smaller fragments, a trend interpreted as indicating greater fragmentation and therefore a higher degree of fire-cracked rock reuse (see Figure 75b).

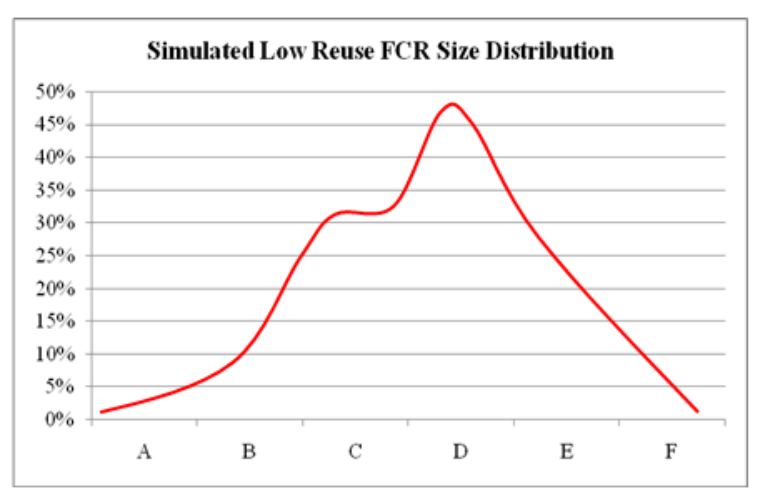

$\mathbf{a}$

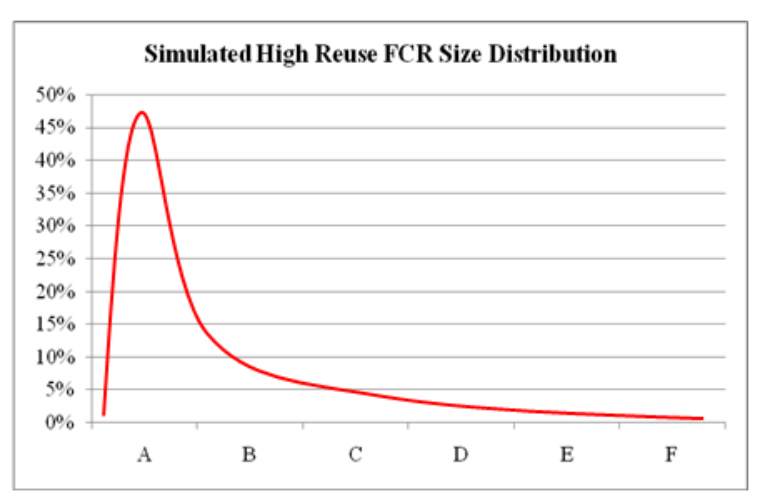

$\mathbf{b}$

Figure 75. Simulated size curves indicating (a) low reuse activity, and (b) high reuse activity (after Thompson and Mauldin 2008). The $\mathrm{X}$ axis letters refer to ascending size classes discussed above.

Thompson and Mauldin (2008) associate this change with the adoption of a subsistence regime focusing on intense processing of low-return plant foods, probably chosen due to increasing populations and decreasing game availability. These points are expanded to a continental scale by Thoms (2009), who proposes a similar trend in an ambitious fire-cracked rock use model based on ethnographic, archaeological, and experimental data from across North America and representing the entire Holocene. It must be stated, however, that at the same time Thoms's model predicts more fire-cracked rock due to greater plant-food processing, it does allow for a decrease corresponding to the use of ceramics, which would obviate the need for stone boiling, a key fire-cracked rock-producing activity in some regions (Thoms 2009).

To test the site's fire-cracked rock assemblage against the simulated curves produced by Thompson and Mauldin (2008), the collected fire-cracked rock was plotted as a series of relative frequency diagrams with columns representing the percentage contribution of each size class for the collection in each zone of Blocks 3 and 4 (Figures $76-81$ ). Within Block 3 the distributions 

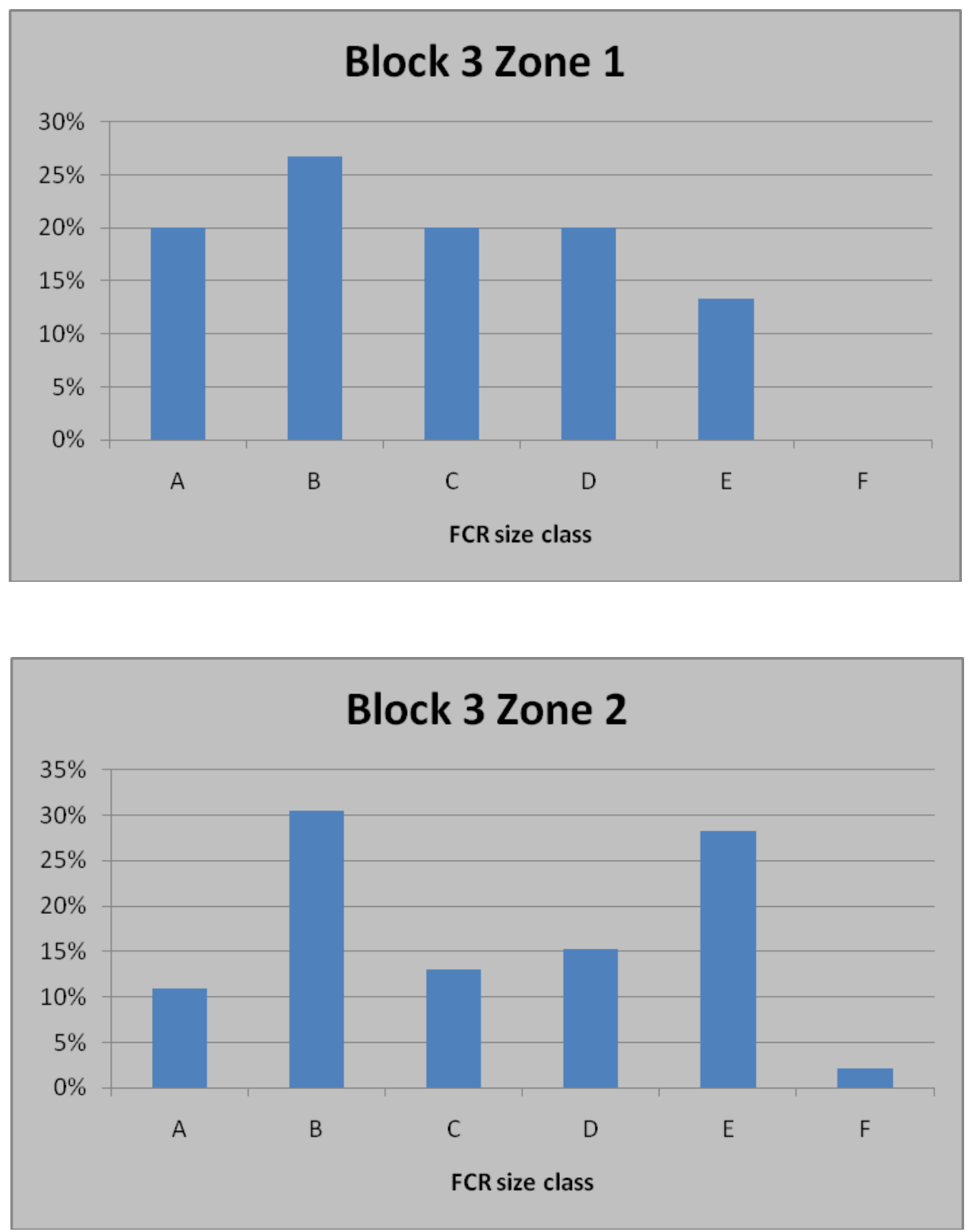

Figure 76. FCR size classes in Block 3, Zones 1 and 2. 

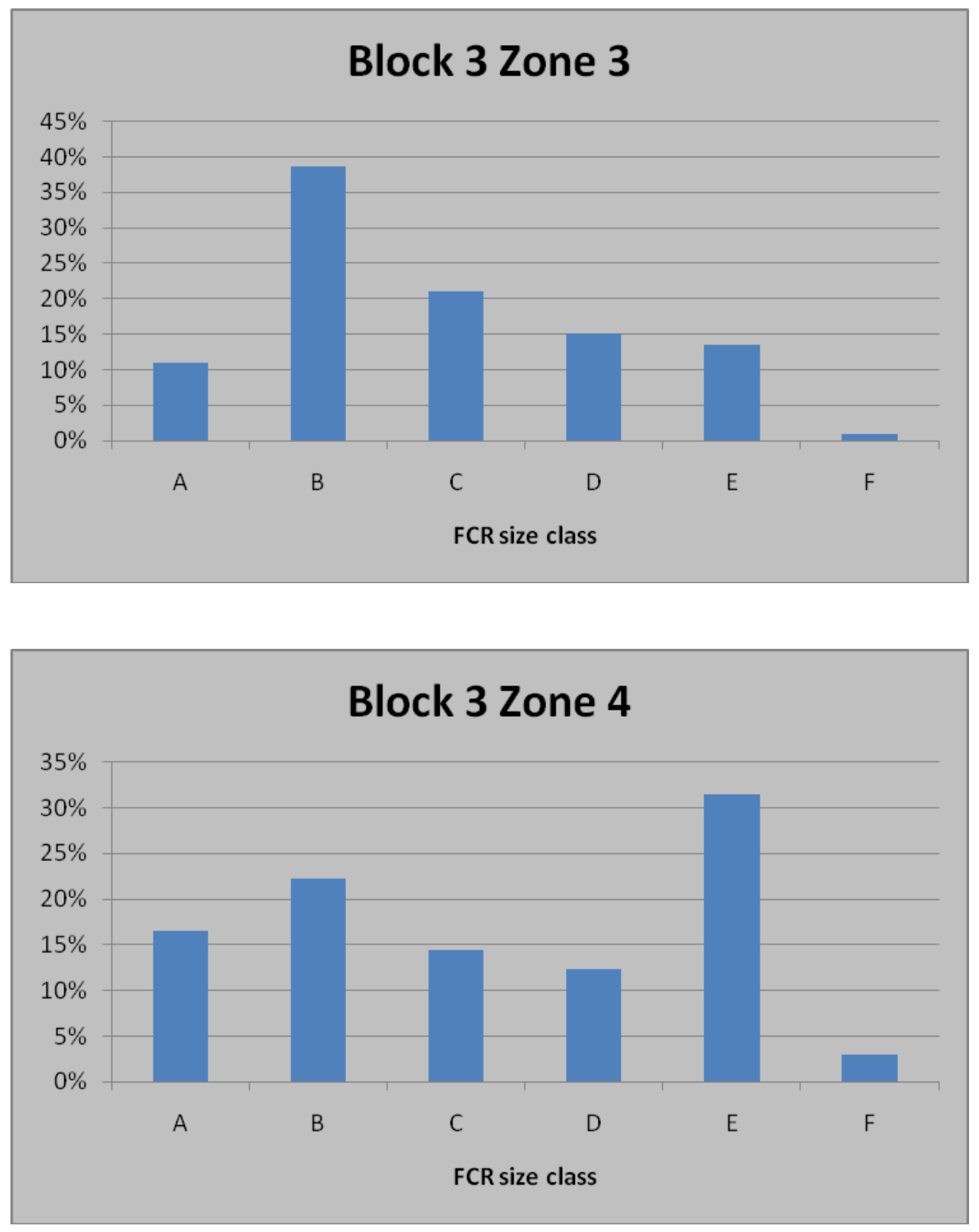

Figure 77. FCR size classes in Block 3, Zones 3 and 4. 

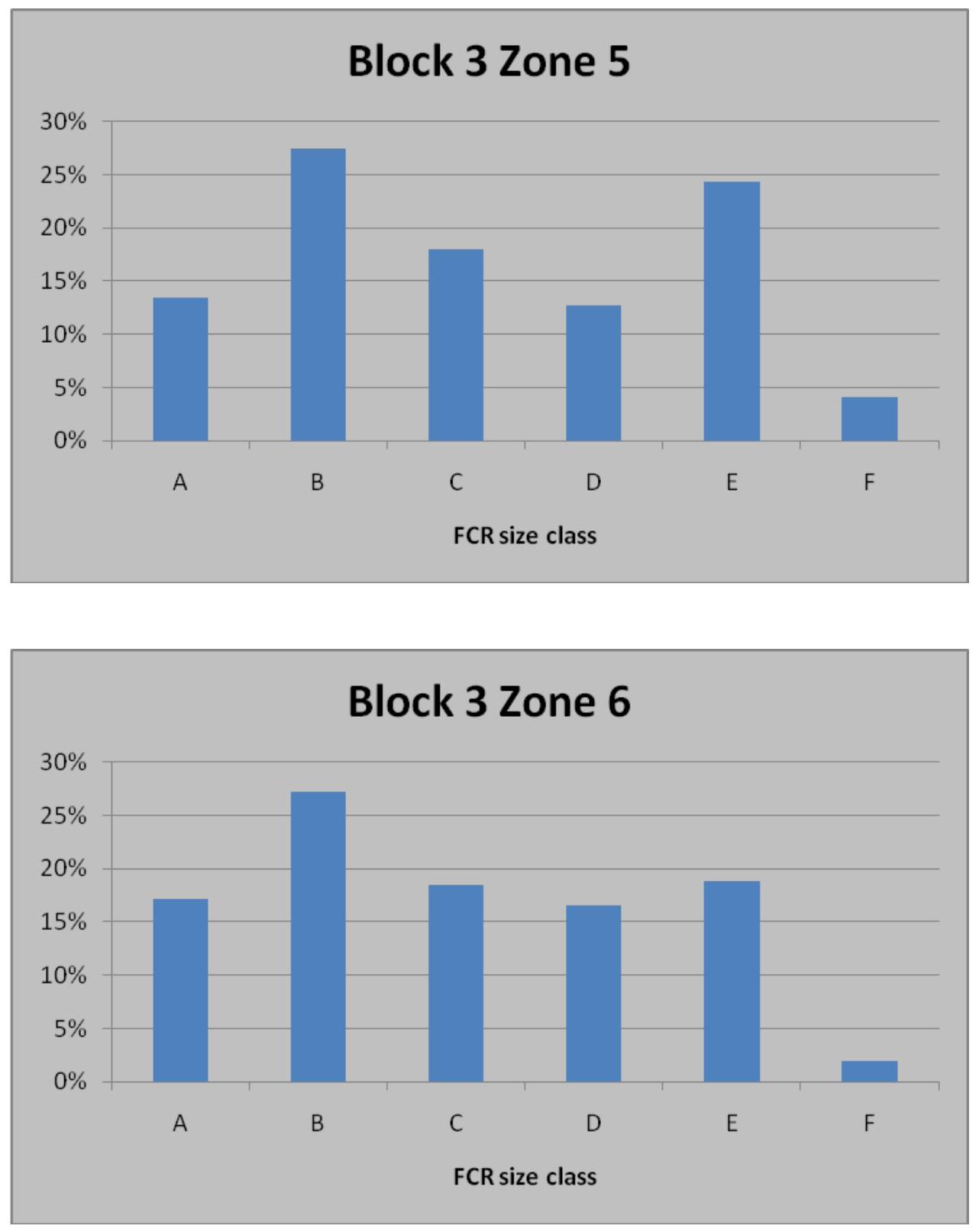

Figure 78. FCR size classes in Block 3, Zones 5 and 6. 


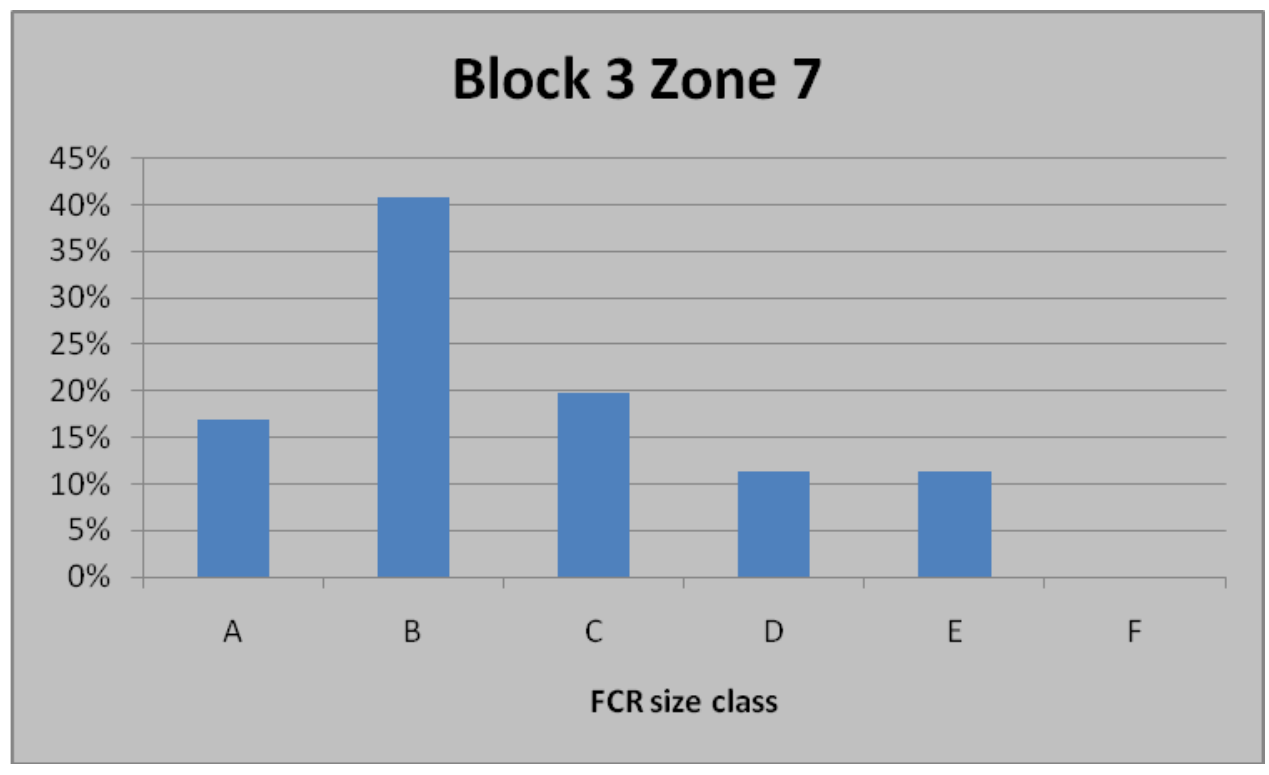

Figure 79. FCR size classes in Block 3, Zone 7.

vary by zone. The fire-cracked rock size distributions in Zones 1 and 2 reflect medium reuse. In Zone 3, the dominance of fire-cracked rock that is less than an inch in cross-section reflects more intensive reuse of the rock. Zone 4, where the greatest majority of the fire-cracked rock was recovered, and Zones 5 and 6 reflect a pattern more similar to that of Zones 1 and 2. The low sample size in Zone 7 (1,578 gm) likely skews the results for Zone 7, for there is little evidence of intensive occupation, but the size distribution suggests intensive reuse of the fire-cracked rock. Within Block 4 (see Figures 80 and 81) the fire-cracked rock dimensions in Zones 1 and 3 reflect medium reuse while Zones 2 and 4 reflect more intensive reuse. It is interesting that the zones with the greatest density of fire-cracked rock (Block 3, Zone 4; Block 4, Zone 3) reflect a more even distribution of the size categories. Of course, this may merely reflect the fact that more intense thermal activities result in a broader distribution of rock fragments reflecting the whole range of cooking activities over an extended period of time. These patterns, however, reflect a pattern of reuse similar to that of the Late Archaic assemblages at site 41KM69 (Thompson and Mauldin 2009). 

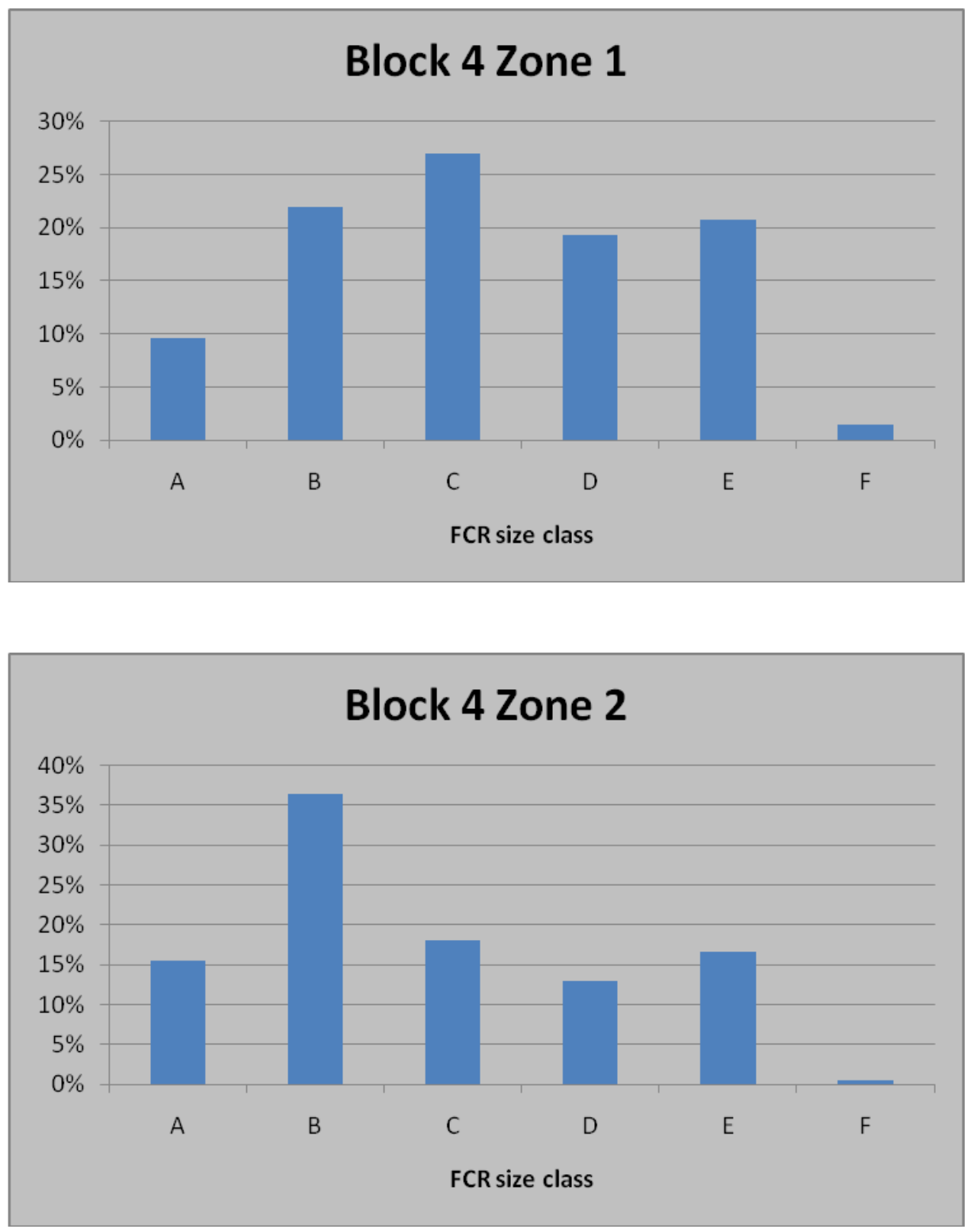

Figure 80. FCR size classes in Block 4, Zones 1 and 2. 

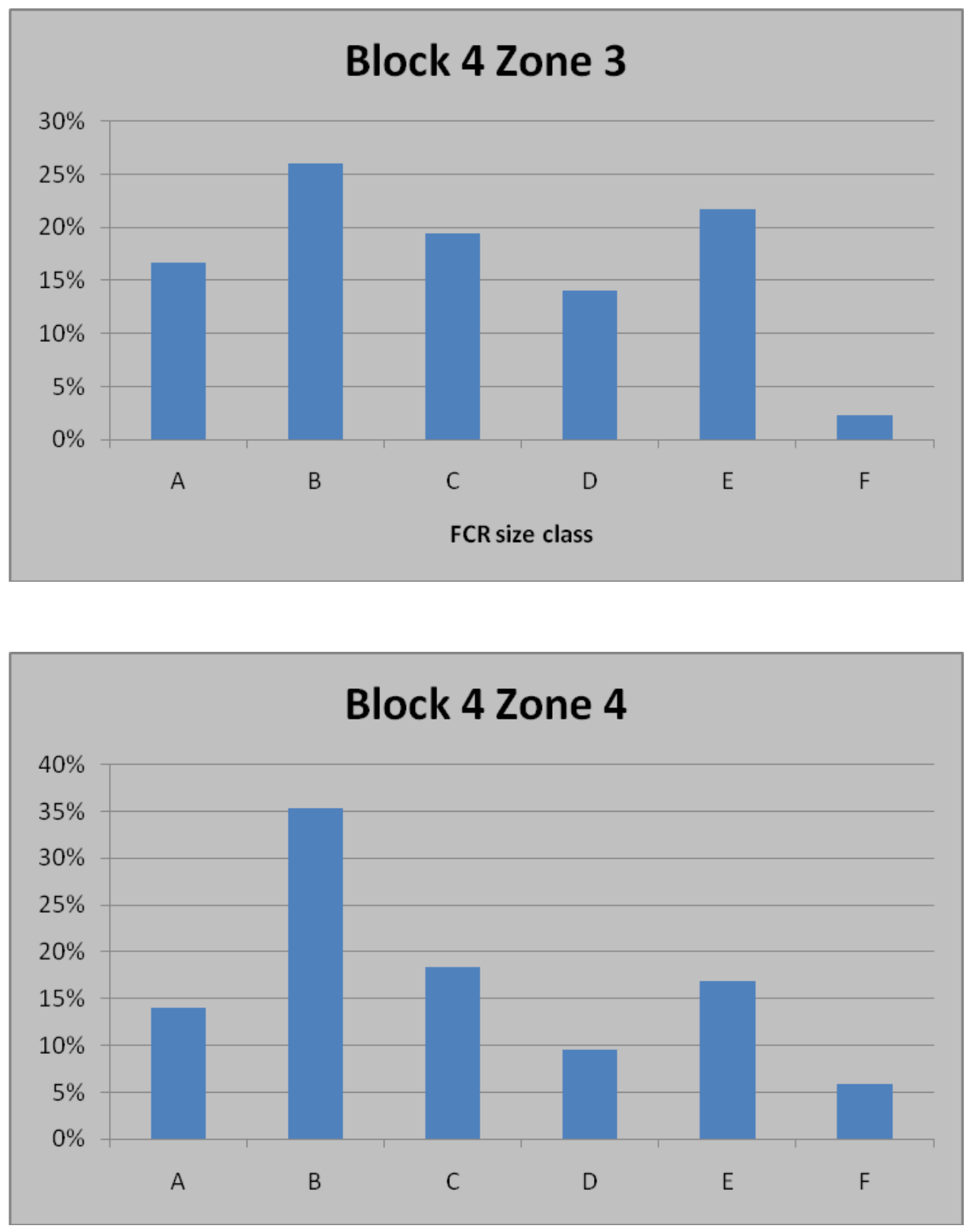

Figure 81. FCR size classes in Block 4, Zones 3 and 4. 


\section{CHAPTER 10 SUBSISTENCE RESOURCES RECOVERED AT SITE 41TR198}

\section{INTRODUCTION}

This chapter presents data recovered from site 41TR198 that provide information related to the subsistence practices of the inhabitants of the site and potentially related to environmental conditions at the time. The vertebrate faunal analysis was conducted by Ms. Julie Densmore of the University of North Texas. Mr. Ben Fullerton of Geo-Marine examined the vertebrate fauna in relation to the prey choice model and dietary breadth. Mr. Charles Randklev of the University of North Texas, under the supervision of Dr. Steve Wolverton, conducted the molluscan faunal analysis. Dr. Phil Dering provided the macrobotanical analysis.

\section{FAUNAL ASSEMBLAGE}

A total of 7,065 bones and bone fragments was recovered from the Crooked Oxbow site (41TR198). Table 41 lists the total bone count by block and level. The majority of the faunal remains were recovered from Block 3 (55.6\%), followed by Block 4 (38.5\%). It should be noted that the level numbers are not universal between blocks/units and begin and end at different depths depending on the location. Therefore, the faunal remains will be discussed in relation to the individual each block. The nature of the faunal assemblage from site 41TR198 is fairly typical for northcentral Texas. White-tailed deer, turkey, eastern cottontail rabbit, black-tailed jack rabbit, 3 species of turtle, snakes, 5 species of freshwater fish, and various small mammals and rodents comprise the faunal assemblage (Table 42). Overall preservation at this site is good, 
Table 41

41TR198 Faunal Counts by Block and Level*

\begin{tabular}{|c|c|c|c|c|c|c|}
\hline \multirow[b]{2}{*}{ Level } & \multicolumn{5}{|c|}{ Block } & \multirow[b]{2}{*}{ Total } \\
\hline & 0 & 1 & 2 & 3 & 4 & \\
\hline 1 & & & 37 & 1 & 12 & 50 \\
\hline 2 & & 2 & & 20 & 142 & 164 \\
\hline 3 & & & & 54 & 304 & 358 \\
\hline 4 & & & & 35 & 793 & 828 \\
\hline 5 & & 2 & & 46 & 562 & 610 \\
\hline 6 & & 31 & & 86 & 328 & 445 \\
\hline 7 & & 7 & & 84 & 66 & 157 \\
\hline 8 & & 17 & & 77 & 44 & 138 \\
\hline 9 & & 3 & & 100 & 89 & 192 \\
\hline 10 & & 12 & & 147 & 139 & 298 \\
\hline 11 & & 1 & & 94 & 139 & 234 \\
\hline 12 & & & & 92 & 39 & 131 \\
\hline 13 & & & & 101 & 16 & 117 \\
\hline 14 & & & & 239 & & 239 \\
\hline 15 & & & & 339 & & 339 \\
\hline 16 & & & & 1040 & & 1040 \\
\hline 17 & & 1 & & 434 & 11 & 446 \\
\hline 18 & & 9 & & 215 & & 224 \\
\hline 19 & & 2 & & 12 & & 14 \\
\hline 20 & & 8 & & 13 & & 21 \\
\hline 21 & & 25 & & 1 & & 26 \\
\hline 22 & & 9 & & 4 & & 13 \\
\hline 23 & & 8 & & 1 & & 9 \\
\hline 24 & & & & 14 & & 14 \\
\hline 25 & & & & 52 & & 52 \\
\hline 26 & & & & 41 & & 41 \\
\hline 27 & & & & 306 & & 306 \\
\hline 28 & & & & 13 & & 13 \\
\hline 29 & & & & 15 & & 15 \\
\hline 30 & & & & 1 & & 1 \\
\hline $35 / 36$ & & & & 1 & & 1 \\
\hline \multirow{2}{*}{$\begin{array}{c}\text { Trench/Other } \\
\text { Total }\end{array}$} & 20 & 147 & 68 & 253 & 42 & 501 \\
\hline & 20 & 284 & 105 & 3,930 & 2,726 & 7,065 \\
\hline
\end{tabular}

*Levels in blocks do not correspond with each other 
Table 42

41TR198 Taxon Counts by Block

\begin{tabular}{|c|c|c|c|c|c|c|}
\hline \multirow[b]{2}{*}{ Taxon } & \multicolumn{5}{|c|}{ Block } & \multirow[b]{2}{*}{ Total } \\
\hline & 0 & 1 & 2 & 3 & 4 & \\
\hline Largemouth bass & & & & 2 & & 2 \\
\hline Black rat & & & & 1 & & 1 \\
\hline Black-tailed jack rabbit & & 2 & & 7 & 4 & 13 \\
\hline Bobwhite quail & & 1 & & & & 1 \\
\hline Bowfin & & & & 5 & 1 & 6 \\
\hline cf cotton mouth & & & & 1 & 2 & 3 \\
\hline cf coyote & & & & 1 & & 1 \\
\hline $\mathrm{cf}$ fox & & & & & 4 & 4 \\
\hline cf mole & & & & 1 & & 1 \\
\hline cf raccoon & & & & 1 & & 1 \\
\hline cf Texas rat snake & & & & & 1 & 1 \\
\hline cf whip snake & & & & 4 & 2 & 6 \\
\hline Cotton rat & & & & 2 & 3 & 5 \\
\hline Coyote & & & & & 1 & 1 \\
\hline Deer & 1 & 23 & 5 & 108 & 39 & 176 \\
\hline Eastern cottontail rabbit & & 4 & & 23 & 45 & 72 \\
\hline Eastern fox squirrel & & & & 10 & 6 & 16 \\
\hline Freshwater catfish & & 4 & & 9 & & 13 \\
\hline Freshwater drum & & & & 6 & 2 & 8 \\
\hline Great horned owl & & & & & 1 & 1 \\
\hline North American beaver & & & & 3 & 6 & 9 \\
\hline Opossum & & 9 & & & & 9 \\
\hline Ornate box turtle & & & & 53 & 13 & 66 \\
\hline Plains pocket gopher & & 1 & & 8 & 3 & 12 \\
\hline Pocket gopher & & & & 1 & & 1 \\
\hline Pocket mouse & & & & & 2 & 2 \\
\hline Pond cooter & & & & 6 & 6 & 12 \\
\hline Prairie vole & & & & 1 & 1 & 2 \\
\hline Raccoon & 4 & & & 6 & 2 & 12 \\
\hline Red fox & & & & & 1 & 1 \\
\hline Red-eared slider & & & & 188 & 135 & 323 \\
\hline Shell & & & & 1 & 1 & 2 \\
\hline Spiny softshell turtle & & 2 & & & & 2 \\
\hline Turkey & & & & 10 & 20 & 30 \\
\hline Unid & & 4 & & 21 & 18 & 43 \\
\hline Unid bird & & 26 & & 153 & 235 & 414 \\
\hline Unid box turtle & & & & 13 & 12 & 25 \\
\hline Unid fish & & 10 & 2 & 81 & 22 & 115 \\
\hline Unid gar & & & & & 13 & 13 \\
\hline Unid mammal & 13 & 160 & 93 & 2,851 & 1,813 & 4,930 \\
\hline
\end{tabular}


Table 42 (cont'd)

\begin{tabular}{lcccccc} 
& \multicolumn{7}{c}{ Block } & \\
\cline { 2 - 6 } Taxon & 0 & 1 & 2 & 3 & 4 & Total \\
\hline Unid pond turtle & & & & & 11 & 11 \\
Unid quail & & & 1 & & 1 \\
Unid rabbit & & & & 22 & 22 \\
Unid rat & 1 & 10 & & 62 & 56 & 129 \\
Unid rodent & & & 1 & & 5 & 6 \\
Unid snake & 1 & 17 & 2 & 195 & 101 & 316 \\
Unid turtle & & 11 & 2 & 92 & 117 & 222 \\
White-tailed deer & & & & 2 & & 2 \\
Wood rat & & & & & \\
$\quad$ Total & 20 & 284 & 105 & 3,930 & 2,726 & 7,065 \\
\hline
\end{tabular}

for the complete elements of very small rodents and even delicate fish elements were recovered. However, nearly 70 percent of the remains recovered are fragmented and only identifiable to a general group such as mammal, bird, or fish. There are 1,435 long bone fragments from large and small mammals, as well as birds. Of these fragments, 90 percent are spirally fractured. The total count of spirally fractured bones was 2,574 , and the long bones account for 50 percent of the fragments in this category.

There are 621 bones and bone fragments that were recovered from features (Table 43). The faunal remains from each individual feature are presented in the following discussion of the features.

Three hundred and twenty bone fragments have been thermally altered, the degree ranging from partially carbonized to calcined (Table 44). The majority of these come from Blocks 3 and 4.

\section{Block 1 Faunal Remains}

Two hundred and eighty-four bones and bone fragments were recovered from the Block 1 excavation (Table 45). The distribution of the bones is fairly even between Units 1 through 3, with less material coming from Unit 4. A large majority of the bones from Block 1 are undetermined mammal fragments (53\%). Of the 30 mammal long bones, 26 are spirally fractured. Over 78 percent of the bones from Block 1 have spiral fracture patterns. 
Table 43

41TR198 Faunal Remains from Features

\begin{tabular}{|c|c|c|c|c|c|c|}
\hline \multirow[b]{2}{*}{ Feature } & \multicolumn{5}{|c|}{ Block } & \multirow[b]{2}{*}{ Total } \\
\hline & 0 & 1 & 2 & 3 & 4 & \\
\hline 2 & 10 & & & & & 10 \\
\hline 3 & 6 & & & & & 6 \\
\hline 5 & & & & 40 & & 40 \\
\hline 8 & & & & 43 & & 43 \\
\hline 10 & & & & 4 & & 4 \\
\hline 12 & 4 & & & & & 4 \\
\hline 15 & & & & 35 & & 35 \\
\hline 16 & & & & 4 & & 4 \\
\hline 17 & & & 63 & & & 63 \\
\hline 18 & & & & 1 & & 1 \\
\hline 21 & & & & & 34 & 34 \\
\hline 25 & & & & & 34 & 34 \\
\hline 27 & & 1 & & & & 1 \\
\hline 29 & & & & 216 & & 216 \\
\hline 30 & & & & 7 & & 7 \\
\hline 31 & & & & 2 & & 2 \\
\hline 38 & & & & 2 & & 2 \\
\hline 39 & & & & & 2 & 2 \\
\hline 41 & & & & 9 & & 9 \\
\hline 44 & & & & & 44 & 44 \\
\hline $44 / 45$ & & & & & 59 & 59 \\
\hline 8 and 29 & & & & 1 & & 1 \\
\hline Total & 20 & 1 & 63 & 367 & 173 & 621 \\
\hline
\end{tabular}

Table 44

Thermally Altered Bone

\begin{tabular}{ccccccc} 
Block & *Pcarb & Carb & Pcal & Cal & TAN & Total \\
\hline 1 & & 5 & 7 & 5 & & 17 \\
2 & & 2 & & 5 & 1 & 109 \\
3 & 2 & 39 & 13 & 54 & 89 & 187 \\
4 & 3 & 62 & 33 & 153 & 1 & 320 \\
Total & 5 & 108 & 53 & 153
\end{tabular}

* Pcarb = partially carbonized (blackened), Carb= carbonized (blackened), Pcal = partially calcined, and Cal = calcined. 
Table 45

41TR198 Block 1 Faunal Count

\begin{tabular}{|c|c|c|c|c|c|}
\hline \multirow[b]{2}{*}{ Level } & \multicolumn{4}{|c|}{ Unit } & \multirow[b]{2}{*}{ Total } \\
\hline & 1 & 2 & 3 & 4 & \\
\hline 2 & 2 & & & & 2 \\
\hline 3 & & & 2 & & 2 \\
\hline 5 & 1 & & & 1 & 2 \\
\hline 6 & & 26 & & 5 & 31 \\
\hline 7 & & 2 & 1 & 4 & 7 \\
\hline 8 & 6 & 4 & 7 & & 17 \\
\hline 9 & 5 & 3 & 3 & & 11 \\
\hline 10 & & & 2 & 10 & 12 \\
\hline 11 & 7 & 3 & 1 & 19 & 30 \\
\hline 12 & 4 & & & 10 & 14 \\
\hline 13 & 2 & 13 & & & 15 \\
\hline 14 & 5 & 10 & & & 15 \\
\hline 17 & 6 & 11 & 1 & & 18 \\
\hline 18 & & & 9 & & 9 \\
\hline 19 & 15 & 10 & & & 25 \\
\hline 20 & 10 & & 8 & & 18 \\
\hline 21 & 10 & & 25 & & 35 \\
\hline 22 & & & 9 & & 9 \\
\hline 23 & & & 8 & & 8 \\
\hline Other & 3 & 1 & & & 4 \\
\hline Total & 76 & 83 & 76 & 49 & 284 \\
\hline
\end{tabular}

The types of animals represented by the Block 1 faunal remains are listed in Table 46 . These bones and fragments will be discussed by level. They indicate at least 3 individual white-tailed deer based on ages derived from tooth wear and eruption patterns.

\section{Identified Faunal Remains Block 1}

The first levels yielded few identifiable remains, consisting of 2 rib fragments of a large mammal, and 3 unidentifiable fragments of bone. At Level 6, the remains of a white-tailed deer (Odocoileus virginianus) mandible with several teeth were recovered. Based on wear patterns this deer was approximately 6.5 years of age at the time of death. The Level 7 and 8 faunal remains consisted mainly of mammal fragments that could not be identified to any species, 8 turtle carapace fragments, and 3 unidentifiable fish fragments. 
Table 46

41TR198 Block 1 Taxa

\begin{tabular}{lc} 
Taxon & QTY \\
Black-tailed jack rabbit & 2 \\
Bobwhite quail & 1 \\
Deer & 23 \\
Eastern cottontail rabbit & 4 \\
Freshwater catfish & 4 \\
Opossum & 9 \\
Plains pocket gopher & 1 \\
Spiny softshell turtle & 2 \\
Unid & 13 \\
Unid bird & 26 \\
Unid fish & 10 \\
Unid mammal & 152 \\
Unid rodent & 9 \\
Unid turtle & 17 \\
White-tailed deer & 11 \\
$\quad$ Total & 284 \\
\hline
\end{tabular}

At Level 9 there is a single molar of a white-tailed deer (O. virginianus); based on wear patterns, this individual was approximately 4.5 years old at the time of death. There are also 2 large mammal long bone fragments that are partially calcined and have spiral fractures. One of the unidentifiable fragments has cut marks, and one is calcined.

The faunal remains from Level 11 include the complete humerus of a Plains pocket gopher (Geomys bursarius), the first phalanx of a black-tailed jack rabbit (Lepus californicus), and the carpal of a white-tailed deer (O. virginianus). In addition 4 vertebrae of a freshwater catfish were identified. It appears that this area may have served as a locus for discard at this point in time.

The remains in Levels 12 through 14 appear to indicate that the faunal refuse may have laid on the surface for a long period of time. Within Level 12 of Unit 1 the distal end of a humerus from an undetermined bird was recovered, along with a carbonated carapace fragment, and two mammal fragments. In Unit 4 there were three long bone fragments of a large mammal; they are spirally fractured and appear to be quite weathered. At Level 13 a distal femur fragment, and three mandible fragments (one with teeth) of an Eastern cottontail rabbit (Sylvilagus floridanus) 
were recovered. Two radius shafts of an undetermined bird were also found. The faunal remains from Level 14 consist mainly of mammal bones. Of the seven long bone fragments, only one is burned, and has been broken into three pieces that refit together. There are also two bird bones, one proximal femur and one femur shaft. The bones at this level have a high percentage of carnivore damage.

Levels 17 through 22 did not yield many identifiable bones. Feature 27, a pit feature in Unit 2, yielded a single bone, the fragment of a small mammal at Level 17. Also found at this level are the right proximal humerus of a quail that compares most favorably with a bobwhite quail (Colinas virginianus), along with 4 other long bone fragments of unidentified bird. There are also 2 carapace fragments of a Texas spiny soft-shell turtle (Apalone spinifera emoryi), a freshwater species. At Level 20 a carpal of a white-tailed deer was identified along with the shaft of a tibia bone from a small mammal that is calcined and appears weathered with numerous cracks on the surface of the bone. At Level 21, two white-tailed deer bones were recovered; the distal end of a second phalange and a carpal. There are also two rib fragments from a large mammal that have cut marks perpendicular to the length of the bone, a long bone fragment that is calcined, and a large fragment of a metacarpal (most likely deer) that has a spiral fracture pattern.

\section{Block 2 Faunal Remains}

There is a total of 105 bones and bone fragments recovered from the Block 2 excavations. Trenching activity uncovered 68 bones and fragments in Unit 8, and 37 bones were found at Level 1 in Units 15 and 11 (Table 47). The types of animals represented in this block are listed in Table 48. They consist mainly of unidentifiable fragments with the exception of a few whitetailed deer bones found in Feature 17. A large ulna fragment was recovered, along with the molar of a juvenile deer. There are four fragments of a scapula and the ball portion of a large femur that compare favorably to deer, but are missing the diagnostic landmark to be able to differentiate between species. Of the 71 mammal fragments, only three are spirally fractured long bones. Two of these fragments are burned; one is carbonized and the other calcined. 
Table 47

41TR198 Block 2 Faunal Count

\begin{tabular}{ccccc} 
& \multicolumn{5}{c}{ Unit } & Total \\
\cline { 2 - 5 } Level & 8 & 9 & 11 & 37 \\
1 & & 15 & 22 & 68 \\
\hline $\begin{array}{c}\text { Trench/Features } \\
\text { Total }\end{array}$ & 68 & & & 105 \\
\cline { 2 - 5 }
\end{tabular}

Table 48

41TR198 Block 2 Faunal Count

\begin{tabular}{lc} 
Taxon & QTY \\
\hline cf deer & 5 \\
Mammal & 71 \\
Testudinata & 2 \\
unid & 22 \\
Unid pisces & 2 \\
Unid snake & 1 \\
White-tailed deer & 2 \\
$\quad$ Total & 105 \\
\hline
\end{tabular}

\section{Block 3 Faunal Remains}

There is a total of 3,930 bones and bone fragments from the Block 3 excavation units. Table 49 lists the counts per unit and level. There is a general trend of increasing bone counts with depth in all excavation units from this block. The frequency of faunal elements is highest in Level 16. Almost one-third of the total faunal sample from Block 3 is represented in Level 16. The taxa represented in the Block 3 fauna are listed in Table 50 and include a variety of fish, birds, small mammals, turtles, deer, and snakes. The majority of the faunal elements are undetermined mammal fragments (72\%). Of these mammal bones, 550 are long bone fragments of both large $(n=312)$ and small $(n=201)$ mammals. Also included are 1,546 fragments of bone that cannot be identified to any particular element. There is a total of 881 bones from this group that have spiral fractures, and 173 that are burned ( 81 of those are calcined). There are 153 bird bones, and 137 are long bone fragments, 132 are spirally fractured. Eight bird bones are calcined. There are a total of 10 turkey bones from the Block 3 assemblage, mostly phalanges. 
Table 49

41TR198 Block 3 Faunal Count by Level and Unit

\begin{tabular}{|c|c|c|c|c|c|c|c|c|c|c|c|c|c|c|c|c|c|c|}
\hline \multirow[b]{2}{*}{ Level } & \multicolumn{17}{|c|}{ Unit } & \multirow[b]{2}{*}{ Total } \\
\hline & 7 & 12 & 13 & 20 & 21 & 22 & 23 & 24 & 25 & 26 & 27 & 28 & 29 & 30 & 31 & 32 & 33 & \\
\hline 1 & & 1 & & & & & & & & & & & & & & & & 1 \\
\hline 2 & 7 & & 1 & & 1 & & & 4 & 1 & & 2 & & & 4 & & & & 20 \\
\hline 3 & 2 & 1 & 1 & 1 & 1 & 1 & 1 & 5 & & 1 & 2 & 6 & 14 & 2 & 11 & 5 & & 54 \\
\hline 4 & 1 & & 4 & 2 & 3 & & & 6 & 3 & & 7 & 1 & 4 & 4 & & & & 35 \\
\hline 5 & 1 & 1 & 10 & 5 & 2 & & 1 & 3 & 3 & 5 & 1 & 1 & 2 & 3 & 8 & & & 46 \\
\hline 6 & & 1 & 4 & 2 & 1 & & 4 & 9 & 18 & 9 & 25 & 8 & 3 & 2 & & & & 86 \\
\hline 7 & & & 3 & 32 & 24 & & 15 & 1 & & 1 & 1 & & & & & & 7 & 84 \\
\hline 8 & & 15 & 9 & 12 & 13 & 2 & & 1 & 9 & 3 & 4 & 2 & 1 & & 3 & 3 & & 77 \\
\hline 9 & & 4 & 5 & 3 & 1 & 11 & 8 & 16 & 2 & 2 & 21 & 4 & 5 & 3 & 8 & 7 & & 100 \\
\hline 10 & & 4 & 1 & 26 & 6 & 1 & 24 & 11 & & & 7 & 11 & 1 & 35 & 5 & 15 & & 147 \\
\hline 11 & 2 & 4 & 12 & 4 & 2 & & 2 & 5 & & 4 & 7 & 23 & 6 & 5 & 12 & 6 & & 94 \\
\hline 12 & 8 & & 5 & 5 & 2 & 3 & 10 & 5 & 2 & 7 & 9 & 22 & 2 & & 6 & 6 & & 92 \\
\hline 13 & 29 & 6 & 1 & 8 & 7 & & 11 & 1 & 6 & 1 & & & 2 & & 8 & 21 & & 101 \\
\hline 14 & 5 & 42 & 12 & 11 & & 40 & 17 & 5 & 1 & 65 & 5 & 7 & 7 & & 14 & 8 & & 239 \\
\hline 15 & 12 & 96 & 14 & 39 & 4 & 20 & 4 & 28 & 5 & 39 & & & 7 & 46 & 22 & 3 & & 339 \\
\hline 16 & 31 & 12 & 43 & 133 & 50 & 132 & 60 & 136 & 73 & 41 & 103 & 137 & 48 & 25 & 14 & 2 & & 1,040 \\
\hline 17 & 18 & 60 & 8 & 49 & 87 & 28 & 16 & 1 & 10 & 128 & 3 & 8 & & 8 & 2 & 8 & & 434 \\
\hline 18 & 31 & 23 & 12 & 34 & 44 & 13 & 3 & 6 & 5 & & 8 & 11 & 8 & 12 & 2 & 3 & & 215 \\
\hline 19 & 10 & & & & & 2 & & & & & & & & & & & & 12 \\
\hline 20 & 10 & & & & 3 & & & & & & & & & & & & & 13 \\
\hline 21 & & & & & 1 & & & & & & & & & & & & & 1 \\
\hline 22 & & & & & 3 & 1 & & & & & & & & & & & & 4 \\
\hline 23 & & & & & & 1 & & & & & & & & & & & & 1 \\
\hline 24 & & & & & 2 & 12 & & & & & & & & & & & & 14 \\
\hline 25 & & & & & 19 & 33 & & & & & & & & & & & & 52 \\
\hline
\end{tabular}


Table 49 (cont'd)

\begin{tabular}{|c|c|c|c|c|c|c|c|c|c|c|c|c|c|c|c|c|c|c|}
\hline \multirow[b]{2}{*}{ Level } & \multicolumn{17}{|c|}{ Unit } & \multirow[b]{2}{*}{ Total } \\
\hline & 7 & 12 & 13 & 20 & 21 & 22 & 23 & 24 & 25 & 26 & 27 & 28 & 29 & 30 & 31 & 32 & 33 & \\
\hline 26 & & & & & 29 & 12 & & & & & & & & & & & & 41 \\
\hline 27 & & & & & 197 & 109 & & & & & & & & & & & & 306 \\
\hline 28 & & & & & 6 & 7 & & & & & & & & & & & & 13 \\
\hline 29 & & & & & 5 & 10 & & & & & & & & & & & & 15 \\
\hline 30 & & & & & 1 & & & & & & & & & & & & & 1 \\
\hline $35 / 36$ & & & & & 1 & & & & & & & & & & & & & 1 \\
\hline (blank) & 15 & 56 & 9 & & 122 & 10 & 2 & 2 & & & & & 33 & & 2 & 1 & & 252 \\
\hline Total & 182 & 326 & 154 & 366 & 637 & 448 & 178 & 245 & 138 & 306 & 205 & 241 & 143 & 149 & 117 & 88 & 7 & 3,930 \\
\hline
\end{tabular}

$\stackrel{N}{\omega}$ 
Table 50

42TR198 Block 3 Faunal Remains

\begin{tabular}{|c|c|}
\hline Taxon & QTY \\
\hline Largemouth bass & 2 \\
\hline Unidentified rodent & 1 \\
\hline Black-tailed jack rabbit & 7 \\
\hline Bowfin & 5 \\
\hline cf Cotton mouth & 1 \\
\hline cf Coyote & 1 \\
\hline cf Mole & 1 \\
\hline cf Raccoon & 1 \\
\hline cf Whip snake & 4 \\
\hline Cotton rat & 2 \\
\hline Deer & 108 \\
\hline Eastern cottontail rabbit & 23 \\
\hline Eastern fox squirrel & 10 \\
\hline Freshwater catfish & 9 \\
\hline Freshwater drum & 6 \\
\hline North American beaver & 3 \\
\hline Ornate box turtle & 53 \\
\hline Plains pocket gopher & 8 \\
\hline Pocket gopher & 1 \\
\hline Pond cooter & 6 \\
\hline Prairie vole & 1 \\
\hline Raccoon & 6 \\
\hline Red-eared slider & 188 \\
\hline Shell & 1 \\
\hline Turkey & 10 \\
\hline unid & 21 \\
\hline Unid bird & 153 \\
\hline Unid box turtle & 13 \\
\hline Unid fish & 81 \\
\hline Unid mammal & 2,851 \\
\hline Unid quail & 1 \\
\hline Unid rat & 1 \\
\hline Unid rodent & 62 \\
\hline Unid turtle & 195 \\
\hline White-tailed deer & 92 \\
\hline Wood rat & 2 \\
\hline Total & 3,930 \\
\hline
\end{tabular}


There is a total of 92 white-tailed deer remains which indicate at least two individuals (two left astragalus). Based on teeth and the fusion of long bones, one is approximately 1.5 years of age and one may be younger based on the size and morphology of molars that have not fully erupted. Of the two left astragali, one has cut marks and carnivore damage. There are also vertebrae fragments, tibia, humerus, radius, ulna, and tarsal bones. In addition there are 108 bones that compare favorably to deer, but are missing certain landmarks needed for species identification. Of these 108 bones, 67 percent are spirally fractured.

The remains of at least two individual eastern cottontail rabbits were recovered from Block 3, based on two right distal humeri. The radius and ulna of a North American beaver were also recovered, as well as the remains of at least one individual black-tailed jack rabbit based on the left femur and ulna, and a right radius bone.

There are 103 fish bones, including bowfin (vertebrae), freshwater drum (vertebrae and spine fragments), freshwater catfish (vertebrae), largemouth bass (vertebrae), and 81 fragments that are not identifiable to a species.

There is a total of 455 turtle bones with 188 carapace and plastron fragments identified as a redeared slider, 53 as ornate box turtle, 6 pond cooter, 13 undetermined box turtle, and 195 turtle fragments that could not be identified to any particular species.

Block 3 is the main excavation area at the site and five major occupational zones have been defined. The following discussion presents the faunal assemblage related to each of the occupational zones.

\section{Identified Faunal Remains from A.D. 1040 Occupation Zone (Levels 2 - 6)}

There is a total of 135 bones and fragments of bone from the first occupational zone, which are listed in Table 51. The faunal assemblage from this occupational zone consists mainly of rabbit, turtle, and deer. In the first level of this occupational zone, there are two skull fragments with teeth identified as an Eastern cottontail rabbit. Also recovered at this level are several whitetailed deer bones; a carpal, the proximal end from a right phalange that is spirally fractured, and 
Table 51

41TR198 A.D. 1040 Occupation Zone Fauna Counts

\begin{tabular}{|c|c|c|c|c|c|c|}
\hline \multirow[b]{2}{*}{ Row Labels } & \multicolumn{5}{|c|}{ Level } & \multirow[b]{2}{*}{ Total } \\
\hline & 2 & 3 & 4 & 5 & 6 & \\
\hline Bowfin & & & & & 4 & 4 \\
\hline cf mole & & & & & 1 & 1 \\
\hline Deer & & 11 & & & 3 & 14 \\
\hline Eastern cottontail rabbit & & 2 & & & & 2 \\
\hline Eastern fox squirrel & & & 2 & & 1 & 3 \\
\hline Freshwater catfish & & & & & 5 & 5 \\
\hline Ornate box turtle & & 3 & 10 & 9 & & 22 \\
\hline Plains pocket gopher & & & 2 & & & 2 \\
\hline Red-eared slider & & & & & 1 & 1 \\
\hline Unid & & & 1 & & & 1 \\
\hline Unid bird & & 2 & & & 1 & 3 \\
\hline Unid fish & & 2 & & 8 & 29 & 39 \\
\hline Unid mammal & & 20 & 14 & 23 & 27 & 84 \\
\hline Unid rodent & & 2 & 3 & & 4 & 9 \\
\hline Unid turtle & & 10 & 3 & 6 & 10 & 29 \\
\hline White-tailed deer & & 2 & & & & 2 \\
\hline Total & & 54 & 35 & 46 & 86 & 221 \\
\hline
\end{tabular}

11 fragments of a sacrum. Carapace fragments of an ornate box turtle, two unidentifiable fish fragments, as well as the long bone of a large and a small animal were found.

None of the bones from the Level 3 are burned or have any visible cut marks on them, however, they are highly fragmented, and 21 fragments could not be assigned to any taxonomic category or element. The faunal remains from Levels 4 and 5 are mostly small mammals and turtle.

At Level 4 these include the Plains pocket gopher (distal end of a humerus and a mandible fragment), Eastern fox squirrel (proximal end of a right ulna and femur), and undetermined rodents (long bone, long bone fragments, and skull fragments). Also recovered from this level are three long bone fragments from a large mammal (most likely deer) that are burned and have spiral fractures. There are also spirally fractured long bone fragments from a small mammal and carapace fragments from an ornate box turtle. 
At Level 5 a spirally fractured mandible and long bone of an undetermined small mammal were recovered. There is also one long bone fragment that is calcined, several carapace bones of an ornate box turtle, and eight vertebrae fragments of an undetermined fish. Many of the bones from this level are also highly fragmented and could not be identified.

At Level 6 (98.7 - 98.65, Feature 29) 86 bones were recovered. The first level of this feature contains 46 percent fish, and 13 percent turtle remains. There are 3 species of identifiable fish remains; bowfin (4 vertebrae), freshwater catfish (vertebrae and skull fragment), and freshwater drum (1 vertebrae). There are also 29 fish fragments that were not able to be identified to a species. There is also a higher percentage of unidentifiable bones at this level (26.5\%).

\section{Identified Faunal Remains from A.D. 900 - 960 Occupation Zone (Levels 7 - 9)}

There is a total of 261 bones recovered from the levels that make up this occupational zone (Table 52). The faunal remains from this occupation zone are unique in relation to the rest of the assemblage, consisting mainly of fish, turtle, and birds, with minor amounts of small and large mammal. The majority of these bones are from a proto-midden, Feature 8 . Feature 8 is primarily a shell lens with 17 bones. The remains from this zone will be discussed by level.

Table 52

41TR198 A.D. 900 - 960 Occupation Zone Faunal Count

\begin{tabular}{|c|c|c|c|c|c|c|c|c|c|c|c|c|c|c|c|c|c|}
\hline \multirow[b]{2}{*}{ Level } & \multicolumn{16}{|c|}{ Unit } & \multirow[b]{2}{*}{ Total } \\
\hline & 12 & 13 & 20 & 21 & 22 & 23 & 24 & 25 & 26 & 27 & 28 & 29 & 30 & 31 & 32 & 33 & \\
\hline 7 & & 3 & 32 & 24 & & 15 & 1 & & 1 & 1 & & & & & & 7 & 84 \\
\hline 8 & 15 & 9 & 12 & 13 & 2 & & 1 & 9 & 3 & 4 & 2 & 1 & & 3 & 3 & & 77 \\
\hline 9 & 4 & 5 & 3 & 1 & 11 & 8 & 16 & 2 & 2 & 21 & 4 & 5 & 3 & 8 & 7 & & 100 \\
\hline Total & 19 & 17 & 47 & 38 & 13 & 23 & 18 & 11 & 6 & 26 & 6 & 6 & 3 & 11 & 10 & 7 & 261 \\
\hline
\end{tabular}


Feature 29 faunal remains at Level 7 (98.65 - 98.6) are 42 percent fish and 39 percent turtle (Table 53). Another species of fish is added to the list, with the vertebrae and a skull bone (opercule) of a largemouth bass. The paraspenoid and three spines of a freshwater drum were also recovered, along with three vertebrae of a freshwater catfish. In addition there were 23 fragments of fish that were not identifiable to a species. It should be noted that the two fragments of deer, the turkey phalange, and the two long bones from an unidentified bird are not from Feature 29 (Unit 33).

Table 53

41TR198 A.D. 900 - 960 Occupation Zone, Level 7 and Feature 29

\begin{tabular}{|c|c|c|c|c|c|c|c|c|c|}
\hline \multirow[b]{2}{*}{ Taxon } & \multicolumn{8}{|c|}{ Unit } & \\
\hline & 13 & 20 & 21 & 23 & 24 & 26 & 27 & 33 & \\
\hline Feature & 29 & 29 & 29 & 29 & 29 & 29 & 29 & & Total \\
\hline Largemouth bass & & & 2 & & & & & & 2 \\
\hline Eastern fox squirrel & & & & & & & & 2 & 2 \\
\hline Freshwater catfish & & 3 & & & & & & & 3 \\
\hline Freshwater drum & & 2 & 2 & & & & & & 4 \\
\hline Plains pocket gopher & & & & & & 1 & & & 1 \\
\hline Pond cooter & & & 6 & & & & & & 6 \\
\hline Red-eared slider & 3 & 15 & & & & & & & 18 \\
\hline Turkey & & & & & & & & 2 & 2 \\
\hline Unid & & & & & 1 & & & & 1 \\
\hline Unid bird & & & & & & & & 1 & 1 \\
\hline Unid fish & & 8 & 9 & 6 & & & & & 23 \\
\hline Unid mammal & & 4 & 2 & 1 & & & 1 & 1 & 9 \\
\hline Unid turtle & & & 1 & 8 & & & & & 9 \\
\hline White-tailed deer & & & & & & & & 1 & 1 \\
\hline Wood rat & & & 2 & & & & & & 2 \\
\hline Total & 3 & 32 & 24 & 15 & 1 & 1 & 1 & 7 & 84 \\
\hline
\end{tabular}

At this depth, Feature 8 and Feature 29 are both evident (Table 54). As previously mentioned Feature 8 (Units 12, 21, 22, 24, and 25) is primarily a shell lens. However, there are 17 bones that were recovered as well. In Unit 12, these consist mostly of fish; a bowfin vertebrae, a freshwater catfish vertebrae, and nine fragments (eight are spine fragments) of fish that are not complete enough to be identified. In Unit 22, the right radius and ulna of a black-tailed jack 
Table 54

41TR198 A.D. 900 - 960 Occupation Zone, Level 8 and Features 8/29

\begin{tabular}{|c|c|c|c|c|c|}
\hline Feature & No Ft. & 8 & 29 & $8 / 29$ & Total \\
\hline Bowfin & & 1 & & & 1 \\
\hline Freshwater drum & & & 2 & & 2 \\
\hline Aves & & & 1 & 3 & 4 \\
\hline Red-eared slider & & & 3 & 1 & 4 \\
\hline Plains pocket gopher & & & & 3 & 3 \\
\hline Black-tailed jack rabbit & & 2 & & & 2 \\
\hline Freshwater catfish & & 1 & & & 1 \\
\hline Ornate box turtle & & & 9 & & 9 \\
\hline Unid & & & 4 & & 4 \\
\hline Unid mammal & 6 & 3 & 2 & & 11 \\
\hline Unid pisces & & 9 & & & 9 \\
\hline Unid rodentia $s p$ & & & 3 & 7 & 10 \\
\hline Unid turtle & 9 & 1 & 7 & & 17 \\
\hline Total & 15 & 17 & 31 & 14 & 77 \\
\hline
\end{tabular}

rabbit were recovered. One turtle bone fragment and three long bone fragments of an undetermined mammal were also found.

In Feature 29 at this level there are 31 bones, mostly turtle (68\%) with the remains of both the red-eared slider and the ornate box turtle. The spine and vertebrae of a freshwater drum are the only fish elements represented at this level (Feature 29). In addition to turtle and fish, there are four long bone fragments of unidentified bird, one long bone of a small mammal, a calcined antler fragment, and one large rib fragment that is carbonized. A large vertebrae fragment and a humerus fragment compare favorably to deer, but are categorized as an undetermined large mammal as they lack the diagnostic landmarks.

There is a total of 100 bones and bone fragments from Level 9, listed by unit in Table 55. These are mostly turtle (45\%) with red-eared slider, ornate box turtle, and 16 fragments of an unidentified turtle. There is at least one individual eastern cottontail rabbit, with three metapodial fragments, two calcaneus, and one metatarsal. Turkey is represented here by two complete phalanges. Of the six bird bones recovered, four are long bone fragments and two are carbonized. One bird tibia fragment was also recovered that has a spiral fracture. There are also several rodent remains, including the right femur of a plains pocket gopher. 
Table 55

41TR198 A.D. 900 - 960 Occupation Zone, Level 9

\begin{tabular}{|c|c|c|c|c|c|c|c|c|c|c|c|c|c|c|c|c|}
\hline \multirow[b]{2}{*}{ Taxon } & \multicolumn{15}{|c|}{ Unit } & \multirow[b]{2}{*}{ Total } \\
\hline & 12 & 13 & 20 & 21 & 22 & 23 & 24 & 25 & 26 & 27 & 28 & 29 & 30 & 31 & 32 & \\
\hline $\begin{array}{l}\text { Eastern cottontail } \\
\text { rabbit }\end{array}$ & 2 & 2 & 1 & & & & & & & & & & 1 & & & 6 \\
\hline Eastern fox squirrel & & & & & 1 & & & & & & & & & & & 1 \\
\hline Ornate box turtle & & & & & & & & & & 14 & & & & & & 14 \\
\hline Plains pocket gopher & & & & & & & & 1 & & & & & & & & 1 \\
\hline Red-eared slider & & & & & & 5 & 10 & & & & & & & & & 15 \\
\hline Turkey & & & & & & & & & & & 2 & & & & & 2 \\
\hline Unid & & & & & & & & & & & & & & & 1 & 1 \\
\hline Unid bird & 2 & & & & & & 1 & & 2 & 1 & & & & & & 6 \\
\hline Unid fish & & & & & & & 2 & & & & & & & & & 2 \\
\hline Unid mammal & & 2 & & 1 & & 3 & 2 & & & 1 & 2 & 2 & 2 & 7 & 6 & 28 \\
\hline Unid quail & & & & & & & 1 & & & & & & & & & 1 \\
\hline Unid rodent & & & & & & & & & & 3 & & & & & & 3 \\
\hline Unid snake & & & 1 & & & & & & & 2 & & & & & & 3 \\
\hline Unid turtle & & 1 & 1 & & 10 & & & 1 & & & & 3 & & & & 16 \\
\hline White-tailed deer & & & & & & & & & & & & & & 1 & & 1 \\
\hline Total & 4 & 5 & 3 & 1 & 11 & 8 & 16 & 2 & 2 & 21 & 4 & 5 & 3 & 8 & 7 & 100 \\
\hline
\end{tabular}

\section{Identified Faunal Remains from A.D. 700 - 900 Occupation Zone (Levels 10 - 11)}

The occupational zone dated to A.D. 700-900 yielded a total of 241 bones and bone fragments. The total count by unit and level is listed in Table 56. The types of animals represented in this zone are listed in Table 57. They consist mostly of mammal bones (62\%), but also include turtle, bird, rodents, and unidentifiable fragments. There are a total of 136 mammal long bone fragments, and 58 long bone fragments of unidentified bird.

Table 56

41 TR198 A.D. 700 - 900 Occupation Zone Fauna Count

\begin{tabular}{|c|c|c|c|c|c|c|c|c|c|c|c|c|c|c|c|c|c|}
\hline \multirow[b]{2}{*}{ Level } & \multicolumn{16}{|c|}{ Unit } & \multirow[b]{2}{*}{ Total } \\
\hline & 7 & 12 & 13 & 20 & 21 & 22 & 23 & 24 & 25 & 26 & 27 & 28 & 29 & 30 & 31 & 32 & \\
\hline 10 & & 4 & 1 & 26 & 6 & 1 & 24 & 11 & & & 7 & 11 & 1 & 35 & 5 & 15 & 147 \\
\hline 11 & 2 & 4 & 12 & 4 & 2 & & 2 & 5 & & 4 & 7 & 23 & 6 & 5 & 12 & 6 & 94 \\
\hline Total & 2 & 8 & 13 & 30 & 8 & 1 & 26 & 16 & 0 & 4 & 14 & 34 & 7 & 40 & 53 & 21 & 241 \\
\hline
\end{tabular}


Table 57

41TR198 A.D. 700 - 900 Occupation Zone Fauna

\begin{tabular}{|c|c|c|c|}
\hline \multirow[b]{2}{*}{ Row Labels } & \multicolumn{2}{|r|}{ Level } & \multirow[b]{2}{*}{ Tota } \\
\hline & 10 & 11 & \\
\hline \multicolumn{4}{|l|}{ Black-tailed jack rabbit } \\
\hline Cotton rat & & 1 & 1 \\
\hline \multicolumn{4}{|l|}{ Coyote } \\
\hline \multicolumn{4}{|l|}{ Deer } \\
\hline Eastern cottontail rabbit & 2 & 3 & 5 \\
\hline Eastern fox squirrel & 1 & & 1 \\
\hline Ornate box turtle & 2 & & 2 \\
\hline Plains pocket gopher & 1 & & 1 \\
\hline Raccoon & 4 & & 4 \\
\hline Red-eared slider & 45 & & \\
\hline \multicolumn{4}{|l|}{ Shell } \\
\hline Turkey & & 1 & 1 \\
\hline Unid & 2 & 3 & 5 \\
\hline Unid bird & 5 & 6 & 11 \\
\hline \multicolumn{4}{|l|}{ Unid box turtle } \\
\hline Unid fish & & 2 & 2 \\
\hline Unid mammal & 68 & 62 & 130 \\
\hline Unid rodent & 2 & 2 & 4 \\
\hline Unid snake & 1 & 1 & 2 \\
\hline Unid turtle & 14 & 13 & 27 \\
\hline \multicolumn{4}{|l|}{ White-tailed deer } \\
\hline Total & 147 & 94 & 241 \\
\hline
\end{tabular}

In the first level of this occupation zone, 147 bones and bone fragments were recovered. The identifiable remains include eastern cottontail rabbit (1 metapodial and 1 tooth fragment), redeared slider (45 carapace fragments), Plains pocket gopher, raccoon, and squirrel.

At Level 11, there is a total of 94 bones. The distal end of a humerus and the distal end of a metapodial identified as eastern cottontail rabbit were recovered, along with a pelvis (inomminate) fragment. Turkey is represented by one phalanx. There are a total of 25 long bone fragments from this depth; three are carbonized and refit together as one bone and four of the long bone fragments are calcined. The maxilla fragment with teeth was identified as a cotton rat (Sigmodon hispidus). 


\section{Identified Faunal Remains from A.D. 350 - 700 Occupation Zone (Levels 12 - 15)}

The remains from Level 12 include the first phalanx of a white-tailed deer, and one calcaneum, one distal humerus, and one pelvis fragment of an eastern cottontail rabbit (Tables 58 and 59). There is a mandible fragment with teeth that compares favorably with raccoon, but the teeth are broken and eroded, preventing a positive identification. There are 25 mammal long bone fragments and eight bird long bone fragments. The majority of these are spirally fractured. Four of the unidentified mammal fragments are calcined.

Table 58

41TR198 A.D. 350 - 700 Occupation Zone Fauna Count

\begin{tabular}{|c|c|c|c|c|c|c|c|c|c|c|c|c|c|c|c|c|c|}
\hline \multirow[b]{2}{*}{ Level } & \multicolumn{16}{|c|}{ Unit } & \multirow[b]{2}{*}{ Total } \\
\hline & 7 & 12 & 13 & 20 & 21 & 22 & 23 & 24 & 25 & 26 & 27 & 28 & 29 & 30 & 31 & 32 & \\
\hline 12 & 8 & & 5 & 5 & 2 & 3 & 10 & 5 & 2 & 7 & 9 & 22 & 2 & & 6 & 6 & 92 \\
\hline 13 & 29 & 6 & 1 & 8 & 7 & & 11 & 1 & 6 & 1 & & & 2 & & 8 & 21 & 101 \\
\hline 14 & 5 & 42 & 12 & 11 & & 40 & 17 & 5 & 1 & 65 & 5 & 7 & 7 & & 14 & 8 & 239 \\
\hline 15 & 12 & 96 & 14 & 39 & 4 & 20 & 4 & 28 & 5 & 39 & & & 7 & 46 & 22 & 3 & 339 \\
\hline Total & 54 & 144 & 32 & 63 & 13 & 63 & 42 & 39 & 14 & 112 & 14 & 29 & 18 & 46 & 50 & 38 & 771 \\
\hline
\end{tabular}

Feature 5 is located in Unit 7 at this depth. There are 40 bones and bone fragments, which include the carpal of a white-tailed deer, the distal radius of an eastern cotton tail rabbit, the proximal end of a deer phalanx, the humerus of a squirrel, three long bone fragments of an undetermined bird, nine turtle fragments, and 24 unidentifiable mammal fragments.

The other remains from Level 13 include two turkey phalanges, six fragments from a distal tibia of a white-tailed deer that came from a juvenile (it is not fused). These pieces are very fragmented and appear to be cut, but it could not be determined if this damage was recent due to the cancellous nature of this portion of the bone. There is also one humerus fragment of a large mammal with several cut marks, and another that has a flake of bone removed from it that is also burned (carbonized). In addition there are 13 turtle carapace fragments. 
Table 59

41TR198 A.D. 350 - 700 Occupation Zone Fauna

\begin{tabular}{|c|c|c|c|c|c|}
\hline Row Labels & 12 & 13 & 14 & 15 & Total \\
\hline Black-tailed jack rabbit & & & & 1 & 1 \\
\hline Coyote & & & & 1 & 1 \\
\hline Deer & & 1 & 2 & 19 & 22 \\
\hline Eastern cottontail rabbit & 3 & 1 & & 2 & 6 \\
\hline Raccoon & & 1 & & & 1 \\
\hline Red-eared slider & & & 1 & 92 & 93 \\
\hline Turkey & & 3 & 2 & & 5 \\
\hline Unid & 1 & & 6 & 1 & 8 \\
\hline Unid bird & 10 & 20 & 6 & 18 & 54 \\
\hline Unid box turtle & & & & 4 & 4 \\
\hline Unid mammal & 66 & 53 & 204 & 192 & 515 \\
\hline Unid rodent & 2 & 2 & 3 & & 7 \\
\hline Unid turtle & 9 & 14 & 10 & 8 & 41 \\
\hline White-tailed deer & 1 & 6 & 4 & 1 & 12 \\
\hline Total & 92 & 101 & 239 & 339 & 770 \\
\hline
\end{tabular}

Feature 5 extends into Level 14 and one long bone fragment of a large mammal that is calcined and two mammal fragments were recovered. The other remains from this level include whitetailed deer (one carpal, one distal fibula, and two astragali fragments that are cut in half); some damage may be recent. There also two bones classified as deer, the shaft and the distal end of an unfused calcaneum. Of the five inomminate fragments of a large mammal, one is a juvenile (the end is not fused). Of the 27 long bone fragments, most are spirally fractured and one is calcined. Turkey is represented by phalanges (one complete and one distal end). All the unidentified bird remains are spirally fractured long bone fragments.

At Level 15 there is a total of 339 bones and bone fragments. The proximal end of a scapula identified as a coyote (Canis latrans) was recovered, as well as the metapodial fragment of a black-tailed jack rabbit. The bone count for this level is slightly elevated due to the 92 carapace and plastron fragments of a large red-eared slider. There is one phalanx of a white-tailed deer, and 11 rib fragments of a large mammal (two of these have cut marks). Inomminate fragments of a cottontail rabbit were also recovered. 


\section{Identified Faunal Remains from A.D. 250 - 350 Occupation Zone (Levels 16 - 19)}

There are a total of 1,701 bones and bone fragments from this occupation zone which are listed by unit and level in Table 60. The majority of these are mammal (96\%, Table 61). There are 71 bones and fragments that are identified as white-tailed deer. The majority of these bones indicate

a juvenile. There is the left tibia that has a complete distal end, the shaft is cut in half, and the proximal end is missing. This bone is not fused at the distal end, making this individual approximately 14-17 months old. There are also several molars and premolars that belong to a juvenile. In addition there are 60 bones that compare favorably with white-tailed deer, but are lacking certain landmarks or are too fragmented to identify to species, which include the distal end and shaft of a calcaneus, the proximal end of a right unfused tibia, a right naviculo-cuboid that is damaged, and several vertebrae, ulnae, and condyle fragments.

Table 60

41 TR198 A.D. 250 - 350 Occupation Zone Fauna Count

\begin{tabular}{|c|c|c|c|c|c|c|c|c|c|c|c|c|c|c|c|c|c|}
\hline \multirow[b]{2}{*}{ Level } & \multicolumn{16}{|c|}{ Unit } & \multirow[b]{2}{*}{ Tota } \\
\hline & 7 & 12 & 13 & 20 & 21 & 22 & 23 & 24 & 25 & 26 & 27 & 28 & 29 & 30 & 31 & 32 & \\
\hline 16 & 31 & 12 & 43 & 133 & 50 & 132 & 60 & 136 & 73 & 41 & 103 & 137 & 48 & 25 & 14 & 2 & 1,040 \\
\hline 17 & 18 & 60 & 8 & 49 & 87 & 28 & 16 & 1 & 10 & 128 & 3 & 8 & & 8 & 2 & 8 & 434 \\
\hline 18 & 31 & 23 & 12 & 34 & 44 & 13 & & 6 & 5 & & 8 & 11 & 8 & 12 & 2 & 3 & 212 \\
\hline 19 & 10 & & & & & 2 & & & & & & & & & & & 12 \\
\hline Total & 90 & 95 & 63 & 216 & 181 & 175 & 76 & 143 & 88 & 169 & 114 & 156 & 56 & 45 & 18 & 13 & 1,701 \\
\hline
\end{tabular}

There are 4 bones identified as black-tailed jack rabbit, and the distal end of a squirrel humerus. There are 1,463 bones and fragments from this zone that are only identifiable as mammal. Of those, 274 are long bone fragments of both large and small mammals, four of the long bones are calcined, 11 others have cut marks, and 231 of them have spiral fractures. Of the 27 bird bones, 24 are long bones and all have spiral fractures. 
Table 61

41 TR198 A.D. 250 - 350 Occupation Zone Fauna

\begin{tabular}{|c|c|c|c|c|c|}
\hline \multirow[b]{2}{*}{ Taxon } & \multicolumn{4}{|c|}{ Level } & \multirow[b]{2}{*}{ Total } \\
\hline & 16 & 17 & 18 & 19 & \\
\hline Black rat & 1 & & & & 1 \\
\hline Black-tailed jack rabbit & 1 & 2 & & 1 & 4 \\
\hline Cotton rat & & 1 & & & 1 \\
\hline Deer & 40 & 9 & 13 & & 62 \\
\hline Eastern cottontail rabbit & & & 1 & & 1 \\
\hline Eastern fox squirrel & 2 & & & & 2 \\
\hline Ornate box turtle & 6 & & & & 6 \\
\hline Pocket gopher & & 1 & & & 1 \\
\hline Prairie vole & & & 1 & & 1 \\
\hline Raccoon & & & 1 & & 1 \\
\hline Unid & & & 2 & & 2 \\
\hline Unid bird & 8 & 4 & 15 & & 27 \\
\hline Unid box turtle & & 9 & & & 9 \\
\hline Unid fish & 3 & 1 & 2 & & 6 \\
\hline Unid mammal & 944 & 347 & 163 & 9 & 1,463 \\
\hline Unid rodent & 12 & 5 & 6 & & 23 \\
\hline Unid turtle & 5 & 7 & 6 & & 18 \\
\hline White-tailed deer & 18 & 48 & 5 & & 71 \\
\hline Total & 1,040 & 434 & 215 & 10 & 1,699 \\
\hline
\end{tabular}

Identified Faunal Remains from 410 B.C. - A.D. 250 Occupation Zone (Levels 20 - 36)

There are 471 bones and bone fragments from this occupation zone (Table 62). These consist mainly of unidentified mammal bones (84\%, Table 63). These include 48 cancellous bone fragments that are highly fragmented, 59 long bone fragments of both large and small mammals, 13 rib fragments of large mammals, 28 vertebrae fragments of small mammals, and 240 fragments that cannot be identified to any particular element. There are eight additional rib fragments that compare favorably with white-tailed deer in morphology and size, but are lacking the diagnostic landmarks. There is one left astragalus of a white-tailed deer that has a deep cut mark near the area of ligament attachment. The proximal end of a femur identified as a blacktailed jack rabbit has been cut in half. In addition the distal end of a humerus identified to an eastern cottontail rabbit has a spiral fracture. The distal and proximal ends of a right radius that refit together belong to a North American beaver (Castor canadensis), along with the proximal 
Table 62

41TR198 410 B.C. - A.D. 250 Occupation Zone Fauna Count

\begin{tabular}{|c|c|c|c|c|}
\hline \multirow[b]{2}{*}{ Row Labels } & \multicolumn{3}{|c|}{ Unit } & \multirow[b]{2}{*}{ Total } \\
\hline & 7 & 21 & 22 & \\
\hline 20 & 10 & 3 & & 13 \\
\hline 21 & & 1 & & 1 \\
\hline 22 & & 3 & 1 & 4 \\
\hline 23 & & & 1 & 1 \\
\hline 24 & & 2 & 12 & 14 \\
\hline 25 & & 19 & 33 & 52 \\
\hline 26 & & 29 & 12 & 41 \\
\hline 27 & & 197 & 109 & 306 \\
\hline 28 & & 6 & 7 & 13 \\
\hline 29 & & 5 & 10 & 15 \\
\hline 30 & & 1 & & 1 \\
\hline $35 / 36$ & & 1 & & 1 \\
\hline Total & 10 & 267 & 185 & 462 \\
\hline
\end{tabular}

Table 63

41TR198 410 B.C. - A.D. 250 Occupation Zone Fauna Count

\begin{tabular}{|c|c|c|c|c|c|c|c|c|c|c|c|c|c|}
\hline & \multicolumn{12}{|c|}{ Level } & \multirow[b]{2}{*}{ Total } \\
\hline & 20 & 21 & 22 & 23 & 24 & 25 & 26 & 27 & 28 & 29 & 30 & $35 / 36$ & \\
\hline Black-tailed jack rabbit & & & & & & & & & & & & & \\
\hline deer & & & & & & & 8 & & & & & & 8 \\
\hline Eastern cottontail rabbit & & & & & 1 & & & & & & & & 1 \\
\hline North American beaver & & & & & & & & 1 & 2 & & & & 3 \\
\hline Red-eared slider & & & & & & 12 & & & & & & & 12 \\
\hline UNID & & 1 & & & & & & 1 & & & & & 2 \\
\hline UNID bird & & & & & 1 & & 2 & 14 & & 2 & & & 19 \\
\hline UNID Mammal & 13 & & 2 & 1 & 5 & 33 & 25 & 287 & 10 & 13 & & 1 & 390 \\
\hline Unid Rat & & & 1 & & & & & & & & & & 1 \\
\hline UNID Rodent & & & & & & 1 & & & & & & & 1 \\
\hline UNID Turtle & & & 1 & & 7 & 6 & 6 & 3 & & & 1 & & 24 \\
\hline White-tailed deer & & & & & & & & & 1 & & & & 1 \\
\hline Total & 13 & 1 & 4 & 1 & 14 & 52 & 41 & 306 & 13 & 15 & 1 & 1 & 462 \\
\hline
\end{tabular}


end of a left ulna. Of the 19 bird bones, 17 are long bone fragments. The carapace fragments of a red-eared slider were recovered as well as 24 other carapace fragments that could not be identified to a species.

\section{Comparison of Faunal Remains within Block 3 Occupation Zones}

A comparison of the faunal remains from the Block 3 occupation zones indicates differences from each time period (Table 64).

\begin{tabular}{lcccc}
\hline \multicolumn{5}{c}{ Table 64 } \\
\multicolumn{5}{c}{ Block 3 Faunal Changes } \\
& Mammal & Fish & Turtle & Bird \\
\hline A.D. 1040 & $50.4 \%(\mathrm{n}=137)$ & $17.6 \%(\mathrm{n}=48)$ & $21.7 \%(\mathrm{n}=59)$ & $1.8 \%(\mathrm{n}=5)$ \\
A.D. 900-960 & $32.1 \%(\mathrm{n}=81)$ & $18.7 \%(\mathrm{n}=47)$ & $43.7 \%(\mathrm{n}=110)$ & $5.6 \%(\mathrm{n}=14)$ \\
A.D. $700-900$ & $62.4 \%(\mathrm{n}=146)$ & $0.9 \%(\mathrm{n}=2)$ & $31.6 \%(\mathrm{n}=74)$ & $5.1 \%(\mathrm{n}=12)$ \\
A.D. 350-700 & $74.1 \%(\mathrm{n}=565)$ & 0 & $18.1 \%(\mathrm{n}=138)$ & $7.7 \%(\mathrm{n}=59)$ \\
A.D. $250-350$ & $96.1 \%(\mathrm{n}=1633)$ & $0.4 \%(\mathrm{n}=6)$ & $1.9 \%(\mathrm{n}=33)$ & $1.6 \%(\mathrm{n}=27)$ \\
B.C. $410-$ A.D. 250 & $88 \%(\mathrm{n}=405)$ & 0 & $7.8 \%(\mathrm{n}=36)$ & $4.1 \%(\mathrm{n}=19)$ \\
\hline
\end{tabular}

The fauna associated with the earliest occupations consist mainly of mammal bones, followed by very small percentages of turtle and bird. The faunal remains also have a large percentage of mammal bones, with a slight increase in the amount of turtle and bird, and less than 1 percent fish remains. The faunal remains from the A.D. 900 - 960 occupation zone are markedly different from the rest. The assemblage is mostly turtle and fish, with a large decrease in the amount of mammal bones recovered. The faunal remains from the A.D. 1040 zone consist mainly of mammal and turtle, followed by fish.

These differences could reflect changes in the subsistence strategies used, as well as changes in the environment in regard to the types of animals that were available in the surrounding area. The data from Table 65 indicate that there is also a decrease through time in the percentage of bones that are identifiable to species (due to fragmentation). Table 66 lists the percentage of bone from each zone that is spirally fractured. Spiral fracturing of the bones, presumably to extract marrow, is more prevalent in the Late Prehistoric period zones than in the earlier Late Archaic zones. 
Table 65

Block 3 Fragmentation

\begin{tabular}{lcc} 
& $\%$ ID & Total \\
\hline A.D. 1040 & $80.3 \%(\mathrm{n}=200)$ & 249 \\
A.D. $900-960$ & $68.3 \%(\mathrm{n}=172)$ & 252 \\
A.D. $700-900$ & $80.8 \%(\mathrm{n}=189)$ & 234 \\
A.D. $350-700$ & $90.2 \%(\mathrm{n}=687)$ & 762 \\
A.D. $250-350$ & $94.7 \%(\mathrm{n}=1609)$ & 1699 \\
B.C. $410-$ A.D. 250 & $97.4 \%(\mathrm{n}=448)$ & 460 \\
\hline
\end{tabular}

Table 66

Block 3 Spiral Fractures

\begin{tabular}{lcc} 
& $\%$ Spiral & Total \\
\hline A.D. 1040 & $17.3 \%(\mathrm{n}=43)$ & 249 \\
A.D. $900-960$ & $12.7 \%(\mathrm{n}=32)$ & 252 \\
A.D. $700-900$ & $37.2 \%(\mathrm{n}=87)$ & 234 \\
A.D. $350-700$ & $21.7 \%(\mathrm{n}=165)$ & 762 \\
A.D. $250-350$ & $33 \%(\mathrm{n}=560)$ & 1699 \\
B.C. $410-$ A.D. 250 & $15.9 \%(\mathrm{n}=73)$ & 460 \\
\hline
\end{tabular}

\section{Block 4 Faunal Remains}

There are 2,726 bones and bone fragments from the Block 4 excavations, which are listed by unit and level in Table 67. The types of animals represented in this block are listed in Table 68. The majority are unidentified mammal fragments (66\%). Of these mammal bones, 489 are long bone fragments of both large $(n=303)$ and small $(n-170)$ mammals. Also included are 1,044 fragments of bone that cannot be identified to any particular element. Of this group, there are 774 bones that have spiral fractures and 173 that are burned ( 81 of those are calcined; Table 69).

There are 235 bird bones, and 207 are long bone fragments, over 90 percent of them are spirally fractured. There are six burned bird bones, two are calcined. 
Table 67

41TR198 Block 4 Faunal Counts

\begin{tabular}{ccccccccccccccc} 
& \multicolumn{10}{c}{ Unit } & \\
\cline { 2 - 12 } & 14 & 15 & 16 & 17 & 18 & 19 & 20 & 26 & 33 & 34 & 35 & 36 & 37 & Total \\
\hline 1 & 2 & 3 & & 1 & & & & & & & 6 & & & 12 \\
2 & 4 & 14 & 2 & & 10 & 18 & & 12 & 5 & 57 & 9 & 11 & 142 \\
3 & & 24 & 5 & 32 & 9 & 56 & & 66 & 15 & 44 & 49 & 4 & 304 \\
4 & 1 & 6 & 11 & 2 & 100 & 2 & & & 60 & 190 & 104 & 201 & 116 & 793 \\
5 & 20 & 57 & & & 25 & 137 & & 104 & 82 & 72 & 21 & 44 & 562 \\
6 & 6 & 8 & 33 & 10 & 44 & 70 & & 36 & 8 & 30 & 25 & 59 & 329 \\
7 & 16 & 11 & 17 & 1 & & & & & & & & 21 & & 66 \\
8 & & 23 & 15 & 34 & & & & & & & & & & 72 \\
9 & 1 & 34 & 32 & 22 & & & & & & & & & & 89 \\
10 & 29 & 30 & 58 & 17 & & & & 5 & & & & & & 139 \\
11 & 49 & 22 & 35 & 33 & & & & & & & & & & 139 \\
12 & 6 & & 33 & & & & & & & & & & & 39 \\
13 & & & 16 & & & & & & & & & & & 16 \\
17 & & & & & & & 11 & & & & & & & 14 \\
Trench & & 6 & 1 & 5 & 2 & & & & & & & \\
Total & 134 & 238 & 258 & 157 & 189 & 283 & 11 & 5 & 278 & 300 & 313 & 326 & 234 & 2,726 \\
\hline
\end{tabular}

Table 68

41TR198 Block 4 Faunal Remains

Taxon

QTY

Black-tailed jack rabbit

Bowfin

cf cotton mouth

4

cf fox

cf Texas rat snake

cf whip snake

Cotton rat

Coyote

Deer

1

Eastern cottontail rabbit

Eastern fox squirrel

6

Freshwater drum

Great horned owl

North American beaver

1

Ornate box turtle

6

Plain pocket gopher

13

Pocket mouse 
Table 68 (cont'd)

\begin{tabular}{lc} 
Taxon & QTY \\
\hline Pond cooter & 6 \\
Prairie vole & 1 \\
Raccoon & 2 \\
Red fox & 1 \\
Red-eared slider & 135 \\
Shell & 1 \\
Turkey & 20 \\
Unid & 18 \\
Unid bird & 235 \\
Unid box turtle & 12 \\
Unid fish & 22 \\
Unid gar & 13 \\
Unid mammal & 1,813 \\
Unid pond turtle & 11 \\
Unid rabbit & 22 \\
Unid rodent & 56 \\
Unid snake & 5 \\
Unid turtle & 101 \\
White-tailed deer & 117 \\
\hline Total & 2,726 \\
\hline
\end{tabular}

Table 69

41TR198 Block 4 Features

\begin{tabular}{|c|c|c|c|c|c|c|}
\hline \multirow[b]{2}{*}{ Level } & \multicolumn{5}{|c|}{ Feature } & \multirow[b]{2}{*}{ Total } \\
\hline & 21 & 25 & 39 & 44 & 45 & \\
\hline 5 & & & & 44 & & 44 \\
\hline 6 & & & & & 59 & 59 \\
\hline 8 & 6 & & & & & 6 \\
\hline 9 & & 22 & & & & 22 \\
\hline Other & 28 & 12 & 2 & & & 42 \\
\hline Total & 34 & 34 & 2 & 44 & 59 & 173 \\
\hline
\end{tabular}

There are 117 white-tailed deer remains which indicate at least two individuals that are both juveniles. Based on teeth and the fusion of long bones, one is approximately 1.5 years of age and one is younger based on the size and morphology of the deciduous premolar. There are also two left astragali, and one has cut marks and carnivore damage. In addition there is the distal 
epiphyseal end of an unfused femur. The mark on the end of this bone is not a cut mark, but a diagnostic landmark (a ligament or muscle attachment area) for this element/species. Over 50 percent of the white-tailed deer remains are spirally fractured.

There are 39 fish bones which represent one bowfin (vertebrae), two freshwater drum (two otoliths), 13 gar scales that are consistent with the alligator gar, and 23 fragments that are not identifiable to a species.

There are 278 turtle bones, including 135 carapace and plastron fragments identified as a redeared slider, 13 as an ornate box turtle, siz as a pond cooter, 12 undetermined box turtle, 11 undetermined pond turtle, and 101 turtle fragments that could not be identified to any particular species.

A complete cervical vertebra of an adult red fox was identified, as well as a mandible fragment with teeth that compares favorably (in size and morphology) to red fox, but the molars are broken on top, and cannot be positively identified to this species.

Twenty turkey bones were recovered from the Block 4 assemblage, including three tarsometatarsals (two are partial), four carpometacarpus fragments, the distal end of a coracoid, and several phalanges.

There are 45 eastern cottontail rabbit bones with at least two individuals represented (two right calcaneus). At least one black-tailed jack rabbit is represented (one astragalus and a calcaneus).

\section{THE PREY CHOICE MODEL}

The prey choice model is used in optimal foraging theory to predict the types of prey items that a forager will pursue or ignore while foraging in a relatively homogeneous environment (Stephens and Krebs 1986). Under the model, prey resources are ranked according to body size, with larger-bodied taxa receiving higher ranks than smaller-bodied taxa (Broughton 1994, 1999). Under this premise, obtaining larger body sized resources during foraging events is correlated to higher net energy returns relative to hunting smaller bodied prey. Importantly, it is also assumed that the decision to pursue or ignore a prey item is based upon the encounter rate of high-ranked 
resources (Stephens and Krebs 1986; Broughton 1999). When high-ranked resources are abundant on the landscape and encounter rates are high, human foragers are expected to always pursue them, often to the near exclusion of other prey. In this situation, foraging efficiency, or the calories obtained per amount of time spent foraging, is high. However, if overexploitation or environmental change causes high-ranked prey to become less abundant on the landscape and encounter rates with high-ranked prey decline as a result, foraging efficiency decreases and changes in the diet are expected to occur. Such changes in diet associated with a diminishing focus on high-ranked resources should include an expansion in diet breadth signaled by an increase in the number of lower-ranked resources exploited and/or an increase in the proportions of lower-ranked resources exploited relative to high-ranked resources. In short, changes in diet breadth and foraging efficiency should be reflected by a shift in the proportion of high and low ranked resources included in the diet.

The prey choice model is applied to the faunal assemblage from Blocks 3 and 4 to track changes in vertebrate subsistence (diet breadth and foraging efficiency) through time at 41TR198. Each block is treated separately due to the different occupation zones represented in each (Table 70). NTAXA, or number of taxa, is calculated by adding the number of species identified for each occupation zone, and does not include more general specimen identification categories (e.g., size class level identifications) or potentially intrusive species. To compare species of similar habitats and body sizes, individual taxa were then grouped under the coarse scale categories of deer, small mammals and carnivores, turtles, birds, fish, and potential intrusive species (Tables 71 and 72). The deer category includes all specimens identified to Odocoileus virginianus, cf. Odocoileus sp., and large mammal. Since deer represent the largest-bodied resource identified within the 41TR198 faunal assemblage, deer are considered the high-ranked resource for the purposes of this analysis. The small mammals and carnivore category includes all mammals smaller in body size than deer. Potential intrusive species, including all snakes and rodents that could have been incorporated into the assemblage through natural death, are excluded from the analysis. Occupation zone 1 (post A.D. 1040) in Block 3 and occupation zone 1 (A.D. 390-590) in Block 4 are also excluded from the analysis due to small sample sizes. 
Table 70

Occupation Zones by Block

\begin{tabular}{|c|c|}
\hline \multicolumn{2}{|c|}{ Block 3 Occupation Zones } \\
\hline post A.D. 1040 & 1 \\
\hline A.D. $960-1040$ & 2 \\
\hline A.D. $900-960$ & 3 \\
\hline A.D. $700-900$ & 4 \\
\hline A.D. $350-700$ & 5 \\
\hline A.D. $250-350$ & 6 \\
\hline 410 B.C.- A.D. 250 & 7 \\
\hline \multicolumn{2}{|c|}{ Block 4 Occupation Zones } \\
\hline A.D. $390-590$ & 1 \\
\hline A.D. $340-390$ & 2 \\
\hline A.D. $340-140$ & 3 \\
\hline A.D. 140 & 4 \\
\hline
\end{tabular}

Table 71

Block 3 Occupation Zone Faunal Counts

\begin{tabular}{|c|c|c|c|c|c|c|c|}
\hline \multirow[b]{2}{*}{ Taxon } & \multirow[b]{2}{*}{ Common Name } & \multicolumn{6}{|c|}{ Occupation Zones } \\
\hline & & 7 & 6 & 5 & 4 & 3 & 2 \\
\hline Amia calva & Bowfin & & & & & 1 & 3 \\
\hline cf drum & Drum & & & & & & 3 \\
\hline cf Pylodictis & Freshwater catfish & & & & & & 4 \\
\hline Pylodictis olivaris & Freshwater catfish & & & & & 4 & 1 \\
\hline Aplodinotus grunniens & Freshwater drum & & & & & 6 & \\
\hline Unid pisces & Unid fish & & 6 & 1 & 2 & 38 & 47 \\
\hline Lepisosteus sp & Unid gar & & & & & & \\
\hline Micropterus salmoides & Largemouth bass & & & & & 2 & \\
\hline Fish Total & & 0 & 6 & 1 & 2 & 51 & 58 \\
\hline Lepus californicus & Black-tailed jack rabbit & & 2 & 3 & & 2 & \\
\hline Sylvilagus floridanus & Eastern cottontail rabbit & 3 & 1 & 5 & 6 & 6 & \\
\hline Sciurus niger & Eastern fox squirrel & & 2 & 1 & 1 & 1 & 3 \\
\hline Castor canadensis & North American beaver & 3 & & & & & \\
\hline Procyon lotor & Raccoon & & 1 & 1 & & & \\
\hline Sylvilagus sp & Unid rabbit & & & & & & \\
\hline Mammal & cf raccoon & & & 2 & 4 & & \\
\hline Mammal & Small mammal & 100 & 122 & 83 & 52 & 21 & 11 \\
\hline cf Canis latrans & cf coyote & & & 1 & & & \\
\hline Vulpes sp & $\mathrm{cf}$ fox & & & & & & \\
\hline cf Canis latrans & Coyote & & & & & & \\
\hline Vulpes vulpes fulva & Red fox & & & & & & \\
\hline Small Mam and Carnivores Total & & 106 & 128 & 96 & 63 & 30 & 14 \\
\hline
\end{tabular}


Table 71 (cont'd)

\begin{tabular}{|c|c|c|c|c|c|c|c|}
\hline \multirow[b]{2}{*}{ Taxon } & \multirow[b]{2}{*}{ Common Name } & \multicolumn{6}{|c|}{ Occupation Zones } \\
\hline & & 7 & 6 & 5 & 4 & 3 & 2 \\
\hline cf Odocoileus & Deer & 10 & 60 & 22 & 1 & & \\
\hline Odocoileus virginianus & White-tailed deer & 2 & 76 & 14 & & 2 & \\
\hline Mammal & Large mammal & 82 & 406 & 124 & 29 & 5 & 9 \\
\hline Deer Total & & 94 & 542 & 160 & 30 & 7 & 9 \\
\hline cf Bubo virginianus & Great horned owl & & & & & & \\
\hline Phasianidae sp & Unid quail & & & & & 1 & \\
\hline Meleagris gallopavo & Turkey & & & 5 & 1 & 2 & \\
\hline Aves & Unid bird & 35 & 25 & 56 & 15 & 15 & 1 \\
\hline Birds Total & & 35 & 25 & 61 & 16 & 18 & 1 \\
\hline Terrapene ornata ornata & Ornate box turtle & & 6 & & 1 & 24 & 18 \\
\hline Pseudemys concinna & Pond cooter & & & & & 6 & \\
\hline Chrysemys scripta & Red-eared slider & 12 & & 93 & 45 & 37 & 1 \\
\hline Terrapene sp & Unid Box Turtle & & 9 & 4 & & & \\
\hline Chrysemys sp & Unid Pond turtle & & & & & & \\
\hline Testudinata sp & Unid Turtle & 31 & 19 & 29 & 38 & 44 & 19 \\
\hline Turtles Total & & 43 & 34 & 126 & 84 & 111 & 38 \\
\hline Sigmodon hispidus & Cotton rat & & 1 & & 1 & & \\
\hline Geomys breviceps & Pocket gopher & & 1 & & & & \\
\hline Perognathus sp & Pocket mouse & & & & & & \\
\hline Microtus ochrogaster & Prairie vole & & 1 & & & & \\
\hline Rattus sp & Unid rat & 1 & & & & & \\
\hline Rodentia sp & Unid rodent & 1 & 27 & 10 & 4 & 15 & 9 \\
\hline Neotoma floridana & Wood rat & & & & & 2 & \\
\hline Geomys bursarius & Plains pocket gopher & & & & 4 & 9 & 2 \\
\hline Rattus rattus & Black rat & & 1 & & & & \\
\hline Rodentia sp & cf mole & & & & & & 1 \\
\hline Snake & cf cotton mouth & & & & 3 & & \\
\hline Snake & cf texas rat snake & & & & & & \\
\hline Snake & cf whip snake & & & & 1 & 3 & \\
\hline Snake & Unid snake & & & & & & \\
\hline Potential Intrusives Total & & 2 & 31 & 10 & 13 & 29 & 12 \\
\hline
\end{tabular}

Block 3

Using the explanatory framework of the prey choice model as described above, interpretations of diet breadth trends from Block 3 at 41TR198 are ambiguous in some instances and clearer in others (Table 73). For example, between the Late Archaic Period occupation zones 7 through 5 (410 B.C. - A.D. 700), the number of prey species (NTAXA) exploited by the occupants of 41TR198 does not appear to fluctuate as expected in response to changes in the percentages of deer specimens (Figure 82; see Table 70). In fact, NTAXA actually increases from 5 to 11 with 
Table 72

Block 4 Occupation Zone Faunal Counts

\begin{tabular}{|c|c|c|c|c|}
\hline \multirow[b]{2}{*}{ Taxon } & \multirow[b]{2}{*}{ Common Name } & \multicolumn{3}{|c|}{ Occupation Zones } \\
\hline & & 2 & 3 & 4 \\
\hline Amia calva & Bowfin & & & 1 \\
\hline cf drum & Drum & & & \\
\hline cf Pylodictis & Freshwater catfish & & & \\
\hline Pylodictis olivaris & Freshwater catfish & & & \\
\hline Aplodinotus grunniens & Freshwater drum & 2 & & \\
\hline Unid pisces & Unid fish & 4 & 6 & 11 \\
\hline Lepisosteus sp & Unid gar & 6 & 6 & 3 \\
\hline Micropterus salmoides & Largemouth bass & & & \\
\hline Fish Total & & 12 & 12 & 15 \\
\hline Lepus californicus & Black-tailed jack rabbit & 2 & 2 & \\
\hline Sylvilagus floridanus & Eastern cottontail rabbit & 15 & 20 & 11 \\
\hline Sciurus niger & Eastern fox squirrel & 4 & & 2 \\
\hline Castor canadensis & North American Beaver & 1 & 1 & 6 \\
\hline Procyon lotor & Raccoon & 2 & & \\
\hline Sylvilagus sp & Unid rabbit & 1 & 23 & \\
\hline Mammal & cf raccoon & & & \\
\hline $\begin{array}{l}\text { Mammal } \\
\text { cf Canis latrans }\end{array}$ & $\begin{array}{l}\text { Small mammal } \\
\text { cf coyote }\end{array}$ & 143 & 190 & 65 \\
\hline Vulpes sp & cf fox & & & 4 \\
\hline cf Canis latrans & Coyote & 1 & & \\
\hline Vulpes vulpes fulva & Red fox & 1 & & \\
\hline Small Mam and Carnivores Total & & 170 & 236 & 88 \\
\hline cf Odocoileus & Deer & 15 & 8 & 16 \\
\hline Odocoileus virginianus & White-tailed deer & 70 & 31 & 18 \\
\hline Mammal & Large Mammal & 251 & 115 & 161 \\
\hline Deer Total & & 336 & 154 & 195 \\
\hline cf Bubo virginianus & Great horned owl & & & 1 \\
\hline Phasianidae sp & Unid quail & & & \\
\hline Meleagris gallopavo & Turkey & 13 & 4 & 1 \\
\hline Aves & Unid bird & 112 & 91 & 35 \\
\hline Birds Total & & 125 & 95 & 37 \\
\hline Terrapene ornata ornata & Ornate box turtle & 3 & 9 & 1 \\
\hline Pseudemys concinna & Pond cooter & 6 & & \\
\hline Chrysemys scripta & Red-eared slider & 46 & 84 & 6 \\
\hline Terrapene sp & Unid box turtle & 12 & & \\
\hline Chrysemys sp & Unid pond turtle & 10 & & 2 \\
\hline Testudinata $\mathrm{sp}$ & Unid turtle & 34 & 37 & 28 \\
\hline Turtles Total & & 111 & 130 & 37 \\
\hline Sigmodon hispidus & Cotton rat & 2 & 1 & \\
\hline Geomys breviceps & Pocket gopher & & & \\
\hline Perognathus sp & Pocket mouse & & 2 & \\
\hline Microtus ochrogaster & Prairie vole & 1 & & \\
\hline Rattus sp & Unid rat & & & \\
\hline Rodentia sp & Unid rodent & 31 & 11 & 10 \\
\hline
\end{tabular}


Table 72 (cont'd)

\begin{tabular}{llll} 
& & \multicolumn{3}{c}{ Occupation Zones } \\
\cline { 3 - 4 } Taxon & Common Name & 2 & 3 \\
\hline \multirow{2}{*}{$\begin{array}{l}\text { Neotoma floridana } \\
\text { Geomys bursarius }\end{array}$} & Wood rat & & \\
Rattus rattus & Plains pocket gopher & 3 & \\
Rodentia sp & Black rat & & \\
Snake & Cf mole & & \\
Snake & Cf cotton mouth & 1 & \\
Snake & Cf texas rat snake & 1 & \\
Snake & Cf whip snake & 1 & \\
Potential Intrusives Total & Unid snake & 5 & \\
\hline
\end{tabular}

Table 73

NTAXA Relative to Deer Abundances Through Time

Occupation Zones

NTAXA

$\%$ Deer NISP

$\begin{array}{lrrr}\text { A.D. } 960-1040 & 2 & 9 & 6.8 \\ \text { A.D. } 900-960 & 3 & 15 & 2.8 \\ \text { A.D. } 700-900 & 4 & 11 & 14.4 \\ \text { A.D. } 350-700 & 5 & 9 & 35.2 \\ \text { A.D. } 250-350 & 6 & 11 & 70.8 \\ 410 \text { B.C.-A.D. } 250 & 7 & 5 & 33.6 \\ \text { Late Archaic } & 7,6,5 & 10 & 46.5 \\ \text { Late Prehistoric } & 4,3,2 & 15 & 24.1\end{array}$

the initial increase in deer between zones 7 and 6 , and then decreases from 11 to 9 with the subsequent decrease in deer between zones 6 and 5. This trend is contrary to predictions under the prey choice model, which predicts that NTAXA should vary inversely, as opposed to directly, to the intensity of deer exploitation. However, it is interesting to note that the time period between zones 7 and 5 represents the only time period in which the percentage of deer specimens outnumbers the percentage of all other prey categories (see Figure 82). It is possible, then, that deer contributed a substantial enough proportion of the diet during the Late Archaic Period zones (zones 5-7) that NTAXA did not respond initially to changes in deer exploitation intensity. Interestingly though, once the percentages of turtles and small mammals outnumber the percentage of deer specimens in the Late Prehistoric Period (zones 2-4) and deer continue to decrease (Figure 83), NTAXA increases from 9 to 11 between zones 5 and 4 (A.D. 350-900) and 


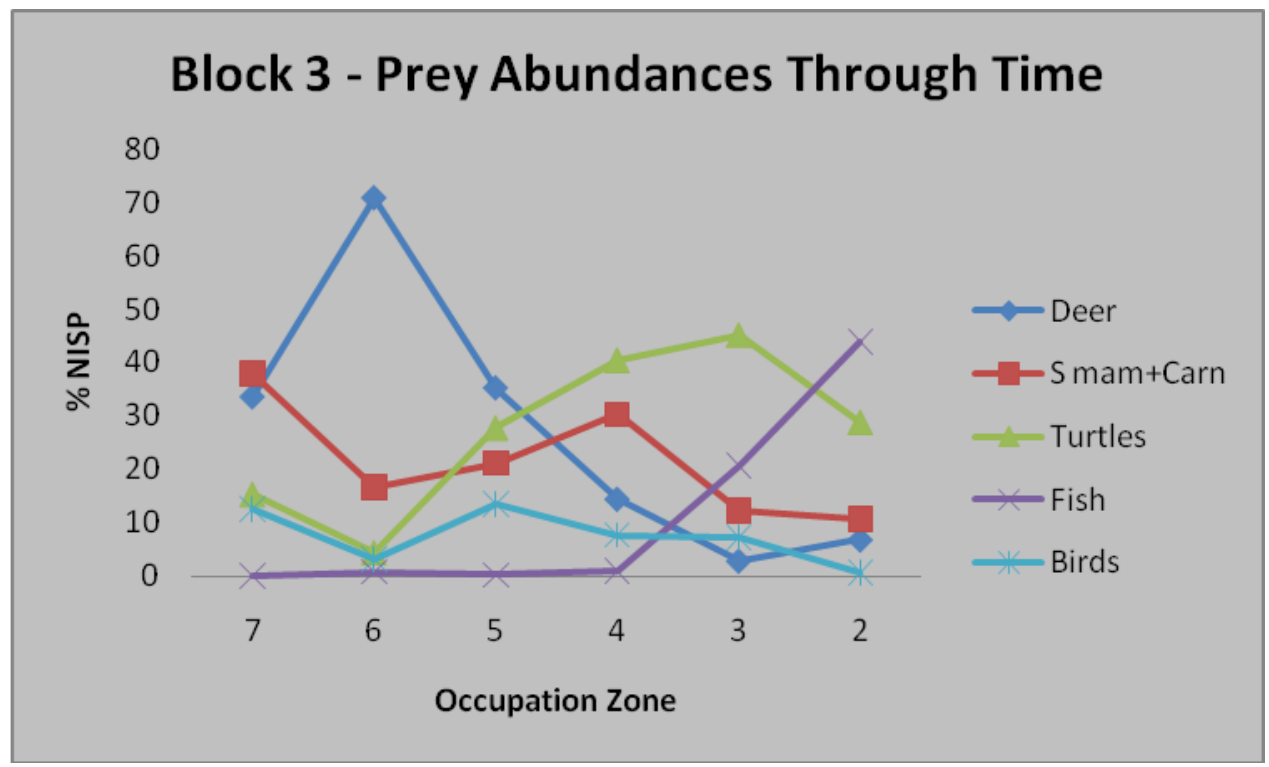

Figure 82. Prey abundances through time from Block 3.

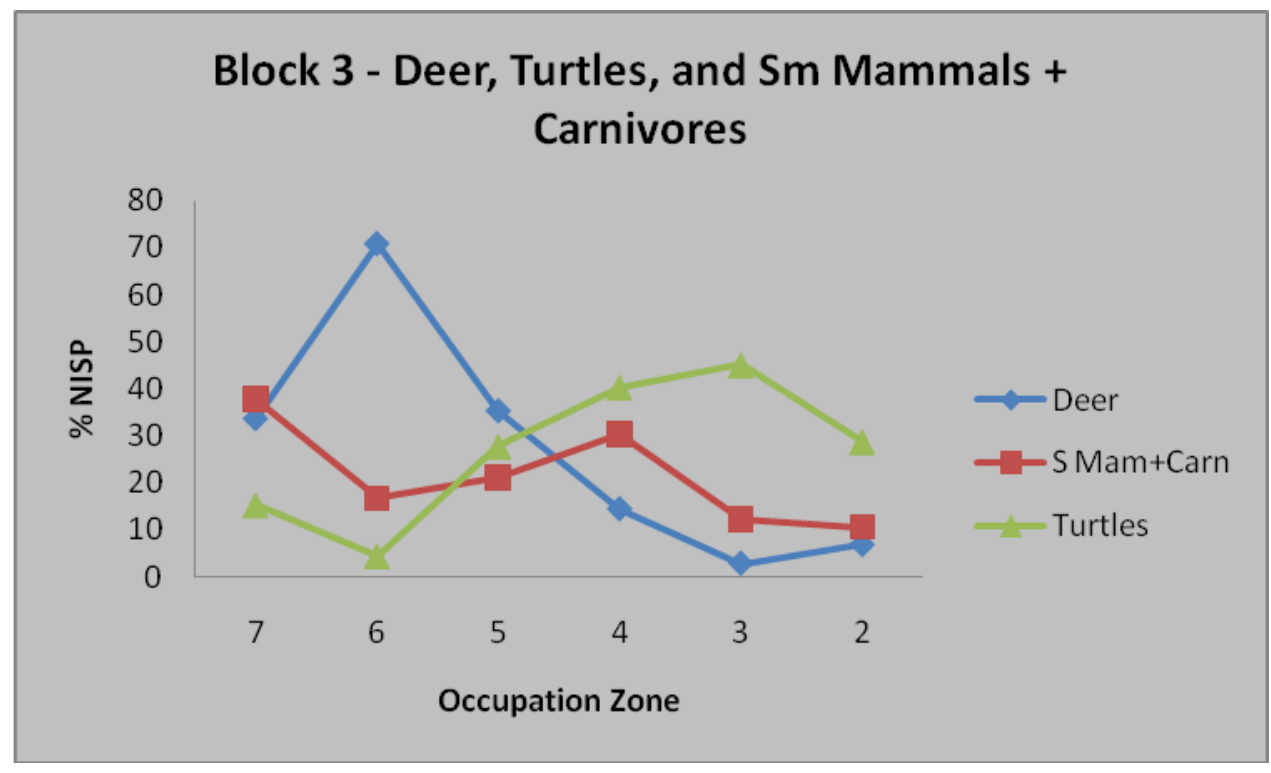

Figure 83. Abundances of deer, turtles, small mammals and carnivores through time from Block 3.

from 11 to 15 between zones 4 and 3 (A.D. 900-960) (see Table 73). Finally, and also in line with predictions under the prey choice model, with a slight increase in deer abundances during zone 2 , NTAXA decreases from 15 to 9. In short, diet breadth predictions by occupation zone, as framed under the prey choice model, follow for the Late Prehistoric Period but yet are inconsistent for the Late Archaic Period. However, when NTAXA is compared at a coarser scale and occupation 
zones are collapsed into their respective Late Archaic and Late Prehistoric Periods, NTAXA increases from 10 to 15 between the Late Archaic and the Late Prehistoric while the percentage of deer specimens decreases from 46.5 to 24.1 percent (see Table 73). This indicates that diet breadth may have indeed expanded in response to the decline in deer abundances through time. To ensure that sample size is not driving the Block 3 diet breadth trends described above, NTAXA was plotted against NISP by occupation zone; however, no relationship between NTAXA and sample size was found (Figure 84).

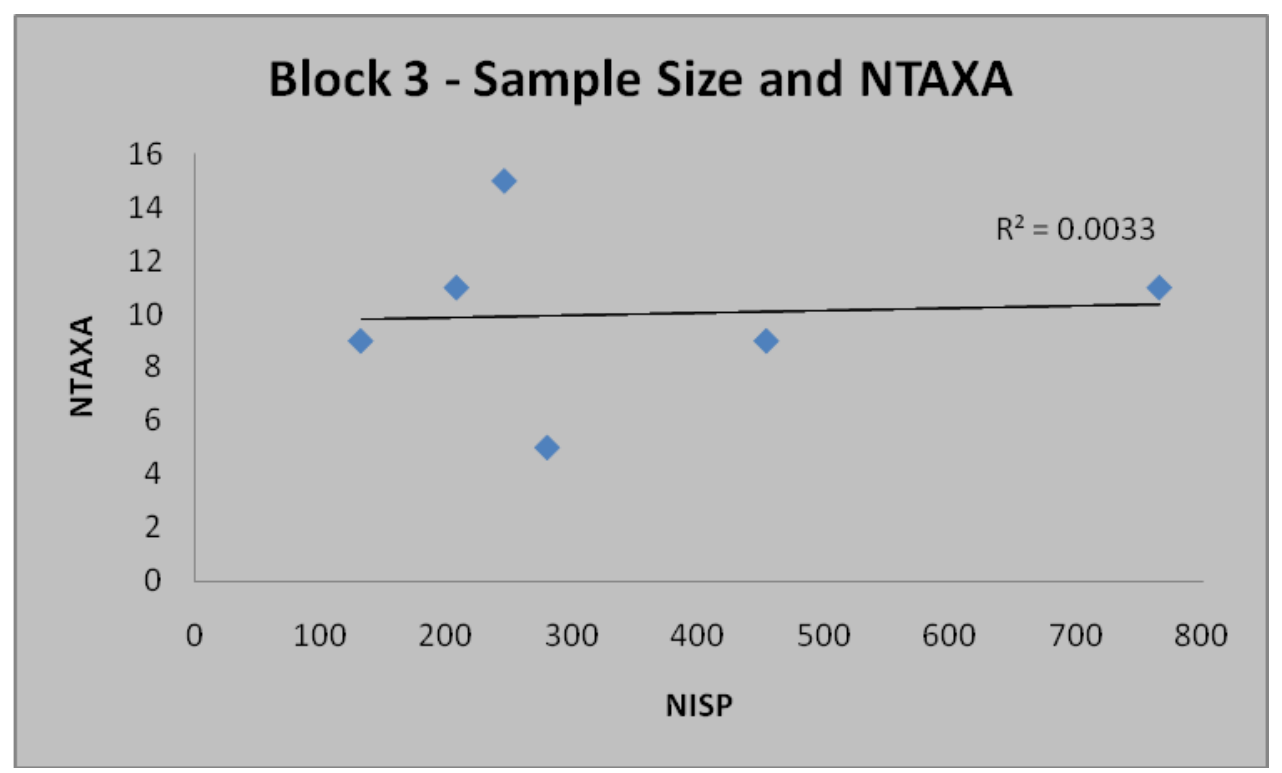

Figure 84. The relationship between sample size and NTAXA in Block 3.

Although in some instances, the diet breadth trends are inconsistent with predictions under the prey choice model, it seems clear from the Block 3 data that overall foraging efficiency declined through time at site 41TR198. This trend is most clearly observed when deer abundances are compared to percentages of turtles, fish, and small mammals and carnivores through time (Figure 85). For example, the initial response of human foragers to a decline in deer appears to have been an increased reliance on turtles and small mammals and carnivores between zones 5 and 4 . Then, between zones 4 and 2, turtles and fish become the most abundant prey and small mammals and carnivores decrease. This last transition towards a reliance on turtles and fish may signify a shift in focus from terrestrial to aquatic resources in response to continued declines in deer abundances or it could represent a shift to a wetter environment towards the end of the occupation sequence. 


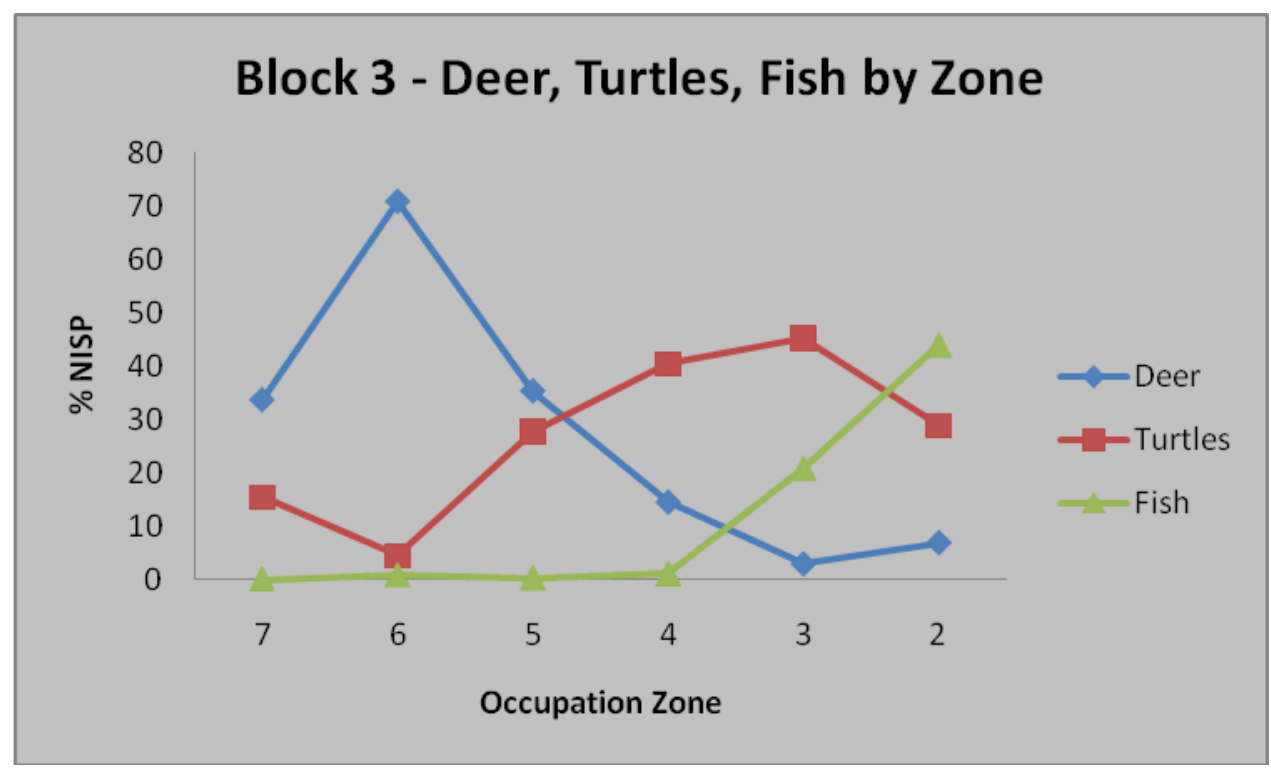

Figure 85. Abundances of deer, turtles, and fish through time from Block 3.

\section{Block 4}

Only the Late Archaic Period is represented in Block 4 and as a result, the same level of analysis could not be carried out for Block 4. However, the collapsed Late Archaic Period assemblages from Blocks 3 and 4 were compared to determine if the proportions of prey exploited during the Late Archaic are consistent across blocks (Figure 86). The results indicate that prey proportions are roughly similar in Blocks 3 and 4. Deer remains represent the majority of specimens in Blocks 3 and 4 with smaller proportions represented by small-bodied resources. Fish are almost entirely absent from the Late Archaic in both blocks.

\section{Conclusions}

The prey choice model predicts changes in the diet breadth and foraging efficiency of foragers to result from changes in the encounter rate of high-ranked resources on the landscape. With a decrease in encounter rates and thus a decrease in the exploitation of high-ranked resources, human foragers are expected to incorporate and exploit lower-ranked resources more intensively. Aside from inconsistencies in the Late Archaic period, the 41TR198 fauna from Block 3 seems to follow this general trend. As deer decrease through time, particularly in the Late Prehistoric, 


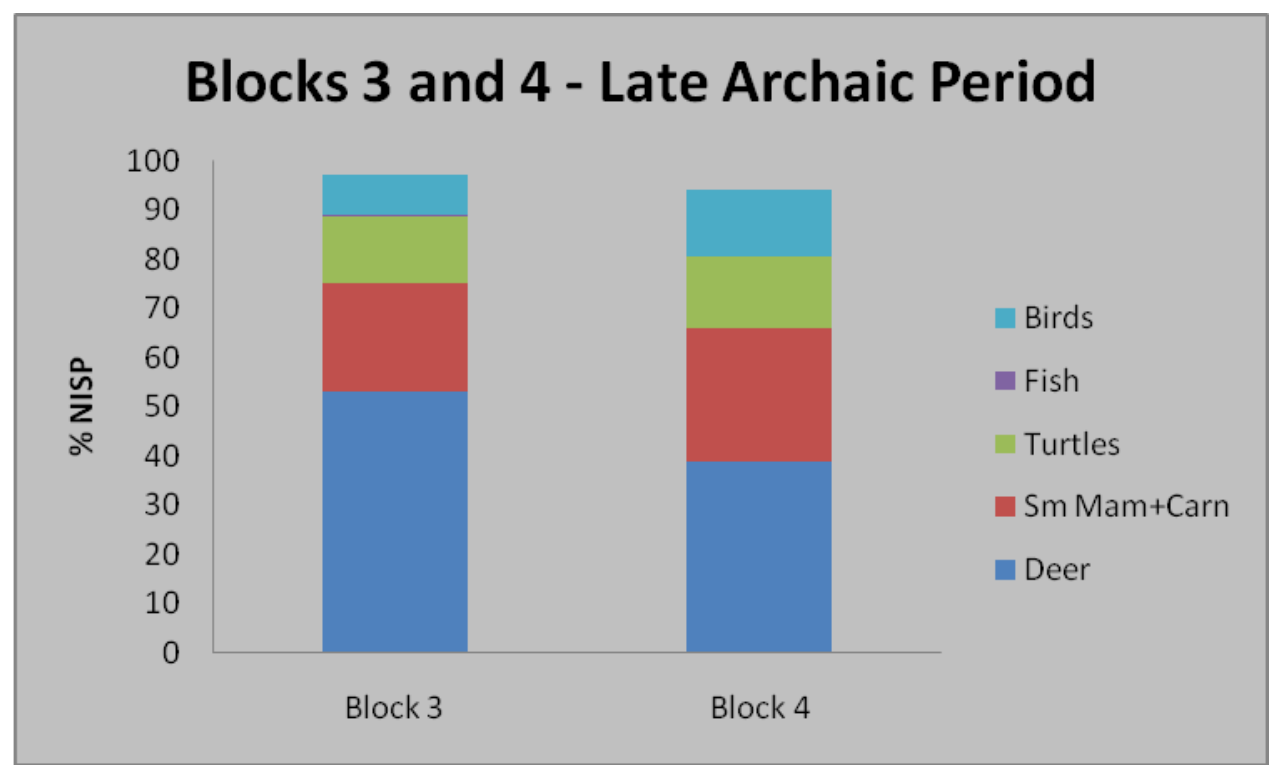

Figure 86. Prey abundances in the Late Archaic Period for Blocks 3 and 4.

NTAXA generally increases and the proportions of specimens from smaller-bodied resources such as turtles, fish, small mammals and carnivores increase as well. It is therefore possible that hunting of deer over time at site 41TR198 caused decreases in deer populations and encounter rates thereby increasing the reliance on lower-ranked resources through time. It is also possible that the changes in prey abundances described above resulted from environmental change or a combination of hunting pressure and environmental change.

\section{ANALYSIS OF ARCHAEOLOGICAL FRESHWATER SHELLFISH REMAINS FROM SITE 41TR198}

\section{Introduction}

This report is a description of freshwater shellfish remains found during archaeological excavation at 41TR198 with a discussion of the systematic paleontology of the fauna, which describes criteria used in identification. A short discussion of taphonomy of the fauna is also covered. In addition, instream environmental conditions are reconstructed and discussed using Warren's (1991) computer program UNIO (Version 3) for analyzing archaeological mussel assemblages. Specimens are counted using two quantitative units NSP (number of specimens 
[identified and unidentified]) and NRE (non-repetitive elements) (Lyman 1994a; Mason et al. 1998; but see Giovas 2009 for more discussion). A non-repetitive element is any hard shell skeletal element that is diagnostic of a single species or genus and can only be counted a limited and set number of times for one individual to have been present (sensu Mason et al. 1998). In our analysis, only NREs (right and left umbos) are identified to the most specific taxon possible. A sizeable portion of remains from the sample are fragmented and cannot be identified to taxon or element (see systematic paleontology below). A complete record of faunal specimen identifications is provided in Appendix C, which is summarized in Table 74.

Table 74

List of Species and NRE for Unionid Remains from 41TR198

\begin{tabular}{|c|c|c|}
\hline Species & Common name & $N R E$ \\
\hline Amblema plicata & Threeridge & 253 \\
\hline Arcidens confragosus & Rock Pocketbook & 2 \\
\hline Fusconaia sp. & & 1,394 \\
\hline Lampsilis hydiana & Louisiana Fatmucket & 61 \\
\hline Lampsilis cf. satura & Sandbank Pocketbook & 9 \\
\hline Lampsilis teres & Yellow Sandshell & 34 \\
\hline Lampsilis sp. & & 6 \\
\hline Leptodea cf. fragilis & Fragile Papershell & 5 \\
\hline Ligumia subrostrata & Pondmussel & 3 \\
\hline Ligumia cf. subrostrata & Pondmussel & 1 \\
\hline Obliquaria reflexa & Threehorn Wartyback & 27 \\
\hline Plectomerus dombeyanus & Bankclimber & 417 \\
\hline Pleurobema riddellii & Louisiana pigtoe & 259 \\
\hline Pleurobema cf. riddellii & Louisiana pigtoe & 3 \\
\hline Potamilus purpuratus & Bleufer & 5 \\
\hline Potamilus cf. purpuratus & Bleufer & 8 \\
\hline Quadrula apiculata & Southern Mapleleaf & 5 \\
\hline Quadrula mortoni & Western Pimpleback & 224 \\
\hline Quadrula nobilis & Gulf Mapleleaf & 2 \\
\hline Quadrula verrucosa & Pistolgrip & 117 \\
\hline Toxolasma texasiensis & Texas Lilliput & 2 \\
\hline Truncilla donaciformis & Fawnsfoot & 2 \\
\hline Truncilla truncata & Deertoe & 76 \\
\hline Unidentified fragments & & 4,380 \\
\hline Total Assemblage & & $N S P 7,295$ \\
\hline
\end{tabular}




\section{Taphonomy}

Two characteristics of mussel shells, shape and structure, drive whether or not shell remains are preserved in depositional contexts (Wolverton et al. 2010). The more spherical the shell of a species, regardless of its shell density (structure), the more likely it is to be preserved (Figure 87). In addition, the more dense that the shell of a particular species is, the more likely it is to be preserved given its shape. Only shells with spherical, dense shell morphology are highly abundant at 41TR198 indicating differential preservation according to interspecific variability in shell robusticity. Other, species with less robust shell morphology, however, are present in the assemblage at low abundances, which is probably (in part at least) a product of large sample size leading to recovery of ecologically rare species or ones that are taphonomically rare because their shells are unlikely to survive. In general, species with shells that exhibit relatively robust morphology in terms of shape and structure, such as Amblema plicata, are common at the site.

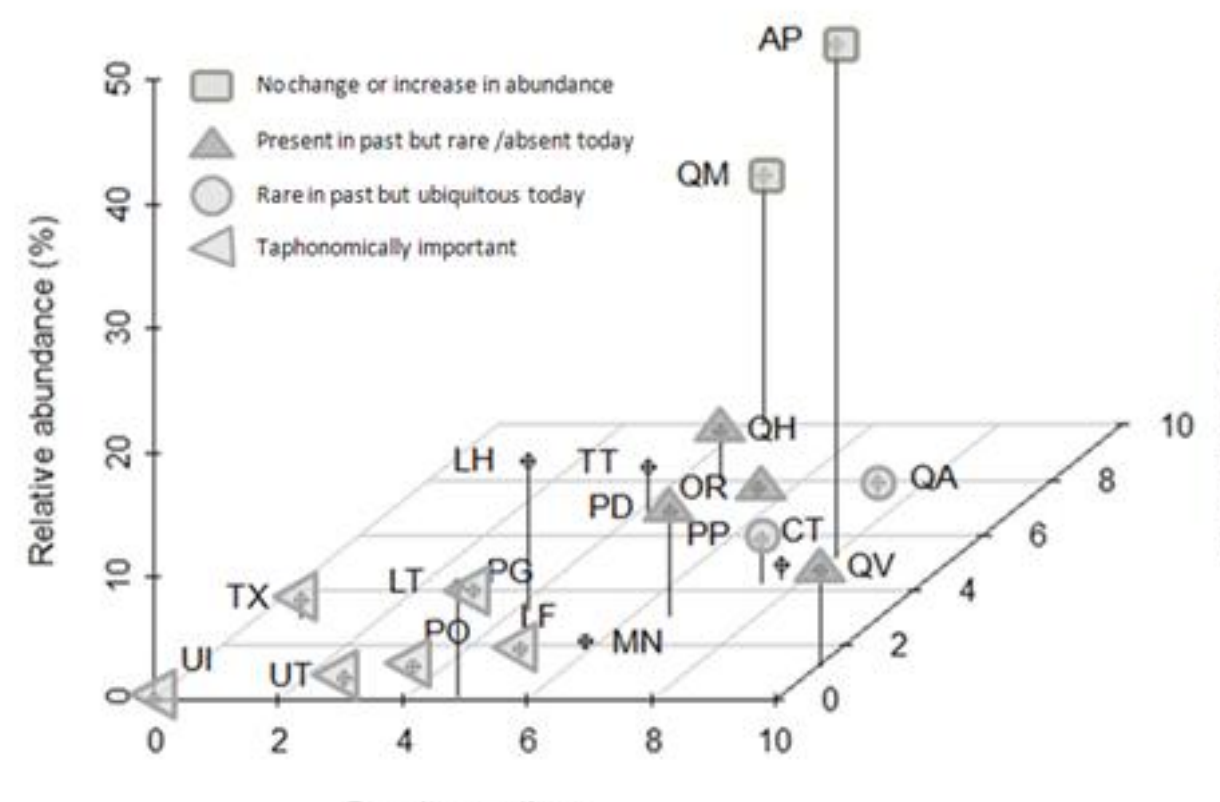

Density gradient

Figure 87. Three-dimensional lollipop graph portraying the average proportional taxonomic abundance of each species from six late Holocene zooarchaeological assemblages in north Texas. Species are coded using shapes to communicate either their biogeographic/interpretive or taphonomic importance in sites in the region. Species names are abbreviated (e.g., UT = Uniomerus tetralasmus, $\mathrm{TX}=$ Toxolasma sp., $\mathrm{AP}=$ Amblema plicata). The high abundance of UT and the presence of TX at 41TR198 indicates that the mussel fauna is well preserved. Figure from Wolverton et al. (2010, figure 6). 
Taxonomic richness of mussel species (NTAXA) changes over time at site 41TR198 (Table 75); however, this pattern cannot be interpreted as subsistence change or environmental change. There is a close association between sample size (NRE or NSP) and NTAXA across temporal assemblages at the site. Further, intensity of fragmentation, as measured by a ratio of NSP to NRE (the higher the value the more common are small unidentifiable fragments [Lyman 1994]), associates closely with taxonomic richness. It is commonly understood in zooarchaeology and ecology that species richness increases with sample size and that identifiability of specimens relates to preservation (Lyman 2008). Sample size and differential preservation across these assemblages appear to drive taxonomic abundance and richness; thus, changes through time should not be interpreted as related to subsistence adaptation and/or environmental change in streams. However, the Block 3 sample from site 41TR198 is large enough to permit an analysis of taxonomic nestedness to determine whether or not it is likely that samples of different sizes derive from the same time-averaged ecological community. A high degree of taxonomic nestedness among assemblages would suggest that species composition from different samples derive from the same community (see below).

Table 75

Taxonomic Abundance, Richness, and Fragmentation Data for Levels from Block 3

Levels 6 \& 7

Levels 8 \& 9

Levels $12 \& 13$

Levels $16-18$

\begin{tabular}{|c|c|c|c|c|}
\hline NRE & 126 & 1452 & 165 & 477 \\
\hline NSP & 629 & 3205 & 665 & 1391 \\
\hline Weight (g) & $1,422.3$ & $10,158.4$ & 1874.5 & 4881.6 \\
\hline NSP:NRE & 5.0 & 2.2 & 4.0 & 2.9 \\
\hline NTAXA & 14 & 18 & 11 & 15 \\
\hline \multirow[t]{20}{*}{ RSI } & 5.8 & 3.3 & 5.1 & 3.6 \\
\hline & Amblema plicata & Amblema plicata & Amblema plicata & Amblema plicata \\
\hline & Fusconaia sp. & Arcidens confragosus & Fusconaia sp. & Arcidens confragosus \\
\hline & Lampsilis hydiana & Fusconaia sp. & Lampsilis hydiana & Fusconaia sp. \\
\hline & Lampsilis teres & Lampsilis hydiana & Lampsilis teres & Lampsilis hydiana \\
\hline & Leptodea cf. fragilis & Lampsilis satura & Obliquaria reflexa & Lampsilis satura \\
\hline & Obliquaria reflexa & Lampsilis teres & Plectomerus dombeyanus & Lampsilis teres \\
\hline & Plectomerus & Leptodea cf. fragilis & Pleurobema riddellii / cf. & Leptodea cf. fragilis \\
\hline & dombeyanus & Ligumia subrostrata / cf. & Potamilus purpuratus & Obliquaria reflexa \\
\hline & Pleurobema riddellii / & Obliquaria reflexa & Quadrula mortoni & Plectomerus dombeyanus \\
\hline & & Plectomerus & Quadrula verrucosa & Pleurobema riddellii / cf. \\
\hline & Potamilus purpuratus & dombeyanus & Truncilla truncata & Potamilus purpuratus \\
\hline & Quadrula apliculata & Pleurobema riddellii / & & Quadrula mortoni \\
\hline & Quadrula verrucosa & Potamilus purpuratus & & Quadrula verrucosa \\
\hline & Toxolasma texasiensis & Quadrula apliculata & & Truncilla truncata \\
\hline & Truncilla truncata & Quadrula mortoni & & \\
\hline & & Quadrula verrucosa & & \\
\hline & & Toxolasma texasiensis & & \\
\hline & & Truncilla donaciformis & & \\
\hline & & Truncilla truncate & & \\
\hline
\end{tabular}




\section{Environmental Reconstruction}

Prehistoric environmental conditions are reconstructed using Warren's (1991) computer program UNIO (Version 3) for analyzing archaeological mussel assemblages. Four variables are examined: water depth, current velocity, substrate composition, and type of freshwater habitat (e.g., lentic or lotic). Water depth is quantified between $0.0 \mathrm{dm}$ to $46 \mathrm{dm}(0.0 \mathrm{~m}$ to $4.6 \mathrm{~m})$. Current velocity is categorized as strong "SW," moderate "MO," slow "SL," and standing "ST." Substrate composition is defined as: cobble-gravel "C-G," gravel "G," gravel-sand "G-S," sand "S," sand-mud "S-M," and mud "M." Finally, water body type is defined as Large river "LR," Medium River "MR," Small River "SR," Large Creek "LC," Small Creek "SC," and "Lake." For each species examined numerical weights $(0,0.5$, and 1$)$ are assigned based on published habitat data, which are then graphed. For example, if a species is routinely reported to occur in a gravelsand substrate a score of 1 would be assigned for that environmental variable. Conversely, if a particular species is rarely documented inhabiting a gravel-sand substrate then a score of 0.5 is enumerated. Presence/absence (Taxa) values are multiplied by weighted habitat variables and then summed across taxa within these categories. The result is a percentage of an archaeological assemblage that is adapted to a particular habitat category (see Warren 1991 and Morey and Crothers 1998 for an in depth discussion of UNIO). UNIO covers 133 unionid species from the Mississippi Basin but does not include the following species found in the paleozoological record from North Texas: Fusconaia sp., Lampsilis hydiana, Lampsilis satura, Pleurobema riddellii, Quadrula apiculata, Quadrula mortoni, and Quadrula nobilis. For L. hydiana, Q. apiculata, and Q. mortoni, Lampsilis siliquoidea, Quadrula quadrula, and Quadrula pustulosa were used instead, respectively, because they share similar ecological requirements for the species not included in UNIO (Parmalee and Bogan 1998; Howells et al. 1996). Lampsilis satura, P. riddellii, and Quadrula nobilis were omitted from the analysis because little is known regarding their habitat or distribution (Howells et al. 1996). Fusconaia sp. was omitted because the taxonomic status of this genus in north Texas is unclear (Howells et al. 1996).

\section{Systematic Paleontology}

Driver (1992) explicates five rules for identification of zooarchaeological remains. First, each specimen (here each shell or shell fragment) should be identified on its own merits and compared individually to reference specimens and materials. The NRE approach appears to violate this rule 
by a priori selecting the portions of shell to be identified (Giovas 2009), but this is unlikely to be problematic with freshwater bivalves because features that are identifiable are those accounted for in the NRE approach. The second rule that Driver (1992) describes is to "set the universe" of species likely to occur in the faunal assemblage. Species likely to occur in northcentral Texas are described by Howells et al. (1996). The third rule is to set diagnostic criteria for taxonomic identifications; we discuss this for each species throughout the systematic paleontology. In general, adhering to this rule entails consistent, thorough comparison of paleozoological specimens to a range of modern reference individuals for species represented in the universe. Driver's fourth rule is to anticipate difficult to separate taxa; in particular, morphologies of many taxa are continuous and overlap, a problem that we discovered with the genera Fusconaia and Pleurobema, which we discuss in more detail below. The final rule is to provide detailed statements of criteria used to make taxonomic identifications, which is the holistic purpose of a systematic paleontology. Without this description, faunal analyses are subject not only to variability in accuracy and precision of identifications (thus also problems of validity) but nonreplicability (see Gobalet 2001). Gobalet (2001) is deeply critical of faunal analysis as a practice and questions the validity of any given grey-literature report that has not been peer reviewed. The practice of writing a systematic paleontology offers quality assurance and circumvents Gobalet's (2001) criticism.

Specimens are assigned to class, order, suborder, family, genus, and species according to their identifiability. Identifications were made using taxonomic references (Howells et al. 1996; Parmalee and Bogan 1998) and through comparison to reference specimens housed at the Elm Fork Heritage Museum at the University of North Texas.

Phylum Mollusca (molluscs)

Class Bivalvia (bivalves)

Order Unionoida (freshwater mussels)

Family Unionidae (pearly mussels)

Genus Amblema

Amblema plicata (Threeridge)

NRE: 253

Remarks: Specimens identified as A. plicata are heavy shelled and characterized by the presence of 3 to 7 ridges, which run diagonal to the ventral margin. The pseudocardinal teeth for these specimens are also diagnostic: the left valve contains two large, divergent, grooved, triangular pseudocardinal teeth. The right valve has one elevated, grooved, triangular pseudocardinal tooth. Threeridge is a robust species, tolerant of drought and low water quality and may inhabit both lakes and streams (Howells et al. 1996). Individuals for this species were elongated and compressed, which is indicative of lotic systems with moderate flow. 
Genus Arcidens

Arcidens confragosus (Rock Pocketbook)

NRE: 2

Remarks: Shells of A. confragosus are thin with numerous wrinkles and corrugations covering the shell surface. Also diagnostic are the pseudocardinal teeth: in the left valve the posterior pseudocardinal tooth is fused with the interdental projection. The right valve has a single large, erect, triangular tooth. Arcidens confragosus is rare to uncommon throughout north Texas and inhabits large creeks and rivers in gravel, sand or mud substrates (Howells et al. 1996; Williams et al. 2009).

Genus Fusconaia

Fusconaia sp.

NISP: 1394

Remarks: Shells of Fusconaia sp. are quadrate to rhomboidal in shape with a shallow sulcus in advance of a pronounced posterior ridge (Figure 88; numeral one and two); these criteria were used to separate individuals for this genus from Pleurobema. Also diagnostic are the pseudocardinal teeth which are strong and torn (see Figure 88; numeral 3); for Pleurobema pseudocardinal teeth are strong and rough, not torn. Also important are the lateral teeth which are straight and thin and rarely protrude onto the interdentum as seen for individuals belonging to Pleurobema (see Figure 88; numeral four). It is important to note that species within this genus exhibit tremendous morphological variability. Consequently, individuals were compared to type specimens collected by J.A. Singley in 1892 from the Trinity River. Most of the individuals categorized to this genus closely resemble voucher specimens (Figure 89) identified as either Fusconaia flava, Fusconaia chunii or Fusconaia cerina; both of these species have been synomized with Fusconaia flava. Unfortunately, very few modern specimens have been collected in Texas (e.g., Strecker 1931); consequently, the taxonomic status of this genus is unclear (Howells et al. 1996). Therefore, individuals identified using the aforementioned criteria are designated as Fusconaia sp.

Genus Lampsilis

Lampsilis hydiana (Louisiana Fatmucket)

NRE: 61

Remarks: Shells of Lampsilis hydiana are often large, swollen, and rhomboidal or oblong in shape. The umbo is raised above the hinge line with a moderately deep beak cavity. The pseudocardinal teeth for both the right and left valves tend to be massive compared to other species within this genus. The depth of the beak cavity and the size of the pseudocardinal teeth are used as diagnostic features to identify this species. Individuals for this species exhibit compressed shell morphology, which is indicative of streams and rivers with moderate flow. Lampsilis hydiana is tolerant of both lentic and lotic systems and can adapt well to no- or lowflow conditions (Howells et al. 1996).

\section{Lampsilis cf. satura (Sandbank Pocketbook)}

NRE: 9

Remarks: Specimens identified as Lampsilis cf. satura are moderately thick shelled and are characterized by beaks that are raised high above the hinge line with a posterior ridge that is broadly rounded. Also important is the presence of muscle scars along the upper portion of the anterior wall of the beak cavity. The presence of lateral teeth that are both long and high is also diagnostic. It is important to note, that because all of the individuals examined were badly 

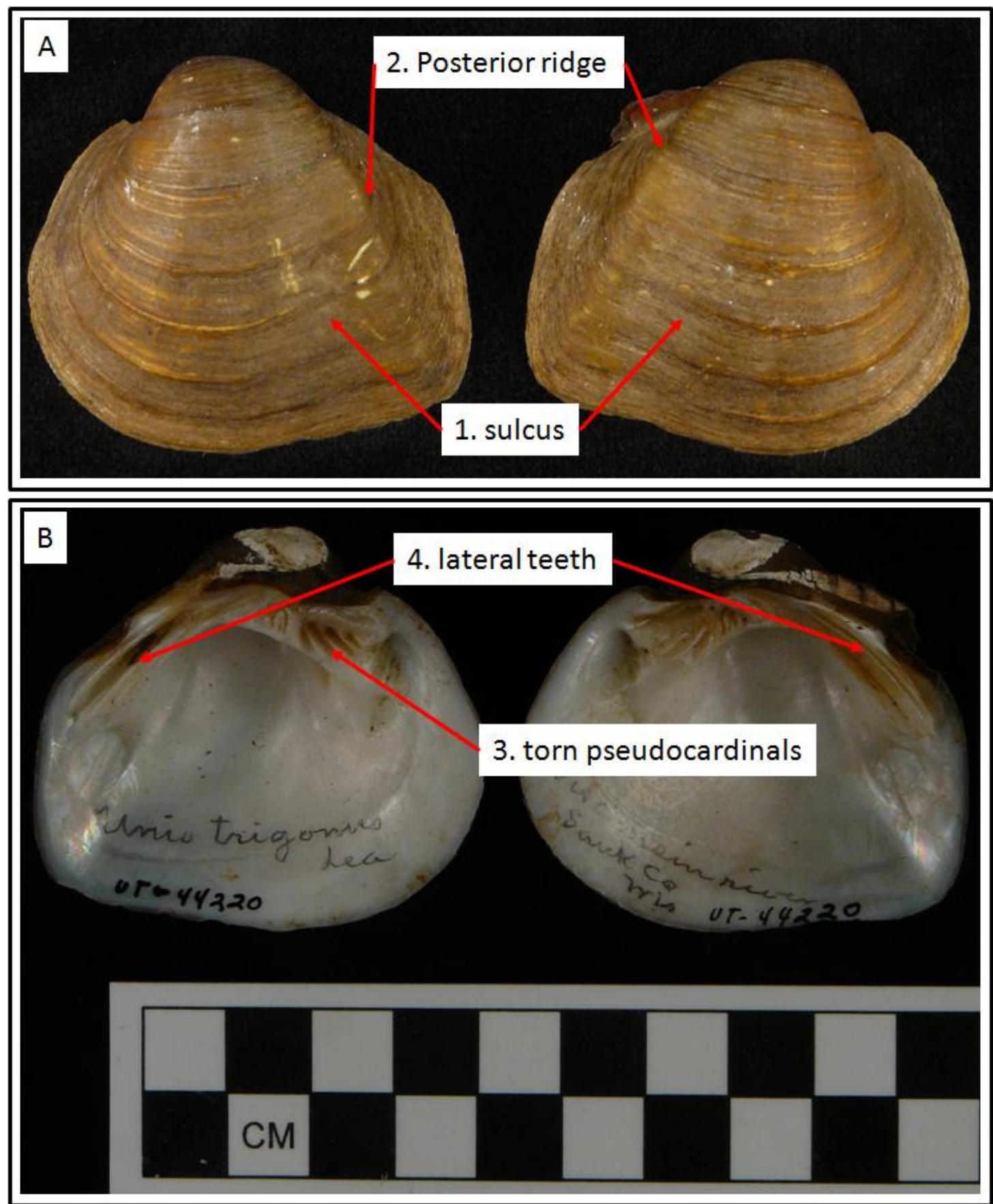

Figure 88. Photograph of Fusconaia flava; Picture A depicts the exterior view whereas picture B depicts the interior view. Numbers correspond to key morphological features used to differentiate this species from Pleurobema riddellii. See Systematic Paleontology section for details and discussion regarding each feature. 

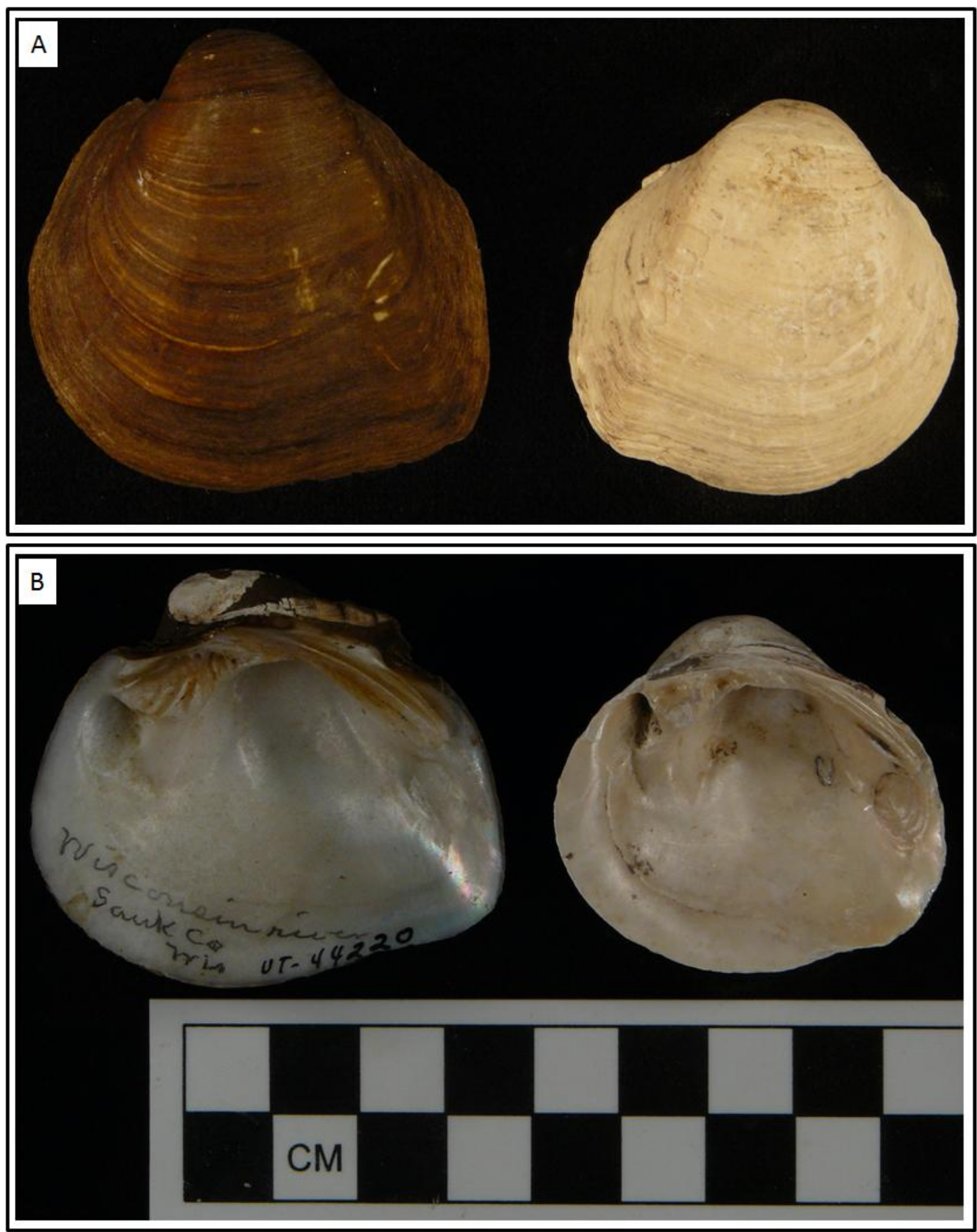

Figure 89. Photograph comparing Fusconaia flava and Fusconaia sp. from site 41TR198. Picture A depicts the external morphology whereas Picture B depicts the internal morphology for both valves. 
fragmented, confident identification to species could not be made. Instead, L. cf. satura is used for individuals that are morphologically similar to modern individuals collected from the Sabine River. The presence of $L$. cf. satura is significant because it currently occurs from the San Jacinto River north and east (Howells et al. 1996); thus, its potential presence in this site might represent a late Holocene extralimital record. Lampsilis satura may inhabit small to large rivers with moderate flows on gravel, gravel-sand, and sand substrates. Sandbank pocketbook is considered threatened by the American Fisheries Society (Howells et al. 1997).

\section{Lampsilis teres (Yellow Sandshell)}

NRE: 34

Remarks: Shells of Yellow Sandshell are thick, moderately inflated and elongated. Unlike $L$. hydiana, the dorsal and ventral margins are nearly straight and the umbo is only slightly elevated above the hinge line; the beak cavity is fairly shallow. The pseudocardinal teeth are compressed and less massive than other species within this genus. Shell ornamentation for both L. hydiana and $L$. teres consists of only a few indistinct ridges, which is useful for differentiating both species from Ligumia subrostrata. Yellow Sandshell is intolerant of environmental perturbations and frequent dewatering, and is found only in lotic habitats (Howells et al. 1996).

Lampsilis sp.

NRE: 6

Remarks: Individuals that are badly fragmented but have pseudocardinal teeth that are clearly representative of the genus Lampsilis are categorized as Lampsilis sp.

Genus Leptodea

Leptodea cf. fragilis (Fragile Papershell)

NRE: 5

Remarks: Shells of Fragile Papershell are thin and brittle and tend to be oblong, elliptical, or ovate in shape. Because the shells for this species are fragile and tend to break upon drying, only a few small fragments were identifiable. The pseudocardinal teeth are its primary diagnostic features. The left valve contains two pseudocardinal teeth that are low and thin; the posterior tooth may be reduced or absent. The right valve contains one pseudocardinal tooth that is also low and thin. This species may occur in small streams to large rivers in still to swiftly flowing waters. This species has been reported as tolerant of environmental alteration (Howells et al. 1996). Its presence in paleozoological contexts is rare given its fragile shell morphology.

\section{Genus Ligumia}

\section{Ligumia subrostrata (Pondmussel)}

NRE: 3

Ligumia cf. subrostrata

NRE: 1

Remarks: Ligumia subrostrata was identified primarily by the presence of v-shaped beak ornamentation. Pondmussel can tolerate a variety of lotic habitats, but adapts well to small streams, ponds and backwater areas (Howells et al. 1996). 
Genus Obliquaria

Obliquaria reflexa (Threehorn Wartyback)

NRE: 27

Remarks: Individuals of Obliquaria reflexa were identified by the presence of 2-5 (usually 3) large knots on the surface of the shell. This species is most often found in medium to large rivers with gravel, sand and gravel, or mud and gravel in areas with moderate currents (Howells et al. 1996).

Genus Plectomerus

Plectomerus dombeyanus (Bankclimber)

NRE: 417

Remarks: Specimens identified as $P$. dombeyanus are heavy shelled, rhomboidal in shape with a pronounced posterior ridge that extends from the ventral margin and terminates near the umbo. Shell ornamentation in the form of pustules and tubercles is restricted to the beak area and is useful for differentiating this species from Quadrula verrucosa. The pseudocardinal teeth for these specimens are diagnostic as well: the left valve contains two large, divergent, grooved pseudocardinal teeth separated by a shallow notch. The right valve has one elevated, grooved, pseudocardinal tooth with an anterior and posterior denticle. Bankclimber is often found near the banks or shallow areas of large, slow flowing rivers (Howells et al. 1996). The presence of $P$. dombeyanus is significant because it is found only in prehistoric assemblages for northcentral Texas, but not in modern streams.

Genus Pleurobema

Pleurobema riddellii (Louisiana Pigtoe)

NISP: 259

Pleurobema cf. riddellii

NISP: 3

Remarks: Shells of Pleurobema riddellii are rather thick and solid, inflated near the central disk, and triangular to quadrate in outline (Figure 90; numeral 1). The surface of the shell is smooth with no ornamentation, which is useful for differentiating this species from others in the genus Quadrula. Shell ornamentation in the form of three to four undulations that form parallel Vshaped ridges is useful for differentiating individuals of this species from Fusconaia flava and Quadrula mortoni (not photographed). The presence of a well defined posterior ridge that is keel-shaped and lacks a sulcus is also diagnostic (see Figure 90, numeral 2). Finally, P. riddellii can be differentiated from $F$. flava by the presence of curved lateral teeth and a large/wide interdentum (see Figure 90, numeral 3). Identifications were made by comparison with specimens collected from the lower Sabine River. Louisiana Pigtoe is considered extremely rare today and is considered threatened by the American Fisheries Society (Howells et al. 1997). This species occurs in small to medium sized rivers with slow to moderate flows.

Genus Potamilus

Potamilus purpuratus (Bleufer)

NRE: 5

Potamilus cf. purpuratus

NRE: 8

Remarks: Individuals indentified as Potamilus purpuratus are characterized by the presence of large, somewhat compressed pseudocardinal teeth. Muscle attachment scars within the umbo are useful for differentiating this species from Cyrtonaias tampicoensis. That is, muscle attachment 

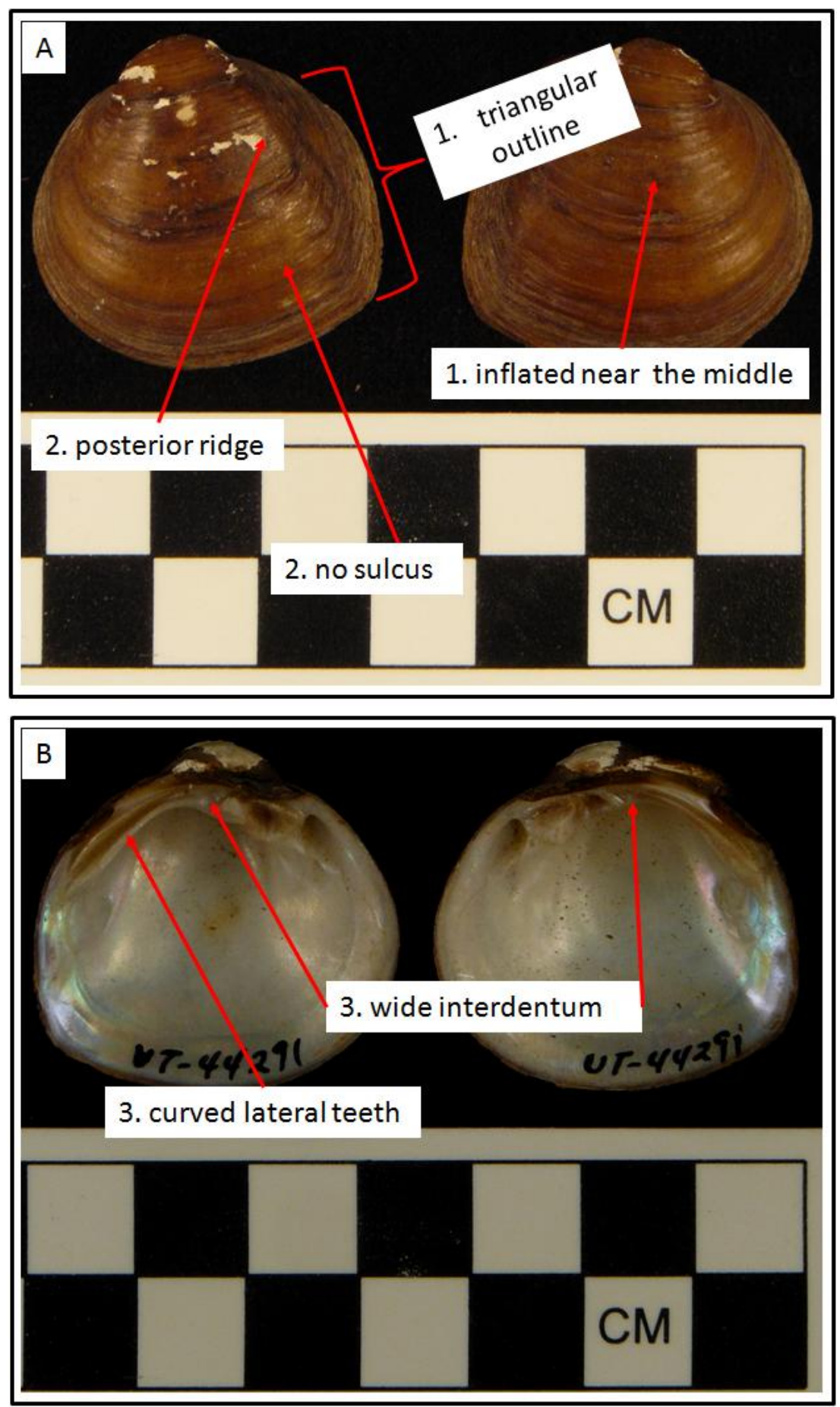

Figure 90. Photograph of Pleurobema riddellii; Picture A depicts the exterior view whereas picture B represents the interior view. Numbers correspond to key morphological features used to differentiate this species from Fusconaia flava. See Systematic Paleontology section for details and discussion regarding each feature. 
scars in the umbo are clearly visible for Bleufer, whereas for $C$. tampicoensis both the left and right valves must be angled in order to view similar muscle attachment scars. Potamilus purpuratus occurs in creeks to large rivers, where it may be found in substrates composed of mud, sand, gravel and cobble. It occurs in areas with slow to swift current and may also be found in some reservoirs and oxbows (Williams et al. 2009).

Genus Quadrula

Quadrula apiculata (Southern Mapleleaf)

NRE: 5

Remarks: Individuals of Quadrula apiculata were identified by the presence of small pustules covering the entire shell surface. Shell ornamentation throughout the sulcus was used to differentiate this species from Quadrula nobilis. Southern Mapleleaf occurs in a variety of habitats from medium creeks to large rivers as well as flood plain lakes, sloughs and reservoirs (Williams et al. 2009).

\section{Quadrula mortoni (Western Pimpleback)}

NRE: 224

Remarks: Valves of Quadrula mortoni are inflated, solid and round in shape. The posterior ridge is well developed but rounded, which is useful for differentiating this species from either Fusconaia sp. or Pleurobema riddellii. Also diagnostic are the pseudocardinal teeth in the left valve; the two left teeth are not widely separated and the posterior tooth is much smaller and deeply grooved. For all individuals examined the surface shell was largely apustulose with the exception of a few pustules or tear-shaped lunules extending from the umbo to the ventral margin.

\section{Quadrula nobilis (Gulf Mapleleaf)}

NRE: 2

Remarks: Valves of Quadrula nobilis are moderately thick, inflated and subquadrate to trapezoidal in shape. The surface of the shell is largely devoid of pustules except for a row of elongate pustules on either side of the sulcus, which is diagnostic. This species is differentiated from Southern Mapleleaf by an apustulose sulcus. This species occurs in large rivers. It may be found in swift to sluggish water in substrates ranging from mud to sand or gravel (Williams et al. 2009).

\section{Quadrula verrucosa (Pistolgrip)}

NRE: 117

Remarks: The shell of Quadrula verrucosa is thick, elongated and rhomboidal in shape. The surface of the shell is covered with pimples, pustules and small tubercles, which is diagnostic. The umbo is slightly elevated above the hinge line, which is useful for differentiating $Q$. verrucosa from Bankclimber. The pseudocardinal teeth are diagnostic as well: the left valve contains two large, divergent, serrated, triangular pseudocardinal teeth, which may be oblique to one another. The right valve has one elevated, grooved, triangular pseudocardinal tooth with only an anterior denticle. Pistolgrip is a lotic species found often in riffles, but may also tolerate slow flowing rivers (Howells et al. 1996). Like other lotic species, Pistolgrip is intolerant to environmental disturbance. 
Genus Toxolasma

Toxolasma texasiensis (Texas Lilliput)

NRE: 2

Remarks: The Texas Lilliput is more elliptical and elongated in outline compared to other species in this genus. Unlike T. parvus, shells for this species have a posterior ridge that is well defined, and an overall shell shape that is less inflated. Beaks are low but full with ornamentation that consists of 7-9 curved ridges, which is unique for this species. Modern reference specimens were used in addition to diagnostic morphological features to differentiate $\mathrm{T}$. texasiensis from $T$. parvus. Toxolasma texasiensis is found in both lakes and streams, preferring habitat with little or no flow (Parmalee and Bogan 1998).

Genus Truncilla

Truncilla donaciformis (Fawnsfoot)

NRE: 2

Remarks: Individuals identified as Truncilla donaciformis are moderately thin with a prominent posterior ridge. Also diagnostic are its thin compressed pseudocardinal teeth. Individuals of this species were differentiated from Truncilla truncata based on a rounded posterior ridge and elongate shell. Fawnsfoot is primarily a large river species occurring most often in flowing water on substrates composed of gravel, sand or mud (Williams et al. 2009). The presence of this species is important because it was thought not to have occurred in north Texas (Neck 1990).

\section{Truncilla truncata (Deertoe)}

NRE: 76

Remarks: Shells of Truncilla truncata are triangular to subquadrate in outline. The posterior ridge is prominent and sharp, which is useful for differentiating this species from T. donaciformis. The pseudocardinal teeth are also diagnostic: the left valve contains two slightly divergent teeth and the right valve contains one tooth that may have a thin accessory denticle. Deertoe occurs primarily in flowing water of creeks and small to medium rivers. This species can inhabit a variety of substrates, including sand, gravel and occasionally firm mud.

\section{Discussion}

\section{Taphonomy and Zoogeography}

The mussel fauna from 41TR198 is important for two reasons. First, large mussel assemblages are rare but this one is very large, and as a result several species that are not commonly encountered in zooarchaeological assemblages in north Texas occur at the site (Randklev et al. 2009). The fauna, thus, represents a bit of a sampling anomaly in that several species with fragile shells (e.g., Toxolasma) are represented. This simply relates to the large size of the fauna in that discovery probability of rare species increases with larger sample sizes (Lyman 2008). Although preservation varies by temporal assemblage at the site, as a whole the site assemblage represents a 
moderately well-preserved late Holocene freshwater mussel fauna. The second important characteristic of the fauna relates to taphonomy; moderately good preservation has resulted in an assemblage that is important in terms of late Holocene zoogeography of mussel species in north Texas. For example, the presence of Lampsilis cf. satura and Plectomerus dombeyanus is significant because these species are found only in late Holocene assemblages for northcentral Texas and are absent today (Randklev et al. in press). Modern populations of both species are restricted primarily to river drainages east of the Trinity River. That is, P. dombeyanus occurs from the San Jacinto River into drainages to the north and east where as L. satura seems to be restricted to the San Jacinto, Neches and Sabine River drainages (Howells et al. 1996). Neck (1990) considered Plectomerus dombeyanus to be absent from the upper Trinity due to intermittent stream conditions. Moreover, during the same study Neck (1990) identified Lampsilis satura in Lake Lewisville. Howells (unpublished) dismissed these records, instead suggesting that specimens identified by Neck (1990) were most likely lentic morphotypes of $L$. hydiana. The identification of this species suggests that $L$. satura may be indigenous to the upper Trinity River drainage. Further, the presence of both species indicates that in general the Upper Trinity was not ephemeral; both species typically occur in streams with at least moderate flows.

Other important findings include Pleurobema riddellii, which is thought to be extirpated from northcentral Texas (Howells et al. 1996). The type locality for this species is near Dallas, where it was thought to have been eliminated as result of industrial effluent being discharged into the Trinity River. This species historically occurred throughout a number of east Texas rivers, but habitat degradation is thought to have eliminated many of these populations (Howells et al. 1997). In fact, since 1992 only a few live individuals have been collected and all of them were from the Neches River drainage (Howells 2009). The presence of Truncilla donaciformis is also important because this species was also thought to have been absent from the upper Trinity River drainage (Neck 1990). Truncilla donaciformis is considered widely distributed in Texas but never in high abundance. This species occurs from waters east and north of the Brazos River basin and the only substantial populations documented in Texas has been on the Neches River (Howells 1999). Finally, the large number of Fusconaia sp. identified from this assemblage is somewhat of an anomaly. Strecker (1931) reported Fusconaia flava from the Elm Fork of the Trinity River. However, surveys by TPWD failed to collect this species either alive or as recently dead (Howells et al. 1996). Therefore, Howells (unpublished) questioned the taxonomic validity of Fusconaia flava in Texas. The Fusconaia sp. examined from this assemblage closely resemble voucher 
specimens of Fusconaia cf. flava (verified by R.G. Howells 2008) collected from the East Fork of the Trinity River.

\section{Paleoenvironmental Reconstruction}

Block 3 produced seventy-six percent of the identifiable assemblage and is dated between 410 B.C. and A.D. 1040. Excavation level assemblages produced samples of varying size; those from Levels 7, 9, 13, 17 and 18 were relatively small (NRE > 70 for each). To bolster sample sizes from Block 3 four temporal assemblages were created by aggregating small level-assemblages with vertically adjacent larger ones combing levels 6 and 7, 8 and 9, 12 and 13, and 16 through 18 (see Table 75). NTAXA is used as a measure of species richness, and Reciprocal of Simpson's Index (RSI) is used as a measure of taxonomic dominance (Magurran 1988). Both measures are discussed in detail by Lyman (2008); of the two, NTAXA is straightforward and easy to use. RSI determines within an assemblage comprising remains of taxa whether or not one or a few taxa dominate the assemblage in terms of relative abundance. RSI is calculated as $1 / \sum \mathrm{n}_{\mathrm{i}}\left(\mathrm{n}_{\mathrm{i}}-1\right) / \mathrm{N}(\mathrm{N}-1)$ where $\mathrm{n}_{\mathrm{i}}$ is the number of specimens (NRE) of a particular taxon and $\mathrm{N}$ represents that total number of specimens from all taxa represented in the assemblage (Lyman 2008:196-197). The lower the RSI value is, the more a single taxon or a few taxa dominate an assemblage; the higher the RSI value the more evenly abundances are distributed across taxa represented (see also Grayson 1984). NTAXA and RSI are potentially influenced by sample size effects; larger samples tend to produce larger arrays of taxa represented because 'discovery probability' increases with sampling effort (sample size: NRE). The presence of very few individuals of rare species in large samples tends to accentuate the dominance of common taxa producing lower RSI values as well. In order to infer that differences in NTAXA or RSI are ecologically or culturally meaningful, sample size effects must be ruled out. At 41TR198 in block three, sample size is positively associated with NTAXA and negatively associated with RSI indicating that sample size effects cannot be ruled out.

A qualitative assessment of taxonomic nestedness, however, highlights that smaller assemblages tend to be nested subsets of taxa represented in larger temporal assemblages. For example, all of the taxa represented in levels $6 / 7$ and in 12/13 (the assemblages with the two lowest NTAXA) are represented in the largest assemblage 8/9. The second largest assemblage (in terms of NRE and 
NTAXA) 16-18 only adds a single new species Quadrula nobilis, but the remaining 14 taxa are a nested subset of the 8/9 taxonomic assemblage. This supports a conclusion that the four temporal assemblages from Block 3 represent the same population and that the largest sample (8/9) is simply a better representation of that late Holocene population than the smaller samples from different excavation levels. The high degree of nestedness across samples supports a conclusion that neither the ecological community nor exploitation of it changed dramatically through time in the West Fork Trinity River near 41TR198.

Paleoenvironmental reconstruction in UNIO using our four defined variables produces important results. First, water body preferences for the majority of mussels examined from this site are medium sized rivers (Figure 91a). The percentage scores generated from the presence/absence data supports the assumption that the West Fork of the Trinity River was at least medium in size during the late Holocene. Second, the species in this assemblage seem to represent depths of between 0.3 and $0.9 \mathrm{~m}$, with the greatest percentage of taxa $(93.75 \%)$ indicating a depth of $0.9 \mathrm{~m}$ (see Figure 91b). Thus, during the late Holocene mussels were most likely collected from shallow areas within the stream. In fact, unionid abundance is often greatest in shallows areas and then decreases as water depth increases (Dillon 2000).

Third, a preference for slow moving waters is observed in our analysis of current-velocity habitat preference (see Figure 91c). Arcidens confragosus, L. hydiana, L. subrostrata, and T. texasiensis are often found in shallow, slow to still waters, backwater areas, or in protected parts of streams (Howells et al. 1996; Neck 1986; Parmalee and Bogan 1998). However, the presence of Fusconaia sp., O. reflexa, L. cf. satura, and T. donaciformis suggests that portions of the West Fork had at least moderate flows during the late Holocene. Fourth, substrate composition for all time periods appears to have consisted primarily of mud with some sand (see Figure 91d). For many east Texas rivers mussels are most often found inhabiting substrata comprised of compact sand and mud (Randklev unpublished data). 


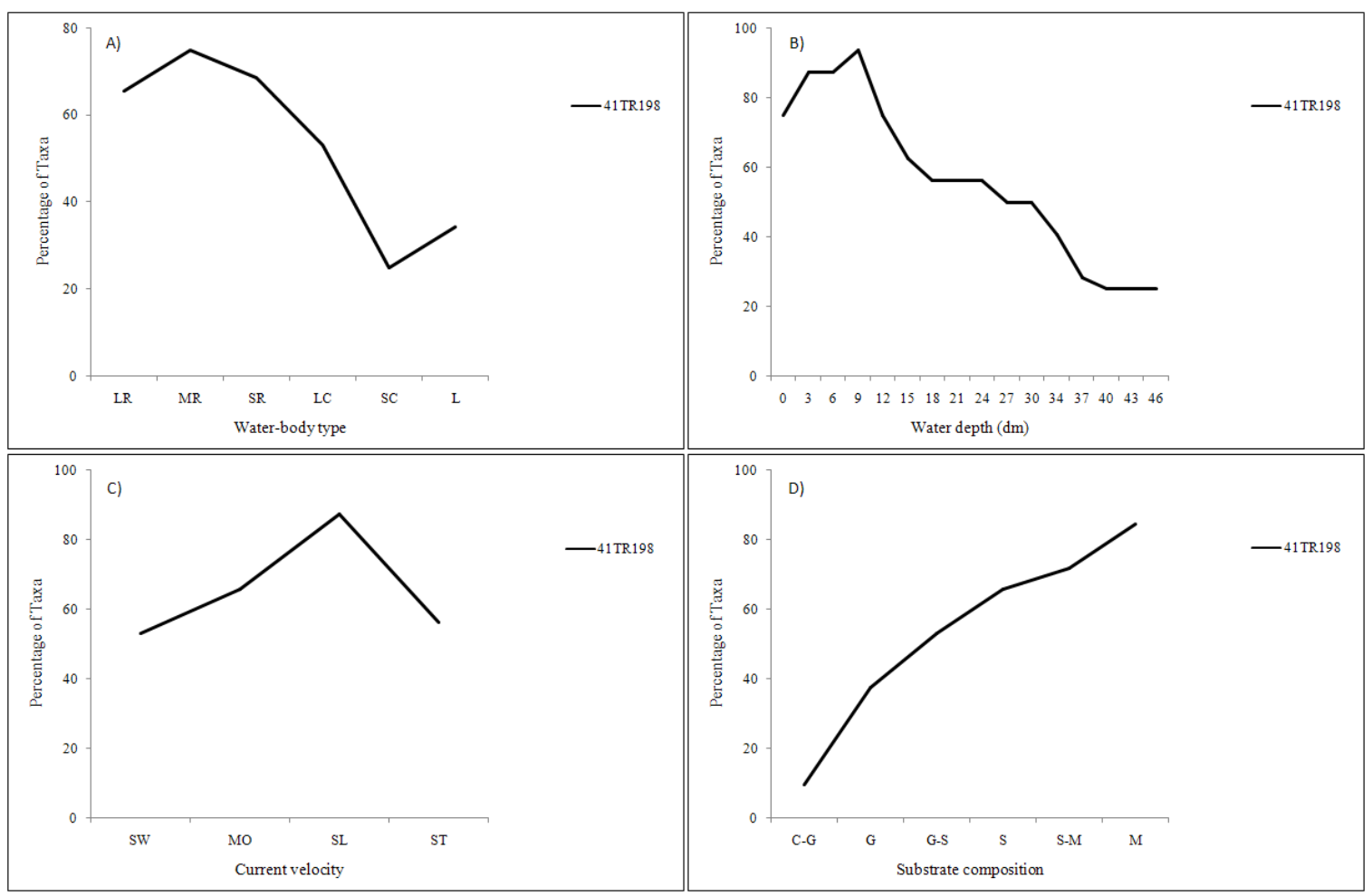

Figure 91. Habitat preference scores generated by the spreadsheet program UNIO (Warren, 1991), based on qualitative (presence/absence) data per time period for 41TR198.

\section{Conclusion}

Contrary to what is often reported and/or published by zooarchaeologists, explaining changes through time in taxonomic abundances can be highly problematic. Examination of changes through time in taxonomic richness (e.g., NTAXA) and evenness (e.g., RSI) requires comparison of highly representative samples from multiple spatial or temporal contexts (Lyman 2008). The freshwater mussel fauna from 41TR198 is relatively large compared to other samples of similar age from northcentral Texas that we have encountered. However, sample size effects among different temporal assemblages negate an ability to assess changes through time in human use of mussel species and or detailed changes (or lack thereof) in aquatic environments. Grayson (1984) has convincingly argued that taxonomic abundance data are at best ordinal scale (more than/less than) measures in zooarchaeology and taxonomic data may be nominal scale. Despite the large size of the 41TR198 mussel fauna, its taxonomic data should be assessed at nominal scale. Our analysis of nestedness is an example of this; the composition (taxa represented) of small samples represents subsets of the largest sample (Levels 8/9). At this coarse scale, it appears that 
taxonomic composition of the mussel fauna in all temporal samples represent the same ecological community. Cumulatively our UNIO habitat reconstruction indicates that the West Fork of the Trinity River was a medium, shallow, slow-flowing river with a substratum dominated primarily by mud. The presence of Fusconaia sp., L. satura, O. reflexa and T. donaciformis suggests that portions of the West Fork had moderate flows.

\section{PLANT REMAINS FROM SITE $41 T R 198$}

The purpose of this analysis is to provide an assessment of the botanical assemblages from 41TR198. Eight flotation samples were submitted for analysis. The soil samples totaled 87-liters before processing. The data are utilized to assess the nature and condition of the plant remains from this site and provide evidence for plant utilization and local environmental conditions.

\section{Methods}

Flotation is a method of recovering organic remains from archaeological sediments by using water to separate heavy or soluble inorganic particles from plant parts and small animal bone. The material floating to the surface is called the light fraction which is caught on a fine mesh screen or strainer. The material that sinks to the bottom is the heavy fraction and it is also caught on a fine mesh screen. Most of the soil including clay and silt is suspended in water and passes through the screens and is either recycled or discarded. In this study the light fractions were submitted for analysis.

The analysis followed standard archeobotanical laboratory procedures. The volume of the light fraction is first measured. In most cases up to $100 \mathrm{ml}$ of light fraction from each sample is set aside for analysis. Then the portion to be analyzed is passed through a nested set of screens of $4 \mathrm{~mm}, 2 \mathrm{~mm}, 1 \mathrm{~mm}$, and $0.450 \mathrm{~mm}$ mesh and examined for charred material, which is separated for identification. The heavy fraction is also scanned for charcoal, which is set aside for identification. The results are combined with identifications from each corresponding light fraction. 
Plant material is sorted into two categories -wood fragments, and seed/fruit or bulb fragments including maize parts when present. Identification of carbonized wood was accomplished by using the snap technique, examining the fragments at 8 to 45 magnifications with a hand lens or a binocular dissecting microscope, and comparing the material to samples in the archeobotanical herbarium. All seed identifications were made using seed manuals and reference collections at Shumla Archeobotanical Services. Only charred plant material is included in the analysis, because uncarbonized material is consumed by insects, fungi and bacteria and does not survive more than a few years in the deposits of open sites.

Up to 25 wood charcoal fragments large enough to be manipulated are examined and identified from each flotation sample. Fragments smaller than 2- or 3- mm cannot be manipulated. They are usually placed in the indeterminate category. When a sample contains more than 25 fragments, the rest of the material is scanned to make sure that no other taxa are present. Then the volume of the charcoal is measured and included along with its weight in the report.

The results for each sample are presented in tabular format. The data from the taxa counts is also presented as presence values. Presence value or ubiquity is defined as the percentage of all analyzed samples, both productive (with charred seeds or wood) and unproductive (no identifiable carbonized plant remains), in which a particular taxon is present. I have used this method primarily to provide a rough measure of the occurrence of the major plant resources identified in the samples. Presence value provides a means of determining how widespread a taxon is throughout the samples recovered from a site, but it does not evaluate the abundance of that taxon.

Disturbance Indicators. Sample content may be affected by various biological disturbance factors, including insect or small mammal activity, and plant root growth. In an effort to assess this impact, the amounts of insect parts, termite pellets, gastropods, mammal remains (including fecal pellets), and modern uncharred seeds are estimated for each flotation sample. These amounts are reported on a scale of 1-5 (+), 6-25 (++), 26-50 (+++), and over $50(++++)$. Termite pellets occur in higher numbers when samples are taken from an area containing wood that has been exposed to the elements for a long time before burning. 


\section{Results and Discussion}

Results of the analysis are presented in Tables 76 and 77. Table 76 lists the sample proveniences along with plant taxa counts from each sample. Identifications and counts of plant material recovered from each sample, including the macrobotanical sample, appear in Table 77. Disturbance indicators were abundant, and clay, usually absent from light fractions, was present in many samples. Roots and gastropods were the only disturbance indicators. None of the samples contained uncharred seeds.

\begin{tabular}{|c|c|c|c|c|c|c|}
\hline \multicolumn{7}{|c|}{$\begin{array}{c}\text { Table } 76 \\
\text { Flotation Sample Summary }\end{array}$} \\
\hline$\underset{\mathrm{C}}{\vec{C}}$ & $\begin{array}{l}\frac{T}{0} \\
\frac{0}{2} \\
0 \\
0 \\
\frac{5}{0} \\
\frac{0}{0}\end{array}$ & 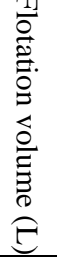 & $\begin{array}{l}\overrightarrow{0} \\
\stackrel{0}{0} \\
\stackrel{0}{0} \\
\stackrel{0}{\vec{Q}} \\
\stackrel{0}{0}\end{array}$ & 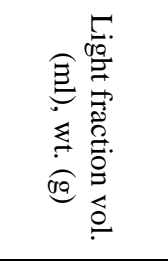 & 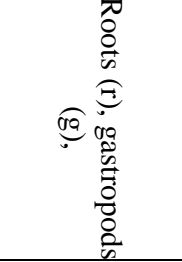 & 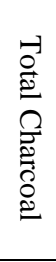 \\
\hline Flotation (LF) & 103 & 6 & Feature 18; L7; BLK3 & $13 \mathrm{ml} ; 3.9 \mathrm{~g}$ & $\mathrm{r}+++$ & $<.1$ \\
\hline Flotation (LF) & 236 & 8 & $\begin{array}{l}\text { Feature 25; U15\&16; 98.95-98.91; } \\
\text { BLK } 4\end{array}$ & $28 \mathrm{ml} ; 3.5 \mathrm{~g}$ & $\mathrm{r}+++, \mathrm{g}+++$ & 0.3 \\
\hline Flotation (LF) & 237 & 9 & Feature $25 ;$ U15\&17; 98.94-98.86 & $48 \mathrm{ml} ; 18.9 \mathrm{~g}$ & $\mathrm{r}+++, \mathrm{g}+++$ & 0.4 \\
\hline Flotation (LF) & 241 & 7 & Feature 25 & $28 \mathrm{ml} ; 7.6 \mathrm{~g}$ & $\mathrm{~g}+++$ & 0.5 \\
\hline Flotation (LF) & 386 & 26 & Feature 34; SW 1/4, Trench 6 & $50 \mathrm{ml} ; 27.9 \mathrm{~g}$ & $\mathrm{r}+++, \mathrm{g}++$ & 1.2 \\
\hline Flotation (LF) & 388 & 8 & Feature 32 ; East $1 / 2$ & $28 \mathrm{ml} ; 10.4 \mathrm{~g}$ & $\mathrm{r}+++, \mathrm{g}+++$ & 0.1 \\
\hline Flotation (LF) & 389 & 5 & Feature 32; U32; L11 & $12 \mathrm{ml} ; 3.7 \mathrm{~g}$ & $\mathrm{r}+, \mathrm{g}+$ & $<.1$ \\
\hline Flotation (LF) & 594 & 18 & BLK 3; U30; L18 & & $\mathrm{r}+++, \mathrm{g}+++$ & 0.1 \\
\hline
\end{tabular}

Considering the size of the flotation samples, the recovered quantity of charred plant material was low. However, the quality of information was unusually good, for in addition to wood remains, both bulb fragments and seeds were recovered from the samples. The total charcoal in each light fraction varied from $<.1 \mathrm{~g}$ to $1.2 \mathrm{~g}$.

As seen in Table 77, bulbs or bulb leaf fragments were recovered from four of the eight samples. In addition to the bulb fragments a single hackberry nutlet and a grass seed (caryopsis) fragment is present in the samples. The bulb material may be either eastern camas or wild onion; 
Table 77

Results from Flotation and Macrobotanical Samples from Site 41TR198

\begin{tabular}{|c|c|c|c|c|c|c|c|c|}
\hline Type & FS & Provenience & Taxon & Common & Part & Count & $\begin{array}{r}\text { Vol } \\
(\mathrm{ml}) \\
\end{array}$ & $\begin{array}{l}\mathrm{Wt} \\
(\mathrm{g})\end{array}$ \\
\hline Flotation (LF) & 103 & Feature 18; L7; BLK3 & Indeterminate & NA & Wood & 6 & -- & $<.1$ \\
\hline Flotation (LF) & 236 & $\begin{array}{l}\text { Feature 25; U15\&16; } \\
\text { 98.95-98.91; BLK } 4\end{array}$ & Liliaceae & $\begin{array}{l}\text { Onion or camas } \\
\text { bulb }\end{array}$ & $\begin{array}{l}\text { Bulb } \\
\text { fragment }\end{array}$ & 1 & -- & $<.1$ \\
\hline Flotation (LF) & 236 & $\begin{array}{l}\text { Feature 25; U15\&16; } \\
\text { 98.95-98.91; BLK } 4\end{array}$ & Poaceae & Grass family & $\begin{array}{l}\text { Seed } \\
\text { fragment }\end{array}$ & 1 & -- & $<.1$ \\
\hline Flotation (LF) & 236 & $\begin{array}{l}\text { Feature 25; U15\&16; } \\
\text { 98.95-98.91; BLK } 4\end{array}$ & Quercus sp. & Oak & Wood & 25 & -- & 0.2 \\
\hline Flotation (LF) & 237 & $\begin{array}{l}\text { Feature 25; U15\&17; } \\
98.94-98.86\end{array}$ & Liliaceae & $\begin{array}{l}\text { Onion or camas } \\
\text { bulb }\end{array}$ & $\begin{array}{l}\text { Bulb } \\
\text { fragment }\end{array}$ & 1 & -- & 0.2 \\
\hline Flotation (LF) & 237 & $\begin{array}{l}\text { Feature 25; U15\&17; } \\
98.94-98.86\end{array}$ & Quercus sp. & Oak & Wood & 25 & -- & 0.2 \\
\hline Flotation (LF) & 241 & Feature 25 & Liliaceae & $\begin{array}{l}\text { Onion or camas } \\
\text { bulb }\end{array}$ & $\begin{array}{l}\text { bulb } \\
\text { fragment }\end{array}$ & 1 & -- & $<.1$ \\
\hline Flotation (LF) & 241 & Feature 25 & Indeterminate & NA & Wood & 5 & -- & $<.1$ \\
\hline Flotation (LF) & 241 & Feature 25 & Quercus sp. & Oak & Wood & 12 & -- & 0.3 \\
\hline Flotation (LF) & 241 & Feature 25 & Juglans sp. & Walnut & Wood & 10 & -- & 0.1 \\
\hline Flotation (LF) & 386 & $\begin{array}{l}\text { Feature 34; SW 1/4, } \\
\text { Trench } 6\end{array}$ & Quercus sp. & Oak & Wood & $25+$ & 5 & 0.9 \\
\hline Flotation (LF) & 388 & Feature 32 ; East $1 / 2$ & Celtis sp. & Hackberry & Seed & 1 & -- & -- \\
\hline Flotation (LF) & 388 & Feature 32 ; East $1 / 2$ & $\begin{array}{l}\text { Platanus } \\
\text { occidentalis }\end{array}$ & Sycamore & Wood & 3 & -- & $<.1$ \\
\hline Flotation (LF) & 388 & Feature 32 ; East $1 / 2$ & Quercus sp. & Oak & Wood & 15 & 6 & 0.1 \\
\hline Flotation (LF) & 389 & Feature 32; U32; L11 & Indeterminate & NA & Wood & 3 & -- & $<.1$ \\
\hline Flotation (LF) & 594 & BLK 3; U30; L18 & Liliaceae & $\begin{array}{l}\text { Onion or camas } \\
\text { bulb }\end{array}$ & $\begin{array}{l}\text { Bulb } \\
\text { fragment }\end{array}$ & 1 & 3 & 0.1 \\
\hline
\end{tabular}

determining the taxon that a bulb represents is very difficult even with high resolution microscopy (electron microscope or motorized stereo microscope). Wood charcoal identified in the samples is oak (Quercus sp.), sycamore (Platanus sp.), and walnut (Juglans sp.).

Feature 25. This feature is rock-lined stacked two-three deep, and the rocks are concentrated in a pattern measuring about $1-\mathrm{x}-0.6$ meters. The size of the feature and the mass of the rocks is indicative of an earth oven. Three flotation samples, FS 236, 237, and 241, contain bulb fragments. The bulb fragments clearly indicate the primary use of the feature as an earth oven utilized for baking bulbs. Additionally, a single grass seed fragment was identified in FS 236. This could have been introduced via the packing material, which often consists of moist grass, or simply the result of the ground disturbance associated with the construction of an earth oven. 
Feature 32. This oval ash concentration measures about $45 \mathrm{~cm}$ in plan view. A small quantity of wood charcoal recovered from this feature includes both sycamore and oak wood. A heat altered hackberry nutlet is also present.

Feature 34. A large charcoal concentration oval or oblong in plan view, this feature is described as an earthen hearth. The flotation sample effort, which is a significant 26 liters, contains more carbonized wood than the rest of the samples combined, but lacks any seeds or bulb fragments.

Block 3, Unit 30. This sample, recovered from a small ash and burned clay concentration, is noted by the excavators as a possible feature. Interestingly, it also contained a single bulb fragment. The presence of a bulb fragment suggests that the material came from the remains of an earth oven, so the ash and burned clay is probably the remains of a clean out event from a nearby oven.

\section{Discussion}

The trees identified in the wood charcoal samples, oak, sycamore, and walnut, are typical woody plants of the Blackland Prairie region, growing along the margins of waterways or erosional breaks in the grasslands. These strips of woody vegetation also include hackberry, hawthorn, yaupon, cedar elm, and willow. Therefore, the wood types identified in the current study mirror the vegetation of the region today.

The presence of several charred bulbs, rather large elements in the plant assemblage, brings up two issues regarding formation processes of the archaeological record. The first issue addresses preservation of plant remains, and the second issue regards the evidence for vegetation change in the botanical record from earth ovens.

The robust flotation effort certainly helped ferret out the charred plant material, but the largest flotation sample, FS 386, produced nothing but wood charcoal. By contrast, three of the four smaller flotation samples that did produce bulbs, FS 236, 237, and 241, came from the same feature and yielded very little wood charcoal. In the fourth sample, FS594, the bulb material weighed more than the wood charcoal. This situation was mirrored in the Early Archaic samples 
at the Wilson-Leonard site, where 8,000 year-old bulbs were picked from a large FCR heating element, Feature 181, but little or no wood charcoal or seeds were recovered from the same context (Dering 2007). These bulbs were identified as eastern camas (Camassia scilloides), a geophyte that produces a larger bulb than onion or false-garlic (Dering 1998). Several other features at the Wilson-Leonard site contained no evidence of bulb cooking or any other edible plant remains. The fact that in the current study, Feature 25 , the only earth oven feature represented in the flotation samples yielded bulbs, ranks as a very fortunate find.

Unpredictable results suggest that one overriding factor leads to the preservation of plant remains - a very bad cooking accident in which the food load is charred. Heated rocks often reach temperatures of 450-degrees Celsius, hot enough to char plant material, but the moist liner and the water content of the food load prevent the temperature inside the bulbs from rising above the boiling point. As soon as all the moisture is driven out, temperatures spike and the food is charred. The idea that plant preservation at open sites is contingent on accidental burning is not a new revelation (see Hally 1981; Miksecek 1987), but it certainly bears repeating. The cook's poor luck is the archaeologist's boon. Bulbs, once charred, apparently are large, compact elements that resist reduction even in the toughest of preservation environments, hence the 8,000 year-old record of bulbs at Wilson-Leonard. When the archaeologist gets lucky, usually only a few bulbs are recovered, but a series of earth oven/midden sites in Brown County yielded hundreds of charred bulbs and bulb fragments (Mauldin et al. 2003).

Earth ovens also provide proxy evidence for environmental change in central and northcentral Texas. Earth ovens containing bulbs strongly suggest that bulbs were growing in densities that allowed repeated exploitation of that resource. This indicates a landscape far different from the one we view today. Along the Southern Plains periphery, earth ovens were used primarily for cooking geophytes east of a north-south line somewhere around the $100^{\text {th }}$ meridian, primarily bulbs both onion and camas (Dering 2008). This marks an east-west trend toward aridity that transitions from a taller grass prairie to a grassy savannah. We can cautiously argue that the Blackland Prairie and its edge environments, formed by riparian corridors and the Edwards Plateau and its outliers, probably supported very large stands of eastern camas, a plant that is a little hard to find these days. But tall-grass prairie is also hard to find now. A quick look at the vegetation map of Texas will confirm that herbaceous prairie vegetation has been all but destroyed during over the last 250 years, and even the abundance of woody taxa has been altered 
drastically (McMahan et al. 1984). Interestingly, the only historical reference to the use of eastern camas notes an occurrence on Cache Creek in Oklahoma in which Comanches baked the bulbs in an earthen pit (Sternberg 1931). This is just across the Red River from north Texas. The discovery, therefore, of earth ovens containing the remains of bulbs in the Trinity River riparian corridor in Tarrant County, serves to bolster the data indicating the widespread importance of geophytes as a carbohydrate source for human populations throughout the Holocene.

\section{Conclusion}

The eight flotation samples contained walnut, sycamore, and oak wood types, as well as a grass seed fragment, a hackberry nutlet, and several bulb fragments. Most of the bulb fragments were recovered from Feature 25, a large pit with a rock heating element. Feature 34, a cylindrical pit lacking a heating element, and Feature 32, an ash concentration both contained wood charcoal but little else. The single hackberry nutlet from Feature 32 may or may not be of prehistoric origin even though it is heat-altered. Hackberry tends to roll down animal burrows and into excavation units.

Bulb fragments are present in samples from Feature 25 and from the non-feature provenience in Block 3, Unit 30, described as an ash and burned clay concentration. Feature 25 is an earth oven in which a cooking accident occurred. The burned ash and clay concentration is probably the result of cleaning out a nearby earth oven.

The archeobotanical assemblage provides excellent evidence for the use of earth ovens in edge environments in the Blackland Prairie and Cross Timbers region. The wood charcoal represents trees typical of the of north-central Texas region. Bulbs identified in Feature 25 add to mounting evidence for the importance of geophytes in the region during the Archaic Period. 


\section{CHAPTER 11 SYNTHESIS}

The 41TR198 data recovery was undertaken by Geo-Marine on behalf of the USACE, Fort Worth District. Major partners include the Tarrant County Water District, the City of Fort Worth, and the Texas Historical Commission. This project is being conducted as part of the cultural resource background work in anticipation of the Riverside Oxbow Habitat Restoration Project. This project plans wetland, riparian, and grassland habitat enhancement and restructuring within this portion of the WF Trinity River valley. As currently conceptualized, the Riverside Oxbow Project proposes to preserve existing green-space adjacent to Gateway Park, improve recreation activities while augmenting the natural environment.

The archaeological investigations were conducted as required under Section 106 of the National Historic Preservation Act (as amended) due to federal oversight and funding of the Riverside Oxbow Project and under State of Texas Antiquities Permit No. 4596, since the Tarrant County Water District is a co-sponsor. The Crooked Oxbow Site had been previously determined to be eligible for the NRHP under Criterion D, applicable to sites "that have yielded or may be likely to yield, information important in prehistory or history" (Huhnke and Wurtz 2004). The USACE, Fort Worth District and the State Historic Preservation Office agreed upon a mitigation strategy in 2008 .

At this 19.5- acre site numerous occupational components stratigraphically separated over $3 \mathrm{~m}$, spanning the Late Archaic and early Late Prehistoric periods, were documented. The longest stratigraphic sequence from the site was obtained in Block 3. Six distinctive occupation zones were noted (see Table 6). The most intensive interval of prehistoric occupation occurred between 
A.D. 140 and 350 near the end of the Late Archaic Period. Diagnostic artifact forms include Yarbrough, Trinity, and Axtell dart points. Occupation of this location continues well into the early Late Prehistoric period (A.D. 700 - 1040 and later); however, the occupation is not at the same level of intensity. Interestingly, an early attempt of ceramic making is represented at site 41TR198, but there is no evidence of use of the bow and arrow. The lack of arrow points does not likely reflect the lack of knowledge of this technology by the inhabitants of the site, but rather a change in subsistence activities at this location or merely sampling bias.

\section{REGIONAL CULTURAL CHRONOLOGY}

One significant research potential of site 41TR198 is related to the refinement of the regional cultural chronology. The existence of potential discrete occupational components within the West Fork basin of the Trinity River with datable material is a rarity. The majority of the regional understanding of prehistory is based on multicomponent sites with mixed assemblages.

The analysis of eight radiocarbon dates (see Table 6) provided a basic temporal framework for the occupational episodes that were examined. Hindsight indicates that more samples from the features, particularly in Block 4, would have clarified the degree of contextual integrity in Block 4. The A.D. 540 date recovered from a faunal sample may not be in a primary context. Overall, however, the dates provide a reliable and consistent chronological framework for interpreting the diachronic patterns in the stratigraphic sequence.

There were no radiocarbon dates directly associated with any of the diagnostic artifacts so date ranges are based on relative stratigraphic position. Each is summarized in Table 78 below. The known regional distribution of projectile point types suggests that groups that visited the site shared an affinity with various regions, all within a general Late Archaic temporal context.

Yarbrough points are reliably found in association with the A.D. 140 - 340 occupation zone, falling near the end of the Late Archaic period. The one Trinity point from a reliable context also dates to this same period. Two Axtell points were recovered, a style that is unusual for northcentral Texas. The first (FS 141) was found near the top of the cultural deposits in a context that potentially dates to A.D. 340 to 390 . The second Axtell point was found stratigraphically deeper in a context that may date as early as A.D. 150. Axtell points are generally assumed to date to the Middle and Late Archaic periods in Texas (Turner and Hester 1999). 
Table 78

The Provenience of Diagnostic Artifacts from Site 41TR198

\begin{tabular}{lllllll} 
FS & Artifact Type & Block & Unit & Level & Depth & Archaeological Context \\
\hline 485 & Yarbrough & 3 & 29 & 13 & 98.13 & Feature 15/ A.D. 250 - 350 zone \\
60 & Trinity Point & 3 & 7 & n/a & n/a & Unknown \\
141 & Axtell point & 4 & 17 & 3 & $99.21-99.11$ & A.D. $340-390$ zone \\
128 & Unidentified point & 4 & 14 & 5 & $98.97-98.88$ & A.D. $140-340$ zone \\
523 & Yarbrough & 4 & 33 & 5 & $99.00-98.90$ & A.D. $140-340$ zone \\
525 & Boatstone & 4 & 19 & 5 & $99.00-98.90$ & A.D. $140-340$ zone \\
591 & Yarbrough & 4 & 36 & 6 & $98.90-98.80$ & A.D. $140-340$ zone \\
591 & Trinity & 4 & 36 & 6 & $98.90-98.80$ & A.D. $140-340$ zone \\
304 & Axtell point & 4 & 17 & 7 & $98.80-98.75$ & A.D. 140 zone \\
\hline
\end{tabular}

The only diagnostic artifacts of the Late Prehistoric period occupation are four sherds of a poorly made, grit-tempered ceramic ware. The more reliable context in Block 3 indicates that these sherds were deposited prior to A.D. 900. Unfortunately, these sherds are presently unique to site 41TR198. Likely representing someone's early attempt at making a ceramic vessel, there is presently no means of relating them to other assemblages in northcentral Texas. They definitely do not share any diagnostic characteristics with the ceramic assemblage from the nearby CobbPool site (41DL148) which dates to approximately A.D. 1200.

\section{PALEOENVIRONMENTAL RECONSTRUCTION}

Collection and identification of macrobotanical and faunal remains were given a high priority at site 41TR198, which clearly exhibits excellent preservation of the faunal assemblage. The archeobotanical assemblage provides excellent evidence for the use of earth ovens in edge environments in the Blackland Prairie and Cross Timbers region. The wood charcoal represents trees typical of the of north-central Texas region. Bulbs identified in Feature 25 add to mounting evidence for the importance of geophytes in the region during the Archaic Period. Dr. Dering also argues that earth ovens also provide proxy evidence for environmental change in central and northcentral Texas. Earth ovens containing bulbs strongly suggest that bulbs were growing in densities that allowed repeated exploitation of that resource. This indicates a landscape far different from the one we view today. Along the Southern Plains periphery, earth ovens were 
used primarily for cooking geophytes, primarily bulbs of both onion and camas (Dering 2008), east of a north-south line somewhere around the $100^{\text {th }}$ meridian,. This marks an east-west trend toward aridity that transitions from a taller grass prairie to a grassy savannah. The Blackland Prairie and its edge environments, formed by riparian corridors and the Edwards Plateau and its outliers, probably supported very large stands of eastern camas, a plant that is a little hard to find today. The discovery, therefore, of earth ovens containing the remains of bulbs in the Trinity River riparian corridor in Tarrant County, serves to bolster the data indicating the widespread importance of geophytes as a carbohydrate source for human populations throughout the Holocene. The previous discovery of bulbs in an earth oven at site 41DL391 along the East Fork of the Trinity River (Peter et al. 2002), further substantiates the use of bulbs within the Blackland Prairie/Cross Timbers ecotone of northcentral Texas.

The analysis of the molluscan fauna from Block 3 by Randklev and Dr. Wolverton (see Chapter 10) revealed that neither the ecological community nor exploitation of it changed dramatically through time in the West Fork of the Trinity River near site 41TR198. Analysis indicated that water body preferences for the majority of mussels examined from the site are medium sized rivers. Second, the species in this assemblage seem to represent depths of between 0.3 and $0.9 \mathrm{~m}$, with the greatest percentage of taxa $(93.75 \%)$ indicating a depth of $0.9 \mathrm{~m}$. Thus, during the late Holocene mussels were most likely collected from shallow areas within the stream. In fact, unionid abundance is often greatest in shallows areas and then decreases as water depth increases (Dillon 2000). Third, a preference for slow moving waters is observed in the analysis of currentvelocity habitat preference. Arcidens confragosus, L. hydiana, L. subrostrata, and T. texasiensis are often found in shallow, slow to still waters, backwater areas, or in protected parts of streams (Howells et al. 1996; Neck 1986; Parmalee and Bogan 1998). However, the presence of Fusconaia sp., O. reflexa, L. cf. satura, and T. donaciformis suggests that portions of the West Fork had at least moderate flows during the late Holocene. Fourth, substrate composition for all time periods appears to have consisted primarily of mud with some sand. For many east Texas rivers mussels are most often found inhabiting substrata comprised of compact sand and mud (Randklev unpublished data). 


\section{SITE FUNCTION AND SETTLEMENT PATTERN}

The determination of site function is critical to the placement of site 41TR198 within the overall settlement pattern of the Late Prehistoric period. Significant quantities of both artifacts and features in primary, isolable contexts are essential for determining site function. The excavations at site 41TR198 revealed a sizable quantity of faunal materials and the presence of several features within isolable contexts or within contexts that are interpretable. Given the lack of tools encountered during the initial recording of site 41TR198 and during data recovery, the interpretation of features, their distribution, and the associated faunal debris focused on the recognition of activity areas and associated functions.

The function of site 41TR198 appears to have been primarily for food collection and processing as represented by the faunal remains and the frequent hot-rock cooking features. Flaked stone tool manufacture and repair in relation to these activities was apparently not a predominant activity. Most effort appears to have been focused on the collection of rocks from the nearby valley walls, the collection of fire wood, and collection of various food resources (bulbs, mussels, and a variety of meat resources) for processing and cooking in earth ovens. Hot-rock cooking in earth ovens is particularly predominant during the Late Archaic period. The association of the ground stone within the same deposits as the cooking features suggests that plant food gathering and processing was an important part of the site function during the Late Archaic period. After A.D. 900, earth ovens are not as well represented and ground stone is absent from the assemblage. Either plant processing became less important or such processing took place elsewhere on the site. Even the densities within the Late Archaic period, however, indicate that occupation episodes were of limited duration. The accumulation of burned rock or faunal remains is not sufficient for long term stays by a band or bands.

It was originally hypothesized that site 41TR198 represents a type of hunting and animal processing station that may have been used on a cyclical basis. The use of the site location on a cyclical basis for short periods of time is likely accurate; however, the primary activity, especially during the Late Archaic period appears to be plant food processing. Hunting of deer and collection of other fauna, however, was important during the Late Archaic period. A comparison of deer to turtle ratios for the Late Archaic and Late Prehistoric assemblages clearly indicates that smaller game animals were collected during the Late Prehistoric period. The lesser dependence 
on the prey of choice, deer, the greater fragmentation of bone, and the growing presence of fish and bird remains in the assemblage during the Late Prehistoric period may be related to changing site function or potentially locally changing environmental conditions. Whatever the causal factor, it appears that site 41TR198 became a less important part of the seasonal cycle for huntergatherers around A.D. 900 .

\section{SUBSISTENCE PRACTICES}

The high level of preservation present at site 41TR198 provided a unique opportunity for the collection of a sizeable faunal assemblage. A sizeable faunal assemblage can be used to address research questions relating to subsistence practices through consideration of foraging efficiency by prey choice as compared to diet breadth models.

The recovery of onion or camas bulbs through flotation provides important information concerning the use of geophytes for subsistence along the Blackland Prairie/Cross Timbers ecotone. The presence of several hot-rock cooking features and ground stone during the Late Archaic period indicates that the processing of plant foods was an important contributor to the overall subsistence of the occupants. Other plant foods were likely processed also, but there was no recovery of other seeds or plant parts.

The faunal assemblage reflects a generalized foraging strategy involving deer, small mammals, mussels, and turtle. It is interesting to note the absence of bison in the assemblage. While this could be the result of sampling bias, the presence of bison in northcentral Texas archaeological sites during the Late Archaic and Late Prehistoric periods is not a certainty. Bison does appear within Late Archaic assemblages (e.g., 41DL203; Tinsley et al. 2011) in small quantities, but bison is more common in late Late Prehistoric contexts (post A.D. 1200), such as the Baggett Branch site at nearby Joe Pool Lake (Peter et al. 1988).

The foraging strategy of the occupants of 41TR198 clearly changes over time. Hot-rock cooking, potentially involving onion or camas bulbs, is clearly more predominant during the Late Archaic period. As the utilization of deer decreases through time, particularly in the Late Prehistoric, the number of taxa exploited generally increases and the proportions of specimens from smaller- 
bodied resources such as turtles, fish, small mammals and carnivores increase as well. The greater fragmentation of bone during the Late Prehistoric period further suggests that the inhabitants are making full use of all potential food sources through bone marrow extraction and grease rendering. Yet another caloric resource, locally available clams, were also a significant addition to the diet between A.D. 900 and 960 (Figure 92). The inhabitants of the site were utilizing all available resources. It is therefore possible that hunting of deer over time at site 41TR198 caused decreases in deer populations and encounter rates thereby increasing the reliance on lower-ranked resources through time. It is also possible that some factor of environmental stress is affecting the availability of resources; however, the particular factor is not evident at this time. The size and nature of the social group visiting the site at this time may have also had an impact on the resources utilized; however, the nature of the social group or groups present is not evident in the present data.

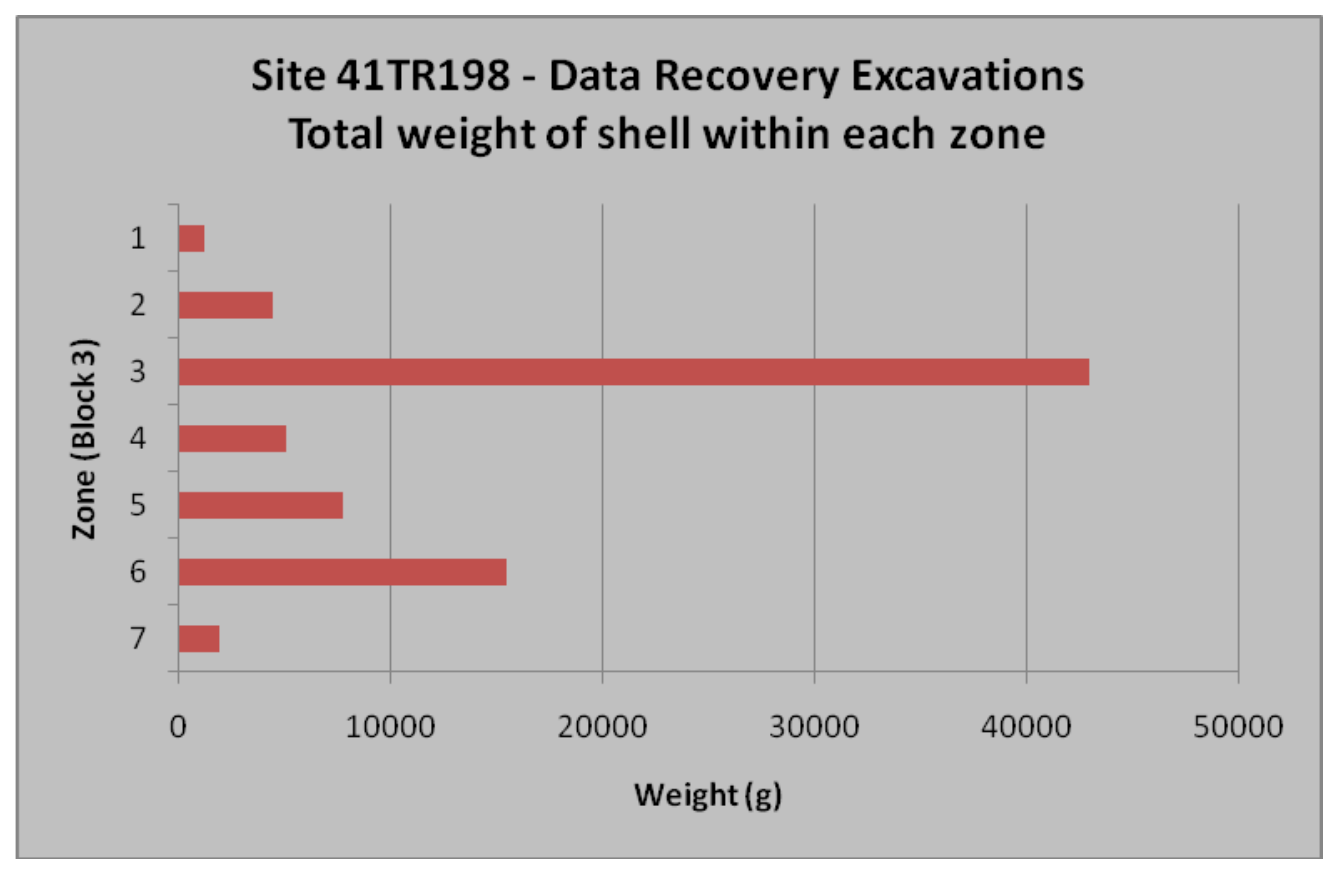

Figure 92. Total weight of shell from Block 3. 


\section{TECHNOLOGICAL PATTERNS}

Technology and the processes prehistoric people used to convert raw materials into consumable goods is the basis for understanding behaviors of Late Archaic and Late Prehistoric period populations in the West Fork of the Trinity River drainage. In light of the kinds of materials associated with these sites, analysis focused on issues relating to hearth and/or oven construction, associated fire-cracked rock, and the processing of game.

Hot-rock cooking is the predominant technology represented within the site 41TR198 deposits. The basic materials for this process, fire wood, and stone, were readily available at or near this site. Water was immediately available from Sycamore Creek or the West Fork of the Trinity River. Due to its local watershed and small size, Sycamore Creek likely provided a pure source of drinking water with a light sediment load. Fire wood was available from the surrounding riparian forest. Limestone cook-stone sources were available in reasonable proximity to the site from small bluffs on the margins of the river valley.

Construction of the earth ovens is not fully evident in the excavated units. It is clear that a basinshaped pit was formed and lined with rock; however, the total depth of the oven is not evident. One can postulate that the upper portion of the pit has not survived subsequent occupations or flooding events, but it may be that wet leaves, dirt and rocks were stacked over the basin-shaped feature. The association of onion or camas bulbs with the hot-rock features together with the association of manos and mutates suggests that the primary use of the earth ovens was for the processing of plant remains. It is postulated that the actual source area for the geophytes was in relatively close proximity to the site; however, we presently do not know the easternmost occurrence of camas within northcentral Texas during the prehistoric period. Camas bulbs may have been collected farther west, but it seems unlikely that they would have been carried long distances before processing. Even given these associations, it is postulated that the earth ovens were used for cooking meat and steaming mussels also.

The pattern of cooking at site 41TR198 seems to differ from that evidenced at the Cobb-Pool site at Joe Pool Lake. Interpretation of the seemingly large pit structure at the Cobb-Pool site postulated the use of numerous, intersecting earth ovens over time. Macrobotanical analysis recognized Psoralea as the likely plant being processed (Fritz 1988) between A.D. 1000 and 1200. 
Corn was also present at the site. The fire-cracked rock assemblage at the Cobb-Pool site was extremely limited in comparison with the fire-cracked rock at site 41TR198. Earth ovens are obviously present at both sites, but the construction of the features and the actual processing seem to differ between the Late Archaic period and the Late Prehistoric occupations. It is also noteworthy that the Late Prehistoric occupations at site 41TR198 reflect a decrease in the use of earth ovens and the lack of processing of onion or camas bulbs. Whether this reflects a decrease in the availability of bulbs, seasonal differences, or sampling bias is presently unknown.

Analysis of fire-cracked rock from site 41TR198 indicates that the size distribution reflects medium reuse of the rock. It is interesting that the zones with the greatest density of fire-cracked rock (Block 3, Zone 4; Block 4, Zone 3) reflect a more even distribution of the size categories. Of course, this may merely reflect the fact that more intense thermal activities result in a broader distribution of rock fragments reflecting the whole range of cooking activities over a longer period of time. Having observed several sites along the Elm and West forks of the Trinity River, it is the primary author's opinion that the burned rock at site 41TR198 is larger and more dense than any nearby site that is downstream of it. As Lintz (2004) pointed out, the presence of firecracked rock and earth ovens becomes more prevalent as one moves westward.

Dr. Charles Frederick's observations of Feature 15 with its deeply oxidized rim resulted in him noting that the depth and degree of apparent heating is clearly anomalous and begs the question of what activities were associated with this feature. Although it is agreed that the question of what activity was taking place remains unanswered, a similar occurrence was noted at site 41DL391. Feature 1 at site 41TR198 exhibited a distinct, bowl-shaped profile (see Peter et al. 2002: 29-31; Figures 7 and 8). The bottom of the feature consisted of a thick layer of almost continuous claydominated burned earth with a distinctly yellowish red (5YR 4/6-5/6) color. The fill was a mixture of clay, charcoal, white ash, white mineral precipitate deposits, calcium carbonate concretions, and what appeared to be concentrations of burned/weathered unconsolidated sandstone. Several small pieces of bone and a few mussel shell fragments were recovered within and around the hearth. There was obviously intense heat generated within this feature, but its exact function is unclear. 
The flaked stone tools and debitage recovered at site 41TR198 reflect very limited production and maintenance of tools. The lithic debitage, particularly the single-event occurrence from Block 4, reflects the bifacial reduction of a chert cobble most likely procured from the lag gravels on one of the upland divides. The dart points reflect hunting or cutting activities, but the almost total lack of unifacial tools suggests that processing of hides was not an important activity. The wear patterns on the bone tools, however, indicate the working of hides or leather or other soft objects.

Perhaps, the most notable technological pattern at the site is the presence of four ceramic sherds of poor construction and the total lack of arrow points within the Late Prehistoric assemblage. The four sherds are poorly made and poorly fired, are not smoothed on the interior or exterior, and were possibly hand-made rather than coiled. The sherds exhibit uneven thicknesses and are made of a fine gritty paste and fine grit temper. These sherds are unlike those recovered at the Cobb-Pool site, for they lack grog temper or a combination of grog and another additive such as bone or quartz, or shell temper (Peter et al. 1988:158). They also lack design elements of incised lines, finger punctuates, or some combination of the two. The occupants of site 41TR198 were obviously experimenting with ceramic technology, but it is unclear what influenced this particular development. Grit-tempered ceramics are more common in the Rolling Plains to the west than in any ceramic wares to the east.

The lack of arrow points in the Late Prehistoric assemblage, if not a product of sampling bias, is a bit puzzling, for they are usually very common in northcentral Texas sites. The short-term nature of the occupations during this period and the emphasis on the generalized gathering of small mammals rather than the hunting of deer are the most likely contributing factors for this situation. The overall lack of flaked stone tools at this site clearly indicates that occupations were shortterm, which did not allow for the extensive discard of tools whose use-life had expired.

\section{REGIONAL EXCHANGE AND INTERACTION}

Other than dart points and one boatstone from the Late Archaic assemblages, there are no artifacts within the 41TR198 assemblages that clearly denote regional exchange and interaction. However, interpreting the dart points and boatstone as evidence of regional exchange and interaction requires some basic assumptions regarding what the styles represent. Do they 
represent temporal developments, functional needs, social groups, or some combination of these factors? Unfortunately, we cannot always rule out any of these influences, but examination of the temporal and spatial distribution of these styles may provide some clues.

The two Trinity points suggest an occupation of the site by a more locally oriented population whose sphere may have included the generally local region east of Fort Worth and south of the Red River where points of this type have been found. More specifically, the greatest numbers of reported finds of Trinity points occur in two clusters, on the Elm Fork of the Trinity River and on the Sabine River in the vicinity of Tyler. From this area the distribution of the style appears to generally radiate outward as frequencies of reported finds drop off precipitously (Prewitt 1995).

The Yarbrough points suggest cultural affinities with groups extending to the northeast into Louisiana and Arkansas (Prewitt 1995; Turner and Hester 1999). The raw materials of both the unidentified novaculite dart point and the volcanic tuff boatstone suggest either trade and exchange or travel to and from the Ouachita Mountains of eastern Oklahoma and western Arkansas (Perttula 2009 personal communication). It should be noted, however, that novaculite can be found in the upland gravels of northcentral and northeast Texas.

A region with reported frequent finds of Axtell points includes the area approximately 100 miles southeast of the Crooked Oxbow Site on the Trinity River, and extending westward to the Brazos River in the vicinity of Oakwood. A second concentration of Axtell points is reported in the area around Lake Belton (Prewitt 1995).

The vertical positions of the Axtell, Trinity, and Yarbrough points within Block 4 indicate that temporal differences in style may not be a factor. The projectile point distributions noted here indicate that the styles recovered from site 41TR198 possibly reflect bands whose seasonal rounds included the Blackland Prairie region that extends from southern Oklahoma to central Texas with potential trade or gift exchange relationships with other bands to the northeast or to the west. Of course, it is also possible that multiple bands came to the West Fork of the Trinity River at various times as a part of their seasonal round or that they congregated there for trade and exchange purposes at a given time of the year. Unfortunately, the stratigraphic context at site 41TR198 does not provide the level of temporal specificity to recognize the particular scenario 
represented. It is clear, however, that mobile hunter-gatherers occupied this site numerous times for over a millennium.

\section{Prehistoric Inhabitants of the West Fork of the Trinity River Valley - Merely Passing Through?}

Prehistoric sites along the West Fork of the Trinity River frequently reveal very limited stone tool assemblages with equally limited expressions of formal features. Recognition of distinct activity areas is frequently difficult. Site 41TR198 offers a unique data set related to use of the West Fork flood plain between 410 B.C. and A.D. 1040. Multiple data sets recovered from discrete living surfaces suggest that groups frequenting the site may have been distinct from those exploiting the woodlands/prairie ecotone elsewhere. The presence of distinctive thermal features and a diverse faunal assemblage contribute to an emerging synthesis of northcentral Texas archaeology. Comparison of the assemblage recovered from site 41TR198 with other site assemblages within the region (41TR170, 41DL203, 41COL172, 41CO144 and 41CO150) permits a better understanding of the cultural dynamics along the woodland/prairie ecotone.

Previous work along the West Fork of the Trinity River has frequently encountered extremely low density sites with very few lithic tools and small scatters of fire-cracked rock and fragile faunal elements. Understanding these sites can be frustrating because any given excavation block reveals a very limited data set. Site 41TR198 is no different for the lithic assemblage recovered from $28 \mathrm{~m}^{3}$ of excavation totals only 219 specimens. Fortunately, the distribution of features, the limited tool assemblage, and well preserved faunal assemblage provides a data set that is significant when compared to other sites in the region.

An initial magnetometer survey encompassing 2.2 acres was conducted at 41TR198. Several truncated high magnetic anomalies were tested and proved to be thermally altered archaeological features consistent with the types of features recovered during previous archaeological investigations at the site (Huhnke and Wurtz 2004). The magnetometer data from a subsequent survey of a total of $78,785 \mathrm{~m}^{2}$ (19.46 acres) suggest that there are hundreds of similar features still intact at site 41TR198 (see Figure 15). The distribution of thermal features as shown in the magnetometer data shows a dense cluster of features in the core area of the site which was subsequently excavated most intensively by Geo-Marine. 
These features appear from .75 to 2.5 meters in depth. Features include shell and faunal lenses, basin-shaped hearths, and burned rock concentrations. No evidence of substantial structures was found. These features are more substantial than those found on nearby sites along the West Fork; however, investigations within the larger Trinity River Basin indicate that burned rock features, including middens, become more common as one moves west and south. As Lintz (2005) indicated in the analysis of site 41TR170 located farther upstream along the West Fork, the prominence of burned rock features to the west in the Brazos drainage clearly indicates that subsistence technologies, and possibly the food elements being cooked, are different. At site 41TR198, analysis of the macrobotanical remains recovered through flotation by Dr. Phil Dering revealed the presence of multiple onion or camas bulb fragments in feature contexts between A.D. 140 and A.D. 340. None of the other Late Archaic assemblages in the region demonstrate this type of preservation. Wood charcoal from oak, walnut, hackberry, and sycamore was found also. All of these are expected species in the gallery forest along the West Fork of the Trinity.

The features found at site 41TR198 are similar in nature to those found within Late Archaic contexts at sites $41 \mathrm{CO} 150$ and $41 \mathrm{CO} 144$ at Lake Ray Roberts. As on the West Fork of the Trinity, however, the presence of burned rock in features and of mussel shell varies considerably between the Late Archaic contexts. At site 41DL203, which is within the drainage of the East Fork of the Trinity, no formal features were discovered in the Late Archaic deposits dating between 3,100 and 1,290 B.P.

The lithic assemblages at these sites show a different pattern. At sites 41TR198 and 41TR170 the lithic assemblage is dominated by cherts found in the Uvalde gravels on local drainage divides or cherts more commonly found in Central Texas. The Late Archaic lithic assemblages at Lake Ray Roberts (41CO144 and 41CO150) are similarly limited in nature, but Ogallala quartzite is the predominant raw material. It should be noted, however, that chert increases in frequency through time. At 41DL203 and 41DL172, quartzite is the raw material of choice; however, some Central Texas cherts are present.

The projectile point styles present at site 41TR198 consist of Yarbrough, Trinity and Axtell. The Yarbrough and Trinity points are typically found in northcentral and northeast Texas. The Axtell point style is more commonly found farther south within the Blackland Prairie region. Trinity and Yarbrough points are also present at site 41TR170. These same stylistic patterns do not 
appear at 41DL203 and at the sites at Lake Ray Roberts. Contracting stemmed points (Gary) predominate at site 41CO150, although Ellis, Ensor, Godley, and Darl point styles are also recognized by the authors. Trinity and Yarbrough points are only minimally represented in the lower Late Archaic strata. Gary and Godley points are the primary styles at site 41CO144. It is our hypothesis that the dominance of Gary points at these latter sites reflects stronger sociocultural ties with populations to the east in contrast to the patterns at sites 41TR198 and 41TR170 which likely reflect stronger connections with populations to the west and south.

The faunal assemblage at 41TR198 reflects a fairly normal use of the regional resources when compared to other Late Archaic assemblages in the region. In Figure 93, the purple line is the lower component of 41TR198 (pre-1,400 B.P.) and the light blue line represents the upper component (1,400 to 50 B.P.). Deer, rabbit, turtle, various birds, and fish are the primary components of the sources of meat for the occupants of the site. Birds and fish are particularly noticeable in the upper component. In fact, of the sites examined here, site 41TR198 is the only site with any measureable amount of birds and fish. On the other hand, bison is absent in both components while it appears sporadically at 41TR170, 41DL203 and at both sites at Lake Ray Roberts.

\section{SUMMARY}

So, what do we conclude about the nature of the occupation at site 41TR198 and the social interaction sphere of which they were a part? The presence of formal burned rock features and the processing of bulbs suggest activities more commonly represented to the west. The lithic assemblage which is primarily chert, likely derived from the local Uvalde gravels or from Central Texas sources, stands in contrast to the remaining assemblages where quartzite is the predominate raw material. The stylistic shapes of the dart points also indicate differential preferences or different interaction spheres. Again, we would argue that the dart points (Axtell) likely represent influence from the south in the Blackland Prairie or to the west. The Yarbrough, on the other hand is more common to the east. Perhaps, our normative perspective limits our consideration of the multiple scenarios that might have contributed to the assemblages found at 41TR198. Social groups and social interaction are complex; consequently, we should instead be looking at the Woodlands/Prairie ecotone as a rich environment where multiple peoples would gather to collect 


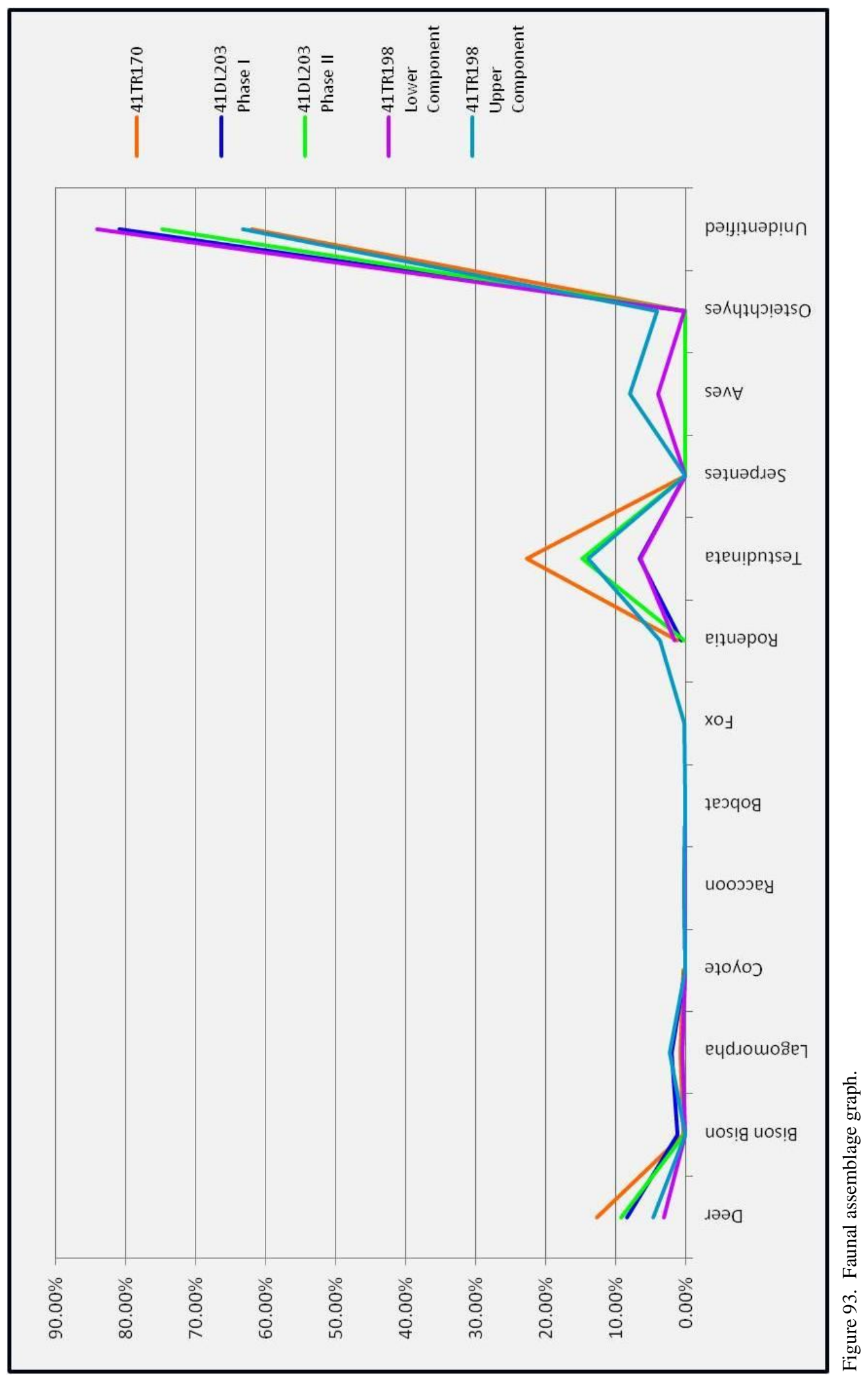


its abundance. Site 41TR198 may reflect usage by groups from multiple directions at different times, or it may reflect a gathering of bands at various times to trade raw materials and finished products, see the relatives who married into a different band, and to find marriage partners. The challenge for us as archaeologists today is determining the theoretical constructs and associated methodologies that will inform us of the social dynamics along the woodland/prairie ecotone. 


\section{REFERENCES CITED}

Adams, J. L.

1999 Ground Stone Analysis: A Technological Analysis. The University of Utah Press, Salt Lake City, Utah.

American Society for Testing Materials (ASTM)

1985 Standard test method for particle size analysis of soils. D-422-63 (1972). 1985 Annual Book of ASTM Standards 04.08:117-127. American Society for Testing Materials, Philadelphia.

Antevs, E.

1955 Geological Climatic Dating in the West. American Antiquity 20(4):317-335.

Bartington, Geoff and C. E. Chapman

2004 A high-stability Fluxgate Magnetic Gradiometer for Shallow Geophysical Survey Applications. Archaeological Prospection 11:19-34.

Berna, Francesco Adi Behar, Ruth Shahack-Gross, John Berg, Elisabetta Boaretto, Ayelet Gilboa, Ilan Sharon, Sariel Shalev, Sana Shilstein, Naama Yahalom-Mack, Jeffrey R. Zorn, Steve Weiner

2007 Sediments exposed to high temperatures: reconstructing pyrotechnological processes in Late Bronze and Iron Age Strata at Tel Dor (Israel). Journal of Archaeological Science, 34 (3): 358-373.

Blair, W. F.

1950 The Biotic Provinces of Texas. Texas Journal of Science 2:93-117.

Bouyoucos, G. J.

1962 Hydrometer method improved for making particle size analyses of soils. Agronomy Journal 54:464-465.

Broughton, J. M.

1994 Late Holocene resource intensification in the Sacramento Valley, California: The vertebrate evidence. Journal of Archaeological Science 21, 501-514. 
1999 Resource Depression and Intensification during the Late Holocene, San Francisco Bay: Evidence from the Emeryville Shellmound, University of California Publications Anthropological Records 32, University of California, Berkeley.

Brown, D. O.

1994a The Denton Creek Paleoenvironment. In Archeological Investigations in the Denton Creek Floodplain: Data Recovery Excavations at 41DL270, Denton and Dallas Counties, Texas, edited by D. Anthony and D. O. Brown, pp. 277-293. Archeology Series 37. Hicks \& Company, Austin.

1994b Oxygen Isotopes and Paleoclimate Studies. In Archeological Investigations in the Denton Creek Floodplain: Data Recovery Excavations at 41DL270, Denton and Dallas Counties, Texas, edited by D. Anthony and D. O. Brown, pp. 251-264. Archeology Series 37. Hicks \& Company, Austin.

Bryant, V. M., Jr., and R. G. Holloway

1985 A Late-Quaternary Paleoenvironmental Record of Texas: An Overview of the Pollen Evidence. In Pollen Records of Late-Quaternary North American Sediments, edited by V. Bryant and R. G. Holloway, pp. 39-70. American Association of Stratigraphic Palynologists Foundation, Dallas.

Bureau of Economic Geology

1972 Geologic Atlas of Texas. Dallas Sheet. Revised 1987. Bureau of Economic Geology, the University of Texas at Austin.

Burson, E. A., S. M. Hunt, D. E. Peter, and D. Shanabrook

2000 Cultural Resources Survey of the Proposed West Fork Relief Interceptor, WF-11B, Tarrant and Dallas Counties, Texas. Miscellaneous Reports of Investigations Number 190. Geo-Marine, Inc., Plano, Texas.

Buxeda i Garrigós, J., V. Kilikoglou and P. M. Day

2001 Chemical and Mineralogical Alteration of Ceramics from A Late Bronze Age Kiln At Kommos, Crete: the Effect On the Formation of A Reference Group. Archaeometry 43(3):349-371.

Buxeda i Garrigós, J., M. A. Cau Ontiveros and V. Kilikoglou

2003 Chemical Variability in Clays and Pottery from a Traditional Cooking Pot Production Village: Testing Assumptions in Pereruela. Archaeometry 45(1):1-17

Buysse, J. L.

2000 An Evaluation of Sites Within the Proposed Dallas Floodway Extension Project, Dallas County, Texas. Miscellaneous Reports of Investigations No. 195. GeoMarine, Inc., Plano, Texas.

Caran, S. C.

1998 Quaternary Paleoenvironmental and Paleoclimatic Reconstruction: A Discussion and Critique, with Examples from the Southern High Plains. Plains Anthropologist 43(164):111-124. 
Chatfield, M.

2009 Clay Recipes and the Spread of European Kiln Technology in Peru. Draft manuscript of paper submitted for the electronic symposium "Archaeological Science and Historic-era Ceramics: A Conversation about Current Understanding and Emergent Perspectives" at the 2008 Conference on Historical and Underwater Archaeology of the Society for Historical Archaeology held in Albuquerque, New Mexico, January 9-12, 2008. Accessed online July 2009, from: http://www.social.mtu.edu/faculty/Scarlett/research/sha08/Chatfield08.pdf.

Cliff, M. B., and D. E. Peter (editors)

1992 Cultural Resources Survey of the Moist Soils Management Area, White Oak Creek Mitigation Area (WOCMA), Cass County, Texas. White Oak Creek Mitigation Area Archeological Technical Series, Reports of Investigations No. 1. Geo-Marine, Inc., Plano, Texas.

Courty, Marie A., Paul Goldberg, and Richard MacPhail

1989 Soils and Micromorphology in Archaeology. Cambridge Manuals in Archaeology. Cambridge University Press, Cambridg, UK.

Crook, W. W., Jr., and R. K. Harris

1957 Hearths and Artifacts of Early Man near Lewisville, Texas, and Associated Faunal Material. Bulletin of the Texas Archeological Society 28:7-79.

1958 A Pleistocene Campsite near Lewisville, Texas. American Antiquity 23:233-246.

1961 Significance of a New Radiocarbon Date from the Lewisville Site. Bulletin of the Texas Archeological Society 32:327-330.

Davis, J. O.

1989 Archeological Paleoenvironments of the Southwestern Division, U.S. Army Corps of Engineers. Arkansas Archeological Survey, Fayetteville.

Dawson, C. L., and T. L. Sullivan

1973 Excavations at Lake Lavon: 1969. Report No. 25. Archaeology Research Program, Southern Methodist University, Dallas.

Dearing, J. A., R.J. L. Dann, K. Hay, J. A. Lees, P. J. Loveland, B. A Maher, and K. O'Grady

1996 Frequency-dependent susceptibility measurements of environmental materials. Geophysical Journal International 124: 228-240

Delcourt, H. R., and P. A. Delcourt

1985 Quaternary Palynology and Vegetational History of the Southeastern United States. In Pollen Records of Late-Quaternary North American Sediments, edited by V. Bryant, Jr., and R. G. Holloway, pp. 1-37. American Association of Stratigraphic Palynologists Foundation, Dallas. 
Dering, $\mathrm{P}$.

2007 Assessment of Botanical and Faunal Assemblages from and Early Archaic Components on the Periphery of the Southern Plains. Bulletin of the Texas Archeological Society 78.

2008 Late Prehistoric Subsistence Economy on the Edwards Plateau. Plains Anthropologist 53 (205): 59-77.

1998 Carbonized Plant Remains. In Wilson-Leonard: An 11,000-year Archeological Record of Hunter-Gatherers in Central Texas Volume V: Special Studies, assembled and edited by M. B. Collins, pp. 1609-1636. Studies in Archeology 31, Texas Archeological Research Laboratory, The University of Texas at Austin, and Archeology Studies Program, Report 10, Texas Department of Transportation, Environmental Affairs Division, Austin.

Dillon, R. F.

2000 The Ecology of Freshwater Mollusks. Cambridge University Press, New York.

Driver, J. C. Identification, classification and zooarchaeology. Circaea 9:35 47.

Dreimani, A.

1962 Quantitative gasometric determination of calcite and dolomite by using a Chittick apparatus. Journal of Sedimentary Petrography 32(3):520-529.

Dury, G. H.

1965 Theoretical implications of underfit streams. U.S. Geological Survey Professional Paper 452-C, 1-43.

Earth Explorer

2001 41TR230. www.EarthExplorer.com [search Elliot Avenue, Fort Worth] (accessed November 15, 2010).

Ellis, G. L.

1998 Environmental Affairs Division Archeological Survey Report. Unpublished Summary Report. Texas Department of Transportation, Austin.

Ferring, C. R.

1986a Late Quaternary geology of the upper Trinity Basin, Texas. Abstracts with Programs - Geological Society of America, 1986, Vol. 18, Issue 6, pp. 601

1986b Late Quaternary Geology and environments of the Upper Trinity basin. In An Assessment of the Cultural Resources in the Upper Trinity River Basin, Dallas, Tarrant and Denton Counties, Texas, B. C. Yates and C. R. Ferring, eds., pp. 32-112. Institute of Applied Sciences, North Texas State University, Denton, Texas.

1990 Late Quaternary Geology and Geoarcheology of the Upper Trinity River Drainage Basin, Texas. Field Trip No. 11 Guidebook. Annual Meeting of the Geological Society of America, Dallas. 
1994 An Archaeological Survey of Trinity River Linear Park, Tarrant County, Texas. Geoarch Consultants, Denton, Texas.

1995 Middle Holocene Environments, Geology, and Archaeology in the Southern Plains. In Archaeological Geology of the Archaic Period in North America, edited by E. A. Bettis, pp. 21-35. Special Paper 297. Geological Society of America, Boulder, Colorado.

Ferring, C. R., and B. C. Yates (with contributions by H. Gill-King and K. Brown)

1997 Holocene Geoarcheology and Prehistory of the Ray Roberts Lake Area, North Central Texas. Institute of Applied Sciences, University of North Texas, Denton.

Gadus, E. F., R. C. Fields, C. B. Bousman, S. A. Tomka, and M. A. Howard

1992 Excavations at the Finley Fan Site (41HP159), Cooper Lake Project, Hopkins County, Texas. Report of Investigations Number 78. Prewitt and Associates, Inc., Austin.

Gaffney, C.

2008 Detecting Trends in the Prediction of the Buried Past: A Review of Geophysical Techniques in Archaeology. Archaeometry 50 (2):313-336.

Gaffney, C., J. A. Gater, P. Linford, V. Gaffney, and R. White

2000 Large-Scale Systematic Fluxgate Gradiometry at the Roman City of Wroxeter. Archaeological Prospection 7:81-99.

Gale, S. J., and P. G. Hoare

1991 Quaternary Sediments: Petrographic Methods for the Study of Unlithified Rocks. London: Belhaven Press.

Gee, G. W., and J. W. Bauder

1986 Particle Size Analysis. In Methods of Soil Analysis, Part 1. Physical and Mineralogical Methods. Agronomy Monograph No. 9 ( $2^{\text {nd }}$ Edition), edited by Arnold Klute, pp. 383-412. American Society of Agronomy - Soil Science Society of America, Madison, Wisconsin.

General Land Office

2010a GLO Land Grants Database: [search Tarrant County Abstract \# 304]. http://www.glo.texas.gov/cf/land-grant-search/index.cfm (accessed November 11, 2010).

2010b GLO Historic Map Database: [search Tarrant County]. http://www.glo.texas.gov/cf/ArcMaps/ArcMapsLookup.cfm (accessed November 11, 2010).

Giovas, C. M.

2009 The shell game: analytic problems in archaeological mollusc quantification. Journal of Archaeological Science 36:1557 - 1564. 
Gobalet, K. W.

2001 A critique of faunal analysis; inconsistency among experts in blind tests. Journal of Archaeological Science 28:377 - 386.

Griffitts, J. L., and J. A. Waters

2005 Bone Tool Use in the Early Agricultural Period. in Material Cultures and Lifeways of Early Agricultural Communities in Southern Arizona. Editor, R. Jane Silva. Anthropological Papers No. 35. Center for Desert Archaeology, Tucson, Arizona.

Gwin, T. B.

1941 An Interesting Type of Indian Artifact from Dallas and Ellis Counties. The Record 2(9):41-43.

Hally, D. J.

1981 Plant Preservation and the Content of Paleobotanical Samples: A Case Study. American Antiquity 46(4):723-742.

Hawker, H. W., N. Gearreald, and M. W. Beck

1924 Soil Survey of Tarrant County, Texas. Government Printing Office, Washington.

Henderson, J.

2000 The Science and Archaeology of Materials: An Investigation of Inorganic Materials. Routledge, London.

Herz, N.

1990 Stable Isotope Geochemistry Applied to Archaeology. In Archaeological Geology of North America, edited by N. P. Lasca and J. Donahue, pp. 585-595. Centennial Special Volume 4. Geological Society of America, Boulder, Colorado.

Howells, R. G., R. W. Neck, and H. D. Murray

1996 Freshwater mussels of Texas. Texas Parks and Wildlife Department, Austin, Texas.

Howells, R. G., C. M. Mather, and J. A. M. Bergmann

1997 Conservation status of selected freshwater mussels in Texas. Pages 117-128 in K.S. Cummings, A.C. Buchanan, C.A. Mayer, and T.J. Naimo. Conservation and management of freshwater mussels II: initiatives for the future. Proceedings of a Upper Mississippi River Conservation Committee symposium, Rock Island, Illinois.

Howells, R. G.

2009 Biological opinion: Conservation status of selected freshwater mussels in Texas. 24 pp.

Huhnke, M. H., and m. D. Wurtz

2004 Cultural Resources Assessment of Riverside Oxbow Environmental Restoration, Fort Worth, Tarrant County, Texas. Miscellaneous Reports of Investigations No. 267. Geo-Marine, Inc., Plano, Texas. 
Humphrey, J. D., and C. R. Ferring

1994 Stable Isotopic Evidence for Latest Pleistocene and Holocene Climatic Change in North-Central Texas. Quaternary Research 41:200-213.

Jurney, D. H., S. A. Lebo, and M. M. Green (compilers)

1988 Historic Farming on the Hogwallow Prairies: Ethnoarcheological Investigations of the Mountain Creek Area, North Central Texas. Joe Pool Lake Archaeological Project, vol. II. Archaeology Research Program, Southern Methodist University, Dallas.

Kibler, K. W., and G. Mehalchick

2010 Hunter-gatherer Resource Acquisition and Use in the Lower Bosque River Basin During the Late Archaic. Bulletin of the Texas Archaeological Society, in Press.

Kvamme, K.

2006a Magnetometry: Nature's Gift to Archaeology, In Remote Sensing in Archaeology: An Explicitly North American Perspective, edited by Jay K. Johnson, pp. 205-233. University of Alabama Press, Tuscaloosa.

2006b Data Processing and Presentation. In Remote Sensing in Archaeology: An Explicitly North American Perspective, edited by Jay K. Johnson, pp. 235-250. University of Alabama Press, Tuscaloosa.

Lintz, C., S. A. Hall, and T. G. Baugh

2005 Archaeological Testing at 41TR170, Along the Clear Fork of the Trinity River, Tarrant County, Texas: An Interim Report. Miscellaneous Reports of Investigations Number 342. Geo-Marine, Inc., Plano, Texas.

Lintz, C. F. B. Largent, Jr., E. Burson, M. Huhnke, and S. M. Hunt

2004 Geomorphology and Archeological Testing at Site 41TR174, Along the Proposed West Fork Relief Interceptor WF-11B Sewer Line, Tarrant County, Texas. Miscellaneous Reports of Investigations Number 300. Geo-Marine, Inc., Plano, Texas.

Lorrain, D., and N. Hoffrichter

1968 The Lower Rockwall Site, Rockwall County, Texas. Salvage Project. Southern Methodist University, Dallas. Submitted to the National Park Service.

Lyman, R. L.

1994 Vertebrate Taphonomy. Cambridge University Press. New York, NY.

2008 Quantitative Paleozoology. Cambridge University Press. New York, NY.

Lynott, M. J.

1975 Archaeological Excavations at Lake Lavon 1974. Contribution in Anthropology No. 16. Archaeology Research Program, Southern Methodist University, Dallas. 
McGregor, D. E.

1988 Archaeological Background. In Late Holocene Prehistory of the Mountain Creek Drainage, edited by D. E. Peter and D. E. McGregor, pp. 27-33. Joe Pool Lake Archaeological Project, vol. I. Archaeology Research Program, Southern Methodist University, Dallas.

McMahan, C.A., R. G. Frye, and K. L. Brown

1984 The Vegetation Types of Texas. Wildlife Division, Texas Parks and Wildlife Department, Austin.

Machette, M.

1986 Calcium and Magnesium Carbonates. In Field and Laboratory Procedures Used in Soil Chronosequence Studies, edited by Michael J. Singer and Peter Janitzky, pp. 30-

33. U.S. Geological Survey Bulletin 1648, United States Government Printing Office, Washington D.C.

Madole, R. F., C. R. Ferring, M. J. Guccione, S. A. Hall, W. C. Johnson, and C. J. Sorenson

1991 Quaternary Geology of the Osage Plains and Interior Highlands. In The Geology of North America, Vol. K-2, Quaternary Nonglacial Geology: Conterminous U.S., edited by R. B. Morrison, pp. 503-546. The Geological Society of America, Inc., Boulder, Colorado.

Magurran, A. E.

1988 Ecological Diversity and its Measurement. Princeton University Press, Princeton.

Maniatis, Y., and M. S. Tite

1981 Technological Examination of Neolithic-Bronze Age Pottery from Central and Southeast Europe and from the Near East. Journal of Archaeological Science 8:59-76

Mason, R. D., M. L. Peterson, and J. A. Tiffany

1998 Weighing vs. Counting: Measurement Reliability and the California School of Midden Analysis. American Antiquity 63:303-324.

Mauldin, R., D. L. Nickels, and C. J. Broehm

2003 Archaeological Testing to Determine the National Register Eligibility Status of 18 Prehistoric Sites on Camp Bowie, Brown County, Texas Vol. 2. Archaeological Survey Report No. 334. Center for Archaeological Research, The University of Texas San Antonio.

Mehringer, P. J., Jr., J. E. King, and E. H. Lindsay

1970 A Record of Wisconsin-age Vegetation and Fauna from the Ozarks of Western Missouri. In Pleistocene and Recent Environments of the Central Great Plains, edited by W. Dort and K. Jones, pp. 173-184. University of Kansas Press, Lawrence.

Miksicek, C. H.

1987 Formation Processes of the Archaeobotanical Record. In Advances in Archaeological Method and Theory vol. 10, edited by Michael B. Schiffer, pp. 211247. Academic Press, New York. 
Milsom, J.

2005 Field Geophysics: The Geological Field Guide Series. Third edition. West Sussex, Wiley.

Morey, D. F., and G. M. Crothers

1998 Clearing up clouded waters: Palaeoenvironmental analysis of freshwater mussel assemblages from the Green River shell middens, western Kentucky. Journal of Archaeological Science, 25:907-926.

Morgan, L. W.

1975 An Empirical Analysis of a Pre-Neo-American Site in Dallas County, Texas. Unpublished Master's thesis, Department of Anthropology, University of Texas at Arlington.

Neck, R. W.

1986 Freshwater bivalves of Lake Tawakoni, Sabine River, Texas. The Texas Journal of Science 38:241-249

1990 Geological substrate and human impact as influences on bivalves of Lake Lewisville, Trinity River, Texas. The Nautilus 104:16-25

Osburn, T. L., D. Shanabrook, and D. E. Peter

2005 Geoarcheological Coring of the Central City Hydraulic Mitigation Areas, Fort Worth, Tarrant County, Texas. Miscellaneous Reports of Investigations Number 335. GeoMarine, Inc., Plano, Texas.

Parmalee, P. W., and M. H. Hughes

1993 Freshwater mussels (Mollusca: Pelecypoda: Unionidae) of Tellico Lake: Twelve years after impoundment of the Little Tennessee River. Annals of Carnegie Museum 62:81-93

Parmalee, P. W., and A. E. Bogan

1998 The Freshwater mussels of Tennessee. University of Tennessee Press, Knoxville, Tennessee.

Perkins, $\mathrm{P}$.

1996 An image processing technique for the suppression of traces of modern agricultural activity in aerial photographs. In, Analecta Praehistorica Leidensia: Interfacing the past, computer applications and quantitative methods in archaeology CAA95. Hans Kamermans and Kelly Fennema Editors. Pp. 139-145. University of Leiden.

Perry-Castaneda Library Map Collection

1955 Topographic maps Haltom City Quadrangle http://www.lib.utexas.edu/maps/topo/ texas/txu-pclmaps-topo-tx-haltom_city-1955.jpg (accessed November 15 2010). 
Peter, D. E., and D. H. Jurney

1988 Environmental Background. In Late Holocene Prehistory of the Mountain Creek Drainage, edited by D. E. Peter and D. E. McGregor, pp. 5-26. Joe Pool Lake Archaeological Project, vol. I. Archaeology Research Program, Southern Methodist University, Dallas.

Peter, D.E., and D. Shanabrook, J. H. Cooper, L. Schniebs, P. Dering, and R. Nawojchik 2002 Phase II Archeological Investigations of Mitigation Area IA of Segment IV of the President George Bush Turnpike, Dallas County, Texas. Miscellaneous Reports of Investigations No. 246. Geo-Marine, Plano, Texas.

Peter, D. E., T. K. Perttula, M. B. Cliff, S. M. Hunt, C. Stiles-Hanson, and N. G. Reese

1991 Red River Army Depot and Lone Star Army Ammunition Plant Cultural Resource Management Plan. Geo-Marine, Inc., Plano, Texas. Prepared for the Red River Army Depot/Lone Star Army Ammunition Plant and the U.S. Army Corps of Engineers, Fort Worth District.

Peter, D. E., and D. E. McGregor (editors)

1988 Late Holocene Prehistory of the Mountain Creek Drainage. Joe Pool Lake Archaeological Project, vol. I. Archaeology Research Program, Southern Methodist University, Dallas.

Peter, D. E., B. Ellwood, J. Schieber, and B. Yates

1987 Test Excavations of the River Bend Site (41TR68). Center for Geoarcheological Studies, University of Texas at Arlington.

Prewitt, E. R.

1995 Distributions of Typed Projectile Points $\mathrm{n}$ Texas. Bulletin of the Texas Archaeological Society 66(1995):XX-XX

Prewitt, E. R., and C. K. Chandler

1992 Axtell: A Middle Archaic Dart Point Type. Journal of the Southern Texas Archaeological Association La Tierra 19(1):15-20.

Prikryl, D. J.

1987 A Synthesis of Prehistory on the Lower Elm Fork of the Trinity River. Unpublished Master's thesis, University of Texas, Austin.

1990 Lower Elm Fork Prehistory: A Redefinition of Cultural Concepts and Chronologies Along the Trinity River, North Central Texas. Report 37. Office of the State Archeologist, Texas Historical Commission, Austin.

Raison, R. J.

1979 Modification of the soil environment by vegetation fires, with particular reference to nitrogen transformation: a review. Plant and Soil 51:73-108. 
Randklev, C. R., S. Wolverton, and J. H. Kennedy

2009 A Biometric Technique for Assessing Prehistoric Freshwater Mussel Population Dynamics (Family: Unionidae) in North Texas. Journal of Archaeological Science 36:205-213.

In press Prehistoric range extension of the freshwater mussel, Plectomerus dombeyanus (Valenciennes, 1827) in north Texas. Ecological Applications.

Rice, P. M.

2005 Pottery Analysis: A Sourcebook. The University of Chicago Press, Chicago.

Ross, R. E.

1966 The Upper Rockwall and Glen Hill Sites, Forney Reservoir, Texas. Papers No. 9. Texas Archeology Salvage Project, University of Texas, Austin.

Schiffer, M. B.

1987 Formation Processes of the Archaeological Record. University of New Mexico Press, Albuquerque, New Mexico.

Schmelzer, J.

2010 "FORT WORTH, TX", Handbook of Texas Online, (http://www.tshaonline.org/handbook/online/articles/hdf01), (accessed November 15, 2010).

Seeman, M. K.

2004 Hopewell Art in Hopewell Places. in Hero, Hawk and Open Hand. The Art Institute of Chicago. Chicago, Illinois.

Shanabrook, D.

2003 Geomorphological Investigations. In Cultural Resources Assessment of Riverside Oxbow Environmental Restoration, Fort Worth, Tarrant County, Texas, by M. H. Huhnke and M. D. Wurtz, pp. 37-42. Miscellaneous Reports of Investigations Number 267. Geo-Marine, Inc., Plano, Texas.

Skinner, S. A., and L. Baird (Editors)

1985 Settlement in a Marginal Zone. Archaeology and History of Lake Ray Roberts, vol. III. AR Consultants, Dallas

Skinner, S. A., and B. B. Whorton

1993 Archaeological Survey of Arcadia Trail Park, Tarrant County, Texas. Cultural Resources Report 93-7. AR Consultants, Dallas.

Skinner, S. A., M. B. Cliff, L. Baird, A. B. Emerson, Jr., J. Bennett, A. R. Faust, J. Kaskey, K. Ladder, M. D. Northern, A. Pitchfork, J. Rally, D. G. Chateaus, and D. Shanabrook

1982 Construction Area Testing. Archaeology and History of Lake Ray Roberts, vol. II. Cultural Resources Report 82-9. Environmental Consultants, Inc., Dallas. 
Slaughter, E. H., and B. R. Hoover

1963 Sulphur River Formation and the Pleistocene Mammals of the Ben Franklin Local Fauna. Journal of the Graduate Research Center 31(3):132-148. Southern Methodist University, Dallas.

Stephens, D.W. \& Krebs, J.R.

1986 Foraging Theory. Princeton University, Princeton.

Sternberg, C. H.

1931 The Life of a Fossil Hunter. Jensen Printing Company. San Diego, California.

Story, D. A.

1990 Environmental Setting. In The Archeology and Bioarcheology of the Gulf Coastal Plain, 2 vols., by D. A. Story, J. A. Guy, B. A. Burnett, M. D. Freeman, J. C. Rose, D. G. Steele, B. W. Olive, and K. J. Reinhard, pp. 1:5-1:26. Research Series No. 38. Arkansas Archeological Survey, Fayetteville.

Strecker, J. K.

1931 The distribution of the naiads or pearly fresh-water mussels of Texas, Baylor University Museum Special Bulletin 2.

Street, S.

1893 Sam Street's Map of Tarrant County, Texas. Copy on file at Geo-Marine, Inc.

Tarrant County Appraisal District

2010 Tarrant Appraisal District. http://www.tad.org/Datasearch/datasearch.cfm [search account number 03819582] (accessed November 11, 2010).

The Portal to Texas History

2010 Soil Map, Texas, Tarrant County Sheet. http://texashistory.unt.edu/ark:/67531/ metapth19671/m1/1/?q=Tarrant County. (accessed November 16, 2010).

Thoms, A. V.

2009 Rocks of Ages: Propagation of Hot-rock cookery in Western North America. Journal of Archaeological Science 36(2009):573-591.

Tobin International, Ltd.

19381938 Aerial map of Fort Worth, Texas. On file at Geo Marine Inc., Plano, Texas.

Todd, J.

2010 The Prehistory of Eastern North Central Texas. Bulletin of the Texas Archaeological Society. In Press.

Tomka, S.

2010 Lithic Analysis of the 41DL203 Collections. In Archaeological Testing and Data Recovery Excavations at Site 41DL203, President George Bush Turnpike-Eastern Extension from SH 78 to IH 30, Dallas County, Texas edited by C. M. Tinsley and C. Dayton. Miscellaneous Reports of Investigations Number 484. Geo-Marine, Inc., Plano, Texas. 
Toomey, R. S., III, M. D. Blum, and S. Valastro, Jr.

1993 Late Quaternary Climates and Environments of the Edwards Plateau, Texas. Global and Planetary Change 7:299-320.

Turner, E. S., and T. R. Hester

1999 A Field Guide to the Stone Artifacts of Texas Indians. Gulf Publishing, Houston, Texas.

U.S. Department of Agriculture

19561956 Aerial map of Fort Worth, Texas. On file at Geo Marine Inc., Plano, Texas

Walker, C. P.

2008 Archaeogeophysical Survey of 41TR198. AGA Report number 2008-20. Report submitted to Geo-Marine, Inc. Plano, Texas.

Warren, R. F.

1991 Freshwater mussels as paleoenvironmental indicators: A quantitative approach to assemblage analysis, p. 23-66. In Beamers, Bobwhites, and Blue-Points: Tributes to the Career of Paul W. Parmalee, edited by J. R. Purdue, W. E. Klippel and B. W. Styles. Illinois State Museum, Scientific Papers, vol. 23. Springfield.

Whitbread, I.

1995 The collection, processing and interpretation of petrographic data. In Greek transport Amphorae: A Petrological and Archaeological Study. Fitch Laboratory Occasional Paper 4, British School at Athens. Short Run Press, Exeter, UK.

Williams, J. D., A. E. Bogan, and J. T Garner

2009 Freshwater Mussels of Alabama and the Mobile Basin in Georgia, Mississippi, and Tennessee. University of Alabama Press, Tuscaloosa.

Willimon, E. L.

1972 New Local Faunas and Paleoecology (Pleistocene) of North Central Texas. Texas Journal of Science 23(4):449-469.

Wöcherl, H.

2005 Pits and the Use of Extramural Space in Early Farming Communities. in Material Cultures and Lifeways of Early Agricultural Communities in Southern Arizona, edited by R. J. Silva. Anthropological Papers No. 35. Center for Desert Archaeology, Tucson, Arizona.

Wolverton, S., C. R. Randklev, and J. H. Kennedy

In press A conceptual model for freshwater shellfish (family: Unionidae) remain preservation in zooarchaeological assemblages. Journal of Archaeological Science

Wright, B. H.

1896 New American Uniondae. The Nautilus 9:133-137. 
Wright, H. E., Jr.

1976 The Dynamic Nature of Holocene Vegetation: A Problem in Paleoclimatology, Biogeography, and Stratigraphic Nomenclature. Quaternary Research 6(4):581-596.

Yates, B. C., and C. R. Ferring (editors)

1986 An Assessment of the Cultural Resources in the Trinity River Basin, Dallas, Tarrant, and Denton Counties, Texas. Institute of Applied Sciences, North Texas State University, Denton. Submitted to the U.S. Army Corps of Engineers, Fort Worth District. 
APPENDIX A

\section{BACKHOE TRENCH DATA}


TR $1 \mathrm{~S}$ At north edge of terrace overlooking former site of sewage settling lagoons just east of levee that surrounded sewage treatment plant adjacent to gravel road; surface lumpy and irregular.

\begin{tabular}{|c|c|l|}
\hline Depth $(\mathrm{cm})$ & Soil Zone & Description \\
\hline $0-66 / 175$ & Fill & $\begin{array}{l}\text { Mixed clods of brown and dark gray clay; abundant gravel; few } \\
\text { pieces of concrete; common flecks of pale orange burned clay; } \\
\text { abundant flecks and pieces of charcoal; abundant fragments of tan } \\
\text { to buff limestone give zone a speckled look; few pieces of black, } \\
\text { decaying organics; common woody roots; zone thickens rapidly } \\
\text { from north to south in trench wall; abrupt irregular boundary. }\end{array}$ \\
\hline $66-166$ & Bbca & $\begin{array}{l}\text { Brown (10YR 5/3) clay; very firm to dense; fine blocky with } \\
\text { trace of silt and clay on ped faces; few fine woody roots which } \\
\text { decrease in number with depth; common white calcareous } \\
\text { deposits along open rootlet traces; few white, soft calcareous } \\
\text { concretions; common open rootlet holes. }\end{array}$ \\
\hline
\end{tabular}

TR 2 S Approximately 25 meters north of TR $1 \mathrm{~S}$ along road.

\begin{tabular}{|c|c|l|}
\hline Depth (cm) & Soil Zone & Description \\
\hline $0-10$ & A & $\begin{array}{l}\text { Very dark grayish brown (10YR 3/2) slightly silty clay; weak } \\
\text { blocky; firm; common fine woody roots and rootlets; common } \\
\text { insect burrows; gradual boundary }\end{array}$ \\
\hline $10-40$ & AC & $\begin{array}{l}\text { Dark grayish brown (10YR 4/2) slightly sandy, silty clay; weak } \\
\text { blocky; firm to slightly friable; abundant yellow colored sand on } \\
\text { ped faces and soil partings; common worm burrows; few whole } \\
\text { gastropod shells; gradual boundary }\end{array}$ \\
\hline $40-50$ & C & $\begin{array}{l}\text { Dark grayish brown (10YR 4/2) slightly sandy, silty clay with } \\
\text { thin pale brown (10YR 6/3) silty fine grained sand interbeds; clay } \\
\text { weak blocky and firm; sand massive and friable; abrupt, smooth } \\
\text { boundary }\end{array}$ \\
\hline $50-98$ & 2Ab & $\begin{array}{l}\text { Very dark gray (10YR 3/1) clay; firm to very firm; strong fine to } \\
\text { medium blocky; vertical krotovina filled with tan silt and sand } \\
\text { from overlying zone; few whole gastropod shells; few woody } \\
\text { roots; fine black colored decaying rootlets and dark maroon Fe } \\
\text { stain along rootlet traces in upper part; white calcareous deposits } \\
\text { along open rootlet traces in lower part, more intense in some } \\
\text { areas than others; gradual to diffuse boundary. }\end{array}$ \\
\hline $98-170$ & 2Bb & $\begin{array}{l}\text { Very dark grayish brown (10YR 3/2) to dark grayish brown } \\
\text { (10YR 4/2) slightly silty clay; very firm; blocky; common open } \\
\text { rootlet traces; common white calcareous deposits along open } \\
\text { rootlet traces, more intense in some areas than other. }\end{array}$ \\
\hline
\end{tabular}


TR 3 S Roughly 75 meters north of TR 2 S along road.

\begin{tabular}{|c|c|l|}
\hline Depth (cm) & Soil Zone & Description \\
\hline $0-30$ & A to AC & $\begin{array}{l}\text { Dark brown (10YR 3/2) silty clay; firm to slightly friable; } \\
\text { massive; few large limestone clasts and gravels; abundant } \\
\text { rootlets; abundant woody roots especially in the upper 20 cm; } \\
\text { gradual to diffuse boundary. }\end{array}$ \\
\hline $30-57$ & C & $\begin{array}{l}\text { Brown (10YR 5/3) clay, few beds somewhat darker in color; } \\
\text { massive; vertical soil partings and bedding panes give it a weak } \\
\text { blocky appearance; trace bedding; few woody roots; abrupt, } \\
\text { smooth, slightly wavy boundary marked by a few inclusions of } \\
\text { material from underlying zone (rip-up clasts). }\end{array}$ \\
\hline $57-72$ & 2A1b & $\begin{array}{l}\text { Very dark grayish brown (10YR 3/2) clay; very firm to plastic; } \\
\text { very weak blocky; black-maroon colored FeMn and Fe stain } \\
\text { along soil partings and on ped faces, few fine rootlets; diffuse } \\
\text { boundary }\end{array}$ \\
\hline $72-127$ & 2A2b & $\begin{array}{l}\text { Very dark gray (10YR 3/1) clay; very firm; strong, very coarse } \\
\text { blocky with heavy clay coats on ped faces (“slickensides”); } \\
\text { common gastropod shell fragments; increasing amounts of white } \\
\text { calcareous deposits along open rootlet traces with depth; gradual } \\
\text { boundary. }\end{array}$ \\
\hline $127-190 / 200$ & 2Bb & $\begin{array}{l}\text { Dark grayish brown (10YR 4/2) slightly silty clay; very firm; } \\
\text { blocky; common white calcareous deposits along open rootlet } \\
\text { traces; common open rootlet traces; few fine rootlets. }\end{array}$ \\
\hline
\end{tabular}

TR 4 S Approximately 60 meters north of TR 3 S.

\begin{tabular}{|c|c|l|}
\hline Depth (cm) & Soil Zone & Description \\
\hline $0-23$ & C & $\begin{array}{l}\text { Brown (10YR 5/3) sandy clay; massive; friable; abundant fine } \\
\text { woody roots; 1 Barque's Root Beer bottle cap; abrupt, smooth } \\
\text { boundary. }\end{array}$ \\
\hline $23-83$ & 2Ab & $\begin{array}{l}\text { Very dark grayish brown (10YR 3/1) slightly silty clay; very } \\
\text { firm; fine blocky with trace of clay coats on ped faces; common } \\
\text { fine woody roots; few gastropod shell fragments; trace white } \\
\text { calcareous deposits along open rootlet traces in lower part; } \\
\text { gradual to diffuse boundary. }\end{array}$ \\
\hline $83-137$ & 2Bbca & $\begin{array}{l}\text { Dark grayish brown (10YR 4/2) clay; very firm; blocky with light } \\
\text { clay coats on ped faces; some white calcareous deposits along } \\
\text { open rootlet traces which increases with depth; few hard, light } \\
\text { gray calcareous concretions in lower part; few gastropod shell } \\
\text { fragments; few fine woody roots; gradual to clear boundary }\end{array}$ \\
\hline $137-170$ & 2Cca & $\begin{array}{l}\text { Dark brown (10YR 4/3) slightly sandy clay; very firm to dense; } \\
\text { weak blocky; common open rootlet traces; few fine buff colored } \\
\text { calcareous concretions; abundant white calcareous deposits along } \\
\text { soil partings and open rootlet traces. }\end{array}$ \\
\hline
\end{tabular}


TR 5 S In old pecan grove, north of old sewage settling pond, and south of First Street.

\begin{tabular}{|c|c|l|}
\hline Depth (cm) & Soil Zone & Description \\
\hline A1p & $0-23$ & $\begin{array}{l}\text { Very dark gray (10YR 3/1) to very dark grayish brown (10YR } \\
\text { 3/2) clay; plastic to firm; massive to very weak blocky; abundant } \\
\text { grass rootlets; bioturbated with common insect burrows; one } \\
\text { piece of green bottle glass; gradual boundary. }\end{array}$ \\
\hline A2 & $23-96$ & $\begin{array}{l}\text { Very dark gray (10YR 3/1) to black (10YR 2/1) clay; firm; } \\
\text { blocky with clay skins on ped faces; few woody roots; few } \\
\text { gastropod shell fragments; common rootlets; few fine vertical } \\
\text { krotovina filled with gray colored silty clay; gradual to diffuse } \\
\text { boundary. }\end{array}$ \\
\hline Bca & $96-133$ & $\begin{array}{l}\text { Very dark grayish brown (10YR 3/2) to dark grayish brown } \\
\text { (10YR 4/2) slightly sandy, silty clay; firm to very firm; fine } \\
\text { blocky with trace of orange Fe stain on ped faces and soil } \\
\text { partings; few fine woody roots; few vertical krotovina filled with } \\
\text { material from overlying zone; few gastropod shell fragments; } \\
\text { increasing number of light gray colored calcareous concretions } \\
\text { with depth; gradual to clear boundary. }\end{array}$ \\
\hline C1cca & $133-176$ & $\begin{array}{l}\text { Brown (10YR 4/3 to 10YR 5/3) slightly sandy clay grading with } \\
\text { depth to sandy clay; firm at top to friable at base; weak blocky at } \\
\text { top to massive at base; abundant white to light gray calcareous } \\
\text { concretions; common to abundant white calcareous deposits } \\
\text { along open rootlet traces; few fine rootlets; zone mottled 30\% } \\
\text { orange (yellowish brown 10YR 5/6); trace black FeMn stain; few } \\
\text { fine black FeMn concretions; clear textural and gradual color } \\
\text { boundary. }\end{array}$ \\
\hline C2ox & $176-200$ & $\begin{array}{l}\text { Dark yellowish brown (10YR 4/6) to yellowish brown (10YR } \\
\text { 5/6) clayey sand; friable; massive to weak blocky; common open } \\
\text { rootlet traces, many with light gray colored reduction haloes. }\end{array}$ \\
\hline
\end{tabular}


TR 6 S Approximately 20 meters west of TR 5 S on north lip of swale that separates sewage pond levee from terrace that pecan grove and First Street are on.

\begin{tabular}{|c|c|l|}
\hline Depth (cm) & Soil Zone & Description \\
\hline A1p & $0-30$ & $\begin{array}{l}\text { Very dark gray (10YR 3/1) clay; plastic to firm; massive to very } \\
\text { weak blocky; abundant grass rootlets; bioturbated with common } \\
\text { insect burrows; few gravels; few rusting metal fragments; one } \\
\text { piece of red brick; one large white plastic box; clear to gradual } \\
\text { boundary. }\end{array}$ \\
\hline A2 & $30-75$ & $\begin{array}{l}\text { Black (10YR 2/1) clay; firm; blocky with clay skins on ped faces; } \\
\text { few woody roots; few gastropod shell fragments; common } \\
\text { rootlets; few fine vertical krotovina filled with gray colored silty } \\
\text { clay; gradual to diffuse boundary. }\end{array}$ \\
\hline Bca & $75-115$ & $\begin{array}{l}\text { Very dark gray (10YR 3/1) to very dark grayish brown (10YR } \\
\text { 3/2) slightly sandy, silty clay; firm to very firm; fine blocky; few } \\
\text { very fine rock fragments; few fine woody roots; few vertical } \\
\text { krotovina filled with material from overlying zone; few gastropod } \\
\text { shell fragments; few light gray colored calcareous concretions in } \\
\text { basal part; gradual to clear boundary. }\end{array}$ \\
\hline C1ca & $115-151$ & $\begin{array}{l}\text { Brown (10YR 4/3 to 10YR 5/3) slightly sandy clay grading with } \\
\text { depth to sandy clay; firm at top to friable at base; weak blocky at } \\
\text { top to massive at base; abundant white to light gray calcareous } \\
\text { concretions; common to abundant white calcareous deposits } \\
\text { along open rootlet traces; few fine rootlets; zone mottled 30\% } \\
\text { orange (yellowish brown 10YR 5/6); few fine rock fragments; } \\
\text { clear textural and gradual color boundary. }\end{array}$ \\
\hline C2ox & $151-180$ & $\begin{array}{l}\text { Dark yellowish brown (10YR 4/6) to yellowish brown (10YR } \\
\text { 5/6) slightly clayey sand; friable; massive to weak blocky; } \\
\text { common open rootlet traces, many with light gray colored } \\
\text { reduction haloes. }\end{array}$ \\
\hline & &
\end{tabular}


APPENDIX B

RADIOCARBON DATA 


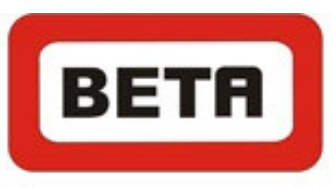

Consistent Accuracy ... ... Delivered On-time

June 23, 2009

Mr. Duane E. Peter/J. Harrison

Geo-Marine, Incorporated

Engineering and Environmental Services

$2201 \mathrm{~K}$ Avenue

Suite A2

Plano, TX 75074-5977

USA

RE: Radiocarbon Dating Results For Samples DOU21:60-50 FS599, F28U20:75-70 FS220, F29U21:5555 FS318, F33U24:40-31 FS335, F39U33:80-75 FS547, F41U13:05-95 FS579, L3U19:20-10 FS516, L16U26:20-15 FS466

Dear Duane:

Enclosed are the radiocarbon dating results for eight samples recently sent to us. They each provided plenty of carbon for accurate measurements and all the analyses proceeded normally. As usual, the method of analysis is listed on the report with the results and calibration data is provided where applicable.

As always, no students or intern researchers who would necessarily be distracted with other obligations and priorities were used in the analyses. We analyzed them with the combined attention of our entire professional staff.

If you have specific questions about the analyses, please contact us. We are always available to answer your questions.

The cost of analysis was previously invoiced. As always, if you have any questions or would like to discuss the results, don't hesitate to contact me.

Sincerely,

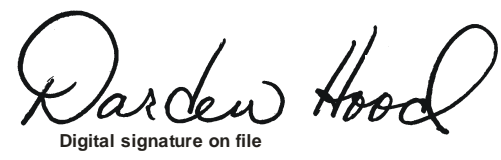




\section{REPORT OF RADIOCARBON DATING ANALYSES}

Mr. Duane E. Peter/J. Harrison

Geo-Marine, Incorporated

Material Received: 5/18/2009

\section{Sample Data}

\author{
Measured \\ Radiocarbon Age
}

$13 \mathrm{C} / 12 \mathrm{C}$

Ratio
Conventional

Radiocarbon Age $\left(^{*}\right)$

\section{Beta -259836}

$2320+/-40$ BP

$-20.3 \mathrm{o} / \mathrm{oo}$

$2400+/-40$ BP

SAMPLE : DOU21:60-50 FS599

ANALYSIS : AMS-Standard delivery

MATERIAL/PRETREATMENT : (bone collagen): collagen extraction: with alkali

2 SIGMA CALIBRATION : $\quad$ Cal BC 740 to 690 (Cal BP 2690 to 2640) AND Cal BC 660 to 640 (Cal BP 2610 to 2590)

Cal BC 550 to 390 (Cal BP 2500 to 2340)

Beta -259837

SAMPLE : F28U20:75-70 FS220

ANALYSIS : AMS-Standard delivery

MATERIAL/PRETREATMENT : (charred material): acid/alkali/acid
2 SIGMA CALIBRATION : $\quad$ Cal AD 1010 to 1170 (Cal BP 940 to 780 )
$920+/-40 \mathrm{BP}$
$-22.3 \mathrm{o} / \mathrm{oo}$

$960+/-40$ BP

Beta - 259838

SAMPLE : F29U21:55-55 FS318

$1020+/-40$ BP

$-19.3 \mathrm{o} / \mathrm{oo}$

$1110+/-40 \mathrm{BP}$

ANALYSIS : AMS-Standard delivery

MATERIAL/PRETREATMENT : (bone collagen): collagen extraction: with alkali

2 SIGMA CALIBRATION : $\quad$ Cal AD 870 to 1010 (Cal BP 1080 to 940)
$1360+/-40 \mathrm{BP}$

-24.8 o/oo

$1360+/-40$ BP

SAMPLE : F33U24:40-31 FS335

ANALYSIS : AMS-Standard delivery

MATERIAL/PRETREATMENT : (charred material): acid/alkali/acid

2 SIGMA CALIBRATION : $\quad$ Cal AD 620 to 690 (Cal BP 1330 to 1260)

Beta - 259840

SAMPLE : F39U33:80-75 FS547

ANALYSIS : AMS-Standard delivery

MATERIAL/PRETREATMENT : (charred material): acid/alkali/acid

2 SIGMA CALIBRATION : $\quad$ Cal AD 70 to 250 (Cal BP 1880 to 1700)
$1830+/-40 \mathrm{BP} \quad-23.5 \mathrm{o} / \mathrm{oo}$

$1850+/-40$ BP
Dates are reported as RCYBP (radiocarbon years before present, "present" = AD 1950). By international convention, the modern reference standard was $95 \%$ the $14 \mathrm{C}$ activity of the National Institute of Standards and Technology (NIST) Oxalic Acid (SRM 4990C) and calculated using the Libby $14 \mathrm{C}$ half-life (5568 years). Quoted errors represent 1 relative standard deviation statistics (68\% probability) counting errors based on the combined measurements of the sample, background, and modern reference standards. Measured $13 \mathrm{C} / 12 \mathrm{C}$ ratios (delta $13 \mathrm{C}$ ) were calculated relative to the PDB- 1 standard.
The Conventional Radiocarbon Age represents the Measured Radiocarbon Age corrected for isotopic fractionation, calculated using the delta 13C. On rare occasion where the Conventional Radiocarbon Age was calculated using an assumed delta $13 \mathrm{C}$, the ratio and the Conventional Radiocarbon Age will be followed by "*”. The Conventional Radiocarbon Age is not calendar calibrated. When available, the Calendar Calibrated result is calculated from the Conventional Radiocarbon Age and is listed as the "Two Sigma Calibrated Result" for each sample. 


\section{REPORT OF RADIOCARBON DATING ANALYSES}

Mr. Duane E. Peter/J. Harrison

Report Date: 6/23/2009

\section{Sample Data}

\author{
Measured \\ Radiocarbon Age
}

$13 \mathrm{C} / 12 \mathrm{C}$

Ratio

$-26.8 \mathrm{o} / \mathrm{oo}$

$1780+/-40 \mathrm{BP}$

Beta - 259841

SAMPLE : F41U13:05-95 FS579

ANALYSIS : AMS-Standard delivery

MATERIAL/PRETREATMENT : (charred material): acid/alkali/acid

2 SIGMA CALIBRATION : $\quad$ Cal AD 210 to 390 (Cal BP 1740 to 1560)
Beta -259842

SAMPLE : L3U19:20-10 FS516

ANALYSIS : AMS-Standard delivery

MATERIAL/PRETREATMENT : (bone collagen): collagen extraction: with alkali

2 SIGMA CALIBRATION : $\quad$ Cal AD 410 to 590 (Cal BP 1540 to 1360)
$1490+/-40$ BP $\quad-20.6$ o/oo

$1560+/-40$ BP
Beta - 259843

SAMPLE : L16U26:20-15 FS466

ANALYSIS : AMS-Standard delivery

MATERIAL/PRETREATMENT : (bone collagen): collagen extraction: with alkali

2 SIGMA CALIBRATION : $\quad$ Cal AD 240 to 420 (Cal BP 1710 to 1530)
-20.6 o/oo

$1700+/-40 \mathrm{BP}$
Dates are reported as RCYBP (radiocarbon years before present, "present" = AD 1950). By international convention, the modern reference standard was $95 \%$ the $14 \mathrm{C}$ activity of the National Institute of Standards and Technology (NIST) Oxalic Acid (SRM 4990C) and calculated using the Libby $14 \mathrm{C}$ half-life (5568 years). Quoted errors represent 1 relative standard deviation statistics (68\% probability) counting errors based on the combined measurements of the sample, background, and modern reference standards. Measured $13 \mathrm{C} / 12 \mathrm{C}$ ratios (delta $13 \mathrm{C}$ ) were calculated relative to the PDB- 1 standard.
The Conventional Radiocarbon Age represents the Measured Radiocarbon Age corrected for isotopic fractionation, calculated using the delta $13 \mathrm{C}$. On rare occasion where the Conventional Radiocarbon Age was calculated using an assumed delta $13 \mathrm{C}$, the ratio and the Conventional Radiocarbon Age will be followed by "*”. The Conventional Radiocarbon Age is not calendar calibrated. When available, the Calendar Calibrated result is calculated from the Conventional Radiocarbon Age and is listed as the "Two Sigma Calibrated Result" for each sample. 


\section{CALIBRATION OF RADIOCARBON AGE TO CALENDAR YEARS}

(Variables: C $13 /$ C $12=-20.3: 1$ ab. mult $=1)$

Laboratory number: Beta-259836

Conventional radiocarbon age: $2400 \pm 40 \mathrm{BP}$

2 Sigm a calibrated results: Cal BC 740 to 690 (Cal BP 2690 to 2640) and

(95\% probability) Cal BC 660 to 640 (Cal BP 2610 to 2590) and

Cal BC 550 to 390 (Cal BP 2500 to 2340)

Intercept data

Intercept of radiocarbon age

with calibration curve:

Cal BC 410 (Cal BP 2360)

1 Sigma calibrated result: Cal BC 520 to 400 (Cal B P 2470 to 2350)

( $68 \%$ probability)

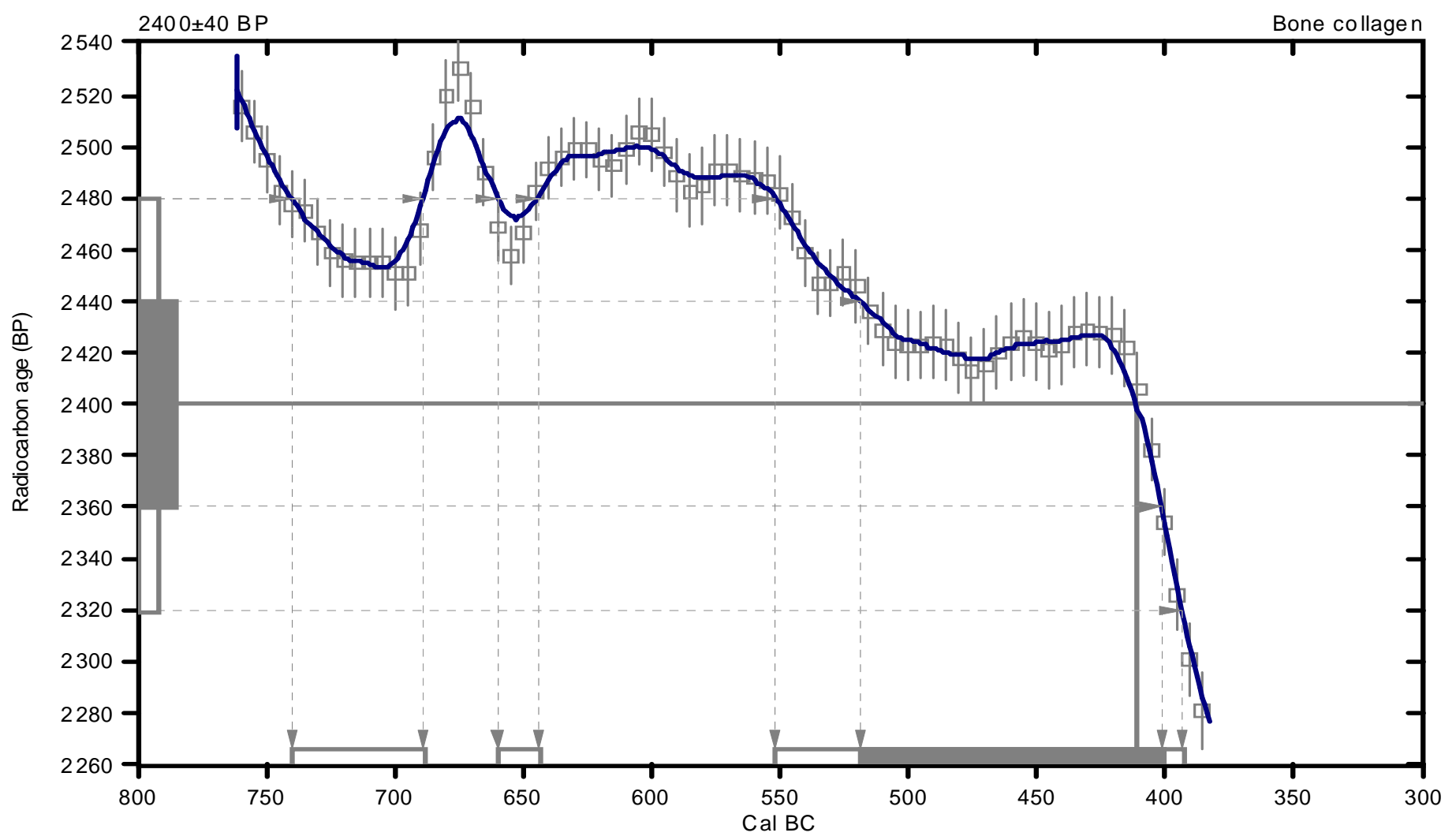

References:

Database used INTCA LO4

Calibration Database

INTCALO4 Radiocarbon Age Calibration

IntCal04: Calibration Iss ue of Radiocarbon (Volume 46, $\mathrm{nr} 3$, 2004).

Mathematics

A Simplified Approach to Calibrating C14 Dates Talma, A. S., Vogel, J. C., 1993, Radiocarbon 35(2), p317-322 


\section{CALIBRATION OF RADIOCARBON AGE TO CALENDAR YEARS}

(Variables: C $13 /$ C $12=-22.3: 1$ ab. mult $=1$ )

Laboratory number : Beta-259837

Conventional radiocarbon age: $\quad 960 \pm 40 \mathrm{BP}$

2 Sigma calibrated result: Cal AD 1010 to 1170 (Cal BP 940 to 780 )

(95\% probability)

Intercept data

Intercept of radiocarbon age

with calibration curve:

Cal AD 1040 (Cal B P 920)

1 Sigma calibrated results: Cal AD 1020 to 1060 (Cal BP 930 to 900) and

(68\% probability) Cal AD 1080 to 1150 (Cal BP 870 to 800 )

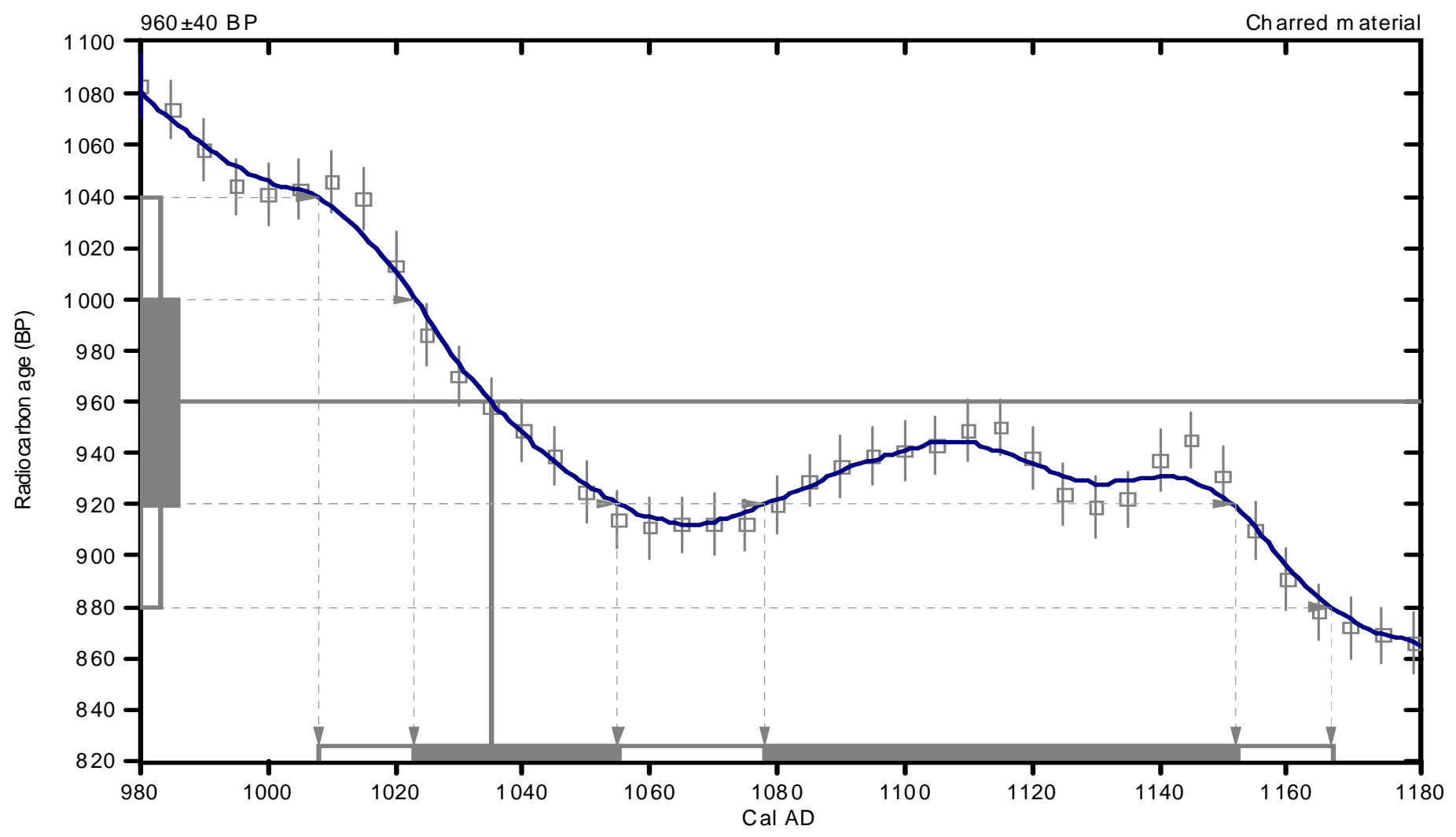

References:

Database used INTCA LO4

Calibration Database

INTCALO4 Radiocarbon Age Calibration

IntCal04: Calibration Iss ue of Radiocarbon (Volume 46, nr 3, 2004).

Mathematics

A Simplified Approach to Calibrating C14 Dates Talma, A.S., Vogel, J. C., 1993, Radiocarbon 35(2), p317-322 


\section{CALIBRATION OF RADIOCARBON AGE TO CALENDAR YEARS}

(Variables: C $13 /$ C $12=-19.3: 1$ ab. mult $=1)$

Laboratory number: Beta-259838

Conventional radiocarbon age: $1110 \pm 40 \mathrm{BP}$

2 Sigma calibrated result: Cal AD 870 to 1010 (Cal BP 1080 to 940) (95\% probability)

Intercept data

Intercepts of radiocarbon age

with calibration curve: Cal AD 900 (Cal B P 1050) and

Cal AD 920 (Cal B P 1040) and

Cal AD 960 (Cal B P 990)

1 Sigma calibrated result: Cal AD 890 to 980 (Cal BP 1060 to 960)

(68\% probability)

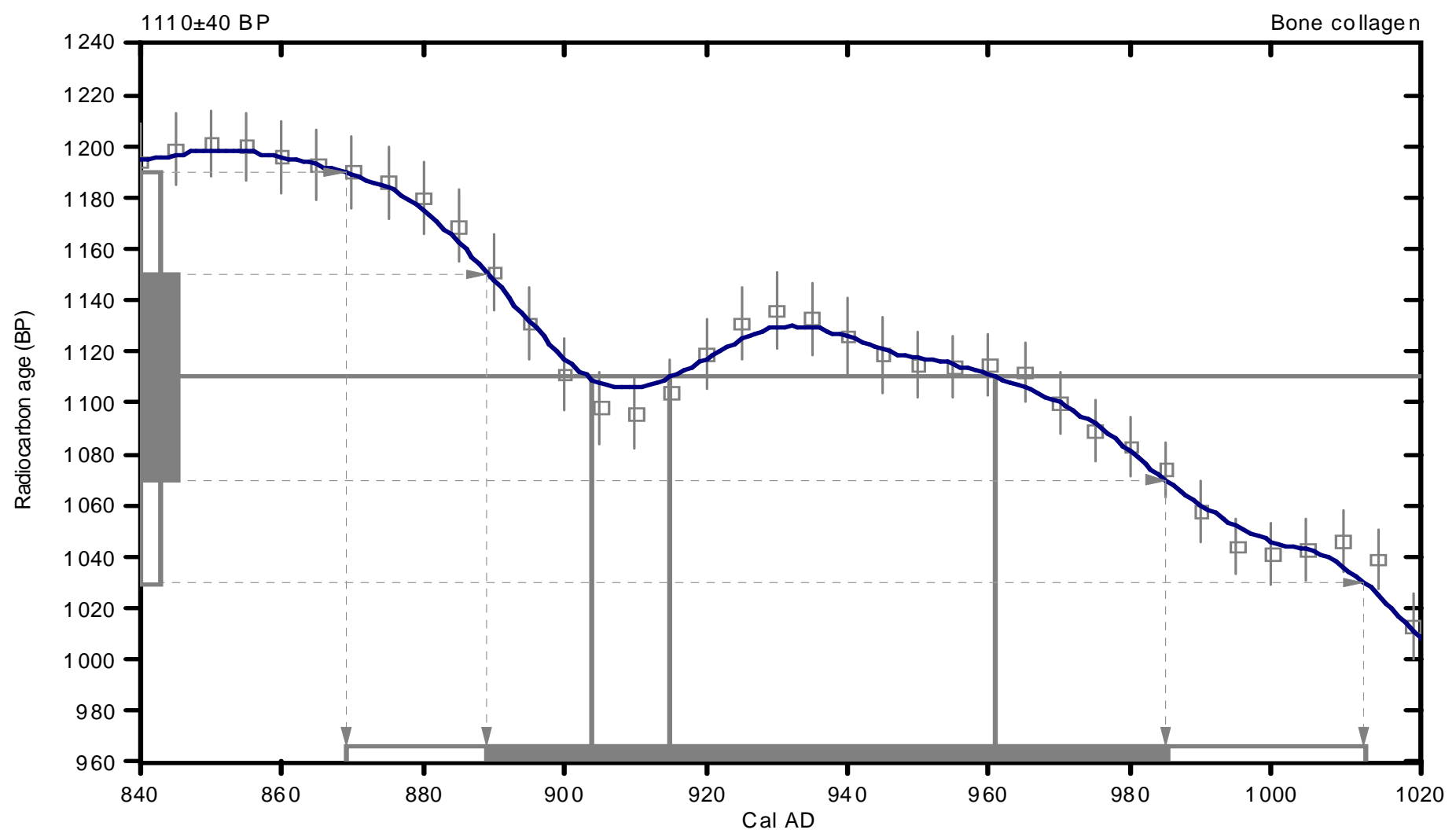

References:

Database used INTCA LO4

Calibration Database

INTCALO4 Radiocarbon Age Calibration

Mathematics

IntCal04: Calibration Iss ue of Radiocarbon (Volume 46, $\mathrm{nr} 3,2004)$.

A Simplified Approach to Calibrating C14 Dates Talma, A.S., Vogel, J. C., 1993, Radiocarbon 35(2), p317-322 


\section{CALIBRATION OF RADIOCARBON AGE TO CALENDAR YEARS}

(Variables: C 13/C 12=-24.8:lab. mult $=1$ )

Laboratory number: Beta-259839

Conventional radiocarbon age: $1360 \pm 40 \mathrm{BP}$

2 Sigma calibrated result: Cal AD 620 to 690 (Cal BP 1330 to 1260) (95\% probability)

Intercept data

Intercept of radiocarbon age

with calibration curve:

Cal AD 660 (Cal B P 1290)

1 Sigma calibrated result:

( $68 \%$ probability)

Cal AD 650 to 670 (Cal BP 1300 to 1280 )

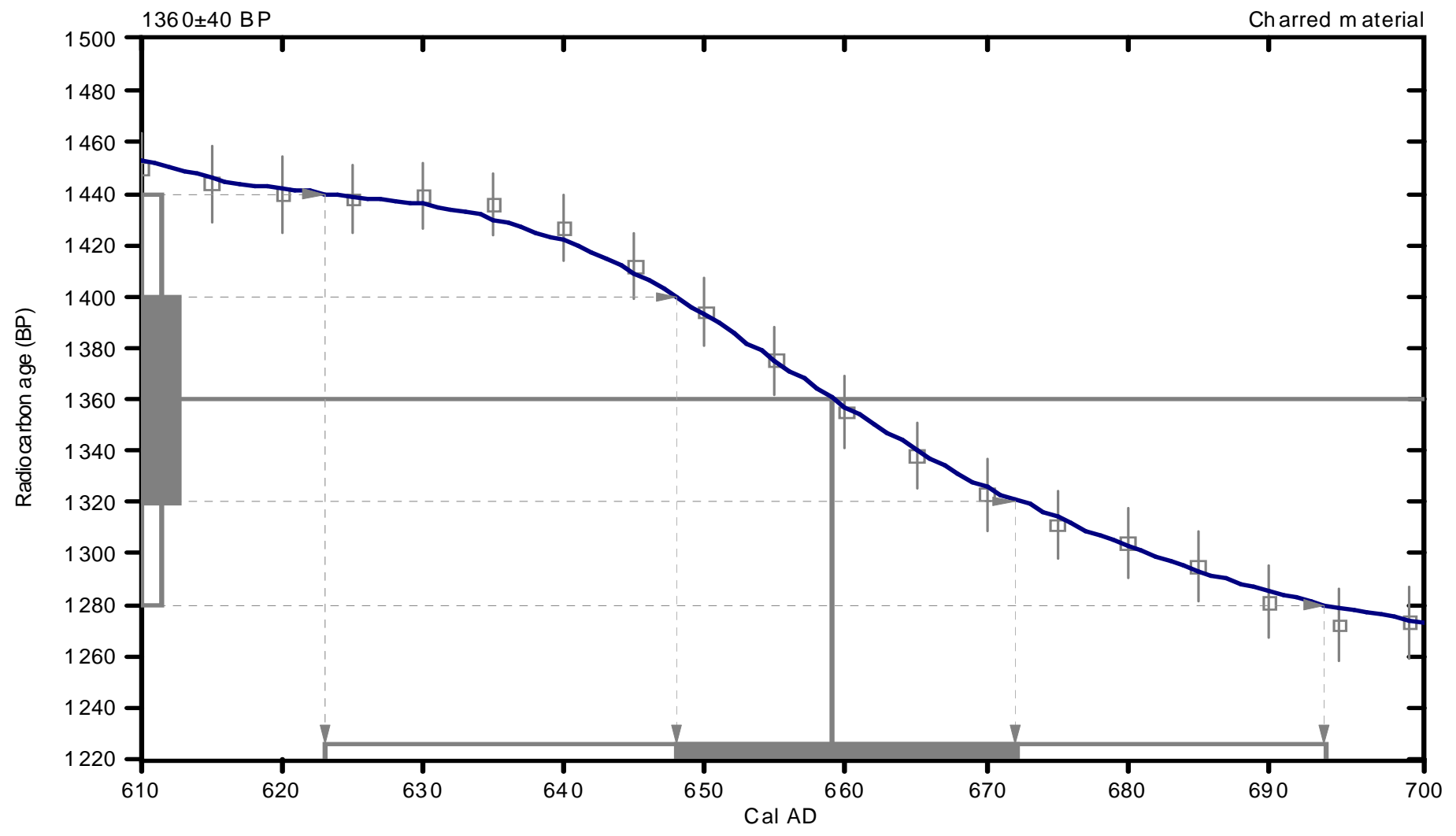

References:

Database used INTCA LO4

Calibration Database

INTCALO4 Radiocarbon Age Calibration

Mathematics

IntCal04: Calibration Iss ue of Radiocarbon (Volume 46, $n$ r 3, 2004).

A Simplified Approach to Calibrating C14 Dates Talma, A.S., Vogel, J. C., 1993, Radiocarbon 35(2), p317-322 


\section{CALIBRATION OF RADIOCARBON AGE TO CALENDAR YEARS}

(Variables: C 13/C 12=-23.5:lab. mult $=1$ )

Laboratory number: Beta-259840

Conventional radiocarbon age: $1850 \pm 40 \mathrm{BP}$

2 Sigma calibrated result: Cal AD 70 to 250 (C al B P 1880 to 1700) (95\% probability)

Intercept data

Intercept of radiocarbon age

with calibration curve: Cal AD 140 (Cal B P 1810)

1 Sigma calibrated result: Cal AD 120 to 230 (Cal BP 1830 to 1720)

(68\% probability)

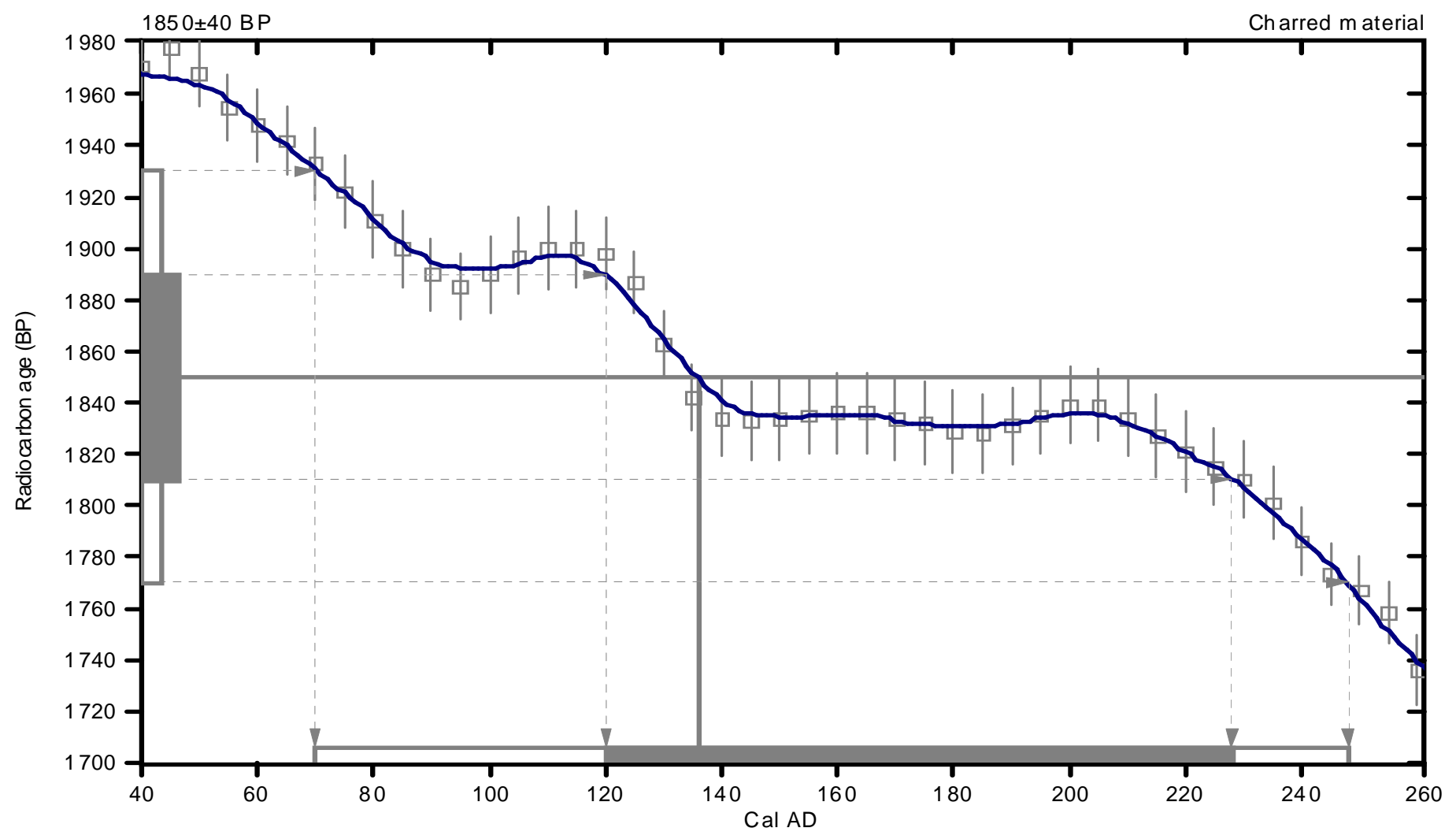

References:

Database used INTCA LO4

Calibration Database

INTCALO4 Radiocarbon Age Calibration

Mathematics

IntCal04: Calibration Iss ue of Radiocarbon (Volume 46, $\mathrm{nr} 3,2004)$.

A Simplified Approach to Calibrating C14 Dates Talma, A.S., Vogel, J. C., 1993, Radiocarbon 35(2), p317-322 


\section{CALIBRATION OF RADIOCARBON AGE TO CALENDAR YEARS}

(Variables: C 13/C 12=-26.8:lab. mult $=1$ )

Laboratory number: Beta-259841

Conventional radiocarbon age: $1750 \pm 40 \mathrm{BP}$

2 Sigma calibrated result: Cal AD 210 to 390 (Cal BP 1740 to 1560)

(95\% probability)

Intercept data

Intercepts of radiocarbon age

with calibration curve: Cal AD 260 (Cal B P 1690) and

Cal AD 300 (Cal B P 1650) and

Cal AD 310 (Cal B P 1640)

1 Sigma calibrated result: Cal AD 240 to 340 (Cal BP 1710 to 1610)

(68\% probability)

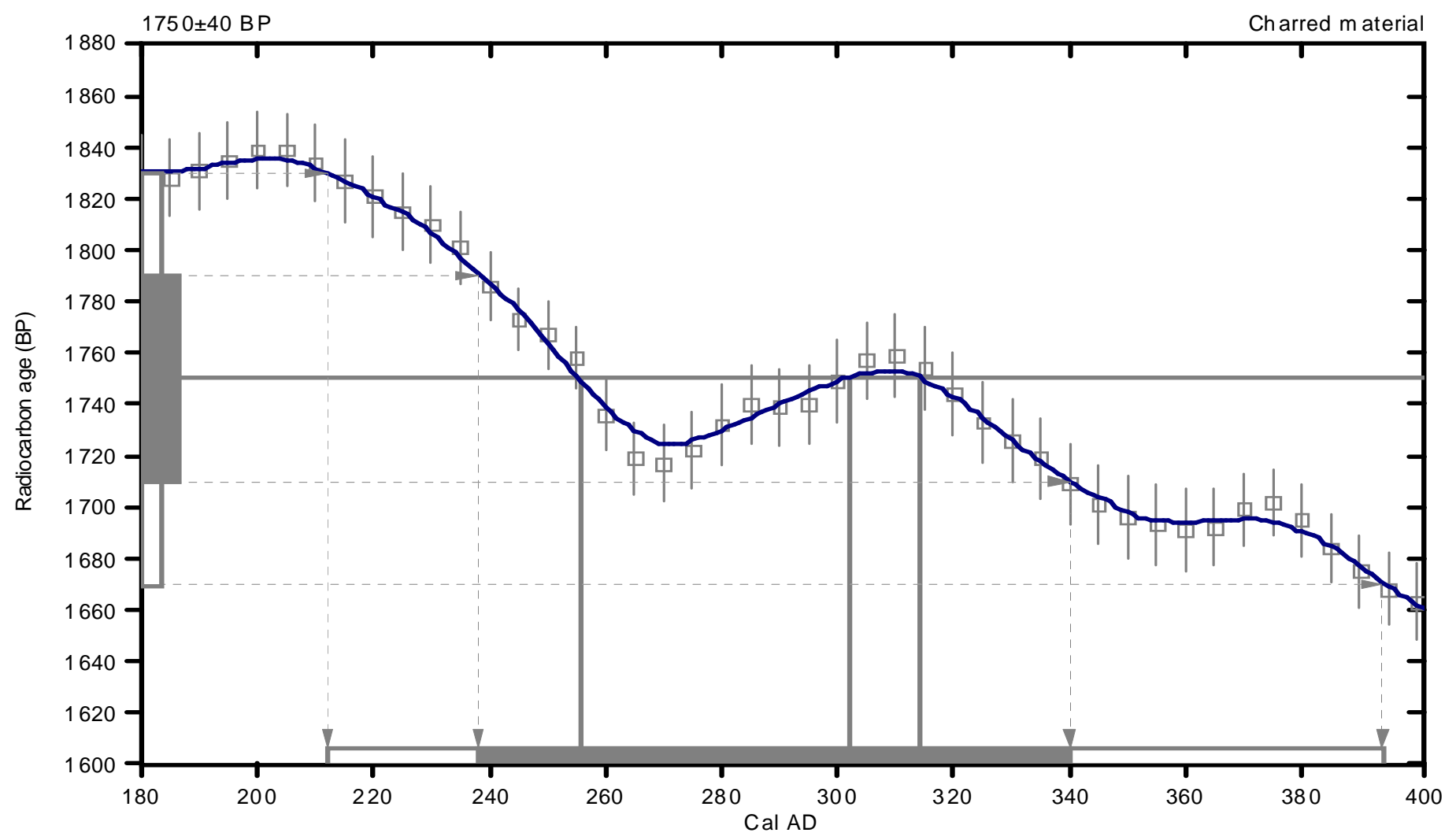

References:

Database used INTCALO4

Calibration Database

INTCALO4 Radiocarbon Age Calibration

IntCal04: Calibration Iss ue of Radiocarbon (Volume 46, nr 3, 2004).

Mathematics

A Simplified Approach to Calibrating C14 Dates Talma, A.S., Vogel, J. C., 1993, Radiocarbon 35(2), p317-322 


\section{CALIBRATION OF RADIOCARBON AGE TO CALENDAR YEARS}

(Variables: C 13/C 12=-20.6:1ab. mult $=1$ )

Laboratory number: Beta-259842

Conventional radiocarbon age: $1560 \pm 40 \mathrm{BP}$

2 Sigma calibrated result: Cal AD 410 to 590 (Cal BP 1540 to 1360) (95\% probability)

Intercept data

Intercept of radiocarbon age

with calibration curve: Cal AD 540 (Cal B P 1420)

1 Sigma calibrated result: Cal AD 430 to 550 (Cal BP 1520 to 1400 )

(68\% probability)

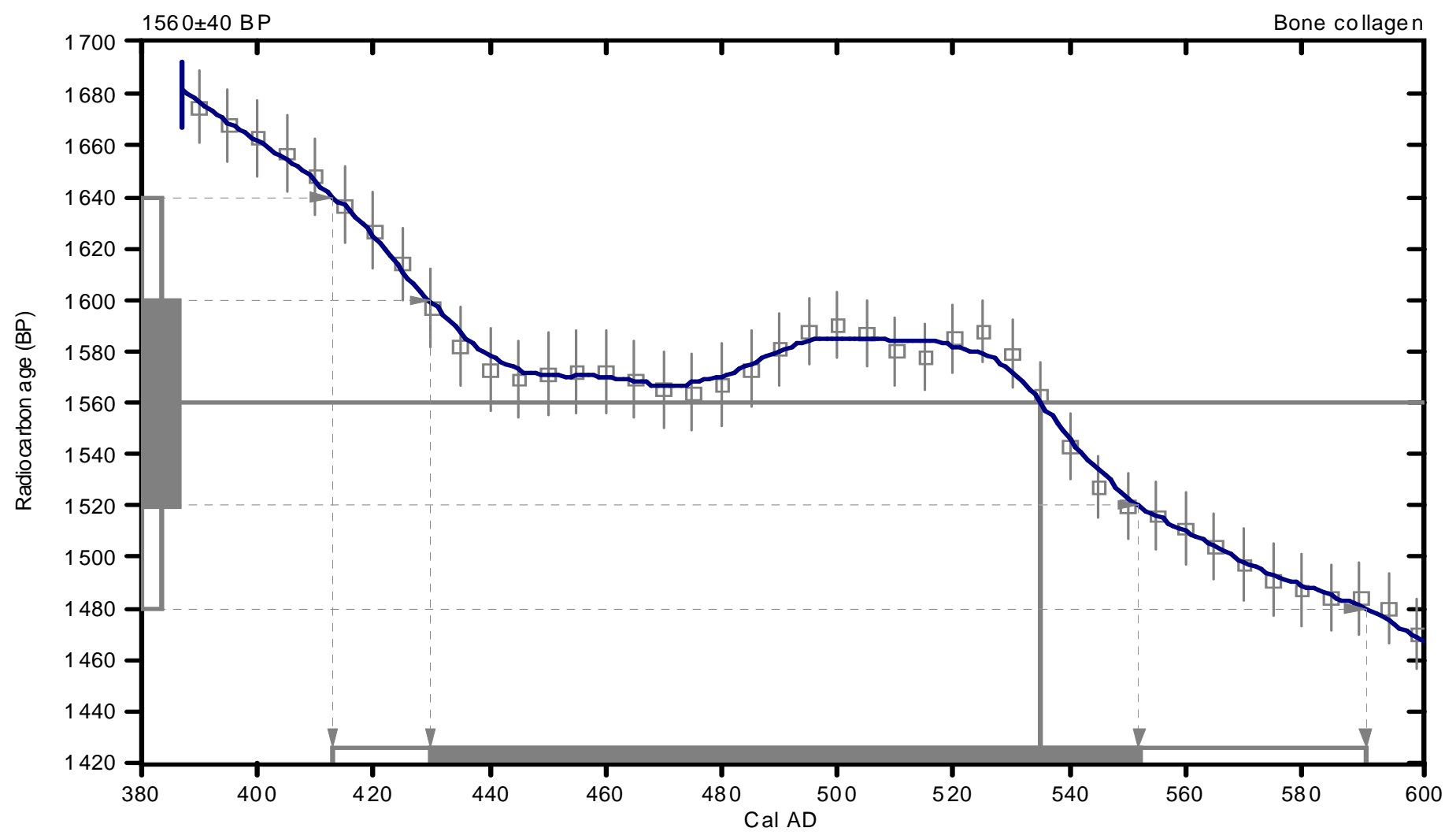

References:

Database used INTCA LO4

Calibration Database

INTCALO4 Radiocarbon Age Calibration

IntCal04: Calibration Iss ue of Radiocarbon (Volume 46, $\mathrm{nr} 3,2004$ ).

Mathematics

A Simplified Approach to Calibrating C14 Dates Talma, A.S., Vogel, J. C., 1993, Radiocarbon 35(2), p317-322 


\section{CALIBRATION OF RADIOCARBON AGE TO CALENDAR YEARS}

(Variables: C 13/C 12=-20.6:lab. mult $=1$ )

Laboratory number: Beta-259843

Conventional radiocarbon age: $1700 \pm 40 \mathrm{BP}$

2 Sigma calibrated result: Cal AD 240 to 420 (Cal BP 1710 to 1530)

(95\% probability)

Intercept data

Intercept of radiocarbon age

with calibration curve:

Cal AD 350 (Cal B P 1600)

1 Sigma calibrated results: Cal AD 260 to 290 (Cal BP 1690 to 1660) and

(68\% probability) Cal AD 320 to 400 (Cal BP 1630 to 1550 )

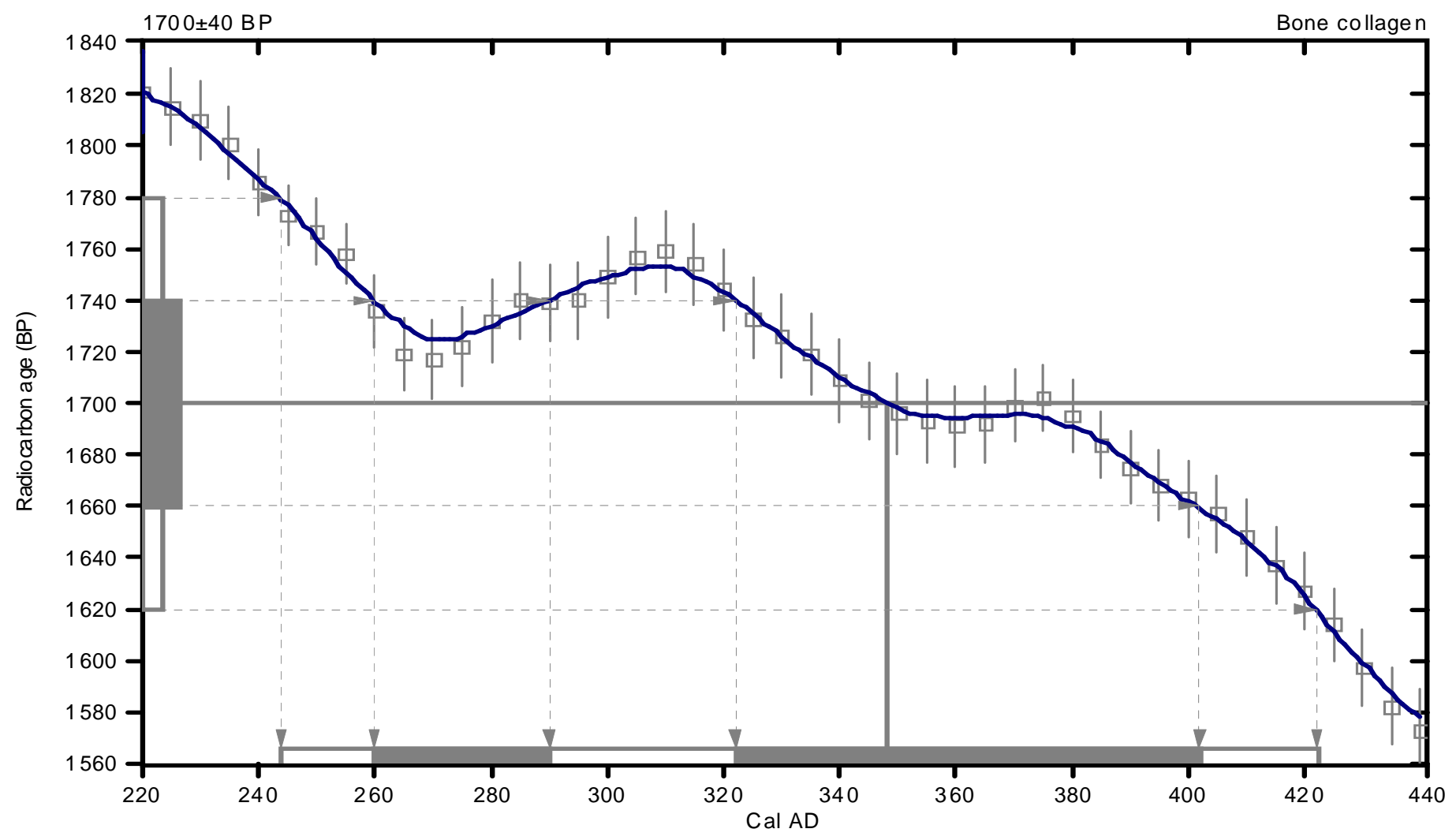

References:

Database used INTCA LO4

Calibration Database

INTCALO4 Radiocarbon Age Calibration

Int Cal04: Calibration Iss ue of Radiocarbon (Volume 46, nr 3, 2004).

Mathematics

A Simplified Approach to Calibrating C14 Dates Talma, A. S., Vogel, J. C., 1993, Radiocarbon 35(2), p317-322 